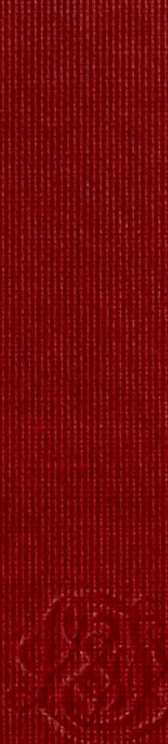





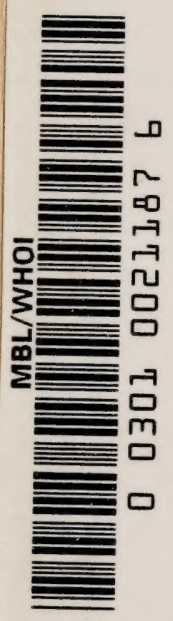







\section{AGRICULTURAL}

\section{BACTERIOLOG Y}

BY

JOSEPH E. GREAVES, M.S., Рн.D.

PROFESSOR OF AGRICULTURAL BACTERIOLOGY AND PHYSIOLOGICAL CHEMISTRY IN UTAH AGRICULTURAL COLLEGE; CHEMIST AND BACTERIOLOGIST IN UTAH EXPERIMENT STATION.

\section{ILLUSTRATED WITH 48 ENGRAVINGS}

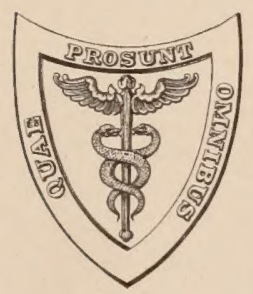

LEA \& FEBIGER

PHILADELPHIA AND NEW YORK 
Copyright

LEA \& FEBIGER

1922

PRINTED IN U. S. A. 


\section{DEDICATED}

IN LOVING REMEMBRANCE OF

\section{PERNECY}

WHO DURING OUR FEW SHORT YEARS TOGETHER CONSTANTLY ENCOURAGED AND

INSPIRED ME 



\section{PREF ACE.}

TuE organisms considered in agricultural bacteriology are specifically the most numerous, chemically the most active, and economically the most important known. This being true, why is so much interest shown in the injurious and so little in the beneficial bacteria? There are two chief reasons for this condition. When an outlaw commits some crime against human society it is heralded far and near and the machinery of the law is set in operation to apprehend the culprit and bring him to justice. So it is with these outlaws in bacterial society. The typhoid, or perchance some other disease-producing organism, attacks some individual, or it may be an entire community. If it be typhoid, we hear of the long-drawnout fight between the human individual on the one hand and the invisible enemy on the other. If disease be not checked it spreads to other places, and, as in the Dark Ages, sweeps like a prairie-fire over a whole continent or, as recently, over the entire world. The second reason why we hear more of the disease-producing organisms than we do of the beneficial bacteria is that man has learned that it is a fight between him and these microbes to determine which shall inherit the earth. He has learned that he must protect him' self against these enemies. For these reasons man has studied the bacterial outlaw, his place and condition of growth.

On the other hand, though we admire the magnificent structures and complex institutions which have been reared by the mind and hand of men, we see and pass on. In many cases we do not stop to contemplate the countless millions, living and dead, who have contributed their mite that things might be as they are. Man does not have to protect himself against these honest toilers; hence, they go unnoticed. The work of the benefactor lacks the sensationalism which is attached to that of the destroyer. So it is with the countless billions of beneficial bacteria; they toil on day and night, generation after generation, accomplishing good for the human race. We do not miss them, for they have always helped us. They never become discouraged, but work for our good until conditions become intolerable, when they die to be in many cases replaced by the bacterial outlaw.

If the following pages help to systematize, to arouse interest, to stimulate curiosity or inquiry in even a small degree in this intensely 
interesting and practical subject, the author will feel that his labors have not been in vain.

It is coming to be recognized that agricultural bacteriology and agricultural chemistry are at many points intimately associated. Hence, the writer has presupposed a knowledge of elementary chemistry on the part of the student. However, most of the more complex equations have been grouped in one chapter so they may be used or omitted as the teacher sees fit.

It has been more a question of what to exclude than what to include. Howerer, the writer has been guided throughout by the needs of the student of agriculture, and hence where good, complete volumes are available, as is the case with milk, water, sewage, and some other subjects, a bare outline is given; so the student should consult other works for a more exhaustive treatment. But in the case of soils an effort has been made to go more into detail. Even in these chapters, however, no attempt has been made to review all of the literature.

In the preparation of this work I have drawn freely from all available sources. Much of the material was first written with a complete reference to the literature, but it soon became apparent that such a procedure would produce a work too large for the purpose for which this was written. Hence, all references have been eliminated. There are, howerer, listed at the end of most chapters a few select works given in most cases because of the references which they contain, and it is to these that the student is referred for further details. At the end of the last chapter is given a list of additional works which have been consulted in the preparation of this book.

To my friends and colleagues my hearty thanks are offered for the valuable encouragement and assistance given in the preparation of this book. I am under particular obligation to President E. G. Peterson, Dr. F. S. Harris, Dr. B. L. Richards, Professors George Sterart, C. 'T. Hirst, and E. G. Carter for reading parts or all of the manuscript and offering many helpful suggestions, also to Mrs. Blanche C. Pittman for her painstaling care in the preparation of the manuscript for the press.

LOGAN, UTAH, 1922.

J. E. G. 


\section{CONTENTS.}

CHAPTER I.

Development of Bacteriology

Spontaneous Generation - • . . . . . . . . 18

Fermentation . . . . . . . 21

Smallpox . . . . . . . . . . . . 24

Anthrax . . . . . . . . . . . . . . 24

Other Work of Pasteur . . . . . . . . . . . 26

Other Plagues Conquered . . . . . . $\quad 26$

Lister . . . . . . . . . . 26

Yellow Fever . . . . . . . . . . 26

Agricultural Bacteriology . . . . . . . . . . . . . . 27

Future Work . . . . . 27

References . . . . . . . . . . . . 28

CHAPTER II.

Bacteria and their Place in Nature

Definition of Bacteria . . . . . . . . . . . . . . 29

Divisions of Plant Kingdom . . . . . . . . . . . 30

Occurrence of Bacteria . . . . . . . . . . . . 31

Role of Bacteria in Nature . . . . . . . . . . . . . 32

Divisions of Bacteriology . . . . . . . . . . . . . 36

CHAPTER III.

Morphology of Bacteria

Bacilli . . . . . . . . . . 37

Cocci . . . . . . . . . . . . . . 37

Spirilla . . . . . . . . . . . . . 38

Gradations . . . . . . . . . . . . . . . 38

Pleiomorphism . . . . . . . . . . . 38

Involution Forms . . . . . . . . . . . . . . 38

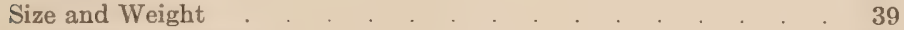

Brownian Movement . . . . . . . . . . . . 40

Organs of Locomotion $\quad . \quad . \quad . \quad 42$

Cell Wall Ectoplasm) _ . . . . . . . . . . . . . 42

Capsules . . . . . . . . . . . . . . . 43

Sheath . . . . . . . . . . . . . 43

Zoöglœa

Cytoplasm . . . . . . . . . . . . . . . . 43

Metachromatic Granules . . . . . . . . . . . . . 43

Spores . . . . . . . . . . . . . . . . . 44

Longevity of Bacteria . . . . . . . . . . . . . 45 
CHAPTER IV.

\section{Classification of Bacterta}

Migula Classification . . . . . . . . . . . . . 46

International Rules of Botanicas Nomenclature . . . . . . . 49

Classification of American Bacteriological Association . . . . 50

The Class Schizomycetes . . . . . . . . . 50

Order Myxobacteriales . . . . . . . . . . . . 50

Order Thiobacteriales . . . . . . . . . . 50

Order Chlamydobacteriales . . . . . . . . . . 50

Order Actinomycetales . . . . . . . . . . . . . 50

Order Eubacteriales . . . . . . . . . . . . . 52

CHAPTER V.

Composition of Bacteria

Elementary Composition .

Moisture. . . . . . . . . . . . . . . 58

Organic Constituents . . . . . . . . . . . . . . . . . 58

Carbohydrates . . . . . . . . . . . . . . . 58

Extractives . . . . . . . . . . . . . . . 58

Proteins . . . . . . . . . . . . . . . . . . 59

Inorganic Constituents _. . . . . . . . . . 61

Variation in Composition of Different Parts of Cell . . . . . 61

References . . . . . . . . . . . . . . 62

CHAPTER VI.

Food Requirements

Minimum Requirements . . . . . . . . . . . . . 63

Maximum Requirements . . . . . . . . . . . . . . 64

Function of Food . . . . . . . . . . . . . . 64

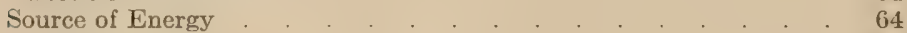

Moisture . . . . . . . . . . . . . . . . 65

Osmotic Pressure . . . . . . . . . . . . . . . . 67

Kinds of Food Required . . . . . . . . . . . . . . 67

Carbon . . . . . . . . . . . . . . 68

Nitrogen . . . . . . . . . . . . . . . . . . 68

Hydrogen . . . . . . . . . . . . . . . 68

Sulphur . . . . . . . . . . . . . . . . . . . . . 69

Phosphorus . . . . . . . . . . . . . . . . . . . . . 69

Potassium . . . . . . . . . . . . . . . . 69

Other Inorganic Substances . . . . . . . . . . . . 69

Oxygen Requirements . . . . . . . . . . . . . . . 69

Vitamines . . . . . . . . . . . . . . . 70

References. . . . . . . . . . . 70

CHAPTER VII.

Bacteriat Metabolism Enzymes

Early Theories of Fermentation . . . . . . . . . . . 71

Definition of Enzymes . . . . . . . . . . . . . 72

Terminology . . . . . . . . . . . . . . . 75

Properties of Enzymes _. . . . . . . . . . . . . . . 76

Classification . . . . . . . . . . . . . . . . . 79

Hydrolytic Enzymes . . . . . . . . . . . . . . . . 79

Oxidizing Enzymes . . . . . . . . . . . . . . 81

References . . . . . . . . . . . . . . . 81 


\section{CHAPTER VIII.}

\section{Bacterial Metabolisa Products}

Physiologic Classification

Carbohydrate Metabolism $\quad 82$

Acid Production _. . . . . . . . 84

Acetic Acid . . . . . . . . . . . . . . . . . . . 85

Lactic Acid

Butyric Acid . . . . . . . . . . 86

Other Acid Fermentations . . . . . . . . . . . . . . 87

Oxidation of Organic Acids . . . . . . . . . . . . . . 87

Fats . . . . . . . . . . . 87

Products from Nitrogenous Compounds . . . . . . . . . 87

Indol and Skatol . . . . . . . . . . . 89

Amins . . . . . . . . . . . . . . . . 90

Pigments . . . . . . . . . . . . . . . 91

Chromophorous Bacteria . . . . . . . . . . 93

Chromoparous, or True Pigment-forming Bacteria . . 93

Parachrome Bacteria . . . . . . . . . 93

Heat . . . . . . . . . . . . 9 94

Light . . . . . . . . . . . . . . 94

References . . . . . . . . . . . . . . . . . 94

\section{CHAPTER IX.}

Influence of Temperature and Light on Bacterta

Temperature and Speed of Reaction . . . . . . . . 95

Relation to Heat . 96

Thermophilic or Heat-loving Bacteria . . . . . . . 96

Psychrophilic Bacteria . . . . . . . . . . . . . . . . 96

Mesophilic Bacteria . . . . . . . . . . . . 97

Thermal Death Point . . . . . . . . . . . . . . 99

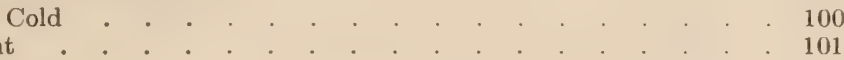

CHAPTER $\mathrm{X}$.

Effect of Other Agents on Bacteria

Radium Rays . . . . . . . . . . . . . . . . 103

Röntgen Rays . . . . . . . . . . . . . . . 103

Electricity . . . . . . . . . . . . . . . . . 103

Drying . . . . . . . . . . . . . . 105

Osmotic Pressure . . . . . . . . . . . . . . 106

Pressure . . . . . . . . . . . . . . . . . . 106

Shaking . . . . . . . . . . . . . 107

CHAPTER XI.

Effect of Chemicals on Bacteria

Chemotaxis . . . . . . . . . . . . . . . 108

Disinfectants . . . . . . . . . . . 110

Laws Governing the Actions of Disinfectants . . . . . 111

Disinfectants of the Chlorine Group . . . . . . . . 114

Formaldehyde . . . . . . . . . . . . . . . 116

Sulphur Dioxide . . . . . . . . . . . . . 116

Hydrocyanic Acid Gas . . . . . . . . . . . 117

Mercuric Chloride . . . . . . . . . . . . . . 117

References . . . . . . . . . . . . 117 
CHAPTER XII.

Influence of Arsenic on Bacterial Activity

Occurrence of Arsenic . . . . . . . . . . . . . 118

Factors Influencing Solubility . . . . . . . . . . 118

Ammonifiers *. . . . . . . . . . . . . 119

Nitrification . . . . . . . . . . . . . . . 119

Nitrogen Fixation . . . . . . . . . . . . . . 120

How Does the Arsenic Act? . . . . . . . . . . . . 120

References . . . . . . . . . . . . . 126

\section{CHAPTER XIII.}

Effect of Heat and Volatile Antiseptics on Soll Bacteria

Influence on Plant . . . . . . . . . . . . . 127

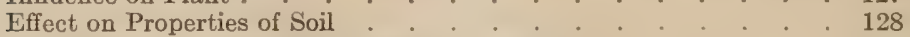

Hypotheses to Account for Observed Phenomena . . . . . . 133

Koch's "Direct Stimulation" Theory . . . . . . . . . 133

Hiltner and Störmer's Indirect Theory . . . . . . . . . . 133

Russell and Hutchinson's Protozoan Theory . . . . . . . 135

Greig-Smith's Bacteriotoxin Theory . . . . . . . . . . 138

References . . . . . . . . . . . . 138

CHAPTER XIV.

Influence of Salts on the Bacterial Activities of the Sorl

Calcium Carbonate . . . . . . . . . . . . . 139

Lime . . . . . . . . . . . . . . . 141

Gypsum . . . . . . . . . . . . . . . . 142

Calcium Chloride . . . . . . . . . . . . . 142

Iron Sulphate . . . . . . . . . . . . . . . 142

Magnesium Salts . . . . . . . . . . . . 143

Manganese . . . . . . . . . . . . . . . 143

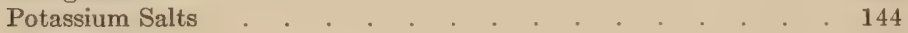

Sodium Salts . . . . . . . . . . . . . . . . 145

Variation in Effect Produced . . . . . . . . . . . . . . 146

Stimulating Action . . . . . . . . . . . . . 147

Toxicity of Various Salts . . . . . . . . . . . . . . 149

Reference . . . . . . . . . . . . . . . 149

HAPTER XV.C

Influence of Manure on the Bacterial Activities of the Soll

Number . . . . . . . . . . . . . . . 151

Ammonification and Nitrification . . . . . . . . 153

Loss of Nitrates . . . . . . . . . . . . . . . 153

Green Manures . . . . . . . . . . . . . 156

Reference . . . . . . . . . . . . . 159

CHAPTER XVI.

The SoIl Flora

Koch Gelatin-Plate Method . . . . . . . . . 160

Hiltner and Störmer Dilution Method . . . . . . . . 160

Defects of Plate Method . . . . . . . . . . . 160

Value of Bacterial Counts . . . . . . . . . . . . 161 
Number of Bacteria in Soil

Factors Influencing Number

Kinds of Microörganisms in Soil . . . . . . . . 164

B. megatherium de Bary . . . . . . . . . . . . 165

Morphology . . . . . . . . . . . . . 165

Cultural Characteristics . . . . . . . . . . . . . 165

Physiology . . . . . . . . . . . . 165

B. mycoides Flügge, $1886 \quad 166$

Morphology . . . . . . . . . . . . . 166

Cultural Characteristics . . . . . . . . . . . 167

Physiology . . . . . . . . . . . . . . 167

B. cereus Frankland, $1887 \quad$. . . . . . . . . . 167

Morphology . . . . . . . . . . . . . 167

Cultural Characteristies . . . . . . . . . . . . . . . 167

Physiology . . . . . . . . . . . . . . 168

Ps. fluorescens (Flügge) Migula . . . . . . . . . . 168

Morphology . . . . . . . . . . . . 168

Cultural Characteristics . . . . . . . . . . . 168

Physiology . . . . . . . . . . . . . 168

Actinomyces . . . . . . . . . . . . 169

Reference . . . . . . . . . . . . . . 170

CHAPTER XVII.

Mineralization and Solvent Action of Bacteria

Bacteria as Soil Formers . . . . . . . . . . . . . 171

Calcium Carbonate . . . . . . . . . . . . . 172

Phosphorus . . . . . . . . . . . . . . . 173

Sulphur . . . . . . . . . . . . . . 178

Iron . . . . . . . . . . . . . . . . 180

Potassium . . . . . . . . . . . . . 180

References . . . . . . . . . . . . . . . 180

CHAPTER XVIII.

The Carbon, Nitrogen, Sulphur and Phosphorus Cycles

The Carbon Cycle . . . . . . . . . . . . . . 182

The Nitrogen Cycle . . . . . . . . . . . . . . . 183

The Sulphur Cycle . . . . . . . . . . . . . . 184

The Phosphorus Cycle . . . . . . . . . . . . . 184

References . . . . . . . . . . . . . . 187

CHAPTERS XIX.

Putrefaction, Fermentation and Decay

Definitions . . . . . . . . . . . . . . . 188

Active Agents . . . . . . . . . . . . . . . . 189

Chemistry of the Process . . . . . . . 192

References . . . . . . . . . . . . . 193

CHAPTERS XX.

AMMONIFICATION

Species and Distribution . . . . . . . . . . . . 196

Methods . . . . . . . . . . . . 198

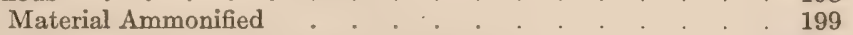

Influence of Soil and Climatic Conditions . . . . . . . 200

Moisture . . . . . . . . . . . . . 200

Aëration . . . . . . . . . . . . . . 202

Lime and Magnesium . . . . . . . . . . . . . 203

Phosphorus . . . . . . . . . . . . . . . . . 203

Chemistry of the Process . . . . . . . . . . . . . 204

References . . . . . . . . . . . . 207 


\section{CHAPTER XXI.}

Nitrification

Early 'Theories . . . . . . . . . . . . . 208

The Dawn of the Biological Theory . . . . . . . . . . 209

Isolation of Nitrifying Ferments . . . . . . . . 211

Distribution . . . . . . . . . . . . . 217

Reaction of Media : . . . . . . . . . . . . 218

Food Requirements of Nitrifiers . . . . . . . . . . 220

Organic Matter . . . . . . . . . . . . . . . . . 222

Energy . . . . . . . . . . . . . . . 223

Metabolism . . . . . . . . . . . . . . . 223

Morphology . . . . . . . . . . . . . . . . 225

Influence of Moisture . . . . . . . . . . . . . . 226

Temperature . . . . . . . . . . . . . . . . 230

Light Rays . . . . . . . . . . . . . . . . . 230

Aëration and Cultivation . . . . . . . . . . . . . 230

Crop and Fallow . . . . . . . . . . . . . . . . . 231

Season . . . . . . . . . . . . 234

Quantity of Nitrates Formed . . . . . . . . 235

Loss of Nitrates . . . . . . . . . . . . . . . 236

References . . . . . . . . . . . . . . 238

CHAPTER XXII.

Early Theories . . . . . . . . . . . . . . 239

Organisms Concerned . . . . . . . . . . . . . . 240

Reaction of the Media . . . . . . . . . . 241

Food Requirements . . . . . . . . . . . . . . 242

Metabolism of Denitrifying Organisms . . . . . . . . . . 243

Influence of Water _ . . . . . . . . . . . . . . 244

Temperature . . . . . . . . . . 245

Losses of Nitrates from Manure and Soil . . . . . . . . . 245

Function of Denitrifiers . . . . . . . . . . . . . 247

References . . . . . . . . . . . . . . 247

CHAPTER XXIII.

Historical . . . . . . . . . . . . . . . . . 248

Distribution . . . . . . . . . . . . 252

Reaction of the Media . . . . . . . . . . . . 254

Food Requirements of the Azofiers . . . . . . . . . . . . 256

Organic Soil Constituents _ . . . . . . . . . . . . . . . 259

Influence of Colloids . . . . . . . . . . . . . . . 260

Sources of Energy for the Azobacter ․ . . . . . . . . . . 261

Manure . . . . . . . . . . . . . 266

Metabolism of Azotobacter . . . . . . . . . . . . . 267

Pigments Produced by Azotobacter . . . . . . . . . . . . 270

Morphology of the Nitrogen-fixing Organisms . . . . . . . . 271

Methods . . . . . . . . . . 272

Relation of Azotobacter to Other Organisms . . . . . . . . 274

The Influence of Water . . . . . . . . . . . . . 276

Temperature . . . . . . . . . . . . 278

Light and Other Rays _. . . . . . . . . . . . . 281

Aëration . . . . . . . . . . . . . . 281

Season . . . . . . . . . . . . . . . 281

Crop . . . . . . . . . . . . . . . . . 282

Climate . . . . . . . . . . . . . 283

Relationship of Azotobacter to Nitrate Accumulations . . . . 284

Soil Inoculation . . . . . . . . . . . . . . . 284

Soil Gains in Nitrogen . . . . . . . . . . . . . 287

Reference . . . . . . . . . . . . . . . . . 289 


\section{CHAPTER XXIV.}

\section{Symbiotic Nitrogen Fixation}

Early Theories

Early Observations on Root Tubercles . . . 291

Species

Cultural Characteristies _. _ _ 297

Morphology of the Colonies . . . . . . . . . . . 299

Morphology of the Bacteria . . . . . . . . . . . . 302

Staining . 303

Bacteroids _. . . . . . . . . 303

Mode of Entrance into the Host . . . . . . . . . . 304

Growth of the Nodule . . . . . . . . . . . . 304

Relationship to Host . . . . . . . . . 305

Mechanism of Fixation (Metabolism) . . . . 306

Chemical . . . . . . . . . . . 308

Source of Energy . _ _ _ _ _ . _ . . . . . . . 312

Aëration . . . . . . . . . . . . . 312

Moisture _. . . . . . . . . . . . 312

Temperature . . . . . . . . . . . . 313

Influence of Fertilizers _. . . . . . . . . . 313

Legumes Associated with Non-legumes _ . . . . . . . . 314

Soil Gains in Nitrogen . . . . . . . . . . . . . 315

Soil Inoculation _. . . . . . . . . . . . . 316

Method Involving the Use of One Commercial Culture . . . . 317

Alternative Method _ _ . . . . . . . 317

Commercial Cultures . . . . . . . . . . . . 318

References . . . . . . . . . . . . 318

\section{CHAPTER XXV.}

\section{Crop Rotation}

Essential Elements _... . . . . . . 319

Element Added by Legumes . . . . . . . . . . . . . . 319

Nitrogen . . . . . . . . . . . . . . 320

Rothamsted Rotation . . . . . . . . . . . . . . 321

Nitrogen Obtained from Atmosphere by Legumes . . . . . . 322

Distribution of Nitrogen in Legumes . . . . . . . . 323

Legumes Feed on Nitrates . . . . . . . . . . . . . . . . 323

Nitrification in Soils . . . . . . . . . . . . . . 324

How to Maintain Soil Nitrogen . . . . . . . . . . . 325

References . . . . . . . . . . . . . . 326

\section{CHAPTERS XXVI.}

Cellulose-decomposing Organisms

Cellulose

Early Observations . . . . . . . . . . . . . . . 327

Work of Omelianski _. . . . . . . . . . 330

Morphology and Physiology . . . . . . . . . . . . 331

Later Work on Cellulose Fermentation . . . . . . . . . 333

Function . . . . . . . . . . . . . 333

References . . . . . . . . . . . . . . . 335

\section{CHAPTER XXVII.}

Bacteria in Air

How Bacteria Enter Air . . . . . . . . . . . . . 336

Number and Kind . . . . . . . . 336

Factors Governing Number and Kind . . . . . . . . . 337

Bacteria in Inspired and Expired Air . . . . . . . . . . . . 339

Air-borne Infection . . . . . . . . . . . . . . 339 
CHAPTER XXVIII.

\section{Water Bacteriology}

Classification of Waters

Numbers of Bacteria in Waters.

Sedimentation

Light

Temperature

Food

Classes of Bacteria

Soil Bacteria

Intestinal Bacteria

CHAPTER XXIX.

Water AND Disease

Disease First Definitely Proved as Due to Water . . . . . . 351

Amount of Sickness Due to Water . . . 352

The Mills-Reincke Phenomenon . . . . . . . . . . . . 353

Cholera . . . . . . . . . . . . . 354

Typhoid . . . . . . . . . . . . . . . . . 354

References . . . . . . . . . . . . 359

\section{CHAPTER XXX.}

Sewage and Sewage Disposal

Source, Composition and Quantity of Sewage . . . . . . . 360

Bacteria in Sewage . . . . . . . . . . . 361

Hydrolyzing Bacteria . . . . . . . . . . . . . . 362

Oxidizing Bacteria . . . . . . . . . . . . . . . 363

Reducing Bacteria . . . . . . . . . . . . . . . . 363

Pathogenic Bacteria . . . . . . . . . . . . . . 364

Necessity of Sewage Disposal ․ . . . . . . . . . 366

What Should Be Accomplished in Sewage Disposal? . . . . . 366

Methods of Dispoasal . . . . . . . . . . . . . . 366

References . . . . . . . . . . . . . . . 367

\section{CHAPTER XXXI.}

\section{Mrlk Bacteriology}

Milk as a Food . . . . . . . . . . . . . . . 368

Classes of Milk . . . . . . . . . . . . . 371

Bacteria in Milk . . . . . . . . . 372

Initial Contamination . . . . . . . . . 372

Growth of Bacteria in Milk . . . . . . . . . . . . . 374

Changes Produced in Milk by Bacteria . . . . . . . . . 375

Abnormal Changes in Milk . . . . . . . . . . . 376

Classes of Bacteria . . . . . . . . . . . . . . . 376

Acid-forming Bacteria . . . . . . . . . . . . . . . . . . 376

Peptonizing Bacteria . . . . . . . . . . . . . 377

Bacteria Producing Milk of Unusual Character . . . . . 377

Inert Organisms . . . . . . . . . . . . 377

Pathogenic Bacteria . . . . . . . . . . . . 377 


\section{CHAPTER XXXII.}

Milk and Disease

Sources of Infection

Character of Milk-borne Diseases

Extent of Milk-borne Disease . . . . . $\quad 380$

The Tuberculin Test . . . . . . . . . . . . . . . . 383

Pasteurization . . . . . . . . . . . . . 385

References . . . . . . . . . . . . . . . 386

CHAPTER XXXIII.

\section{Bacteria in Other Foods}

Bacteria in Butter.

Bacteria in Cheese .

Bacteria in Ice Cream

Bacteria in Condensed Milk

Bacteria in Bread

Bacteria in Eggs

Bacteria in Meat

\section{CHAPTER XXXIV.}

\section{Bacteria AND Food-Poisoning}

Classes of Food-poisoning

Poisonous Foods

Metallic Poisons

Animals Suffering from Disease

Typical Paratyphoid Outbreaks

Offending Foods

Human Infection

Ptomain Poisoning

\section{CHAPTER XXXV.}

Preservation of Food

Methods of Preserving Food

Cold

Drying .

\section{CHAPTER XXXVI.}

Bacteria in the Arts and Industries

Alcoholic Fermentation

Vinegar .

Sauerkraut

Ensilage .

Retting .

Tanning . 



\title{
AGRICULTURAL BACTERIOLOGI.
}

\author{
CHAPTER I.
}

\section{DEVELOPMEN'T OF BACTERIOLOGY.}

NowHere in the whole realm of human endeavor has research been crowned with more glorious achievements, at least in so far as the welfare of the human race is concerned, than in the field of bacteriology, and this in face of the fact that bacteriological research had a most humble and recent origin. Even the dawn of bacteriology dates back only to the last quarter of the seventeenth century to the time when a Dutch linen-draper, Anton van Leeuwenhoek, spent his leisure time in grinding lenses. He became so proficient in this that his lenses were superior to any made before. Turning them on various substances - raindrops, saliva, and many putrifying things-he found in all these living, moving forms, which prior to this time had been unrecognized. We can imagine his joy and surprise from this statement: "I saw with wonder that my material contained many tiny animals which moved about in a most amusing fashion. The largest of these $A$ (Fig. 1) showed the liveliest and most active motion, moving through the water or saliva as a fish of prey darts through the sea; they were found everywhere, although not in large numbers. A second lind was similar to that marked $B$ (Fig. 1) which sometimes spun around in a circle like a top. 'These were present in larger numbers and sometimes described a path like that shown in $C$ to $D$ (Fig. 1). A third kind could not be distinguished so clearly; now they appeared oblong, now quite round. 'They were so very small that they did not seem larger than the bodies marked $E$, and besides they moved so rapidly that they were continually running into one another. 'They looked like a swarm of gnats or flies dancing about together. I had the impression that I was looking at several thousand in a given part of the water or saliva mixed with a particle from the teeth no larger than a grain of sand, even when only one part of the material was added to nine parts of water or saliva. Further, the greater part of the material consisted of an extraordinary number of rods, of widely different lengths, but of the same diameter; some were 
curved, some straight, as is shown in $F$; they lay irregularly and were interlaced. Since I had previously seen living animalcules of this same kind in water, I endeavored to observe whether there was life in them, but in none did I see the smallest movement that might be taken as a sign of life."

This patient worker, supplied with his crude microscope, gives a fairly accurate description of these minute forms of life. But this did not awaken the world to even a faint realization of the wonderful invisible forms of life which were present in everything and were always working for good or evil. It did, however, revive a discussion which had waxed long and furious as to whether life can spring spontaneously from inanimate matter or whether it is the descendant of preëxisting living organisms.

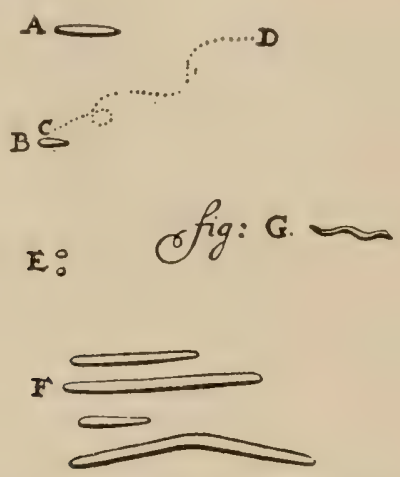

Frg. 1. - The first drawings of bacteria by Leeuwenhoek. The dotted line $C-D$ indicates movement of the organism. - (Morrey.)

Spontaneous Generation.-Back in the sixteenth century a famous physicist and chemist, van Helmont, stated that mice can be spontaneously generated by merely placing some dirty rags in a receptible together with a few grains of wheat or a piece of cheese. The same philosopher's method of engendering scorpions is also amusing.

"Scoop out a hole in a brick, put into it some sweet basil. Lay a second brick upon the first, so that the hole may be imperfectly corered. Expose the two bricks to the sun, and at the end of a few days the smell of the sweet basil, acting as a ferment, will change the herb into a real scorpion."

An Italian, Bouonami, tells of a wonderful metamorphosis which he had witnessed. Rotten timber, rescued from the sea, produced worms; these gave rise to butterflies; and strangest of all, the butterflies became birds.

Everyone thought it a self-evident fact that maggots sprang spontaneously from decomposing_meat or cheese, until an Italian 
poet and physician, Redi, took the simple precaution of screening the mouth of jars containing meat so that flies could not enter. Flies were attracted by the odor and deposited their eggs on the gauze, and it was from these that the so-called "worms" arose.

The theory of the spontaneous generation of mice, scorpions, and maggots had been proved untenable. But how about these microscopic organisms? They surely could develop directly from organic material. For now anyone provided with this new instrument, the microscope, could easily demonstrate for himself the spontaneous generation of microscopic eels in vinegar, or produce myriads of different and interesting living creatures in simple infusion of hav or other organic material.

Needham, a Catholic priest, evolved the theory that a force called "productive" or "vegetative" existed which was responsible for the formation of organized beings. 'The great naturalist, Buffon, elaborated the theory that there were certain unchangeable parts common to all living creatures. After death these ultimate constituents were supposed to be set free and become active, until, with one another and still other particles, they gave rise to swarms of microscopic creatures.

Needham in 1745 took decaying organic matter and enclosed it in a vessel; this he placed upon hot ashes to destroy any existing animalculæ. On examining the contents of the flasks he found microorganisms which he had not noted at first. Later (1769), Spallanzani repeated the work. He felt that Needham had not exercised sufficient care and that the organisms had gotten in from the outside. Accordingly he boiled the material for one hour and kept it in hermetically sealed flasks. He wrote: "I used hermetically sealed vessels. I kept them for one hour in boiling water, and after opening and examining their contents after a reasonable interval, I found not the slightest trace of animalculæ, though I had examined the infusion from nineteen different vessels."

But the believers in the theory of abiogenesis were not convinced, for they claimed that the boiling altered the character of the infusion so that it was unable to produce life. Voltaire, with his characteristic satire, took up the fight at this point and ridiculed the operations of the English clergy "who had engendered the eels in the gravy of boiled mutton," and he wittily remarks: "It is strange that men should deny a creator and yet attribute to themselves the power of creating eels." But this was a controversy to be settled not by ridicule but by experimental evidence.

Spallanzani answered this by cracking one of the flasks so that air could enter. Decay soon set in. Even this was not sufficient to overthrow a popular belief, for the claim was made that the sealing of the flasks excluded the air, and air was essential to the generation of these forms of life. This objection was answered by the work of 
many ingenious investigators. Schulze, in 1836, passed air through strong acids and then into boiled infusions and failed to find any living organisms in the infusion, whereas Schwann passed the air through highly heated tubes with the same results. This was criticized by their opponents who claimed that the chemical alteration

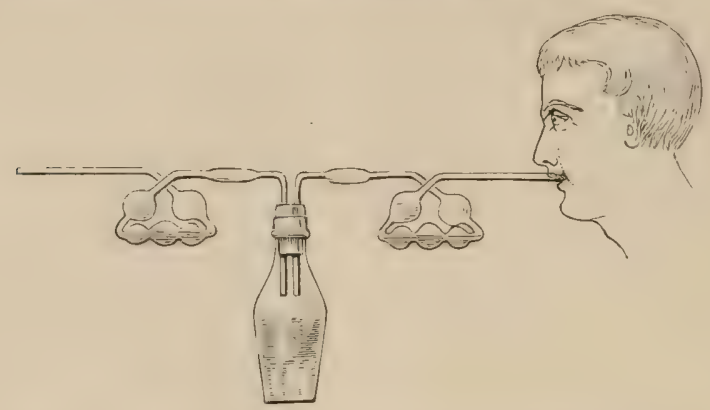

Fig. 2.-Experiment of Schulze: Forcing air through sulphuric acid. (Lafar.)

of the air subjected to such drastic treatment had been responsible for the absence of bacteria in the infusion. The work of Schroeder and Dusch (1853) was more convincing, for they found that it was sufficient to stopper the bottles with cotton plugs; the air passed in but the microörganisms were held back by the cotton and the

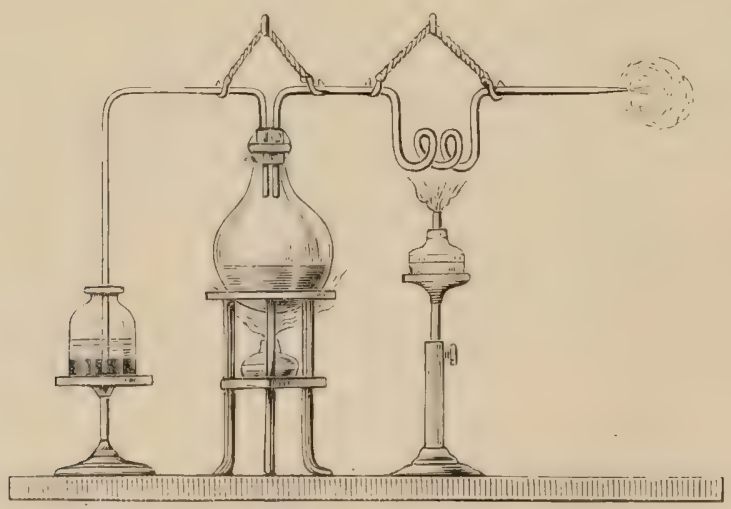

FIG. 3.--Experiment of - Schwann: Heating air to make it sterile. (Lafar.)

contents of the flasks kept in good condition. Every now and then the contents of a flask would spoil, even after it had been carefully stoppered and boiled. 'This remained a stumbling block in the way of those who maintained that life sprang only from life, until in the year 1865 when Pasteur demonstrated that many bacteria may pass 
into a resting stage, and while in this condition will withstand conditions which quickly kill them in the regetative stage. Eleven years later Cohn of Breslau carefully investigated organisms in this resting or spore stage, and today forms of microörganisms are known which will withstand boiling water for sixteen hours without being killed, and otlers resistant enough even to endure for many hours a 10 per cent. solution of carbolic acid.

Fermentation. - Since the dawn of history man las been interested in that wonderful process known as fermentation, and although many an ingenious theory has been formulated to explain it, little more than theory existed until the classic work of Pasteur on fermentation appeared about 1837. Pasteur claimed that all forms of fermentation were due to the action of microscopic organized cells. An idea such as this, even at this late date, did not go unchallenged, for we find no less illustrious workers than Helmholtz and Liebig opposing it. Liebig scoffed at such an idea, writing: "Those who pretend to explain the putrefaction of animal substance by the presence of microörganisms reason very much like a child who would explain the rapidity of the Rhine by attributing it to the violent motions imparted to it in the direction of Burgen by the numerous wheels of the mills of Venice."

However, Pasteur's carefully planned experiments soon demonstrated that without the microörganisms there would be no fermentation, no putrefaction, no decay of any tissue, except by the slow process of oxidation. The care with which his experiments were planned and executed are well shown in the experiments with grape sugar, concerning which he wrote: "I prepared forty flasks of a capacity of from two hundred and fifty to three hundred cubic centimeters and filled them half full with filtered grape-must, perfectly clear, and which, as is the case of all acidulated liquids that have been boiled for a few seconds, remains uncontaminated, although the curved neck of the flask containing them remains constantly open during several months or years.

"In a small quantity of water, I washed a part of a bunch of grapes, the grapes and the stalks together, and the stalks separately. This washing was easily done by means of a small barber's hairbrush. The washing-water collected the dust upon the surface of the grapes and the stalks and it was easily shown under the microscope that this water held in suspension a multitude of minute organisms closely resembling either fungoid spores or those of alcoholic yeast, or those of Mycoderma vimi, ete. This being done, ten of the forty flasks were preserved for reference; in ten of the remainder, through the straight tube attached to each, some drops of the washing-water were introduced; in a third series of ten flasks a few drops of the same liquid were placed after it had been boiled; and finally in the ten remaining flasks were placed some drops of grape-juice taken 
from the inside of perfect fruit. In order to carry out this experiment the straight tube of each flask was drawn out into a fine and firm point in the lamp, and then curved. This fine and closed point was filed round near the end and inserted into the grape while resting upon some hard substance. When the point was felt to touch the support of the grape it was by a slight pressure broken off at the file mark. Then if care had been taken to create a slight racuum in the flask, a drop of the juice of the grape got into it; the filed point was withdrawn and the aperture immediately closed in the alcohol lamp. This decreased pressure of the atmosphere in the flask was obtained by the following means: After warming the sides of the flask, either in the hands or in the lamp flame, thus causing a small quantity of air to be driven out of the end of the curved neck, this end was closed in the lamp. After the flask was cooled, there was a tendency to suck in the drop of grape-juice in the manner just described.

"The drop of grape-juice which enters into the flask by this suction ordinarily remains in the curved part of the tube, so that to mix it with the must it was necessary to incline the flask so as to bring the must into contact with the juice and then replace the flask in its normal position. The four series of comparative experiments produced the following results:

"The first ten flasks containing the grape-must boiled in pure air did not show the production of any organisms. The grape-must could possibly remain in them for an indefinite number of years. Those in the second series, containing the water in which the grapes had been washed separately and together, showed without exception an alcoholic fermentation which in several cases began to appear at the end of forty-eight hours when the experiment took place at ordinary summer temperature. At the same time that the yeast appeared, in the form of white traces, which little by little united themselves in the form of a deposit on the sides of all the flasks, there were seen to form little flakes of Mycelium, often as a single fungoid growth or in combination, these fungoid growths being quite independent of the must or of any alcoholic yeast. Often, also, the Iycoderma imi appeared after some days upon the surface of the liquid. The vibria and the lactic ferments, properly so-caller, did not appear on account of the nature of the liquid.

"The third series of flasks, the washing-water of which had been previously boiled, remained unchanged, as in the first series. Those of the fourth series, in which was the juice of the interior of the grapes, remained equally free from change, although I was not alway's able, on account of the delicacy of the experiment to eliminate every chance of error. 'These experiments cannot leave the least doubt in the mind as to the following facts:

"(irape-must, after heating, never ferments on contact with air, 
when the air has been deprived of the germs which it ordinarily holds in a state of suspension.

"The boiled grape-must ferments when there is introduced into it a very small quantity of water in which the surface of the grapes of their stalks have been washed.

"The grape-must does not ferment when there is added to it a small quantity of the juice of the inside of the grape.

"The yeast, therefore, which causes the fermentation of the grapes in the vintage-tub comes from the outside and not from the inside

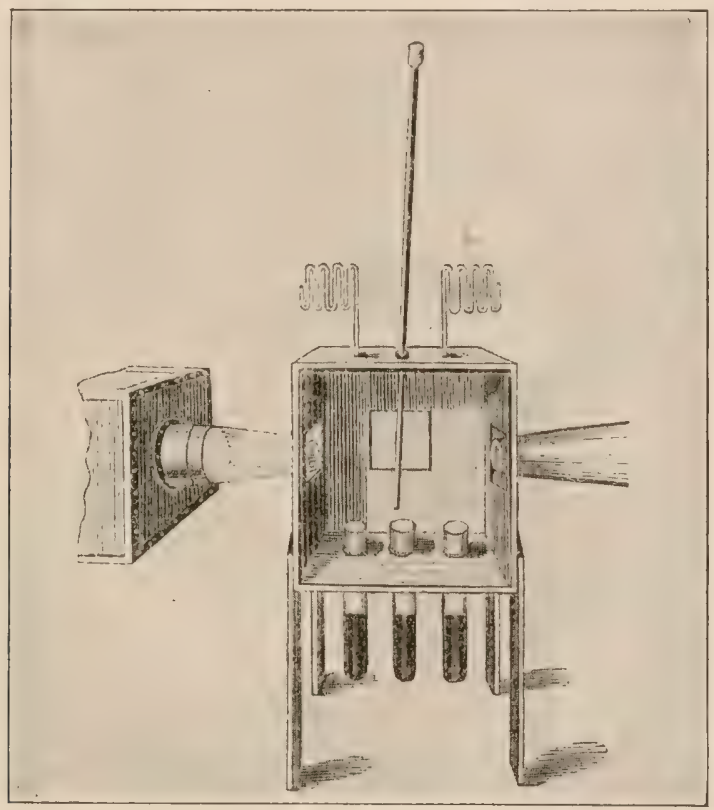

Fig. 4.-Tyndall's box. One side is removed to show the construction. The bent tubes at the top are to permit a free circulation of air into the interior. The window at the back has one corresponding in the front (removed). Through these the beam of light sent through from the lamp at the side was observed. The three tubes received the infusion and were then boiled in an oil bath. The pipette was for filling the tubes. (Popular Science Monthly, April, 1877.)

of the grapes. Thus it destroyed the hypothesis of MIM. Trecol and Fremy, who surmised that the albuminous matter transformed itself into yeast on account of the vital germs which were natural to it. With greater reason, therefore, there is no longer any question of the theory of Liebig of the transformation of albuminoid matter into ferments on account of the oxidation."

Pasteur's work did not stop here, for he soon proved that a disease that was attacking the silkworm was caused by bacteria. And from this there developed the idea that disease in general is due to bacteria. 
If there were any doubts left in the minds of the scientific world as to the fallacy of the theory of spontaneous generation, after the work of Pasteur, they were dispelled by the work of Tyndall. Tyndall proved that in an atmosphere devoid of dust, as on the tops of mountains and in some ingeniously constructed boxes used by him, perishable substances, such as beef tea, if sterile when placed in such an atmosphere, will keep for an indefinite period.

Smallpox. - Smallpox was formerly looked upon as practically unavoidable by all members of the human family, as is seen from a popular saying current in Germany in the eighteenth century: "von Pocken und Liebe bleiben nur wenige frei," from smallpox and love few remain free.

Concerning smallpox Macaulay wrote in referring to the death of Queen Mary from the disease in 1694: "The havoc of the plague had been far more rapid; but plague had visited our shores only once or twice within living memory, and the smallpox was always present, filling the churchyards with corpses, tormenting with constant fears all whom it had not yet stricken, leaving in those whose lives it spared the hideous traces of its power, turning the babe into a changeling at which the mother shuddered, and making the eyes and cheeks of the betrothed maiden objects of horror to the lover."

For the different condition which exists today in civilized countries where the fear of smallpox is nearly as remote as that of leprosy, Edward Jenner (1749-1823) is chiefly to be thanked. His attention was at first directed to the subject by the remark of a young girl: "I cannot take smallpox for I have had cowpox." After considerable labor and opposition he developed and gave to the world, without monetary consideration, his vaccine which has all but banished from the world the dreaded disease-smallpox.

Anthrax.-As early as 1863 investigators had seen in the blood of some animals that had died of a disease known as anthrax, a very small rod-like organism which permeated all the capillaries. Their experiments showed that the blood from such an animal, when injected into the veins of a second animal, caused it to die of the same disease. But they found that there were times when the organism could not be discovered in the blood of the dead animal, although. injection with blood from this animal would cause the death of another. This fact left a doubt in the minds of thinking men assto whether this rod-shaped organism was the cause of the animal's death or whether it was "some invisible element in the blood." Not until thirteen years later was this fully settled by the work of Robert Kioch. He not only saw the rod-shaped organism, but obtained it free from all other substances, and proved that it was the specific cause of the disease. 'This was followed by many other discoveries, until today it is known that practically all diseases are due 
to microscopic organisms. Yes, even many of the changes taking place in the body and associated with old age are attributed by some writers to the products generated by bacteria.

The workers in this field are not satisfied with knowing the cause of a disease, but they wish to know how they may ward off disease and how to cure it when once it gains access to the body of an animal. Pasteur soon announced that he had found a preventive for anthrax. His statement was immediately challenged by the president of an agricultural society in such a way that it was brought to the attention of the entire civilized world. He suggested that the subject be submitted to a decisive public test and offered to furnish fifty sheep, half of which should be protected by the attenuated virus prepared by Pasteur. Later they were all to be infected by the diseaseproducing organisms and if the vaccine were a success the protected ones were to remain healthy, the unprotected ones to die of the disease. Pasteur accepted the challenge and suggested that for two of the sheep there should be substituted two goats, and that there be added to the herd ten cows, but he stated that these latter animals should not be considered as falling rigidly within the test, for his experiments had not yet been extended to cattle. Before this time the fame of Pasteur had been considered firmly established, but now all the world looked on with doubt to think that any man should make such a preposterous claim. On May 5 the animals to be protected received their first treatment with the vaccine and a second two weeks later. Virulent cultures of the disease-producing organism were then inoculated into the animals. 'The results of the test were indeed dramatic.

"Two days later, June 2, at the appointed hour of rendezvous, a vast crowd, composed of veterinary surgeons, newspaper correspondents, and farmers from far and near, gathered to witness the closing scenes of this scientific tourney. What they saw was one of the most dramatic scenes in the history of peaceful science, a scene which Pasteur declared afterward, 'amazed the assembly.' Scattered about the enclosure, dead, dying, or manifestly sick unto death, lay the umprotected animals, one and all, while each and every protected animal stalked unconcernedly about with every appearance of perfect health. Twenty of the sheep and the one goat were already dead; two other sheep expired under the eyes of the spectators; the remaining victims lingered but a few hours longer. Thus, in a manner theatrical enough, not to say tragic, was proclaimed the unequivocal victory of science."

It has been estimated by conservative writers that Pasteur's discovery of the means of preventing or curing anthrax, silkworms' disease, and chicken cholera, adds annually to the wealth of France a sum equivalent to the entire indemnity paid by France to Germany after the War of 1870. 
Other Work of Pasteur.- This was only a part of the work of this great man, for in 1SS:5 he announced a cure for hydrophobia. P'rior' to this time the disease developed in at least 16 per cent. of the individuals bitten hy marl dogs, and of this 16 per cent., 100 per cent. died. Since Pasteur's discovery the number of deaths from this cause has been reduced almost to zero. The profound importance of his work has been well summarized by Lord Lister: "Truly there does not exist in the entire world any individual to whom the medical science owes more than they do to you. Your researches on fermentation have thrown a powerful beam which lightened the baleful darkness of surgery and has transformed the treatment of wounds from a matter of uncertain and too often disastrous empiricisms into a scientific art of sure beneficence. Thanks to you, surgery has undergone a complete revolution which has deprived it of its terrors and has extended almost without limit its efficacious powers."

And Tyndall writes: "Te have been scourged by miserable throngs, attacked from impenetrable ambuscades, and it is only today that the light of science is being let in upon the murderous dominion of foes."

Other Plagues Conquered. - In the realm of medicine one discovery after another has followed in rapid succession during the last few years, until today diphtheria instead of having a death-rate of orer 30 per cent. has one of less than 3. 'Typhoid ferer is all but conquered. Asiatic cholera and the yellow fever have been nearly wiped from the face of the earth, thus making possible the building of the Panama Canal.

Lister.- Thanks to the wonderful work of Lord Lister we no longer have that terrible suppuration, which before his time followed even slight wounds. At the close of the nineteenth century it was asserted that "Listerism" had saved more lives than had been sacrificed by" all the wars of the nineteenth century. Although continually brought in contact with suffering and misery, this truly great man did not lose his tender-hearted nature and love of children, as is shown by the following story related by one of Lister's students.

"One day when Lister was visiting his wards in the Glasgow Royal Infirmary, there was a little girl whose elbow-joint had been excised, and this had to be dressed daily. Lister undertook this dressing himself. 'The little creature bore the pain without complaint, and when finished she suddenly produced from under the clothes a dilapidated doll, one leg of which had burst, allowing the sawdust to escape. She handed the doll to Lister, who gravely examined it; then asking for a needle and thread, he sat down and stitched the rent, and then returned the doll to its gratified owner."

Yellow Fever.-The investigators in some of these fields have gone into it not only with a knowledge of the fact that failure way be their lot, but they even risked their lives in the work, as is shown 
in the fight against yellow fever. I)r. Lazear, an Anerican army surgeon, allowed himself to be bitten by a nosquito in an infected ward. IIe soon acquired yellow ferer in the most terrible form and died a martyr to science and a true hero. He gave up his life for others; the plain record of his sacrifice is recorded thus upon a tablet erected to his memory: "With more than the courage and derotion of the soldier, he risked and lost his life to show how a fearful pestilence is communicated and how its rarages may be prevented." That this is convered only by the bite of the mosquito was shown by the following: Three brave men slept for twenty nights in a small, ill-rentilated room screened from mosquitoes but containing furniture and clothing smeared with the excretion of yellow fever patients - some of whom had died of the disease. None of the men contracted yellow ferer, thus indicating the disease was not of a contagious nature.

Agricultural Bacteriology. - In 1883 Burrill, by the discovery of the organism which causes fire- or pear-blight, opened up a similar interesting and practical field in the plant kingdom which even at the present day is only in its infancy.

It may appear from the preceding that bacteria are all enemies of man, but this is not true, for there are many more beneficial bacteria than injurious ones.

Even in the field of agricultural bacteriology rapid advances have been and are being made. To Beijerinck, Ilellriegel, Wilfarth, Lipman, and a host of others, we owe our knowledge concerning the morphology and physiology of the nitrogen-fixing organisms. In 1888 Winogradsky isolated the nitrifying organisms which grow on a medium devoid of all organic matter and since that time there is an ever-increasing volume of work on this phase of the subject. Hansen's investigation in industrial fermentation is also important.

Future Work. - One may think from the preceding that in this field of science there is little to be done, but this is not tlie case, for there are diseases still unconquered. The great "White Plague" still claims its millions each year. There are diseases which are sapping the very life-blood of the nation, yet they go unchecked. Science as yet has not come to the aid of the unfortunate victims.

As regards the beneficial organism we have only just started to realize their great possibilities. In the soil are five great classes of organisms which deal with the transformation of nitrogen. One class carries on putrefaction, changing the insoluble proteins into ammonia, another picks the ammonia up as formed, transforming it into nitrites, and even this must be changed into nitrates before plants can use it. Under what condition are these changes carried on at a maximum rate? What influence has moisture, temperature crop, and method of tillage on this change? Some of these questions are being answered by the work now being conducted, but there are 
many yet unanswered. Still they are vital questions, for, in many cases, the crop yields will be determined by the skill with which these various changes are controlled. There is another set of organisms in the soil, the function of which is to take the practically valueless nitrogen of the atmosphere and change it into forms such as the higher plants can feed upon. How may we control them for maximum yields? For if treated properly they will nerer tire, but toil on forever. Then again it is possible that bacterial action may be used as a measure of soil fertility and methods so perfected which are more sensitive than any now in use. Truly, in this field great things have been accomplished, but there remains yet to conquer fields richer by far than the workers of the past have ever dreamed.

\section{REFERENCES.}

Locy: Biology and its Makers.

Paget: Pasteur and after Pasteur.

Gregory: Discovery-The Spirit and Service of Science.

Vollery-Radot: The Life of Pasteur.

Libby: History of Science. 


\section{BACTERIA AND THEIR PLACE IN NATURE.}

BACTERIOLOGY in the strictest sense is that branch of science which deals with the distribution, morphology, classification, and function of bacteria. However, it is often used more general to include bacteria, yeasts, molds, and protozoa. A better term where all four groups are included is "microbiology." Many of the modern writers use this term.

Definition of Bacteria.-Bacteria are extremely minute, simple, unicellular organisms which multiply with great rapidity, usually by transverse fission, and are devoid of chlorophyl. Although they contain nuclear material which is usually diffused throughout the cell body in the form of larger or smaller granules, they possess no definite organized nucleus. They are generally accepted as belonging to the regetable kingdom. This is not without some opposition, due to the inherent difficulty of the subject, as is so admirably pointed out by Fischer: "The terms 'animal' and 'plant' are collective terms invented by laymen to describe familiar living things, insects and elephants, mosses and oak trees, and they date from a time when such minute beings as bacteria were quite unknown. It is therefore as superfluous as it is futile to attempt, as many have done, to detect the distinguishing characters of the 'animal' and the 'regetable' kingdoms among organisms for which these terms were never intended. For this reason, Haeckel and others have proposed to establish a third dominion, that of the Protista, which shall include all those forms in which differentiation has not been pronounced on the lines of either animal or plant development. The new group would take up Radiolarians, Flagellata, and Infusoria from the animal side, and the Cyanophycex as well as some low forms of Algre and Fungi from the plants. The border-line between protista on the one hand and plants and animals on the other isit must be confessed-artificial. 'To these protista, which embrace approximately all those forms of life we commonly call microorganisms or microbes, the bacteria belong."

It is generally stated that the plant cell differs from the animal cell by the possession of a firm and well differentiated wall, wholly distinct from the containing protoplasm, whereas the boundary surface of the animal cell is more often an outer layer of the protoplasm and not separable from it. Moreover, the typical cell wall 
of plants is usually made up of cellulose or one of its derivatives; the outer membrane of the animal cell is nitrogenous and where there is a heavy cell wall it is chitinous. Both of these distinctions break down in the case of the lower forms of plant and animal life.

The "blue-green" algre, or Schizophycex, possess chlorophyll and are obviously plants. Structurally, many of these are practically identical with bacteria. This constitutes a strong argument for the plant affinities of the bacteria.

Nor is it an easy task to differentiate nicely between bacteria, yeasts, and molds. Generally speaking, typical bacteria, yeasts, and molds may be distinguished from each other as follows: Bacteria are unicellular, devoid of a definite organized nucleus but con-
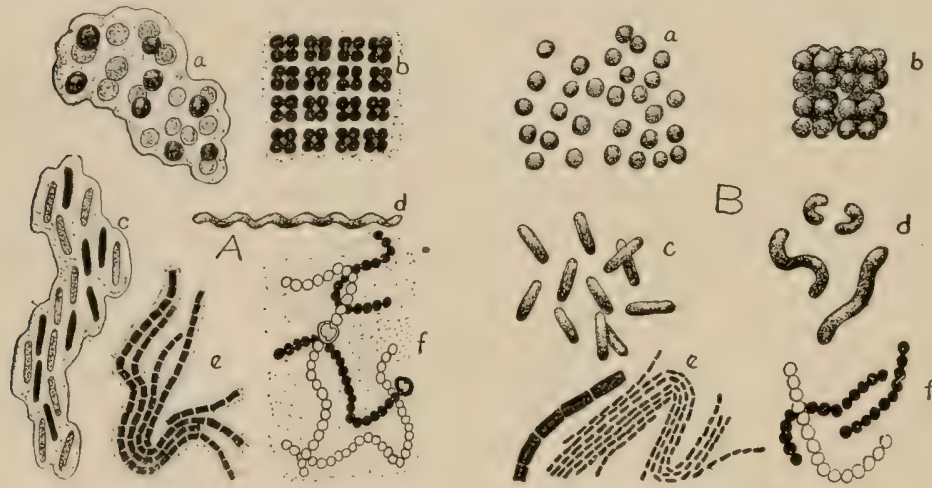

FIG. 5.-To illustrate the close relationship of the bacteria to the blue-green algæ. The figures to the left $(A)$ are blue-green algæ, those to the right $(B)$ bacteria. Those forms most closely resembling each other are lettered alike. $A$, blue-green algæ: $a$, Aphanocapsa; $b$, Merismopedia; $c$, Gleotheca; $d$, Spirulina; $e$, Phormidium; $f$, Nostoc. (All adapted from West.) $B$, bacteria: $a$, Micrococcus; $b$, Sarcina; $c$, Bacillus; $d$, Spirillum; $e$, Bacillus in chains; $f$, Streptococcus. (Buchanan's Household Bacteriology.)

taining nuclear material. They multiply by transverse fission. At times they are united into filaments or masses, but are usually easily separated. Yeast cells are usually, though not always, larger than bacteria. Although unicellular they contain a definite organized nucleus. They may remain united after cell division, but each cell constitutes a definite entity. Nost yeasts multiply by budding - only a few by simple fission. Molds are multicellular, nucleated organisms which are usually made up of a mass of interwoven or radiating threads consisting of chains of cells.

Divisions of Plant Kingdom. - Plants are divided into four great (rroups: Spermatophytes or seed plants, Pteridophytes or fern plants, Bryophytes or liver-worts and mosses, and Thallophytes or thallus plants. 'This last group has little or no differentiation of vegetative 
organs, such as stems and leaves. Two groups stand out conspicuously-known as algxe and fungi, but there are other groups whose relationship is not so clear. The main divisions of the Thallophytes are (1) Myxomycetes, commonly known as slime molds, or slime fungi, which combine characters of plants and animals; and (2) Schizophytes or fission plants, characterized by cell divisions occurring in rapid succession which is their only method of reproduction. They consist of two groups: the Cyanophycere, or blue-green algæ, and the Schizomycetes, or bacteria.

The relationship is shown diagrammatically below:

Thallophytes-simple, undifferentiated plants; do not develop roots, stems or leaves. $\left\{\begin{array}{l}\text { Myxomycetes-slime molds, or slime fungi. } \\ \text { Schizophytes-fission plants }\left\{\begin{array}{l}\text { Cyanophyceæ-blue-green } \\ \text { algæ. } \\ \text { Schizomycetes-bacteria. }\end{array}\right.\end{array}\right.$

Algæ, including seaweeds, pond scums, water-silks, etc.; contain chlorophyll.

Fungi without chlorophyll. $\left\{\begin{array}{l}\text { Yeasts. } \\ \text { Molds. } \\ \text { Mildews. } \\ \text { Smuts. } \\ \text { Rusts, etc. }\end{array}\right.$

Occurrence of Bacteria.-Bacteria are ubiquitous, occurring as they do nearly everywhere. They are found in soil to great depths, their number decreasing with the depth and nature of the soil, being more numerous in soil containing organic matter than in those practically devoid of it. Although they occur in the atmosphere, it is not their normal habitat, for growth and multiplication cannot take place in it under ordinary conditions. The number and kind found in air vary with a number of factors, chief among which is locality. The air of some high mountains is practically devoid of bacteria; city and country air also differ from each other in the number and kind of bacteria they contain. Other controlling factors are moisture, presence or absence of injurious substance, and minute particles in the atmosphere.

Most natural waters contain great numbers of bacteria. In sewage and polluted water they are especially numerous, but occur only in small numbers or not at all in deep wells and springs. The kind of organism varies with the composition of the water and with the original contamination. Milk as secreted by the milk glands of cows is practically free from bacteria, but the vessels in which it is handled so contaminate it that it rapidly gains in bacteria. Often by the time it reaches the consumer it contains millions in every cubic centimeter. In short, all food except that recently cooked contains bacteria, the number and kind of which vary with the nature and age of the food.

Living as we do in a world which is teeming with bacteria, we can expect to find them on the surfaces of the skin and mucous mem- 
brane: Normally, the infant enters the world free from bacteria, but they soon begin to settle on the skin; they penetrate the nose and mouth; the first respiratory movements and cries carry them into the respiratory passages; and between the tenth and serenteenth hour they have reached the intestines.

Ordinarily, the deeper respiratory passages contain but few bacteria, but it has been proved that even the tubercle bacillus can penetrate with the inspired air to the bottom of the pulmonary alveoli.

On account of its acidity, yeasts and molds flourish better in the stomach than do bacteria. However, at least thirty species of bacteria (occurring in the stomach) have been described, many of which have attracted special attention on account of the belief that their presence may favor other more injurious species.

The intestines, on account of their alkaline reaction and the partly digested condition of their contents, are a great reservoir of bacterial activity. Metchnikoff and others have given an immense amount of work to a consideration of their function within the body and the probable result in their absence. The only conclusion which is possible at present is that. living as we are in a world filled with microorganisms, life without them is impossible. All that can be done is to make conditions such that the injurious species are suppressed and the beneficial ones farored. Out of this has grown sour-milk therapy.

The normal tissues of plants and the blood and tissues of animals are free from bacteria. 'They are rarely found on certain healthy' mucous membranes, such as those of the kidney, bladder, and lungs. Occasionally they pass through the skin or the mucous membrane of the digestive tract after which they may be found for a short time in the blood. This is especially the case during the height of digestion and it probably accounts for the large number of leukocy tes which swarm in the intestinal mucosa and which have been thought to be in some way associated with the process of fat absorption.

In certain diseased conditions the blood and many of the tissues of the human body are found to contain numerous bacteria. Soon after death even the saprophytes rapidly invade and decompose the body tissues.

Role of Bacteria in Nature.-Bacteria play a wonderful rôle in the many transformations going on in this world. It is difficult to conceive of life without them and their help. For the beneficial ones we turn first to the soil, for from this-either directly or indirectlyman largely draws his food, clothing, and other necessities of life. 'The soil is not, as many think, a dead, inert mass, but it is teeming with life! Both microscopic plants and animals inhabit it by the millions. 'These have been at work within it long before man began 
to till the soil. In the formation of soil from the primitive rock, bacteria played no small part, the changes wrought by the elements first giving them a foothold.

Changes in temperature tear loose huge rocks and break them into fragments. It is well known that most substances when heated expand and contract in such varying degrees that parts are put under a strain. This strain at times is sufficient to cause cracks of various sizes to occur in the rock, a result which may be illustrated by the sudden cooling of hot glass or the sudden heating of cool glass. Throughout the long, hot days of summer rock is heated to a comparatively high temperature, as the boy who has chased barefoot over their surface in quest of grasshoppers or butterflies will testify. At night they cool. 'This is repeated day after day. This continued heating and cooling gradually causes small crevices to appear in even the most resistant. 'These become filled with water and dust; when the cold nights of autumn come the water freezes. In freezing, the water expands and the rocks are broken into pieces. So it continues day after day and year after year, until the rock becomes a fine powder. Even then, however, the plant-food is still insoluble and cannot be taken up by the plant. Long before it has reached the form of powder, bacteria begin to grow upon the surface of the rock and in the crevices. In their growth they form acids which act upon the insoluble plant-foods, rendering them soluble. Bacteria continue their work long after the rocks have been changed to soil, each day liberating a little more plant-food for the growth of plants during that day. During the year the bacteria are able in a fertile soil to liberate enough plant-food for the production of a good crop. When manure is applied, it not only supplies food for the growing crop, but it also supplies food for the microörganisms, and they in turn liberate more of the insoluble constituents of the fine rock particles of which the soil is mainly composed. There are millions of them in every ounce of soil, struggling, to be sure, for their very existence, but always zendering a little more mineral plant-food available.

One of the essential elements for crop production, and the one which is usually in the soil in the smallest quantities, is nitrogen. This, unless it be applied to the soil in the form of the costly fertilizer, nitrates, must be prepared for the plant by bacteria. The farmer finds his crops are limited directly by the speed with which these organisms prepare the food for his growing crop. If they are active, other things being favorable, he will get a good crop; but if they do not play their part, though everything else may be ideal, yet there is no crop.

Bacteriological examinations of cultivated soils have shown that usually those that are richest contain the greatest number of bacteria. 'The number in the soil is dependent upon the quantity and 
character of food the bacteria find in the soil. If the soil is rich in plant residues-barnyard manures and the like-many bacteria will be found there pulling these substances to pieces, liberating gases and acids which act upon insoluble particles of the soil and render them soluble. One class of organisms changes the protein constituents of the soil into ammonia. This type is called "ammonifiers." A person can often detect their activity from the odor of ammonia coming from manure heaps.

Most plants camnot, however, use nitrogen in the form of ammonia; it must be in the form of nitrates. This transformation is brought about by two distinct types of organisms. One of them feeds upon the ammonia produced and manufactures nitrous acid. Should the change cease at this point and nitrites accumulate in the soil in large quantities, plants would not grow upon it, for this is a poison to plants. But in soils properly cared for only minute quantities of nitrites accumulate. As soon as they are formed another type of organism feeds upon them and manufactures nitric acid for the growing plant. This, when formed, reacts with other constituents of the soil, such as limestone. It is then ready to be taken up by the plant and manufactured into nourishing food, beautiful flowers, or fragrant perfumes for the human family.

Were it not for bacteria the world in time would be filled with never-changing organic matter. The plant residues, trees, and animal bodies would remain stored up in the soil, and with it that element-carbon-which, in the form of carbon dioxid, is required by all chlorophyl plants. Bacteria, in getting the energy which they require in their life activity, are continually liberating carbon so that it may start again on its journey of construction. If carbon and nitrogen could but speak, what tales of wonderment they would tell! The chemist, the bacteriologist, and the farmer would each be wiser, for many of the changes through which carbon and nitrogen pass, due either to the action of the lower plants-bacteria - or that of the higher plants are so complex that even the scientist with his apparently magical methods cannot follow them.

So far only the plant-food in the soil and the changes through which it passes have been considered. 'The farmer, however, is usually more concerned with that substance his soil lacks and which must be supplied in order to get good crops. In many cases the lacking element is nitrogen. One notes from the fertilizer quotations that the elements will cost fifteen cents a pound or over if purchased in the form of sodium nitrate, ammonium sulfate, or dried blood. If one stops to make a simple calculation he finds that it would cost fifteen dollars for enough to produce 100 bushels of corn, eleven dollars for cnough to produce 50 bushels of wheat, and seven dollars and fifty cents for enough to produce one ton of alfalfa hay. In these calculations it has been assumed that one could get back in 
the form of corn, wheat, or alfalfa every pound of commercial nitrogen that has been applied to the soil, which, on the face of it, is an utter impossibility. So we have to look to other means of getting nitrogen for our growing crop, and here again bacteria come to our rescue.

There are seventy-five million pounds of atmospheric nitrogen resting upon every acre of land. None of the higher plants, however, have the power of taking this directly out of the air. One family of plants, the Leguminosx, in which are included peas, beans, alfalfa, clover, and many others, if properly infected by bacteria have the power of using this atmospheric nitrogen. Inder this condition and with these plants nitrogen no longer remains the limiting element of crop production. For these microscopic organisms which live within small nodules upon the alfalfa are master chemists. Within their tiny laboratory they can bring about changes which man can imitate but imperfectly with costly machinery and under the action of powerful electric currents. In some of the experiments carried on at the Illinois Experiment Station these minute organisms were found to be able to increase the value of the first cutting of alfalfa hay $\$ 27.80$ an acre, if the nitrogen in the alfalfa be counted only at the same price as we would have to pay on the market for an equivalent quantity of nitrogen in the form of a commercial fertilizer! If these crops be plowed under the fertility of the soil would be increased to just that extent. One writer has said of them: "They not only work for nothing and board themselves, but they pay for the privilege." This is strictly true, for all they require is a plant on which to grow and a well-aërated moist soil containing limestone. They cannot work in an acid soil.

There is a nother class of nitrogen-gathering organisms within the soil which differs from the above in that they live free in the soil and gather nitrogen. Inder ideal conditions they may gather appreciable quantities.

It is quite possible that much of the benefit derived from the summer fallowing of land is due to the growth within the soil of this class of organism which stores up nitrogen for future generations of plants. It has been found that they are more active and found in greater numbers in such a soil. All the work that the farmer puts upon the soil to render it more porous reacts beneficially upon these organisms, because they not only love atmospheric nitrogen and oxygen, but must have them. These elements are absolutely essential to their life activities and they must be obtained from within the soil since the minute organisms cannot live upon the surface for the direct rays of the sun kills them in a short time.

But these are only a few of the many that help the farmer. They are at work in his silo rendering the feed more palatable and nutritious for his cattle. They are working in his milk and cream, and 
if they be the right kind they give to butter and cheese a desirable flavor. They take part in the tanning of leather, the retting of flax, the curing of tobacco, and, in short, they help us in a hundred and one ways we little suspect. One of the most fascinating and instructive tasks set for man is to learn how to increase the work of the beneficial bacteria and to suppress or entirely weed out the injurious bacteria.

Divisions of Bacteriology.-Bacteriology, although one of the youngest of sciences, is no longer confined to one branch which can be adequately covered by one text or its whole field covered by any one individual, but is, as are the other sciences, divided into a number of divisions each dealing with a certain phase of the subject. The main divisions are:

1. Agricultural bacteriology which deals with the bacteria of the soil and their relation to plant life.

2. Dairy bacteriology which deals with the bacteria of milk and their relations to dairy products such as pure milk, butter, and cheese.

3. Industrial bacteriology, which considers the use of bacteria in the arts and which also deals with methods of suppressing injurious bacteria and favoring the beneficial.

4. Plant pathology which deals with the cause and prevention of those diseases that attack plants by invading their tissues.

5. Animal pathology which deals with bacteria in relation to the diseases of the lower animals.

6. Iuman pathology which deals with the distribution, morphology, physiology, and pathological changes produced by bacteria which are pathogenic to man. 


\section{MORPHOLOGY OF BACTERIA.}

In shape, bacteria have the very simplest conceivable structure, and although there are thousands of different kinds differing in properties, they all have one of three general forms: rod-shaped, spherical, or spiral.

Bacilli.-The rod-shaped organisms, which may be compared to a lead pencil, are cylindrical organisms in which a longer and shorter dimension may be recognized. They are the bacilli (sing. bacillus). The ends of the organisms may be convex, less often flat or even concave. The size also varies, some being so short that it is next to impossible to tell whether they are rods or globular organisms; others are comparatively long.

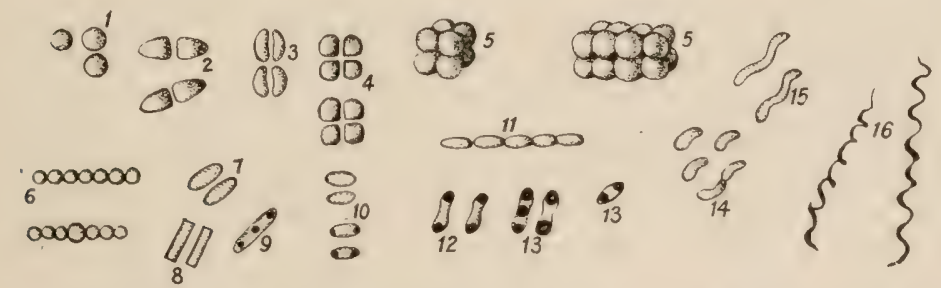

FIG. 6. - The normal types of bacteria. 1-6, cocci; 7-13, bacilli; 14-16, spirilla; 1 , micrococcus; 2 and 3 , diplococci; 4 , tetracoccus; 5 , sarcina; 6 , streptococcus (the lower chain includes an arthrospore); 7 and 8 , bacilli; $9,10,12$ and 13 , bacilli with various granules; 11 , streptobacillus; 14 , vibrio; 15 , spirillum; 16 , Spirocheta treponema. (Kendall.)

Cocci.-The cocci (sing. coccus) are typically spherical and may be likened to a ball or at times to an egg. They may in the early stages of cell division appear temporarily as bacilli with convex ends. 'They often occur in pairs, diplococci, in which case usually their proximate surfaces are flattened. This flattening of the organism may at times be accompanied by an elongation of the axis of the organisms parallel to the plane of opposition. This leads to the coffee-bean shape exemplified in the gonococcus and miningococcus. At other times we have the flattening perpendicular to the plane of the flattened surface as seen in the "lance-shaped" pneumococcus. The cocci may be large or small and group themselves in various ways. 
Spirilla. - The third group is the spirillia (sing. spirillum) and may be likened unto a corkscrew. 'The spiral may be loosely or tightly coiled or there may be one, two, or many coils. At times the curve may be so slight that the organism viewed under the microscope appears "comma-shaped."

More bacilli are known than cocei and more cocci than spirilla. Migula enumerates 8.33 bacilli, 343 cocci, and 96 spirilla, a total of 1272. Other workers have tabulated more with a similar proportional distribution among the various groups.

Gradations.- The difference between these fundamental types is at times very slight. In fact the cocci often merge into the bacilli and the bacilli into the spirilla. It is often difficult accurately to distinguish between the various groups, as is exemplified by the fact that at times $B$. prodigious has been described by one investigator as a coccus and at another time by a different worker as a bacillus. This same condition holds for the pneumonia germ and the one causing pear blight, whereas the cholera organism has been described both as a bacillus and a spirillum.

Pleiomorphism.-By pleiomorphism is meant a permanent or semipermanent change in the normal form of the organism. The organism may at one time represent a coccus, at another a bacillus, and at still another a spirillum. This led the early writers to believe that there was a mutability of species. The condition is especially likely to occur among some soil organism and much light has been thrown on the subject by Löhnis who finds the life history of bacteria to be only slightly less complex than that of other organisms.

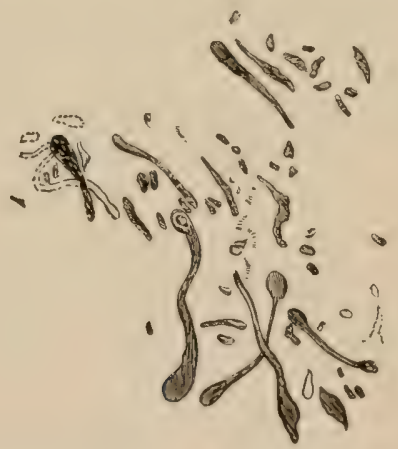

FIG. 7.-Involution forms from bacilli. (From Flügge.)

Involution Forms. - Although the form of bacteria is quite constant under normal conditions, yet there is a tendency with many organisms, especially when grown for some time on artificial media, to show abnormal or bizarre forms. Such organisms are known as involution forms. Some of the rod-shaped organisms may appear 
as clubs many times larger than the ordinary, or they may appear as crosses or stars. The formation of large club-shaped organisms is very characteristic of the organism which causes diphtheria, whereas the formation of crosses, stars, and the like is characteristic of the organism which grows in the roots of alfalfa. Some writers have considered them degenerate forms and compared them to the "Tame and halt" in the human species: This, however, is hardly an apt illustration, for these peculiar shaped organisms have all of the powers possessed by others and if they found their way into the body of an animal, they would be just as likely to produce the disease which is characteristic of the organism as would the ones with the normal shape.

In some cases this characteristic has served as a valuable aid to the differential diagnosis of the organism. 'This is especially true with the plague bacillus which, when grown on nutrient agar containing from 2.5 to 3.5 per cent. of sodium chlorid, is prone to give rise to involution forms.

Size and Weight. - The unit of measurement in microscopy is the micron $(\mu)$, or micromillimeter. This is 0.001 of a millimeter or approximately $\frac{1}{2} 00$ of an inch. The majority of the organisms vary from $0.2 \mu$ up to $30 \mu$ or $40 \mu$. They are smallest in the case of the cocci and largest in the case of the spirilla.

Although there is a great variation in the size of bacteria, all are extremely small; eren the largest are not visible to the naked eye. The smallest are beyond the range of our most powerful microscopes, and others appear as mere dots. The Pfeiffer bacillus, the one which was thought to cause influenza, are rod-shaped organisms, and if they be placed end to end it would take fifty thousand of them to reach one inch, or it would require about fifteen thousand of the bacteria which cause typhoid to form a line one inch in length. Of the very largest known it would require seven thousand to reach an inch. We often magnify bacteria one thousand times and then they appear as dots under the microscope, but if we would magnify a man to that extent he would appear to be six thousand feet tall and fifteen hundred feet wide. Bacteria are so small that at times we find five millions in a small drop of milk and yet they have plenty of room to move about, for it would require one hundred and twenty-five billion to weigh the same as a drop of milk.

A person may wonder, since bacteria are so small, how they can bring about such enormous changes, for it takes but a short time for them to tear to pieces the body of a large animal that has died. All know how fast various plants and fruits decay under appropriate conditions. Decay is due to bacteria. One organism could of itself bring about only a small change, but they multiply with almost inconceivable rapidity. The bacilli grow until they have reached a certain length, then divide into two, and these in turn 
grow to maturity and then divide. Some of them may remain linked together, and hence appear as long chains.

In the case of the cocci, they may divide into two and remain linked together as diplococci or a great many may remain counected together, thus giving the appearance of a string of beads; Streptococcus. This is the characteristic of the common blood-poison organism. Other spherical shaped organisms divide alternately in two planes and when they remain connected together and great masses are formed they resemble a bunch of grapes; Staphylococcus. This is a characteristic of the common boil-causing organism. Still others of the spherical organisms divide alternately in three planes and when they remain connected appear very similar to a bale of cotton; Sarcina. This is a characteristic of many of the organisms found in air.

It has been estimated that if bacterial multiplication went on unchecked, the descendants of one cell would in two days number $281,500,000,000$, and that in three days the descendants of this single cell would weigh $148,356,000$ pounds. It has been further estimated by an eminent biologist that if proper conditions could be maintained for their life activity, in less than five days they would make a mass which would completely fill as much space as is occupied by all of the oceans on the earth's surface, if the water has an average depth of one mile!

Even in the face of these assumptions one need not fear, for bacteria have been on this earth, and have been multiplying probably long before the advent of man, and as yet the earth has not been filled by them. This is due to there being a struggle among them, just as there is among higher plants and animals. One knows that if wheat be sown too thick, none of it will mature. Sometimes it is a lack of food, other times a lack of sunshine, at still other times it is a lack of moisture which prevents the growth. So it is with bacteria, the food or water may give out, but more often it is the products which they form that prevent them from continuing to multiply.

Brownian Movements. - If one examines under a microscope a suspension or colloidal solution containing particles about $1 \mu$ in diameter, they are seen to be in motion oscillating through a distance about equal to their own diameter. With smaller particles the oscillation is much greater proportionately. When the diameter is about $4 \mu$ the motions are hardly perceptible. 'The mean velocity for a particle of platinum weighing $2.5 \times 10^{-15} \mathrm{gm}$. has been estimated to be $3 \times 10^{2} \mathrm{~cm}$. per second at ordinary temperature. These smaller particles often travel in straight lines and suddenly change their direction. 'Zsigmondy, describing the movement of the gold particles in a gold hydrosol, compared them to a swarm of dancing gnats. This interesting phenomenon is called "Brownian Move- 
ment" from Robert Brown (1773-1558), an English botanist, who first observed them in 1827 when studying grains of pollen. Observations made by ingenious methods upon the Brownian movements

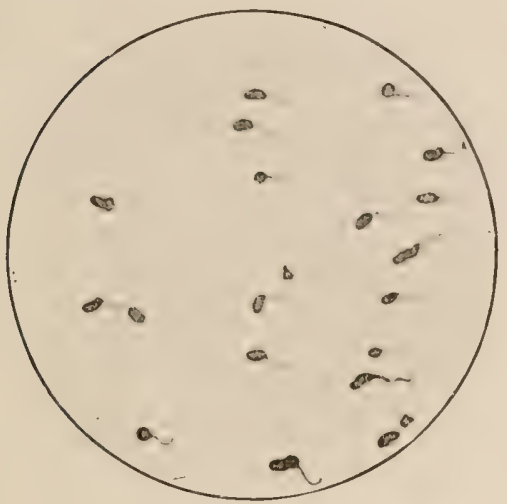

FIG. 8.-Spirillum of Asiatic cholera, showing single flagellum. (Kolle and Zetnow.)

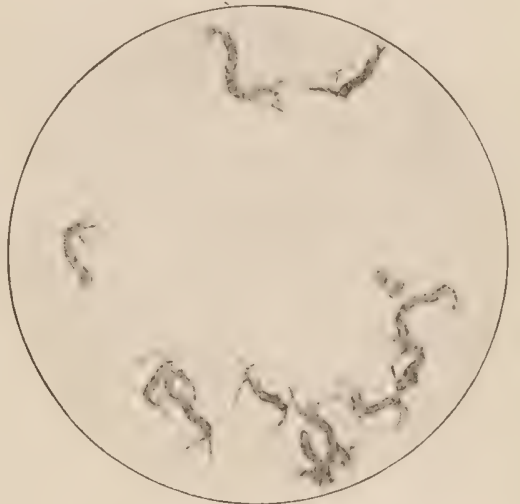

FIg. 9.-Spirillum volutans, showing flagella at either end of the bacterium. (Herzog.)

of colloidal suspensoids are exactly what the kinetic theory indicates would be the behavior of molecules of that size. Both dead and non-motile bacilli show this movement as do also small particles freely suspended in the liquid. Howerer, many bacteria show a

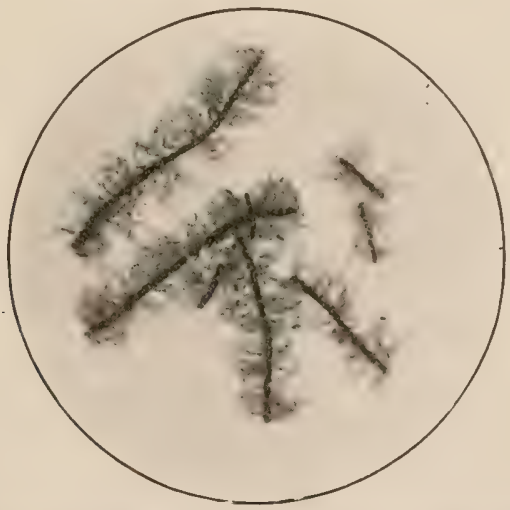

FIG. 10.-Bacillus proteus vulgaris, showing numerous flagella around the entire body. of the bacterium. (Herzog.)

true independent motion and if watched the organism will be found to change its position with relation to other organisms. This is known as "vital movement." 
The speed with which they travel, being magnified to the same extent as are the organisms, makes them appear to be travelling with enormous speed, insomuch that Leeuwenhock, who first described it, stated that "they seemed to tear through each other." The actual speed, however, is not great for the typhoid bacillus may travel a distance of $4 \mathrm{~mm}$. or about 2000 times its own length in one hour, whereas the cholera spirillum has been known to attain a speed of $18 \mathrm{~cm}$. per hour. Some organisms are motile if grown on one cultural media, and non-motile if grown on another; for example, the colon bacillus is usually motile if examined from young cultures grown on gelatin or agar, but non-motile if taken from boullion.

Organs of Locomotion. - The protoplasmic threads called organs of locomotion are flagella or cilia. A cilium differs from a flagellum in that the former has a simple curve whereas the latter has a compound curve, like a whip lash. The size, the number, and the arrangement of the flagella are characteristic of the organism. Most bacteria possess flagella rather than cilia. Differences exist in respect to the number and position of the flagella on the cell body. Some forms possess only a single flagellum at one pole and are called monotricha, others a flagellum at each pole (amphitricha), others a tuft of flagella at one pole (lophotricha), others flagella projecting from the whole body of the cell (peritricha); and still others possess no flagella and are known as atricha.

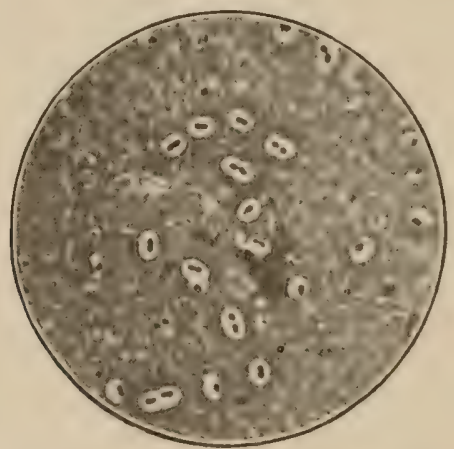

Fig. 11.-Pneumococci with unstained capsules. From pneumonia sputum, stained with carbol-fuchsin and differentiated with weak acid alcohol. Magnifieation 1000. (Karg and Schmorl.)

Cell Wall (Ectoplasm).-The cell wall is the slightly differentiated outer portion of the cell substance. Many writers prefer to call it "ectoplasm." Early in the history of bacteriology it was considered that the absence of cellulose in bacteria indicated that they belonged to the animal rather than to the plant kingdom. But cellulose or hemicellulose has been identified in bacteria from pus, 
B. subtilis, tubercle bacilli, and diphtheria bacilli. IIowever, the great majority of the organisms contain chitin, a substance which on hydrolysis yields glucosamin, $\mathrm{CH}_{2} \mathrm{OH}(\mathrm{CHOH})_{3} \mathrm{CHNH}_{2} \mathrm{CHO}$, and acetic acid. Chitin is typically animal in origin and for this reason some have argued that the bacteria belong to the animal and not to the plant kingdom. 'The flagella probably originate from the ectoplasm.

Capsules.--Many bacteria possess a capsule which is an outgrowth of the cell membrane and is composed of mucin. In stained cultures it usually appears as a halo surrounding the organism. The formation of a capsule is not confined to only a few species, some writers arguing that under appropriate conditions all organisms form them; yet the so-called capsulates are especially prone to do so. Some organisms produce capsules when grown on one media, but not if grown on another. Milk especially farors the formation of capsules.

Sheath.-Often a distinct tube is formed in which is inclosed the chain of cells; to this tube is given the name "sheath." It is especially characteristic of some of the trichobacteria as crenothrix in which there is a deposition of iron. Sometimes these become fossilized, occurring in hugh deposits in ferruginous water.

Zoöglœa.-Often the gelatinous material of the cell causes great masses of cells to adhere to each other, to which condition is given the name "zoögløe." 'This is especially characteristic of the nitrifying bacteria.

Cytoplasm.-Chemical analysis of the cytoplasm of the bacteria cell shows it to be richer in nitrogen and phosphorus than are the cells of higher plants. Moreover, on being stained the cytoplasm appears as a homogeneous mass filling the whole cell, thus making it certain that bacteria do not possess a nucleus in the ordinarily accepted sense of the term. But the fact that the organisms stain so readily with the ordinary nuclear stains has led some to believe that the organisms are made up mainly of nuclear material. This is the view held by Zettnow who has succeeded in staining some large spirilla in a living motile condition. Hence the idea held by the majority of workers at the present time is that the bacterial cell is composed of small quantities of cytoplasm in which is imbedded large quantities of fragmented, irregularly distributed chromatin.

Metachromatic Granules. - Some bacteria contain various granules within the cell which stain differently from the substance of the cell body; these are known as "metachromatic" granules or "BabesErnst" granules, or because of their frequent position at the ends of bacilli as polar bodies. Microchemical examination has shown them to be composed of various substances: fat, sulphur granules, glycogen, lecithin, and protein-like compounds.

Their function has been variously interpreted. Some have compared them to the centrosomes of more highly specialized cells. 
Others consider there to be a relationship between the richness of the cell in granules and its virulence. Irill, however, considers that, inasmuch as nitrates increase the nitrogen assimilated by -I zotobacter and the number and size of the rolutin bodies, they bear some relationship to the organisms' power to fix nitrogen. Although it

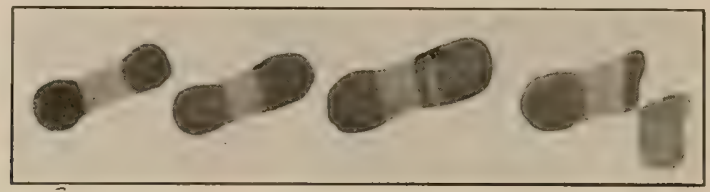

FIG. 12.- Successive stages in division of Bacillus diphtherice, showing relation of line of division to metachromatic granule. Continuous observation of living bacillus drawn without camera lucida. (Williams.)

is quite possible that they may possess various functions in different organisms, the majority of them would seem to be, as suggested by Meyer, reserve food materials which occur in the cytoplasm of the cells of various bacteria. They are most numerous in rapidly growing young cultures and usually disappear when the food becomes scarce.

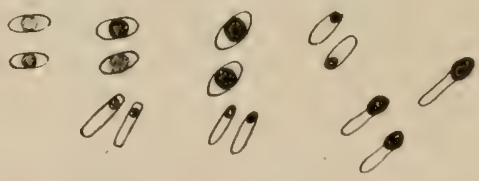

Fig. 13.-Types of bacterial spores. (Kendall.)

Spores.-Bacteria possess the power of mobilizing the vital parts of their body into a much smaller space than they occupy during their normal life. They exclude all of the excess moisture and surround themselves by a tough resistant coat. In some respects this form of the organism resembles the seed of the higher plant and we speak of it as a spore. While in this stage they will withstand many conditions which would quickly prove fatal to growing bacteria. Some of them can withstand the temperature of boiling water for many hours, or they may survive treatment with strong carbolic acid. For the time being they have lost the power of multiplying, but they are still alive and if they are brought into appropriate surroundings they will change back into normal bacteria just as a kernel of wheat changes into the young plant when placed in moist soil. It is indeed fortunate for mankind that but few of the disease-producing organisms form spores. There are, however, many of the bacteria which cause fruit, meat, and various other food products to spoil, which do form very resistant spores and this 
is why many food products have to be heated for such a long time, or to such a high temperature to keep them.

The manner of formation of spores within the body of the organism is characteristic. 'They develop within the cell body and hence are called "endospores." They are formed by the bacilli and spirilla, but not by the cocci. The begimning of spore formation is marked by a granulation of the cell contents. As the process proceeds the granules become larger and eventually fuse and collect at one portion of the cell which is then surrounded by a spore wall. The spore may be either smaller or larger than the mother cell. In the latter case there is a bulging of the mother cell. The spore may be equatorial, polar, or intermediate within the cell depending on its position. When situated equatorially and larger than the mother cell it gives to it a boat-shape appearance (clostridia). If situated at the pole and large, we have the capitate or drumstick appearance. When bacteria are found in chains and spores form in the end, there is a tendency for them to occur in adjacent ends of contiguous cells. A cell usually forms only one spore; hence, this camnot be considered a process of reproduction.

When the spores are brought under favorable conditions of food supply, temperature, and moisture they germinate. The process differs according to species. In some species the spore ruptures at the pole and the young cell emerges in such a way that its long axis is in the same direction as the long axis of the spore, thus leaving the spore membrane still visible at one of the poles. In other species the spore germinates equatorially and the young cell emerges with its long axis at right angles to the long axis of the spore. In still other species there is no rupturing of the spore, but germination occurs by a gradual elongation and absorption of the spore.

Longevity of Bacteria.-Due to their method of multiplication there is no such condition as old age among bacteria since both daughter cells are similar in age and composition. It is well known that while in the spore condition many organisms can survive for over two decades. Both the spore-forming and non-spore-forming organisms have been obtained from soil which had been kept in bottles in an air dry condition for more than fifty years. Recently Sarcina lutea and other well-known air organisms have been obtained from a Mastodon uncovered by the recession of the ice in Siberia. This animal must have been covered for hundreds of years. This would, therefore, seem to indicate that the longevity of bacteria may be extremely great. 


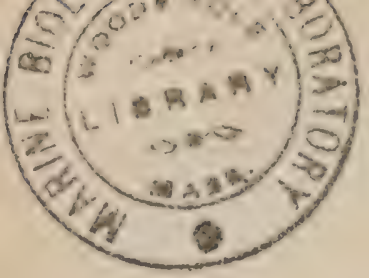

\section{CLASSIFICATION OF BACTERIA.}

THe difficulties inherent in the classification of bacteria are numerous and, due to the small simple structure of the organism, cannot be worked out on a purely morphological basis as is the case with the higher plant. Moreover, phrsiological characteristics, such as pigment production which at first sight may appear useful are not constant. Even morphology of bacteria was not considered constant until 1872 at which date Cohn established upon morphological bases a classification which with minor changes has been retained until the present. Bacteria play a part in many fields of activity, and hence the criteria whereby they are recognized vary greatly according to the art or science in which they are studied. This has led to considerable confusion in classification and nomenclature as is so admirably pointed out by Jordan.

"The present nomenclature of bacteriology may be criticized on two grounds: first, as already pointed out, for the unwieldy size that certain 'genera' have been allowed to assume; and second, for the haphazard way in which trinomial and even quadrinomial names have been bestowed. Such names can be properly employed only with reference to subspecies or varieties; and designations, like B. coli communis, Granulobacillus saccharobutryicus mobitis nonliquefaciens and Micrecoccus acidi paralactici liquefaciens Halensi, are both cumbersome and unscientific. The use of a single genus name for a multitude of organisms is in fact responsible for the tendency toward trinomial nomenclature, and the remedy for both conditions would seem to lie in the abandonment of such a term as Bacillus for the name of a genus and the frank establishment of new genera on the basis of physiological characters, such, for example as distinguish the colon-typhoid group or the diphtheria group of bacilli. Until some such reform in nomenclature is brought about the names used to designate different kinds of bacteria will fail to make clear the group relationships which undoubtedly exist, and will continue to be a stumbling block to all students of the subject."

The classification most commonly accepted at the present day is that formulated by Migula. 'This, with certain modifications, is given below.

Bacteria, Schizomycetes, fission fungi (chlorophyll-free), cell division in one, two or three planes; many varieties possess the power of forming endospores. Whenever motility is present, it is due to flagella, or more rarely to undulating membranes. 
FAnul I. - Coccacex - cells in free state spherical; division in one, two or three planes; endospore formation rare.

Genus I.-Streptococcus - cells divide in one plane only for which reason; if they remain connected after fission bead-like chains may be formed; no organs of locomotion.

Genus II.-Micrococcus (Staphylococcus)-cells divide in two planes, whereby, after fission, tetrad and grape-like clusters may be formed; no organs of locomotion.

Genus III. - Sarcina-cells divide in three planes, whereby, after fission, bale-like packets are formed; no organs of locomotion.

Genus IV.-Planococcus-cells divide in two planes, as in Micrococcus; possess flagella.

Genus V.-Planosarcina-cells divide in three planes, as in Sarcina; posses flagella.

FAMILY II. - Bacteriacea - cells long or short; cylindrical, straight never spiral; division in one plane only, after preliminary elongation of the rods.

Genus I. - Bacterinm - cells without flagella; of ten with endospores.

Genus II.-Bacillus - cells with peritrichal flagella; often with endospores.

Genus III.-Pscudomonas - cells with polar flagella; endospores occur in a few species but are rare.

Family III.-Spirillacea - cells spirally curved or representing a part of a spiral curve; division in one plane only, after elongation of cell.

Genus I.-Spirosoma-cells without organs of locomotion; rigid.

Genus II.-Microspira-cells rigid, with one or more rarely, two or three polar undulated flagella.

Genus III.-Spirillum-cells rigid, with polar tufts of five to twenty flagella usually curved in semicircular or flat undulating curves.

Genus IV.-Sprirochata-cells sinously flexible; organs of locomotion unknown, perhaps a marginal undulating membrane.

Family IV.-Chlamydobacteriacee-Forms of varying stages of evolution, all possessing a rigid sheath, which surrounds the cells; cells united in branched or unbranched threads.

Genus I. - Streptothrix - cells united in simple, unbranched threads; division in one plane only; reproduction by non-motile conidia.

Genus II.-C'ladothrix-cells united or pseudodichotomously branching threads; division in one plane only; vegetative multiplication by separation of entire branches; reproduction by swarming forms with polar flagella.

Genus III.-Crenothrix-cells united in unbranched threads; division at first in one plane only. Later the cells divide in all three planes; the daughter cells become rounded and develop into reproductive cells. 
Genus IV.-Phragmidiothrix-cells at first united in unbranched threads, dividing in three planes, thus forming a rope of cells; later some of the cells may penetrate through sheath and thus give rise to branches.

FAmIL T.-Beggisatuacea-cells united in sheathless threads; division in one direction of space only; motility by undulating membrane as in Oscillaria.

Genus I.-Thiothrix-unbranched, non-motile threads, inclosed in fine sheaths; division of cells in one plane only; cells contain sulphur granules.

Genus II.-Beggiatoa-cells with sulphur granules.

The difficulties inherent in this classification and especially the needs of reform to the agricultural bacteriologist are seen from the ,following:

"Many workers in medical bacteriology and in other special fields of applied microbiology, who deal with only a few wellrecognized species, may perhaps feel no need for any change in current practice. Few can deny, however, that it is a serious inconvenience for such names as B. welchii, B. sporogenes, B. perfringens to be used by various workers, sometimes for the same, sometimes for different organisms, or for the same form to be described as Bacterium lactis aërogenes or Streptococcus lacticus when it is isolated from milk and as Streptococcus salivarius or Str. fecalis when it is isolated from the human mouth or intestine."

"When one passes from a study of the practical effects of the activity of some particular microbe to a consideration of its relationship to other forms it becomes essential not only to have a name for each kind of organism but to have also a system of nomenclature which will make it possible to express such relationship with reasonable clearness and accuracy.

"This need is met by the Linnaean system of classification universally adopted by all biologists outside our own limited and systematically undeveloped fields. According to this Limnaean system each recognizable lind of plant or animal receives a binomial Iatinized name, the first half designating the genus or group to which it belongs and the second half the particular kind or species to which the name applies. The genera in turn are grouped in tribes, the tribes in families, the families in orders, and the orders in classes. These divisions will often be artificial and often of greatly unequal size and importance in different groups. They make it possible, however, to express in a simple manner the essential facts of biological relationship-the fact that $\mathrm{A}, \mathrm{B}$, and $\mathrm{C}$ are more nearly related to each other than are any of them to $\mathrm{D}, \mathrm{E}$, and $\mathrm{F}$; and that the series A-F exhibits common relationships closer than any similarities which its members bear to $\mathrm{G}$ or $\mathrm{H}$.

"If such a system is accepted it is in the next place important to 
make sure that each group, from species to class, shall bear a single universal name. The name need not be appropriate; it need only be stable. It is an arbitrary label, not a description. If the door be once opened to criticism on the ground of inappropriateness, stability must disappear.

"It is in order to ensure uniformity and stability of nomenclature that the International Codes referred to have been formulated; and it is to the International Rules of Botanical Nomenclature (1910) that we, as bacteriologists, should naturally turn for guidance.

"Learing out a great many minor rules and recommendations, the most important of the rules which would affect bacteriological practice may be cited as follows:

Chapter I, Article 7.- "Scientific names are in Latin for all groups."

Chapter II, Article 10.- "Every individual plant belongs to a species (species), every species to a genus (gemus), every genus to a family (familia), every family to an order (ordo), every order to a class (classis), every class to a division (divisio)."

Chapter III, Section 1, Article 15.- "Each natural group of plants can bear in science only one valid designation, namely, the oldest, provided that it is in conformity with the rules of Nomenclature and the conditions laid down in Articles 19 and 20 of Section 2.'

Chapter III, Section 2, Record iii.--"Orders are designated preferably by the name of one of the principal families, with the ending ales."

Chapter III, Section 3, Article 21.- "Families (familia ) are designated by the name of one of their genera or ancient generic names, with the ending acea."

Chapter III, Section 3, Article 23.- "Names of subfamilies (subfamilia) are taken from the name of one of the genera in the group, with the ending oidea. The same holds for the tribes (tribus) with the ending ear and for the subtribes (subtribus) with the ending inœ."

Chapter III, Section 3, Article 24.- "Genera receive names (substantive adjectives used as substantives) in the regular singular number and written with a capital letter which may be compared with our own family names. These names may be taken from any source whatever and may even be composed in an absolutely arbitrary manner."

Chapter III, Section 3, Article 26.- "All species, even those that singly constitute a genus, are designated by the name of the genus to which they belong, followed by a name (or epithet) termed specific, usually of the nature of an adjective (forming a combination of two names, a binomial or binary name)."

Chapter III, Section 3, Article 26, Record yiii,- "The specific 
name should in general give some indication of the appearance, the characters, the origin, the history or the properties of the species. If taken from the name of a person it usually recalls the name of the one who discovered or described it, or was in some way concerned with it.

Chapter III, Section 3, Record x.- "Specific names begin with a small letter except those which are taken from names of persons (substantives or adjectives) or those which are taken from generic names (substantives or adjectives)."

The classification suggested by the Committee of the Society of American Bacteriologists has many points of merit to the agricultural bacteriologist. The classification in brief is as follows:

\section{THE CLASS SCHIZOMYCETES.}

Minute, one-celled chlorophyll-free, colorless, rarely violet-red or green-colored plants, which typically multiply by dividing in one, two, or three directions of space. 'The cells thus formed are usually spherical, cylindrical, comma-shaped, spiral, or filamentous and are often united into filamentous, flat, or cubical aggregates. Filamentous species often surrounded by a common sheath. The cell plasma generally homogeneous without a morphologically differentiated nucleus. Reproduction by simple fission. In many species resting bodies are produced, either endospores or gonidia. Cells may be motile by means of flagella.

A. Order Myxobacteriales.-Cells united during the regetative stage into a pseudoplasmodium which passes over into a highlydeveloped cyst-producing resting stage.

B. Order Thiobacteriales.-Cells free or united in elongated filaments. Typically water forms, not cultivable on ordinary media. Life energy derived mainly from oxidative processes. Cells typically containing either granules of free sulfur or bacteriopurpurin or both, usually growing best in the presence of lydrogen sulphid.

C. Order Chlamydobacteriales. - Cells normally united in elongated filaments, of ten showing false but never true branching. Typically water forms. Sulphur and bacteriopurpurin are absent. Iron of ten present and usually a well-marked sheath.

D. Order Actinomycetales. - Cells usually elongated, frequently filamentous and with a decided tendency to the derelopment of branches, in some genera giving rise to the formation of a definite branched mycelium. Cells frequently show swellings, clubbed, or irregular shapes. No pseudoplasmodium. No deposits of free sulphur or iron. No bacteriopurpurin. Endospores not produced, but conidia developed in some genera. Isually (iram-positive. Nonmotile. Some species are parasitic in animals or plants. Not water forms. Complex proteins frequently required. As a rule 
strongly aërobic (except for some species of Actinomyces and the genera Fusiformis and Leptotrichia) and oxidative. Growth on culture media often slow; some genera show mold-like colonies.

FAnILY I. - Actinomycetacex. - Filamentous forms often branched and sometimes forming mycelia. Conidia sometimes present. Some species parasitic.

Genus 1.-Actinobacillus. - Filament formation, resembling streptobacilli. In lesions no mycelium formed, but at peripheries fingershaped branched cells are visible. Gram-negative. Not acid-fast. Type species, Act. Lignieresi.

Genus 2.-Leptotrichia.-Thick, long, straight or curved threads, unbranched, frequently clubbed at one end and tapering to the other. Gram-positive when young. Threads fragment into short, thick rods. Anaërobic or facultative. Non-motile. Filaments sometimes granular. No aërial hyphæ or conidia. Parasites or facultative parasites. Type species, Lep. buccalis.

Genus 3.-Actinomyces.-Organism growing in form of a muchbranched mycelium which may break up into segments that function as conidia. Sometimes parasitic, with clubbed ends of radiating threads conspicuous in lesions in animal body. Some species are micro-aërophilic or anaërobic. Non-motile. Type species, Act. bovis Harz.

Genus 4.-Erysipelothrix.-Rod-shaped organisms with a tendency to the formation of long filaments which may show branching. The filaments may also thicken and show characteristic granules. No spores. Non-motile. Gram-positive. Do not produce acid. Micro-aërophilic. Usually parasitic. Type species, Bacillus rhusiopathice suis Kitt 1893; Mycobacterium rhusiopathic Chester 1901; Erysipelothrix porci Rosenbach 1909, the causal organism of swine erysipelas.

FAMILY II.-Mycobácteriacee.-Parasitic forms. Rod-shaped, frequently irregular in form but rarely filamentous and with only slight and occasional branching. Often stain unevenly (showing variations in staining reaction within the cell). No conidia.

Genus 1.-Mycobacterium.-Slender rods which are stained with difficulty, but when once stained are acid-fast. Cells sometimes show swollen, clavate, or cuneate forms, and occasionally evenbranched cells. Non-motile. Gram-positive. No endospores. Growth on media slow. Aërobic. Several species pathogenic to animals. Type species, Mycobacterium tuberculosis.

Genus 2.-Corynebacterium.-Slender, often slightly curved, rods with tendency to club and pointed forms, branching cells reported in old cultures. Barred uneven staining. Not acid-fast. Grampositive. Non-motile. Aërobic. No endospores. Some pathogenic species produce a powerful exotoxin. Characteristic snapping motion is exhibited when cells divide. Type species, Cornynebacterium diphtheria. 
Genus 3.-Fusiformis.-Obligate parasites. Anaërobic or microaërophilic. Cells frequently elongate and fusiform, staining somewhat unerenly. Filaments sometimes formed; non-branching. Non-motile. No spores. Growth in laboratory media feeble. Type species, Fusiformis termitidis Heelling.

Genus 4.-Pfcifferella.-Non-motile rods, slender, Gram-negative, stain poorly, sometimes forming threads and showing a tendency toward branching. Gelatin may be slowly liquefied. Do not ferment carbohydrates. Growth on potato characteristically honey-like. Type species, Pfeifferella mallei.

E. Order Eubacteriales. - The order Eubucteriales includes the forms usually termed the true bacteria, that is, those forms which are considered least differentiated and least specialized. The cell metabolism is not primarily bound up with hydrogen sulphid or other sulphur compounds, the cells in consequence containing neither sulphur granules nor bacteriopurpurin. The cells apparently do not possess a well-organized or well-differentiated nucleus. These organisms are usually minute and spherical, rod-shaped or spiral, in most genera not producing true filaments, and rarely branching. 'The cells may occur' singly, in chains, or other groupings. They may be motile by means of flagella, or non-motile, but they are never notably flexuous. Cell multiplication occurs always by transverse, never by longitudinal, fission. Some genera produce endospores, particularly the rod-shaped types. Conidia are not observed. Chlorophyll is absent, though the cells may be pigmented. 'The cells may be united into gelatinous masses, but they never form motile pseudoplasmodia nor develop a highly specialized cystproducing fruiting stage, such as is characteristic of the My.robacteriales.

FAum 1.-Nitrobacteriacex.-Organisms usually rod-shaped (sometimes nearly spherical in Nitrosomonas and possibly in Azotobacter). Cells motile or non-motile. Branched involution forms in Rhizobium and Acetobacter. Endospores never formed. Obligate aërobes, capable of securing growth energy by the direct oxidation of carbon, hydrogen, or nitrogen, or of simple compounds of these. Non-parasitic (except in Genus Rhizobium) - usually water or earth forms.

Tribe 1.- Vitrobacterea.-Organisms deriving their life energy from oxidation of simple compounds of carbon and nitrogen (or of alcohol).

Genus 1.--Mydrogenommonas.-Monotrichic short rods capable of growing in the absence of organic matter and securing growth energy by the oxidation of hydrogen (forming water). Kaserer (1905) who first described the organism states that his species will also grow well on a variety of organic substances. 'Type species, Hydrogenomonas pantetropha (Kaserer 1906) Orla-Jensen. Nikleuski (1910) described two additional species, $H$. vitrea and $H$. flava. 
Genus 2.-Methanomonas. - Monotrichic short rods cajuable of growing in the absence of organic matter and securing growth energy by the oxidation of methane (forming carbon dioxid and water). 'Type species, Meth. methanica.

Genus 3.-Carboxydomonas.-Autotrophic rod-shaped (ells cap)able of securing growth energy by the oxidation of carbon monoxid (forming carbon dioxid). Type species, Carb. oligocarbophila (Beijerinck and ran Delden (1903) Orla-Jensen is described as nonmotile.

Genus 4.-Acetobacter.-Cells rod-shaped, frequently in chains, non-motile. Cells grow usually on the surface of alcoholic solutions as obligate aërobes, securing growth energy by the oxidation of alcohol to acetic acid. Also capable of utilizing certain other carbonaceous compounds, as sugar and acetic acid. Elongated, filamentous, club-shaped, swollen, and even-branched cells may occur as involution forms. Type species, Ace. aceti.

Genus 5.-Nitrosomonas.-Cells rod-shaped or spherical, motile, or non-motile, if motile with polar flagella. Capable of securing growth energy by the oxidation of ammonia to nitrites. Growth on media containing organic substances scanty or absent. Type species, Nitro europóa Winogradsky.

Genus 6.-Nitrobacter.-Cells rod-shaped, non-motile, not growing readily on organic media or in the presence of ammonia. ('ells capable of securing growth energy by the oxidation of nitrites to nitrates. Type species, Nitro. Winogradskyi.

Tribe 2.-Azotobacterea (Nitrogen-fixing organisms).

Genus 7.-Azotobacter.--Relatively large rods, or even cocci, sometimes almost yeast-like in appearance, dependent primarily for growth energy upon the oxidation of carbohydrates. Motile or non-motile; when motile, with tuft of polar flagella. Obligate aërobes usually growing in a film upon the surface of the culture medium. Capable of fixing atmospheric nitrogen when grown in solutions containing carbohydrates and deficient in combined nitrogen. Type species, 1zotobacter chrö̈coccum Beijerinck.

Genus 8.--Rhizobium.-Minute rods, motile when young. Involution forms abundant and characteristic when grown under suitable conditions. Obligate aërobes, capable of fixing atmospheric nitrogen when grown in the presence of carbohydrates in the absence of compounds of nitrogen. Produce nodules upon the roots of leguminous plants. 'Type species, $R$. leguminosarum Frank.

FAnily II.-Pseudomonadacea.-Rod-shaped, short, usually motile by means of polar flagella or rarely non-motile. Aërobic and facultative. Frequently gelatin liquefiers and active ammonifiers. No endospores. Gram stain variable though usually negative. Fermentation of carbohydrates as a rule not active. Frequently produces a water-soluble pigment which diffuses through the medium 
as green, blue, purple, brown, etc. In some cases a non-diffusible yellow pigment is formed. Many vellow species are plant parasites.

Genus 1.-Pseudomonas.-Characters, those of family. 'Type species, $P s$. aëruginosa (Schroeter) Frost?

FAnily III.-Spirillacea.-Cells elongate, more or less spirally curved. Cell division always transverse, never longitudinal. Cells non-flexuous. Usually without endospores. As a rule motile by means of polar flagella, sometimes non-motile. Typically water forms, though some species are intestinal parasites.

Genus 1. - Tibrio. - Cells short bent rods, rigid, single, or united into spirals. Motile by means of a single (rarely two or three) polar flagellum which is usually relatively short. Many species liquefy gelatin and are active ammonifiers. Aërobic and anaërobic. No endospores. Usually Gram-negative. Water forms, a few parasites. Type species, $V$. comma (Koch 1884) Schroeter 1886.

Genus 2.-Spirillum.-Cells, rigid rods of various thicknesses, length, and pitch of the spiral, forming either long screws or portions of a turn. Usually motile by means of a tuft of polar flagella (5 to 20) which are mostly half circular, rarely wavy-bent. These flagella occur on one or both poles; their number varies greatly and difficult to determine; since in stained preparations several are often united into a common strand. Endospore formation has been reported in some species. Habitat: water or putrid infusions. Type species, S. undula (Mueller 1786) Ehrenberg.

Fanily IV.-Coccacea.-Cells in their free conditions, spherical; during division somewhat elliptical. Division in one, two, or three planes. If the cells remain in contact after division they are frequently flattened in the plane of division and form chains, packets, or irregular masses. Motility rare. Endospores absent. Metabolism complex, usually involving the utilization of amino-acids or carbohydrates. Pigment often produced.

Tribe A. - Neisserea. - Strict parasites, failing to grow or growing very poorly on artificial media. Cells normally in pairs. Gramnegative. Growth fairly abundant on serum media.

Genus 1.-Neisseria.-Characters, those of tribe. Type species, N. gonorrhoex Trevisan.

Tribe B.--Streptococcea.-Parasites (thriving only or best on or in the animal body) except genus Leuconostoc. Grow well under anaërobic conditions. Many forms grow with difficulty on serumfree media, none very abundantly. Planes of fission usually parallel producing pairs, or short, or long chains, never packets. Generally stain by Gram. Produce acid but no gas in glucose and generally in lactose broth. Pigment, if any, white or orange.

Genus 2.-Diplococcus.-Parasites, growing poorly, or not at all, on artificial media. Cells usually in pairs of somewhat elongated cells, often capsulated, sometimes in chains. Gram-positive. Fer- 
mentative powers high, most strains forming acid in glucose, lactose, sucrose, and inulin. 'Type species, I). menmonia' Weichselhaum.

Genus 3.-Lencmostoc. - Saprophytes usually growing in cane sugar solutions. Cells in chains or pairs uniterl in large zoögleal masses. Some types at least Gram-negative. Type species $L$. mesenteroides (Cienkowski) van Tieghem.

Genus 4.-Streptococcus. - Chiefly parasites. Cells normally in short or long chains (under unfarorable conditions sometimes in pairs and small groups, never in large packets). Generally stain by Gram. Capsules rarely present, no zoögleal masses. On agar streak, effused translucent growth often with isolated colonies. In stab culture little surface growth. Many sugars fermented with formation of large amount of acid, but inulin is rarely attacked. Generally fail to liquefy gelatin or reduce nitrates. Type species, S. pyogenes Rosenbach.

Genus 5.-Staphylococcus.-Parasites. Cells in groups and short chains, very rarely in packets. Generally stain by Gram. On agar streak good growth, of white or orange color. Glucose, maltose, sucrose, and often lactose, fermented with formation of moderate amount of acid. Gelatin often liquefied very actively. 'Type species, S. aureus Rosenbach.

Tribe C.-Micrococcea.-Facultative parasites or saprophytes. Thrive best under aërobic conditions. Grow well on artificial media, producing abundant surface growths. Planes of fission often at right angles; cell aggregates in groups, packets, or zö̈gleal masses. Generally decolorize by Gram. Pigment yellow or red.

Genus 6.-Micrococcus.-Facultative parasites or saprophytes. Cells in plates or irregular masses (never in long chains or packets). Generally decolorize by Gram. Growth on agar abundant, with formation of vellow pigment. Glucose broth slightly acid, lactose broth generally neutral. Gelatin frequently liquefied, but not rapidly. Type species, M. luteus ('. chroeter) $1872 \mathrm{~b}$, Cohn.

Genus 7.-Sarcina.-Sarcina differs from Micrococcus solely in the fact that cell division occurs under favorable conditions in three planes, forming regular packets. 'Type species, Sarcina ventriculi Goodsir.

Genus 8.- Rhodococcus. - Saprophytes. Cells in groups or regular packets. Generally decolorize by Gram. Growth on agar abundant with formation of red pigment. Glucose broth slightly acid, lactose broth neutral. Gelatin rarely liquefied. Nitrates generally reduced. Type species, $R$. rhodochrous Zopf.

Fanily V.-Bacteriaceœ.-Rod-shaped cells without endospores. Usually Gram-negative. Flagella when present peritrichic. Metabolism complex, amino-acids being utilized and generally carbohydrates. 
Tribe 1.-Chromobactera.- Water bacteria producing a red or violet pigment.

Genus 1.-Erythrobacillus. -Small aërobie bacteria, producing a red or pink pigment, usually a lipochrome. Gram stain rariable. It is possible that related yellow and orange chromogens should be included here as well. Type species, E. prodigiosus (Ehrenberg).

Genus 2.-Chromobacterium.-Aërobic bacteria, producing a violet chromoparous pigment, soluble in alcohol but not in chloroform. Motility and Gram reaction variable. Type species, Chr. violacum Bergonzini.

Tribe 2.-Enimea.-Plant pathogens. Growth usually whitish, often slimy. Indol generally not produced. Acid usually formed in certain carbohydrate media, but as a rule no gas.

Genus 3.-Erwinia.-Characters those of the tribe. Type species, E. amylovora.

Tribe 3.-Zopfea.-Gram-positive rods, growing freely on artificial media. Not attacking carbohydrates.

Genus 4.-Zopfius.-Long rods occurring in evenly curved chains. Gram-positive. Motile. Proteus-like growth on media. Facultative anaërobes. Carbohydrates and gelatin not attacked, hydrogen sulphid not formed. Type species, Z. zopfi (Kurth) Wenner and Rettger.

Tribe 4.-Bacterea.-Gram-negative rods growing freely on artificial media. Generally forming acid from carbohydrates and often gas composed of $\mathrm{CO}_{2}$ and $\mathrm{H}_{2}$.

Genus 5.-Proteus.-Highly pleomorphic rods, filaments and curved cells being common as involution forms. Gram-negative. Actively motile. Characteristic ameboid colonies on moist media. Liquefy gelatin rapidly and produce vigorous decomposition of proteins. Ferment glucose and sucrose (but usually not lactose) with formation of acid and gas (the latter being $\mathrm{CO}_{2}$ only). Type species, $P$. vulgaris Hauser.

Genus 6.-Bacterium.-Gram-negative, evenly staining rods. Often motile, with peritrichic flagella. Easily cultivable, forming grape-vine leaf or convex whitish surface colonies. Liquefy gelatin rarely. All forms except $B$. alcaligenes and the $B$. abortus group attack the hexoses and most species ferment a large series of carbohydrates. Acid formed by all, gas $\left(\mathrm{CO}_{2}\right.$ and $\left.\mathrm{H}_{2}\right)$ only by one series. Typically intestinal parasites of man and the higher animals although several species may occur on plants, and one (B. aërogenes) is widely distributed in nature. Many species pathogenic. Type species, B. coli Escherich.

Tribe 5.-Lactobacillec.-IRods often long and slender, Grampositive, non-motile, without endospores. 'T'sually produce acid from carbohydrates, as a rule lactic. When gas is formed it is $\mathrm{C}^{\circ} \mathrm{O}_{2}$ 
without $\mathrm{II}_{2}$. The organisms are usually somewhat thermophilic. As a rule micro-aërophilic; surface growth on media poor.

Genus 7.-Lactobacillus. - Generic characters those of the tribe. Type species, L. caucasicus (Kern?) Beijerinck.

Tribe 6.-Pasteurellew. - Gram-negative rods, showing hipolar staining. Parasitic forms of slight fermentative power.

Genus S.-Pasteurella.-Aërobic and facultative. Powers of carbohydrate fermentation slight; no gas produced. Gelatin not liquefied. Parasitic, frequently pathogenic, producing plague in man and hemorrhagic septicemia in the lower animals. Type species, P. choleræ-gallinarum (Flïgge) 1886 Trerisan.

Tribe 7.-Hemophilaæ.-Ninute parasitic forms growing only in presence of hemoglobin, ascitic fluid or other body fluids.

Genus 9.-IIemophilus.-Ninute rod-shaped cells, sometimes thread forming and pleomorphic, non-motile, without spores, strict parasites, growing best (or only) in presence of hemoglobin, and in general requiring blood serum or ascitic fluid. Gram-negative. Type species $H$. influenzae (Pfeiffer 1893).

Famity VII.-Bacillacea.-Rods producing endospores, usually Gram-positive. Flagella when present peritrichic. Often decompose protein media actively through agency of enzymes.

Genus 1.-Bacillus.-Aërobic forms. Mostly saprophytes. Liquefy gelatin. Often occur in long threads and form rhizoid colonies. Form of rod usually not greatly changed at sporulation. Type species, B. subtilis Coln.

Genus 2.-Clostridium.-Anaërobes or micro-aërophiles. Often parasitic. Rods frequently enlarged at sporulation, producing clostridium or pleotridium forms. Type species, C. butyricum . Prazmowski. 


\section{CHAPTER V.}

\section{COMPOSITION OF BACTERIA.}

THE elementary composition of bacteria is the same as that of the higher plants. This is also true concerning the main chemical constituents composing their body. But the proportions of these latter at times vary quite widely. Noreover, some microorganisms contain constituents not found in higher plants.

Elementary Composition. - Bacteria on analysis yield carbon, hydrogen, oxygen, nitrogen, potassium, phosphorus, sulphur, calcium, magnesium, iron, aluminum and manganese. As to whether the last two are essential to normal development is not certain. In some species they are known to be non-essential, whereas in others, for instance the Izotobacter, they seem to play an important part.

Moisture.-Moisture is essential for all plant and animal life and is always abundant in actively growing cells; hence, we expect, and do actually find, large quantities of water in bacteria. The quantity present in the actively growing cell varies from as low as 70 per cent. to as high as 90 per cent. Generally speaking, young cultures contain less moisture than do older cultures; this appears to be true until the spore stage is reached, after which the quantity of water greatly decreases. The temperature at which the cultures are grown also governs in a measure the quantity of water present, this being less when grown at $37^{\circ} \mathrm{C}$. than when grown at $20^{\circ} \mathrm{C}$. The cultural media undoubtedly play a great part in determining the moisture content of the cells. It is probably rather low in bacteria obtained from alkali soil or from saline waters.

Organic Constituents. - The bacterial cell contains carbohydratelike bodies, proteins, extractives (fats, fatty acids, waxes and lipoids), and enzymes. In addition to these some bacteria also contain pigments, toxins and possibly ptomains. The quantity and quality of each, especially of the last four, vary greatly with the class of organisms and the conditions under which they are grown.

Carbohydrates are really conspicuous by their absence in most bacterial cells, but the following members of the carbohydrate group have been recognized in varying quantities in some bacteria: cellulose, hemicellulose, dextrin, starch, glycogen and a number of the sugars.

lixtractives, although found to a limited extent in all microörganisms, are found in larger quantities in the tubercle bacillus and other 
members of the acid-fast group. In some members of this group the extractives vary from 26 to 40 per cent. of the total dry residue. In the early studies of the chemistry of bacterial cells it was assumed that the alcoholic and ethereal extracts consisted of fats exclusively. Tributyrin, tripalmatin, tristearin, triolein, lecithin and various waxes have been recognized.

Klebs found in the tubercle bacillus 20.5 per cent. of a red fat melting at $42^{\circ}$ and 1.14 per cent. of a white fat melting above $50^{\circ}$, the latter being insoluble in ether but soluble in benzol. De Schweinitz and Dorset concluded that the fat of the tubercle bacillus contains palmitic and arachidic acids, while that of the glanders bacillus contains oleic and palmitic. 'They also obtained a crystalline acid, for which they suggested the name tuberculinic acid. 'This is quite different from Ruppel's nucleic acid. It had an elementary composition of $\mathrm{C}_{7} \mathrm{H}_{10} \mathrm{O}_{4}$. The authors called attention to the similarity in composition and properties of this body and tetraconic acid. They suggest that it may be the substance which is responsible for the coagulating necrosis and reduction in temperature.

Kresslig extracted tubercle bacilli successfully with ether, chloroform, benzol and alcohol, and obtained 38.95 per cent. of fatty and waxy substances. Repeated extraction with chloroform gave a dark brown mass of the consistency and color of beeswax and melting at $46^{\circ}$. He found 14.38 per cent. of free fatty acid, 76.25 per cent. of neutral fat and esters of fatty acids, and some volatile fatty acid, probably butyric. Ile concluded that the fat of the tubercle bacillus is quite different from that obtained from any other source.

The fats and waxes are probably both intra- and extracellular, for extraction of the intact cell yields some and the crushed cell yields still more. The quantity found within the cell varies greatly, depending on the media upon which the organism is grown. Neyer found that the fat in Bacillus tumescens gradually increases until spore formation occurs, when it disappears; the spores are also free from fat. This, however, is not general for the spores of some organisms contain proportionally more fat than do the vegetative forms.

Proteins. - The bulk of the dry matter of the bacterial cell is composed of proteins. 'The following analysis reported by Ruppel indicates the composition of the tubercle cell:

Nucleic (tuberculinic acid)
Nucleoprotamin
Nucleoproteid $:$
Albuminoids
Fat and wax
Ash.

8.5 per cent.

25.5

23.0

8.3

26.5

9.2

The wonderful synthetic reaction catalyzed by the .1zotobacter cell has directed the attention of workers to this specific organism. 
Therefore, our knowledge of the composition of this organism is probably more nearly complete than it is of many other species.

Berthelot early recognized that the nitrogen fixed by the Izotobacter is insoluble in water, thus indicating its protein nature. Lipman found there was a small but appreciable quantity of nitrogen in both young and old cultures of $A$. vinelandii not precipitated by lead acetate and a large proportion not precipitated by phosphotungstic or tannic acid. Further work indicated that the substance was either amino-acids or comparatively simple peptids. He considered that one of the early substances synthesized by these organisms was alanin. An analysis of the Azotobacter membrane gave the following:

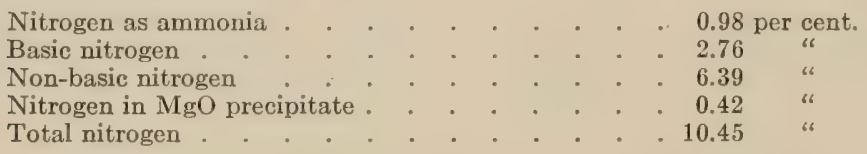

This, he finds, corresponds remarkably closely to legumin. That it is complex is indicated by the fact that it is not readily assimilated by plants.

Stoklasa found the 1zotobacter cell to contain 10.2 per cent. of total nitrogen and $\$ .6$ per cent. of ash. The ash was from 58 to 62.35 per cent. phosphoric acid. The nitrogen and phosphorus were mainly in the forms of nucleoproteins and lecithin. The percentage of both nitrogen and phosphorus in the cell increases with age.

The most complete analysis of the Azotobacter cells, so far reported shows them to contain, when grown on dextrin agar and rapidly dried at $30^{\circ} \mathrm{C}, 12.92$ per cent. of protein. The protein is similar to other plant proteins. It contains 10 per cent. of ammonia nitrogen, 26.5 per cent. of diamino-nitrogen, and 60 per cent. of mono-amino-nitrogen. It contains the amino-acids normally found in proteins but the quantity of lysin present is high, whereas the histidin is present only in traces.

An examination made by Nishimura of a pure culture of a water bacillus gave the following as the composition of the dry matter in the bacillus.

Albumin
Carbohydrates
Alcohol extract
Ether extract
Ash
Lecithin. :
Xanthin :
Guanin :
Adenin :


The organism is, therefore, extremely rich in protein, and, although the albumin predominates it is not free from nucleoprotein, as is seen from the presence of the purine bases, xanthin, guanin and adenin.

Inorganic Constituents. - The ash-content of the bacterial cell is not far different qualitatively from that of the higher plants. Quantitatively, however, there is a marked difference, the ashcontent of bacteria being comparatively high. The ash-content of the cell is subject to wide variation, depending on the specific organisms and especially on the media upon which it is grown. This may be seen from the following results by Cramer who grew the Cholera vibrio on various media.

Composition of medium in
which organisms were grown.

\section{1 per cent. soda | Phosphate \\ bouillon (regular bouillon (regular $\mathrm{NaCl}$ bouillon \\ broth +1 per cent. broth +1 per cent. (regular broth + $\mathrm{NaOH}$ ). sod. phosphate).}

Ash-content of bacteria in dry substance

Ash-content of moist mass

9.30

1.34

Ash-content of medium in moist mass

Phosphoric acid in bacterial ash

Phosphoric acid in media ash

Chlorin in bacterial ash

Chlorin in media ash
1. 25

28.70

7.90

16. 90

23.00
22. 30

2.75

2.50

34.80

39.80

7.97

11. 40
25. 90

3. 73

4. 12

10.90

2. 10

40.70

49.20

Analyses have been reported in which the phosphoric acid-content reaches as high as one-half the total ash-content of the cell. It is quite probable that a great proportion of this is combined with the nucleic acid in the nucleoproteins.

Variation in Composition of Different Parts of the Cell.-As has been pointed out, the bacterial cell is not homogeneous but is made up of fairly distinct parts, namely, ectoplasm, capsule and cytoplasm and nuclear material. These constituents vary noticeably in their chemical composition. Although the ectoplasm at times contains in some species of bacteria small quantities of cellulose and hemicellulose, yet the predominating substance is chitin, a substance which may be considered as an intermediary compound between the carbohydrates and proteins. When pure, chitin yields over 80 per cent. of its weight as glucosamine. It yields first acetic acid and chitosan:

$$
\underset{\text { Chitin. }}{\mathrm{C}_{18} \mathrm{H}_{30} \mathrm{~N}_{2} \mathrm{O}_{12}}+2 \mathrm{H}_{2} \mathrm{O}=\underset{\text { Acetic acid. }}{2 \mathrm{CH}_{3} \mathrm{COOH}}+\underset{\text { Chitosan. }}{\mathrm{C}_{14} \mathrm{H}_{26} \mathrm{~N}_{2} \mathrm{O}_{10}}
$$

Chitosan on further hydrolysis yields acetic acid and glucosamine:

$$
\underset{\text { Chitosan. }}{\mathrm{C}_{14} \mathrm{H}_{26} \mathrm{~N}_{2} \mathrm{O}_{10}}+2 \mathrm{H}_{2} \mathrm{O}=\underset{\text { Acotio acid. }}{\mathrm{CH}_{3} \mathrm{COOH}}+\underset{\text { Glycosamine. }}{2 \mathrm{CH}_{2} \mathrm{OH}(\mathrm{CHOH})_{3} \mathrm{CHNH}_{2} \mathrm{CHO}}
$$


The cell membrane is, therefore, more nearly that of the animal than the plant. The brown color obtained on staining some bacteria mith iodin has led observers to believe that they contain glycogen, whereas the blue color with the same reagent is attributed to starch.

The capsules contain comparatively large quantities of mucin. These are protein-like substances which may be precipitated by alcohol. They give most of the protein reactions and, in addition, when heated with an acid, acquire the property of reducing Fehling's solution, thus showing them to contain a carbohydrate complex in addition to the protein.

The cytoplasm consists largely of bacterial proteins which appear to be specific in character for any given species. Within this are large quantities of the nucleoproteins, for on hydrolysis large quantities of the purine bases are obtained. Vaughan, Wheeler and Leach conclude that the bacterial cytoplasm contains carbohydrates, nuclein bodies, and polymers of mono- and di-amino-acids. They are glyconucleoproteins. Spores differ from the vegetative organism in that they contain but small quantities of water.

\section{REFERENCES.}

Vaughan: Protein-split Products in Relation to Immunity and Discase.

Kendall: Bacteriology-General, Pathological, Intestinal.

Kruse: Allgemeine Microbiologie. 


\section{CHAPTER VI.}

\section{FOOD REQUIREMENTS.}

FOOD is any substance which bacteria can utilize in obtaining either building material or energy for the cell activity. The quantity and quality of food necessary vary widely with the different species. Howerer, all foods must contain certain essential elements. Our knowledge at the present time indicates these elements to be carbon, hydrogen, oxygen, phosphorus, potassium, nitrogen, sulphur, calcium, iron and magnesium, or, using the key for remembering as suggested by Dr. IIopkins, we have ('. I Iopk'ns $\mathrm{CaFe} \mathrm{Mg}$ - - - "C. Hopk'ns Cafe - - mighty good."

Minimum Requirements. - In considering the food used by bacteria a minimum and a maximum requirement must be recognized. These two extremes differ greatly, for although the minimum quantities appear inconceivably small the maximum ones are enormous. One may obtain a fair idea of the minimum requirements from the following calculation made by Rahn: "The quantity of organic and inorganic matter just sufficient to support a very weak growth is certainly very small, since a few species will multiply to some extent in ordinary distilled water. Such water, after having stood for some time, is found to contain several thousand bacteria per cubic centimeter. It may seem to the laymen that in such water it would be possible to detect easily the organic and inorganic matter of the microörganisms so that it could not be considered distilled water. An estimate of the weight of bacteria demonstrates, however, that this is not the case. If we suppose the average bacterial cell to be a cylinder whose base measures 1 square micron and whose height is 2 microns (which is a high estimate). The volume of such a cell would be $1 \times 1 \times 2$ cubic microns $=0.001 \times 0.001$ $\times 0.002 \mathrm{~mm} .=0.000,000,002 \mathrm{cu} . \mathrm{mm}$. The specific gravity of bacteria being very nearly one, the weight of one bacterium would be $0.000,000,002 \mathrm{mg}$. One hundred thousand cells per cubic centimeter means $100,000,000$ cells per liter, which would weight 0.2 mg. Of this total weight, at least four-fifths is water and only onefifth is solid matter. The total solid matter in 1 liter of water containing 100,000 bacteria per cubic centimeter amounts to the immeasurable quantity of $0.04 \mathrm{mg}$. Such water will pass the test for distilled water. IIow much food the bacteria in distilled water have used is impossible to say, since, besides the traces of minerals 
in the water, they obtain some food from volatile compounds of the air, like carbon monoxid $(\mathrm{CO})$, carbon dioxid $\left(\mathrm{CO}_{2}\right)$, ammonia $\left(\mathrm{NH}_{3}\right)$, hydrogen (H) and perhaps methane $\left(\mathrm{CH}_{4}\right)$. Lnder all circumstances the amount of food used is very small."

Maximum Requirements. - The maximum quantity of food which may be decomposed by bacteria is often enormous. They quickly decompose the body of an ox after its death. Tons of material run into the septic tanks of large cities, all of which is rapidly decomposed by bacteria. It is, however, usually the case that the speed of the reaction is great at first, but soon slows up or comes to a complete stop. This is due to the fact that the accumulation of end-products interferes with the growth of bacteria. This is true in milk where at first the lactose is rapidly changed to lactic acid, which if not neutralized soon becomes concentrated enough, to slow up the reaction. This is also true with the changes going on in sauerkraut and silage.

Function of the Food.-The food utilized by bacteria has two functions, namely, the furnishing of energy and the acting as cellular building material. The quantity required by each bacterial cell for building material is not great, for MacNeal and his associates found that the dry matter of $550,000,000$ cells of $B$. coli weigh only $0.1 \mathrm{mg}$. Others have estimated the weight of a single colon bacillus to be $0.000,000,163 \mathrm{mg}$., or it would require $1,600,000,000$ colon bacilli to weight approximately $1 \mathrm{mg}$. The waste products and repair material would make the cellular requirements slightly greater than this, but from these figures it is evident that the actual quantity required by a cell for building material is extremely small. Even this, however, is not immaterial, for Conn starting with the assumption that the period of generation is a half hour makes the following calculation. "If we take a single bacillus measuring $2 \mu$ in length and $1 \mu$ in breadth, with a weight of $0.000,000,001,571$ mg., it will increase, according to the aforesaid assumption, at such a rate that in two days' time its progeny will amount to $2 \$ 1,000,000,000$, and will occupy a volume equal to about $\frac{1}{2}$ liter (30.51 cu. in.); within a further three days the quantity would increase to a mass sufficient completely to fill the beds of all the oceans of the globe." Due to the accumulation of waste products they never continue to multiply long at such a rate, but the numbers in suitable media often become hundreds of millions per cubic centimeter before retardation occurs.

Source of Energy.-Animals and plants require energy in their life activity, the former obtaining it directly from the kinetic energy of the sum which they store up as potential energy. This is liberated by the animal in the process of oxidation. Now, hacteria do not possess the powers of the higher plants to utilize directly the energy of the sun, but, like the animals they are 
dependent on the stored energy of the plant and animal kingdom. From their method of oxidation it is necessary to recognize two groups of bacteria: (1) Those which completely oxidize their food, the carbon and hydrogen occurring in the final products as carbon dioxid and water; (2) those which only partly decompose their food, thus leaving much of the energy still within the food. Now the actual food requirements of the two classes of organism for the accomplishment of the same end, in so far as energy is concerned, is materially different. For instance, the complete oxidation of glucose to carbon dioxid and water as brought about by some yeasts according to the equation $\mathrm{C}_{6} \mathrm{H}_{12} \mathrm{O}_{6}+6 \mathrm{O}_{2}=6 \mathrm{CO}_{2}+6 \mathrm{H}_{2} \mathrm{O}+$ 674 cal.; whereas, when only partly oxidized to alcohol it would be $\mathrm{C}_{6} \mathrm{H}_{12} \mathrm{O}_{6}=2 \mathrm{C}_{2} \mathrm{H}_{5} \mathrm{OH}+2 \mathrm{CO}_{2}+22$ cal.

The energy obtained in the first case is over thirty times that obtained in the second, and the quantity of food decomposed would be relatively greater in the latter than in the former. It has been estimated that the lactic acid bacteria decompose their own weight of sugar in one hour.

Although all organisms require the elements listed at the beginning of this chapter, yet the nature of the organic compound required varies greatly with different species.

Moisture.-Moisture may be considered the most important factor of life. "It is little short of astounding that living matter with all its wonderful properties of growth, movement, memory, intelligence, devotion, suffering and happiness should be composed to the extent of from 70 to 90 per cent. of nothing more complex or mysterious than water. Such a fact as this is most perplexing, especially when all experiments show that this water is playing a profoundly important part in the generation of the vital phenomena. Any interference with the amount normally present makes a change at once in the activities of the cell. In fact we might say that 'all living matter lives in water,' as Claude Bernard put it. For not only is this obviously true in the lower and simpler forms of animals and plants, which are little more than naked masses of protoplasm living in water, but it is no less true of the higher forms, since in all of them an internal medium, or environment, of a liquid nature, the lymph, the blood or sap, is found which is the immediate environment of the cells. Water is the largest and one of the most important constituents of living matter, and if organisms are carefully examined the most various devices are found to assure the regulation of the water content of the cells of the body. The younger, the more vigorous, the more alive, the more actively groming, the more impressible cells are, the more watery are they."

Water enters very largely into the composition of the bacterial cell, since they consist of from 70 to 95 per cent. water; moreover, it enters into nearly every change which they bring about. When 
bacteria decompose the carbohydrates, one or more molecules of water are taken up; when they synthesize, water is eliminated. The hydrolysis of fats requires for every molecule three of water; when they are synthesized from glycerin and fatty acids three molecules are eliminated. The digestion of the proteins by bacteria is usually hydrolysis in which a number of molecules of water are caused to enter the large protein molecule, thus causing it to break down into elementary diffusible foods. When the bacteria build their own proteins from the peptones and amino-acids, it requires that water be eliminated. Thus water plays an all-important part in all bacterial syntheses and decompositions.

Water accelerates or is essential in all reactions taking place in the cell. It has a higher inductive capacity, or dielectric constant, than any other liquid, except possibly hydrogen dioxid. "It is a good insulator. It does not in itself, at ordinary temperatures, conduct the current readily. In virtue of this property it happens that when electrical disturbances occur in a cell they are not instantly compensated, so that oppositely charged particles may coëxist in water. It is probably because of this property that water forms such a good ionizing medium. At any rate, this property may account for the undoubted fact, whatever explanation we may choose to give of that fact, that substances dissolved in water interact with greater ease and speed than when dissolved in any other medium. It has the property then, so important for the cell, of accelerating all kinds of chemical reaction. Thus hydrogen and oxygen will not unite, except at very high temperatures, unless some water is present. Hydrochloric acid and sodium hydrate react vigorously in the presence of water, but not when they are quite dry. Chlorin and hydrogen do not form hydrochloric acid, except at very high temperatures, unless water be present, and everyone knows that the rusting of iron does not occur unless water is there too. Water has, then, this fundamental property of making reactions go on between bodies dissolved in it or wet by it. This property is believed by many to be correlated with its ionizing powers and with the fact that its solutions conduct electrical currents more than those of any other solvent."

Another very remarkable property of water is its power of solution. No other solvent surpasses it. All substances dissolve in it to some extent. It is a solvent for salts, carbohydrates, proteins and even for fats to some extent. This universal solvent power has not yet been fully explained, but it is probable that it is correlated with, or due to, the extra valances on the oxygen atoms which are perhaps able to unite with the extra valances on the dissolving molecules and thus to produce solution. But be the explanation what it may, it is well known that its solvent action contributes much to life. Bacteria are able to absorb their food only 
when in solution, while in solution it reacts and after it has served its purpose the waste products are carried from the cell in solution.

Osmotic Pressure.-If a cell be placed in a strong salt solution, there is a shrinking of the cell which may result in plasmolysis. If, on the other hand, a cell be suspended in pure water the cell greatly increases in size and finally bursts. This is the case when any solution is separated from pure water or from a less-concentrated solution by a membrane which to the dissolved substance is impermeable but to the water of the solution permeable. The solution exerts pressure on the membrane and the water passes through the membrane into the solution. The pressure is called osmotic pressure, and depends not upon the percentage of solute, but upon the number of particles-molecules and ions-per unit volume. 'The amount of this pressure varies in different cells, but for mammals it is supposed to be about that of a 0.9 per cent. sodium chlorid $(\mathrm{NaCl})$ solution, since in such a solution the tissue neither gains nor loses weight. This is about 7.1 atmospheres.

However, some bacteria and many molds can survive and even grow in salt solution which would be fatal to the life of the cell of higher plants. Penicillium and Aspergillus have been known to thrive in solutions, the osmotic pressure of which is equivalent to a 20 per cent. potassium nitrate solution. Bacillus anthracis flourishes on agar containing as much as from 8 to 10 per cent. of sodium chlorid. Since turgidity is essential to growth, it follows that these organisms must have some means of altering the pressure of their cell contents according to the concentration of the surrounding medium; only in this way can plasmolysis be avoided. The plasmotic membrane in the case of many bacteria is highly permeable; this would be the case, especially with those organisms which grow in brines. Fven some pathogenic bacteria possess the power of accommodating themselves to high osmotic pressures. Bacillus cholerce are temporarily plasmolyzed by salt and sucrose solutions but not at all by a glycerin solution, the cell membrane being permeable to the latter. The plasmolysis produced by the salt and sugar disappear in the course of an hour or two as a rule, showing that even salt and sugar slowly penetrate the plasmotic membrane.

Kind of Food Required.-The quality of the food required by bacteria varies greatly with the species. This is well exemplified in Jensen's classification of bacteria which is based upon the sources of nutrition and distinguishes the following groups:

"1. Bacteria which, like green plants, need neither organic ('arbon nor organic nitrogen. These so-called 'autotrophic bacteria' can build up both carbohydrates and proteins out of carbon dioxid and inorganic salts.

"2. Bacteria which need organic carbon compounds, but can 
dispense with organic nitrogen. These bacteria are able to șnthesize protein substances out of carbohydrates (or organic acids) and ammonia, nitrogen or nitrates.

"3. Bacteria which, like the higher animals, require both organic carbon and organic nitrogen compounds. These bacteria cannot accomplish either carbohydrate or protein sinthesis out of inorganic substances."

Carbon.-The carbon dioxid of the air cannot be utilized by bacteria as a source of energy since it is already fully oxidized. There are, however, some organisms which possess the power of utilizing both carbon monoxid and methane. On the contrary, the carbon of carbohydrates, fats and proteins are readily utilized by bacteria. The hydrocarbons of both the aliphatic and aromatic series are resistant to bacteria, but those compounds which contain oxygen in addition to the carbon and hydrogen are more readily attacked. Many organic acids and oxy-acids are used by some bacteria. Only a few bacteria can use the simpler alcohols. The more complex alcohols, like glycerin and mannite, are utilized by many. The carbohydrates are especially valuable to most bacteria, those containing six or twelve carbon atoms being the most valuable.

Nitrogen.-The nature of the nitrogen requirements of bacteria are extremely different, depending upon the specific organism. Some organisms, such as the symbiotic nitrogen-fixers and the azofiers, are able to obtain all the nitrogen required from the atmosphere. The nitrosomonas obtains its nitrogen from ammonia, whereas the nitromonas obtain it from nitrites. The majority of bacteria obtain their nitrogen from peptones, proteoses, and even amino-acids. Rettger concludes from oft-repeated experiments on animal and regetable proteins that bacteria are unable to derive nourishment from native proteins, and that in a medium in which there is no possible source of nitrogen other than the proteins themselves they will thrive no better than in a chemically pure saline solution. When proteolytic enzymes are present the complex protein molecules are broken up and, at least in part, made available for cell nutrition. It would appear that "it is as essential to break down complex nitrogenous food substances into their simple components, before they can be utilized, as it is to reduce the walls of an old church brick by brick before they can be made over into a modern schoolhouse." The more strictly pathogenic organisms, as the gonococeus and the leprosy bacillus, may require nitrogen in the form of highly specific tissue proteins. As a rule, animal proteins are more readily utilized than are plant proteins.

Hydrogen. - Hydrogen is obtained from many organic compounds containing hydrogen and oxygen, such as the carbohydrates, fats 
and proteins, but usually not those componds which contain only (arbon and hydrogen, such as methane and its homologenes.

Sulphur. - Sulphur is recuired by all bacteria possibly for the formation of the proteinaceons material of their bodies. In addition to this, some organisms use it as a somre of energr. For instance, the Beggiatoa sometimes use two to four times their own weight of hydrogen sulphid in a day, under which conditions the sulphur grains may be seen in the cell-protoplasm and may be looked upon as an intermediate stage in the oxidation process, the reaction proceeding as follows:

$$
\begin{aligned}
& 2 \mathrm{H}_{2} \mathrm{~S}+\mathrm{O}_{2}=2 \mathrm{H}_{2} \mathrm{O}+2 \mathrm{~S} \\
& 2 \mathrm{~S}+3 \mathrm{O}_{2}+2 \mathrm{H}_{2} \mathrm{O}=2 \mathrm{H}_{2} \mathrm{SO}_{4}
\end{aligned}
$$

Some bacteria may get their reguired sulphur from sulphates, sulphites or thiosulphates, but probably the great majority of them obtain it from the proteins.

Phosphorus.-Phosphorus is used by bacteria in large quantities, being essential for the building of the nucleoproteins and phosphoproteins in which the unicellular organisms are especially rich. The form and quantities required by the organisms vary greatly with the species. The 1zotobacter are able to utilize it from most organic and inorganic sources, some, however, being much more valuable than others.

Potassium.-Potassium is essential to the higher plants and cannot be replaced entirely by related substances, yet Gerlach and Vogel early reached the conclusion that potassium and magnesium are not essential to i i otobacter. 'Their results, however, were considered for a long time to be erroneous. But if these elements are essential to Azotobacter it must be in extremely small quantities. Potassium does, however, favor their development; and is probably valuable, if not essential, to all bacteria. Most inorganic potassium compounds can be utilized.

Other Inorganic Substances.-The other inorganic constituents are required by bacteria only in small quantities and are obtained from either organic or inorganic compounds, depending upon the specific organism.

Oxygen Requirements. - Bacteria, like all other plants and animals, require oxygen in their life activity. The various classes of organisms are not indifferent as to the form in which they obtain their oxygen. One great class requires that their oxygen be furnished free; to these is given the name "aërobic." Another requires their oxygen in the combined form; they are called "anaërobic." Some organisms grow best in the presence of free oxygen but may become adapted to combined oxygen; these are known as "facultative anaërobes." Others grow best in the absence of free oxygen but may become adapted to it; they are known as "facultative aërobes." 
Few bacteria are true aërobes or anaërobes, but many gradually hlend from one class into another, as some will withstand small quantities of free oxygen but not a full atmospheric pressure of it.

Vitamines. - The extracts of animal organs, as well as those of some plant tissues, are valuable nutrient material for bacteria which it is as yet impossible to supply in any medium of known chemical composition. The composition of these more or less unstable but highly nutritive substances is a matter of purest speculation. For want of a better name they are termed "vitamines" or "accessory growth factors." These accessory bodies are moderately heat-stable and are soluble in alcohol and in water. They are rapidly absorbed from solution by filter paper, but not by glass wool. They increase the reaction velocity of the proteolytic metabolism of the meningococcus and are essential to many other organisms. After the first or primary cultivation some organisms become independent of these substances. This phase of bacterial nutrition, which is only just beginning to receive attention, is beset by many difficulties. The work being done, however, gives promise of so clearing up the field that much that was impossible of explanation in the past will be readily explained. But the present status of the case is well summarized by Rettger when he stated: "We are as yet in the dark regarding the real food requirements of bacteria."

Marshall: Microbiology.

\section{REFERENCES.}

Kendall: Bacteriology-General, Pathological and Intestinal.

Kruse: Allgemeine Microbiologie.

Berman, Nathan, and Rettger, Leo F.: Bacterial Nutrition-Further Studies on the Utilization of Protein and Non-protein, Jour. Bacteriol., 1918, iii, 367-388.

Berman, (Nathan), and Rettger (Leo F.): The Influence of Carbohydrates on the Nitrogen Metabolism of Bacteria, Jour. Bacteriol., 1918, iii, 389-402. 


\section{BACTERIAL METABOLISAI-ENZYMIES.}

$\mathrm{IT}_{\mathrm{T}}$ was pointed out in the last chapter that bacteria require food for at least two purposes-building material and the liberation of energy. In fulfilling these functions the foods are profoundly changed; at times they are broken up into comparatively simple products, after which they are built into the complex molecules composing the bacterial cell; at other times they are split and the energy utilized; at still other times they are completely oxidized, the organisms thus obtaining all the stored potential energy. The sum of all these changes which the food undergoes, including the deterioration of the cell, is called metabolism. These changes consist of two separate processes; the one-construction of new cells or parts of cells-is a process of synthesis and is called anabolism. The other is analytical or the breaking-down of the cell and is called katabolism. Although these two processes are usually going on simultaneously in the cell, yet it is true that during the first few hours after inoculation of a culture the anabolic aspect predominates; later the katabolic phase predominates. That this should be the case can be readily seen, for the bacterial cell must be morphologically complete before it can bring about its characteristic energy transformations, which continues until the death of the cell.

Moreover, recent investigations have demonstrated that it is just as true of bacteria as of animals that "it is as essential to break down complex nitrogenous food substances into their simple components before they can be utilized, as it is to reduce the walls of an old church brick by brick before they can be made over into a modern schoolhouse." The development and present status of our knowledge of this represents one of the most interesting and valuable chapters of bacteriology.

Early Theories of Fermentation. - Even as early as 1595 the great medical chemist, Labavius, considered fermentation a process akin to digestion, and von Helmont (16tS) stated that out of the ferment something passes into the fermenting liquid which grows in it as a seed. But it was the great chemist, Liebig, who first developed the purely chemical explanation of fermentation. It was he who developed the idea of catalysis, a word already invented by Berzelius. Liebig compared fermentation changes to the action of finely divided platinum which possesses the power of bringing about the union of gases at low temperatures. The ferment he 
considered to be in a state of unstable equilibrium or decomposition. This is communicated to its surroundings, producing chemical changes. 'This was opposed by Pasteur and Tyndall who showed that in the absence of microörganisms formentation does not take place.

There were certain changes which they proved to be due to bacteria and yeast; others which were brought about by pepsin, tripsin, etc. This led to the classification of ferments as organized and unorganized. Under organized ferments were grouped such substances as some bacteria and yeasts, which, when examined under the microscope, possess a definite organized structure and which act by virtue of vital processes. Thie unorganized ferments included amylase, pepsin, rennin, etc., and were described as "non-living unorganized substances of a chemical nature." Kühne designated this last class of substances, enzymes. This classification into organized and unorganized ferments was generally accepted and practically unquestioned until overthrown by Büchner (1897) in his epoch-making investigation of yeast. He carefully mixed 1000 grams of brewers' yeast with an equal weight of quartz sand and 250 grams of infusorial earth generally known as Kieselguhr. This mixture was ground together until plastic; 100 c.c. of water was added and wrapped in a press cloth and filtered in a press capable of exerting a pressure of from 400 to 500 atmospheres. The juice was clarified by shaking with Kieselguhr and filtering. The liquid so obtained is slightly heavier than water and possesses a pleasant odor. On boiling, a quantity of proteinaceous matter separates and the liquid becomes nearly solid.

The unboiled juice possesses all the power of the yeast cell in so far as fermentation is concerned. However, the action is not stopped by chloroform nor by the passage of the liquid through a Berkefeld filter nor through a dialyzing membrane. The enzyme which is present in the solution has been termed by Biichner zymase. Later the lactic acid- and the acetic acid-producing bacteria were subjected by Büchner to similar treatment to that given the yeast cells, and the active intracellular enzymes were obtained. Since that time the list of unorganized ferments or enzymes has continued to grow at the expense of the organized ferments until it is generally conceded today that all fermentations are due to enzymes, there being only this difference-that some are formed and readily diffuse out of the body of the cell during its life and are known as extracellular ferments, whereas others remain in the cell and are known as intracellular ferments.

Definition of Enzymes.-Enzymes have been defined as "unorganized, soluble ferments, which are elaborated by an animal or vegetable cell and whose activity is entirely independent of any of the life processes of such a cell."” 
Enzymes act by catalysis and hence are often stated to be "selective colloidal catalysts, present in living cells and destroyed by heat." A catalyzer is "a substance which alters the relocity of a chemical reaction without undergoing any apparent physical or chemical change itself and without becoming a part of the product formed." It is a well-known fact that the speed of many chemical reactions is accelerated by catalyzers; for example, the inversion of cane sugar by acid and the numerous reactions affected by platinum. Negative catalysis is not as common, but the stopping of the slow oxidation of phosphorus in air by a trace of ether vapor may be taken as an example. The general characteristics of catalysts are admirably illustrated by Bayliss:

"There are certain phenomena which, at first sight, might be confused with those of catalysis, but which must be carefully distinguished from them. A mechanical model will serve to make this clear. If a brass weight of, say 500 grams, be placed at the top of an inclined plane of polished plate-glass, it will be possible to find a slope of the plane such that the weight will slowly slide down. This represents any reaction taking time to complete. If now the bottom of the weight be oiled (oil-catalyst) the rate of its fall will be greatly increased. We see, that in either case, the weight if placed at the top of the plane does not remain there, but sooner or later reaches the bottom. It may, however, be kept at the top by some kind of catch or trigger arrangement, in which case it will remain there indefinitely until the catch is released. The amount of energy lost by the weight in its fall, being the product of its weight and the vertical height from which it has fallen, is in no way affected by the work required to remove the obstacle preventing its fall, nor is the rate at which it falls when set free. A typical instance of such a 'trigger' action is that of supersaturated solutions, which remain for any length of time unchanged unless infected with a crystal. It has, moreover, been shown by $B$. Moore (1893) that the rate at which the solidification of supercooled glacial acetic acid moves along a tube is independent of the quantity of crystals placed at one end to start the process. Not so with true catalytic action; although the work done by our sliding weight is in no way affected by the amount of catalyst (oil) used, the rate of the fall is, within limits, directly proportional to it, and this is a property of catalysts in general.

"It cannot be expected that a rough model of this kind would show all of the characteristics of catalytic phenomena, but there are two instructive points shown by it in addition to those already spoken of. The first is the disappearance of the catalyst by sticking to the glass as the weight slides down. An analogous phenomenon is often met with in catalytic processes, as will be seen later. The second point is one of importance with regard to 
certain enzyme actions; it consists in the fact that, although the presence of the catalyst neither adds to nor subtracts from the total energy change in the reaction, the form of this energy may be altered. When the weight falls slowly by itself, nearly the whole of the energy appears as heat due to friction along the glass plane, so that the weight arrives at the bottom with very little kinetic energy; on the contrary, when oiled, nearly the whole of the energy is present in the weight at the end of its fall as kinetic energy, very little friction having been met with in its descent. We may notice, also, comparing the effects of different amounts of oil, that small amounts produce a much more marked result than the subsequent addition of further quantities. This is also characteristic of enzymes, as we shall see later.

"From what has been said it follows that a catalyst is merely capable of changing the rate of a reaction already in progress. In opposition to this it may reasonably be said that a reaction does sometimes seem to be initiated. Such a case is that of a mixture of oxygen and hydrogen gases caused to combine by spongy platinum. Now there are reasons for the belief that an extremely slow combination is taking place at ordinary temperatures without catalysis. One thing to be considered in reference to this belief is the enormous acceleration of chemical reactions by rise of temperature, the majority being about doubled by a rise of $10^{\circ} \mathrm{C}$. In this way a reaction having a velocity of 1 at $0^{\circ}$ would reach one of 2 at $10^{\circ}, 4$ at $20^{\circ}$ and $1 \times 2^{10}=1024$ at $100^{\circ}$. At the temperature of $500^{\circ}$ there is appreciable formation of water in the case in point, and Bodenstein (1899) has shown that if the velocity at $689^{\circ}$ be represented by 163 , that at $482^{\circ}$ has already sunk to $0.2 S$; so that at room temperature the velocity would be quite incapable of detection by chemical means, since centuries would be needed to produce a fraction of a milligram of water. Grove's gas battery also proves that the two gases are not in equilibrium at ordinary temperatures, since electrical energy is obtained by their slow combination.

"To take another case of a reaction which progresses at a slow rate when left to itself: When methyl acetate is mixed with water at ordinary temperatures it is very slowly hydrolyzed to alcohol and acetic acid until a certain proportion of it is decomposed, so that a state of equilibrium is finally arrived at. This process takes many days for its completion, but the time may be shortened to a few hours by the addition of a small amount of hydrochloric acid.

"The objection may be made to the former of these two examples that the combination of oxygen and hydrogen does not take place except in the presence of water vapor, which probably acts as a catalyst. Similarly, the hydrolysis of esters by water may be said to be due to the hydrion present therein. This point of view does 
not, however, in reality, affect the reasoning, since the reactions can be enormously accelerated by other bodies, which act as additional catalysts and may be investigated independently. It is, in fact, a matter of considerable difficulty to discover a slow reaction which is definitely known to take place in the complete absence of any catalyst.

"Moreover, it must not be forgotten that, as J. J. Thomson and others believe, a catalyst may possibly start a reaction. This is not, theoretically, in disagreement with the view taken by Ostwald. 'To return to our mechanical illustration, the 'friction' between the weight and the glass plane may be sufficiently great to prevent movement altogether, until oil is applied. But the use of the name 'friction' implies the idea of movement and the existence of forces tending to produce it. One may indeed suppose that the weight actually does move for an infinitesimal distance, but is at once arrested by the resistance met with. From this point of view the definition of a catalyst would be expressed some. what thus: A substance which changes the rate of a reaction which is actually in progress, or which is capable of proceeding without any supply of energy from without, if certain resisting influences are removed. The difference between diminution of friction by oil and the removal of a catch is that, in the former case the action is continuous throughout the fall of the weight, whereas in the latter case the action is only momentary, at the commencement of the fall, on the rate of which it has no further effect."

Terminology. - Within recent years attempts have been made to systematize the terminology used in referring to enzyme action. The name of the substance on which the enzyme acts is called substrate.

As to the names of the enzymes themselves it is customary to use the termination "ase" which denotes an enzyme and this termination should be added to the root of the word which names the substrate; for example, lactase is the enzyme accelerating the hydrolysis of lactose, sucrase of sucrose, maltase of maltose, etc. Infortunately, in many cases old names have become so fixed that it is not desirable to replace them, as, for example, pepsin for the acid proteinase and trypsin for the alkali proteinase. At other times the enzymes are incorrectly named from the simpler substance in place of the more complex substrate; for example, invertase for the ferment which inverts sucrose.

It is the custom with many writers to speak of the enzymes which attack, say, starch or protein, as "amylolytic" or "proteolytic," respectively; but Armstrong has pointed out that these names are incorrectly formed. "Amylolytic" in analogy with "electrolytic" should mean a decomposition by means of starch. "To avoid this misuse of words he advocates the use of the termination "clastic" 
instead of "Iytic," giving us terms such as "amyloclastic," "proteoclastic," "lipoclastic," etc.

Enzymes ordinarily do not occur active within the cell, but are present in the form of a zymogen or mother substance. This substance, when acted upon by a specific substance, becomes active and the process is termed "activation." The agency which is instrumental in activating a zymogen is termed "zymo-excitor" or kinase.

Properties of Enzymes.-Enzymes are known from the reactions which they catalyze and they are found to follow quite definite laws in their reactions. Some of the more important are as follows:

1. An enzyme does not initiate a chemical reaction but only alters its velocity; nor does it appear in the final products of the reaction which it accelerates. We must, therefore, assume that substances are slowly changing and that the catalyst does nothing more than alter the speed of this reaction. The state of affairs is, therefore, similar to that of a mixture of oxygen and hydrogen gases catalyzed by platinum in which there is evidence that the combination takes place at room temperatures, although at an unmeasurable rate. Salicin, which is readily hydrolized by ptyalin and emulsin to glucose and saligenin slowly decomposes in water at $150^{\circ} \mathrm{C}$. It would, therefore, be inferred that the process also takes place at room temperature. Starch solutions slowly undergo a spontaneous change into dextrin and sugar and solutions of ammonium caseinogenate increase in electrical conductivity when left to themselves, a change similar to that which occurs when they are acted upon by trypsin. Taylor has shown that an appreciable proportion of pure sterile globulin kept in distilled water at ordinary temperature for eighteen months is hydrolyzed to protease and that leucin may be recovered from a sterile suspension of casein in pure water and that arginin may be recovered from a solution of protamin sulphate in pure water. True, the reaction is slow and the products have accumulated only in small quantities after the lapse of a year; nevertheless, it is evident that the process is slowly occurring in the absence of the catalyzer.

It is likely that the ferment enters temporarily into chemical combination with the substance acted upon. This assumption is made on the ground that the sensitiveness of the enzyme often changes when brought in contact with the substrate and may at first be hard to separate. Moreover, it is definitely known that in some simple catalytic processes the catalyzer does temporarily combine with the reacting substance. This is the case in the manufacture of sulphuric acid, where steam, sulphur dioxid, oxygen and the oxids of nitrogen are introduced simultaneously into a large chamber when the following reactions probably occur.

$$
\begin{aligned}
\mathrm{SO}_{2}+\mathrm{N}_{2} \mathrm{O}_{3} & =\mathrm{SO}_{3}+2 \mathrm{NO} \\
\mathrm{SO}_{3}+\mathrm{H}_{2} \mathrm{O} & =\mathrm{H}_{2} \mathrm{SO}_{4} \\
2 \mathrm{NO}+\mathrm{O}_{2} & =2 \mathrm{NO}_{2}
\end{aligned}
$$


Thus it is that the oxids of nitrogen serve to convert the sulphur dioxid to the trioxid and in the presence of air reverts to the original condition and again repeats the cycle. While in the Gay-Lussac tower the nitrosul-sulphuric acid is formed:

$$
\begin{aligned}
& \mathrm{N}_{2} \mathrm{O}_{3}+\mathrm{H}_{2} \mathrm{SO}_{4}=2 \mathrm{NO}_{2} \mathrm{HOSO}_{2}+\mathrm{H}_{2} \mathrm{O} \\
& 2 \mathrm{NO}_{2} \mathrm{HOSO}_{2}+{ }_{2} \mathrm{H}_{2} \mathrm{O}=2 \mathrm{H}_{2} \mathrm{SO}_{4}+\mathrm{N}_{2} \mathrm{O}_{3}
\end{aligned}
$$

Where there are a number of steps in a reaction, as is the case with the above, it is necessary, as pointed out by Ostwald, that the sum of all the reactions in the catalyzed system are more rapid than are the changes in the uncatalyzed.

The classic illustration of an organic reaction of this type is that afforded by the production of ether from alcohol. In this process sulphuric acid is employed as catalyzer and as well known this first combines with alcohol with the formation of ethyl-sulphuric acid.

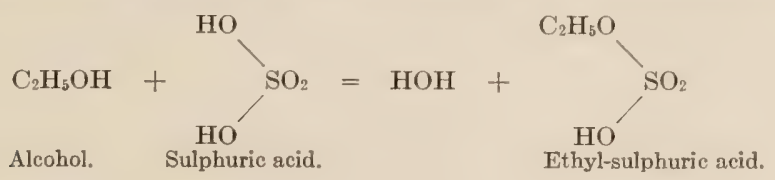

The ethyl-sulphuric acid reacts with another molecule of alcohol forming ether and regenerating sulphuric acid.

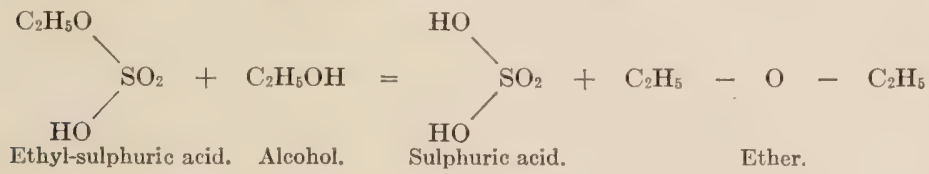

Similar combinations occur with the enzymes, for it is found that sucrase will withstand uninjured a temperature $25^{\circ} \mathrm{C}$. higher in the presence of sucrose than in its absence. It is difficult to see how this could happen unless the enzyme entered into some sort of union with the sugar.

Intimately connected with the subject of combination of enzyme with substrate is that of specificity, an example of which is seen in the fact that certain enzymes act only on carbohydrates, others on fats, and still others on proteins. The group of those transforming carbohydrates is further subdivided into specific enzymes each of which has the power of acting alone upon only one sugar. This property is so specific that in many cases the enzyme will act upon one optically active compound leaving the opposite optical isomer untouched. 'This led Fischer to the formulation of his famous simile of the "lock and key" relationship. In this he considers that the enzyme and its substrate must have an interrelation, such as the key has to the lock; otherwise, the reaction 
does not occur. By means of this theorem it has been possible to foretell the structure of many complex substances and explain hitherto obscure points in biology.

2. The chemical change brought about by an enzyme in infinite time is independent of the concentration of the enzyme, but for shorter periods it is clearly and usually a definite function of the concentration of the enzyme. This means that a small quantity of enzyme will bring about as much change as a large one, providing unlimited time is given: In this regard, then, enzyme reactions differ from ordinary reactions in that they do not follow the law of mass action. This may be illustrated by the carrying of brick to the top of a building by men. Give one man sufficient time and he would be as able to transfer the whole pile to the top as would a group of men, but in the latter case the time occupied would be inversely proportional to the number of men working. So it is with enzymes; the intensity is almost directly proportional to the concentration of the enzymes. In certain instances where this generalization has been found not to hold, attempts have been made to apply the Schutz-Borissow Law-that the intensity of enzyme reaction is directly proportional to the square root of the concentration. But eren this generalization does not hold, for there are a number of factors which tend to retard or accelerate enzyme action. (hief among these which retard are $(a)$ reversibility, (b) combination of enzyme with products, (c) negative autocatalysis, which with the previous factor leads to reversible inactivation of the enzyme, $(d)$ destrucion or similar drastic changes in the properties of the enzyme. Those which accelerate are as follows: (a) combination of the whole of the enzyme with the substrate when the latter is in relatively large excess, $(b)$ positive autocatalysis.

3. Reactions which are catalyzed by enzymes are reversible. It has been conclusively shown in the case of many reactions and is generalized for others that where a reaction is being catalyzed by enzymes it is, unless the products so formed are removed from the reaction medium, reversible. This is illustrated by the saponification of ethyl-butyrate by means of lipase.

$$
\underset{\text { Ethyl-butyrate. }}{\mathrm{C}_{3} \mathrm{H}_{7} \mathrm{COOC}_{2} \mathrm{H}_{5}}+\mathrm{H}_{2} \mathrm{O}=\underset{\text { Butyric acid. }}{\mathrm{C}_{3} \mathrm{H}_{7} \mathrm{COOH}}+\underset{\text { Ethyl alcohol. }}{\mathrm{C}_{2} \mathrm{H}_{5} \mathrm{OH}}
$$

Starting with a definite quantity of ethyl-butyrate, after a time we find in the reacting media ethyl-butyrate, butyric acid and ethyl alcohol; commencing with butyrie acid and ethyl alcohol, we obtain the same products as in the first case. This implies that the synthetic reactions which are going on in the cell are catalyzed by the same enzymes as are the analytic reactions; hence reactions that are catalyzed by enz,rmes are never complete unless the resulting products are removed as fast as formed. 
4. Enzymes are usually characterized by great sensitiveness to comparatively low temperatures and to many poisons. This property formerly was used to determine whether or not a reaction was being catalyzed by an enzyme; but there are known a few cases in which the enzyme is not destroyed by boiling water. The great majority of all enzymes are, however, destroyed by a temperature somewhat below $100^{\circ} \mathrm{C}$., many even as low as $60^{\circ} \mathrm{C}$. This property is no doubt due to the colloidal nature of the ferment which, on being heated, coagulates-probably much as does a protein, for it is well known that enzymes are more sensitive in the presence of water than in its absence.

Although the addition of hydrocyanic acid or formaldelyyde to a media in which reactions are being catalyzed by enzymes puts a stop to the reaction, yet the concentration necessary is usually greater than that which can be borne by the living protoplasm. This makes it possible to kill the cell and still have the enzyme reactions going on in the medium by carefully adjusting the concentration of the antiseptic used.

Varioùs methods are used in the extraction of enzymes. Some readily diffuse out of the cell and may be taken up with water; others are extracted with glycerin or acids; in still other cases it is necessary to decompose completely the cells as did Büchner in obtaining zymase. The resulting product is then often purified by alcoholic or other precipitants. 'This drastic treatment, however, often impairs the activity of the ferment.

Classification.-Fuhrmann has classified enzymes of bacterial origin into four types as follows:

A. Schizases (hydrolytic) cleavage enzymes:

1. Carbohydrate-splitting enzymes.

2. Glucoside-splitting enzymes (synaptase).

3. Fat-splitting enzymes. Lipases (esterases).

4. Proteases, protein-splitting enzymes, pepsin, trypsin (lysins, coagulases).

B. Fermentation enzymes:

Zymase urease, lactic-acid enzyme.

C. Oxidizing enzymes:

Tyrosinase, acetic bacteria, oxidase.

D. Reducing enzymes:

Reductase.

Hydrolytic Enzymes. - As a type of the hydrolytic enzymes which act upon carbohydrates, we may take maltase which converts maltose into dextrose according to the following equation:

$$
\underset{\text { Maltose. }}{\mathrm{C}_{12} \mathrm{H}_{22} \mathrm{O}_{11}}+\mathrm{H}_{2} \mathrm{O}=\underset{\substack{\text { Dextrose. } \\ \mathrm{C}_{6} \mathrm{H}_{12} \mathrm{O}_{6}}}{\text { Dextrose. }}+\underset{\text { Dextrose. }}{\mathrm{C}_{6} \mathrm{H}_{12} \mathrm{O}_{6}}
$$

Maltase is an enzyme which occurs in yeast, many bacteria, and numerous other cells. It is of special interest inasmuch as it is 
the first case of reversible action that was studied. Craft Ilill found that the addition of maltase to a very concentrated solution of dextrose resulted in the formation of a disaccharid. This he at first thought was a simple reversion of dextrose into maltose, but later work showed that the sugar formed was an isomer of maltose. The essential fact, however, remained that the one enzyme possessed both synthetic and analytic properties.

Emulsion is an enzyme which possesses the power of decomposing mandelic-nitrile-glucose into glucose, benzaldehyde, and hydrocyanic acid. The mandelic-nitrile-glucose is obtained by the action of maltase upon the glucoside amygdalin. The total change brought about by the two ferments is indicated by the following equation:

$$
\underset{\text { Amygdalin. }}{\mathrm{C}_{20} \mathrm{H}_{27} \mathrm{NO}_{11}}+2 \mathrm{H}_{2} \mathrm{O}=\underset{\text { Benzaldehyde }}{\mathrm{C}_{6} \mathrm{H}_{5} \mathrm{CHO}}+\underset{\mathrm{H} \text { ydrogen }}{\mathrm{HCN}}+\underset{2 \mathrm{C}_{6} \mathrm{H}_{12} \mathrm{O}_{6}}{2}
$$

Lipases act upon the neutral fats and are widely distributed in both plant and animal cells. They bring about a reaction which may be expressed by the following general reaction, where $R=$ the residue of a fatty acid.

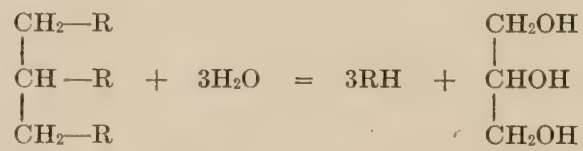

One molecule of neutral fat is split into three molecules of fatty acid and one of glycerin. This is the general reaction which occurs in the spoiling of butter or fat due to bacterial activity.

Proteases, which possess the power of splitting proteins, are widely distributed in bacteria, as is exemplified by their gelatinliquefying powers. This also is a hydrolytic reaction in which a number of molecules of water is caused to enter the protein molecule with its subsequent breaking down into proteoses, peptones, and finally amino-acid. Even this, as complex a reaction as it is, has been shown to be reversible in at least two cases.

Zymases, which occur in the yeast cell, are endo-enzymes and their function is to liberate energy for the use of the cell, as is shown by the following table from the work of Rahn:

\section{ENERGY LIBERATED FROM 1 GRAM OF SUBSTANCE.}

Soluble enzymes.

Pepsin, trypsin

Lipase

Maltase sucrase

Lactase

$\begin{array}{ll}0 & \text { calories } \\ 4 & \text { " } \\ 10 & \text { " } \\ 23 & \text { " }\end{array}$

0 calorics

10

23

\begin{tabular}{|c|c|c|c|c|}
\hline Lactacidase & . & . & \multicolumn{2}{|c|}{80 calories } \\
\hline Alcoholase & . & . & 120 & \\
\hline Urease & . & . & . 230 & 6 \\
\hline Vinegar oxid & ase & . & .2500 & " \\
\hline
\end{tabular}

The first zymase isolated from a microörganism was that of urease, or the ferment which converts urea into ammonium car- 
bonate, and which was shown by Musculus to be present in the dead cells of Micrococcus uree which develops in putrid urine. Zymase was obtained by Büchner through the pressing of the ground yeast cells, as has been described. This same method was later applied to the lactic acid bacteria and the lactacidase obtained.

Oxidizing Enzymes. - The most typical example of an oxidizing enzrme is the vinegar oxidase, the action of which is fairly well known. The reaction may be written in the simple form

$$
\mathrm{CH}_{3} \mathrm{CH}_{2} \mathrm{OH}+\mathrm{O}_{2}=\mathrm{CH}_{3} \mathrm{COOH}+\mathrm{H}_{2} \mathrm{O} \text {. }
$$

Since, however, many side reactions may occur, the bacterial oxidation of alcohol is not in reality capable of so simple an expression.

Reducing enzrmes are the most common of ferments. They are formed by practically all plants and animals and contained by all but a very few bacteria, Strept. lacticus being one of the few exceptions. In this case the absence of the enzrme is used as a diagnostic test for the organism. One of the most important reductases is the peroxidase which reduces hydrogen peroxid to water with the liberation of oxygen.

$$
2 \mathrm{H}_{2} \mathrm{O}_{2}+\text { peroxidase }=2 \mathrm{H}_{2} \mathrm{O}+\mathrm{O}_{2} \text {. }
$$

Others which reduce nitrates to nitrites of particular interest to students of agriculture are

$$
2 \mathrm{KNO}_{3}=2 \mathrm{KNO}_{2}+\mathrm{O}_{2}
$$

Or at times they may reduce the nitrite to elementary nitrogen:

$$
2 \mathrm{Ca}\left(\mathrm{NO}_{3}\right)_{2}=2 \mathrm{CaO}+2 \mathrm{~N}_{2}+5 \mathrm{O}_{2} \text {. }
$$

Inder appropriate conditions the important element, nitrogen, may thus be lost from the soil by denitrification. In a similar way' sulphates are reduced to hydrogen sulphid:

$$
\mathrm{H}_{2} \mathrm{SO}_{4}=\mathrm{H}_{2} \mathrm{~S}+2 \mathrm{O}_{2} \text { 。 }
$$

REFERENCES.

Bayliss: The Nature of Enzyme Action.

Euler: General Chemistry of the Enzymes.

Falk: The Chemistry of Enzyme Actions.

Robertson: The Physical Chemistry of the Proteins. 


\section{BACTERIAL METABOLISM PRODUCTS.}

BACTERIA are able to bring about enormous changes in their media in a very short time. This is due in no small measure to their method of metabolism which differs from that of the animal, in most cases, in being a process of incomplete oxidation, whereas that of the animal is a process of complete oxidation. For this reason, many of the organisms of especial economic importance often leave products of considerable commercial value.

Physiologic Classification. - From a physiologic viewpoint Jordan divides the substances produced by bacterial metabolism into four classes:

1. The secretions, or those substances which serve some purposeful end in the cell economy. These may either be retained within the cell or may pass out into the surrounding medium.

2. The excretions, or those substances that are ejected because useless to the organism; the ashes of cell metabolism.

3. The disintegration products, or those bodies that are produced by the breaking down of food substances. Their nature is determined partly by the chemical structure of the nutrient and partly by the specific bacteria concerned in the disintegration. Some of the most conspicuous, if not the most important, of bacterial products belong to this class, enzyme activity being largely responsible for their existence.

4. The true cell substance. To this class belongs the cell protoplasm, those products which are being built up into cell protoplasm, and those substances which are being broken down but have not yet reached the stage where they are cast off from the cell.

The great objection which may be brought against such a classification is that although many products can be definitely placed, others, for instance pigments, cannot.

Carbohydrate Metabolism.-Products from carbohydrate metabolism vary greatly, depending upon the species of bacteria, age, medium, and whether grown in the presence or absence of oxygen. Some writers distinguish six types of microörganisms, depending upon the change which they produce in their media, namely:

1. ('omplete oxidation which occurs' only to a limited extent among bacteria and then only where there is a ready supply of oxygen, as is the case in a well-aërated soil in filters or on the surface of decaying substances.

2. Partial oxidation is much more common among microörganisms than is complete oxidation. The product formed is also often of considerable commercial value. This is the case in the oxidation 
of alcohol to acetic acid. On the other hand, the products formed may serve as food to other microörganisms and thus be completely oxidized. Acetic acid, if not too strong, may be further oxidized to carbon dioxid and water, as sometimes occurs, resulting in a decrease in the strength of vinegar.

3. Alcoholic fermentation is brought about by yeast; yet there are bacteria which possess the power of producing alcohol, but none of them are of economic value. Such organisms have been obtained from hay (B. fitiziams) and sheep manure (B. ethaceticus). The Bact. pneumonize of Friedländer is not only a pathogenic organism, but also possesses the power of decomposing sugar solutions with the formation of ethyl alcohol and acetic acid.

The reaction as brought about by yeast is due to the endo-enzyme, zymase, first isolated by Büchner. The reaction is dependent upon a readily available supply of phosphate, and according to Harden this forms an intermediate product with glucose, thus:

$$
\begin{gathered}
2 \mathrm{C}_{6} \mathrm{H}_{12} \mathrm{O}_{6}+2 \mathrm{PO}_{4}^{\prime} \mathrm{HR}_{2}=2 \mathrm{CO}_{2}+\underset{\mathrm{I}}{2 \mathrm{C}_{2} \mathrm{H}_{6} \mathrm{O}+2 \mathrm{H}_{2} \mathrm{O}+\mathrm{C}_{6} \mathrm{H}_{10} \mathrm{O}_{4}\left(\mathrm{PO}_{4} \mathrm{R}_{2}\right)_{2}} \\
\text { II } \\
\mathrm{C}_{6} \mathrm{H}_{10} \mathrm{O}_{4}\left(\mathrm{PO}_{4} \mathrm{R}_{2}\right)_{2}+2 \mathrm{H}_{2} \mathrm{O}=\mathrm{C}_{6} \mathrm{H}_{12} \mathrm{O}_{6}+2 \mathrm{PO}_{4} \mathrm{HR}_{2}
\end{gathered}
$$

According to equation (I), two molecules of glucose are concerned in the change, the carbon dioxid and alcohol being equal in weight to one-half of the sugar used, and the hexosephosphate and water representing the other half. In the second equation the phosphate is again liberated, and the hexose presumably fermented.

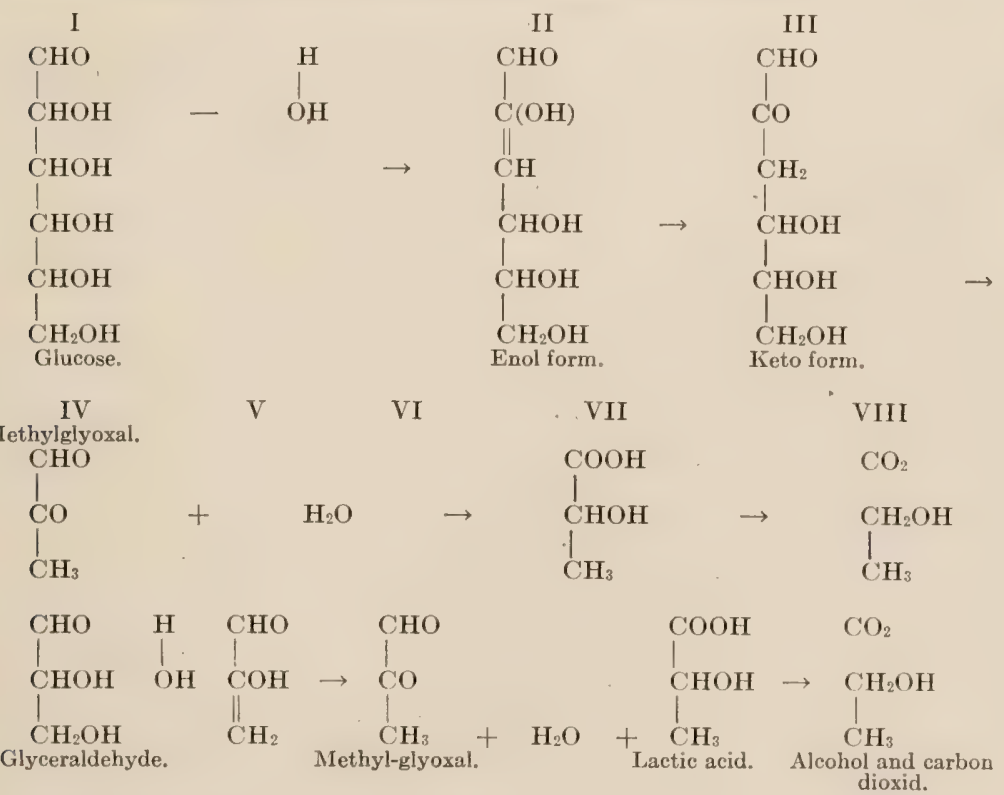


Wohl has developed a theoretical scheme of reactions by which the process of alcoholic fermentation could be represented. In the first place the elements of water are removed from the $\alpha$ and $\beta$ carbon atoms of glucose (I) and the resulting enol (II) undergoes conversion into the corresponding keton (III), which has the constitution of a condensation product of methylglyoxal and glyceraldehyde, and hence is readily resolved by hydrolysis into these compounds (IV). The glyceraldehyde passes by a similar series of changes $(\mathrm{V}, \mathrm{VI})$ into methylglyoxal, and this is then converted by addition of water into lactic acid (VII), a reaction common to all ketoaldehydes of this kind. Finally, the lactic acid is split up into alcohol and carbon dioxid (VIII).

In alcoholic fermentation there also results small quantities (0.1 to 0.7 per cent.) of fusel oil. This contains normal propyl alcohol, primary isobutyl alcohol, primary iso-amyl alcohol, and the optically active (primary) iso-amyl alcohol. It was thought at one time that these resulted from the fermentation of the glucose, but Ehrlich in a series of masterly researches, shows conclusively that their origin is the amino-acid which result from the hydrolysis of the proteins, the reactions of which may be given as follows:

I

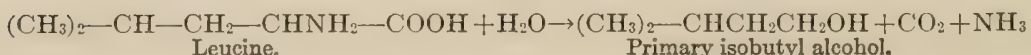

II

$\mathrm{CH}_{3} \mathrm{CH}\left(\mathrm{C}_{2} \mathrm{H}_{5}\right)-\mathrm{CH}\left(\mathrm{NH}_{2}\right) \mathrm{COOH}+\mathrm{H}_{2} \mathrm{O} \rightarrow \mathrm{CH}_{3} \mathrm{CHC}_{2} \mathrm{H}_{5} \mathrm{CH}_{2} \mathrm{OH}+\mathrm{CO}_{2}+\mathrm{NH}_{3}$ Isoleucine.

Primary iso-amyl alcohol.

Succinic acid also occurs among the products resulting from alcoholic fermentation of sugar and has its origin in the amino-acids. It results when aspartic acid is acted upon by putrefactive bacteria-

$$
\mathrm{COOH}-\mathrm{CH}_{2}-\mathrm{CH}-\mathrm{NH}_{2} \mathrm{COOH}+\mathrm{H}_{2}=\mathrm{COOH}-\mathrm{CH}_{2}-\mathrm{CH}_{2}-\mathrm{COOH}+\mathrm{NH}_{3}
$$

This, however, differs from the first reaction in that it is a process of partiai reduction and not hydrolysis.

Other bacteria have been studied which possess the power of producing butyl and amyl alcohol from carbohydrates. It is still an open question to what extent the amyl alcohol (fusel oil) produced during an impure alcoholic fermentation is due to bacteria, for it is known that some alcohol yeasts possess the power of decomposing two protein decomposition products, leucin and isoleucin, with the production of fusel oil.

4. Acid Production.-In general it may be stated that an acid reaction is caused by the fermentation of one of the sugars, glycerin, or a similar substance in the nutrient media. It is one of the more constant physiologic characteristics of bacteria, and in addition to 
being of considerable economic value is often used advantageously to distinguish closely related species, notably in the groups of paratyphoid and dysenteria bacilli. In addition to the acid produced by the fermentation of carbohydrates, many bacteria hydrolyze proteins with the formation of an acid reaction. Formic acid is the simplest organic acid which can be formed. It is produced by $B$. typhosus, the causative agent of typhoid fever. B. typhosus does not form gas, but $B$. coli does; and in this latter case it may result from the decomposition of the formic acid.

$$
\mathrm{HCOOH}=\mathrm{H}_{2}+\mathrm{CO}_{2} \text {. }
$$

Acetic acid is one of the most important acids formed by bacteria. Bact. aceti and Bact. pasteurianum are two of the more important acetic acid-forming bacteria. They occur in fermenting fruit juices and convert the alcohol into acetic acid.

$$
\mathrm{CH}_{3}-\mathrm{CH}_{2}-\mathrm{OH}+\mathrm{O}_{2}={ }^{2} \mathrm{H}_{3} \mathrm{COOH}+\mathrm{H}_{2} \mathrm{O} \text {. }
$$

Many other species also possess the power of transforming alcohol and other substances containing the characteristic radical $-\mathrm{CH}_{2} \mathrm{CH}_{2} \mathrm{OH}$-into acetic acid. This fermentation, however, can take place only within certain limits of concentration, and even then there must be available nitrogen in the form of proteoses, peptones or amino-acids, and mineral elements, especially phosphorus in the form of a phosphate. Acetic acid is produced on the commercial scale by a number of processes. Two of the best are the Orleans and the Quick, or German, methods.

Lactic Acid.- This product is formed by a great number of bacteria. 'The chief species, however, is the Streptucoccus lacticus which produces only a scanty growth on agar, but an excellent growth in milk, bringing about a solid curdling in a few days. The lactose of the milk is first inverted forming two hexoses-dextrose and galactose.

$$
\underset{\text { Lactose. }}{\mathrm{C}_{12} \mathrm{H}_{22} \mathrm{O}_{11}}+\mathrm{H}_{2} \mathrm{O}=\underset{\text { Dextrose. }}{\mathrm{C}_{6} \mathrm{H}_{12} \mathrm{O}_{6}}+\underset{\text { Galactose. }}{\mathrm{C}_{6} \mathrm{H}_{12} \mathrm{O}_{6}}
$$

The hexose in turn is decomposed yielding two molecules of lactic acid.

$$
\underset{\text { Dextrose. }}{\mathrm{C}_{6} \mathrm{H}_{12} \mathrm{O}_{6}}=\underset{\text { Lactic acid. }}{2 \mathrm{C}_{3} \mathrm{H}_{6} \mathrm{O}_{3}}
$$

In actual experience the reaction occurring is not as simple as written in the equation, but there are other products formed. For instance, $B$. coli ferments glucose with the formation of alcohol, carbon dioxid, hydrogen, lactic acid, succinic acid, and other 
products. The mechanism of the fermentation as outlined by Harden is illustrated by the reaction.

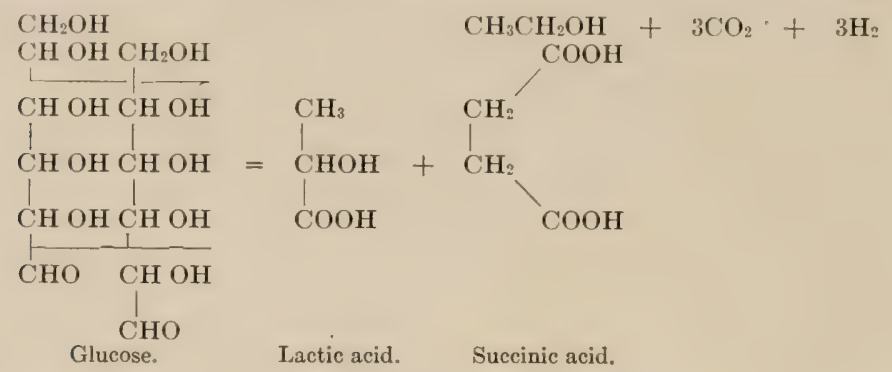

Unless some base be added to neutralize the acid as formed, the lactose of milk is never completely converted into lactic acid because the accumulation of the acid is sufficient to stop most bacterial growth, as is seen by the fact that meat placed in buttermilk will keep for some time.

Butyric Acid.-- Inder certain conditions a further decomposition of the lactic acid may occur with the formation of butyric acid according to the following equation:

$$
\underset{\text { Lactic acid. }}{2 \mathrm{C}_{3} \mathrm{H}_{6} \mathrm{O}_{3}}=\underset{\text { Butyric acid. }}{\mathrm{C}_{4} \mathrm{H}_{8} \mathrm{O}_{2}}+2 \mathrm{CO}_{2}+2 \mathrm{H}_{2}
$$

However, the butyric acid bacteria possess the power of fermenting sugar with the formation of butyric acid.

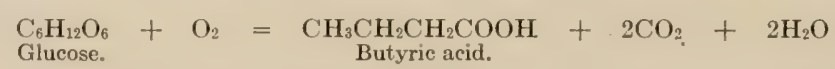

Although the number of organisms which possess the power of producing butyric acid are large, they are not as numerous as those which possess the power of forming lactic acid. They are usually anaërobic spore-bearers with a tendency to form spindle-shaped cells, for which reason they have been given the name Clostridium. Many members of this group possess the power of fixing nitrogen; they probably play an important part in maintaining the nitrogen supply of the soil. B. botulinus, the causative agent in meat poisoning, forms butyric acid as does also $B$. tetani.

In the great majority of cases bacteria produce a number of different products; for instance, Azotobacter chroöcoccum produces from the carbohydrates, ethyl alcohol, glycocoll, acetic acid, butyric acid, lactic acid, carbon dioxid, and hydrogen. The quantity and quality of the different products vary with the species and with the carbohydrate used.

Bacterium pasteurianum grows in wine and cider vinegars. It produces a variety of products, depending upon the specific substance acted upon. It produces gluconic acid $\left(\mathrm{CH}_{2} \mathrm{OH}(\mathrm{CHOH})_{4}\right.$ COOII from dextrose, propionic acid $\left(\mathrm{C}_{2} \mathrm{H}_{5} \mathrm{COOH}\right)$ from propyl 
alcohol $\left(\mathrm{C}_{3} \mathrm{H}_{7} \mathrm{OH}\right)$, and acetic acid $\left(\mathrm{CH}_{3} \mathrm{COOH}\right)$ from ethyl alcohol $\left(\mathrm{C}_{2} \mathrm{H}_{5} \mathrm{OH}\right)$.

Other Acid Fermentation.-In addition to the ardids described many others have been identified among the products of arbohydrate fermentation. Many molds, especially, possess the power of fermenting dextrose with the formation of citric acid, the general reaction being as follows:

$$
\begin{aligned}
& 2 \mathrm{C}_{6} \mathrm{H}_{12} \mathrm{O}_{6}+2 \mathrm{O}_{2}=2 \mathrm{HOC}-\mathrm{COOH}+2 \mathrm{H}_{2} \mathrm{O} \\
& \mathrm{CH}_{2} \mathrm{COOH} \\
& \text { Dextrose. } \\
& \text { Citric acid. }
\end{aligned}
$$

Patents have been taken out on this method and attempts made to produce citric acid on a commercial scale, but so far without any great success.

Oxalic acid is also produced by certain molds in sugar solutions and where care has been taken to neutralize the acid so formed one-half the calculated theoretical yield has been obtained from cane sugar. Formic (H $\mathrm{COOH}$ ) and valeric acids $\left(\mathrm{C}_{4} \mathrm{H}_{3}\left({ }^{\circ} \mathrm{OOH}\right)\right.$ are also produced by some microörganisms.

Oxidation of Organic Acids.- The organic acids formed in the various processes of carbohydrate fermentation are often further oxidized by bacteria, yeasts, or molds to simpler products. Ordinarily the process consists of a complete oxidation. 'This may be the case in sauerkraut, ensilage, jickles, ete. 'Thus ()idlium lactis destroy's the lactic acid of sour milk with the formation of carbon dioxid and water.

$$
\mathrm{C}_{3} \mathrm{H}_{6} \mathrm{O}_{3}+3 \mathrm{O}_{2}=3 \mathrm{CO}_{2}+3 \mathrm{H}_{2} \mathrm{O} \text {. }
$$

At times the spoiling of pickles is due to the oxidation of the acetic acid by yeasts which grow in a thin white scum orer the surface.

Fats.-A comparatively few microörganisms attack fat. When they do the decomposition of the fat is comparatively simple. One molecule of the neutral fat is split with the formation of one molecule of glycerin and three of fatty acids.
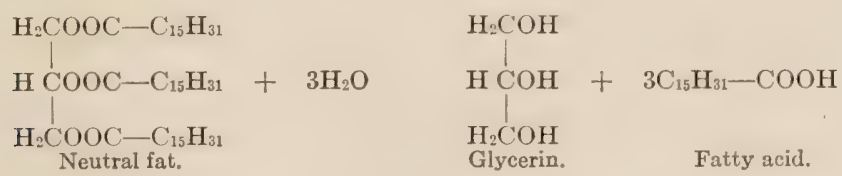

The glycerin is readily used by the microörganism, whereas the fatty acids are but very slowly oxidized and that by only a few species.

Products from Nitrogenous Compounds.-Proteins are complex organic substances composed of carbon, hydrogen, oxygen, nitrogen, 
and generally, but not always, sulphur, and sometimes phosphorus. The proportion of these constituents is approximately $C, 5()-5,5$ per cent.; H, 6-7.3 per cent.; O, 19-24 per cent.; N, 15-19 per cent. $S$, when present, $0.3-2.5$ per cent.; and $\mathrm{P}, 0.4-0 . S$ per cent. They are substances which in the main consist of combinations of $\propto$ aminoacids or their derivatives. The decomposition products of proteins include proteoses, peptones, peptides, carbon dioxid, ammonia, hydrogen sulphid and amino-acids. The amino-acids constitute a long list of important substances which contain nuclei belonging either to the aliphatic, carbocylic, or heterocyclic series. The present list includes glycocoll (glycin) alanin, serin, phenylalanin, tyrosein, cystin, tryptophan, histidin, valin, argin, leucin, isoleucin, lysin, aspartic acid, glutamic acid, prolin, oxyprolin, and norleucin.

Many, especially of the saprophytic bacteria which occur in the soil, have the power of breaking down native proteins with the formation of the various amino-acids. Indoubtedly the complex organic compounds which are being isolated from the soil, and which are assumed by some to play such an important part in soil fertility, have just such an origin. But it is usually the case in all media that the bacterial catabolism carry the substance much farther than the amino-acid. The extent of this change varies greatly with the species of microörganisms and the conditions under which they are acting. Kendall summarizes some of the further changes which may occur as follows:

1. The reductive deaminization of amino-acids to fatty acids with the same number of carbon atoms.

$$
\mathrm{RCH}_{2} \mathrm{CHNH}_{2} \mathrm{COOH}+\mathrm{H}_{2}=\mathrm{RCH}_{2} \mathrm{CH}_{2} \mathrm{COOH}+\mathrm{NH}_{3}
$$

2. Hydrolytic deaminization of amino-acids to oxyacids with the same number of carbon atoms.

$$
\mathrm{R}-\mathrm{CH}_{2}-\mathrm{CHNH}_{2}-\mathrm{COOH}+\mathrm{H}_{2} \mathrm{O}=\mathrm{R}-\mathrm{CH}_{2}-\mathrm{CHOH}-\mathrm{COOH}+\mathrm{NH}_{3}
$$

3. Oxidative deaminization of amino-acids to keto-acids with the same number of carbon atoms.

$$
\mathrm{R}-\mathrm{CH}_{2}-\mathrm{CHNH}_{2}-\mathrm{COOH}+\mathrm{O}_{2}=\mathrm{R}-\mathrm{CH}_{2}-\mathrm{CO}-\mathrm{COOH}+\mathrm{NH}_{3}
$$

The above reactions may be taken as types of the last stages of the reactions brought about by the ammonifying bacteria within the soil.

4. Carboxylic decomposition of amino-acid to amine with one less carbon atom.

$$
\mathrm{R}-\mathrm{CH}_{2}-\mathrm{CH}-\mathrm{NH}_{2}-\mathrm{COOH}=\mathrm{R}-\mathrm{CH}_{2}-\mathrm{CH}_{2}-\mathrm{NH}_{2}+\mathrm{CO}_{2}
$$

5. ('arboxylic decomposition with the formation of fatty acids.

$$
\mathrm{R}-\mathrm{CH}_{2}-\mathrm{CH}_{2}-\mathrm{COOH}=\mathrm{R}-\mathrm{CH}_{2}-\mathrm{CH}_{3}+\mathrm{CO}_{2}
$$


6. Carboxylic decomposition with the formation of a fatty acid with one less carbon atom.

$$
\mathrm{R}-\mathrm{CH}_{2}-\mathrm{CH}_{2} \mathrm{COOH}+3 \mathrm{O}=\mathrm{R}-\mathrm{CH}_{2}-\mathrm{COOH}+\mathrm{CO}_{2}+\mathrm{H}_{2} \mathrm{O}
$$

Some of these changes are often produced either within food or in the alimentary canal and are of considerable clinical significance. The most important of these are indol, skatol and the amins, the simplest of which is trimethylamin.

Indol and sliatol are substances produced in the intestinal tract from tryptophan chiefly by $B$. coli and $B$. proteus. They are also formed in putrifying proteins and it is to indol and skatol that putrifying substances owe their intensely disagreeable odor. Indol gives a rose color with nitrites in acid solution and this is used as a method of identifying certain bacteria. 'The tryptophan is deaminized with the formation of indol propionic acid. This is oxidized to indol-acetic acid. From this latter there is split off acetic acid with the formation of indol. The reactions are as follows:<smiles>NC(Cc1c[nH]c2ccccc12)C(=O)O</smiles><smiles>O=C(O)CCc1c[nH]c2ccccc12</smiles>

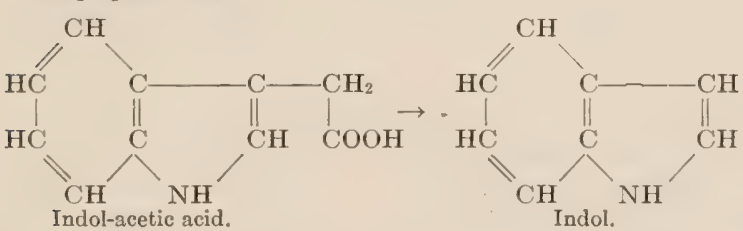

Often the bacteria split out carbon dioxid from the indol-acetic acid with the formation of skatol:<smiles>Cc1c[nH]c2c1C=C[C@H]2CC(=O)O</smiles> 
These substances when formed in the intestinal tract are absorbed and carried to the liver where they are enjugated with the formation of indican which is then eliminated by the kidneys. The stages through which indol passes in forming indican are as follows:<smiles>O=C(O)c1cc2cc(Br)ccc2[nH]1</smiles><smiles>O=C(O)c1ccccc1S(=O)(=O)O</smiles>

Indoxyl sulphuric acid.

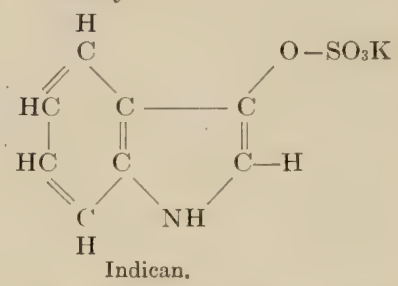

Amins. - The simplest member of this series is methylamin $\left(\mathrm{CH}_{3} \mathrm{NH}_{2}\right)$ which is produced in small quantities in the decomposition of nitrogenous organic matter. It occurs in herring brine along with dimethylamin $\left(\mathrm{CH}_{3}\right)_{2} \mathrm{NH}$ and trimethylamin $\left(\mathrm{CH}_{3}\right)_{3} \mathrm{~N}$. When alinin is acted upon by the carboxylase the carboxyl group of the amino-acid is split off with the formation of ethylamin according to the following reaction:

$$
\underset{\text { Alanin. }}{\mathrm{CH}_{3} \mathrm{CHNH}_{2} \mathrm{COOH}}=\underset{\text { Ethyl amin. }}{\mathrm{CH}_{3} \mathrm{CH}_{2} \mathrm{NH}_{2}}+\mathrm{CO}_{2}
$$

Others of special interest which may be due to bacterial activity are:

1. Cadaverin from lysin:

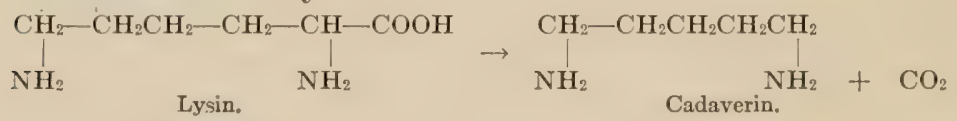

2. Putrescin from ornithin:<smiles>NCCCC(N)C(=O)O</smiles><smiles>NCCCC(N)N</smiles>

3. Beta-imidazole ethylamin from histidin:<smiles>NC(Cc1c[nH]cn1)C(=O)O</smiles><smiles>N=C(C=NCCCN)C(=O)Cl</smiles> 
Vaughan considers that beta-imidazole-ethylamin is the active principle of the protein molecule. Some of these amins are strong stimulants of the heart or vasodilators. It is quite likely that their liberation by bacterial activity in the intestinal tract and their subsequent absorption may result in severe constitutional symptoms. These compounds belong to a group of substances called "ptomains." They are alkaloid-like bodies of basic character and of more or less well-known structure. Some of them are harmless, while others are apparently violent poisons. It is interesting to note that in the majority of cases the poisonous properties decrease or at times entirely disappear as purification proceeds thus indicating that the poisonous principle in some cases at least is an impurity associated with them. Their production is not limited to any one special class of bacteria, for Zinsser defines ptomains as "poisons elaborated by all bacteria that are capable of producing protein cleavage, if planted on suitable nutrient materials under conditions favoring growth. The matrix of these poisons is the protein nutriment; they are not products of intracellular metabolism specifically characteristic of the bacteria which produce them."

Bacterial toxins, in contradistinction to the ptomains, are specific bacterial poisons which are characteristic of each individual species of bacteria and are truly the products of bacterial metabolism in that they emanate from the cell itself either as a secretion or excretion during cell life, or as an inherent element of the cytoplasm liberated after death.

Enzymes which are true products of bacterial metabolism have been considered in detail in the preceding chapter.

Erea, uric acid, and hippuric acid are the forms in which the waste nitrogen is excreted by the higher animals. There are a great number of organisms occurring widely distributed which possess the power of changing urea into ammonium carbonate. This is a simple hydrolysis.

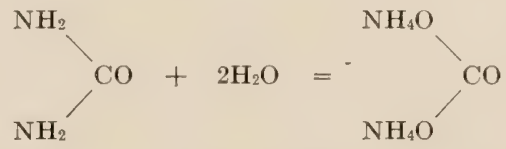

Uric acid can be changed in several ways by bacteria, that is, it may be hydrolyzed with the formation of dialuric acid and urea.

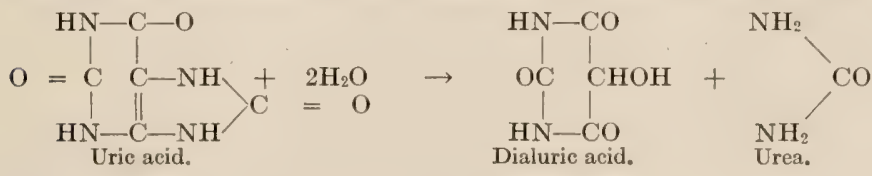

On oxidation uric acid yields various substances, alloxan, urea, oxalic acid, carbonic acid, tartronic acid, allantoinic and uroxanic 
acid. If uric acid is given to man the greater portion of it is probably destrored by bacteria in the alimentary tract, but the liver or kidneys of some animals secrete a uric acid-destroying enzyme or uricolytic enzyme, called uricase. It is presumably through the formation of such an enzyme that bacteria are able to decompose uric acid.

Hippuric acid is hydrolyzed by certain bacteria with the formation of benzoic acid and glycocoll.<smiles>O=C(O)CNC(=O)c1ccccc1</smiles>

$\mathrm{H}$

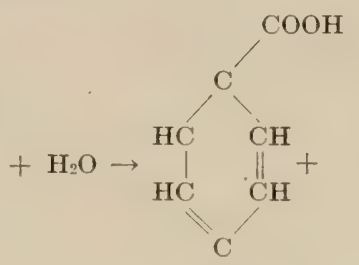

Hippuric acid.

$\mathrm{H}$

$\mathrm{CH}_{2} \mathrm{NH}_{2} \mathrm{COOH}$

Benzoic acid.

Glycocoll

The glycocoll may then be deäminized with the formation of ammonia and acetic acid. Many extremely complex transformations of organic substances occur in the soil, due to bacterial activity. In this medium many of the changes considered above occur. These have been summarized diagrammatically for the carbohydrates, proteins, oils, and waxes by Russell.

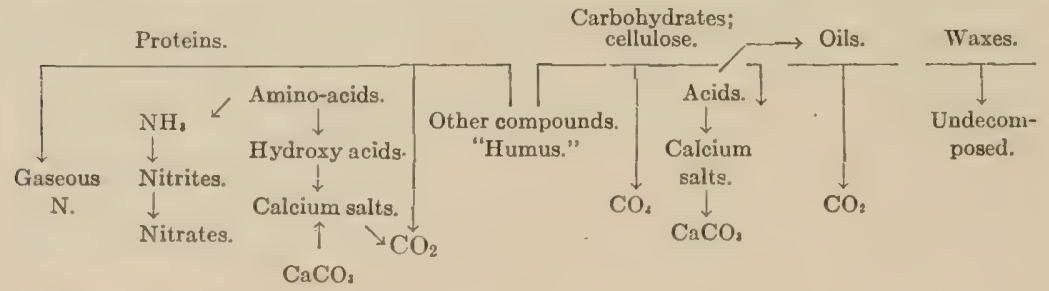

Products from mineral compounds may be either oxidized or reduced by bacteria. Some of the important oxidations are the oxidation of ammonia to nitrites, and these in turn to nitrates.

$$
\begin{aligned}
& \mathrm{NH}_{3}+3 \mathrm{O}=\mathrm{HNO}_{2}+\mathrm{H}_{2} \mathrm{O} \\
& \mathrm{HNO}_{2}+\mathrm{O}=\mathrm{HNO}_{3}
\end{aligned}
$$

These changes are of especial interest to the student of soils and are brought about by the nitrosomonas and nitromonas, respectively.

Ferrous salts may be oxidized to ferric, while sulfur may be oxidized to sulphuric acid.

$$
\mathrm{S}+3 \mathrm{O}+\mathrm{H}_{2} \mathrm{O}=\mathrm{H}_{2} \mathrm{SO}_{4}
$$

'The important reduction reactions are the ones which occur in denitrification wherein the nitrate is changed to nitrite.

$$
\mathrm{Ca}\left(\mathrm{NO}_{3}\right)_{2}=\mathrm{Ca}\left(\mathrm{NO}_{2}\right)_{2}+\mathrm{O}_{2}
$$


Or the nitrate may be completely reduced with the liberation of gaseous nitrogen, thus completely removing it from the soil.

$$
2 \mathrm{Ca}\left(\mathrm{NO}_{3}\right)_{2}=2 \mathrm{CaO}+2 \mathrm{~N}_{2}+5 \mathrm{O}_{2}
$$

Sulphates may in a similar manner be reduced to hydrogen sulphid.

$$
\mathrm{H}_{2} \mathrm{SO}_{4}=\mathrm{H}_{2} \mathrm{~S}+2 \mathrm{O}_{2}
$$

Hence, water containing calcium sulphate if shut oft from air may give rise to that ill-smelling gas, hydrogen sulphid.

Pigments.-Many bacteria produce pigments, among which are practically all the colors of the spectrum-violet, indigo blue $(B$. violaceus, B. janthinus, B. cyanogenes, B. pyocyaneus), green (B. fluorescens), yellow (Staphylococcus aureus, Sarcina lutea), orange (Sarcina aurantiaca), and red (B. prodigiosus). Usually oxygen is essential to the production of pigments and their intensity varies, depending upon the media upon which the organism is grown.

The phenomenon of pigment production has long attracted the attention of bacteriologists, and many attempts have been made to explain their occurrence; but so far none of the explanations would seem to be wholly satisfactory. The pigment seems to be of no material advantage to the organism, for colorless strains may be cultivated which possess all of the properties of the original strain with the exception of pigment production. There is no evidence that they protect the organism against light, nor is there anything that would lead to the belief that (analogous to hemoglobin) they form a loose combination with the oxygen which under certain circumstances may be liberated. 'The pigment does not make it possible for the organisms to assimilate carbon dioxid as does the chlorophyll of the higher plants in the majority of cases. 'The best evidence, therefore, points to the conclusion that they are mere by-products that have no particular meaning to the organism.

Beijerinck divides chromogenic bacteria into three classes:

1. Chromophorous bacteria, in which the pigment remains within the cell and has a certain biological significance analogous to the chlorophyll of higher plants. To this class belong the green bacteria and the red sulphur bacteria, or purple bacteria.

2. Chromoparous, or true pigment-forming bacteria, which set free the pigment as a useless excretion, either as a color-body or as a leuco-body which becomes colored through the action of atmospheric oxygen. The cells themselves are colorless and may under certain conditions cease to produce pigments. To this class belong $B$. prodigiosus and others.

3. Parachrome bacteria which form their pigment as an excretory product but retain it within their body, as B. janthimus and others.

The chemical nature of pigments is not well understood, but it is known that they differ in solubility and are usually classified according to solubility in water, alcohol, chloroform, ether, benzol, 
and other solvents. The pigment produced by Azotobacter chroöcoccum is insoluble in all of these solvents but dissolves in alkalies undergoing decomposition with the formation of a dark brown solution.

Heat.-Probably all bacteria liberate energy as heat in their metabolic process and there are a number which liberate it in sufficient amount perceptibly to change the temperature of the media in which they grow. This is exemplified in the heating of fermenting silage, manure, and hay. At times the temperature is raised to the kindling point with the result that spontaneous combustion may occur in hay and grain stacks. Bacteria generate considerable of the heat, but other chemical processes are also active.

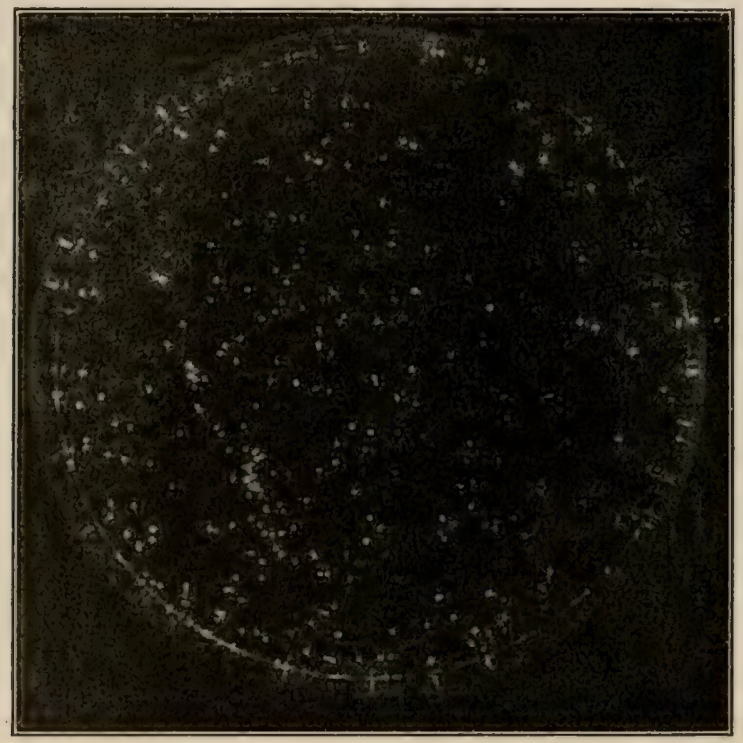

FIG, 14.-Photogenic bacteria colonies on a plate photographed by means of their own light. (Lafar.) (Buchanan's Household Bacteriology.)

Light.--Sometimes one sees on the surface of decaying wood, fish, or various meats a bright illuminated surface which at times may be sufficient for the photographing of objects in an otherwise dark room. This is due to the growth of certain light-producing bacteria. Other organisms produce a beautiful phosphorescence. The organisms producing light are especially prone to occur in saline waters and are invariably aërobes.

Marshall: Microbiology.

\section{REFFRENCHS.}

Taylor: Digestion and Metabolism.

Lafar: Technical Mycology.

Kendall: Bacteriology-General, Pathological and Intestinal. 


\section{CHAPTER IX.}

\section{INFLIENCE OF TEMPERATURE AND LIGHT ON BACTERIA.}

Temperature influences life phenomena in two ways-chemically and physically. Chemically, heat influences powerfully the reacting velocity within the cell and the aggregate condition of the molecules, or coagulation. Physically, temperature influences the viscosity of the liquids composing the cell.

Temperature and Speed of Reaction.-According to the law of Van't Hoff and Arrhenius, a chemical reaction is increased two or more times its original speed whenever the temperature is increased $10^{\circ} \mathrm{C}$. This holds good for the reactions in living organisms, within certain limits of temperature, as well as for non-living, as may be seen from the following table given by Clausen in which is recorded the number of milligrams of carbon dioxid produced by 100 grams of lupine seeds in one hour:

$\begin{array}{cc}\text { Temperature. } & \begin{array}{c}\text { Carbon dioxid } \\ \text { produced. }\end{array} \\ 0^{\circ} & 7.27 \\ 5 & 13.87 \\ 10 & 18.11 \\ 15 & 34.37 \\ 20 & 43.55 \\ 25 & 58.76 \\ 30 & 85.00 \\ 35 & 100.00 \\ 40 & 115.90 \\ 45 & 104.45 \\ 50 & 46.20 \\ 55 & 17.70\end{array}$

\section{Increasc
tor $10^{=} \mathrm{C}$. \\ 10.84 \\ 25.44 \\ 41.45 \\ 30.90 \\ 69.70}

The above table shows that for temperatures below $40^{\circ} \mathrm{C}$. there is a general increase in the speed of the reactions with increases in temperature. However, at higher temperatures the amount of carbon dioxid diminishes rapidly with further increase in temperature. This is very generally observed in enzymatic processes, as at temperatures orer $60^{\circ} \mathrm{C}$. enzymes are rapidly decomposed and many become immediately inactive when they are heated up to $6.3^{\circ}$ to $65^{\circ} \mathrm{C}$. This may be due to the fact that the enzymes themselves undergo hydrolysis which also would follow the temperature law of Van't Hoff and Arrhenius. Furthermore, enzymes are probably protein and would undergo heat coagulation. This would reduce the reacting areas between enzymes and fermentable sub- 
stance, and hence decrease proportionally the speed of the catalyzed reaction.

The protoplasm composing the bacterial cell consists of carbohydrates, lipins, proteins, and ash having a definite structural arrangement within the living cell. The cellular protoplasm is, therefore, a colloid existing during life in the soluble condition, but when heated there occurs an irreversible reaction with the formation of a gel. This heat-coagulation of the protein is explained by Robertson as essentially a phenomenon of dehydration, the first stage of which consists of internal neutralization through the loss of the elements of water from end-groups $\left(-\mathrm{NH}_{2}\right.$ and $\left.-\mathrm{COOH}\right)$, thus:

$$
\mathrm{H}_{2} \mathrm{~N}-\mathrm{RCOH}-\mathrm{N}-\mathrm{R}-\mathrm{COOH}=\mathrm{HN}-\mathrm{R}-\mathrm{COH}-\mathrm{N}-\mathrm{R}-\mathrm{CO}+\mathrm{H}_{2} \mathrm{O}
$$

In the second stage, or true coagulation, there is a polymerization of the amino-acids with the formation of the irreversible gel.

$$
\begin{array}{r}
2 \mathrm{H}_{2} \mathrm{~N}-\mathrm{R}-\mathrm{COH}-\mathrm{N}-\mathrm{R}-\mathrm{COOH}=\mathrm{H}_{2} \mathrm{~N}-\mathrm{R}-\mathrm{COH}-\mathrm{N}-\mathrm{R}-\mathrm{COH}-\mathrm{N}- \\
\mathrm{R}-\mathrm{COH}-\mathrm{N}-\mathrm{R}-\mathrm{COOH}+\mathrm{H}_{2} \mathrm{O}
\end{array}
$$

Relation to Heat. - From the above theoretical consideration we should expect to find, and do actually find, an upper temperature limit at which all organisms cease to function. 'This upper limit varies considerably with the species of bacteria and the condition under which it is being held. $B$. phosphorescens will not grow above $37^{\circ} \mathrm{C}$., B. tuberculosis above $42^{\circ} \mathrm{C}$., $\mathrm{B}$. thermophilis above $72^{\circ} \mathrm{C}$, and Setchell has found bacteria living in the water of hot springs at a temperature of $89^{\circ} \mathrm{C}$.

This great variation in temperature requirement of bacteria has led to their division into four classes:

1. Thermophilic, or heat-loving bacteria, are those that develop at relatively high temperatures, usually above $45^{\circ}$ to $50^{\circ} \mathrm{C}$. 'These organisms occur in the water of hot springs, in decaying piles of compost or manure, in fermenting ensilage, in the intestinal contents of man and animals. 'To this class belong the non-motile bacilli isolated by Miquel from the Seine, which grew rapidly at temperatures around $70^{\circ} \mathrm{C}$., as does also the so-called "Mudedimus thermophiles," described by Tsiklinsky, which develop readily at temperatures slightly above this. Most of the thermophiles are spore-bearing bacilli of little or no practical importance.

2. Psychrophitic bacteria are those which grow best at relatively low temperatures, usually below $10^{\circ} \mathrm{C}$. 'They are most common in cold waters such as those of springs, wells, the depths of lakes or oceans and the soils of aretic regions. Forster has described certain phosphorescent bacteria, which he isolated from sea water which grow readily at $10^{\circ} \mathrm{C}$. Many bacteria of the soil must belong to this class, as Conn and Brown have repeatedly shown that soil bacteria 
increase in number near the freezing-point. Some bacteria of this type probably play important rôles in soil fertility and in the decay of foods in cold storage.

3. Mesophilic bacteria are those whose optimum temperature is between these two extremes. They comprise the great group of pathogenic organisms occurring in the bodies of men and animals. To this class also belong many of the decay and putrefying organisms found in the soil. All of the more important bacteria belong to this group.

Three temperature limits may be distinguished for bacterial growth: (a) Minimum, the lowest temperature at which bacterial growth will occur. 'This for the true thermophiles is about $40^{\circ} \mathrm{C}$., for some pathogenic $29^{\circ} \mathrm{C}$., and for the mesophilic as low as $0^{\circ} \mathrm{C}$., or in solutions which do not solidify it may be even lower than this. (b) Optimum, that of most luxuriant growth. This, like the minimum temperature, varies greatly with the species. (c) Maximum, the highest temperature at which growth and multiplication can take place. This may be a few or many degrees above the optimum. For the thermophilic it may be as high as $89^{\circ} \mathrm{C}$, whereas for the pathogenic bacteria it lies between $40^{\circ}$ and $50^{\circ} \mathrm{C}$. 'The growth of some pathogenic organisms at a high temperature for some time causes them to lose their virulence or disease-producing power, and is, therefore, made use of in the preparation of vaccines.

The temperature relations are seen from the following table reported by Fischer:

\begin{tabular}{|c|c|c|c|c|}
\hline & \multicolumn{3}{|c|}{ Temperature. } & \multirow{2}{*}{ Species. } \\
\hline & Minimum. & Optimum. & Maximum. & \\
\hline Psychrophilic bacteria & 0 & $15-20$ & 30 & Many water bacteria. \\
\hline Mesophilic bacteria. & $15-25$ & 37 & 43 & $\begin{array}{l}\text { Pathogenic bacteria } \\
\text { and others. }\end{array}$ \\
\hline Thermophilic bacteria & $25-45$ & $50-55$ & 85 & $\begin{array}{l}\text { Spore-bearing bac- } \\
\text { teria from soil, feces } \\
\text { and thermal springs. }\end{array}$ \\
\hline
\end{tabular}

The growth temperature range of an organism is the number of degrees difference between the minimum and maximum. This is very small with some bacteria like the gonococcus, the pneumococcus, the tubercle bacillus, and others which are highly susceptible to temperature changes and have the power of growing only within limits varying but a few degrees from the optimum. However, most pathogenic bacteria may grow at temperatures ranging between $20^{\circ} \mathrm{C}$. and $40^{\circ} \mathrm{C}$. Others, like the colon bacilli group, the Bacillus anthracis, and the Spirillum cholera asiatica, may develop at temperatures as low as $10^{\circ} \mathrm{C}$. and as high as $40^{\circ} \mathrm{C}$. or over. The 
range of temperature at which saprophytic bacteria, including soil organisms, may develop is usually a far wider one. These points are well illustrated by the following table taken from Fischer:

\begin{tabular}{|c|c|c|c|c|c|c|}
\hline & & & \multicolumn{3}{|c|}{ Temperature. } & \multirow{2}{*}{$\begin{array}{l}\text { Difference between Mini- } \\
\text { mum and maximum. }\end{array}$} \\
\hline & & & Minimum. & Optimum. & Maximum. & \\
\hline B. phosphorescen & . & & 9 & 20 & 38 & 29 \\
\hline B. fluorescens & . & . & 5 & $20-25$ & 38 & 33 \\
\hline B. subtilis . & . & . & 6 & 30 & 50 & 44 \\
\hline B. anthracis : & . & . & 12 & 37 & 45 & 33 \\
\hline Vibrio choleræ & . & . & 10 & 37 & 40 & 30 \\
\hline B. diphtheriæ & . & . & 18 & $33-37$ & 45 & 27 \\
\hline Mic. gonorrheæ . & . & & 25 & 37 & 39 & 14 \\
\hline Bact. tuberculosis & . & . & 30 & 37 & 42 & 12 \\
\hline B. thermophilis . & . & . & 40 & $60^{\circ}$ & 80 & 40 \\
\hline
\end{tabular}

The fatal temperature may be even somewhat higher than this. It will vary with a number of factors, the condition of the organism playing a great part. For instance, Duclaux found that certain bacilli (Tyrothrix) found in cheese are killed in one minute at a temperature of from $80^{\circ}$ to $90^{\circ} \mathrm{C}$., whereas for the spores of the same bacillus a temperature of from $105^{\circ} \mathrm{C}$. to $120^{\circ} \mathrm{C}$. was required.

Duclaux considers it erroneus to speak of a definite temperature as a fatal one; instead he considers it better to speak of it as deadly. This is due to the fact that the length of time an organism is exposed to a high temperature is important. This is illustrated by the experiments of Christen on the spores of the bacilli of the soil and of hay. The spores were exposed to a stream of steam and the time noted which was necessary to kill the spores at the various temperatures.

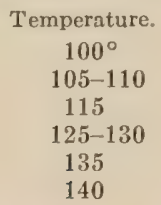

Time reqired to kill spores.

over 16 hours.

2 to 4 hours.

30 to 60 minutes.

5 minutes or more.

1 to 5 minutes.

1 minute.

Moist heat is much more effective as a germicide than is dry heat. The probable explanation of this is that where dry heat is applied it must be high enough to decompose the organic constituents of the cell, the proteinaceous substance being in the form of the anhydride which can, in the presence of moisture, take up water according to the following equation:

$$
\mathrm{HN}-\mathrm{R}-\mathrm{COH}-\mathrm{N}-\mathrm{RCO}+\mathrm{H}_{2} \mathrm{O}=\mathrm{H}_{2} \mathrm{~N}-\mathrm{RCOH}-\mathrm{N}-\mathrm{R}-\mathrm{COOH}
$$

'Two or more molecules of this hydrated protein would then condense with the formation of the non-reversible gel.

$$
\begin{aligned}
2 \mathrm{H}_{2} \mathrm{NRCOHNRCOOH}= & \mathrm{H}_{2} \mathrm{~N}-\mathrm{R}-\mathrm{COH}-\mathrm{N}-\mathrm{R} \mathrm{COH}-\mathrm{N}-\mathrm{R} \mathrm{COH} \mathrm{NR}- \\
& \mathrm{COHNR}-\mathrm{COOH}+\mathrm{H}_{2} \mathrm{O}
\end{aligned}
$$


That moisture is essential for coagulation of proteins is illustrated by the following table from the work of Hiss and Zinsser:

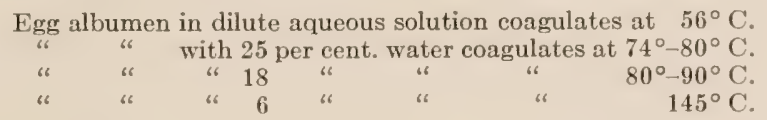

Absolute anhydrous albumin, according to Haas, may be heated to $170^{\circ} \mathrm{C}$. without coagulation.

Moreover, moist heat is much more penetrating than is dry heat. This is illustrated by an experiment carried out by Koch and his associates. Small packages of garden soil were wrapped with varying thicknesses of linen with thermometers so placed that the temperature under a definite number of layers could be determined. These were exposed to hot air and steam for four and three hours, respectively, with the following results:

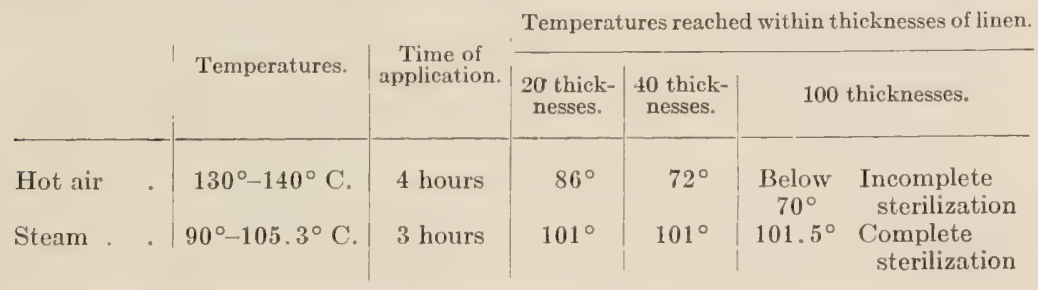

The comparatively low specific density of the steam enables it to displace the air from the interior of materials. Furthermore, when the steam comes in contact with the substance to be sterilized it condenses with a liberation of heat. This in the case of water vapor amounts to 536.6 calories.

Although the spores of certain bacteria of the soil can withstand live steam for several hours, they may be destroyed in a few minutes or even instantaneously in compressed steam ranging in temperature from $120^{\circ}$ to $140^{\circ} \mathrm{C}$.

The germicidal action of the great majority of disinfectants is due to a chemical reaction taking place between the protoplasm of the bacterial cell and the germicide. This reaction follows the temperature law of Van't Hoff and Arrhenius. Hence, the mere raising of the temperature a few degrees of a sugar, salt, acid or alkali solution makes of it a disinfectant.

Thermal Death Point.-The thermal death point of an organism is the lowest temperature that will certainly destroy it under definite conditions. These conditions are time (which is generally taken as ten minutes), amount of moisture present, the reaction and composition of the medium in which the organism is heated, and the 
presence or absence of spores. The thermal death point of bacteria varies with the specific character of the organism (some organisms being much more resistant to heat than are others) and the age of the culture, roung cultures being more resistant than older cultures which have not formed spores, especially when heated in the products resulting from their metabolism.

C'old.-It has been shown that the criterion for death is the nonreversibility of the change brought about by the agency in question. Now, does the lowering of the temperature bring about irreversible changes in the protoplasm as does the raising of the temperature? It is known that even intense cold does not cause these irreversible reactions in proteins. Where death does occur in cold-blooded animals and in plants, it must be due to the formation of ice crystals in the cells which may mechanically injure and kill them. This seems to be the case in the freezing of plants. Another irreversible change is comnected with the thawing of the cells which have been frozen. Barring these two secondary and mechanical complications, the lowering of the temperatures does not seem to bring about irreversible changes in the condition of the protoplasm which are incompatible with life.

When the temperature of the protoplasm becomes sufficiently low, for example, approximately $0^{\circ} \mathrm{C}$., the velocity of the chemical reaction becomes so small that the manifestations of life cease. The same is the case where the water content is sufficiently decreased. This is the reason why seeds of higher plants and spores of bacteria can be kept alive so long. Lack of water may reduce the reaction velocity of the hydrolytic processes in these at ordinary temperature to such an extent that it may become practically zero. So resistant are bacteria to low temperature that they may be frozen solid and kept in this condition for days and even weeks, and many survive. Many bacteria, including the typhoid and colon bacilli, will survive freezing for twenty-four hours in liquid hydrogen $\left(-252^{\circ}\right.$ (.) and develop vigorously when brought into suitable media at an optimum temperature. Bacteria do not lose their virulence when exposed to low temperatures, as is the case when exposed to comparatively high temperatures. There is, however, a tendency for the number of organisms gradually to decrease as they are kept in the frozen endition. When typhoid bacilli are frozen in water, approximately 90 per cent. of them die during the first week, 9.5 per cent. suceumb by the end of four weeks; but from four to six months' (ontimous freezing is required to kill all of the organisms. 'The speed with which bacteria disalpesear from a frozen medium varies greatly with the nature of the medium. It is very slow in colloidal substances and much faster in crystalloids. Alternate freeging and thawing in colloids is much less disastrous to bacteria than the same treatment in aqueous solutions. It is prob- 
able that the crystals formed in the freezing of water play a great part in the mechanical injuring of the bateria. The freezing of the soil increases not only the number of hacteria within it, but the ammonifying and nitrogen-fixing powers of the soil. Whether or not this will vary with the water content of the soil has not yet been answered, but it is likely that as the moisture content increased the greater would be the injurious influence of the low temperatures.

Light.-That light greatly affects the metabolism of the living cell is well known. However, bacteria are even more sensitive to light than are most cells. I )iffused darlight exerts a hindering effect

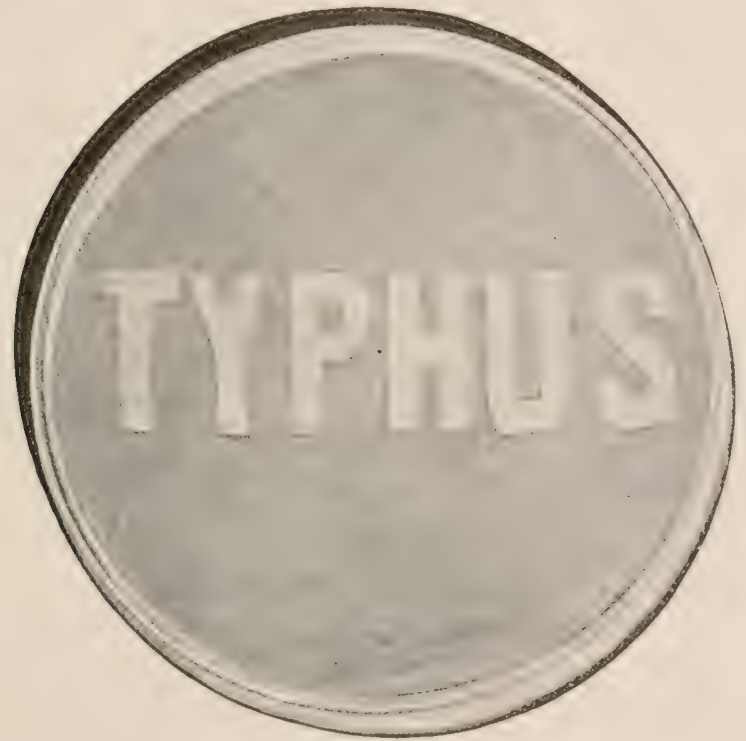

FIG. 15.-Thickly sown plate culture of typhus bacilli on agar-agar. Covered with paper letters and exposed to the sun's rays for one and a half hours, then kept twenty-four hours in the dark, whereupon development of thickly congregated whitish colonies was found only at the parts covered by letters. (After H. Büchner.)

upon bacterial growth and metabolism, whereas direct sunlight is highly injurious to certain bacteria, many microörganisms being killed almost instantly when exposed to the full action of the sun's rays. The different colors of the spectrum do not act alike. The longer rays, from red to green, are practically without influence upon bacteria, but the blue and violet rays have the most marked germicidal power.

Since light has no effect upon bacteria in a vacuum, it has been inferred that the changes brought about in the bacterial cell are primarily oxidation changes which are incompatible with the life of the cell. This reaction is brought about more rapidly in those 
cells which contain considerable fat, and this may be the reason why some spores which contain an oily substance are especially sensitive to light. Death of the cell in many cases may be due to a type of coagulation like heat coagulation, for Boris has shown that protein solutions in quart vessels are coagulated by exposure to ultra-violent light. This consists of two stages - first, that of denaturation, and second, agglutination, or flocculation. 


\section{CHAPTER X.}

\section{EFFECT OF OTHER AGENTS ON BACTERIA.}

Radium Rays. - Fernan and Pauli have shown that the exposure of proteins (serum albumin) in acid or alkali solution to radium radiations causes their coagulation. It is well known that the exposure of living tissue to these rays cause their destruction, and attempts have been made to treat certain bacterial diseases by their use, but so far without any great degree of success. The sterilization of milk and other foods by this method has been suggested, but its practical application appears to be improbable on account of the cost and uncertainty of the results.

The fixation of elementary nitrogen by $A$. chroöcoccum is distinctly increased when the air is activated by pitchblend, somewhat better results being obtained with weak than with stronger radioactive intensity. Attempts have been made to force higher plants by its use, but so far without any practical success.

Röntgen Rays. - Although röntgen rays are used in the treatment of microbial diseases of the scalp and skin, it has been conclusively shown that they are not even inhibitory, let alone fatal to the cells. This is seen from the results by Zeit, who found that bouillon and hydrocell-fluid cultures in test-tubes of non-resistant forms of bacteria was not killed röntgen rays after forty-eight hours' exposure at a distance of $20 \mathrm{~mm}$. from the tube. Tubercular sputum exposed to these rays for six hours at a distance of $20 \mathrm{~mm}$. from the tube caused acute miliary tuberculosis of guinea-pigs inoculated with it. The hopes that were entertained of being able to disinfect the diseased body by this means have not been realized. The clinical results which are sometimes obtained must be explained by factors other than their direct germicidal influence, possibly by the production of ozone, hypochlorous acid, extensive necrosis of the deeper layers of the skin and phagocytosis.

Electricity.-The influence of electricity itself upon microorganisms is probably very slight, but it is often difficult nicely to differentiate between purely electrical effects and chemical changes which are produced in the media by the electric current. A direct current passing through a nutrient medium will cause an electrolysis which is usually manifest by the generation of acid on the positive electrode and alkali on the negative. The passing of 
an electric current through a sodium chlorid solution brings about an extremely complex change, as indicated in the following equations:

$$
\begin{array}{ll}
2 \mathrm{NaCl} & =2 \mathrm{Na}+\mathrm{Cl}_{2} \\
2 \mathrm{Na}+2 \mathrm{HOH} & =2 \mathrm{NaOH}+\mathrm{H}_{2} \\
4 \mathrm{Cl}+2 \mathrm{HOH} & =4 \mathrm{HCl}+\mathrm{O}_{2} \\
2 \mathrm{NaOH}+2 \mathrm{Cl} & =\mathrm{NaClO}+\mathrm{NaCl}+\mathrm{H}_{2} \mathrm{O} \\
3 \mathrm{NaClO} & =\mathrm{NaClO}_{3}+2 \mathrm{NaCl}
\end{array}
$$

Many of the products so formed, if in sufficient concentration, are good germicides and would be, therefore, the agents causing death instead of the electricity doing it. Moreover, the passing of an alternate current through a medium may heat it sufficiently to kill many bacteria. When the solution is properly cooled the action of the current is practically zero.

Zeit, who has made a very careful study of the effect of electricity upon bacteria, summarizes his findings as follows:

"1. A continuous current of 260 to 320 milliampères passed through bouillon cultures kills bacteria of low thermal death points in ten minutes by the production of heat $-98.5^{\circ} \mathrm{C}$. The antiseptics produced by electrolysis during this time are not sufficient to prevent growth of even non-spore-bearing bacteria. The effect is a purely physical one.

"2. A continuous current of 48 milliampères passed through bouillon cultures for from two to three hours does not kill even non-resistant forms of bacteria. The temperature produced by such a current does not rise above $37^{\circ} \mathrm{C}$. and the electrolytic products are antiseptic but not germicidal.

" 3 . A continuous current of 100 milliampères passed through bouillon cultures for seventy-five minutes kills all non-resistant forms of bacteria even if the temperature is artificially kept below $37^{\circ} \mathrm{C}$. The effect is due to the formation of germicidal electrolytic products in the culture. Anthrax spores are killed in two hours. Subtilis spores were still alive after the current was passed for three hours.

"4. A continuous current passed through bouillon cultures of bacteria produces a strong acid reaction at the positive pole, due to the liberation of chlorin which combines with oxygen to form hypochlorous acid. The strongly alkaline reaction of the bouillon culture at the negative pole is due to the formation of sodium hydroxid and the liberation of hydrogen in gas bubbles. With a current of 100 milliampères for two hours it required $8.52 \mathrm{mg}$. of sulphuric acid to neutralize 1 c.c. of the culture fluid at the negative pole, and all the most resistant forms of bacteria were destroyed at the positive pole, including anthrax and subtilis spores. At the negative pole anthrax spores were killed also, but subtilis spores remained alive for four hours. 
"5. The continuous current alone, by means of I)uBois-Raymond's method of non-polarizing electrodes and exchusion of chemical effects by ions in Kruger's sense, is neither bactericidal not antiseptic. 'The apparent antiseptic effect on suspensions of bacteria is due to electric osmose. The continuous electric current has no bactericidal nor antiseptic properties, but can destroy bacteria only by its physical effects - heat - or chemical effects - the production of bactericidal substances by electrolysis.

" 6 . A magnetic field, either with a helix of wire or between the poles of a powerful electromagnet has no antiseptic or bactericidal effects whatever.

"7. Alternating currents of a three-inch Ruhmkorff coil passed through bouillon cultures for ten hours favor growth and pigment production.

" 8 . High frequency, high potential currents-Tesla currentshave neither antiseptic nor bactericidal properties when passed around a bacterial suspension within a solenoid. When exposed to the brush discharges, ozone is produced and kills the bacteria."

The electric current is used in the purification of sewage, the sterilization of milk, the improvement of wines, and the purification of water. In all of these cases the effect is due to a chemical produced by the electricity. 'The purification of water is due to the ozone formed, which in turn acts as an oxidizing agent toward the bacteria. Although expensive, it is one of the most effective means of rendering water safe.

Drying.- The results which have been reported on the influence of drving upon bacteria are exceedingly divergent. This is due mainly to the fact that the influence exerted by drying varies with a number of factors, chief among which are:

1. Light.-Bacteria that are killed in a few minutes in direct sunlight may live for weeks in a dark place or even in diffused light.

2. O. ygen.--Pauli and his associates consider death through drying as due to an oxidation process. They found that bacteria die much faster in pure oxygen than in air. Moreover, they found that the number of bacteria dying in unit time under constant conditions is proportional to the number surviving, therefore, comparable with the simplest chemical processes, the monomolecular reactions.

3. Thicliness and Nature of the Medium in Ihich They Ire Dried.- In a dried medium bacteria usually die quickly but may survive long in sputum or feces. Moreover, bacteria suspended in the extract from a rich clay loam before being subjected to desiccation in sand live longer than if subjected to desiccation after suspensions in a physiological salt solution.

4. The Hore Complete the Drying the Shorter the Life.-Alternate drying and moistening is unfavorable. 
5. The II igher the Temperature the Sooner the Bacteria Perish.Death due to drying is probably in some cases due to a non-reversible reaction which follows the well-known temperature law of Van't Hoff and Arrhenius. In other cases it is undoubtedly due to the increased osmotic pressure produced by the removal of the moisture.

6. Old cultures, unless they be spore bearers, succumb sooner to drying than do young cultures.

7. The influence of drying upon bacteria varies greatly with the species. Whereas the gonococcus, pneumococcus, spirochete of syphilis, cholera spirilla, and Pfeiffer bacillus can withstand drying only a few hours, the typhoid, diphtheria, and tubercle bacilli may survive days; and tetanus, anthrax, and many soil organisms may survive drying for months or even years. Ammonifying, nitrifying, and nitrogen-fixing bacteria have been isolated in great numbers from soils which have been kept in tight bottles air-dry for more than fifty years. Even the non-spore-forming types of Azotobacter will withstand desiccation over sulphuric acid for a considerable time.

Osmotic Pressure.-Bacteria vary greatly in their ability to withstand great osmotic changes. Some are quickly plasmolyzed in solutions having low osmotic pressure, whereas others can grow in strong sugar or salt solutions. This factor plays a great part in the preserving of fruits by means of sugar, of pickles and cabbage by means of salt, and many fruits by drying. Those fruits which have the highest carbohydrate content, such as grapes and prunes, are especially easy to preserve by drying.

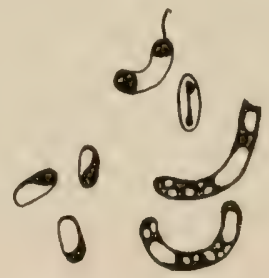

FIG. 16.-Plasmolysis of various bacterial cells. (Buchanan's Household Bacteriology.)

Probably the great osmotic pressure in the soil solution of alkali soils plays a great part in retarding the bacterial activity of these soils. In this case, however, there is also a physiological factor in which the living protoplasm of the cell is so changed in its chemical and physical properties that it cannot function normally. It is found that equivalent osmotic concentrations of sodium and potassium salts act very differently upon some bacteria.

Pressure.-Bridgman found that the application of very great hydrostatic pressure resulted in the coagulation of white of egg. 
He applied the pressure very slowly to avoid any rise in temperature due to the compression. That the effect is not due to heat is further demonstrated by the fact that it is more easily obtained at $0^{\circ}$ ( $^{\circ}$. than at $20^{\circ} \mathrm{C}$. The application of five thousand atmospheres produces stiffening of the white of egg; six thousand atmospheres applied, for thirty minutes, produced an appearance of the white resembling that of curdled milk; and seven thousand atmospheres' pressure brought about complete gelatination.

These facts seem to indicate that high pressure is fatal to many bacteria. Experiments have shown this to be the case. B. anthracis, B. pseudodiphtherio, M. pyogenes, var. aureus, and Ö̈dium lactis survived after being subjected to a pressure of 2000 atmospheres for ninety-six hours. The pigment production and virulence of pathogenic organisms were either diminished or completely lost after such treatment.

Successful attempts have been made to preserve fruit and vegetables by exposing them to high pressure. Apple juice subjected to 4000 to 6000 atmospheres' pressure for thirty minutes did not later develop gas. Peaches and pears exposed to this pressure did not spoil for five years. Those vegetables on which are found resistant spores could not be preserved by such pressures. It therefore appears that pressure high enough for the coagulation of the proteins is fatal to the less resistant bacteria.

The power of resisting and actually functioning under high pressure is especially necessary for the denitrifying bacteria which live at the bottom of the ocean and return to the atmosphere the thousands of tons of combined nitrogen which is carried each year to the ocean from the soil and in the sewers.

Shaking. - It is well known that proteins may be coagulated by shaking and that proteolytic enzymes undergo important modifications under the influence of shaking. An active solution of proteolytic enzyme introduced into a reaction tube and agitated for two minutes may lose as much as 75 per cent. of its activity. After five minutes the disappearance is almost total. The effect of shäking varies with the speed, temperature, and reaction of the medium in which the ferment is placed. This phenomenon is known to be due to a coagulation or absorption of the substance, and it is quite possible that part of the influence exerted by shaking upon bacteria is due to this factor. It is known, however, that bacteria may be broken into the finest particles by the rapid shaking of cultures causing death at times by a disintegration of the cell body. 


\section{CHAPTER XI.}

\section{EFFECT OF CHEMICALS ON BACTERIA.}

Chemotaxis. - It has been repeatedly demonstrated that bacteria, like other free-moving organisms, are apparently attracted by certain chemical substances in solution (positive chemotaxis), and repelled by others (negative chemotaxis).

Pfeiffer, who was the first to study this phenomenon, developed a very simple and efficient method of studying it with bacteria. A capillary tube, sealed at one end and from 5 to $10 \mathrm{~mm}$. long, is filled with a 5 per cent. slightly alkaline solution of Liebig's beef extract or of peptone. The outer surface of the glass is carefully cleaned from any traces of the bouillon and is placed in a drop of water containing bacteria. In a few seconds the bacteria are found to thickly congregate around the open end of the capillary tube. According to the view held by Jemnings, the swarming of bacteria around any point, where favorable nutrient conditions exist is not to be looked upon as due to a definite attraction exerted upon the bacterial cell, but as caused simply by the tendency to remain at those points where the conditions are favorable. But this does not seem to be the true explanation, for had the capillary tube been filled with sugar, or glycerin, which are the best foodstuff's and richest sources of energy, there would have been no such gathering of the the bacteria at the end of the tube. Moreover, a solution of 0.019 per cent. potassium chlorid plus 0.01 per cent. mercuric chlorid attracts bacteria by reason of the potassium which it contains, but they rush into the tube only to meet their death from the mercury salt.

The explanation given by Loeb seems to be more reasonable: "Theoretically, we may assume that if substances diffuse in air or in water, the particles move in a straight line away from the center of diffusion. If they strike an organism whose surface is affected by the diffusing substance on one side only, the contractile protoplasm, or the muscles, turning the tip or the head of the whole organism toward that side, are thrown into a different state of contraction from their antagonists. The consequence is a turning or binding of the tip of the heard until srmmetrical points of the chemically sensitive surface of the body are struck by the line of diffusion (or the diffusing particles) at the same angle. As soon as this occurs the contractile elements on both sides of the organ or organisms are in an equal state of contraction, and the animal will 
bend or more in the direction of the lines of diffusion." Why one substance should act positive and another negative is at present quite inexplicable.

Chemotaxis can take place only in media which permit free movement and its sphere of action is comparatively small. Different kinds of bacteria by no means react in the same way to the same substance. Furthermore, the action, whether positive or negative, chemotaxis or neutral, varies with the chemical. The salts of potassium are among the more active positive chemotactic substances, followed by sodium and rubidium. The alkaline earths are less effective. The influence of a salt is attributed mainly to its electropositive constituent; asparagin and peptone are strongly chemotactic, whereas sugar and glycerin are inactive.

Negative chemotaxis is noted when capillary tubes are filled with free acids and alkalies or with alcohol. In some salts the action of the acid radical and that of the base neutralize each other (ammonium carbonate and monobasic potassium phosphate). In this case the bacteria are neither attracted nor repelled by the substance.

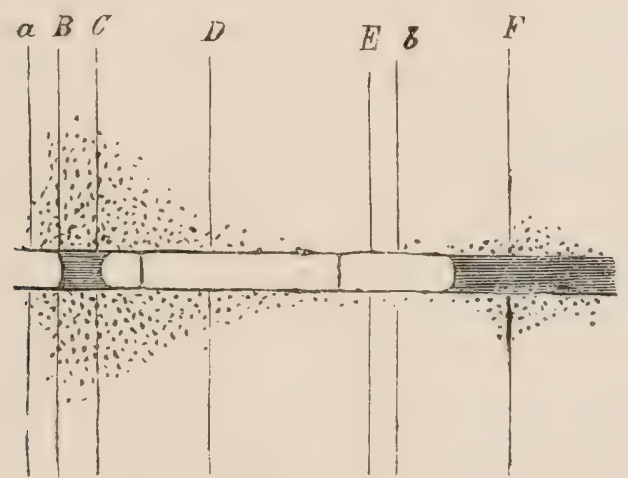

Fig. 17.-Oxygen-loving bacteria infesting a thread of alga lying in the microspectrum. The chlorophyll granules contained in the alga cells are not shown, but the spectrum lines are given to denote the position of the spectrum. Mag. 200. (After Engelmann.)

Fingelmann ingeniously made use of this phenomenon as a test for oxyen and the effect exerted upon assimilation by the different parts of the solar spectrum. If a thread of alga and some aërobic bacteria are placed under an air-tight cover-glass, the bacteria are active; but if the preparation is kept in the dark the action of the bacteria will cease, showing that all the oxyen has been consumed. If brought back to the light as the algae assimilate arbon dioxid with the elimination of oxygen the bacteria again become active. If exposed to the spectrum the greatest aggregation of bacteria occurs at the red end of the spectrum, indicating that the maximum assimilative activity of the algie protoplasm is proceeding at this 
point. By means of this highly sensitive test as little as one-billionth part of a milligram of oxygen may be detected.

It is quite possible that the phagocytes which play such a part in freeing the body of bacteria are directed or guided in their choice and perception by chemotaxis to the bodies which they ingest. The attraction of leukocytes toward the point of bacterial invasion is, in part at least, due to the properties of the bacterial proteins. This attraction is sometimes increased by injecting into the tissues at the point of infection some bland substance, such for instance as bismuth subnitrate.

Disinfectants.-- Of great interest are those substances which in minute quantities destroy the life of the cell. These substances when considered in their effects upon man and animals are called poisons. But when considered from the standpoint of microorganisms they are called germicides. Analogous with the general term germicide, are the terms bactericide and fungicide. A disinfectant is a substance which destroys the causative agent of infection. Although disinfection may occasionally mean sterilization, in the majority of cases it does not. It implies the destruction of those minute forms of life which cause disease.

Antiseptics prevent decomposition and decay. They do not necessarily destroy microörganisms; they prevent their growth and activity. One and the same substance may be a disinfectant under one condition and an antiseptic under another. Formalin in the proportion of 1 to 50,000 is an antiseptic, whereas it requires from 3 to 10 per cent. solution to be a disinfectant in a reasonably short time. Mercuric bichlorid in the proportion of 1 to 300,000 will sometimes prevent the germination of anthrax spores. Tet it requires a 1 to 1000 solution to kill them.

The term preservative is usually applied to those substances which are added to foods, feeding-stuff, and substances of similar origin with the intention of preventing decomposition or decay. These may be either comparatively poisonous - benzoic acid, boric acid, salicylic acid, formalin, or sulphates-or the non-poisonous substances-common salt or sugar. The method of action of the two is markedly different, the first combining with the protoplasm of the cell, the second acting through increased osmotic pressure.

Deodorants are substances which have the power of destroying or masking unpleasant odors arising from putrifying or fermenting organic matter. 1)eodorants destroy odors, disinfectants destroy germs. A deodorant may or may not be a disinfectant. Formalin is a good disinfectant and deodorant, whereas charcoal is a good deodorant but has no value as a disinfectant.

The classification of disinfectants is difficult, inasmuch as we do not understand in many cases their complete mode of action. Moreover, almost any compound, if used in sufficient concentration, may act as an antiseptic if not as a disinfectant. The methods 
most often used in classification are according to either composition or mode of action. The simplest method is by chemical structures and qualities under which are distinguished the following natural groups: acids, alkalies, metallic salts, hỵdrocarbons, alcohols, aldehyds, anesthetics, essential oils, and oxidizing and reducing agents. The first three-acids, alkalies, and salts - are distinguished from the rest by being electrolytes. The strength of acids and alkalies is dependent upon the hydrogen or hydroxyl ion concentration with the metallic salt; the action is dependent upon the nature of the metallic ion and the degree of electrolytic dissociation.

Rosenau classified disinfectants according to mode of action as follows: (1) Those compounds which destroy by oxidation, as ozone, chlorinated lime, potassium permanganate, and the halogens. (2) The destruction by ionic poison with coagulation, as the metallic salts, mercury, and lead salts. (3) Destruction by coagulation and poisoning not ionic in character, as carbolic acid and its derivatives. (4) Destruction by emulsoid action, that is, through Brownian movement and adsorption; soap solutions and creolin.

Lar's Goxerning the Action of Disinfectants.-These have been mainly worked out by Chick who found that disinfection is an orderly time-process, which may be considered analogous with a chemical reaction, viz., a reaction between the bacterium on the one hand and the disinfectant on the other. In the ideal case disinfection proceeds in accordance with some rule analogous to the mass law, so that if the disinfectant is present in large excess, disinfection rate at any moment is proportional to the concentration of bacteria $\left(-{ }_{d t}=K n\right.$, where $n$ is the concentration of bacteria at the time $t$, and $K$ is a constant, depending on the temperature concentration of disinfectant, etc.).

The velocity of disinfection increases with rise in temperature in an orderly manner according to the well-known equation of Arrhenius. Some idea of the magnitude of the effect of temperature may be gained from the fact that with metallic salts the mean velocity of disinfection increases two- to four-fold for a rise in temperature of $10^{\circ} \mathrm{C}$., whereas with phenol it was as high as eight-fold, using B. paratyphosus as the test organism in each case. Hence, the use of a disinfectant at a comparatively high temperature, other things being equal, is more effective than its use at a low temperature. In reality, a solution which at one temperature is only an antiseptic may become a disinfectant by a small increase in temperature.

The efficiency of a disinfectant varies with the moisture. A dry poison has but slight action on microörganisms. For this reason, dry formaldehyde gas is practically without effect. In a similar manner absolute alcohol has not nearly the same germicidal power as has 50 to 70 per cent. alcohol. This is probably due to the absolute alcohol coagulating the outer membrane of the organism 
and thus prevents the poison from diffusing into the rital part. The burning of sulphur in a dry atmosphere has little if any effect upon bacteria, but in the presence of moisture there is formed sulphurous acid which is a rather efficient disinfectant.

The germicidal property of salts of the heavy metals, acids, and alkalies is governed in a large measure by the degree of ionization. Mercuric chlorid in water is a good disinfectant, but in alcohol has little or practically no germicidal properties. The addition of sodium chlorid to mercuric chlorid increases the solubility of the latter and yet decreases its germicidal power. This is due to the fact that there is formed a double salt:

$$
2 \mathrm{NaCl}+\mathrm{HgCl}_{2}=\mathrm{Na}_{2} \mathrm{HgCl}_{4}
$$

This is poorly dissociated by steps into $\stackrel{+}{\mathrm{Na}}+\underset{\mathrm{NaHgCl}_{4}}{-}, \frac{+}{\mathrm{Na}}+$ $\overline{\mathrm{HgCl}}_{4}, \overline{\mathrm{Hg}}+4 \overline{\mathrm{Cl}}$. The number of $\mathrm{Hg}$ ions formed is very small, therefore, in the presence of sodium chlorid.

As a general rule the addition of a common negative ion decreases the number of ions of the metal going into solution. If mercuric chlorid is shaken with water, the salt dissolves until there is an equilibrium between the solid phase and the undissociated molecules in solution. As the molecules dissociate, the equilibrium is disturbed and more of the solid dissolves to restore it, until a second equilibrium is established between the ions and the molecules. These equilibria may be expressed by the equation

$$
\frac{\left[\mathrm{Hg}^{\prime \prime}\right] \times\left[\mathrm{Cl}^{\prime}\right]^{2}}{\left[\mathrm{HgCl}_{2}\right]}=\mathrm{a} \text { constant; }
$$

since the concentration of the undissociated molecules is constant. So long as there is any undissolved salt, the equation becomes

$$
\mathrm{Hg} \times \mathrm{Cl}=\text { a constant. }
$$

If we add $\mathrm{NaCl}$, the $\mathrm{Cl}$ will increase the concentration of the $\mathrm{Cl}$ ions which will combine with the $\mathrm{Hg}$, giving $\mathrm{HgCl}_{2}$, which will crystallize out. Moreover, in this case the $\mathrm{NaCl}$ combines with the $\mathrm{HgCl}_{2}$ giving the $\mathrm{Na}_{2} \mathrm{HgCl}_{4}$ which greatly decreases the $\mathrm{Hg}$ ions in solution. The effect of this on the disinfecting power of different

\begin{tabular}{|c|c|c|c|c|}
\hline salt. & Concentration. & $\begin{array}{l}\text { Colonies after } 20 \\
\text { minutes' exposure. }\end{array}$ & $\begin{array}{l}\text { Colonies after } \$ 5 \\
\text { minutes' cxposure. }\end{array}$ & $\begin{array}{l}\text { Colonies after } 90 \\
\text { ninutes' exposure. }\end{array}$ \\
\hline $\mathrm{HgCl}_{2}$. & $1 / 64 \mathrm{~mol}$. & 7 & 0 & 0 \\
\hline $\mathrm{HgBr}_{2}$ & $1 / 64 \mathrm{~mol}$. & 34 & 0 & 0 \\
\hline $\mathrm{HgCn}_{2}$ & $1 / 16 \mathrm{~mol}$. & 0 & 33 & 0 \\
\hline $\mathrm{K}_{2} \mathrm{HgCl}_{4}$ & $1 / 16 \mathrm{~mol}$. & $\ldots$ & .. & 0 \\
\hline $\mathrm{K}_{2} \mathrm{HgBr}_{4}$ & $1 / 16 \mathrm{~mol}$. & . & & 5 \\
\hline $\mathrm{K}_{2} \mathrm{HgI}_{4}$ & $1 / 16 \mathrm{~mol}$. & . & & 389 \\
\hline $\mathrm{K}_{2} \mathrm{HgCn}_{4}$ & $1 / 16 \mathrm{~mol}$. & & & 1035 \\
\hline
\end{tabular}
dissociated salts of mercury on anthrax spores is indicated in the following from Paul and Kronig: 
The power of a disinfectant to kill bacteria is dependent in a remarkable degree upon the nature of the medium in which bacteria are present when the germicide is applied. Almost invariably the greatest germicidal activity is shown when the substance acts upon the bacteria freed from all contaminating culture media and suspended in distilled water or salt solution. The presence of proteins, peptones, and similar substances usually cause a great reduction in the germicidal powers of the substance. This is also the case in the presence of pus, many of the organisms being partly digested in the body of dead leukocytes. This property is illustrated by the following table reported by Dakin and Dunham. The - sign indicates sterilization as indicated by negative subcultures, and the + sign incomplete sterilization.

Antiseptic.

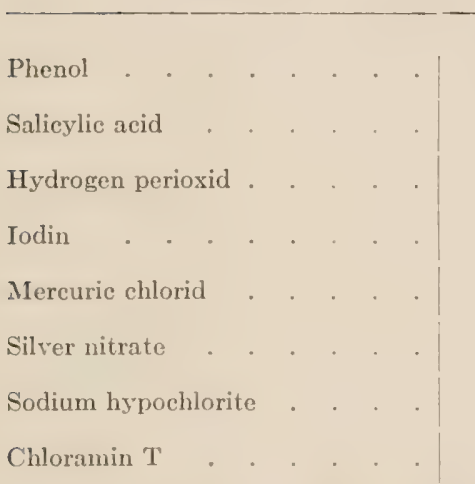

Staphylococci in water.

$1: 250-$

$1: 500+$

$1: 2,500-$

$1: 5,000+$

$1: 3,500-$

$1: 8,000+$

1:100,000-

$1: 1,000,000+$

$1: 5,000,000-$

$1: 10,000,000+$

$1: 1,000,000-$

1:10,000,000+

1: $500,000-$

$1: 1,000,000+$

1: $500,000-$

$1: 1,000,000+$
Staphylococci in 50 per cent. horse serum.

This decreased efficiency in the presence of a protein is variously explainer. In the case of such disinfectants as phenol and the dyestuffs, it is frequently stated that the disinfectant is "quenched" or "fixed" by the protein medium, Adsorption in some cases may play a part, but in the case of salts of the heavy metals, they combine with the protein giving an insoluble non-ionizing proteinate. The low germicidal action shown by most antiseptics against pus is due in part no doubt to the mechanical difficulties of penetrating the mucoid particles in the pus.

Young cultures of bacteria are usually more resistant than are older cultures. 'This is especially true when the disinfectant is applied to cultures living in the products resulting from their metabolism. Cultures, the organisms of which form spores, become more resistant to disinfectants as the spore stage is reached.

Emulsions as a rule have greater germicidal power than have solutions. According to Chick and Martin, emulsions or soapy 
preparations of the coal-tar acids exhibit active Brownian motion. Often the bacteria are considerably larger than the mean diameter of the emulsified particles. These bombard the bacteria and in this way frequently bring them into intimate contact with the undiluted particles of the disinfectant, which would not occur in solutions. Emulsions act upon bacteria first through physiochemical adsorption and second through chemical combination. But other particles held in suspension also possess this power of adsorption, and hence the strength of emulsions is rapidly reduced. 'Thus the value of phenol is barely impaired by the presence of organic matter in solution, whereas emulsified disinfectants are reduced to one-third or one-half of their original value.

Disinfectants of the Chlorin Group.-To this group belong many of the more active disinfectants. 'They are all characterized by a chemical instability in the presence of organic matter. The members of this group contain active chlorin in distinction to inert chlorin, such as that in common salt. The phrase "active chlorin" does not, however, necessarily imply that free chlorin is contained in the substance or liberated by it. The active agent may be hypochlorous acid or some other compound containing chlorin.

It used to be assumed that they acted mainly by the liberation of nascent oxygen. Hypochlorous acid decomposes thus:

$$
4 \mathrm{HClO}=2 \mathrm{H}_{2} \mathrm{O}+2 \mathrm{Cl}_{2}+\mathrm{O}_{2}
$$

The chlorin then reacts with water, liberating more nascent oxygen:

$$
2 \mathrm{Cl}_{2}+2 \mathrm{H}_{2} \mathrm{O}=4 \mathrm{HCl}+\mathrm{O}_{2}
$$

Dakin, however, defines a substance as possessing active chlorin when it will part with chlorin either free or combined in such a way that it can effect the chlorination of bacteria and other proteins.

All proteins are made up of amino-acids in which the aminogroup of the one has reacted with the carboxyl group of the other with the elimination of water. This gives imino $\mathrm{NH}-$ groups. It is assumed by some that the chlorin replaces the hydrogen in this group, thus:<smiles>[Z1]C(NC(=O)C([1H])N)C(=O)O</smiles> 
Or it may be that the extra bonds of the nitrogen in the imino group is utilized:<smiles>NCCNC(=O)[OH2+]</smiles><smiles>[R]C(N)C(=O)N(C(=O)O)C(=O)O</smiles>

according to this explanation hypochlorous acid may react without decomposing into chlorin:<smiles>[R]C(N)C(=O)NC([R])C(=O)O</smiles>

In any case the chemical and physical properties of the protoplasm would be so changed as to be incompatible with the life processes of the microörganisms.

Compounds containing the group-NCI--belong to the class of chloramins. Their chlorin is still active and they are themselves active germicides. Such compounds have been studied thoroughly by Dakin who used them extensively in the disinfecting of wounds in the great European war of 1914-18.

Chlorinated lime, or bleaching powder, may be taken as a type of the chlorin disinfectants. Its precise chemical composition is not known although calcium oxychlorid $\left(\mathrm{CaOCl}_{2}\right)$ is now generally accepted as being the essential agent of dry bleaching powder and calcium hypochlorite $\left(\mathrm{Ca}(\mathrm{OCl})_{2}\right)$ to be the active germicide of the solution. Although the reactions which occur are quite complicated, it is certain that the active substances are nascent oxygen, chlorin, and hypochlorous acid, and are probably formed as follows:

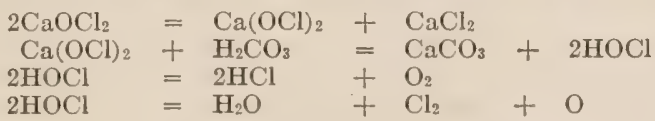

The substance is extensively used in the disinfection of sewage, outhouses, cellars, and for miscellaneous purposes. Since 1908 it has been used rather extensively in water purification. In practice 
from 5 to 12 or more pounds of bleaching powder is used to each million gallons of water. It cannot be detected by the sense of taste provided the amount does not exceed 25 pounds to $1,000,000$ gallons. Waters containing considerable organic material of any kind give rise to amins, chloramins, and other compounds with unpleasant flavors. The method, however, is cheap, reliable, efficient, harmless, and easy of application.

Formaldehyd is one of the best volatile antiseptics. If used in sufficient concentration and under proper conditions it can be depended upon for surface disinfection. Although more penetrating than sulphur dioxid, it is not sufficient to depend upon in deep layers of cloth and similar bodies. It does not rot nor bleach fabric nor tarnish metal as does sulphur dioxid. Moreover, formaldehyd unites with nitrogenous substances forming new chemical compounds which are both sterile and odorless. It is, therefore, good both as a germicide and as a disinfectant.

Although there are numerous methods of using, one of the best is that recommended by the Pennsylvania Department of Public Health:

Sodium dichromate.

Formalin

$10 \mathrm{oz}$.

Commercial sulphuric acid

$16 \mathrm{oz}$.

$1 \frac{1}{2} \mathrm{oz}$.

The sulphuric acid is added to the formalin and the mixture poured over the crystals of sodium dichromate causing immediate liberation of formaldehyd gas. Five hundred c.c. of formalin and $250 \mathrm{gm}$. of sodium dichromate should be used for each thousand cubic feet of air. The floor should be protected against the heat by placing the bucket upon a brick or other suitable device.

Sulphur Dioxid. - Sulphur dioxid is not very efficient as a germicide; it is, however, an effective insecticide. It is also good to use against diseases spread by rats, mice, flies, fleas, mosquitoes, etc.

Its action as a germicide depends upon the presence of moisture. The dry gas is practically inert against bacteria. It cannot be depended upon where penetration is required, its action being merely upon the surface. It does not kill spores. Moreover, it is a bleaching agent and tarnishes metals. In sterilization by means of sulphur, time is an important factor. The things to be disinfected should be exposed for eight hours to an atmosphere of at least 4 per cent. by rolumes of sulphur dioxid gas in the presence of water. This requires the burning of 4 to 5 pounds of sulphur for every 1000 cubic feet of air space. About one-fifth of a pound of water should be volatilized for every pound of sulphur used.

One method of using it follows: The required quantity of sulphur is placed in a pan which is put into a second larger pan containing water. 'The sulphur is made into little craters and liberally soaked 
with alcohol. It is well to place the generator on a table or box as sulphur dioxid is heavier than air and hence tends to sink and would, therefore, extinguish the flame if placed on the floor.

Hydrocyanic acid gas is an extremely powerful insecticide, but a poor germicide. It is used rather extensively against mosquitoes, lice, bedbugs, and roaches, but on account of its highly poisonous nature it must be used with extreme caution. It is effective against bacteria no hardier than those of diphtheria and typhoid, but it cannot be depended upon as a general disinfectant.

Mercuric chlorid is one of the best known and most effective of the metallic salt disinfectants. A solution of 1 to 1000 is ample for the destruction of all non-spore-bearing bacteria, provided it comes in direct contact with the organisms for some time. It is especially valuable for disinfecting the hands and for washing floors, woodwork, and furniture. It attacks metals and hence cannot be used to disinfect them; it is rendered inactive by protein substances; it acts on bacteria by a coagulation of the protoplasm.

Its germicidal value as usually given is too high. 'This is due to the fact that it may inhibit the growth of bacteria and in the planting of the cultures the metallic salt is carried over into the new medium, there preventing growth but not necessarily killing the organism. The explanation of this is given by Miss Chick who found that if bacteria are subjected to the action of $1: 1000,1: 10,000$, or even weaker solutions of mercuric chlorid, there is an interval during which some at least of them may be resuscitated by the timely administration of an antidote - in this case a sulphid solution. If, however, this antidotal treatment is not employed, no amount of subsequent dilution beyond the limits of inhibition can prevent the death of the organism.

\section{REFERENCES.}

Loeb: The Dynamies of Living Matter.

McClendon: Physical Chefnistry of Vital Phenomena.

Dakin and Dunham: Handbook of Antiseptics. 


\section{CHAPTER XII.}

\section{INFLUENCE OF ARSENIC ON BACTERIAL ACTIYITY.}

Occurrence of Arsenic.-Kunkel showed the presence of arsenic in many rocks and water, while Czapek states that traces are nearly always present in soils. Herzfeld and Lange found arsenic in certain German raw sugars and traced it to the lime which had been used in the manufacture of sugar. Headden found some virgin prairie soils relatively rich in arsenic, an observation in accord with my own experience. I have found arsenic to the extent of 4 parts per million in virgin soil; and, as in the cases referred to by Headden, it did not result from smelter fumes or any such source, but was derived from the decay of native rocks. On the other hand, Headden found arsenic in some cultivated orchard soils to the extent of 138 parts per million. He claims that in many places arsenic from spray is accumulating in sufficient quantities to become injurious to vegetation. François, however, thinks there is little danger of the soil's becoming unfit for regetation from the proper use of insecticides. Grunner, who found arsenic to the extent of from 0.026 per cent. to 1.426 per cent. in the Reichenstein soil, is not so optimistic. An extensive analysis of the sprayed orchard soils of western America showed arsenic to be present in all of those soils and varying from mere traces to 500 pounds an acre. In some cases it occurred to a depth of three or four feet. The most interesting fact is that in some of these soils there were as much as 17 pounds per acre of water-soluble arsenic. It is not, however, always the case that the greatest quantity of water-soluble arsenic is found in those soils which contain the greatest total quantity of arsenic, for often soils are found which contain only a few pounds to the acre-foot, probably twothirds of which is in a soluble form. So the conclusion has been reached that some virgin and many cultivated soils contain arsenic in large quantities, but the proportion in a soil is no index of the amount that is soluble in water. The latter is probably goremed by many factors; for example, kind of soil, water-soluble salts, and form in which the arsenic was applied to the soil.

Factors Influencing Solubility. - That the form in which the arsenic is applied govern largely its solubility is shown by an experiment in which 100 grams of arsenic in the form of lead arsenate was applied to a soil, and to another portion of the same soil was added 100 grams of arsenic in the form of Paris green. 'To still another soil 
was added enough arsenic in the form of zinc arsenite to make 100 grams of arsenic. These were carefully mixed and allowed to stand for some time, after which an examination was made for soluble arsenic. The analysis revealed the fact that $1+$ per cent. of the lead arsenate, 30 per cent. of the zinc arsenite, and over $\$ 0$ per cent. of the Paris green were in the water-soluble form.

Arsenic being in the soil, some soluble and some insoluble, very naturally suggests the question as to what effect it has upon the bacteria of the soil. Any factor which influences the bacterial activities must indirectly influence the crop yield.

Extensive studies have been made on the influence of various arsenic compounds upon the bacterial flora of the soil with the result that arsenic was found to be a stimulant in low concentration and toxic only in larger quantities. The extent of stimulation and toxicity varies greatly with the specific type of organism and the form in which the arsenic is applied.

Ammonifiers. - Experiments on ammonifiers show that this class of bacteria are not at first poisoned by the arsenic, but their speed of action is increased. The actual results showed that whereas the untreated soil produced in unit time 100 parts of ammonia, soil to which 60 pounds of arsenic an acre was applied produced 103 parts of ammonia in the same length of time. And it was not until 2500 pounds of arsenic an acre was applied to the soil that the production of ammonia was reduced to one-half. The Paris green, on the other hand, retarded the action of this class of bacteria even in the lowest concentration added, and by the time, 600 pounds an acre had been applied the ammonia produced in unit time had been reduced to one-half normal. This poisonous action of arsenic on bacteria is in a direct relationship to its solubility. An extremely large quantity of lead arsenate would have to be applied to a soil before it would interfere with ammonification.

Nitrification. - The nitrifying flora of a soil are more resistant and are stimulated to a greater extent by arsenic than are the ammonifiers. Tests made in soil have shown that whereas untreated soil produced 100 parts of nitrates in unit time, the same soil to which had been added arsenic in the form of lead arsenate at the rate of 120 pounds an acre produced 178 parts of nitrates. In other words, in place of being injured by the arsenic, the bacteria were nearly twice as active in the presence of this quantity of arsenic as they were in its total absence. It was not until more than 700 pounds of arsenic, in the form of lead arsenate, an acre, had been applied to the soil that the bacterial activity fell back to 100 . Even when arsenic in the form of lead arsenate was applied at the rate of 3500 pounds an acre there was 68 per cent. as much ammonia produced as in the untreated soil. The Paris green gave similar results. The untreated soil produced 100 parts of nitrates in given time, while 
similar soil to which arsenic in the form of Paris green was added produced, under the same condition, 129 parts of nitrates. When, howerer, higher concentrations of arsenic in the form of Paris green were added it became toxic, and eventually stopped all bacterial activity; but the quantity added had to be so large that it is not likely that sufficient would ever occur under agricultural practice.

Arsenic, then, does not injure the ammonifying or nitrifying organisms of the soil. But how about the other beneficial bacteria of the soil? What effect has it upon them?

Nitrogen Fixation.-There are $75,000,000$ pounds of atmospheric nitrogen resting upon every acre of land, but none of the higher plants have the power of taking this directly from the air. Certain bacteria, however, can live in connection with the legumes and assist them to take nitrogen from the air. Then there is another set of nitrogen-gathering organisms which live free in the soil, and which may, under ideal conditions, gather appreciable quantities of nitrogen. It is rather possible that much of the benefit derived from the summer fallowing of land is due to the growth of this class of organisms in the soil and storage by them of nitrogen for future generations of plants. In such soils they are both more active and are also found in greater numbers. All the work put on soil to render it more porous reacts beneficially upon these organisms. They not only require atmospheric nitrogen and oxygen, which are absolutely essential to their life activities, but they must obtain them from within the soil, for the minute organisms cannot live upon the surface of the soil because to them the direct rays of the sun means death. How does arsenic influence this class of organisms which are so beneficial to the soil, but which are so much more sensitive to adverse conditions than are the other kinds of bacteria? Arsenic in the form of lead arsenate, zinc arsenite, and arsenic trisulphid stimulate these bacteria. When arsenic in the form of lead arsenate was applied to the soil at the rate of 500 pounds an acre, the nitrogen-fixing organism gathered twice as much nitrogen in unit time as it did in the absence of arsenic. The Paris green, however, is poisonous to this group of organisms in the minutest quantitics. 'This is most likely due to the copper rather than to the arsenic in the compound.

How Does the Arsenic Act?-It may, therefore, be concluded that arsenic stimulates all the beneficial bacteria. But how does it act? Will it stimulate for a short time and then allow the organism to drop back to its original or to a lower level as does alcohol and various stimulants when given to animals? Will it act as does caffeine-continue to stimulate? From the results on men and horses the former might be expected, for although the arsenic eaters of India and Hungary maintain that the eating of arsenic increases 
their endurance, and there is considerable evidence to indicate this, it is only for a short time. If the use be discontinued the arsenic eaters cannot endure as much physical exertion as can others who are not addicted to the drug. Many European horse dealers place small quantities of arsenic in the daily corn given to the horse, for they find it improves the coat of the horse. If a horse, however, has been doped on arsenic for a long time it seems necessary to continue the practice; otherwise, the animal rapidly "loses his condition."

Similar results might be expected with the bacteria, and experiments have shown that although during the first few weeks the bacterial activity of soils containing small quantities of arsenic is much greater than it is in a similar soil without arsenic, this activity continues to get less and less, until at the end of several weeks it is no greater than in soil containing no arsenic. It is interesting to note that if proper aëration is maintained bacterial activity never becomes lower than in untreated soil.

Now why this stimulating influence of arsenic upon soil bacteria? A similar condition has been found to exist when soils are treated with carbon bisulphid, chloroform, or other disinfectants, or even when the soil is heated. Many theories have been offered to account for it, but probably the most interesting is the one held by Russell and Hutchinson. They maintain that within the soil are microscopic plants, bacteria, and also microscopic animals, protozoa. The minute animals are continually feeding upon the minute plants, with the result that the bacterial plants cannot multiply as they could in the absence of the protozoa. Now when a weak solution of an antiseptic is applied to the soil it kills many of the protozoa, and the bacteria being no longer preyed upon by their natural foe rapidly multiply. As the antiseptic evaporates the few remaining protozoa start to multiply and soon are able to keep in check the bacterial flora of the soil. So within the soil one species preys upon another. It is possible that microscopic forms of life wage within the soil battles as terrific as those waged by the higher forms of life upon the earth's surface.

It is likely that this is one of the ways in which arsenic stimulates the bacterial activities of the soil. It acts more readily upon the protozoa than upon the bacteria. After the arsenic has been in the soil for some time it may become insoluble or some of it may be changed by molds into a gas arsine and pass into the air. Then the few protozoa which have not been destroyed by its presence rapidly multiply and soon hold the bacteria in check.

This, however, is not the only way in which arsenic acts, for pure cultures of the Azotobacter have been obtained from these soils, and it is found that these are so stimulated that they bring about greater changes in the presence of arsenic than they do in its absence. This is due to the action of the arsenic upon these minute specks of living 
protoplasm, causing them to utilize their food more economically in the presence of arsenic than in its absence. This is similar to the influence of the arsenic upon the cells within the horse.

Other experiments have demonstrated that the addition of arsenic to a soil increases the liberation of the insoluble plant-foods of the soil, especially of the phosphorus. 'Thus arsenic by various means stimulates all the bacterial activities of the soil, and these increased activities, as experiments have shown, are reflected in greater crops. This increased growth must be looked upon as due to a stimulus and not to the direct nutritive value of the substance added. Soils so treated would produce larger crops and wear out more quickly than would untreated soils. It is interesting and important to know that arsenic has to be applied to a soil in enormous quantities before it retards microscopic plant life, and probably before it retards the growth of higher plants.

The data available prove conclusively that the arsenical compounds, with the single exception of Paris green, stimulate the nitrogen-fixing organisms of the soil and that this influence varies qualitatively but not quantitatively with the various soils. The results also bring out the fact that both the anion and the cation of the compounds have a marked influence upon the growth of the organisms." With some compounds both the anion and cation act as stimulants, but with other compounds one stimulates and the other retards. It is likely that little or no influence is exerted upon the nitrogen-gathering organisms by the sodium of sodium arsenate and that the stimulating influence noted with dilute solutions and the toxic influence exerted with more concentrated solutions are due entirely to the arsenic. It is rather likely that the stimulating influence which Riviere and Bouilhac have found sodium arsenate to have upon wheat and oats is an indirect effect which is exerted upon the bacterial flora of the soil and which in turn influences the yield of the various grains.

Both the anion and cation undoubtedly act as stimulants in the lead arsenate. Stoklasa has shown that lead when present in soil stimulates the growth of higher plants. This he ascribes to the catalytic action of these elements on the chlorophyll. The results reported indicate that it is due to the influence of the compounds upon the biological transformation of the nitrogen in the soil. The fact that the lead plays no small part in the stimulating influence is borne out by the work of Lipman and Burgess who found lead to stimulate nitrifying organisms.

Paris green is toxic to the nitrogen-fixing organism in the lowest concentration tested. This is due to the copper and not to the arsenic, as it is well known that the copper ion is a strong poison to many of the lower plants. Brenchley found it to be toxic to higher plants when present in water to the extent of one part in 
$4,000,000,000$. Although Russell states that it is not as toxic in soil as in water, Darbishire and Russell found it to be toxic in soils, and they failed to get a stimulating influence with it. Montematini has noted a stimulation with copper sulphate when used in dilute solutions. This, however, may have been due to the anion and not to the cation, as sulphates do stimulate plants by their action on insoluble constituents of the soil. The same interpretation could be placed upon the results obtained by Lipman and Wilson and also those reported by Voelcker in which they noted a stimulation with copper salts. Clark and Gage have found that very dilute solutions of copper have an invigorating influence upon bacterial activity. In order that the stimulation may be noted the copper must be present in small quantities. Jackson found that 1 part of copper sulphate in 50,000 parts of water kill Bacillus coli and Bacillus typhosus. Kellemamn and Beckwith found that the common saprophytic bacteria are more resistant to copper than is $B$. coli. There is considerable evidence that copper stimulates the ammonifying and nitrifying organisms of the soil, but these results show the nitrogenfixing organisms of the soil to be very sensitive to copper, and if it is to act as a stimulant it must be in extremely dilute solutions. The toxicity of the copper in the Paris green is great enough in the dilution of 10 parts in $1,000,000$ to oft set the great stimulating influence of the arsenic in combination with it.

The marked stimulating influence noted where the arsenic trisulphid is used is very probably due to the stimulating action of both the arsenic and sulphur. Demolon attributed much of the fertilizing action of sulphur to its action upon bacteria, and Togel found that sulphur decidedly increased the activity of the nitrogen-fixing organisms. The results which Russell and IIutchinson obtained with calcium sulphid are interesting in this comnection. They found that after thirty days there were five times as many organisms in a soil to which calcium sulphid had been added as in an untreated soil, and the yield of ammonia and nitrates in the same length of time was one-third greater in the treated soil than in the untreated soil. This in turn reacts upon the crop harvested, as shown by shedd.

The first part of the curve for zinc arsenite nearly coincides with that of sodium arsenate, save that zinc arsenite stimulates in greater concentrations than does sodium arsenate. This is partly due to the difference in solubility of the two compounds, but there is another factor-that the zine also acts as a stimulant. Latham found that small quantities of zinc stimulated algax. The same results have been obtained by Silberberg in working with higher plants. Ehrenberg concludes that zinc salts are always toxic when the action is simply on the plant, but that they may lead to increased growth through some indirect action on the soil. IIe found that zinc stimulated plant growth in soils, but when the soil was sterilized the 
zinc became toxic. Lipman and Burgess have shown that it stimulates the nitrifying organisms and that the influence is shown in the crop yield. The great rariation in the results reported by the different investigators for zinc, arsenic, and lead is probably due to the fact that it modifies the bacterial flora of the soil. When heated soil or water cultures are used a different result is noted. This, however, is not the only factor, for these results show a marked difference in soil and in water culture. The lead arsenate stimulates the nitrogen-fixing organisms when placed in soils but becomes highly toxic to the same organisms when placed in nutritive solutions.

The difference is due in part to adsorption by the soil, but this would have to be attributed to the silica compounds of the soil, for the nitrogen-fixing organisms are stimulated by arsenic in quartz sand free from organic colloids. In this case the arsenic becomes

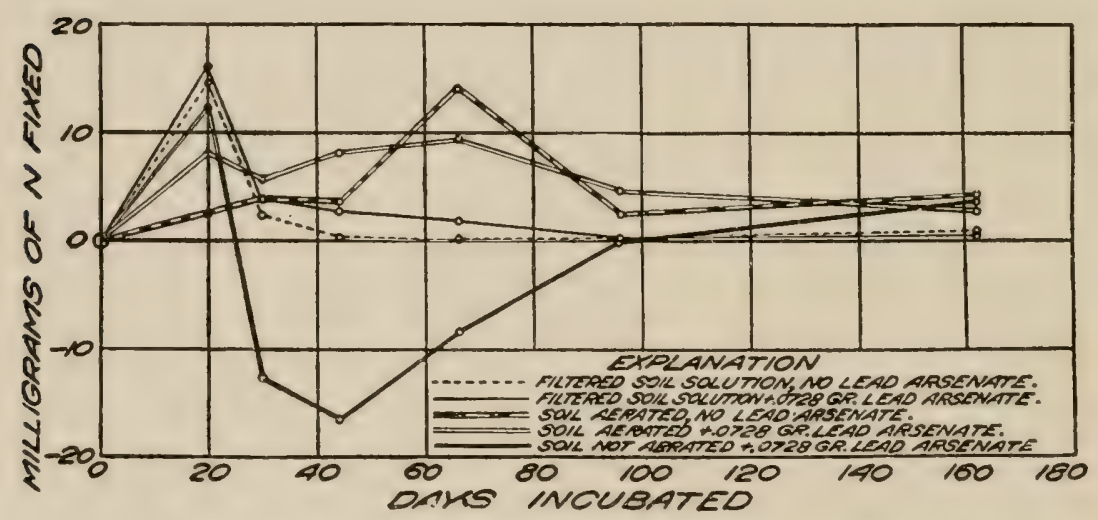

FIG. 18. - Graph showing the effect of aëration on the nitrogen-fixing activity of soilcontaining compounds of arsenic. (Soil Science.)

concentrated at the surface, layers of the silica leaving the inner part of the water film comparatively free from arsenic, in which the microörganisms multiply and carry on their metabolic processes. This being the case, it is probable that a water solution weak enough to stimulate bacteria could be found. A great difference, however, between the solution and the sand-culture method is the greater aëration in the latter than in the former. That the aëration of a cultural medium does play a great part in determining the activity of the nitrogen-fixing powers of a soil is strikingly brought out in Fig. 18.

It is remarkable how the aëration of the soil or the filtering of the soil extract can prevent the high loss of nitrogen which is noted at first in the unaërated soil. This cannot be attributed directly to the denitrifying organisms; otherwise, it would not be removed by filtra- 
tion. The graphs also bring out the fact that adding arsenic and filtering the soil only shift for the time the equilibrium within the soil, which later tends to regain its old equilibrium. This is a condition that coincides well with what would be expected if the limiting element were some other microscopic forms of life. The filter would not separate them quantitatively, and it is possible that the arsenic has only a selective influence. Later, many of the organisms become accustomed to its presence; or, what is more likely, the arsenic becomes fixed within the soil.

That this limiting factor is a thermolabile body is brought out more clearly by Fig. 19. The quantity of nitrogen fixed by the unheated soil receiving no arsenic has been taken as 100 , the heated soil with and without arsenic being compared with this.

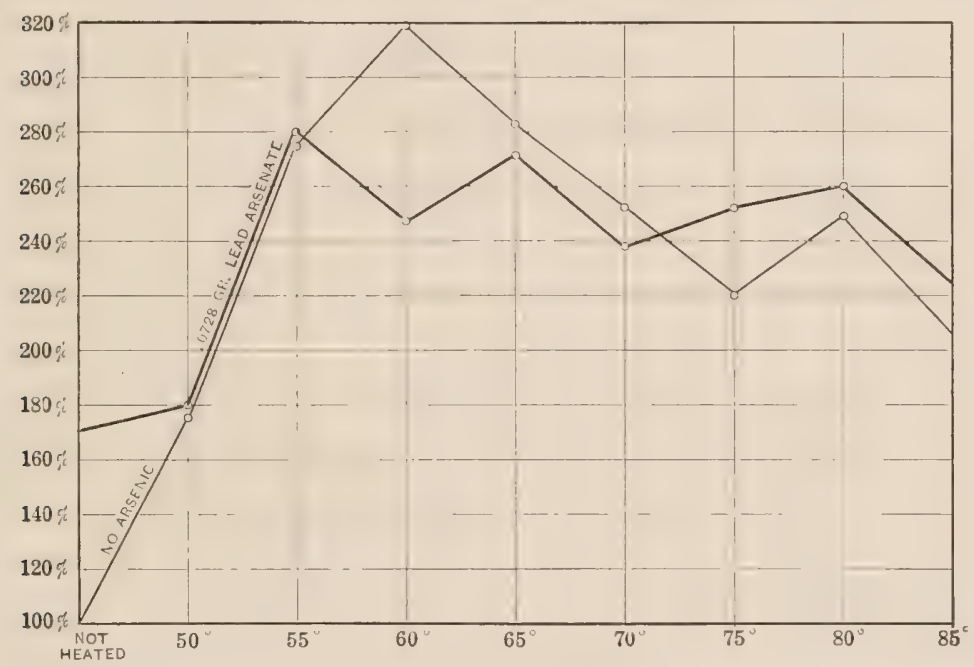

FIG. 19.-Graph showing the effect of the heat on the nitrogen-fixing power of soil treated and not treated with arsenic.

The heating of the soil extract to $50^{\circ} \mathrm{C}$. for fifteen minutes has exactly the same influence measured in terms of nitrogen fixed as does $0.0728 \mathrm{gm}$. of lead arsenate. The stimulating influence of heat is noted even in the presence of arsenic and reaches its maximum effect in the absence of arsenic at $60^{\circ}$, and in the presence of arsenic at $65^{\circ} \mathrm{C}$. Ahove these temperatures there is a decline in the nitrogen fixed. Even soils inoculated with solutions which had been heated to a temperature of $85^{\circ}$ fixed nitrogen; at least there is more nitrogen accumulated in such soil than in that inoculated with the untreated soil solution. The results indicate that many of the organisms which take part in the gathering of nitrogen in soils are very resistant to heat. It is also significant that the greatest stimulating influence 
is exerted in soil which had been inoculated with solutions heated just above that point which Cunningham and Löhnis found to be the thermal death point of soil protozoa.

\section{REFERENCES.}

Greaves, J. E.: The Occurrence of Arsenic in Soils (Bichem. Bull., 1913, ii, 519523).

Greaves, J. E.: Some Factors Influencing Ammonification and Nitrification in Soil (Centr. f. Bakt., Bd. xxxix, Abt. II, 1913, 542-560).

Greaves, J E.: Stimulating Influence of Arsenic upon the Nitrogen-fixing Orgauisms of the Soil (Journal Agricultural Research, 1916, vi, 389-416). 


\section{CHAPTER XIII.}

\section{EFFECT OF HEAT AND VOLATILE ANTISEPTICS ON SOIL BACTERIA.}

SoiLs are often heated, steamed, or treated with volatile or nonvolatile antisepties both for experimental and practical purposes. The process is not sufficient to destroy all forms of life within the soil. It only destroys some of the weaker species and the aim is usually to destroy an injurious species. Yet the process is often referred to as sterilization. In view of the fact that they fail to render the soil sterile, some workers prefer the terms partial sterilization or pasteurization, which more accurately describe the process.

Although it was well known that the kiln-burning of clay produced a far-reaching chemical and physical effect, yet soil investigators considered that the process of sterilization produced no change either in the mechanical nature or chemical composition of a soil until the work of Frank appeared in 1sSS. IIe found that heated soils contained a great deal more soluble matter than unheated soil, peaty soils containing more than twice as much and heated sandy soils not quite twice as much. This increased soluble matter he considered sufficient to account for the increase in crops which was often found to follow the heating of a soil.

A great impetus was given to the work in $189+$ by Oberlin in Germany and Girard in France who found that the application of carbon bisulphid increased the crop-producing power of the soil. Oberlin found that vineyards treated with carbon bisulphid to kill phylloxera showed greatly increased productivity after the treatment, and he founded on this his system of grape culture, where fallowing and rotation could be dispensed with in the resetting of vineyards. Girard noticed that soil treated with carbon bisulphid for the purpose of combating a parasitic disease of sugar-beet was more productive than it was before such treatment. The beneficial influence of the treatment extended even into the second year. These facts stimulated investigation and created much discussion, particularly as to the manner of its action. No working hypothesis was, however, formulated until 1899 when Koch announced his direct "stimulation theory," since which time numerous theories have been formulated to account for the noted phenomena.

Influence on Plant.- The use of carbon bisulphid at the rate of 2904 pounds an acre resulted in a gain of 15 to 46 per cent. in the yield 
of wheat grain and of 21 to 80 per cent. in wheat straw. The yield of potatoes was similarly increased by 5 to 38 per cent. and that of beets from 18 to 29 per cent. Although the yields of the legumes were not always increased, yet some fields of clover treated with carbon bisulphid gave increases of 119 per cent.

Wollny clearly showed that the application of carbon bisulphid to a soil within the growing season may lead, according to the amount introduced, to a complete destruction of the growing crop, or to a temporary retardation merely, involving a greater or slighter depression in the production of plant substance. Its application several months before planting increases the fertility of the soil to a considerable extent. This influence is felt, according to the amount of carbon bisulphid used, through one or several growing seasons, after which if no manure or fertilizer has been applied a marked decrease in the yields becomes evident.

There was the dark green color and the vigorous development of the plants together with the decided tendency of grain crops to lodge just as if too great quantities of nitrogen were at their disposal. These facts led Heinze to conclude that on the whole we must seek the cause of the beneficial effect of carbon bisulphid on the soil in the enormous increase of soil organisms at the proper time, thus rendering available, or possibly increasing, the nitrogen supply to growing plant.

The large amounts of nitrogen thus made available to the crops are derived partly from the soil and partly from the atmosphere. Kruger and Ileinze not only demonstrated that soils treated with carbon bisulphid showed an increase in their total nitrogen content, but also that the increase was the result of the more vigorous growth of the nitrogen-fixing Azotobacter species. This, Heinze considers, resulted from the initial suppression of amid-ammonia formation and nitrification which would create favorable conditions for the development of nitrogen-fixing flora. Later there would be more intense transformation of the bacterial proteins and of other nitrogenous organic substances into amino- and ammonia compounds which would result in a more vigorous nitrification, thus placing at the disposal of the plant an abundant and uniform supply of soluble nitrogen compounds. The various organic materials in the soil-such as plant residues, pectins, pentosans, humic substances, and the like, together with the rapid growth of alga and moldsmay furnish the carbon food for the Izotobacter species.

Effect on Properties of Soil.--Egorow, who investigated the effects of carbon bisulphid upon the physical properties of the soil, found that (1) the capillary rise of water in the soil treated with carbon bisulphid to be slower than in the untreated; (2) the moisture content is reduced considerably, especially in peaty soils; and (3) the waterholding capacity of the soil is decreased. Thus, he concludes that 
the treatment of soils with carbon bisulphid acts unfavorably upon the water content of the soil.

Other characteristic effects of treatment with volatile antiseptics reported by yarious investigators are:

1. An initial decrease in the number of bacteria followed by a long-continued increase. A careful piece of experimentation illustrating this is that of Fred who used loam soil (mixed with sand) and found that 2 per cent. carbon bisulphid has little effect upon the moisture content of the soil. With varying percentages of ether (together with 2 per cent. of sugar) in the soil, he finds an initial depression in bacterial numbers followed by a considerable increase in eight hours, 4 per cent. giving the maximum count.

2. A disturbance of the equilibrium of the bacteria, by which certain types multiply more rapidly than others. Hiltner and Störmer found that under normal conditions there is a certain equilibrium established among the various groups of soil bacteria, and that the organisms capable of growing on meat extract gelatin are composed of Streptothrix species 20 per cent., gelatin-liquefying species 75 per cent., and the non-liquefying species 5 per cent.

When carbon bisulphid is applied to a soil, its bacterial inhabitants are injured, though not completely destroyed, the injury varying with the changing conditions of temperature, moisture, and amount of carbon bisulphid applied, as well as with the duration of its action. Not all of the bacterial species are depressed in their development to an equal extent, the injury being most pronounced in the streptothrix species and least pronounced in the gelatin-liquefying species. The depressing action of carbon bisulphid disappears after a shorter or longer interval and is followed by a rapid multiplication of the microörganisms in the soil. The equilibrium having been destroyed, however, the new development follows along different channels, and there occurs not only an enormous increase in the total number of soil bacteria, but also an abnormal predominance of certain species. The new conditions thus established for a time favor a more ready utilization of the stores of soil nitrogen, and likewise the fixation of atmospheric nitrogen by certain bacterial species. These conclusions are borne out by the work of Lipman and Brown who examined abnormal soil after applying carbon bisulphid in various quantities alone, and in combination with muriate of potash and acid phosphate. They then determined the ammonifying, nitrifying, denitrifying, and nitrogen-fixing powers of the soil. They concluded that in normal soil flora the different groups occur in fairly definite relations which are evidently disturbed by the addition of carbon bisulphid, which, destroying the bacterial equilibrium prepares the way for an entirely new bacterial development whereby certain species become far more prominent than previously. This applies especially to the nitrifying and nitrogen-fixing bacteria. 
3. A slight initial increase in ammonia content, followed by a considerable increase in the production of ammonia. This, although noted by the majority of workers, is especially brought out by the work of liussell and IIutchinson, as is illustrated by the following results from their work:

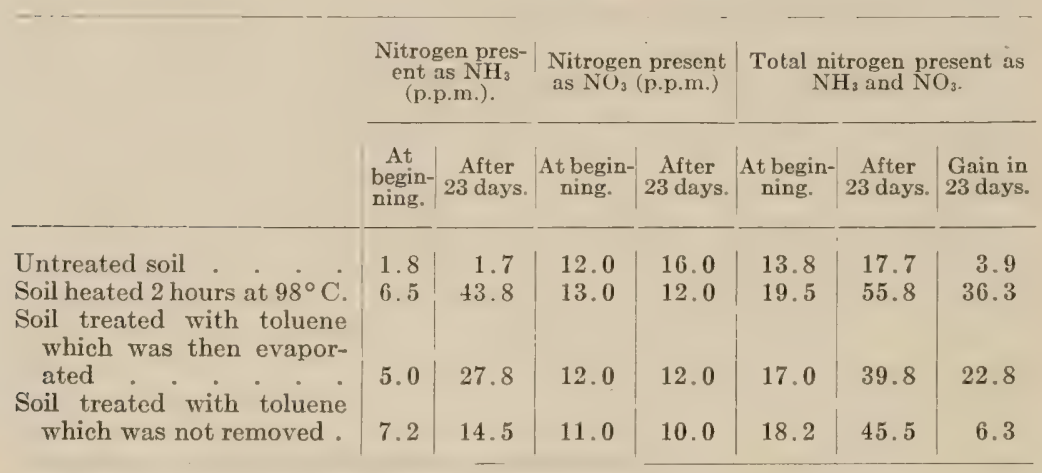

4. A depression of the processes by which ammonia is converted into nitric acid, and a very slow recovery of the activity of the bacteria concerned, as a result of which ammonia accumulates in the soil. Warington, in his early investigation on the biological nature of nitrification, observed that when air containing carbon bisulphid was passed through the soil the process was inhibited, whereas C. de Briailles noted that during the winter the carbon bisulphid seemed to exert a hamful influence on the accumulation of nitrates. IHowever, with the first open weather in spring the reverse seemed to be true - the carbon bisulphid caused a marked increase in nitrates over the untreated.

5. An increase in the rate at which oxidation takes place in the soil. In a study of oxidation in soils and its relationship to productiveness, Darbishire and liussell found that the absorption of oxygen by soil is mainly brought about by the action of microorganisms and is greatly diminished if the soil has been previously heated to $120^{\circ} \mathrm{C}$. When heated to $95^{\circ} \mathrm{C}$., it was found that the rate of oxidation on a sand, two loams, and a chalky soil, instead of being reduced was considerably increased, as was the case after treatment with and removal of volatile antiseptics, such as toluene, chloroform, carbon bisulphid, and other volatile antiseptics.

The rates of oxidation of heated soils were as follows:

Hop garden soil, unheated Milligrams of oxygen absorbed in
3 days. 6 days.

Hop garden soil, heated to $95^{\circ} \mathrm{C}$

3.7

5.2

7.0

Garden soil, unheated

6.0

8.2

12.0

Garden soil, heated to $95^{\circ} \mathrm{C}$.

7.5

10.2

27.2 
6. It has been repeatedly demonstrated by many workers that both heat and antiseptics destroy all or part of the protozoa found in the soil, depending on the degree of heat applied or the strength of antiseptic used.

7. Some workers have found antiseptics and heat to depress denitrification in soil. Both Wagner and Morgan found that carbon bisulphid kills denitrifying organisms.

8. Especially significant is the fact that there is a considerable increase in the soluble matter in the heated soil, not only of inorganic matter, as phosphorus and potash, but even more in the organic matter made soluble. Stoklasa holds that the plants are able to get more phosphate-ions from a soil as a result of the disintegration of the bacteria killed by the treatment with carbon bisulphid.

Fred found that the application of carbon bisulphid to a soil increases the insoluble compounds of nitrogen and sulphur as well as the bacterial activities. Lyon and Bizzell determined the effect of sterilizing soils by steam on the water-soluble material and found that steaming the soil at two atmospheres reduced the nitrates to nitrites and ammonia, but that most of the ammonia is formed from organic nitrogen in the soil.

9. Although the majority of workers report an increase in nitrogen fixed in a soil treated with carbon bisulphid, yet Koch reports cases in which carbon bisulphid added to a soil containing fairly large quantities of cane sugar has resulted in a weakening rather than in a strengthening of their nitrogen-fixing powers. The increase in nitrogen fixation may at times be rery pronounced, as may be seen from the following experiments in which tumblers containing soil were all carefully sterilized and half of them placed in the incubator in the sterile condition. To the others was added a soil extract prepared by shaking one part of soil with two parts of sterile distilled water for three minutes. After standing for about five minutes the liquid was decanted and 10 c.c. portions were used to inoculate the soil. Before inoculating, this extract was placed in thin-walled test-tubes in 10 c.c. portions and then kept at the required temperature for exactly fifteen minutes before adding to the soil. The moisture content was made up to 18 per cent. and the whole incubated for twenty days. The milligrams of nitrogen fixed under the varying treatments were as follows:

Temperature of soil extract $\left({ }^{\circ} \mathrm{C}.\right)$.

Milligrams nitrogen-fixed.

Roo
50
55
60
65
70
75
80
85

5. 11

9.00

14. 14

16. 38

14. 42

13. 02

11. 34

12. 66

10. 36 
10. Although strongly contested by many experimenters, there are some workers who have produced strong evidence that the heating of a soil destroys toxins which have been formed in it due either to bacterial activity or to plant growth. Fletcher grew plants in a nutrient solution until he considered it to be made toxic by plant excreta. He then steamed it at a pressure of 150 pounds for two hours. Flakes of an organic substance were thrown down, which did not dissolve on removal of pressure. This substance he considered to be the toxic excreta.

The principal changes produced in and by sterilizing soil are thus summarized by Johnson:

I. Destruction of Life:

(a) Normal soil flora and fauna, desirable and undesirable forms of bacteria, fungi, protozoa, and higher animals.

(b) Plant parasites, especially pathogenic bacteria, fungi, nematodes, and injurious soil-infection insects.

(c) Propagative organs of higher plants, especially weed seeds.

II. Immediate Chemical Action (formation of toxic and beneficial compounds) :

(a) Decomposition of organic material resulting in the formation of ammonia, carbon dioxid, and various new and complex organic compounds.

(b) Decomposition of inorganic material, reduction of nitrates and nitrites to ammonia and increased solubility of potassium, phosphorus, and other salts.

III. Biochemical Action:

(a) Increased ammonification, particularly, and modified nitrification, denitrification, and nitrogen-fixation.

IV. Physical Action:

(a) Absorption capacity of soil modified for water, gases and salts.

(b) Increased concentration of soil solution.

(c) Modified capillarity, colloidal state, and mechanical condition.

(d) Modified color and odor.

V. Action on Organisms Growing in Sterilized Soils:

(a) Lower organisms.

1. Increased development due to reduced competition, increased food supply, destruction of "bacterio-toxins," "stimulation," by products added or formed, or other causes.

2. Retardation in growth in rare cases due to injurious conditions produced. 
(b) Green plants.

1. Injurious action as indicated by retarded rate and percentage of seed germination and by retarded rate of plant growth.

2. Beneficial action as shown by increased rate and percentage of seed germination and increased rate and amount of plant growth.

3. Modified in form, color, and other "qualitative" changes.

Hypotheses to Account for Observed Phenomena.-A number of hypotheses have been formulated to account for the increased plant growth and for the many changes produced in soils by treatment with heat and volatile antiseptics. A number of these theories are considered, but it must be borne in mind that there is a wide disagreement among workers as to the real cause. No single hypothesis yet formulated can be said to fully account for all of the observed phenomena.

Koch's "Direct Stimulation" Theory. - The first theory offered to account for the increased yield obtained from soils treated with an antiseptic was the "direct stimulation" theory advanced by Koch in 1899. He considered carbon bisulphid to have a direct stimulating effect on the plants themselves. He later found ether to have a similar effect. In experiments dealing with the addition of ether to the soil Koch found that the increased yield was pronounced on the first crop, whereas the residual effect was slight, as with carbon bisulphid the beneficial effect increases with the amount of application. He further found that soils sterilized with heat produced better crops when treated with carbon bisulphid than when not so treated and concludes that the effect of the antiseptic, therefore, cannot be due to its effect on bacteria.

The theory of Koch has been supported by Fred who fertilized soil with an abundant supply of sodium nitrate and found that in every case in which carbon bisulphid was added the growth and yield of crop were much superior to those in the corresponding pots not treated with that substance. He concludes that as there was no lack of plant-food and other conditions were favorable to plant growth, the effect of the antiseptic must have been directly upon the plant. There is ample evidence to prove that many of these antiseptics in dilute solutions stimulate the plants directly, yet there is no evidence which will substantiate the claim that this is the only or even the principal influence on the plant and soil.

Hiltner and Stormer's "indirect" theory of antiseptic action is outlined by them as follows:

"1. By destroying the existing bacterial equilibrium in the soil, the carbon bisulphid opens the way for an entirely new bacterial development. This is achieved through the unequal retardation 
in the growth of the different groups of bacteria. IIence, certain groups become disproportionately prominent, while others are almost entirely suppressed.

"2. The rapid increase in the numbers of the bacteria is followed by a more intense transformation of plant-food substances. Decomposition and fixation processes result in an accumulation of readily available nitrogen compounds utilized by the crops. Hence, the action of carbon bisulphid is in the nature of nitrogen action.

"3. The initial suppression of the nitrifying species becomes of advantage in that the nitrogen compounds, simplified by other species, are prevented from being rapidly changed into nitrates and being leached out of the soil.

" $t$. The more or less permanent suppression of the denitrifying. organisms must be regarded as an additional factor favoring plant growth.

"The introduction of the poison into the soil at first decimates its bacterial flora, but with the disappearance of the injurious carbon-bisulphid vapors it also encourages a vigorous and longcontinued increase of the organisms, resulting in an increase of the store of more readily available nitrogen. It is still to be determined whether this increase is largely due to the fixation of atmospheric nitrogen or to the unlocking of the vast store of combined nitrogen in the soil. It is most probable, however, that even though one of these processes predominates the other is surely more extensive than it would be in normal soil. The nitrogen thus secured is not at once made accessible to the higher plants, but is at first laid fast in the bacterial bodies. This assumption would best explain the fact that plants growing upon a soil treated with carbon bisulphid show retarded growth, even some time after the application of the latter, and the explanation hitherto accepted that the injury results from the direct action of the poison seems hardly reasonable after our discovery that the most intense bacterial activities are asserting themselves just at that time. The nitrogen fixed in the bacterial bodies is gradually rendered soluble by decomposition processes, and thereby made accessible to nitrification and the higher plants. Hence, when the carbon bisulphid is applied in the fall, there is enough time left until the planting of the following spring crop for the mineralization of the bacterial nitrogen. It is quite evident, of course, that the nitrogen combined in the bodies of generations of bacteria is not all made soluble within a single year, but only in the course of several growing seasons, so that we may readily account for the increased harvests secured for two or more successive years after strong applications of carbon bisulphid, even though the bacterial transformations had by that time declined. The exhaustion of the soil finally manifesting itself after a shorter or longer time may be explained by the deep-seated changes in the bacterial soil 
flora, which does not return so easily to its normal state. It is quite possible that the return to the normal conditions is prevented by the exhaustion for years to come of the more available portions of the plant nutrients."

Evidence corroborating this theory has been brought forward by Heinze, Stoklasa, Lipman, and Brown, whereas Sirker furnishes evidence in the cultivation of the mulberry which opposes it. He found that the addition of carbon bisulphid to a completely fertilized mulberry plant increases the vegetation $4 t$ per cent., whereas a heavy application of sodium nitrate was of slight value.

Russell and Hutchinson's Protozoan Theory.-They consider that the microscopic flora of the ordinary arable soil includes a wide variety of organisms performing very different functions which may be divided roughly into two classes: $(a)$ saprophytes, tending to increase the fertility of the soil, for example, producing ammonia, fixing nitrogen, and similar changes; and $(b)$ phagocytes and large organisms inimical to bacteria which limit fertility. Between these two classes of organisms there is an equilibrium under natural conditions, but when partial sterilization takes place the phagocytes are killed but the bacterial spores are not; and subsequently the latter develop with great rapidity, since they are freed from the attacks of their enemies, and there is an increase not only in ammonia but likewise in crop production.

In support of this theory they point out the following: "In untreated soil there is no accumulation of ammonia, whereas the 'toluene evaporated' soil, as well as the soil heated to $98^{\circ} \mathrm{C}$., show an increased production of ammonia. That this is mainly the work of microörganisms is proved by the following considerations: $(a)$ The curves belong to the type associated with bacterial, rather than with purely chemical activities. (b) Soil which has been heated to $125^{\circ} \mathrm{C}$. (at which temperature all organisms are killed) behaves altogether differently; after the first production of ammonia due to heating there is no further change. (c) If the toluene is left in the soil there is only a slow production of ammonia, and never a rapid rate; the curve is more nearly linear. The action of microorganisms is here excluded, but enzymes may still act. (d) The rapid period sets in only when the soil is sufficiently moist. Thus the two significant changes induced by partial sterilization are, (1) an increase in the amount of ammonia; and (2) cessation of the nitrifying process.

"It now becomes necessary to determine the part played by" bacteria, and why they can increase so much more rapidly in the partially sterilized soil (which accounts for the increased ammonia production) than in the untreated soils. That the comparative inertness of the bacteria in the untreated soil cannot be caused by any bacterial factor is evidenced by the following considerations: 
(a) If a filtered soil extract containing bacteria from an untreated soil is added to a toluened soil, there is an increase in the rate of ammonia production, and also in the number of bacteria. (b) Ilowever, if untreated soil is added to toluened soil, there is no increase, but on the contrary a reduction. (c) As pointed out above, an extract of the toluened soil is more active than an extract of untreated soil. (d) But when the extract of toluened soil is added to the untreated soil there is no increase in ammonia production.

"The conclusion drawn is that the untreated soil contains a factor, not bacterial, limiting the development of bacteria, this factor being put out of action by toluening or heating.'

"Having determined the presence of a limiting factor in untreated soils an examination of its nature reveals that: $(a)$ it is not a toxin, for if it were it would be sure to affect the nitrifying bacteria most; (b) barley seedlings grown in aqueous extracts of untreated and toluened soils showed no difference in growth over a period of four weeks; (c) the limiting factor is probably biological, for when untreated soil is added to toluened soil the reduction in the rate of ammonia is not at once operative. It is also a large organism, since it is only in the soil and not the filtered extract of the untreated soil that is effective in reducing the rate of ammonia production in toluened soil. An examination of treated and untreated soil was made, and the latter revealed the presence of large organisms, protozoa, etc., which constitute the factor, or one of the factors, limiting the bacterial activity, and therefore the fertility of untreated soil. Direct evidence is furnished by inoculating toluened soil or soil extract with cultures of large organisms and studying the effect produced - which is a consequent depression in the rate of ammonia formation."

Although accepted by many workers, there are many of what appear to be fatal objections that have been brought against this theory: (1) It has been demonstrated that the soil contains many species of fungi which are capable of producing considerable quantities of ammonia' and these would withstand the actions of the antiseptic or partial sterilization by heat and may develop later and produce large quantities of ammonia. (2) There may be a great difference in the physiological efficiencies of the surviving ammonifiers. (3) The work of Russell and Iutchinson does not consider the probability of the protozoa being in soil as cysts. (4) The direct laboratory work of Fred and Gainey cannot be interpreted in the light of this theory. Kopeloff and Coleman analyze the work of Fred in the light of the protozoan theory as follows:

"In order to test the validity of Russell and Iutchinson's conclusion that the absence of protozoa (by treatment with toluene) is responsible for increased production of ammonia, Fred, using ether instead of toluene, subjected one series of flasks containing 
compost soil to $100^{\circ} \mathrm{C}$. moist heat for an hour and used a similar series, unheated, as a check. All the flasks received 0.2 per cent. ammonium sulphate-some of the flasks received 2 per cent. and 5 per cent. ether. In order to obtain vigorous nitrification 170 c.c. of amebrefree extract was inoculated into all the flasks. (This was prepared by leaching $2 \mathrm{~kg}$. of compost soil and 4 liters of sterile water and filtering through filter paper; the microscopic examination revealed the presence of no amebæ.)

"The analyses for nitrate nitrogen were made at the beginning of the experiments and at the end of 100 and 150 days, respectively; the results showed that heating the soil to remove amebre did not have a beneficial effect upon nitrate formation, contrary to Russell and IUtchinson's work-although the addition of a small amount of ether increased nitrification in the flasks containing amebr, and had the opposite effect in the soil free from amebre. This, the authors believe, may be accounted for by the stimulating effect upon the nitrifying bacteria, since the heated soil not treated with ether showed no such increase.

"Fred concludes (in addition to the above mentioned observations) that ether and carbon bisulphid cause an increased fixation of nitrogen in pure cultures of Lzotobacter. The development of denitrifying organisms is hindered for only a short time, because of treatment with antiseptics. Both 1zotobacter and denitrifying organisms are insignificant in a normal soil. Nitrification is at first inhibited and later accelerated by antiseptics, while toxins remain unaffected by treatment. Carbon bisulphid and ether cause an increase in crop yield under sterile conditions.

"He holds that the increased growth of plants following the use of antiseptics in the soil depends essentially upon the stimulation to the plant itself, in combination with a similar effect on the lower organisms.

"Fred's work is highly suggestive, but the determination of nitrogen produced is in the form of nitrates alone, and no data are set forth concerning ammonia. That this might aflect his results is evident when one takes into consideration the fact that most investigators have proved that nitrification is depressed by antiseptics.

"Furthermore, like many other experimenters he does not consider the possibility of protozæ cysts passing through the filter paper in the preparation of 'amebæ-free extract.' And we have found in our experimental work that cysts do pass through several thicknesses of high-grade filter paper.

"In much the same manner, Gainey concludes that investigations relative to the effect of toluol and carbon bisulphid upon the microflora and fauna of the soil, that: (a) small quantities of carbon bisulphid, toluol, and chloroform, such as have been used practically and experimentally, when applied to soils studies, exert a stimulative 
rather than a diminishing effect upon the total number of bacteria present; (b) an application of such quantities of toluol and carbon bisulphid does not have an appreciable effect upon the number of types of protozoa present; $(c)$ a very marked increase in yield may be noted following such an application when no evident change occurs in the total number of bacteria present."

Greig-Smith's Bacteriotoxin Theory. - A widely different theory from any so far considered is that advanced by Greig-Smith. IIe considers that when disinfectants are added to the soil their action is two-fold: They kill the less resistant bacteria and dissolve from the surface of the soil particles a waxy covering to which he has given the name "agricere." The surviving bacteria, which he assumes are the beneficial ones, are then able to function much more rapidly on account of the exposure of the food due to the removal of the "agricere."

Moreover, he considers that there is a toxin contained in the soil which is soluble in dilute saline, partially destroyed by heating to $94^{\circ} \mathrm{C}$., and rapidly decayed in aqueous solution; boiling water converts it into a nutrient, or by destroying the toxin enables the nutrients dissolved in the saline to act. Thus, heating the soil destroys the bacteria toxin, which accounts for enhanced fertility. Bottomley and others also claim to have found soluble bacteriotoxins in soils. Russell and Hutchinson, on the other hand, obtained wholly negative results, and conclude that soluble bacteriotoxins are not normal constituents of soils, but must represent unusual conditions wherever they occur. Not only could no experimental evidence of the existence of bacteriotoxins be obtained, but Russell and Thaysen showed that the assumption of toxins leads to difficulties. It is necessary to suppose that heating fresh soil for fifteen minutes is sufficient to produce toxins but not to destroy them, whereas heating for sixty minutes both produces and destroys them, and in the case of air-dried soils fifteen minutes' heating causes their decomposition.

\section{REFERENCES.}

Vorhees, E. B. and Lipman, J. G.: A Review of Investigations in Soils Bacteriology (U. S. D. A. Off. Exp. Sta. Bul. 194).

Löhnis: Handbuch der Landwirtschaftlichen Bakteriologie.

Kopeloff, Nicholas and Coleman, D. A.: A Review of Investigations in Soil Protozoa and Soil Sterilization, Soil Science, 1917, iii, 197-269.

Johnson, James: The Influence of Heated Soils on Seed Germination and Plant Growth, Soil Science, 1919, vii, 1-103. 


\section{CHAPTER XIV.}

\section{TIIE INFLUTENCE OF SALTS ON THE BACTERIAI, ACTIVITIES OF THE SOIL.}

SALTS that occur naturally in soils and those applied to them in various operations influence the number, species, and activity of the soil microflora. These factors are in turn reflected by yields obtained. Some substances applied to a soil serve as food for the growing plant; others increase plant growth but not through the direct furnishing of food. This latter effect may be due to a change brought about by the salt on the physical, chemical, or bacterial properties of the soil. The substance may alter the physical properties of the soil to such an extent that the bacterial flora is modified; this in turn may increase or decrease the crop produced upon the soil. Other substances may react chemically with constituents within the soil and in so doing liberate substances which ean be directly utilized by the growing plant. Again, they may directly modify the microflora and microfauna of the soil both as to numbers and physiological efficiency. In some cases all three changes may be wrought by the same salt. 'The question, therefore, arises as to what effect this or that fertilizer or soil amendment is going to have upon the bacterial activity of the soil. Furthermore, there are millions of acres of land in arid America which contain varying amounts of soluble salts. Some of these soils contain such large quantities of these so-called "alkalies" that no regetation is found upon them. Other soils contain only a medium amount of soluble salts and the regetation is composed chiefly of alkali-resisting plants. Still other soils contain much smaller quantities of soluble salts and they become injurious only when the soil is improperly handled. The reclaiming of the heavily charged soils and the maintaining of the others in a productive condition can be carried on successfully only when we understand the influence of salts upon the growing plants and their action upon the biological, chemical, and physical properties of the soil.

Calcium C'arbonate.-Much work has been done to determine the influence of calcium carbonate, especially when applied to acid soils, on the bacterial content and activity of the soil, but the conclusions reached have not always been concordant. Withers and Fraps found that calcium carbonate added to a soil greatly accelerated nitrification and that it is especially desirable that it should be 
added where ammonium sulphate is being used as a fertilizer. Lipman's work showed that calcium carbonate stimulated nitrification more than did gypsum, that sodium chlorid was injurious to nitrifying organisms, and that ferrous sulphate in amounts from 10 to 100 mg. per $100 \mathrm{gm}$. of soil was without effect. Later, he and Brown decided that both ammonification and nitrification were promoted by magnesia lime to a more marked extent than they were by nonmagnesia lime. 'This, however, was to a certain extent dependent upon the treatment and crop growing on the soil. Both ammonification and nitrification were accelerated by sodium nitrate. In a more recent work Lipman, Brown, and Owen found that smali applications of calcium carbonate stimulated bacterial activity, whereas large applications had a detrimental effect upon ammonification.

In Owen's experiments, magnesium carbonate was more efficient in promoting ammonification and nitrification than was either calcium or potassium carbonate. According to Engberding ammonium sulphate, sodium nitrate, potassium nitrate, and caustic lime all increase the bacterial content of the soil, but decrease its nitrogenfixing powers. Kruger's work indicated that calcium carbonate was more effective in promoting nitrification than was lime, the reverse being true with regard to the putrefactive bacteria. The formation of ammonia from peptone was especially favored by calcium carbonate. Lyon and Bizzell found that lime favored nitrification, as did also certain nodule-bearing legumes. Fischer concluded that the presence of calcium carbonate in a nutritive solution favored the formation of protein nitrogen, but magnesium carbonate lessened the transformation of ammonia into protein nitrogen. Calcium oxid, however, exerted a much greater influence upon soil bacteria than did calcium carbonate.

Kellermann and Robinson's results are of especial interest as they indicate that magnesium carbonate, applied in amounts exceeding 0.25 per cent. to a soil fairly high in magnesium carbonate, positively inhibited nitrification, whereas calcium carbonate up to 2 per cent. favored it, thus indicating that the lime-magnesia ratio is of great importance with regard to bacteria as well as the higher plants. These results have been confirmed by C. B. Lipman and Burgess in whose experiments magnesium carbonate was highly toxic both in soil and in solution to 1zotobacter chroöcoccum, while calcium carbonate was never toxic even in quantities up to 2 per cent. Furthermore, calcium carbonate exerted a protective influence against the toxic properties of magnesium carbonate. The optimum ratio varied, depending upon the medium.

Peck studied the influence of a number of salts upon bacterial activity when applied to the soil, with the result that the carbonate, sulphate, and phosphate of calcium were found to stimulate ammoni- 
fication, while sodium nitrate depressed it; both potassium sulphate and calcium carbonate accelerated nitrification in soil. Brown, working with a typical Wisconsin drift soil, found that the application of ground lime up to 3 tons an acre increased the number of bacteria in the soil, and also the ammonifying, nitrifying, and nitrogen-fixing powers of the soil. The increase was in every case nearly proportional to the limestone applied.

At times the increase noted in ammonification is due to the retention of the volatile ammonia by the carbonate, as is shown by Lemmermann's results where the addition of calcium carbonate to a soil up to 1 per cent. reduced the volatilization of ammonia, but calcium oxid had the opposite effect. Both calcium chlorid and calcium sulfate reduced the loss of ammonia, but the chlorid was the only salt of magnesium tested which had this effect. Potassium and sodium chlorids, sulphates, and carbonates all reduced the absorptive powers of the soil. Paterson studied the influence of a number of substances upon nitrification with the result that caustic lime was found practically to stop all nitrification. Calcium carbonate promoted it, as did also magnesium carbonate; gypsum was less effective, while ferric hydrate had a decidedly farorable effect. Sodium chlorid, on the other hand, had a distinctly injurious effect.

Kelley studied the effect of calcium and magnesium carbonate alone and in combination upon ammonification and nitrification. In his work calcium carbonate only slightly stimulated ammonification of dried blood, but it had a marked stimulating effect upon nitrification. The magnesium carbonate was found to be toxic to both groups of organisms. No antagonism was found to exist between calcium and magnesium. Later, when working with Hawaiian soils, he reports a stimulation for both. The results, however, varied with different soils, and he considers the limemagnesia ratio of little importance as regards the ammonifying and nitrifying organisms. Allen's conclusion is that large quantities of limestone must be applied to a non-calcareous soil in order to bring its nitrifying powers up to those of natural calcareous soils.

Lime.-Peterson and Wollny found that lime increased the carbon dioxid given off by soils, and Ebermayer, Hilgard, and Hartwell and Kellogg proved conclusively that lime increases the decay taking place in a soil.

Chester showed that lime increased the number of bacteria in soil, the increase being proportional to the lime applied up to 4000 pounds an acre. He considered the effect as being due to the lime giving to the soil a more favorable reaction for the growth of bacteria and not to its direct action upon the organisms themselves.

Lime not only increases the number of organisms in a soil, but it increases the ammonifying powers of the soil, as is seen from the work of Remy, Ehrenberg, Vorhees, and Lipman. 
The literature dealing with the influence of lime upon the nitrifying organisms is so voluminous that no attempt is made here to refer to all of it. In most cases the experiments were conducted on soils which were acid and the lime supplied neutralized the acidity of the soil, thus giving the necessary neutral medium for the action of the nitrifying organisms. Such results give little if any idea of the direct stimulating or toxic influence of calcium. Furthermore, the work has recently been summarized by Brown who concludes that the application of lime increased nitrate production from ammonium sulphate and dried blood, the gain being almost proportional to the quantity of lime applied. This, in turn, was found to bear a close relationship to the number of organisms developing on synthetic agar.

Gypsum.-Gypsum is a strong soil stimulant and in most cases it greatly increases the crop yield. The beneficial effect may be due to its liberating potassium or supplying sulphur for the direct nutrition of the plant. At other times it may react with the ammonia formed by the ammonifying organisms, the ammonium sulphates formed being readily nitrified. There is also the possibility that calcium sulphate acts as a direct stimulant to the microörganisms of the soil. The literature is meager and inconclusive on this phase of the subject.

Severin concludes from his work that gypsum not only prevents the loss of ammonia from manure, but it increases the speed of decomposition from 10 to 20 per cent., while Paterson states that gypsum slightly increases nitrification in soil, as determined by laboratory experiments. Prior to this Pichard had shom that the sulphates of calcium, potassium, and sodium promote nitrification.

Opposite results are reported by Dezani who found that gypsum in amounts varying from 0.5 to 2 per cent. had no appreciable effect on nitrification. The results obtained by Lipman and others varied and were inconclusive.

Calcium Chlorid. - According to Lipman calcium chlorid in solutions accelerated the action of ammonifiers. It is interesting to note that in a later work he failed to find antagonism between either calcium and magnesium or calcium and sodium. The chlorids of calcium, magnesium, potassium, and sodium were found to be toxic in the order named. Marked antagonism exists between calcium and potassium magnesium and sodium, and potassium and sodium. Sea water was found to be a phesiologically balanced solution for Bacillus subtilis.

Iron Sulphate.--Nany writers have made great claims for iron sulphate as a fertilizer. A goodly number of these have been made by individuals who wished to profit by its sale, but even when these cases are ignored there are still many cases in which it has produced good results. The composition of the crop usually indicates that 
iron sulphate influences the phosphorus metabolism of the plant. It is hard to see how this is possible unless it be that the iron stimulates the bacterial activity, which in turn liberates phosphorus from its insoluble forms within the soil. It has already been noted that Lipman found ferrous sulphate to have but little effect upon nitrification, but his results were not conclusive. Guffroy found sulphate of iron decidedly beneficial to oats, less beneficial to rye, without action on rye-grass, and harmful to wheat. He concluded that its action must be due to its influence on the biological processes of the soil. According to Paterson and scott, ferric hydrate has a distinctly beneficial effect upon nitrification. In this latter case its action could be due to its serving as a base. According to Lipman and Burgess the ammonifiers are more sensitive to iron sulphate than are the nitrifiers, for though small amounts of iron sulphate stimulated the latter, it was toxic to the former in all concentrations tested.

Magnesium Salts.-Magnesium compounds usually stimulate bacterial activities to a greater extent than do calcium compounds, as has been noted in some of the literature already cited, Engberding's results, however, showerl that, while magnesium sulphate stimulated bacterial activities, it was not as effective in this regard as was ammonium sulphate, sodium nitrate, or potassium sulphate. The work of Makrinov is of interest since he found pure magnesium carbonate a very suitable substance on which to grow the nitrous organism. Furthermore, magnesium carbonate had a strongly beneficial effect on the physiological action of the organism. Kellermann and Robinson, on the other hand, found that magnesium carbonate when applied to a soil already rich in magnesium carbonate positively inhibited nitrification if the quantity arded exceeded 0.25 per cent. This is an apparent contradiction, but it may be due to the different conditions of the experiments, since one investigator was working with culture of the organisms whereas the other was using the soil with its complex flora. Furthermore, it is quite possible that magnesium carbonate may be without effect upon or even accelerate the growth and activity of the Nitrosomonas and yet inhibit the Nitromonas.

Manganese. - Some experiments by Skinner and Sullivan demonstrate that manganese acts in various ways as a fertilizer. It is often without influence, occasionally injurious, but usually beneficial, its effect depending apparently upon the composition and character of the soil. The oxidation in soils under treatment with manganese salts was also studied and it was found that an increase in oxidation and growth frequently oceurred in aqueous extracts of poor, unproductive soils. Although oxidation was increased in fertile soils, growth was decreased, the plants showing indications of excessive oxidation. Field experiments showed practically no 
effect due to the manganese salts, but the soil was acid, a condition which may have accounted to a considerable degree for the nature of the results.

It is suggested that when the action of manganese is beneficial, "it is probably due (1) to the increased oxidation produced in the plant roots whereby the plant is stimulated to greater activity and to increased absorption of the material useful for its growth and general metabolism; (2) to the stimulation of the activity of microorganisms in the soil; (3) to an increased oxidation within the soil."

The same authors also suggest that when large applications of manganese have been found to be injurious, the injury is undoubtedly due to the "excessive stimulation and excessive oxidation in microörganisms and in the plant, with a resulting change in the biochemical activities of plant and microörganisms and in the conditions of inorganic and organic soil constituents, the ultimate result of which change is injurious to the growing crop."

Montanan found that manganese carbonate, sulphate, and dioxid greatly stimulated nitrification, but attributed it to either the direct or the indirect furnishing of oxygen to the nitrifying organisms, and not to any catalytic effect of the manganese itself. Beijerinck observes that some soil organisms have the power of oxidizing manganous carbonate. Olaru found that manganese in the proportion of one part to 200,000 parts of nutritive media greatly increases nitrogen fixation. He also considers it rather likely that the increased yield obtained after the application of manganese compounds to a soil is due to its accelerating the action of the nitrogenfixing organisms of the soil.

Leoncini found that the application of manganese oxid to the soil at the rate of 0.035 to 2.2 per cent. favored nitrification, whereas larger amounts had no effect.

Brown's work, which is probably the most extensive study of the influence of manganese compounds on bacterial activities so far reported, shows that the influence of the manganese salt upon bacterial activities varies with (1) the kind of salt added-manganese chlorid and sulphate acting in low concentrations as stimulants to both ammonifying and nitrifying bacteria, but in greater concentration being highly toxic; (2) its action varies with the specific class of organisms which were being studied, the ammonifiers being more resistant than are the nitrifiers.

Potassium Salts.-Because potassium is essential for the nutrition of both the higher and lower forms of plant life, it is to be expected that when added to a soil medium poor in potassium it will increase bacterial growth, but, like many other true nutrients, may become toxic if present in too high concentrations. As already noted, Engberding states that potassium sulphate caused a slight increase in the bacterial content of a soil. While Peck found it to increase 
nitrification in soils, Renault claims that slow ammonification and subsequent nitrification is always accompanied by a low percentage of potash. Dumont's experiments showed that potassium carbonate, added to a soil at the rate of from 1 to $2 . \overline{5} \mathrm{gm}$. per $1000 \mathrm{gm}$. of soil, markedly increased nitrification, but that larger applications of the salt progressively diminished the rate of nitrification, while the addition of $S \mathrm{gm}$. to $1000 \mathrm{gm}$. of soil completely checked it. Lumia concluded that potassium chlorid and sulphate were nearly as effective in promoting the activity of alcoholic ferments as were phosphates.

Fred and Hart found that both calcium and potassium sulphates increased ammonification in solution and that the sulphates of potassium, calcium, and magnesium each increased the volume of carbon dioxid from soil. From the results obtained with different salts, they conclude that the addition of the potassium ion did not materially increase ammonification in the soil examined.

Sodium Salts. - Sodium salts are often used as fertilizers and with good results. Furthermore, many alkali soils contain sodium salts in quantities sufficient to be toxic to both the higher and lower plants. For these reasons many investigations have been conducted to determine the influence of sodium compounds upon higher plants, and many have had as their object the determination of their influence upon soil bacteria.

As early as 1884 Warington showed that the presence of 0.032 per cent. of sodium bicarbonate distinctly retarded nitrification, and that in the presence of 0.096 per cent. nitrification was very slight. Schlösing had added various salts to the soil in quantities not exceeding 485 parts per million with no apparent effect upon nitrification. However, Dehérain found that common salt commenced to be harmful when it exceeded one-thousandth of the weight of soil, and when larger quantities are applied nitrification almost ceased. According to the same observer sodium nitrate may stop nitrification for a time, but later it recommences. Lipman and others found that sodium nitrate increased the accumulation of nitrates in a soil. They found, however, a certain periodicity in the accumulation of nitrates which would account for the different results reported by rarious investigators. In later investigator's they concluded that at times sodium nitrate stimulates ammonification. McBeth and Wright found that carbonates, chlorids, and sulphates inhibited nitrification and that the former were more injurious than the latter.

The most far-reaching and systematic work which has been reported on the influence of salts upon bacterial activity is the excellent work by C. B. Lipman who demonstrated that ammonification is inhibited by sodium chlorid, sodium sulphate, and sodium carbonate. The points at which the salts became toxic are: for 
sodium chlorid, between 0.1 per cent. and 0.2 per cent.; for sodium sulphate, 0.4 per cent.; and for sodium carbonate, 2.0 per cent. A stimulating influence was noted in the case of sodium carbonate, but not in the case of the sulphate or the chlorid. The points at which they became toxic to nitrifiers were found to be: for sodium carbonate, 0.025 per cent.; for sodium sulphate, 0.35) per cent.; and for sodium chlorid, less than 0.1 per cent.

All except sodium chlorid acted as a stimulant in lower concentrations. Later Lipman and Sharp found the point at which sodium chlorid became toxic to nitrogen-fixing organisms in soil to be from 0.5 to 0.6 per cent.; sodium, sulphate, at 1.25 per cent.; and sodium carbonate, at 0.4 to 0.5 per cent. Sodium chlorid was the only one which acted as a stimulant. Recently Lipman has demonstrated that there exists, as measured by ammonification, a true antagonism between sodium chlorid and sodium sulphate; between sodium chlorid and sodium carbonate; and between sodium sulphate and sodium carbonate.

Brown and Hitchcock found nitrification to be stimulated by small amounts of sodium chlorid, sodium sulphate, and magnesium carbonate, and large amounts of calcium carbonate. The large quantities, however, became toxic, the point at which toxicity and probably stimulation occurs varying with the different soils.

Variation in Effect Produced. - It is quite erident from the literature reviewed that the addition of a salt to a soil may produce a number of different effects, depending upon the nature and quantity of the salt added: (1) 'The salt may stimulate some or all of the bacterial activities of the soil; (2) it may be without effect; (3) it may be toxic to some and without effect or stimulating to others; (4) it may be toxic to all of the bacteria of the soil and hence either kill the organisms or, what is more often the case, materially decrease their metabolic activity.

These factors are well illustrated in an extensive study carried on by the author on the chlorids, nitrates, sulphates, and carbonates of sodium, potassium, calcium, magnesium, manganese, and iron. They are especially interesting in that it indicates the influence of these twenty-four salts on the ammonifying and nitrifying powers of a soil all tested under similar conditions. Though the results are not absolute, they do represent rather nearly the relative action of the various salts, as may be seen by comparing them with the results reported by others. One fact, however, which the student must bear in mind with these, as with all other results, is that an accumulation of a specific substance within the soil may represent either an acceleration of the activity of the organisms inhich form that compound or a decrease of the efficiency of the organism which destroys it. 
Stimulating Action.-Only six of the twenty-four compounds tested failed to stimulate the ammonifying organisms at some concentration. Those which did not stimulate were calcium chlorid,

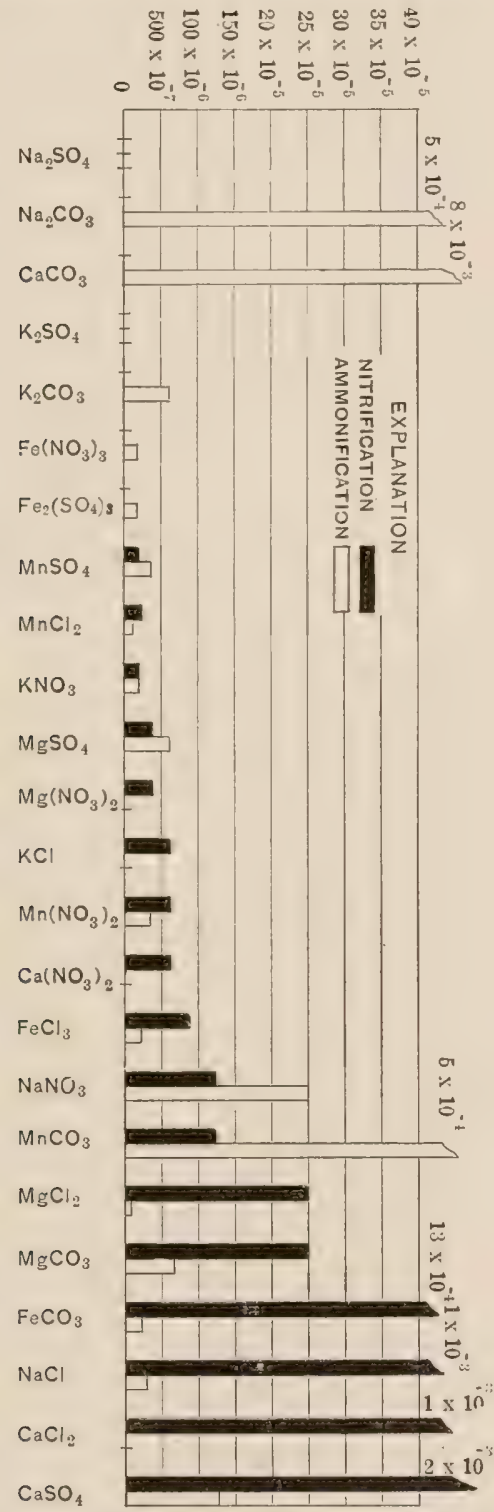

FIG. 20.-Graphs showing molecular concentrations at which the various salts exert greatest stimulation on bacteria in soil. 
calcium nitrate, potassium chlorid, potassium sulphate, magnesium nitrate, and sodium sulphate.

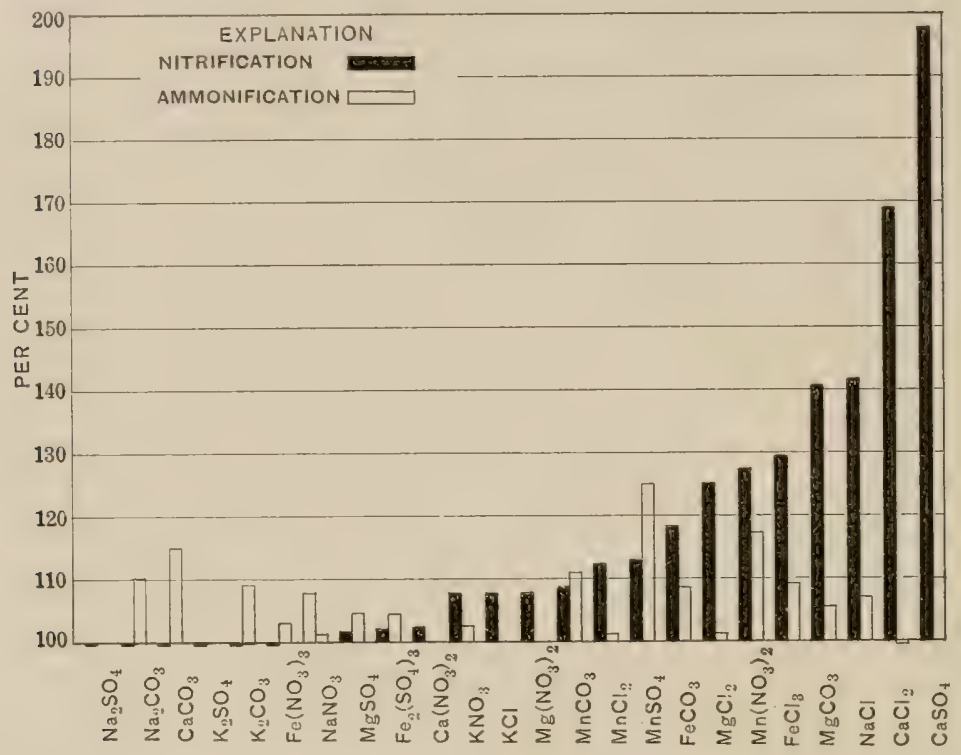

FIG. 21. -Graphs showing the percentage of stimulation at the above noted molecular concentrations (See Fig. 20), the untreated soil being counted as producing 100 per cent. of nitric nitrogen.

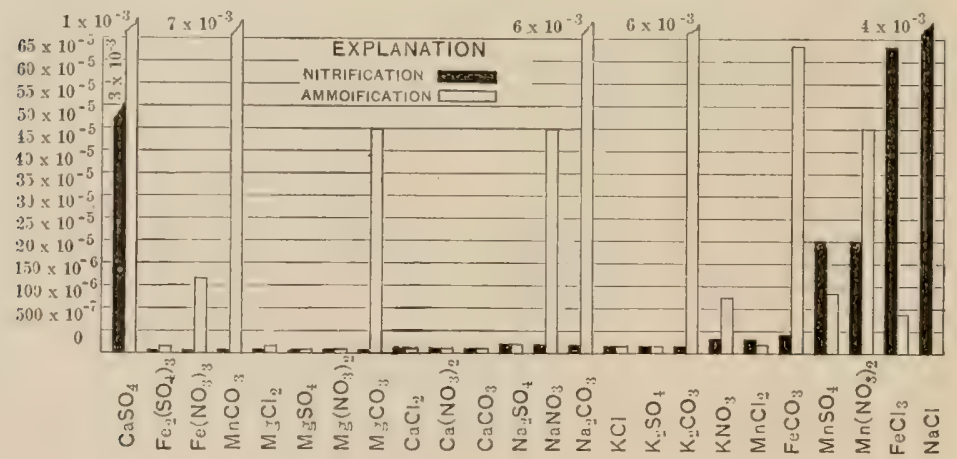

FIG. 22.-Graphs showing the molecular concentrations at which the various salts are toxic to ammonifying and nitrifying organisms in the soil.

There were also six which failed to stimulate the nitrifiers, but it is quite evident from the results giren in Fig. 20 that in the majority of cases these are different from the ones which failed to stimulate the ammonifiers. 'This is remarkable when we remember 
that the speed of the nitrification process is controlled and dependent upon the speed of ammonification. The results clearly indicate that there are other side reactions taking place which are influenced by the salts but which are not measured by the ordinary bacteriological method.

It is evident, however, from the results reported in Fig. 221 that those compounds which are most active as stimulants to the higher plants are also most active in stimulating bacteria. It is likely that the effect upon the plant is due in a large measure to the action of the compound upon the bacteria, which in turn render available more plant-food.

Toxicity of Various Salts. - There is an extremely wide variation in the concentration at which rarious salts become toxic to soil bacteria (Fig. 22). Some must occur in soils in large quantities before becoming toxic, whereas others are toxic when present in only minute quantities. 'The toxicity of the salts to ammonifying organisms are controlled largely by the electronegative ion, but this is not as pronounced in the case of the nitrifiers. The latter class of organisms is, however, more sensitive to salts than are the ammonifiers. The ammonifiers represent more nearly the higher plant.

It is apparent from these results that the increased osmotic pressure exerted by a salt within the soil plays a part in retarding the bacterial activity of such a soil, but it is not the only factor. The main factor is probable a physiological one, due to the action of the substance upon the living protoplasm of the cell changing its chemical and physical properties in such a way that it cannot function normally.

\section{REFERENCE.}

Greaves, J. E.: "The Influence of Salts on the Bacterial Activity of the Soil" (Soil Science, 1916, ii, 443-480). 


\section{CHAPTER XV.}

\section{INFLUENCE OF MANURE ON THE BACTERIAL ACTIVITIES OF THE SOIL.}

Tue application of barnyard manure to a soil brings about a far-reaching change within the soil. It has been found that, on the average, one ton of barnyard manure contains 10 or 12 pounds each of nitrogen and potassium and 2 or 3 pounds of phosphorus. It also carries other substances of less importance which may be directly utilized by the growing plant or which may react with substances within the soil, changing their solubility. This direct and indirect nutritive value of a manure is not its only function, for it greatly changes the physical structure of the soil. It improves the tilth of a clay soil by increasing the granulation within it, while in a sandy soil it tends to bind the particles together, making it less porous. Each of these changes react upon the water-holding capacity and the capillarity of the soil, greatly altering the aëration of the soil and with the aëration the temperature.

The biological changes which the nanure produces in the soil, especially when small quantities are added, may be even more farreaching than either the chemical or physical changes which it produces. Every pound of manure carries with it to the soil millions of bacteria. Many of these will find the new conditions unsuited for their growth, but some will continue to multiply, and in so doing not only will decompose the constituents of the manure but also will greatly alter other organic and inorganic substances of the soil. The bacterial content of the soil is, therefore, changed both quantitatively and qualitatively. There are added with the manure many new species; the changed physical and chemical conditions of the soil due to the manure will greatly modify those already present, for the microflora and microfauna originally present in the soil were due to specific soil properties.

This changed flora and fauna will in turn change the chemical and physical properties of the soil still more. Acids are generated, which react with insoluble constituents, rendering them soluble. Gases are formed, which change the air within the soil; in these reactions heat is generated, thus changing the temperature of the soil. The metabolism of the bacterial cell requires untritive substances, among which are water and the elements essential to plant growth. Some soluble constituents will be changed to insoluble and 
some inorganic to organic. All of these changes are reflected in the crop yield.

Number. - That the addition of manure to a soil increases the number of bacteria has been shown by Remy and Fischer.

Caron found that the number of bacteria present depends not only upon the manure added but upon the cultural methods and the crop grown on the soil. Fabricius and von Feilitzen found that bacteria increased in the soil on the addition of manure and that a direct relationship existed between the temperature of a soil and the number of bacteria found in it. That the temperature of the soil is influenced by the addition of manure is shown by Wagner who observed that manure increased the temperature of soil from 1 to $2.8^{\circ} \mathrm{C}$, depending on the kind and condition of manure added. Troop noted an average increase of $5^{\circ}$ in temperature of soil receiving 25 tons an acre of manure over an ummanured soil. Petit, however, claimed that, while there was at first an increase in the temperature of manured soils, later it became lower than the unmanured. Stigell concluded that bacteria under favorable conditions for de relopment retarded the conduction of heat in soils and thereby reduced the temperature changes due to the variation in the outside temperature. This, in a way, might neutralize the effect of manure, for Hecker found that although the temperature of soil to which well-rotted manure had been added was higher than adjacent unmanured soil during the day, the opposite was true during the night. Grazia stated that manures greatly increase the temperature of the soil. King found that a definite increase in bacterial activity occurred with increased temperature, but that an excessive moisture content greatly reduced the number of bacteria in a soil. Engberding claimed that manure increased the number of bacteria in a soil, but he considered that the moisture content had a greater influence on numbers than did temperature. That the moisture content greatly influenced bacterial activity was shown by Dehérain and I emoussy, who found that the bacterial action of a soil was at its maximum when a rich soil contained 17 per cent. of water, but that it decreased if the proportion of water fell to 10 per cent. or rose to 25 per cent. With soils less rich in humus a somewhat higher proportion of water was necessary to retard oxidation to any marked degree. In a manured soil the coarse manure tended to cause the surface soil to dry out, while fine manure prevented evaporation. King observed that manured land contained more moisture throughout the year than unmanured, and this was reflected in both a greater number of bacteria and in a larger crop. The bacteria themselves may play a small part in this difference in moisture content, as was shown by Stigell, who found that bacteria decreased the speed of evaporation of water from Petri dishes. Iiltner and Störmer's results indicate that the addition of manure to a soil brought about 
a marked change in the number of bacteria. The temperature, cultural methods, and crop had an influence, but it was not nearly so pronounced as that produced by the manure, as is seen from the following in which is given the number, stated as millions per gram, of bacteria found in manured and unmanured soils at different seasons.

Cropped land, grass and clover Cultivated fallow, unmanured Cultivated fallow, manured

\begin{tabular}{|r|r|r|r|r|r}
\multicolumn{2}{|c|}{1901.} & \multicolumn{2}{c}{1902.} \\
\hline 10 May. & 27 Aug. & 18 Oct. & 1 Feb. & 12 June. & 18 Aug. \\
\hline 8.3 & 3.2 & 6.4 & 6.6 & 8.1 & 4.9 \\
8.0 & 4.2 & 4.0 & 4.1 & 5.7 & 4.1 \\
11.0 & 10.5 & 11.0 & 9.3 & 7.2 & 8.4
\end{tabular}

Brown, in a study of the influence of manure on the bacterial activities of a loam soil, found that applications of manure up to 16 tons an acre increased the number of bacteria and also the ammonifying and nitrifying powers of the soil. The greatest increase in the processes was brought about by small applications of manure, 8 to 12 tons to the acre. He observed a close relationship between the ammonifying powers of the soil, the bacterial content, and the crop produced on the soil.

Temple stated that the addition to a soil of 10 tons an acre of cow manure greatly increased the number of bacteria in the soil, but that a greater increase occurred when a sterilized manure was applied. This, however, is not in keeping with the results obtained by other investigators. Hellström concluded that manures possessed a fertilizing effect aside from the quantities of fertilizer constituents contained within them; and this, he maintained is due to their great bacterial content. Stoklasa found that manure increased the bacterial content and activity of a soil, the increase being greater with small, frequent applications of manure than with large applications made at longer intervals. Moreover, Lipman and others observed that the bacteria conveyed to soil in small quantities of manure were valuable in bringing about a more rapid decomposition of a green-manure crop. Briscoe said that a direct relationship existed between the organic matter added to a soil and the bacterial count, and that a light dressing of manure with green manure produced a marlied increase upon both the yield of the crop and number of bacteria. Bacterial cultures added with the green manure gave just as pronounced an effect as did the stable manure. Lemmermann and Finecke, however, obtained no increase on adding stable manure with green manure. This may be due to the different kind of manure used, for Emmerich and others maintained that a more favorable effect was obtained from the use of well-rotted manure than from the 
use of fresh manure. 'This, they maintained, was due to the production in the latter of formic, acetic, and butrric acid, indol, skatol, and hydrogen sulphid, which are toxic to the plant. Inder some conditions, the large quantities of carbon dioxid liberated from the rapidly decomposing fresh manure may be valuable in rendering the plant-food soluble. Bornemann found that soil constantly supplied with carbon dioxid through a pipe buried in the ground gave an increase in yield of 12.2 per cent. over the crop grown on untreated soil. Wollny has shown that manure greatly increased the carbondioxid production in a soil.

Ammonification and Nitrification. - Moll considered that the season of the year, and not the kind of fertilizer used, nor even the weather conditions, is the principal factor in determining the extent of peptone decomposition, nitrification, and nitrogen fixation of a soil. According to Wohltmann, Fischer, and Schneider, ammonification, nitrification, and nitrogen fixation were all more or less increased by the application of manure. Heinze found that manure was especially beneficial to the nitrifying organisms. Warington reports that much more nitric nitrogen was found in the soil of plots which had received ammually for thirty-eight years a dressing of 14 tons of manure to the acre than in any of the other manured or ummanured plots. Stevens found that nitrification was much more active in manured than in unmanured soil, but Frankfurt and Inschechlin observed an increase in nitrification only on those manured plots on which the vield had increased. Welbel has shown that the chief factors controlling nitrification in fallow soil were the humus and the humus-nitrogen content, the nitrification having increased directly with the humus. He noted, howerer, a certain amount of denitrification at first, but later in the summer nitrification became more rapid on the manured than on the unmanured soil, the effect of the manure being still perceptible after four rears. Some investigators have reported a reduction of nitrates, but the quantity of manure applied was excessive, or else of a very coarse nature, or the soil poorly aërated. Barthel found that nitrification did not take place in the presence of soluble organic matter, but he considered it unlikely that sufficient quantities of soluble organic constituents occurred in normal agricultural soils to interfere greatly with nitrification. Niklewski maintained that nitrification occurred in solid stable manure when there was not much liquid present. He stated that on the first day some nitrite bacteria were present and at the end of four weeks there were 10,000 in each gram. Associated with these were nitrate bacteria which were identical with those isolated by Winogradsky. Millard, howerer, was unable to find many nitrifying bacteria in manure.

Loss of Nitrates. - Many of the cases in which individuals have reported a disappearance of nitrates in soil are due to synthetic 
reactions, the nitrates being built up into complex proteins. For Gerlach and Vogel have shown that there are sereral varieties of bacteria in the soil which have the power of converting ammonia, nitrites, and nitrates into insoluble proteins.

It is erident from the literature cited that there is a wide variation in the ideas held concerning the influence of manure upon the bacterial flora of the soil. This is due to a number of factors, chief among which are: (1) variation in the physical and chemical composition of the soil; (2) a great variation in the composition of the manure used; and (3) the manure added may have influenced either beneficially or injuriously the water content of the soil. The results noted may have been due to the moisture factor and not to the manure. An experiment was conducted at the Utah Experiment Station both in pots and under field conditions. Each ton of the manure added was partly rotted and contained in one ton 734 pounds of dry matter, 3.04 pounds of phosphorus, 13.7 pounds of potassium, and 16.08 pounds of nitrogen.

The conclusions reached follow: A calcareous soil kept in pots with varying amounts of manure and different percentages of moisture gave on bacteriological analysis at the end of four months the following results: The temperatures of the manured and unmanured were practically the same for the period, but the temperature of the soil with 12.5 per cent. of water was $1^{\circ} \mathrm{C}$. higher than soils with 22.5 per cent. of water. The greatest number of organisms dereloped on synthetic media from the soils receiving the greatest quantity, 25 tons, of manure. 'There were more colonies developed from the soil receiving 12.5 per cent. of water than from any of the other soils receiving higher quantities of water.

The nitrifying powers of the soil increased as the manure and water applied increased up to 25 tons of manure and 22.5 per cent. of water.

The nitrogen-fixing powers of the soil were greatest in those pots receiving manure at the rate of 10 tons an acre. Increasing the water above 12.5 per cent. but not above 22.5 per cent. slightly increased the nitrogen-fixing powers of the soil. Nothing in the results indicated that the application of manure up to 25 tons an acre and of water up to 22.5 per cent. caused denitrification in the soil.

Bacteriological analyses of fallow field soil receiving no manure, 5 tons, and 15 tons an acre and receiving no water, 5 inches, 10 inches, 20 inches, 30 inches, and 40 inches of irrigation water, indicated that the maximum number of bacteria were obtained from the soil receiving 15 tons of manure. 'The application of irrigation water up to 2() inches increased the bacterial count, the increase being most noticeable in the soil receiving the greatest quantity of manure.

If the ammonifying power of the ummanured soils is considered 
as 100 per cent. and that of the unirrigated as 100 per cent., the manured and irrigated soils then become with 5 tons of manure, 147 per cent.; with 15 tons of manure, 188 per cent.; 5 inches of water, 106 per cent.; 10 inches of water, 117 per cent.; 20 inches of water,

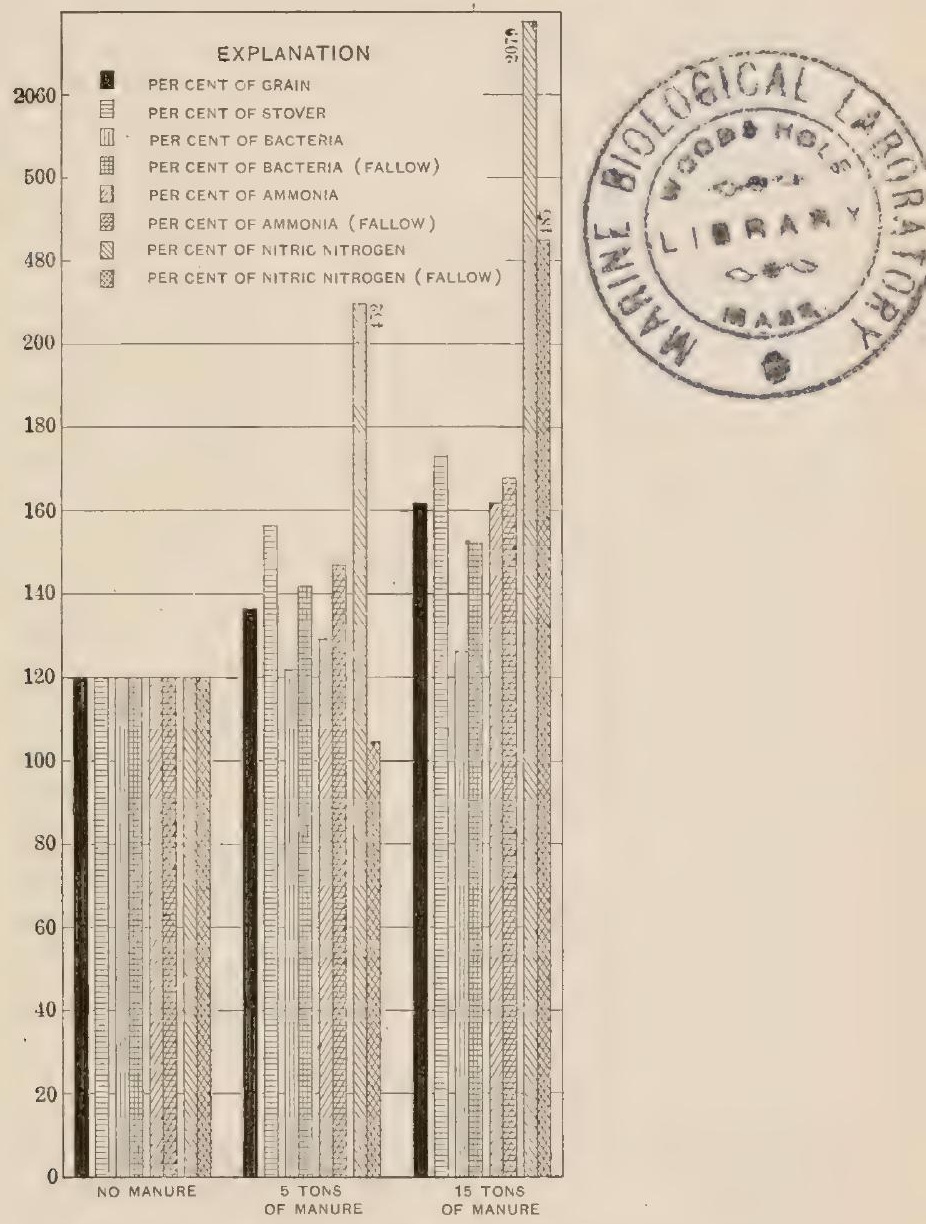

Frg. 23.-Diagram showing the influence of manure on the yield and bacterial activities of a soil. The unmanured soil is expressed as 100 per cent.

108 per cent. Large quantities of irrigation water produced the greatest depressing effect in the presence of 1.5 tons of manure to the acre.

Fewer organisms develop on synthetic agar from a cropped than from a fallow soil. The application of manure to a cropped soil 
increases the bacterial count of the soil. The greatest number of organisms developed from the soil receiving 10 inches of irrigation water.

The ammonifying power of the cropped soils was slightly lower than similarly treated fallow soils. 'The application of 5 and 15 tons of manure on each acre increases the ammonifying power of the soil. The application of irrigation water up to 30 inches increases the ammonifying porrer of the soil. The greatest increase resulted in those soils receiving 15 tons of manure to the acre. The application of 40 inches of irrigation water to corn land, especially to that receiving 15 tons of manure an acre, depresses the ammonifying power of the soil.

The nitrifying power of fallow soil was higher than similarly treated cropped soils. The application of manure to a cropped soil greatly increases the rate of nitrification. The application of irrigation water up to 30 inches, especially to a soil receiving 15 tons of manure, greatly increases its nitrifying power.

Green manures are rapidly taking the place of bare fallows in all of the better systems of agriculture where the rainfall will permit of the practice. 'The practice of green-manuring consists, essentially, of the turning under of green crops for the benefit of succeeding crops. In addition to the various legumes, which are preferred on account of their ability to take nitrogen direct from the air, crops like rye, wheat, oats, buckwheat, mustard, rape and even turnips have been used more or less extensively as green manures.

The plowing under of green manure produces either a beneficial or injurious effect, depending upon the nature of the soil to which it is applied, the kind of manure added, and the season of the year when applied. Some of the beneficial influences noted are:

1. They carry to the soil large quantities of organic matter which on decaying yield humus, and this in turn changes materially the physical and chemical composition of the soil. Schultz started in 1855 on an extremely poor, coarse-grained, sandy soil, and gradually improved it by the use of lime, phosphoric acid, and potash in connection with such green-manuring crops as lupines, serradella, and field-peas, until he could produce three hundred to four hundred bushels of potatoes to the acre. Neale noted a marked gain in the yield of corn when crimson clover was used as a green manure. He believed the nitrogen thus applied to be much more economical than when nitrate of soda is used. For sandy soils the results of Delwiche would indicate cowpeas, hairy vetch, soy beans, and crimson clover to be best, and I'feiffer's results indicate that it is the open, sandy soils which give the best results with green manures. The actual effect produced, however, varies with the time of application. Bässler recommends that where lupines, serradella, crimson clover, and hairy vetch are used for green manure on sandy soils they should 
be turned under as late as possible in the life of the plants and not in the hot summer when the plants are green. This agrees with the findings of Causemann who recommends that they be turned under late in September. It has been observed by Bredemann that the addition of organic matter, such as hay and sugar, produces a harmful effect the first year and a beneficial effect the two following years.

2. Green manures change the number and kind of organisms occurring in the soil. Hill found the total number of bacteria in soils treated with green manures to be much greater than in those receiving no green-manure treatuent. I cegumes gave in most cases a greater increase than non-legumes. Müntz considers the value of green manures proportional to the rapidity with which their nitrogen is converted into nitric nitrogen. Ileinze, on contrasting stall and green manures, found that the latter carried but few organisms which would break down the insoluble material. The decomposition of green manure was found to be due to dust organisms and to organisms found in soil. For this reason the number and kind of organisms in a given soil determine in a great measure the influence of green manures on succeeding crops. Decomposition is rapid in an open, sandy soil rich in bacteria and relatively slow in a soil poor in bacteria. In an open, sandy soil the nitrogen of the green manure may pass over into nitrates and be washed out, whereas in a heavier soil the nitrogen becomes available more slowly and is not washed out so rapidly. For this reason in heary soils green manures often give the best results the second year.

Koch thinks the good effects produced when green manure is added to stable manure may be due to an increased nitrogen fixation by dzotobacter, the organism using the cellulose of the manure as a source of energy; whereas Ileinze considers that the results which he obtained from studying the action of carbon bisulphid on soils may help us to understand the peculiar effects produced at times by the turning under of mustard, buck wheat, rye, and other non-leguminous crops. It has been noted rejeatedly that these crops when plowed under in a green state lead to a better growth of the following cereal or root crops on nitrogen-poor soils. As Heinze points out, there may have been more or less justification for this belief, so far as the indirect influence of mustard is concerned. It would seem at times that the action of mustard is not unlike that of carbon bisulphid in affecting the bacterial flora of the soil, and it really appears from facts already known that the green mustard substance in the soil retards the development of the acid-forming species and encourages the growth of the nitrogen-fixing A sotobarter species. Heinze, therefore, thinks that further study may enable us to make extensive use of mustard as an indirect source of combined nitrogen, and tries to find theoretical support for this belief in the fact that allyl isothiocyanid mustard oil, $\mathrm{C}_{3} \mathrm{H}_{5}-\mathrm{N}=\mathrm{C}=\mathrm{s}$, which is a constit- 
uent of the mustard plant, may be regarded as a derivative of carbon bisulphid and probably would have a similar influence upon the soil microflora.

3. The growing of a crop during the season of the year when the heavy rains would wash much of the nitric nitrogen beyond the roots of the plants prevents this loss, for the nitrogen is stored in the body of the plants and is later liberated by decomposition for succeeding plants.

4. The growth of the legumes may actually lead to an increase in the nitrogen of the soil. The method, extent, and conditions under which this occurs is considered in detail in later chapters.

The results, however, following the use of green manures are not uniformly beneficial, for the following ill effects have at times followed its use:

1. The physical condition of the soil may be injured. It becomes too loose and open, decomposition being thereby decreased and leaching increased. This was probably the reason why Brown did not always find an increase in the bacterial activities following the application of green manure. This is also true with regard to the work reported by Laurent.

2. Engberding, studying the effect of straw and sugar upon the number of bacteria in the soil, found at first an increase, followed by a decrease. The ammonifying and nitrogen-fixing groups of bacteria showed an increase, but the nitrifying group was retarded.

Fischer, in his paper on the changes undergone by nitrogen in sandy and clayey soils, offers an explanation for the loss of nitrates in a soil to which carbohydrates have been added in the following reaction:

$$
24 \mathrm{NaNO}_{3}+5 \mathrm{C}_{6} \mathrm{H}_{12} \mathrm{O}_{6}=24 \mathrm{NaOH}+12 \mathrm{~N}_{2}+30 \mathrm{CO}_{2}+18 \mathrm{H}_{2} \mathrm{O}
$$

The oxygen of the nitrate is used by the ferments for the oxidation of the carbohydrate and the nitrogen is liberated as a gas.

Frankfurt and Duschechkin state that green manure under field conditions caused a diminution of the nitrate content. Both legumes showed this effect, but they consider it as due to the action of the manure upon the soil moisture.

Stevens and Withers give two reasons why the activity of nitrifying organisms, in pure culture under laboratory conditions, cannot be compared with their activities under conditions in the field: (1) "In mixed culture their symbiotic and physiologic relations are so different from those obtained in pure cultures that their metabolic processes are with difficulty expressed;" (2) "the presence of large amounts of solid matter, sand, or earth, in contact with the liquid medium, so alters its relation to the nitrifying organisms that their physiologic activities and metabolic products are different." These aluthors say in conclusion: "In the light of the facts set forth, the 
direct application of Winogradsky's conclusions to the field must be abandoned and with them any practices based upon them, and the activities of these soil bacteria must, in the future, be studied more largely under their natural environments."

Lipman, commenting on these earlier views, believes that "the exact relation of organic matter in the soil to the activities of nitrifying bacteria is but beginning to be properly understood. Earlier observation made it manifest that heary applications of animal manures, or green manure, may not only retard nitrification but may actually cause the disappearance of a part or of all of the nitrate in the soil. Subsequent experiments by Winogradsky and Omelianski showed that in pure cultures the presence of even slight amounts of soluble organic matter may depress or even suppress the development of the nitrifying bacteria. It was, therefore, concluded by these authors that relatively small amounts of soluble organic matter may inhibit nitrification. These conclusions, based on the study of liquid cultures only, were given a very broad application by many writers on agricultural topies. Nore recent experiments make it certain, however, that in the soil itself small amounts of soluble matter, for example, dextrose, are not only harmless but may really stimulate nitrification. It was shown, likewise, that humus and extracts of humus may, under suitable conditions, stimulate nitrification to a very striking extent."

\section{REFERENCE.}

Greaves, J. E., and Carter, E. G.: Influence of Barnyard Manure and Water upon the Bacterial Activities of the Soil (Journal Agricultural Research, 1916, vi, 889-926). 


\section{CHAPTER X VI.}

\section{THE SOIL FLORA.}

T'wo methods are in general use for the quantitative determination of bacteria in the soil: the Koch gelatin-plate method and the Hiltner and Störmer dilution method.

Koch Gelatin-plate Method.-The determination by the gelatinplate method is made as follows: Samples of soil are carefully mixed, usually by shaking, and 100 grams of the mixed soil weighed on sterile paper or watch-glasses into 200 c.c. of sterile water. This is shaken for one minute. Ten c.c. of this is transferred to 90 c.c. of sterile water. This is continued until the proper dilution is obtained, usually 1 to 20,000 and 1 to 200,000 , then they are plated on gelatin or some other solid media. The number of colonies developing is counted at the end of four or seven days. The longer period is preferable for many of the important soil organisms are missed in the shorter incubation period.

Hiltner and Störmer Dilution Method.-The IHiltner and Störmer method uses solutions prepared to favor in each case the development of one of the various groups of bacteria (ammonifying, nitrifying, nitrogen-fixing, etc.). The soil is inoculated into the appropriate media in constantly decreasing quantities usually 100, 10, 1 , $0.1,0.01,2$, and $0.001 \mathrm{mg}$. of soil. The material is incubated and after the appropriate time the gain in ammonia, nitrites, nitrates, etc. determined. By this procedure a point is finally reached where the small quantity of soil employed contains none of the specific organisms, and hence fails to give rise to the specific physiological reaction. By this method a fairly accurate estimation may be made of the number of different microörganisms in the soil.

Löhnis clearly demonstrated that the Hiltner and Störmer method is more exact than is the gelatin-plate method. He found that a soil which yielded $1,270,000$ bacteria per gram by the gelatinplate method, by the Hiltner and Störmer method yielded $3,750,000$ peptone-decomposing bacteria, 50,000 urea-decomposing bacteria, 50,000 denitrifying bacteria, 7000 nitrifying bacteria, and 25 nitrogen-fixing bacteria, making a total of $3,557,025$, which is over three times the number obtained by the plate methor.

Defects of Plate Method.-The number of organisms found in soil by this method varies with the media used and the period elapsing between plating and counting. But even under the most favorable 
conditions, the numbers are far below the number actually occurring in the soil. Some of the reasons for this are as follows:

1. Even many of the peptone-decomposing bacteria fail to grow on the gelatin plates. 'This may be due to overcrowding or to the sudden change of conditions and the resulting osmotic disturbances.

2. The nitrifiers do not grow on the ordinary organic laboratory media; moreover, they have not been found in soil in sufficient numbers to occur on plates dilute enough to show the more abundant organisms. The nitrogen-fixing organisms-both symbiotic and non-symbiotic-usually occur in soil in too small a number to be noted by the ordinary plate method.

3. The strict anaërobes which occur in soils in vast numbers do not grow on the gelatin plate under the ordinary conditions of aërobic culture.

4. No medium yet devised resembles the soil in composition and structure, and hence the plate does not necessarily reflect the flora active in the soil. Moreover, it is impossible to tell which of the forms developing on the plate are active and which are spores in the soil.

A third method for the determination of the bacteria in the soil is the direct microscopic count. This method, however, has not been used sufficiently as yet to permit a conclusion as to its relative value.

Value of Bacterial Counts. -The methods for determining the number of bacteria in soil are admittedly faulty; yet they have the advantage of showing whether the number is high or low and whether they are increasing or decreasing. The counts show fairly accurately whether any given treatment of the soil has raised or lowered the number of bacteria in the soil. But numbers alone furnish only meager information, for, as pointed out by Remy, the number of colonies of aërohic soil bacteria appearing on plates show no direct relationship to the ammonifying, nitrifying, or denitrifying powers of the corresponding soil. Löhnis is even more emphatic than Remy in designating mere quantitative methods as untrustworthy. He points out that it is quite possible that two million very efficient ammonia-producing bacteria present in $1 \mathrm{gram}$ of soil will accomplish more work than five million less efficient ones will in another soil.

This same principle is brought out by Chester when he states that a soil may be low in the total number of bacteria, but contain such a bacterial flora, or combination of bacterial species, which are known to be favorable to the rapid digestion of plant-food, as to give it what might be termed a high bacterial potential. In other words, he holds that we should consider not alone numbers but also physiological efficiency.

Number of Bacteria in Soil.-The number of bacteria, as determined by the plate method, in good arable soil well supplied with 
organic matter usually ranges from three to forty million. 'Tight, non-porous soils, as well as alkali and soils low in humus and moisture, yield low bacterial counts.

The number of microörganisms in light, sandy, very tight clay, desert and forest soils is usually much smaller, other things being equal, than in normal cultivated soils. Cultivation of soils tends to increase greatly the number of bacteria. The average of several hundred determinations made on cultivated soil of the arid regions gave a bacterial count of $4,452,000$, whereas the average of a similar number of samples taken from adjoining virgin soils was 2,270,000.

Factors Influencing Number--Optimum moisture, organic matter and aëration tend to increase the number as does also the addition of sugar and certain antiseptics:

\begin{tabular}{|c|c|c|}
\hline & \multicolumn{2}{|c|}{ Bacterial number after 50 days. } \\
\hline & Control soil. & $\begin{array}{l}\text { Soll treated with antiseptics, } \\
\text { millions per gram. }\end{array}$ \\
\hline Cane sugar (p. 25 per cent.) & . 21 & 51 \\
\hline Amyl alcohol ( 0.1 per cent.) & 30 & 85 \\
\hline Phenol (m/200 per kilo) . & $\therefore 27$ & 101 \\
\hline Hydroquinone (m/200 per kilo) & 16 & 55 \\
\hline
\end{tabular}

There is a direct relation between the number of bacteria found in the soil and the quantity of organic manure added. This is illustrated in results obtained by the author and given in tabular' form below. The unmanured soil is taken as 100 per cent.

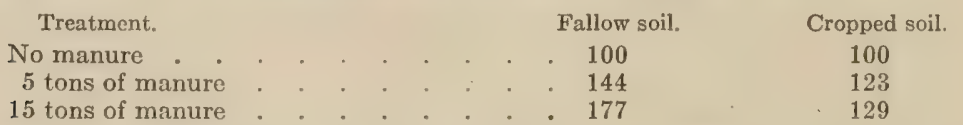

The aëration of the soil often increases manyfold the number of bacteria, and according to Conn the greatest numerical increase occurs in the group of non-spore-forming bacteria.

The number of bacteria found in the soil varies considerably with the season of the year. A very interesting phenomenon, noted by Conn and confirmed by Brown, was that the number of bacteria in soil increase on freezing. 'This fact is illustrated in the following table from the work of Conn. In it are listed a series of gelatinplate counts made from a single soil plate at intervals throughout the course of three years.

During the three years over which the sampling was conducted the plate count of non-spore-formers varied from 5,000,000 to $44,000,000$ per gram, whereas the spore-forming bacteria and Actinomycetes varied only from $3,200,000$ to $10,500,000$. The increase which occurs during the winter is in the slow-growing bacteria and not in those which liquefy gelatin rapidly or in the Actinomycetes. Conn tries to account for the noted phenomenon by assuming two groups of bacteria-winter and summer bacteria. The latter, he thinks, prevent the former from multiplying rapidly in warm weather. Hence, the increase in the frozen soil is due to the depressing effect of the cold upon the summer bacteria. 'There is, 
however, the possibility that the freezing breaks up the clumps of bacteria and the noted increase is apparent and not real. Little relationship has been found between the moisture and cropping of a soil and the bacterial count.

\begin{tabular}{|c|c|c|c|c|c|}
\hline \multirow{2}{*}{ Date. } & & \multirow{2}{*}{$\begin{array}{l}\text { Moisture } \\
\text { content. } \\
\text { Per cent. }\end{array}$} & \multicolumn{2}{|c|}{$\begin{array}{c}\text { Number of colonies per gram of dry } \\
\text { soil. }\end{array}$} & \multirow{2}{*}{ Remarks. } \\
\hline & & & $\begin{array}{l}\text { Non-spore-form- } \\
\text { ing bacteria. }\end{array}$ & $\begin{array}{l}\text { Other colonies- } \\
\text { spore formers and } \\
\text { actinomycetes. }\end{array}$ & \\
\hline Nov. 24,1911 & . & 25.0 & $22,500,000$ & $5,500,000$ & \\
\hline Jan. 13, 1912 & . & 40.0 & $28,500,000$ & $7,500,000$ & Frozen 8 days. \\
\hline Jan. 23,1912 & . & 37.0 & $31,000,000$ & $9,000,000$ & Frozen 18 days. \\
\hline Feb. 13,1912 & . & 43.0 & $11,000,000$ & $10,000,000$ & Frozen 39 days. \\
\hline Mar. 1, 1912 & . & 37.0 & $20,500,000$ & $6,500,000$ & Frozen 57 days. \\
\hline Apr. 24, 1912 & . & 23.4 & $18,000,000$ & $4,500,000$ & \\
\hline May 6,1912 & . & 40.0 & $20,000,000$ & $9,000,000$ & \\
\hline June 5,1912 & . & 20.4 & $19,200,000$ & $4,500,000$ & \\
\hline Sept. 23, 1912 & . & 22.5 & $28,500,000$ & $10,500,000$ & \\
\hline Oct. 25,1912 & . & 24.5 & $14,500,000$ & $5,500,000$ & \\
\hline Dec. 3,1912 & . & 26.2 & $28,500,000$ & $6,500,000$ & \\
\hline Jan. 15,1913 & . & 39.5 & $14,000,000$ & $6,000,000$ & Frozen 7 days. \\
\hline Feb. 5,1913 & . & 22.0 & $22,300,000$ & $7,700,000$ & Frozen 4 days. \\
\hline Feb. 14,1913 & . & 26.2 & $44,000,000$ & $10,000,000$ & Frozen 13 days. \\
\hline Mar. 11, 1913 & . & 38.8 & $22,000,000$ & $7,000,000$ & Partly frozen. \\
\hline Apr. 4,1913 & . & 22.8 & $19,300,000$ & $7,700,000$ & \\
\hline July 10,1913 & . & 17.0 & $16,800,000$ & $5,200,000$ & \\
\hline Nov. 26, 1913 & . & 21.5 & $11,800,000$ & $4,200,000$ & \\
\hline Dec. 15,1913 & . & 19.6 & $7,800,000$ & $3,200,000$ & \\
\hline Jan. 16,1914 & . & 31.2 & $15,500,000$ & $3,500,000$ & Frozen 9 days. \\
\hline Jan. 30,1914 & . & 24.6 & $26,000,000$ & $7,000,000$ & Thawed 1 day. \\
\hline Feb. $\quad 7,1914$ & . & 27.7 & $22,700,000$ & $7,300,000$ & Partly frozen. \\
\hline Feb. 26,1914 & . & 32.0 & $31,000,000$ & $7,000,000$ & Frozen 21 days. \\
\hline Apr. 15,1914 & . & 20.0 & $13,700,000$ & $7,300,000$ & \\
\hline Apr. 29,1914 & . & 20.0 & $11,800,000$ & $4,200,000$ & \\
\hline Aug. 7,1914 & & 9.0 & $5,000,000$ & $4,000,000$ & \\
\hline Aug. 19,1914 & . & 20.0 & $18,000,000$ & $4,700,000$ & \\
\hline
\end{tabular}

The number of organisms in the soil vary greatly with the depth. Due to the lack of moisture and the germicidal action of light, the number of bacteria in the uppermost inch or two of soil is lower than in the layers of soil immediately below. Beyond the depth of eight or nine inches, the number diminish rapidly, and in humid regions the number below two feet is extremely low. This is illustrated by results reported by Chester:

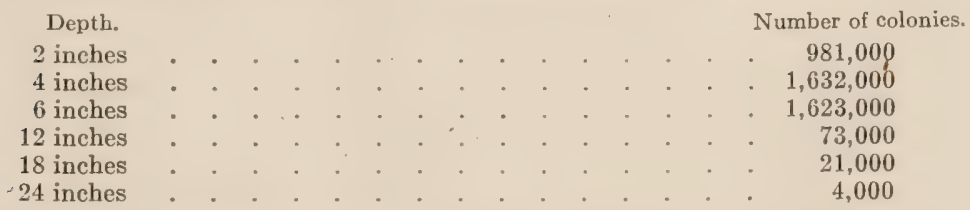

The conditions, however, are quite different in the arid regions where we have the slow formation of clay substances in the soil, and, therefore, the absence of the cementing substances in the soil. 
This results in greater aëration, and hence often ideal conditions for bacterial growth to a great depth. Moreover, the roots in search for water penetrate to a great depth in the soils of the arid regions. This results in an aeration of the soil and the supplying of organic matter to bacteria at a great depth. Lipman found the ammonifying organisms at all depths to the tenth foot and at times the nitrifying organisms to a depth of eight feet. The nitrogen-fixing organisms seldom occurred below the third or fourth foot. I have found great numbers of bacteria in both dry-farm and irrigated soils of the arid regions in the second and third foot. The average of several hundred such determinations is given below:

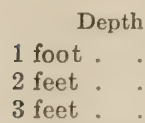

$\begin{array}{cc}\begin{array}{c}\text { Number of } \\ \text { Irrigated soil. }\end{array} & \begin{array}{c}\text { colonies. } \\ \text { Dry-farm soil. }\end{array} \\ 6,240,000 & 4,372,000 \\ 1,760,000 & 1,267,000 \\ 1,147,000 & 1,174,000\end{array}$

The larger number found in the irrigated soil is due to the presence of a better supply of organic matter and not to the moisture supplied.

Kinds of Microörganisms in Soil.-The work so far done in this field clearly establishes the fact that soils have a definite bacterial flora as do water and cheese. The work done on the soil so far is meager and has been carried on by a few investigators - Hiltner and Störmer in Germany, and Chester, Harding, and Conn in this country. By far the best and most extensive piece of work is that of Conn, and it is on his work that the main points of the following are based.

Hiltner and Störmer found that normally soil contains 5 per cent. of liquefiers, 70 per cent. of non-liquefiers, and 20 per cent. Streptothrix. 'The 5 per cent. liquefiers include the $B$. subtilis and $P$ s. fluorescens groups. ('hester showed that the relative abundance of these three groups is nearly constant in normal soil and that any external influence which disturbed the equilibrium of the soil flora would be indicated by a change in the relative abundance of these three groups. This conception of the soil microörganisms as being normally in a state of equilibrium has proved of considerable value in interpreting soil phenomena.

('om divides soil bacteria into the following groups:

1. Spore-producers

2. Non-spore-producers

Liquefaction rapid

Liquefaction slow or none Rods

Yellow chromogenic

Non-chromogenic

Cocci

3. Actinomycetes

"Rapid liquefiers"

"Slow growers" 
Ife found the relative number of these organisms occurring in soils to be as follows:

1. From is to 10 per cent. spore-formers (the B. subtilis group). Nearly all the colonies of these hacteria, however, seem to come from spores instead of from active organisms.

2. Under 10 per cent. rapidly liquefying, non-spore-forming, short rods with polar flagella (principally Ps. fluorescens).

3. From 40 to 75 per cent. slowly liquefying or non-liquefying, non-spore-forming, short rods.

4. A few micrococci. In cultural characteristics these are almost identical with the last mentioned group.

5. From 12 to 50 per cent. Actinomycetes.

The most abundant spore-former's found in the soil and described by ('onn were $B$. megatherium I)e Bary, $B$. mycoides Flügge, $B$. cereus Frankland, and B. simplex Gottheil.

"B. megatherium De Bary, 1884. - This species is to be distinguished from $B$. mycoides and $B$. cereus by the larger average size of its spores, by its poor growth in liquid media, its failure to grow in the closed arm of fermentation tubes of dextrose broth, and by its comparatively slow liquefaction of gelatin.

"Morphology. - Tery young cultures (under twelve hours) consist of large rods about 1 to $1.5 \mu$ in diameter and albout ;) to $6 \mu$ long. They often occur in chains with connecting threads between the rods, resembling strings of sausages. In older cultures the rods generally become swollen and are sometimes full of highly refractive globules (fat drops"). One of the most distinctive characteristics is the presence in cultures a day or more old of large ovoid bodies about 2 by $4 \mu$ in size, which seem to have heavy walls and stain much more lightly than the young rods. Only the young rods are motile, and they are not vigorously so. The flagella are difficult to stain, and the best preparations made show comparatively few flagella on each rod. Spores are formed in the center of the rods and immediately become free from all trace of the sporangium wall. They are oval to oroid (or occasionally reniform) and vary considerably in size, from 1.3 to $2 \mu$ in diameter and from 1.5 to $3 \mu$ in length, both extremes often occurring in the same preparation.

"Cultural Characteristics.-Growth in broth flocculent or none, with no surface growth. Gelatin colonies under $10 \mathrm{~mm}$. in diameter, center white, opaque, flocculent or granular, surrounded by a clear liquefied zone. Growth on agar streak cultures smooth, soft, glistening, cream-color, typically with minute drop-like areas of lighter color.

"Physiology.-The typical group number is B. 111.41420"4. As indicated by this group number, there is ordinarily no growth in sugar and glycerin broths. This does not mean, however, that no 
acid is produced from sugar or glycerin. Some cultures have produced growth and have acidified one or even all of the sugars. 'This suggests that the irregularity may be due to the poor growth in liquids, tested on "slants" of litmus agar, in fact, B. megatherium has been found to produce acid from dextrose and sucrose quite regularly. Similarly, its poor growth in broth raises a doubt as to whether the second figure of its group number (denoting it to be a strict aërobe) may be correct; for it grows so poorly even in the open arm of a fermentation tube that its failure to grow in the closed arm

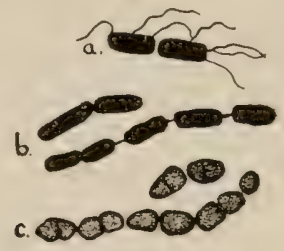

d. 0000000

FIG. 24.-B. megatherium. $\times 1000$ diameters. (After Conn)

does not necessarily prove its inability to grow in the absence of oxygen. It is also possible that its failure to reduce nitrates may be due merely to the fact that it grows poorly in nitrate broth.

"B. mycoides Flügge, 1886. - This is the most easily recognized of all the soil bacteria. It can readily be distinguished by its rhizoid growth on agar.

"Morphology. - Young cultures consist of rods about 0.8 to 1.3 by 2 to $6 \mu$. They occur in long chains which often lie parallel and show false branching, an arrangement which gives the colonies

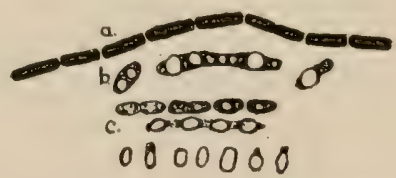

FIG. 25.-B. mycoides. $\times 1000$ diameters. (After Conn)

their rhizoid structure. The very young rods are apparently slightly motile, but no success has been obtained in staining flagella. Gottheil describes several peritrichic flagella. In older cultures, highly refractive globules that do not take ordinary stains (probably fat drops) appear within the rods, particularly if growing on dextrose agar, sometimes causing the rods to swell to extremely large size and to lose all resemblance to their original form. The lightly stained ovoid bodies that characterize $B$. megatherium have never been observed. Spores are borne centrally and the remnants of the 
sporangium wall persist for some little time at either end of the spores. Spores are oval to cylindrical 1.0 to 1.6 by 2 to $2.5 \mu$ often in fairly long chains.

"Cultural Characteristics. -Growth in broth vigorous, flocculent, with no persistent surface growth. Gelatin colonies rapidly liquefying, filamentous to rhizoid. Growth on agar streak rhizoid, mostly beneath the surface of the medium.

"Physiology.-The typical group number is B. 121.23230?2. It shows less variation than does the group number of $B$. megatherium, probably because $B$. mycoides grows better in the media used for making the tests. The same acid reactions are obtained in broth culture and on litmus agar.

"B. cereus Frankland, 1887. - This type can be distinguished from $B$. megatherium by the smaller size of its spores and by its more vigorous growth in liquid media, and from B. mycoides by the absence of rhizoid growth on agar.

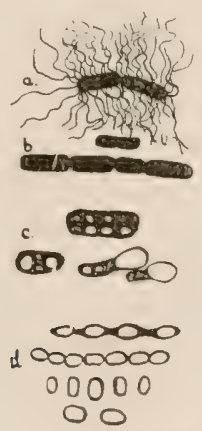

FIG. 26. - B. cereus, $\times 1000$ diameters. (After Conn)

"Morphology. - In morphology it is scarcely to be distinguished from $B$. mycoides. Young rods are 0.8 to 1.3 by 2. to $6 \mu$ forming long chains, but unlike $B$. mycoides they are very actively motile and are easily shown to be surrounded with numerous flagella. Older rods are often swollen and contain unstained globules. Oval to cylindrical spores, 1.2 to 1.6 by 2 . to $2.5 \mu$, are produced centrally, retain the remnants of the sporangium wall for a short time and often cling together in chains.

"Cultural Characteristics. - Growth in broth vigorous, with uniform turbidity, sediment and a surface pellicle. Gelatin colonies quite large, ordinarily round, with entire margin, and covered with a pellicle that generally shows concentric rings, although under some conditions the colonies are filamentous and resemble those of $B$. mycoides. Growth on agar streak raised, ordinarily rugose, soft to membranous, generally dull; never rhizoid or beneath the surface 
of the medium like B. mycoides or full of clear drop-like areas like B. megatherium.

"Physiology. - The typical group number is the same as that for B. mycoides, B. 121.23230?2, although considerable variation has been observed, particularly in the production of acid from sugars and from glycerin. In the earlier work, two subtypes were recognized, basing the distinction upon the production of acid from glycerin; but no such distinction is now recognized, because of the inconsistent results obtained in regard to acid production. Dextrose is always acidified by this organism; sucrose is generally acidified; glycerin less frequently, and lactose very seldom. A strain that acidifies lactose has always been found to produce acid from all three of the other compounds. The production of acid from lactose may be a better basis for subdividing the type than acid-production from glycerin. Out of 130 cultures studied, 19 acidified lactose; but it seems unwise to consider them as constituting a separate species, in view of the variation that has been found when cultures have been retested.

"Although many of the spore-formers are active ammonifiers in solution and occur in soils in comparatively large numbers, yet it is doubtful if they play any very important role in soil fertility.

"Although of considerable importance, except for the nitrifiers and some other organisms concerned with the transformation of nitrogen, scant consideration has been given to any non-spore-forming bacteria found in soil."

Ps. fluorescens which belongs to this group is described by Conn as follows:

"Ps. fluorescens (Flugge) Migula. - The most striking characteristic of this type is its fluorescence, which is observed in broth, beef-extract-peptone agar, and sometimes in gelatin. Ability to produce fluorescence is often lost, however, and then the type must be recognized by other characteristics, such as rapid liquefaction of gelatin, uniform turbidity in broth, cloudy, structureless colony in gelatin, and acid production from dextrose.

"Morphology. - Rods 0.4 to 0.8 by 0.8 to 1.5 microns in old cultures nearly the same shape and size as in young cultures. Flagella 3 to 6 , arranged in a clump at one pole. Motility great. Rods do not form chains.

"Cultural Characteristics. - Good growth in broth; no surface growth, uniform turbidity, causing distinct cloudiness of medium; sediment scant or none. Gelatin colonies liquefying with great rapidity; round to irregular in shape, cloudy, structureless, occasionally fluorescent. Growth on agar streak cultures, smooth, soft, glistening generally causing the medium to show a green fluorescence.

"Physiology.-The typical group number is Ps. 211.2332133. Fairly consistent results can be obtained in determining its group 
number, although certain variations oceur. Occasionally there is no acid from dextrose. Some of the cultures reduce nitrates. The power of producing fluorescence is often lost. These variations may indicate the existence of separate species that are now grouped under this one head.'

Actinomyces from 12 to 50 per cent. of the organisms found in soil are the Actinomycetes. This genus, the Actinomyces Harz, em. Gasperini, is characterized by the possession of a mycelium composed of hyphe which show true branching, like those of the higher fungi (seldom measuring over 2 microns in diameter), and judging by their staining reactions resemble true bacteria in their protoplasmic properties. Their growth is not wholly within the agar or gelatin medium upon which they have been inoculated; for when conditions favor, an aërial mycelium is produced. In the aërial mycelium "conidia" are formed. These conidia are sometimes round, sometimes oval, and sometimes rod-shaped. They resemble bacteria closely in size, shape, and staining properties. They are generally between 0.6 and 1.5 microns in diameter, and if oval or rod-shaped, between 1 and 2 microns long. They stain readily with ordinary bacterial stains, and in a microscopic preparation which does not contain any hypha, often cannot be distinguished from true hacteria. In many cases deep-stained granules show at the poles, strongly suggestive of the metachromatic granules of the diphtheria organism. According to Sanfelice, some of the actinomycetes are acid-fast like the tubercle organism. The diphtheria and tubercle organisms, moreover, sometimes produce branching forms, and some writers place these two organisms in the same group with Actinomyces.

The growth of actinomycetes on solid media is very characteristic. The mass of growth is generally of a tough, leathery consistency, sometimes smooth, sometimes wrinkled, and often piled high above the surface of the medium. Often the mass is brilliantly colored, and the color produced varies greatly with differences in the composition of the medium, but with constant composition of the medium, the color of the growth may be characteristic of the species. The aërial mycelium, often produced above this growth, may also be brilliantly colored and of an entirely different color from the mass of growth beneath it. Sometimes the aërial hyphr are short and give the growth a chalky or mildewy appearance; but often they are long enough to cover the growth with a light, delicate nap, 1 or $2 \mathrm{~mm}$. thick. Some species produce pigments that diffuse through the medium, coloring it gray, yellow, brown, red, blue, or green. The color varies with the species and with the composition of the medium. It is not so definitely characteristic of the species as is the color of the growth itself or of the aërial mycelium; but with a medium of constant composition, the color produced is of considerable value 
in the recognition of species. On gelatin there is less diversity of growth than on agar. The growth is generally gray, brown, or colorless; the aërial mycelium is often lacking, and if present is white, gray, or colorless; and if the medium itself is colored, it generally becomes a reddish brown.

The growth in liquid media is also characteristic. The medium remains clear except for small colonies that may sink to the bottom, remain in suspension, float on the surface, or adhere to the walls of the tube. The surface colonies often grow together and become covered with a mass of aërial mycelium, sometimes forming a firm, wrinkled membrane that strongly suggests the surface membrane of the tubercle organism growing on broth. Pigments are often produced in liquid culture, the pigment varying with the composition of the medium and with the species growing in it.

Nearly all liquefy gelatin and ammonify proteid, Münter maintaning that ammonification is their chief function. Nitrate reduction has often been observed, as has the decomposition of cellulose. Some are animal pathogens, and at least one a plant pathogen. Other important physiological activities will undoubtediy be worked out when the technic for studying them is further developed. It is not impossible that they are as diverse in physiology as are the true bacteria.

One of the most common characteristics of many members of this group is their peculiar odor. They have a pungent, musty odor, difficult to describe, but impossible to mistake after once having it brought to the attention. It is sometimes spoken of as an earthy odor, but it would be more correct to say that soil often has an actinomyces-odor, as the odor of the cultures is much stronger than that of soil, and the soil odor is undoubtedly due to the actinomycetes it contains. 'The odor seems to be associated with the aërial conidia, and does not seem to be produced by cultures that do not possess aërial mycelium. Not all species of Actinomyces have this odor, however, even when an abundant aërial mycelium is produced.

Various functions have been ascribed to the actinomycetesammonification, nitrate reduction, and cellulose-decomposition-but enough work has not been done to enable a definite statement as to whether these are their functions in the soil. Conn has demonstrated that the addition of grass roots to a soil materially increases this group of organisms and Waksman and coworkers consider that inasmuch as the actinomyces are strong cellulose decomposer's and weak producers of ammonia their probable role in soil fertility lies in the formation of humus.

\section{REFERENCES.}

Conn, H. Joel: Soil Flora Studies, New York Agr. Exp. Sta. Tech. Buls., 57, 58, 59, and 60 .

Waksman, Silman A.: Cultural Studies of Spccies of Actinomyces. Soil Science, 1919, viii, 71-215. 


\section{CHAPTER XVII.}

\section{MINERALIZATION AND SOLVENT ACTION OF BACTERIA.}

SolLs are the earthy material in which plants have their anchorage, and from which they obtain their water and part of their food. They are in reality disintegrated rock intimately mixed throughout with varying quantities of decaying plant and animal residues. They are derived from the native rocks by a complex process known as weathering. The agents at work to bring this about are changes of temperature, the action of air, water, ice, and plant and animal life.

Bacteria as Soil Formers.-Early in the history of soil formation bacteria appear and play an essential part in rendering the soil fertile. Their life activities result in the production of carbon dioxid, organic and inorganic acids, and alkalies. These in turn react with the constituents of the rock particles, thereby changing their solubility. When water becomes charged with substances from the soil, its solvent powers are greatly increased. Especially is this true when it becomes filled with carbon dioxid either from the atmosphere or from the decay of plants and animals.

Common limestone is one of the rocks most actively attacked by carbonated water; none are wholly resistant to its action. Even quartz is slowly dissolved. Granite and related rock are rather quickly acted on by water due to the feldspar minerals which it contains. The bases-potash, soda, lime, and alumina-are dissolved out. 'The last is deposited as clay, the first as beneficial or injurious soil constituents, depending on the lind and the concentration left in a particular soil. In a similar manner the sulphur, iron, and phosphorus of the soil are changed to available forms.

Moreover, bacteria play a very important part in the mineralization of plant and animal residues which continually find their way into the soil. The phosphorus, sulphur, iron, calcium, magnesium, and potassium in the plants and animals are mainly in the form of organic compounds and as such are not available to other plants. Bacteria act upon them, liberating carbon dioxid, ammonia, hydrogen sulphid or sulphur with the liberation of the plant-food. In this manner, the biological activities become of the utmost importance in the transformation and migration of mineral substances in Nature. The bacteria act merely as the link between the living and the dead. 
Calcium and magnesium oceur in soils mainly as carbonate, sulphate, silicate. and as the cation in the salts of organic acids which have resulted during the breaking down of the organic plant and animal residues.

Soil bacteria in their life processes are continually forming large quantities of carbon dioxid, nitrous, nitric, and sulphuric acid, together with organic acids which are in the main combined with calcium or magnesium of the soil, with the formation, often, of a soluble compound. The waters carry these to the lakes, seas, and oceans - there to be taken up by marine life. In the course of time these are deposited as coral reefs, chalk cliffs, and marl beds. At times the speed with which the lime is taken from the waters by marine life is faster than it is carried into a lake by its tributaries. The result is that, in spite of the evaporation and concentration which is going on, the main body of water contains less lime than does its tributaries. This is the case with Bear Lake, Utah, the tributaries of which have an average lime content of 101.7 parts per million, whereas the lake contains only 13.2 parts per million.

Calcium Carbonate.-The loss of calcium carbonate from a soil varies with (1) the methods of agriculture, intense methods increasing the loss; (2) with the application of animal manures and green manures, which increases the bacterial activity and also the solubility of the calcium carbonate; (3) with the addition of commercial fertilizers added to a soil which hasten the loss of calcium in drainage water.

The carbon dioxid generated by bacteria reacts with the calcium carbonate forming the much more soluble calcium bicarbonate: or

$$
\mathrm{CaCO}_{3}+\mathrm{CO}_{2}+\mathrm{H}_{2} \mathrm{O}=\mathrm{Ca}\left(\mathrm{HCO}_{3}\right)_{2}
$$

Ammonium sulphate resulting either from ammonification or from the addition of a fertilizer changes the calcium from an insoluble to a soluble form:

$$
\begin{gathered}
\left(\mathrm{NH}_{4}\right)_{2} \mathrm{SO}_{4}+2 \mathrm{CaCO}_{3}+4 \mathrm{O}_{2}=\mathrm{Ca}\left(\mathrm{NO}_{3}\right)_{2}+\mathrm{CaSO}_{4}+4 \mathrm{H}_{2} \mathrm{O}+2 \mathrm{CO}_{2} \\
\left(\mathrm{NH}_{4}\right)_{2} \mathrm{SO}_{4}+\mathrm{CaCO}_{3}=\left(\mathrm{NH}_{4}\right)_{2} \mathrm{CO}_{3}+\mathrm{CaSO}_{4}
\end{gathered}
$$

The addition of acid phosphate or potassium chlorid also helps deplete the soil of its calcium carbonate:

$$
\begin{aligned}
\mathrm{CaH}_{4}\left(\mathrm{PO}_{4}\right)_{2}+2 \mathrm{CaCO}_{3} & =\mathrm{Ca}_{3}\left(\mathrm{PO}_{4}\right)_{2}+2 \mathrm{H}_{2} \mathrm{O}+2 \mathrm{CO}_{2} \\
2 \mathrm{KCl} & +\mathrm{CaCO}_{3}=\mathrm{K}_{2} \mathrm{CO}_{3}+\mathrm{CaCl}_{2}
\end{aligned}
$$

The absolute amount of calcium and magnesium lost from a soil varies with the aridity of a region as well as with the composition of the soil. Hall estimates that the annual loss from the Rothamsted soil, which contains about 3 per cent. of calcium carbonate, is from 800 to 1000 pounds an acre annually, whereas in some parts 
of Scotland, where liming has been practised for some time, the loss is from 500 to 600 pounds. In this country, where liming is necessary, the farmers usually provide for a loss of 400 pounds an acre annually.

Bacteria are also responsible for the restoration of varying amounts of carbonates. In the weathering of complex silicates, carbonates and silicic acid may be formed in considerable quantities:

$$
\mathrm{CaAl}_{2} \mathrm{Si}_{2} \mathrm{O}_{8}+\mathrm{CO}_{2}+2 \mathrm{H}_{2} \mathrm{O}=\mathrm{Al}_{2} \mathrm{Si}_{2} \mathrm{O}_{5}(\mathrm{OH})_{4}+\mathrm{CaCO}_{3}
$$

According to Nadson, soil bacteria may cause the formation of calcium carbonate from calcium sulphate through the reacting of ammonium carbonate formed in the decay of protein substances with calcium sulphate:

$$
\left(\mathrm{NH}_{4}\right)_{2} \mathrm{CO}_{3}+\mathrm{CaSO}_{4}=\left(\mathrm{NH}_{4}\right)_{2} \mathrm{SO}_{4}+\mathrm{CaCO}_{3}
$$

Or even after the sulphate has lost its oxygen through the action of reducing bacteria, calcium carbonate may be formed through the action of carbon dioxid and water on the calcium sulphid:

$$
\mathrm{CaS}+\mathrm{CO}_{2}+\mathrm{H}_{2} \mathrm{O}=\mathrm{CaCO}_{3}+\mathrm{H}_{2} \mathrm{~S}
$$

Denitrifying bacteria may act on calcium nitrate with the formation of calcium carbonate:

$$
2 \mathrm{Ca}\left(\mathrm{NO}_{3}\right)_{2}+2 \mathrm{CO}_{2} \rightarrow 2 \mathrm{CaCO}_{3}+2 \mathrm{~N}_{2}+5 \mathrm{O}_{2}
$$

Calcium carbonate may also be formed in the soil due to the action of bacteria upon humates and calcium salts of simpler organic acids:

$$
(\mathrm{RCOO})_{2} \mathrm{Ca}=\mathrm{CaCO}_{3}+\mathrm{RCOR}
$$

Cunningham has demonstrated that 1zotobacter chroöcoccum is capable of growing in solution of calcium oxalate with the formation of calcium carbonate, as were also six other types of organisms isolated by him. 'The presence of oxygen is essential for the process. He considers that an equilibrium is set up by which the withdrawal of calcium carbonate is balanced by the results of another set of reactions which restores the base to the soil. This enables many soils which contain only very small quantities of lime to retain their neutral reaction and so to produce fair crops. This, however, is not always the case, as is witnessed by the acid soils occurring in many agricultural districts.

Phosphorus. - Phosphorus oceurs mainly in the form of the calcium, iron, or aluminum phosphate; in any soil the quantity soluble is small. Moreorer, as soluble phosphorus compounds are applied to the soil they become fixed as insoluble compounds. Hence, the loss through leaching of this element from the soil is small under any conditions. 
There are also rarving amounts of organic phosphorus in soil. This occurs in the form of lecithin, phospho-proteins, and nucleoproteins. Little has been done to determine the action of bacteria upon these compounds, but it is to be expected that they would be hydrolyzed by bacteria as they are by ferments.

Lecithin yields on hydrolysis glycerin, two molecules of fatty acid, phosphoric acid, and cholin:

$$
\begin{aligned}
& \underset{\text { lecithin }}{\mathrm{C}_{42} \mathrm{H}_{84} \mathrm{NPO}_{9}}+\underset{\text { water }}{4 \mathrm{H}_{2} \mathrm{O}}=\underset{\text { oleic acid }}{\mathrm{C}_{13} \mathrm{H}_{34} \mathrm{O}_{2}}+\underset{\text { palmitic acid }}{\mathrm{C}_{16} \mathrm{H}_{32} \mathrm{O}_{2}}+\underset{\text { glycerol }}{\mathrm{C}_{3} \mathrm{H}_{8} \mathrm{O}_{3}}+
\end{aligned}
$$

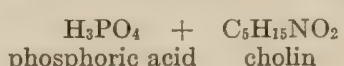

The phospho-proteins yield on hydrolysis amino-acids and phosphoric acid, whereas hydrolytic cleavage produces from nucleoproteins carbohydrates, phosphoric acid, purin and pyrimidin bases, with the intermediate formation of nucleins and nucleic acid, as may be represented by the following scheme:

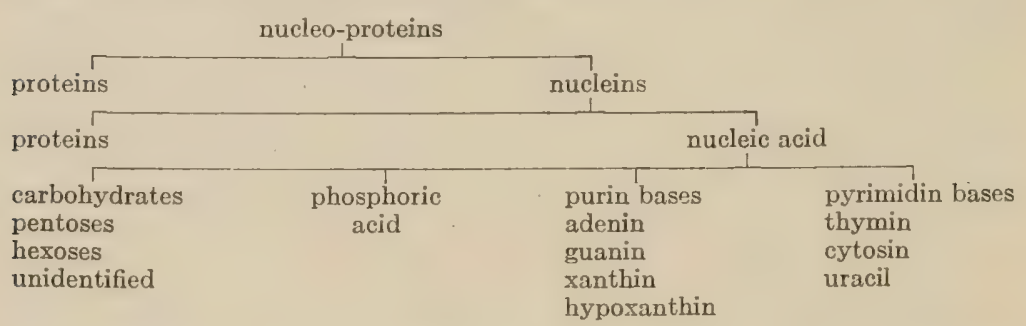

Schettenhelm has shown that nearly all of the nuclein substances of feces disappear as they undergo autoputrefaction. He and Schroeter showed that bacteria may bring about a deep cleavage of yeast nucleic acid. Plenge showed that some bacteria have the power to liquefy the sodium salt of nucleic acid from thymus.

It seems reasonable, therefore, to believe that phosphorus would be liberated by soil bacteria in a somewhat similar manner. It is known that the bacterial flora of the soil play a highly important rôle in rendering the phosphorus of the inorganic phosphates available to the higher plant.

Brown found that twelve out of twenty-three bacteria isolated from soil exerted a definite solvent action on difficultly soluble plant-food. One organism which produced no gas but a large amount of acid showed the greatest solvent action upon calcium carbonate, whereas other organisms which produced gas-largely carbon dioxid-but not as much acid as the former, gave an action more marked than that of the stronger acid-producer upon the dicalcium and tricalcium phosphates. B. subtilis, B. mycoides, B. proteus vulgaris, and B. coli communis, as well as several agar cultures from garden soil, were found to be capable of dissolving 
the phosphates of bone and to a less extent that of mineral phosphates. The greatest solvent action was exerted in media containing sodium chlorid, potassium sulphate, and ferrous sulphate. Even reast may be important in dissolving phosphates. As suggested by Krober the life activity of the bacteria, that is, assimilation of phosphorus by the living organism, probably plays little or no direct part in dissolving the phosphates, but it is due to the action of the organic acids and of the carbon dioxid produced.

The acids produced by bacteria act upon all phosphates, converting them into the soluble monophosphate, but the rate of solution varies widely with the different phosphates. Tricalcium phosphate in precipitated form, dicalcium phosphate, and tetracalcium phosphate of Thomas slag are much more rapidly dissolved than the crystalline or the so-called amorphous phosphates. The general reaction is as follows:

$$
2 \mathrm{R} \mathrm{COOH}+\mathrm{Ca}_{3}\left(\mathrm{PO}_{4}\right)_{2} \rightarrow \mathrm{Ca}_{2} \mathrm{H}_{2}\left(\mathrm{PO}_{4}\right)_{2}+(\mathrm{R} \mathrm{COO})_{2} \mathrm{Ca}
$$

The reaction takes place most rapidly in soils containing large quantities of organic matter due to the active fermentation taking place in such soils.

Grazia considers enzyme action to play a part in the dissolving of phosphates in soil, for he found the addition of chloroform to a soil reduced bacterial activity and decreased the acid produced, but at the same time the solution of phosphates was increased. This is in keeping with the finding of Bychiklin.

The presence of ammonium chloride and sulphate in the cultural media is especially effective in increasing the solvent action of bacteria, according to Perotti, who considers the successive steps in the solution or decomposition of phosphorus compounds by bacteria as follows: (1) generation of acids, (2) secondary reactions in the solution, and (3) production of a soluble phosphorus containing organic substance. 'The first two of these are the result of the activity of the bacteria on the phosphorus, and the last is due to the metabolic assimilation of the microörganisms.

The oxidation of sulphur by soil bacteria may at times generate sufficient acid to play a very important rôle in dissolving soil phosphorus. Hopkins and Whiting, however, consider that the nitrite bacteria are of the first importance in rendering phosphorus and calcium soluble when they oxidize ammonia into nitrites:

$$
\left(\mathrm{NH}_{4}\right)_{2} \mathrm{CO}_{3}+3 \mathrm{O}_{2}=2 \mathrm{HNO}_{2}+\mathrm{H}_{2} \mathrm{CO}_{3}+2 \mathrm{H}_{2} \mathrm{O}
$$

The resulting nitrous acid then reacts with the raw rock phosphate, rendering it soluble, thus:

$$
\mathrm{Ca}_{3}\left(\mathrm{PO}_{4}\right)_{2}+4 \mathrm{HNO}_{2}=\mathrm{CaH}_{4}\left(\mathrm{PO}_{4}\right)_{2}+2 \mathrm{Ca}\left(\mathrm{NO}_{2}\right)_{2}
$$


The actual ratio found showed that about one pound of phosphorus and about two pounds of calcium are made soluble for each pound of nitrogen oxidized, aside from the action of the acid radicals associated with the ammonia. The carbonic acid would play an important part also in this reaction:

$$
4 \mathrm{H}_{2} \mathrm{CO}_{3}+\mathrm{Ca}_{3}\left(\mathrm{PO}_{4}\right)_{2}=2 \mathrm{Ca}\left(\mathrm{HCO}_{3}\right)_{2}+\mathrm{CaH}_{4}\left(\mathrm{PO}_{4}\right)_{2}
$$

They found that neither ammonia-producing bacteria nor nitrate bacteria liberated appreciable quantities of soluble phosphorus from insoluble phosphates.

Whereas this would readily occur in soil poor in calcium carbonate, in those rich in calcium carbonate there would be only small quantities of phosphorus liberated, according to Kelley. But where the soluble phosphorus is being rapidly remored by the growing plant, or even by bacteria, there is little doubt that the various soil organisms play an important part in rendering phosphorus soluble, for results obtained at the Utah Experiment Station show there to be a relationship between the increased nitrification produced by various salts, and the quantity of water-soluble and organic phosphorus in the soil. 'This is illustrated by the following results which give the nitric nitrogen, water-soluble and organic phosphorus in a soil after various treatments, the untreated soil being considered as 100 per cent.

PER CENT. NITRIC NITROGEN WATER-SOLUBLE AND ORGANIC PHOSPHORUS OCCURRING IN SOIL RECEIVING VARIOUS SALTS.

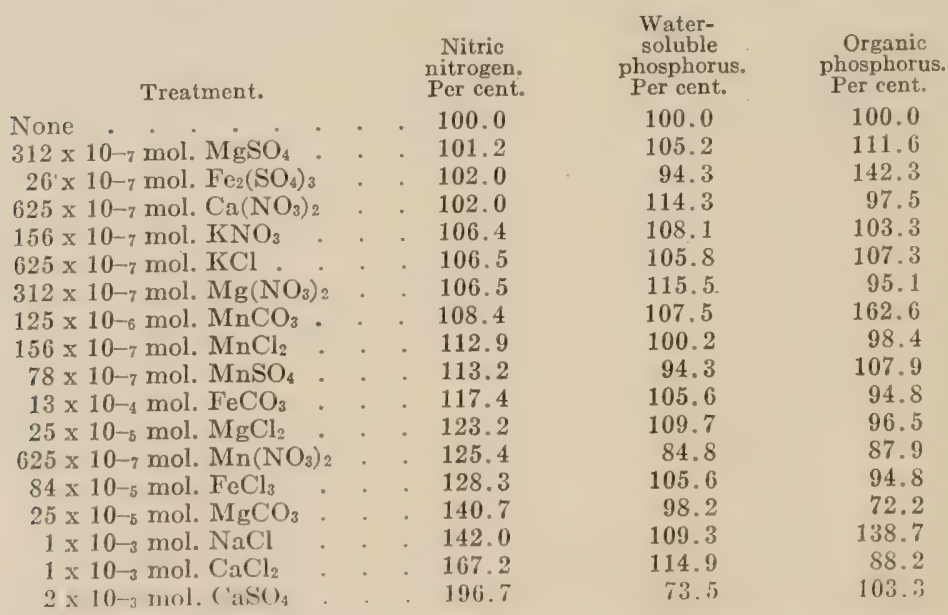

Moreover, it is evident that Azotobacter in their metabolism transform soluble inorganic soil constituents either into soluble or into insoluble organic forms. 'This is especially true of phosphorus which 
is found in the ash of these organisms in such large quantities. The phosphorus, on the death of the organism, would be returned to the soil in a readily available form, for Stoklasa has found that 50 per cent. of the nitrogen of these organisms is nitrified within six weeks, and there is no reason for believing that the phosphorus would be liberated much more slowly. Then there is the possibility that many of the constituents of the bacterial cell may become arailable, through the action of autolytic enzymes without the intervention of other bacteria.

It is further evident that an organism which possesses the power, when growing under appropriate conditions, of generating 1.3 times its own body weight in carbon dioxid during twenty-four hours, as does the Azotobacter, must greatly change the composition of the media in which it is growing. Water charged with carbon dioxid is a universal solvent and will attack even ordinary quartz rock. Granite and rocks related to it are rather quickly attacked, with the liberation of potassium and other elements. Carbonated water would act upon the tricalcium phosphate of the soil with the formation of more readily soluble phosphates, for this substance is four times as soluble in water charged with carbon dioxid as it is in pure water:

$$
\mathrm{Ca}_{3}\left(\mathrm{PO}_{4}\right)_{2}+2 \mathrm{CO}_{2}+2 \mathrm{H}_{2} \mathrm{O}=\mathrm{Ca}_{2} \mathrm{H}_{2}\left(\mathrm{PO}_{4}\right)_{2}+\mathrm{Ca}\left(\mathrm{HCO}_{3}\right)_{2}
$$

Moreover, the nitrogen-fixing organisms form, among other products, formic, acetic, lactic, butyric, and other acids. The kind and quantity of each depends upon the specific organisms and upon the substance on which they are acting. These substances are sure to come in contact with some insoluble plant-food which may be rendered soluble, for they have a highly solvent action on the insoluble phosphates. The resulting salts of calcium would be further attacked by bacteria, with the formation of calcium carbonate.

Whether these processes will give rise to an increase in the watersoluble plant-food of the soil depends upon whether the products of the second, the analytic reactions, exceed the products of the first, the sinthetic reactions. It must not be forgotten that, although many of the organic phosphorus constituents may not be soluble in pure water, ther may be more available to the living plant than are the constituents from which they were at first derived through bacterial activity.

This being the case, variations in the results reported from laboratory tests are to be expected. Stoklasa found that bacterial activity rendered the phosphorus of the soil more soluble, whereas Severin, in his early work, found the opposite to be true. Others have found that the solvent action of bacteria for insoluble phosphates is in direct proportion to the acid secreted by the organism. 
In a later work, Severin obtained different results. He used three soils-one sterile, a second sterilized and inoculated with pure cultures of Azotobacter, and a third sterilized and inoculated with cultures of $P s$. radicicola and Azotobacter. The solubility of the phosphorus increased 8 to 14 per cent. over that in the sterile soil. The acid-producing organisms, due to the acid secreted and their intimate contact with the soil particles, possess the power of dissolving silicates. Moreover, arsenic greatly stimulates nitrogen fixation, and there is a relationship between this increased bacterial activity and the form and quantity of phosphorus found in a soil.

Although the metabolic activity of Azotobaster gives rise to large quantities of phosphate solvents, yet these organisms transform phosphorus into organic phosphorus compounds less rapidly than do the ammonifiers. There are, however, cases in which bacterial activity has decreased the water-soluble phosphorus of the soil and of raw rock phosphate. This does not mean, however, that it is less arailable, for, as pointed out by Truog, the mixing of floats with manure caused an immediate decrease in the solubility of the phosphorus in 0.2 per cent. citric acid solution, yet when thoroughly mixed with the feeding area of the soil its availability was increased to such an extent that some species of plants were apparently able to secure almost an adequate supply of phosphorus from this material. The addition of manure to a soil greatly increased the carbon-dioxid production, and for a short time measurably increased the solvent action on floats. Where there is for a time a decrease of water-soluble phosphorus in fermenting media, it is probably due to the formation of phospho-proteins within the bodies of the bacteria which would later be rendered soluble due either to further bacterial activity or to autolytic enzymes.

Sulphur. - Sulphur is an essential element for all plants, but the quantity required is relatively small and most soils contain sufficient for maximum crop production. It occurs within the soil mainly as sulphate or organic sulphur, and these substances are often materially changed by bacterial activity.

Bacteria act on sulphur compounds in three ways: (1) on complex organic compounds with the production of hydrogen sulphid or mercaptans, (2) the oxidation of sulphur compounds occurring in the soil, and (3) the oxidation of sulphur compounds, especially hydrogen sulphid by the true sulphur bacteria, with the production of metallic sulphur, sulphuric acid, and erentually mineral sulphates.

Hydrogen sulphid is produced by the majority of the common laboratory forms of bacteria. Lafar states that this faculty is even very common among the pathogenic bacteria and was absent in not a single one of :37 species examined. Other bacteria possess the power of reducing sulphates. Beijerinck found in soil an organism which he named Spirillum desulphuricans and which Van Delden 
later classified as Microspira desulphuricans which possessed the power of reducing sulphates. Another sulphate-reducing organism is Msp aestuarii. These organisms act only in the presence of organic matter:

$$
\mathrm{MSO}_{4}+2 \mathrm{C}=2 \mathrm{CO}_{2}+\mathrm{MS}
$$

The true sulphur bacteria possess a directly opposite physiological action to the reducing bacteria. There are two genera of the true sulphur bacteria recognized-Beggiatoa and Thiothrix. Beggiatoa is filamentous, motile, and morphologically resembles the bluegreen alga, Oscillaria. Thiothrix is not filamentous nor motile and possesses a sheath and forms spores. The sulphur bacteria contain in their protoplasm highly refractive inclusions of amorphous sulphur. According to Winogradsky, a single Beggiatoa thread used in a day two to four times their own weight of hydrogen sulphid with the production of sulphur:

$$
4 \mathrm{H}_{2} \mathrm{~S}+2 \mathrm{O}_{2}=4 \mathrm{H}_{2} \mathrm{O}+4 \mathrm{~S}
$$

The sulphur seen within the cell protoplasm is to be looked upon as an intermediate state in the oxidation process, for if the organisms be transferred to fresh water these soon disappear with the formation of sulphuric acid:

$$
2 \mathrm{~S}+3 \mathrm{O}_{2}+2 \mathrm{H}_{2} \mathrm{O}=2 \mathrm{H}_{2} \mathrm{SO}_{4}
$$

This reacts with a base, usually calcium carbonate, with the formation of calcium sulphate:

$$
\mathrm{CaCO}_{3}+\mathrm{H}_{2} \mathrm{SO}_{4}=\mathrm{CaSO}_{4}+\mathrm{H}_{2} \mathrm{O}+\mathrm{CO}_{2}
$$

There are also organisms in soil that can oxidize sulphur to sulphuric acid which in turn would act as a solvent for plant-food. Moreover, small quantities of sulphur added to a soil will increase ammonification. It is likely that much of the benefit resulting from sulphur fertilization is due to these factors.

Brown has recently shown the power of oxidizing sulphur to vary with different soils. Aëration and optimum moisture favor it, whereas the addition of carbohydrates, depresses the process. He has elaborated a method of measuring the speed of sulphur oxidation in soils and given to it the name of sulphofication.

According to Lafar, the importance of the sulphur bacteria in the economy of nature is unmistakable. In coöperation with the sulphatereducing bacteria they insure that the sulphur cycle pursues an uninterrupted course, the elements being taken up by the higher plants in the condition of sulphates and deposited in the cells in the torm of organic compounds from which, in the course of putrefaction, sulphur is liberated as hydrogen sulphid, and finally reconverted intosulphateby the sulphur bacteria. It then recommences its course through the higher plants. 
Iron. - The iron bacteria resemble the sulphur bacteria greatly in their metabolic activity. The best known of these organisms are the ('renothrix polyspora, Chlamydothrix ochracea, and Spirophyllum ferminineum. Winogradsky considers that the iron is deposited in the sheath of the organisms due to a physiological reaction, the organisms oxidizing ferrous to ferric compounds:

$$
4 \mathrm{FeCO}_{3}+6 \mathrm{H}_{2} \mathrm{O}+\mathrm{O}_{2}=2 \mathrm{Fe}_{2}(\mathrm{OH})_{6}+4 \mathrm{CO}_{2}
$$

The energy so liberated is utilized in their growth. However, the investigations of Molisch, Adler, and Ellis show that they grow well in a medium devoid of iron and that the precipitation of the iron is due to chemical and mechanical processes independent of the physiological activity of the organism. They play a great part in the deposition of bog-iron, though not the only cause, for Molisch considers that well-known physio-chemical agencies often play an important part in the process. Manganese may at times be found in the sheath of Crenothrix, in large quantities.

Potassium. - This element is required by all plants in comparatively large quantities, and the total supply in nearly all soils is exceedingly large as compared to crop requirements. Yet potassium is quite extensively used as a fertilizer, and this with beneficial results. This is due to the fact that its addition to a soil well supplied with available potassium results in the liberation of other more deficient plant-food elements. Moreover, it may be applied to soils having a large quantity of total potassium, but a small quantity available to plants. Therefore, one of the problems which is confronting the farmer is how to render available as needed by plants the large supply of potassium in the soil.

The potassium occurs in the soil mainly as silicates and is rendered soluble by the nitrous, nitric, sulphuric, acetic, lactic, and butyric acids, and by carbon dioxid. The last may react with inert potassium resulting in the formation of available potassium according to the following equation:

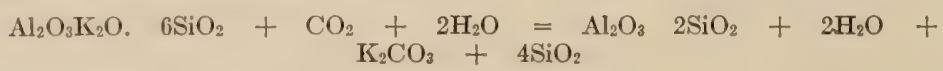

Hence, the addition of animal manure, green manures, commercial fertilizers, or even soil amendments may increase bacterial activity and in a similar degree increase the soluble soil potassium.

\section{REFERENCES.}

Lafar, Franz: "Handbuch der Technischen Mykologie," Dritter Band.

Greaves, J. E., Carter, E. G.: "The Action of Some Common Soil Amendments" (Soil Science, vol. vii (1919), pp. 121-160).

Kossowicz, Alex.: "Agrikulturmykologie, I Bodenbakteriologie."

Ellis, David: Iron Bacteria, London, 1919. 


\section{CHAP'TER XVIII.}

\section{THE CARBON, NITROGEN, SLLPHIR, AND PHOSPHORUS CYCLES.}

Plants contain ten essential elements, and these elements found in the body of the plants or animals today are the same as those which constituted the organic world thousands of years ago. But between these dates they may have played many parts, or, in the words of Duncan, "We believe - we must believe in this day-that everything in the universe of world and stars is made of atoms, in quantities $x, y$, or $z$, respectively. Men and women, mice and elephants, the red belts of Jupiter and the rings of Saturn, are, one and all, but ever-shifting, ever-varying swarms of atoms. Every mechanical work of earth, air, fire, and water, every criminal act, every human deed of love or valor; what is it all, pray, but the relation of one swarm of atoms to another?

"Here, for example, is a swarm of atoms, vibrating, scintillant, martial - they call it a soldier - and, anon, some thousands of miles away upon the South African veldt, that swarm dissolves-dissolves, forsooth, because of another little swarm-they call it lead.

"What a phantasmagoric dance it is, this dance of atoms! And what a task for the master of the ceremonies! For, mark you, the mutabilities of things. These same atoms may come together again, vibrating, clustering, interlocking, combining, and there results a woman, a flower, a blackbird, or a locust, as the case may be. But tomorrow again the dance is ended, and the atoms are far away; some of them in the fever germs that broke up the dance, others are the green hair of the grave, and others are blown about the Antipodes on the wings of ocean, and the eternal everchanging dance goes on."

In this building up and breaking down, bacteria play an allimportant part. The higher plants build up the carbon and nitrogen into complex organic compounds. This same end is also accomplished to a lesser degree by the animals which, however, mainly act as analyzers of organic matter, but the master analysts are the bacteria which are continually resolving into simple and often elementary constituents, the plant and animal débris. IVere this not true, all the carbon and combined nitrogen of the world would soon become locked up in the dead bodies of animals; plants would starve and die, and animals would likewise become extinct. Therefore, bacteria are the link between the living and the dead. The 
ahsence of bacteria is incompatible. with life on this earth, or', as stated by Pasteur, "they are the important, almost the only, agents of universal hygiene. They clear away more quickly than the dogs of ( onstantinople or the wild beasts of the desert, the remains of all that has had life; they protect the living against the dead; they do more; if there are still living beings, if, since the hundreds of centuries the world has been inhabited, life continues, it is to them we owe it."

The Carbon Cycle.-Carbon occurs free in the earth as coal to the extent of over 500 billion tons. Chemically combined, it is found in far larger quantities in limestone, chalk, marble, and dolomiterocks which form such a considerable portion of the surface of the earth. According to Pettenkofer, a man weighing 154 pounds contains 26.4 pounds of carbon; no less than 257 million tons' weight of it is, therefore, stored up in the bodies of men and women living upon the earth at the present time, to say nothing of the far greater quantities occurring in the tissues of trees, plants, and lower animals.

Carbon dioxid occurs in the atmosphere to the extent of three parts in 10,000 . This is the equivalent of 600 billion tons of carbon. Moreover, the ocean is a vast reservoir of carbon dioxid, which is partly in solution and partly combined. Between the surface of the sea and the atmosphere there is a continual interchange, each at times losing and at times gaining the gas.

Carbon dioxid is being added to the air from several sources: the combustion of fuel, the respiration of animals, and the decay of organic matter. It is also being evolved in enormous quantities from mineral springs and volcanoes. Krogh estimates that the annual consumption of coal adds yearly to the atmosphere about one-thousandth of its present content in carbon dioxid. Were there no factors off setting this increase in atmospheric carbon dioxid animal life would soon become extinct.

On the other hand, there are two large factors at work removing carbon from the atmosphere-first, the decomposition of carbon dioxid by plants with the liberation of oxygen, and second, the consumption of carbon dioxid in the weathering of rocks. No precise valuation can be given to either of these factors, although various writers have attempted to estimate their magnitude. Cook computes that leaf action alone more than compensates for the production of carbon dioxid. Chamberlain estimates that the amount of carbon dioxid annually withdrawn from the atinosphere is 1,620,000,000 tons, and that the greater part of this is taken up by the weathering of mineral. This is continually being returned to the atmosphere by the factors considered in the preceding chapter. 'There are then two compensating sets of factors-decay, respiration, and combustion liberating carbon; plant growth and rock weathering fixing it. 'These balance each other, thereby completing 
the carbon cycle and rendering the carbon-dioxid (ontent of the atmosphere nearly constant.

The Nitrogen Cycle.-Since nitrogen occurs as an essential part of the structure of every plant and animal, it is found in all crops and crop residues. It occurs in the top soil in proteins, protein decomposition products, ammonia, nitrites, and nitrates. It is not found in the mineral matter of the earth except in shales and other deposits containing the residues of plant and animal bodies. Hence, the quantity in the combined form is not great when compared with other essential elements. Yet it is required by all living organisms in large quantities. Many of these are returning it to its inert atmospheric form. This fact led Sir William Crooks, in his famous address before the British Association for the Adrancement of Science in 1898 , to predict dire calamity to the human race if science were not able to utilize atmospheric nitrogen.

In the free form, nitrogen occurs in enormous quantities; fourfifths of the atmosphere is composed of it. Dr. IIoplins has pointed out that the total supply of nitrogen over each acre of the earth's surface, if available, would meet the needs of a hundred-bushel crop) of corn every year for 500,000 years, whereas the supply of carbon is sufficient for such crops for only two years. Nevertheless, carbon has no commercial value as plant-food, while nitrogen in available form is worth from 15 to 20 cents a pound on the market.

The same atom of nitrogen at different times plays many different rôles. One of the triumphs of agricultural bacteriology is the advancement which it has made in following nitrogen through its cycle.

Nitrogen occurs in the plant and animal mainly in the form of protein. The plant protein may be eaten by the animal and produce animal protein. Either may reach the soil and decay. 'The nitrogen eaten by animals may be deposited as tissues of the animal or excreted as urea, hippuric or uric acid. These products are acted upon by bacteria with the formation of ammonia.

Either the plant or animal proteins may reach the soil where decay sets in with the formation of albumoses, proteoses, peptones, peptids, and amino-acids. The amino-acids are then deaminized with the formation of an acid and ammonia. The process is spoken of as ammonification.

The ammonia does not accumulate in the soil, but is acted upon by other bacteria, the nitrosomonas, with the formation of nitrous acid. This is quickly taken up by the nitrobacter and oxidized to nitric acid which reacts with bases in the soil with the formation of nitrates. The nitrates are the main source of nitrogen for the plants which build from them and carbon dioxid, amino-acids, peptids, peptones, proteoses, albumoses, and finally plant proteinsand the nitrogen has completed its cycle. If this were the whole 
story the quantity of combined nitrogen in the world would remain constant. But it is not-there are many leaks in the cycle. Some of the plants and animals may be burned with the liberation of free nitrogen. Millions of pounds of it reach sewers, and from here rivers, lakes, and oceans. In time this is broken down and the nitrates so formed are reduced by denitrifying bacteria with the liberation of gaseous nitrogen. The processes of decay continually going on may also liberate free nitrogen. Furthermore, millions of pounds of nitrogen are returned to the air by explosives. So the combined nitrogen would continue to grow less were it not that other factors are at work in nature causing it to combine. Every flash of lightning causes some nitrogen to combine as oxids, but the quantity of combined nitrogen thus formed is relatively insignificant. 'The major factors are biological. There are within the soil two great groups of bacteria which possess the power of fixing nitrogen. The first-the non-symbiotic nitrogen-fixing organisms living free in the soil-are able, with the energy they obtain from the oxidation of organic carbon, to build up complex organic nitrogen compounds. There are two groups of these organisms - the aërobic and the anaërobic, the first being the more important. The other class of nitrogen-fixers is the symbiotic; these live in conjunction with legumes and obtain from them carbonaceous material, and in return give combined nitrogen. In either case the combined nitrogen becomes available for higher plants. Then it again starts on its journey through the living and the dead.

The Sulphur Cycle.-Sulphur is an essential element for all plants and animals, but the quantity required for normal growth and development is relatively small even when compared with the small percentage found in soil. It occurs in the soil as organic and inorganic sulphur. The former is derived from the plant and animal residues. These are acted upon by microörganisms with the liberation of hydrogen sulphid, sulphur dioxid; and sulphates. Some of the hydrogen sulphid is carried into the ocean or soil by the first rain; some of it reacts upon the iron silicates of the soil and forms pyrite or marcasite, but most of it is oxidized by bacteria with the formation of sulphates. The sulphur dioxid is also further oxidized to sulphates, when they are again taken up by plants and start anew upon their wonderful journey through bacteria, higher plants, and animals.

The Phosphorus Cycle.-Phosphorus occurs in the soil in the form of calcium, aluminum, and iron phosphate, also as organic phosphorus. It is also found in places as huge deposits of rock phosphate. It is an integral part of every living plant and animal cell. In these it occurs in two forms - organic and inorganic. The organic phosphorus occurs in the nucleo-proteins, phospho-proteins, and phospho-lipins.

'The mineral phosphates of the soil are rendered soluble through 
bacterial anctivity, as outlined in a preceding chapter. 'This is talien up by the living plant and deposited either as organic or inorganic phosphorus compounds within the plant tissues. The plant tissues, if eaten by animals, yield phosphorus to the animal to be laid down in the body of the animal as organic or inorganic compounds. 'The excreta of animals always contain phosphorus in both organic and inorganic forms. The inorganic phosphorus is readily utilized by plants and again starts on its cycle. However, the organic and animal residues must be mineralized by bacteria before they can be utilized again by plants. Microörganisms split oft the carbonaceous material and the phosphorus is liberated mainly in the form of phosphates. Lnder some conditions mold action may give rise to small quantities of phosphin which must be again oxidized before being available to higher plants. In either event, the resulting phosphate is now ready to start on its eyclic journey through the plant and animal organism. This is dramatically outlined for a phosphorus atom by one writer as follows:

"Where was I born? Ah, that I cannot tell you. It was far, far away from here, deep in the endless abyss of space, at an epoch so distant that even the earth on which you live had not been formed as yet; not even the great sun, now blazing in his glory, nor any of the innumerable multitudes of stars of the great univer'se now shining in the sky, had as yet come into being. No, they were mere cold whiff's of invisible vapor, scattered over all space, remmants of worlds vanished xons before this great universe began. Out of the vast I came, born into that great sea of ether which stretches unbroken from star to star through all the endless depths of space. some vast change, some murmuring and stirring of gigantic forces in its bosom, forces searce known, scarce dreamt of, but working there in irresistible might, first brought me into being, and I hung suspended in the great void. It was utterly cold and utterly dark, and gleaming afar in the distance I could see the myriad fires of the great worlds and suns of space shining at me through the darkness. How long I hung in the void I know not. It was millions upon millions of years. Then atoms began to gather round me, streamwise, coming from afar in phosphorescing torrents, and I perceived that I already formed part of a mighty mass of gas, a huge nebula, which stretched its gigantic arms out for millions of miles, like vast flaming swords, through the darkness of space. And so I hung for xons of time, while atom after atom in an endless stream flashed past me in the gloom, while the great nebula slowly drew together in its glory, and began to take shape and form. Then the temperature began to rise in leaps and bounds, it grew stifling hot, and great lightnings flashed and quivered about me, and we atoms crowded more and more together, colliding, whirling, flying. Each second I smote a thousand million atoms and at each collison my motion grew 
more and more violent, until after millions upon millions of rears of this tumult, I found myself part of an immensely hot flaming mass of gas, part of an embryo sum. There in the whirl and roar of this elemental flame I remained for unthinkable ages, but at last rast thunders beneath and around me made me aware that something tremendous was happening. It was a world-my first worldgradually condensing out of the fire mist, and the gigantic explosions which occurred from time to time were just great seas of boiling rock leaping upwards. I will spare you the account of how I entered into that world, and saw it slowly form and develop into a fair planet, covered with wonderful swarming masses of living creatures, with great cities filled with busy life, and wonderful civilizations. Nor will I tell you of how that world grew old, and passed into a rast desert, and finally, after wandering for a ons of time in darkness and silence, burst suddenly forth into flame, the victim of a great cosmical catastrophe, and, like a bubble, ranished, exploding into incandescent gas. Nor will I tell you of how, far flung, I fell upon another world, and saw this world too in time perish; and of how I passed from world to world, and formed part of world after world, wandering in mighty migrations through space, until at last I joined the fire mist from out of which, ultimately, this present world of yours condensed amidst titanic convulsions. You will, therefore, see that eren before your world began, I was old, immensely old. I will pass over all this and come to a time quite recent, when I found myself forming part of the molten fire underground. Here I lay for age after age, while the land above me was being eaten away by wind and rain and storm, and was buried-continent after continent crumbling into ruin-into the great ocean waiting patiently to receive it. Now I was urged upward by rast forces, slowly, steadily, for thousands of years, until I finally was uplifted to form part of a hard, cold rock, which soon reared itself into a mighty clifi, beaten upon by wind and rain and storm; I have a dim recollection of looking out from the cliff face upon a widespread blue sea, filled with strange rast monsters, which have long since ranished from the earth. But at last the clift was washed away and I passed into the great body of the sea, and was absorbed into a tiny plant, living beneath the salt waters; but this was devoured by a glittering rorgeous fish, and so I entered his body. Then this fish was devoured by a reptile, which, creeping out of the water, entered a swamp and died, and its huge body decaying, I was washed into the soil, and there meeting with the rootlet of a plant, I entered into and formed part of it; and this was eaten by an animal; and so I entered into its body and formed part of it; and this was eaten by an animal; and so I entered into its body and formed part of his bones. While we were crossing a ravine one bright sunshiny day, millions of years ago, a green monster flashed out upon us and slew my master and 
devoured me. After a time my new host wats also slain in a similar manner, and his body, decaying in the rank grass and regetation of the swamp, I was ultimately washed out to sea in a sudden flood, which, coming down from the hills, swept me away. Here I mingled with the mud at the bottom of the sea, and stayed there for millions of years, and became covered over with mighty layers of mud and sand, and sank ever deeper and deeper into the earth, and at last once more felt the glow of the nether fires. Here in the great gleaming-furnaces of the deep I remained for many millions of years, while miles above me the world changed and dereloped, mountains came and went, new and strange creatures erolved, dereloped, filled all the earth, and died out again. One day, I was hurled forth amidst rast thunderings through the throat of a mreat rolcano, and formed part of a molten lava stream, which in time hecame a fertile field covered with waring crops and golden grain. 'Then I entered into a grain of corn, and was devoured by a man living thousands of years ago, a mere savage you would term him, wild and fierce. From him I passed to earth once more, and since then have been passing in a ceaseless round of change through the bodies of living creatures. I have flown through the air in a bird, I have swum in the sea in a fish, I have roamed over the earth in a beast, I have formed part of innumerable plants. But the full tale would only weary you, wonderful as it is. One day, a few years ago, I was deroured by an ox while forming part of a piece of grass, and soon by the mysterious chemical forces of its body I was made to form part of its bone. The great beast was slaughtered by men, and his flesh eaten, and his bones burnt to a fine white dust in a furnace. Out of this dust, I, the tiny phosphorus atom, was distilled in a furnace and found my way to a match factory, and am now in this little match-box lying in the table before you. Is my journey finished? Oh dear no, far from it. I shall go on changing and journering and dancing, age after age, even until the world fades away like a mist, and long after all that you see and hear around you has crumbled away and vanished into the awful maw of time. I have been taking part in the great dance of atoms which forms the basis of all passing things and events, for millions upon millions of years, and shall continue to do so for millions and millions of years to come. I may, indeed, see this world perish, and may yet dance in worlds as yet unborn. My future will be probably even more strange than my past."

\section{REFERENCES.}

Kossowicz, Alex.: "Agrikulturmykologie, I Bodenbakteriologie."

Lafar, Franz: "Handbuch der Technischen Mykologie," Dritter Band. 


\section{CHA PTER X I X.}

\section{PUTREFACTION, FERMENTATION, AND DECAY.}

Putrefaction, fermentation, and decay are in reality terms which are essentially distinct although they have been greatly confused and used symonymously even by professional men. As pointed out by Kendall, this confusion is attributed partly to the use of terms to designate certain processes which occur in nature before these changes were studied either biologically or chemically.

Definitions. - Fischer considers the term fermentation, as it should be used in bacteriology, as the biochemical decomposition of nitrogen-free compounds, chiefly carbohydrates, due to the action of microörganisms, and putrefaction as the biochemical decomposition of nitrogenous organic compounds by the action of microörganisms.

The distinction which is usually drawn between decav and putrefaction - as the decomposition of nitrogenous organic substances in the presence of oxygen on the one hand, and the absence of oxygen (or with a limited supply) on the other-is not always sharply. defined. The end products in both cases may be quite similar. Nencki found that in the decomposition of gelatin at $40^{\circ} \mathrm{C}$. in the presence of air, there were formed in four days for every 100 parts of the original substance 9.48 parts of ammonia, 24.2 parts of volatile fatty acids, 12.2 parts of glycocol, $19.1 \pm$ parts of peptone, and 6.45 parts of carbon dioxid, the other 28.53 parts being undetermined. Jeannert repeated these experiments with the exclusion of air and found as the decomposition products of gelatin, carbon dioxid, ammonia, a gas smelling like carbon bisulphid, acetic, butrric, and valeric acids, glycocol, leucin, and a colloidin base-like substance. He concluded from these and other experiments that (1) the decomposition of nitrogenous substances and of carbohydrates may be accomplished with access or exclusion of air; (2) in the latter case the decomposition is considerably less rapid, and complete decomposition requires a period six times as long; and (3) the more simple chemical products formed are in the two cases identical.

Nor is it a safe criterion to state that putrefaction is accompanied by the formation of ill-smelling substances, for this is usually a quantitative and not a qualitative difference. Moreover, Hirschler has pointed out that the putrefaction of protein substances is modified by the presence of carbohydrates. 'The addition of various ('arbohydrates, glycerin, and calcium carbonate changed the decom- 
position of meat so that aromatic products of putrefaction could not be detected. From this he drew the conclusion that the decomposition of protein substances in the presence of cane sugar, starch, dextrin, glycerin, or lactic acid may not be accompanied by the formation of the characteristic putrefaction products - indol, phenol, and oxyacids. Nevertheless, there is a marked quantitative difference in the two processes-decay and putrefaction. The former is marked by the volatilization of the organic constituents-either protein or non-protein-while the non-volatile mineral constituents are left behind in a form largely available. Putrefaction is the rapid and intense decomposition of nitrogenous (for the most part protein) bodies by certain bacteria, usually with the formation of large quantities of gaseous, ill-smelling products. There may result as intermediate products, basic substances often having highly toxic properties. These substances have been named ptomaines by Brieger. Many of them contain only carbon, hydrogen, and nitrogen, and are ammonia-substitution products. Some of the simpler ones are:

\section{Methylamin \\ Dimethylamin \\ Trimethylamin \\ Putrescin \\ Cadaverin}

\author{
$\left(\mathrm{CH}_{3}\right) \mathrm{NH}_{2}$ \\ $\left(\mathrm{CH}_{3}\right)_{2} \mathrm{NH}$ \\ $\left(\mathrm{CH}_{3}\right)_{3} \mathrm{~N}$ \\ $\mathrm{NH}_{2}\left(\mathrm{CH}_{2}\right)_{4} \mathrm{NH}_{2}$ \\ $\mathrm{NH}_{2}\left(\mathrm{CH}_{2}\right)_{5} \mathrm{NH}_{2}$
}

They are usually protein-cleavage products, sometimes resulting from the mere removal of carbon dioxid from the carboxyl of the amino-acid. Putrescin may be formed from ornithin thus:

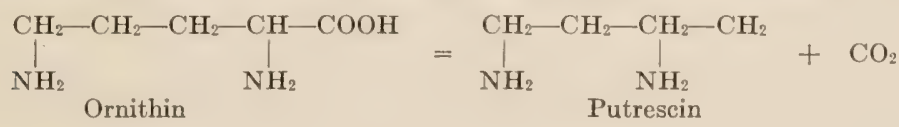

and cadaverin from lysin:

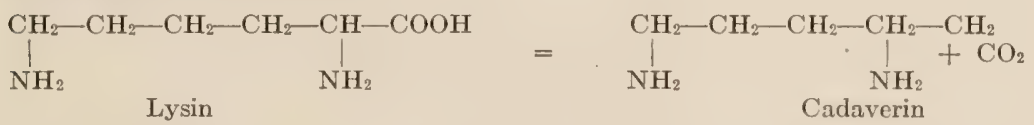

In putrefying mixtures the ptomaines appear on or about the fifth or serenth day after putrefaction sets in, and disappear, by further cleavage, more or less rapidly, yielding less complex nitrogenous substances that are non-toxic.

Active Agents. - Liebig and the early workers considered these changes to be purely chemical processes. The ferment was to them an extremely alterable organic substance which decomposed, and by decomposing set in motion its own elements. The momentum thus engendered is sufficient to tear to pieces the fermenting substance. This in turn then possesses the power of imparting to other compounds this same property, or, in other words, they considered 
fermentation a true chemical process. This was orerthrown by Pasteur, who proved fermentation to be due to living microscopic organisms, and it came to be generally believed that putrefaction was due to a certain microörganism-Bacterium termo. Cohn wrote in 18.2 that through his own experiments, as well as through those of other investigators, he was convinced that Bact. termo was the ferment of putrefaction in the same way that yeast is the alcoholic ferment. IIe considered that other bacteria may play a secondary rôle, but that Bact.termo is the primary cause of putrefaction. However, bacteriologists soon came to realize that Bact. termo was only a general name given to the many species of rod-shaped organisms occurring in decaying substances. In 1884 and 1885 Hauser isolated three distinct species of bacteria capable of causing putrefaction-Protcus vulgaris (B. proteus, B. vulyaris, B. zopfi), Proteus mirabilis, and Proteus zentieri. The first two are capable of liquefying gelatin, while the last is not. Many different bacteria are encountered in a spontaneously putrefying substance. Among the most active which have been studied are, according to Effront: the family of Proteus, B. putrificus coli (Bienstock), B. perfringens (Veillon and Zuber), Micrococcus flavus liquefaciens (Fluegge), B. gracilis putidus (Tissier and Martelly), B. bifermentans sporogenes B. diplococcus griseus non-liquefaciens (Tissier and Martelly), B. coli communis (Escherich), Streptococcus pyogenes (Doleris and Pasteur), and Staphylococcus pyogenes albus (Rosenbach). These bacteria are very widely distributed, $B$. proteus being especially apt to occur in substances undergoing decomposition. Its presence is constant in rotten meat, is very frequent in manure, and is met with in large numbers even in normal dejecta. The putrefying bacteria are usually anaërobic, but there are often very active aërobes.

H. Martelly made a careful study of the bacterial flora of putrefying material and found that it changed from period to period. He found at first Micrococcus flavus, Staphylococcus albus, B. coli, and Diplococcus griseus. Then at the end of three or four days $B$. perfingens, $B$. sporogenes appeared, at the end of eight to ten days he detected the presence of B. putidus, B. putrificus, and Proteus zenlieri, and after three months there remained only $B$. putrificus, B. putidus, and Diplococcus griseus.

Products of Putrefaction and Decay.-Due to the trypsin and erepsin secreted by the bacteria the proteins are broken into albumoses, peptones, proteoses, and amino-acids, and even in very advanced putrefaction nitrogenous substances are always found which give the protein reactions. The amidases secreted by hacteria give rise to volatile acids, amins, phenol and indol derivatives. Effront summarizes the products formed as follows: (1) Ammonia and amins-ethylamin, propylamin, and trimethylamin; (2) rolatile acids, comprising all the members of the fatty series up to caproic acid; (3) aromatic acids and oxyacids, like phenylpro- 
pionic, oxyphenylacetic, and oxyphenylpropionic acids; (4) phenol, indol, skatol, pyrrol, and its derivatives, these bodies sometimes being in very small quantities or even completely absent; (5) sulphur derivatives like methyl-mercaptan; (6) various amino-acids, leucin, tyrosin, tryptophan, and sometimes glycin, creatinin, etc.; (7) various ptomains, like putrescin and cadaverin, the guanidins, cholin, and nurin, pyridin, hydrocolloidin, etc.

In the process of decay the carbon and hydrogen is liberated as carbon dioxid, methane, water, and other rolatile products with the result that the carbon in the soil tends to fall off relatively to the nitrogen and the ratio $\frac{\mathrm{C}}{\mathrm{N}}$, which in the original plant material is about 40 , is reduced in the soil to 10 . This carbon-nitrogen ratio varies with climatic conditions, also with soil type and previous treatment. Lawes and Gilbert, as quoted by Lipman, give the following carbon-nitrogen ratio in the organic matter of different soils:

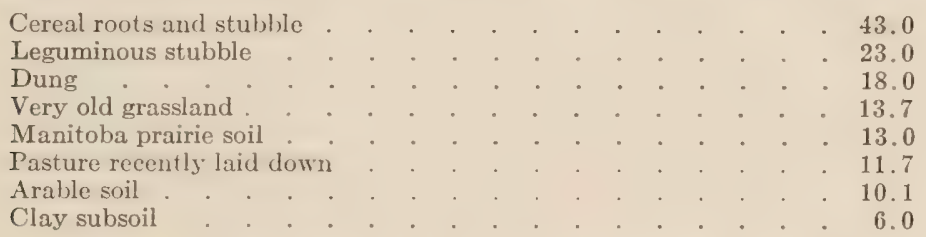

Other things being equal, a wide carbon-nitrogen ratio indicates a more fertile soil than a narrow carbon-nitrogen ratio. But this must always be interpreted with regard to the climatic condition. In the arid regions the carbon-nitrogen ratio is narrow when compared with soils of the humid regions, yet the bacterial activity of the former is just as active as that of the latter.

The organic substances found within the soil are called humus and result from the action of bacteria upon the plant residues. The composition of the substance raries with the products from which it has been formed, also the degree of humification which has taken place. Moreover, the quantity and speed with which humus is formed depends upon the nature and condition of the material used and the physical, chemical, and biological conditions of the soil. Hilgard thinks that in the humid regions one part of normal soil humus may be formed from five to six parts of dry-plant débris, whereas in the arid regions from eighteen to twenty parts of the same material would be required. Snyder allowed various organic substances to humify for one year with the following results:

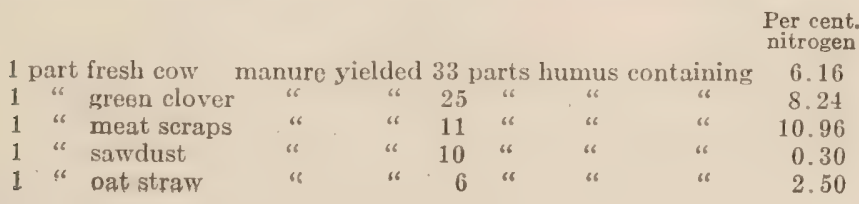


Humus is mainly valuable because of its physical effect upon the soil and because of its content of nitrogen, potassium, and phosphorus which are slowly liberated by bacteria. The beneficial effect of organic matter upon the bacterial flora of the soil and soil fertility, however, is mainly exerted before it reaches the stage of humus.

Chemistry of the Processes. - The primary and secondary products resulting from the decay of organic matter in the soil are classed as humus. They are not, as was once believed, a few comparatively simple organic compounds but are a heterogeneous mixture of colloidal and crystalline organic compounds resulting from the action of bacteria upon plant residues.

The chemical composition of the end products being in many cases unknown, the chemistry of the process is still to be explained, but we have some very suggestive information due to the fact that acids and alkalies when they act upon carbohydrates rield brown humus-like substances very similar to, if not identical with, the substances found in the soil and resulting from bacterial activity.

It is known that the aldehyd group of a carbohydrate easily opens its double bonds between carbon and oxygen and adds water to form a polyhydric alcohol, as follows:

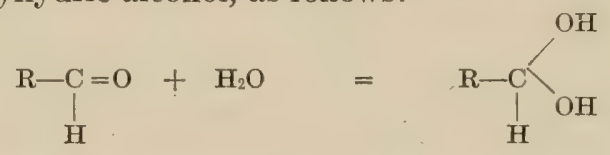

This reacts with sodium hydroxid with the formation of the following salt:<smiles>[R]C(O)C(O)C(O)C(O)O[Na]</smiles>

This salt is unstable and the molecule forms enols:<smiles>O=C[18O]C(O)C(O)=CCO</smiles>

These break apart at the double bonds:<smiles>OCC=CC(O)C(O)C(O)C(O)CO</smiles> 
By this process pieces having various numbers of carbon atoms are formed, all of which are very reactive in their nascent state due to the free open bonds on the carbon atom. These react with each other and give rise to long chain compounds, the more complex of which have a brown color and other physical and chemical characteristics of soil humus.

Soil humus also contains nitrogen which would come through the action of bacteria upon proteins. The products resulting through such action are numerous and varied, but the work of Schreiner and his associates has shown them to be the following:

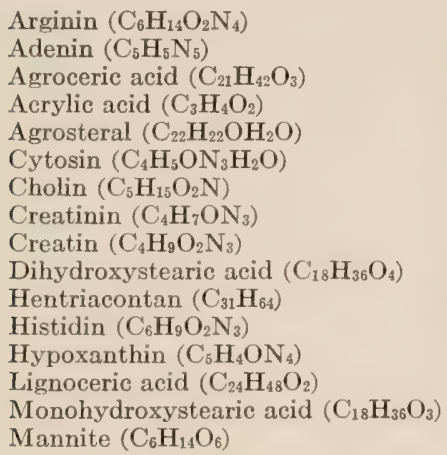

Nucleic acid (constituents unknown)

Oxalic acid $\left(\mathrm{C}_{2} \mathrm{H}_{2} \mathrm{O}_{4}\right)$

Picolin carboxylic acid $\left(\mathrm{C}_{7} \mathrm{H}_{7} \mathrm{O}_{2} \mathrm{~N}\right)$

Paraffinic acid $\left(\mathrm{C}_{24} \mathrm{H}_{48} \mathrm{O}_{2}\right)$

Phytosterol $\left(\mathrm{C}_{26} \mathrm{H}_{44} \mathrm{O} . \mathrm{H}_{2} \mathrm{O}\right)$

Pentosan $\left(\mathrm{C}_{5} \mathrm{H}_{8} \mathrm{O}_{4}\right)$

Quanin $\left(\mathrm{CH}_{5} \mathrm{~N}_{3}\right)$

Rhamose $\left(\mathrm{C}_{6} \mathrm{H}_{44} \mathrm{O}_{10}\right)$

Succinic acid $\left(\mathrm{C}_{4} \mathrm{H}_{6} \mathrm{O}_{4}\right)$

Saccharic acid $\left(\mathrm{C}_{6} \mathrm{H}_{8} \mathrm{O}_{10}\right)$

Salicylic aldehyd $\left(\mathrm{C}_{6} \mathrm{H}_{4} \mathrm{CHOOH}\right)$

Trimethylamin $\left(\mathrm{C}_{3} \mathrm{H}_{9} \mathrm{~N}\right)$

Trithiobenzaldehyd $\left(\mathrm{C}_{6} \mathrm{H}_{5} \mathrm{CSH}\right)_{3}$

\section{REFERENCES.}

Vorhees, Edward B. and Lipman, Jacob G.: "A Review of Investigations in Soil Bacteriology," U. S. Dept. Agr., Off. Exp. Sta. Bul. 194.

Fuller, George W.: "Sewage Disposal."

Effront, Prescott: "Biochemical Catalysts in Life and Industry." 


\section{CHAPTER XX.}

\section{AMMONIFICATION.}

IN the preceding chapter it was shown that one of the final products resulting from putrefaction, fermentation, and decay is ammonia. The production of ammonia through the intervention of microörganisms is known as ammonification. The speed with which this ammonia is formed within a soil varies with the physical and chemical composition of the soil together with the number and physiological efficiency of the various organisms taking part in the process.

Although it has been known for some time that small quantities of ammonia occur in all arable soil, its formation was not known to be due to a biological process until 1893 when Muntz and Coudon demonstrated that ammonia is no longer formed in soils sterilized by heat. They, together with Kayser, isolated from soil two species of Bacterium, one of Bacillus, two of Micrococcus, and two of molds - all of which produced ammonia in veal bouillon, and all but one (a micrococcus) gave the same results in soil. From these results they concluded that the formation of ammonia in the soil is the result exclusively of the conjoint activity of numerous lower organisms of very widely different characters.

This conclusion was confirmed the same year by Marchal who isolated from the soil the species of microörganisms (molds, yeast, and bacteria) which were the most prevalent, and determined which of these had the power of transforming nitrogenous material into ammonia. Of 31 species tested, 17 displayed a strong ammonifying power. Most of the others displayed a smaller but none the less distinct ammonifying power. Molds and yeast were also found to produce ammonia. On inoculation into a solution containing $1.365 \mathrm{gms}$. of organic matter per liter the various organisms were found to transform the following proportion of nitrogen into ammonia in twenty days:

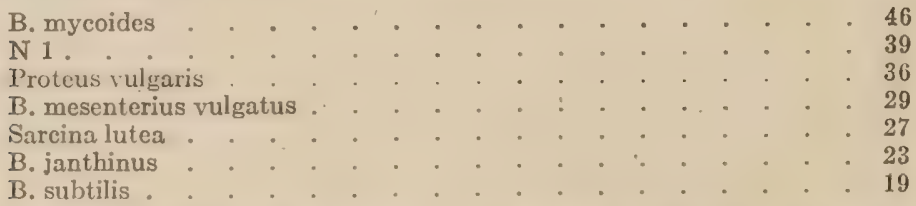

The B. mycoides was selected by him for special investigation. This organism is found very widely distributed in nature. It is 
always present in the surface layers of cultivated soil, and is found frequently in manure, vegetable mold, composts, and in the humus of forests. It occurs at times in air and natural waters. He found that when inoculated into a neutral solution of albumen the medium soon becomes strongly alkaline due to the accumulation of ammonium carbonate; simultaneously there was a corresponding decrease of albumin. The analysis of the atmosphere in which the culture was confined showed a marked decrease of oxygen with a corresponding increase of carbon dioxid. IIydrogen and nitrogen were not among the gaseous products. The quantity of carbon dioxid and ammonia formed in the respiration of this organism were nearly in the proportion in which they are formed in the complete combustion of albumin. In addition to these two substances, there were found in the solution small quantities of peptones, leucin, tryosin, and formic, butyric and propionic acids. Marchal considered that in the life processes of $B$. mycoides atmospheric oxygen is made to combine with the constituents of albumin, its carbon being transformed into carbon dioxid, its sulphur into sulphuric acid, a portion of the hydrogen into water, the ammonia appearing as a residual product. He assumed the following equation:

$$
\mathrm{C}_{72} \mathrm{H}_{112} \mathrm{~N}_{18} \mathrm{SO}_{22}+77 \mathrm{O}_{2}=29 \mathrm{H}_{2} \mathrm{O}+72 \mathrm{CO}_{2}+\mathrm{SO}_{3}+18 \mathrm{NH}_{3}
$$

The best conditions for the activity of the organisms are: (1) A temperature of about $30^{\circ} \mathrm{C} .,(2)$ thorough aëration, (3) a slightly alkaline medium, and (4) a dilute solution of protein. It was also found that this organism can ammonify not only albumin but also casein, fibrin, legumin, glutin, myosin, serin. peptones, creatin, leucin, tyrosin, and asparagin, but was unable to utilize urea, urea nitrate, or ammonium salts. In the main these results have been amply confirmed by a great number of investigators.

C. B. Lipman and Burgess, howerer, have demonstrated that $B$. mycoides is by no means always the most efficient ammonifying bacterium, for even this organism varies greatly in its activity, depending upon the chemical and physical conditions of the substrata. They make the following critical statements concerning Marchal's findings: "First, the results of solution cultures are no criterion as to the results to be obtained in soils. Secondly, that no two forms of organic nitrogen are attacked and ammonified with the same vigor by any one organism. Thirdly, that different soils will modify an organism's power to ammonify any one given form of nitrogen very markedly, so that it may be efficient in one case and feeble in another. Fourthly, that the ammonifying efficiency of organisms is greater in sandy soil, and possibly in others, than in solutions, for we have obtained a transformation of 41.98 per cent. of peptone nitrogen and 36.06 per cent. of bat guano into ammonia 
by Sarcina lutea and $B$. mycoides, respectively, in twelve days at temperatures between $27^{\circ} \mathrm{C}$. and $30^{\circ} \mathrm{C}$., while Marchal only obtained similar transformation in thirty days at $30^{\circ} \mathrm{C}$. in albumin solutions."

Species and Distribution.-As was pointed out by Marchal, the ammonifying organisms are very widely distributed in nature. The power to split off ammonia from protein is a characteristic of the majority of soil bacteria. Gage noted the production of ammonia in thirteen out of twenty cultures of sewage bacteria tested

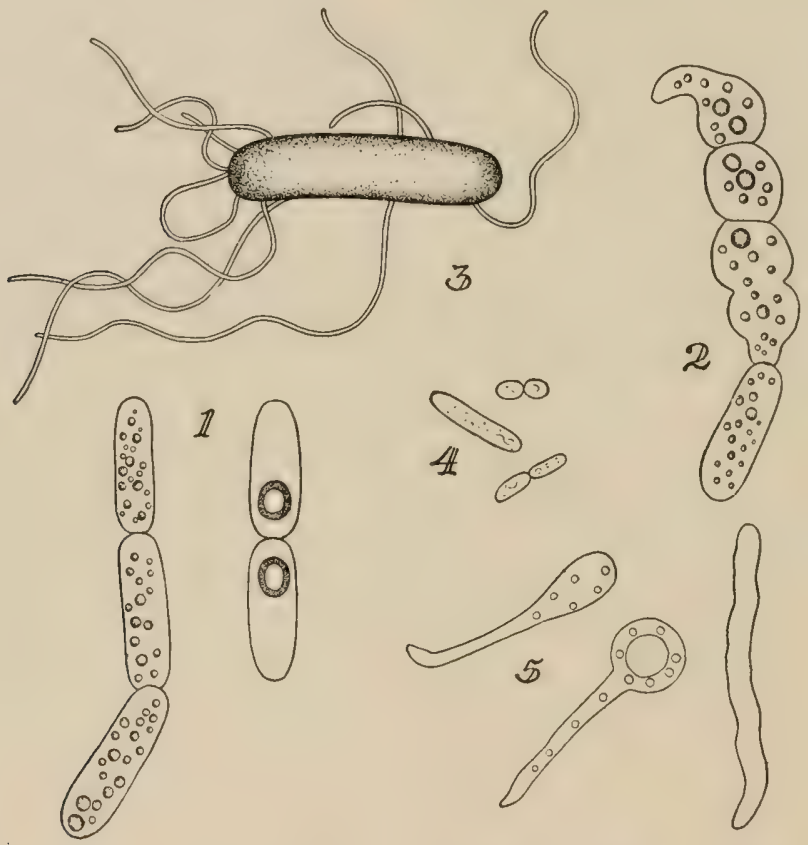

FIG. 27.-Ammonifying bacteria. - 1. Bacterium mycoides; $\times 3,000$. (Nadson.) 2. Bacterium mycoides; involution forms; $\times 3,000$. (Nadson.) 3. Bacterium tumescens. (Myer.) 4. Proteus vulgaris; $\times 3,000$. (Nadson.) 5. Proteus vulgaris; involution forms; $\times 3,000$. (Nadson.) (Lipman's "Bacteria in Relation to Country Life.")

by him. Ife further found that the gelatin liquefiers have an ammonifying power nearly twice as great as the non-liquefiers. C'hester found all but one of the organisms tested by him capable of producing ammonia. (C. B. Lipman tested the following fifteen organisms in soils: B. mesentericus vulgatus, Ps. putida, B. vulgatus, 13. megatherium, B. mycoides, B. subtitis, B. tumescens, Sarcina lutea, B. proteus vulyaris, B. icteroides, B. ramosus, Streptothix, sp., P's. fluoreseens, B. mulgaris (navy strain), and Mic. tetregenus as to their ammonifying powers of dried blood, tankage, cotton-seed 
ineal, sheep and goat manure, peptone, fish guano, and bat guano. He found that while all produced ammonia, their efficiency varied greatly, depending upon the nature of the soil and the nitrogenous material to be ammonified, B. tumseens. howerer, on the whole appeared to be the most efficient organism tested.
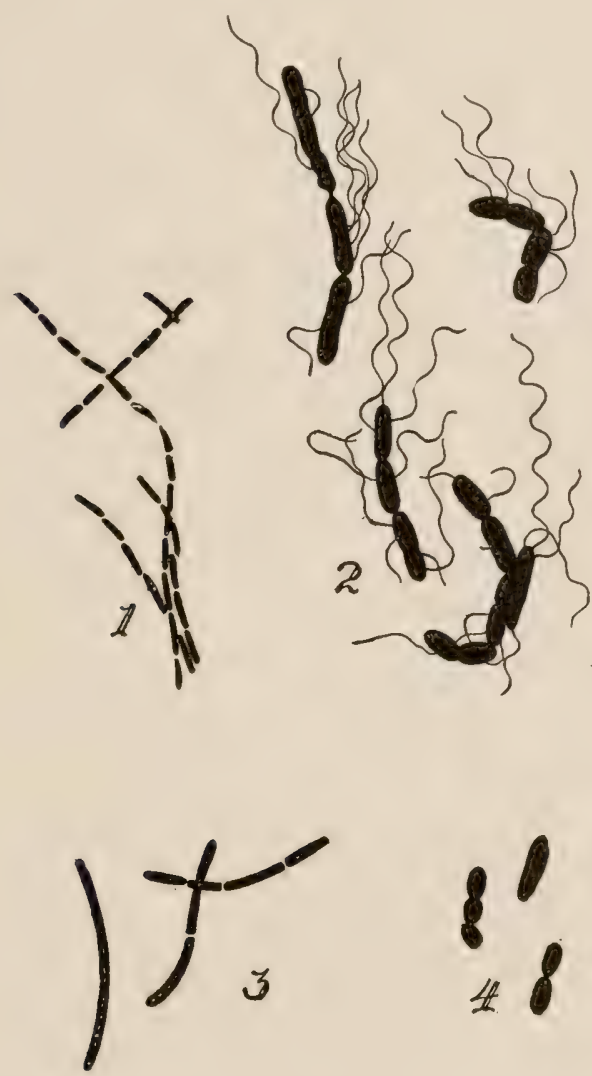

Fig. 28.-Ammonifying bacteria.-1. Proteus rulgaris; $\times 2,600$. (Rodella.) 2. Bacillus megatherium; $\times 2,600$. (Hinterberger.) 3. Bacillus mycoides; $\times 2,600$. (Emmerling.) 4. Bacillus cereus; $\times 2,600$. (Wilhelmy.) Lipman's "Bacteria in Relation to Country Life."

Moreover, many fungi, as shown by McLean and Wilson, possess the power of rapidly ammonifying cotton-seed meal and dried blood. Fungi belonging to the Moniliace were more active ammonifiers than were members of the Aspergillacece, Mucoracex, or Dematiaceœ.

An idea as to the number of ammonifying organisms which must occur in soils may be gleaned from the fact that Conn found about 10 per cent. of a soil's flora to be rapid liquefiers, principally Ps. 
fluorescens, and many others are slow liquefiers. 'This indicates that the class of organisms must play a very important rôle in the degradation of the nitrogenous material of the soil.

It is quite likely that the organisms are even more efficient in the soil in the mixed cultures than they are in the pure cultures. For the transforming of protein nitrogen to ammonia is a complex process which must proceed by steps and some organisms must be more efficient than are others in specific phases of the reaction. But so far we have little definite information on this subject.

Methods. - Two methods are in general use for the determination of the ammonifying powers of the soil. The one in which a definite portion of soil is inoculated into a liquid media and after a given time the ammonia determined; in the other the nitrogenous substance is incorporated into the soil and after a definite period the ammonia determined. The latter method would appear to approach more nearly field conditions, but both methods have their advocates. It is not my purpose to go into the claims made for each, but suffice it to state that Löhnis, who has made a careful study of each, finds the more important factors in both to be: (1) Nature and quantity of material used as substrata; (2) concentration and distribution of the substrata in the medium; (3) aëration; (4) diffusion, absorption, destruction or evaporation of metabolic products; $(5)$ reaction of the medium; (6) temperature; and (7) duration of the experiment.

As was pointed out by Pagnoul in 1895, the formation of ammonia in the soil is only a transition state of organic nitrogen in passing to the nitrates. So that with either the solution or soil method, what we measure is the accumulation of ammonia in the media and not the actual quantity formed. Various factors may enter and slow down the quantity of ammonia formed. This would be indicated by a smaller quantity of ammonia in the soil, or the speed with which the ammonia is transformed into nitrates may decrease, and hence the ammonia accumulates while the actual quantity found is the same. Moreover, it is well known that many microörganisms possess the power of transforming ammonia into protein nitrogen, and this factor may either increase or decrease with a corresponding change in the ammonia of the soil. Where large quantities of ammonia are being formed, part of it may be lost from the medium by volatilization. The extent of this loss varies with the soil. Lemmermann and Fresenius found the addition of calcium carbonate to a soil to the extent of 1 per cent. reduced the volatilization of ammonium carbonate and increased the absorptive power of the soil for ammonia. Calcium sulphate and chlorid and magnesium chlorid have a similar effect. Caustic lime has the opposite effect. The zeolites are very effective in reducing the loss of ammonia from soil, and according to Pfeifler and coworkers the nitrogen so fixed is so firmly held that it does not become available to plants during the first season. 
Material Ammonified. - The speed with which ammonia is formed within a soil varies greatly, depending upon the nature of the material to be ammonified. Lipman and his associates found the following proportions of nitrogen were transformed into ammonia in six days:

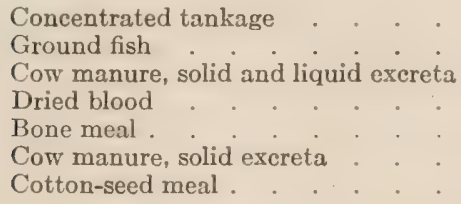

56.66 per cent.

47.16

32.60

16.74

16.65

5.39

4.95

However, this order is not always maintained, for C. B. Lipman has found it to vary with the soil and with the bacterial flora. Lipman and Brown consider the carbon-nitrogen ratio important in determining the rate of ammonification of nitrogenous materials, and then the modification of this ratio by soluble carbohydrates or by other soluble compounds may lead to changes in the numbers and species of the microörganisms in the soil or culture solutions and a consequent depressed or intensified ammonification, depending on the character of the nitrogenous fertilizer.

The addition of dextrose, sucrose, lactose, maltose, and mannite, according to Lipman and Brown, decrease the accumulation of ammonia in the soil. Kelley found that by adding $1.556 \mathrm{gms}$. of starch to $1.072 \mathrm{gms}$. of casein the quantity of ammonia in the soil at the end of nine days was decreased 50 per cent.

In the presence of the carbohydrates the decrease may be either real or apparent. The true decrease may be due to the carbohydrate which causes the organism to use only sufficient protein to meet its nitrogen metabolism when only a small quantity of ammonia would accumulate.

The apparent decrease is probably due to an acceleration of the speed with which ammonia is transformed into protein nitrogen. Inert organic substances in general, such as starch, cellulose, and peat, usually decrease the speed of ammonification. This is due, according to Rahn, to the substance making some of the soil moisture unavailable to the bacteria, for he found that when the moisture is sufficiently great cellulose acts as a stimulant to ammonification, probably by holding the sand particles farther apart and thus increasing aëration. Dzierzbicki has found that small amounts of some humic acid salts increase ammonification.

The addition of manure to a soil greatly increases the ammonia produced in a soil. This is illustrated by the following results obtained by Greaves and Carter. In the first column is giren the per cent. of ammonia found, the untreated soil being taken as 100 per cent. The various quantities of manure were applied to the 
soil in pots and after four months the ammonifying powers retermined. In the second and third columns are given the results from actual field soil receiving each rear the designated quantity of manure.

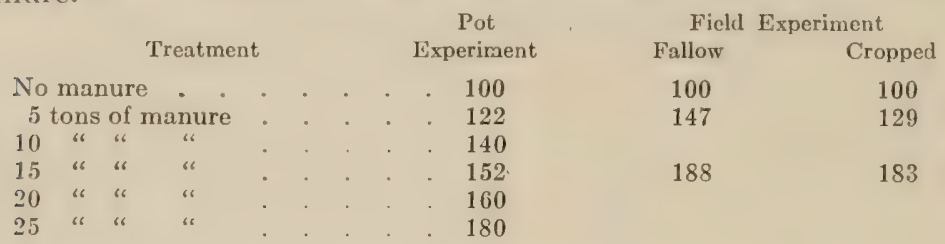

Crops grown on a soil decrease its ammonifying powers. In the order of their decreasing ammonifving powers came fallow, potato, corn, oats, and alfalfa.

Influence of Soil and Climatic Conditions.-Lipman points out that the ammonia production in a soil is affected by (1) its mechanical and chemical composition, (2) by fertilizer treatment, and (3) by methods of tillage and cropping. He further states that the mechanical composition of the soil determines the proportion of aërobic and anaërobic organisıns in a soil. If the latter predominate, the production of ammonia is comparatively rapid. Yet Fischer reports a more intense ammonification of dried blood in light than in heary soils, but under this case it is possible that the loss of nitrogen from the sandr soil was sufficient to account for the observed difference. (. B. Lipman has shown that the order within various soils differs with the various ammonifying organisms. Moreover, he and Waynick found the removal of California soil to Kansas increased the ammonifying powers about one-third, but removal to Maryland had little effect. Whereas Kansas soil removed to ('alifornia loses greatly in its ammonifying power, yet Kansas soil transported to Maryland suffers little change. IVe must, therefore, conclude that climate exerts a great influence on the ammonifying powers of the soil.

The quantity of ammonia in a soil raries from season to season and from period to period. Green found that as regards the ammonification of the organic manures-flesh meal, horn meal, and blood meal - the bacterial activities rise from August to October, with a tendency to fall or remain constant in November, rising to a maximum in I)ecember. 'This was followed by a minimum in February and a low maximum in April, and from April to July there was a slight fall which probably continued to a summer minimum commencing in August.

Moisture. - The influence of moisture on the ammonia formed in the soil is very great. Lipman and Brown found ammonification in a loam soil increased with increased water content even up to 35 per cent. of the weight of the soil. However, later they and 
Owen found ammonification to increase as the water added increased up to a certain percentage, which varies with the phrsical nature of the soil, but larger quantities of water reduced the ammonia recovered. The work clearly demonstrated that the optimum moisture content for maximum ammonification is higher than it is for maximum nitrification. The quantitative difference between the two processes in the same soil was found by Sharp. Ammonification was most rapid with a 25 per cent. moisture content and was not markedly affected by 3 per cent. differences. Nitrification was at its maximum when the soil contained 19 per cent. of water. When it was increased to 25 per cent., the rate of nitrification was dècreased 50 per cent.

The work of Greaves and Carter shows that ammonification is at its maximum in a soil containing 60 per cent. of its water-holding capacity, as is illustrated in Fig. 29 which gives the results obtained with twenty-two soils. Moreover, according to Briggs the moistureholding capacity, the wilting coefficient, the moisture equivalent, and the hygroscopic coefficient are related by linear equations:

$$
\begin{aligned}
& \mathrm{C}=2.9 \mathrm{~W}+21 \\
& \mathrm{C}=1.57 \mathrm{E}+21 \\
& \mathrm{C}=4.26 \mathrm{H}+21
\end{aligned}
$$

where $C$ is written for the moisture capacity as defined by Hilgard, $U^{\prime}$ for wilting coefficient, $E$ for moisture equivalent, and $H$ for hygroscopic coefficient. Therefore, taking the maximum ammonication at 0.6 of the water-holding capacity we could relate these other soil constants to maximum ammonification by a similar set of linear equations. Thus:

$$
\begin{aligned}
& \mathrm{Ma}=.942 \mathrm{E}+12.6 \\
& \mathrm{Ma}=1.74 \mathrm{~W}+12.6 \\
& \mathrm{Ma}=2.55 \mathrm{H}+12.6
\end{aligned}
$$

writing $M a$ for per cent. water for maximum ammonification.

Variation in moisture content of a soil changes its ammonifying flora, for soils held at various moisture contents for several months show different ammonifying efficiency, as may be seen from the following results obtained by Greaves and Carter. These soils were held at the indicated moisture content for three months and then all brought to 20 per cent. moisture and after four days the ammonia determined.

Moisture Added

12.5 per cent. water

15.0 per cent. water

17.5 per cent. water

20.0 per cent. water

22.5 per cent. water
Per cent. Ammonia Produced 100 111 
This increased ammonification with increased moisture content is due, according to Lipman, to the suppression of the aërobic decay bacteria and an acceleration of the anaërobic putrefactive bacteria.

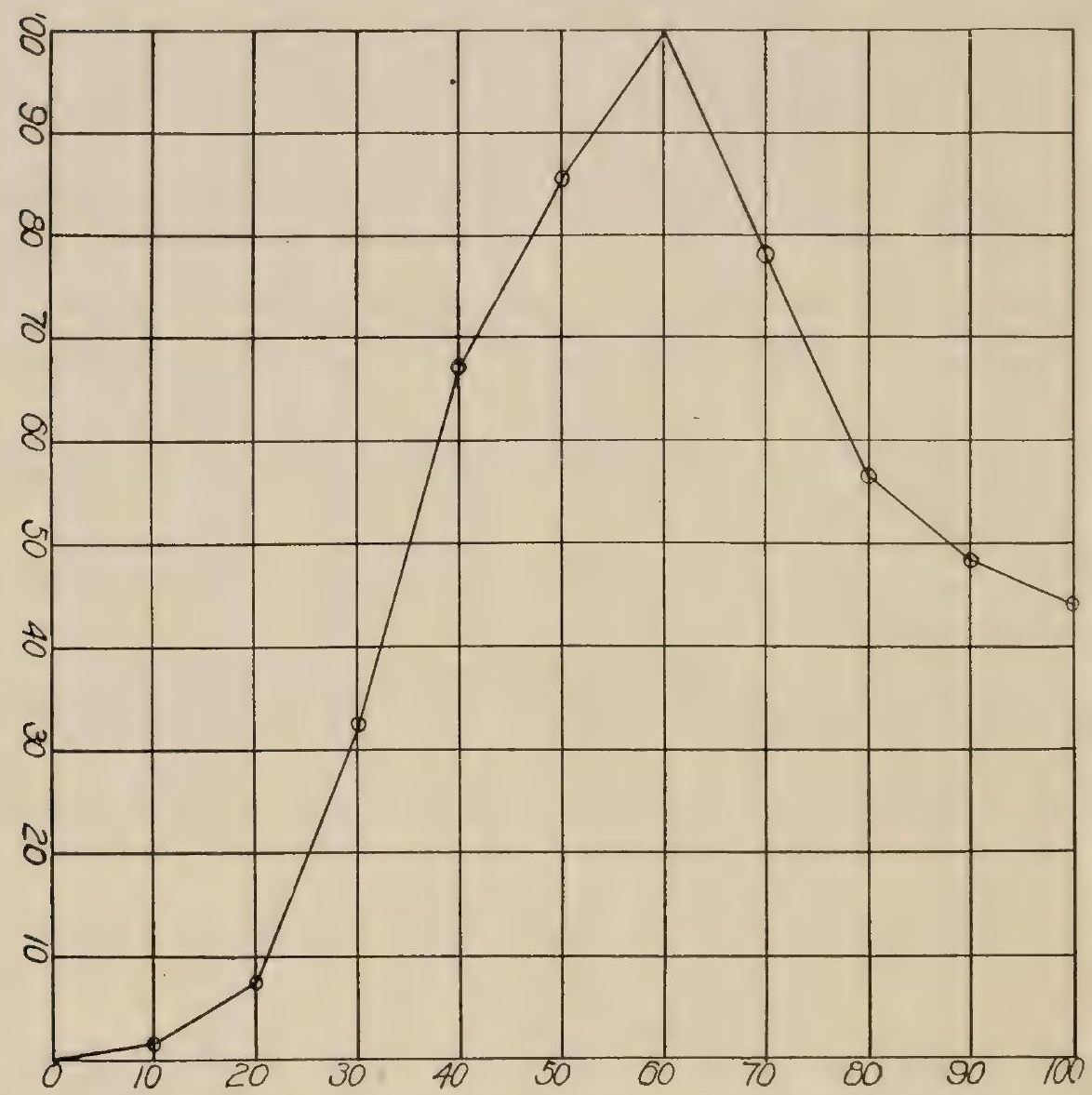

FIG. 29.-Average percentages of ammonia produced in soils receiving varying quantities of water. The quantity produced at 60 per cent. is taken as 100 ; on the ordinate is given the per cent. of ammonia formed whereas on the abscissa is given water applied as per cent. of water-holding capacity.

Aëration.-Carbone considers oxygen essential as a rule to the most efficient action of organisms in decomposing organic matter, and he points out that it is not possible to segregate the agents of decomposition strictly into aërobes and anaërobes. The aërobes are the more active agents in the decomposition of carbonaceous material with the formation of humus. But Dzierzbicki found a 
strong aëration decreased - at least in many cases - the quantity of ammonia split off from peptone solutions which had been inoculated with soil. Plimmer, working with a Inukirk clay loam, failed to find any optimum oxygen content for the maximum production of ammonia. Under purely anaërobic conditions, caused by an atmosphere of pure carbon dioxid, there was somewhat less ammonia produced than when oxygen was present at the beginning, but even under these conditions ammonia was formed in rather large proportions. This would probably vary with the specific bacterial flora of the soil, for the work of Marchal demonstrated that the formation of ammonia is favored by the unhindered access of oxygen, and in the process considerable quantities of oxygen are used up and a nearly corresponding quantity of carbon dioxid produced. There is the possibility of the carbon dioxid resulting from side reactions, the oxidation of the carbon chain compounds which have been deaminized, and not due to the main process of ammonification. For theoretically, at least, ammonification can be considered as a true hydrolytic reaction. The microörganism, however, gets its energy from the oxidation of the carbon, and where conditions are favorable ammonia production follows very closely the evolution of carbon dioxid. But Gainey found unfavorable conditions to have a more detrimental effect upon the formation of ammonia than upon the production of carbon dioxid.

Lime and Magnesia. - These exert a marked effect on ammonification, and Vorhees, Lipman, and Brown found magnesium lime usually superior to non-magnesium lime in this respect. Its effect varied, depending upon the character of the organic matter to be ammonified and the crop grown upon the soil. Lipman, Brown, and Owen found lime carbonate in which the large per cent. of boron proved to be the factor which hindered decay bacteria.

The increased ammonia resulting from the use of the magnesium lime may be due to an apparent and not to a real increase in ammonification. For Fischer has noted that calcium carbonate increased the speed with which ammonia sulphate is transformed into protein to a greater extent than did magnesium carbonate. Moreover, Lipman and Green found that magnesium carbonate interferes with the speed with which nitrite is converted into nitrate which would slow down the action of the nitrosomonas. In either case this would increase the accumulation of ammonia in the soil, which may be interpreted as increased ammonification.

Phosphorus. - In experiments on ammonia cleavage by Dzierzbicki in peptone solutions, it was found that the intensity of such cleavage depends not only on the bacterial flora of the soil but more so on its chemical composition and especially on the presence of phosphoric acid. Monocalcium and dicalcium phosphate are equally effective, 
according to Lipman, in stimulating the activities of the decay bacteria. Thomas slag increases the production of ammonia to a considerable extent. Where acid phosphate is applied to a soil the increased ammonification resulting, according to McLean and Wilson, is due to fungi rather than to bacteria, but this would probably vary with the magnesium and calcium carbonate content of the soil.

Chemistry of the Process.-Rettger and his associates have shown that bacteria are unable to attack or bring about the decomposition of proteins without the aid of enzymes or other proteolytic agents, whereas Itano using the formal titration method of Sörenson has shown that $B$. subtilis produces a gradual increase of formal-titrating nitrogen for a period of two hundred and forty hours. The greatest proteolysis took place toward the optimum hydrogen-ion concentration. He, therefore, suggested that the enzyme is probably trypticlike in nature, and endocellular. Moreover, as was seen in the preceding chapter, a number of amino-acids have been isolated from the soil. Hence it is most natural to assume that the disintegration of proteins in the soil is primarily protein hydrolysis catalyzed by endoor exo-enzymes secreted by the decay bacteria. The enzymespepsin, trypsin, erepsin, and probably other protoclastic enzymesare capable of hydrolyzing proteins with the formation of some eighteen amino-acids. The number and quantity of each depends upon the specific protein hydrolyzed. Incomplete hydrolysis results in the production of a number of intermediate substances variously designated in the order of decreasing complexityproteoses, peptones, and polypeptids.

Taylor suggests the scheme given on page 205 as indicating the stages in the hydrolysis of the protein molecule.

There are reasons for believing that in the process of ammonification the hydrolysis is similar to this, for Marchal showed that the ammonifiers are capable of hydrolyzing proteins, proteoses, and peptones. Moreover, many of the protein hydrolytic products are found in the soil, and Miyaka has shown from a mathematical analysis that the process of ammonification is an autocatalytic chemical reaction in which the increase of ammonia in the process is in accordance with the formula:

$$
\log \frac{x}{A-x}=K\left(t-t_{1}\right)
$$

Where $x$ is the amount of ammonia which has been produced at time $(t), a$ is the total amount of ammonia produced during the process, $K$ is a constant, and $t_{1}$ is the time at which half of the total amount of ammonia is produced. 


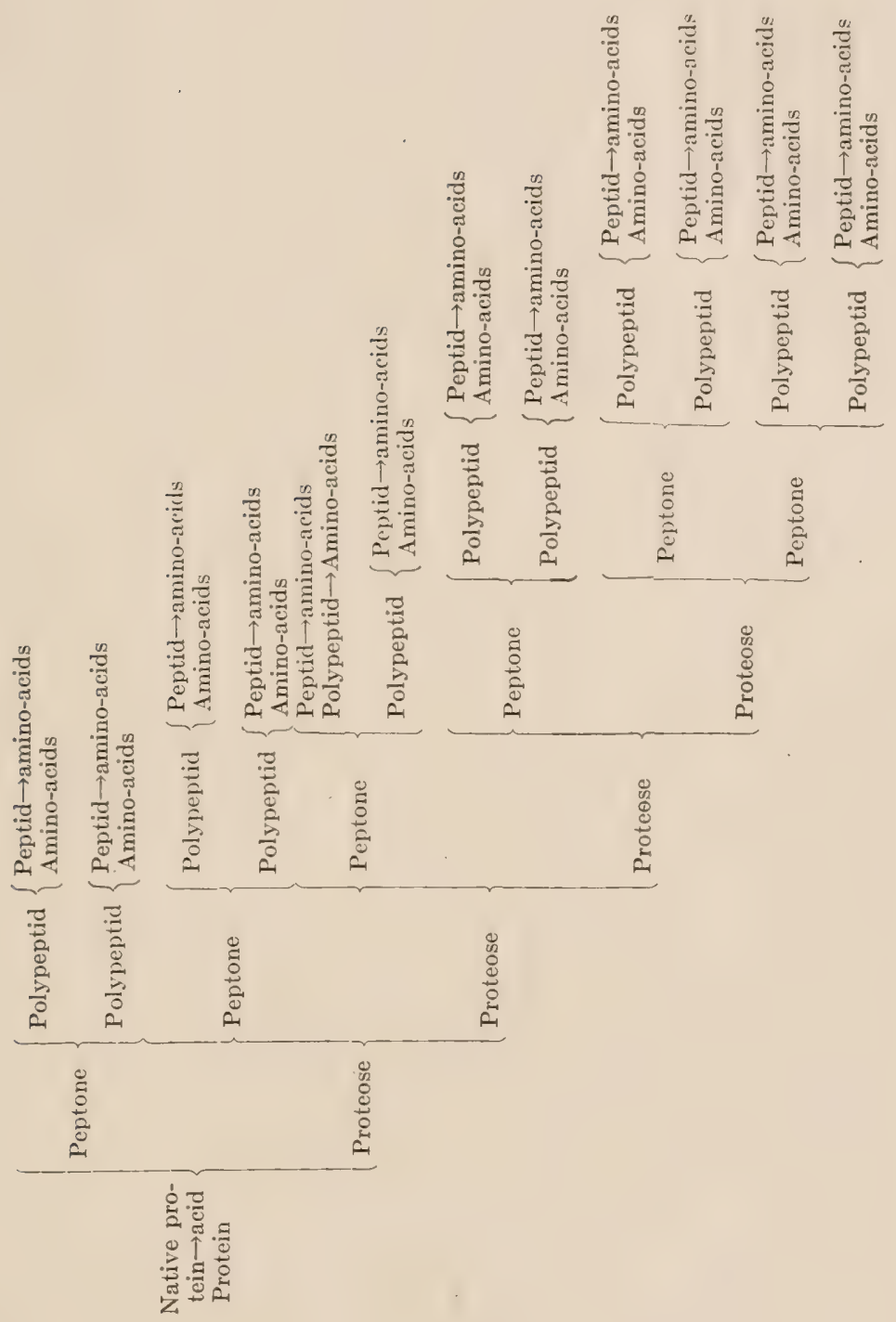


The quantity and quality of the products formed would depend upon the specific enzyme or enzymes secreted by the microörganisms. Where pepsin is the main ferment large quantities of proteoses and peptones would be formed, while if trypsin is the active agent the amino-acids would also occur, and with erepsin the amino-acids would be formed even more rapidly. It is not unreasonable to suppose that in a soil having a high ammonifying efficiency the ammonifying flora are not only numerous but they are active secreters of proteoclastic ferments. Moreover, this disintegration of the protein molecule which eventually converts nearly the whole of the organic nitrogen into ammonia results from the combined action of numerous microörganisms of different species. The products elaborated by one class probably serve as the point of attack for another.

Potter and Snyder found there was no tendency for the aminoacids to accumulate in the soil, but they fluctuated with the ammonia, thus indicating a connection between the two. Jodidi added various amino-acids and acid amids, including glycocol, leucin, phenylalanin, asparagin, aspartic acid, glutanic acid, tyrosin, alanin, cadarerin, acetimid and propionamid to the soil, and after from two to ten days determined the ammonia, although the transformation was not quantitative, probably due to other reactions occurring simultaneously. Yet it was evident that the amino-acids and acid amids examined readily undergo in the soil the process of ammonification, and, all other things being equal, the rate of transformation is greatly influenced by the chemical structure so that amino-acids and acid amids of equal structure vield about the same proportion of ammonia.

Effront in 1905 demonstrated that there are produced by soil bacteria amidases. The process of deamination was at first thought to be one of simple hydrolysis, as follows:

R. $\mathrm{CH} \mathrm{NH} \mathrm{H}_{2}-\mathrm{COOH}+\mathrm{HOH}=\mathrm{R}-\mathrm{CHOH}-\mathrm{COOH}+\mathrm{NH}_{3}$

But Neubauer and Fromberz concluded that the primary pathway of deamination within the animal organism was oxidative and not hydrolytic:

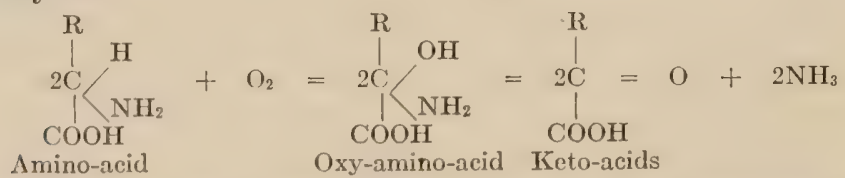

The amino-acids containing sulphur would probably in the presence of sufficient oxygen first oxidize the sulphur atom forming a derivative of sulphuric acid:

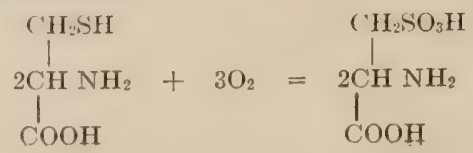


And this would be deaminized:

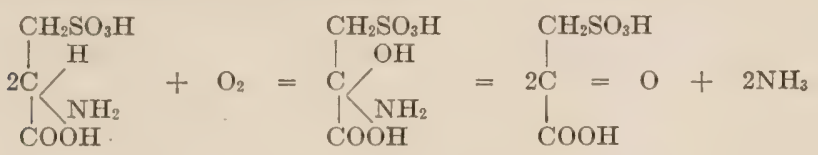

In any case the resulting ammonia would be fixed within the soil by the zeolites, acid radicals, or lost through volatilization. That which is retained in the soil is later taken up by plants or transformed by bacteria into protein or nitrate nitrogen.

For each molecule of ammonia formed there would result a corresponding molecule of volatile acid, or oxy-acid, or else of alcohol which may serve as a source of carbon for other microörganisms, possible for the azofiers.

\section{REFERENCES.}

Löhnis, F.: "Handbuch der Landwirtschaftlichen Bakteriologie."

Lafar, Franz: "Handbuch der Technischen Mykologie," Dritter Band.

Voorhees, Edward, B., and Lipman, J. G.: "Review of Investigations in Soil Bacteriology" (U.S.D.A. Off. Exp. Sta. Bul. 194). 


\section{CHAPTER XXI.}

\section{NITRIFICATION.}

Tue term nitrification refers to the oxidation of ether ammonia or nitrites to nitrates. It is often used in a broader sense to imply the production of nitrates from decomposing organic material. The process of nitrification was made use of in the manufacture of saltpeter to supply the large quantities of gunpowder consumed in the almost incessant wars of Europe. In the eighteen century the artificial production of saltpeter in beds of decaying organic matter reached a high degree of perfection. Especially was this true in Sweden, Switzerland, and France, where nitre was collected as a part of each farmer's tax. In the year 1767 the French Government issued special instructions for manufacture of saltpeter. In these there was given special attention to the form of pit to be used, the covering of the organic matter, the arrangement for the free entry of air, the necessity of a minerai base, and the optimum amount of moisture which was best supplied from the drainage of stables.

Early Theories.-Even though the process had reached such a high state of development, the underlying principles were entirely unknown until the last third of the nineteenth century. At this time attempts were made to explain the oxidation of ammonia to nitric acid, on the strength of certain chemical reactions which could be brought about in the laboratory. These were the experiments of Kuhlmann and I)umas. The first investigator found, on passing ammonia and air through a heated tube containing a platinum sponge, that they combined with the formation of ammonium nitrate, while Dumas found that nitric acid was produced when air and ammonia were heated to $100^{\circ} \mathrm{C}$. with moistened lime. It was considered possible that the porosity of the soil could act as did the platinum sponge or the lime of the soil act in a manner similar to that used in l)umas experiments. After the discovery of ozone by hehönbein this substance was used to explain all natural processes of oxidation, and hence naturally the anse with nitrification. Mulder stated that investigations had shown that ozone is capable of oxidizing ammonia to nitric acid and water, and that it is probable that the same reaction could take place in the soil, the soil acting merely as a catalyzer in the reaction. 
It may be seen that in all the early theories it was supposed to be a purely chemical process; it was not until the time of P'asteur that the biological explanation for the formation of nitrates received any support.

It is interesting, however, to note the careful work of Boussingault in the rears between 1860 and 1878 , on the natural occurring saltpeter beds, especially those of Peru and Ecuador. He raised the question: "Have not the nitrates in these natural deposits resulted from the breaking down of organic substances rich in nitrogen?" for it had long been the practice to use blood, urine, and other animal refuse for the production of nitrates. For this reason, Boussingault did not think it likely that the gaseous nitrogen of the air played a very great part in the process of nitrification. In order to test this, he placed soil with known nitrogen content in 100-liter jars and allowed them to remain for eleren rears. At the end of this time they were analyzed, and, in spite of the fact that a very active nitrification had taken place, there was no increase in the total nitrogen of the soil. From this he concluded that free nitrogen takes no part in the formation of nitrates, but that they result from the organic matter of the soil. In another set of experiments he added organic manure to soil, sand, and chalk, and left them to nitrify. He obtained an active nitrification in the soil, but none in the sand or chalk. This fact had a great influence on the old theories of nitrification. Why this difference if the soil acts merely as a catalyzer? It may be said that this was the beginning of the end of the old chemical theories of nitrification.

The Dawn of the Biological Theory. - At this time (1S7S) the work of Pasteur was beginning to take firm root. There had appeared a series of reports on fermentation, one of the earliest (1862) being on the fermentation of acetic acid. 'This was similar to nitrification, for it was known that alcohol could be oxidized to acetic acid by use of the platinum sponge. In fact in this early publication Pasteur suggested that nitrification was due to a ferment, and soon after Miiller observed that the ammonia in sewerage is rapidly changed into nitrates, but no corresponding change takes place in pure ammonia solution. He suggested that the sewage probably contained a ferment which was absent from the pure solution prepared in the laboratory. He, however, took no steps to prove that the process was a true fermentation. Between 1S71-75 Gilbert noted that the drainage waters from the Rothamsted experiment fields contained more nitrates as the ammonium salts applied to the soil increased.

To the chemists, Schlösing and Müntz, belongs the credit of establishing by experiment the fact that nitrification is a biological process. They were trying to ascertain if the presence of humus is 
essential in the purification of sewage by soil. They filled a glass tube one meter long with ignited quartz sand and powdered limestone. Serrage passed through his filter at first unchanged, but later nitrates began to appear, and soon the filtrate contained no ammonium salts. They suspected microörganisms as being the active agent, and hence treated the contents with chloroform rapor. Nitrification entirely ceased and was not renewed for seven weeks, although the supply of chloroform was suspended. A water extract of fresh garden soil added to the tube soon restarted the process.

These experiments were immediately repeated by Warington who confirmed the results of Schlösing and Müntz and showed that: (1) The power of nitrification could be communicated to media which did not nitrify by simply seeding them with a nitrifying substance; (2) the process of nitrification in garden soil is entirely suspended by the presence of the rapor of chloroform or carbon disulphid. Since these early experiments much additional proof has been furnished by investigators showing that the process of nitrification both in soils and waters is undoubtedly due to living microörganisms. Some of these are the limits of temperature within which nitrification is possible, the necessity of a suitable food, and finally the isolation of specific organisms having the power of producing nitrates.

Schlösing and Müntz were unable to isolate any specific ferment capable of causing nitrification, but the true nature of the process not being known, many investigator's turned to this phase of the work and the race to see who would first reach the coveted goal became intensely interesting. Celli-Zuco and Heraeus, in 1886, succeeded in isolating from water rich in nitrates a number of forms of bacteria which they considered possessed very feeble nitrifying properties. Inasmuch as the nitric acid in their cultures may have been ainsorbed from the air, and as they did not succeed in isolating and proving any organism to be capable of nitrification their experiments were considered to be inconclusive. Frank attempted a similar isolation but without success, and he even concluded that nitrification was not due to the direct action of microörganisms but was a purely chemical process. But this view was opposed by a number of writers, notably Landolt, Platt, and Baumann.

Warington and Frankland studied a large number of soil organisms, but neither was able to find any which produced active nitrification. Frankland continued to maintain that the nitrifying organism was present in soil, and in 1890 succeeded in isolating a spherical organism about $0.8 \mu$ in diameter which possessed the power of converting ammonium salts into nitrites, but not into nitrates. 'The separation was made by means of the dilution method, using only inorganic salts. 
Isolation of Nitrifying Ferments.--The only definite result which had been reached up to 1890 was that there must exist in soil microörganisms which possess the power of nitrifying. Iowever, up to the time Winogradsky took up the subject all attempts to isolate such organisms had proved futile. His previous experience had been such as to confirm his belief in such organisms. He had discovered microörganisms which oxidized hỹdrogen sulphid (sulpho-bacteria) and an iron compound (ferro-bacteria). $\mathrm{He}$ reasoned that it was extremely probable that organisms should exist in water and in soil capable of availing themselves of the abundant energy which would come from the oxidation of the ammonium compounds contained therein. He considered that the number of such species would be small and that the way to secure and study. such organisms would be: (1) 'To find a medium and condition under which they would thrive and by which the growth of denitrifying organisms would be discouraged; (2) to continue the cultivation by such a method long enough to eliminate for the most part other organisms; and (3) when the cultures of the oxidizing organisms should have been obtained reasonably pure and their nitrification of ammonia active, to proceed to isolate the various organisms and study the character, and especially the nitrifying power of each in pure cultures. He knew that all previous attempts to isolate the organism on gelatin plates had failed and he considered that probably the organism would not grow on gelatin. He began by working with two soils, one rich in organic matter, the other poor, but both rich in carbonate, and soon he learned that organic matter hindered nitrification. After considerable work he finally adopted a medium having the following composition:

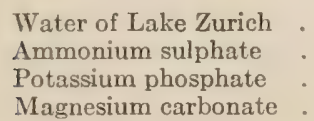

1000 c.c.

$1 \mathrm{gm}$.

$1 \mathrm{gm}$.

$0.5-1 \mathrm{gm}$. per 100 c.c.

When such a medium was inoculated with suitable material, nitrification was so active that after fifteen days every trace of ammonia had disappeared, whereas check solution contained only slight traces of nitric acid.

Cultures were continued and repeated in this medium for three months, when he considered that only the organisms suited to this medium had survived. These were inoculated on to gelatin plates and five species of organisms were found to form coloniesthree bacteria, one oildium, and the fifth a peculiar organism which he designated as "fungus." None, however, possessed the power of converting ammonia into nitric acid.

In the liquid cultures it was observed that a very thin film gradually formed on the surface of the culture and at times a slight 
cloudiness of the solution was noted. The latter disappeared after a time and a microscopic examination showed it to be due to the presence of an oval somewhat spindle-shaped organism which moved about very rapidly. Nitrification was at the same time very active. It was thought that the film on the surface might contain the nitrifying organisms as the acetic acid bacteria and other oxidizing ferments work at the surface where plenty of oxygen can be obtained, but tests with this gave negative results.

The plan of work was then somewhat changed. 'The attempt was made to cultivate the nitrifying organisms more abundantly. To this end a quantity of ammonium sulphate was added to the

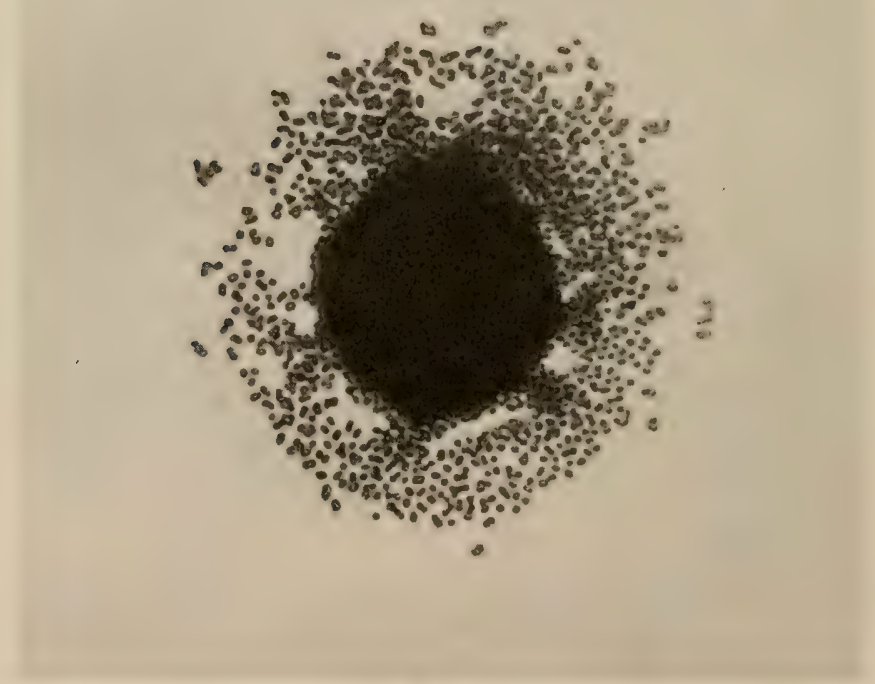

FIG. 30.-Surface colonies of nitrosomonas on silicic acid gelatin, stained with Fuchsin without removal from the gelatin. $\times 1200 . \quad$ (After Gibbs: Soil Science.)

nitrifying cultures, and the process of nitrification thus continued in the culture for some time. A change was noticed in the magnesium carbonate at the bottom of the solution which gradually assumed a grayish color and a gelatinous consistency. By shaking the solution vigorously this mass was broken up into small flakes, which a microscopic examination showed to consist of transparent particles of the salt covered with a mass of oval bacteria, identical in form with those which had previously been noticed as the cause of the cloudiness. These bacteria seemed to be on the particles exclusively and not on the walls of the flask, and slowly enveloped the salt which was finally dissolved. 
A culture medium was then prepared which was free from every trace of organic matter. On being inoculated, nitrification took place in this energetically, and it was found to contain large num-

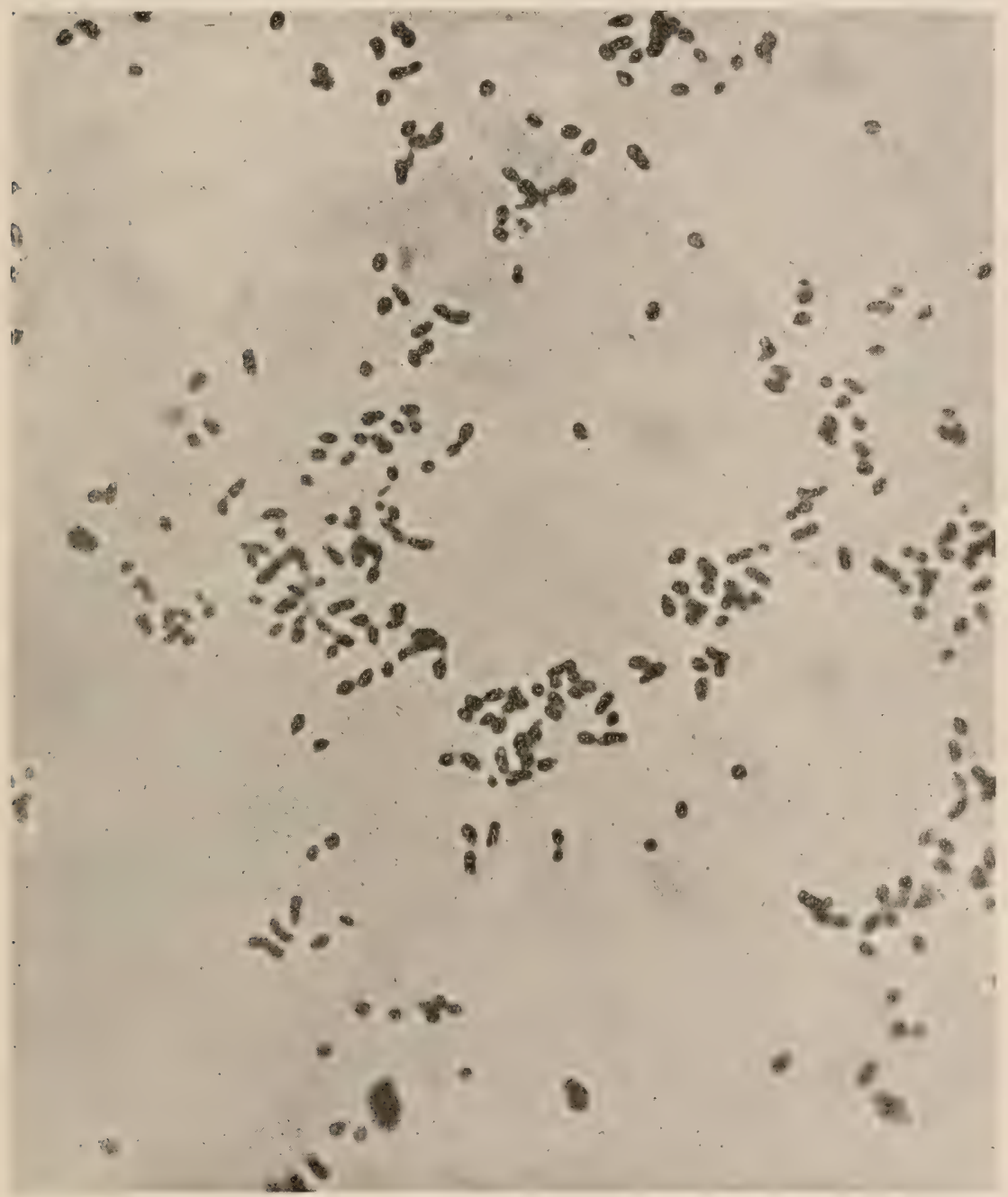

FIG. 31.-Nitrobacteria from cultures in liquid medium stained with earbol Fuchsin. $\times 2500$. (After Gibbs: Soil Science.)

bers of the oval bacteria, as well as the fungus form previously noticed, but the other forms had all disappeared. The fungus remained constant, and all attempts to cultivate it out were unsuccessful. 
The research was thus brought to the stage where it seemed probable that the oval bacteria might be the nitrifying agents. To test their nature and action satisfactorily the removal of the sprouting fungus was called for. 'To accomplish this, Winogradsky resorted to a very ingenious though a simple device. The fungus would develop in gelatin; the bacteria would not. Small particles of the carbonate, more or less enveloped by the bacteria, were taken from the bottom of the culture flask by means of a capillary tube and placed in a large flask of sterilized water. The contents of the flask were then well shaken and a gelatin plate inoculated with drops of the liquid, the particles of carbonate serving to indicate the places where the gelatin had been inoculated. In some of these the fungus developed. Inoculations of the culture liquid from the other spots failed to yield the fungus but developed the bacteria. By this method of "inverse gelatin culture" the bacteria were obtained pure. Liquid cultures inoculated with the bacteria oxidized ammonia rapidly. The inference was that the bacteria were the nitrifying organisms of the soil.

Winogradsky describes the nitrite-forming organisms as of oval form, about 1.1 to $1.8 \mu$ long and 0.9 to $1 \mu$ wide, usually at rest but at times capable of motion and dividing perpendicularly to the longest axis. He places it in a genus by itself, which he calls Nitrosomonas.

The nitrate-forming organism, nitrobacter, is 0.3 to $0.4 \mu$ wide and about $1 \mu$ long. The cells occur singly or in pairs and occasionally in threes. They are spindle-shaped, non-motile, and possess a capsule which makes them difficult to stain.

By way of comparing the activity of the nitrobacter with that of the ferments as they actually occur in soil, Winogradsky made a series of experiments to compare the amount of nitrification in his culture liquid with that observed by Schlösing in a soil to which, however, more oxygen had access than was the case with Winogradsky's liquid.

While in Schlösing's experiments by the use of 200 grams of earth, 3.4, 9, and $4.1 \mathrm{mg}$. of nitrogen, respectively, were nitrified, Winogradsky's pure cultures of bacteria nitrified $860 \mathrm{mg}$. of ammonium sulphate in twenty-seven days and $930 \mathrm{mg}$. in thirty day's. Therefore, during the period at which nitrification was most energetic there would be formed about $7.2 \mathrm{mg}$. of nitrogen per day.

Winogradsky further investigated the interesting and very remarkable fact previously cited, that the nitrobacter, although containing no chlorophyll, grows and is able to multiply in a solution entirely free from organic matter. To prove this fact beyond doubt he prepared a culture medium absolutely free from every trace of organic matter by using twice distilled and tested water and salts which had been carefully purified by recrystallization. 
Ile thoroughly removed all organic matter from the glass dishes and apparatus to be used, and inoculated separate portions of the medium with the nitrobacter. The cultures developed normally in the dark as well as in the light. 'To gain an idea of the extent of the assimilation of carbon, the carbon in the organic matter which had been formed by the organism in its growth was determined by analysis. Four cultures contained 10.2, 7.1, t.6, and $4.8 \mathrm{mg}$., respectively, of assimilated carbon, and in these cultures 928, 604, and $83.5 \mathrm{mg}$., respectively, of nitric acid had been formed. This seemed to leave no doubt that nitrobacter is able to assimilate the carbon of carbonic acid.

Later, in 1891, Warington, in a solution containing mineral salts, obtained after repeated generation a culture which nitrified vigorously. This contained no organisms which would grow on gelatin and was regarded by him as containing only nitrifying bacteria. The organisms thus obtained were oval in form and seldom 1 micromillimeter thick and only slightly longer.

At this time Winogradsky made a decided improvement in the separation of the nitrifying organism from solutions by use of the Kühne gelatin silica medium. The nutrient basis of this medium as used by Winogradsky was composed of ammonium sulphate, 0.41 grams; magnesium sulphate, 0.05 grams; potassium phosphate, 0.1 gram; sodium carbonate, 0.6-0.9 gram; calcium chlorid, a trace; and water, 100 c.c.

The inoculation of the plates took place either by mixing the inoculating material with the above solution before the addition of gelatinous silica, or it was made as a streak or smear culture on the already hardened material. In this way the nitrifying organisms developed distinct colonies from which pure cultures were obtained.

The investigations of Winogradsky and simultaneously of Warington showed the following: (1) That in the soil the nitrifying process was effected by two distinct but closely related organisms, the one converting ammonia into nitrous acid and nitrite and the other changing the nitrites into nitrates. (2) That these two processes follow one another in such rapid succession that the production of nitrites is only a transitory phenomenon, so that if both the nitrite and nitrate organism be added to sterilized soil the process is completed in the natural way, only the merest traces of nitrous acid appearing.

If to a mineral solution containing ammonium salts, a pure culture of nitrosomonas be added, only nitrites will appear and these will remain unchanged in the absence of the nitrobacter. If, however, the two organisms be added simultaneously nitrates will be rapidly formed. 
According to Kaserer there is an organism which can oxidize ammonia direct to nitric acid, but so far this has not been confirmed.

In 1S92 Winogradsky studied the nitrifying organisms of the soil from a number of different localities. Those from sereral parts of Europe, from Africa, and from Japan, which he considers to be the same organism, he names Nitrosomonas europea. A second form from Java soil differing from the first, he names Nitrosomonas jatenensis. Both of these comprise the nitrate ferments of Winogradsky, the second nitrate ferment was isolated by Winogradsky from Quito soil and differs from the first not only as to size, as above mentioned, but also by entirely lacking the motility common to the latter.

In 1895 Burri and Stutzer isolated from soil a nitrate organism with properties akin to the Quito bacillus of Winogradsky. It was a motile organism, $0.75-1.5 \times 0.5$ micromillimeters, growing on gelatin which it liquefied, said organism, according to these workers, being able to convert nitrites into nitrates, but losing such power when grown on organic media.

The results of Burri and Stutzer, so contrary to those of Winogradsky, brought forth a vigorous rejoinder from the latter. In this Winogradsky stated that he tested the same earth used by Burri and Stutzer and isolated therefrom his own nitrosomonas, and that the latter when tested in bouillon, meat peptone, gelatin, and agar failed to grow. He, therefore, regards the German work as erroneous.

In 1897 Stutzer and Hartleb appeared with a still more startling series of discoveries in which they not only maintained the ability of the nitrifying organisms to grow in organic media, but also showed that the latter possessed a polymorphic habit never imagined in this or any other like group in the whole domain of mycology-the ability of simple coccoid or rod-shaped forms to develop into filaments or eren into branched forms, with the further production of true gonidia and other even more highly organized fructification bodies.

Gärtner discussed the work of Burri, Stutzer and Hartleb on the polymorphism of the nitrifying organism, and from presumably pure cultures of the latter's nitrifying ferment was able to isolate thirteen different microörganisms, including a fungus form (Schimmelpil\%), thus proving their impure character. Furthermore, Gärtner showed that these several organisms, when once separated in their pure state, retained their fixed character, with no tendency to polymorphism, and indicated none of those transition stages from hacteria to fungi noted by Stutzer. Again, none of these isolated organisms possessed the power to convert ammonia into nitrites. ( . Fraenkel simultaneously isolated from Burri and Stutyer's cultures 11 different organisms, including 7 bacilli 
2 streptothrices, and 2 fungi (a Fadempilz and a schimmelpilz). These showed no polymorphism, but all retained constant characters.

In 1902.2 (hester summarized the knowledge on nitrification as follows:

1. That nitrification in the soil is caused by a distinct or rather by two distinct organisms possessing certain definite characters.

2. That these organisms will not grow in the presence of any considerable amount of organic matter, and that all reported attempts, to cultivate them on ordinary organic media are without authentication.

3. That the above nitrifying organisms are found abundantly in all cultivated soils and in ordinary soil water containing a due proportion of ammonium carbonate, sulphate, etc., they find a favorable medium for their development.

t. That the result of such development is: (a) The conversion of ammonia into nitrous acids through the agency of the nitrous organism; and $(b)$ the immediate conversion of the previous nitrous into nitric acid by means of the equally abundant nitric ferment.

Distribution.- Probably the nitrif ving bacteria were some of the first living organisms to appear upon this plinet, and even ret they act as the pioneers preparing the soil for other plants. Müntz has found the decayed rocks of Alpine summits, where no other life exists, swarming with the nitrifying ferments. The limestones and micaceous schists of the Pic du Midi, in the Pyrenees, and the decayed calcareous schists of the Faulhorn, in the Bernese Oberland, offer good examples of this kind. The organisms draw their nourishment from the nitrogen compounds brought down in snow and rain; they convert the ammonia into nitric acid, and this in turn corrodes the calcareous portions of the rock. Stützer and Hartleb have observed a similar decomposition of cement by nitrifying bacteria.

The nitrifying bacteria appear to be very widely distributed Müntz and Aubin have observed their presence not only in all cultivated soils which they have examined, but also in those of deserts. They are not usually found in the air or in rain water. River water and sewage contain them. They are usually present in well waters. In the case of deep wells their origin is due to surface soil or to drainage from the surface soil which has found its way into the well, the water of deep wells not being their natural habitat. Thomasen found the nitrite organism in samples of ooze from the bottom of the Kiel Fjord, but not in the sea water nor on the Plankton or the fixed algre. It was also found in similar samples of soil from the vicinity of Helgoland and in slime from the bottom of the Bay of Naples, but only in samples taken near the land. 
Warington failed to find the nitrifying ferments in a clay soil below eighteen inches, and this is in keeping with the findings of Ladd at North 1)akota. For a long time it was considered that they are found only in the surface soil, but in 1906 Welbel presented results with soils where nitrification is almost as active in the subsoil as in the surface soil when the subsoil is aërated. In 1912 C. B. Lipman found them often to a depth of five or six feet in soils of the arid regions. In one case soil from the eight-foot depth showed a vigorous nitrifying power. The author found soil from second and third foot-sections to nitrify dried blood quite readily, as is shown below:

Depth

First truelve inches

Second twelve inches

Third twelve inches
Irrigated
Soil

19.39

2.70

1.98

\section{$\underset{\substack{\text { Dry-farm } \\ \text { Soil }}}{ }$}

5.25

2.41

1.55

These are the averages of several hundred examinations, and many soils which were fairly heavy clays showed active nitrification in the second and third foot-sections. This great difference observed in the arid regions is due mainly to a better aëration of these subsoils which, because of the peculiar climatic conditions, the arid soils are not as rich in clay as are the subsoils of the humid regions. Moreover, the plants in the arid regions root to a great depth in search of water. These decaying roots loosen up the subsoil and also furnish food for bacterial growth.

Reaction of Media.-Boussingault long ago observed that many forest soils do not contain nitrates, and later this was verified by Bréal and others. We now know that the absence of nitrates is due to the acid reaction of a soil which contains an excess of organic matter. The nitric ferment does not act in an acid medium; hence, we have the explanation of the great benefit derived from the use of basic substance.

Experiments by Wiley and Elwell in which solutions containing calcium chlorid and water were seeded with nitrifying ferments continued to nitrify until the medium contained an acidity equivalent to 4 c.c. of normal acid per 100 .

Dumont and Crochetelle's experiments are of the same order. They took soil which had been in grass from time immemorial and which contained 6.84 per cent. of humus. 'This was treated with variable quantities of potassium carbonate. It was stirred and watered several times during the experiment and after one month the nitrates were extracted with the following results: nitric nitrogen, per 1000 grams, of soil without addition of potassium carbonate, $70 \mathrm{mgs}$; with 1 gram of potassium carbonate, $160 \mathrm{mgs}$; with 2 grams of potassium carbonate, $230 \mathrm{mgs}$; with 3 grams, 250 mgs.; with 4 grams, 130 mgs.; with 5 grams, 73 mgs. In similar 
experiments, Kochenavski demonstrated that potassium carbonate is more efficient in this regard than is calcium carbonate, probably because the potassium acts as a food in addition to the neutralizing of the acid. Owen has found magnesium carbonate even more efficient than potassium carbonate, and this is in keeping with the findings of Lyon, and Bizzell and White. Panganiban's findings appear to differ from these, for he claims that liming greatly increases nitrification only when the limestone contains little magnesium carbonate. The soil of the Utah Greenville farms contains 16.88 per cent. of lime $(\mathrm{CaO})$ and 6.1 per cent. magnesium $(\mathrm{MgO})$, and they nitrify ammonium sulphate, dried blood, and cottonseed meal readily.

The carbonates are not the only substances in the soil which serve as bases for nitrification, since, according to Ashby, a marked nitrification of ammonium salt can be brought about in the presence of ferric hydrate, either in the freshly precipitated state or as "iron rust." In solutions, however, nitrification is not completed where iron is the only base, probably because the ferric nitrite or nitrate formed dissociates and the solution becomes acid.

The double ammonium combination formed by the absorption of ammonium salts by modelling clay can most probably be nitrified in the absence of any base, but the corresponding combination with peat undergoes no nitrification in the absence of a base.

One of the functions of the base in nitrification is to form ammonium carbonate, and the facility with which nitrification is set up by different carbonates depends upon the rapidity with which they can react with a neutral ammonium salt to produce ammonium carbonate. This reaction is greater with magnesium carbonate than with calcium carbonate, but is almost absent with copper carbonate.

The quantity of lime which must be added to a soil for maximum nitrification varies with the original reaction of the soil and the fertilizer to be nitrified; ammonium sulphate requires more than bone meal, cottonseed meal, or dried blood.

There should always be an excess of the base present, for Fischer found that the theoretical amount of lime (200 grams of calcium (carbonate) required for the nitrification of ammonium sulphate (132.7 grams) was not sufficient for complete nitrification, but about three and one-half times the theoretical amount was required. Even much larger quantities of either magnesium carbonate or calcium carbonate may be used without ill effect, but large quantities of quicklime may cause a rapid burning out of the organic matter and even volatilization of ammonia and may even stop nitrification. For, while nitrification takes place in a feebly alkaline medium, yet the presence of anything beyond a small quantity of an alkaline salt is a hindrance to the process, and a large 
amount will check it entirely. Thus Warington found that the presence of 0.032 per cent. of bicarbonate of soda distinctly retarded nitrification, and in the presence of 0.096 per cent. nitrification was only barely possible. The same author also showed that the presence of 0.0477 per cent. of ammonia in urine rendered it unnitrifiable. Dumont and Crochetelle found that potassium carbonate added to soil at the rate of from 1 to 2.5) grams per 1000 grams of soil markedly increased nitrification, but larger applications of the salt progressively diminished the rate of nitrification, and that the addition of 8 grams per 1000 grams of soil completely checked it. A heary dose of lime by unduly increasing the alkalinity of the soil may at first check or suspend nitrification until the said lime has been converted into carbonate. This, however, takes place, rapidly, diminishing in turn its strong alkaline properties and permitting nitrification to commence more actively than before.

Food Requirements of Nitrifiers. - The nitrifying organisms require the same elements as do other bacteria, and hence will be considered in this chapter only in a very general way, except in regard to the source of the required elements.

Winogradsky found that the nitrosomonas were able to grow in a medium consisting of 2.25 grams of ammonium sulphate, 2 grams of common salt, and 1 grams of magnesium carbonate in 1 liter of well water. For the nitrobacter the aminonia is replaced by sodium nitrite. In media such as the above, devoid of organic carbon, the nitrifying organisms are able to function in the dark and form from the inorganic carbon, organic carbon compounds. He proved by numerous quantitative determinations that during nitrification an increase in the amount of carbon compounds takes place. "Since this bound carbon in the cultures can have no other source than the carbon dioxid and since the process itself can have no other cause than the activity of the nitrifying organism, no other alternative was left but to ascribe to it the power of assimilating carbon dioxid.

"Since the oxidation of ammonia is the only source of chemical energy which the nitrifying organisms can use, it is a priori that the vield in assimilation must correspond to the quantity of oxidized nitrogen. It turned out that an approximately constant ratio exists between the values of assimilated carbon and those of oxidized nitrogen." This is illustrated by the following results:

$\begin{array}{lrrrr} & \text { No. } 5 . & \text { No. } 6 . & \text { No. } 7 . & \text { No. 8. } \\ \text { Oxidized nitrogen } & 722.0 & 506.1 & 928.3 & 815.4 \\ \text { Assimilated carbon } \quad 19.7 & 15.2 & 26.4 & 22.4 \\ \text { Ratio-nitrogen: carbon } & 36.6 & 33.3 & 35.2 & 36.4\end{array}$

It is evident that 1 part of assimilated carbon corresponds to about 35.4 parts of oxidized nitrogen or 96 parts of nitrous acid. 
More recently, Coleman using pure cultures of nitrate producers obtained ratios varying from 40 to 44 .

Now there are two sources of carbon dioxid which are available to the nitrifying organisms -one, the carbonate, which is present in the soil; the other, the carbon, in the air. According to IVinogradsky, the carbonate supplies the carbon for the bacterial growth, it being liberated by means of the acids, which they produce. On the other hand, Godlewski considered that it is chiefly from the atmosphere that the carbon dioxid requisite for the construction of new cellular substance is derived. He found that derelopment did not occur in cultures containing magnesium carbonate when air free from carbon dioxid was admitted, and concluded that: (1) Nitrosomonas placed in a pure mineral solution are unable to assimilate the carbon of magnesium carbonate; (2) it is very improbable that the nitrobacter derive their carbon from the organic substances of the air; (3) it is very probable that these organisms find the carbon which they need in the free carbonic acid or in the carbonic acid of bicarbonates. But Owen, after careful experiments in which he used a specially derised flask for the elimination of the carbon dioxid of the air, concluded that "the nitrifying organisms of the soil do not depend to any appreciable extent on the carbon dioxid of the air for their carbon supply." Hence, the evidence seems to be that the organisms under appropriate conditions possess the power of utilizing either source of carbon.

The nitrite bacteria obtain their nitrogen both for oxidation in the production of energy and as building material from ammonia preferably in the form of ammonium carbonate. They are, however, according to Ashby, able to utilize the double ammonium combination formed through the absorption of ammonium salts by modelling clay, but the corresponding combination with peat undergoes no nitrification in the absence of a base. However, according to Marcille, the nitrogen of ammonium phosphate is not so readily transformed into nitrous acid as is that of ammonium sulphate. Tet the phosphate appears to furnish a much more favorable medium for the transformation of nitrites into nitrates than does the sulphate.

While calcium cyanamid is nitrified when added to a soil, it is not until it has been transformed into ammonia by other bacteria, chief among which are, according to Löhnis, $B$. putidum, $B$. mycoides, B. vulgare var., B. zopfii lepsiense (n.sp.), B. liirchneri (n. sp.), B. meyatherium, B. fluorescens, B. subtilis, B. ellenbachensis and $B$. vulgare. According to Boullanger, the nitrous organism does not attack hydroxylamin hydrochlorid.

Excessive quantities of ammonia or ammonium salts hinder the multiplication of nitrifying organisms but do not interfere with the action of those already present. Boullanger and Massol found 
the minimum retarding amount of ammonia to be about 2 parts per million. It is seldom sufficient ammonia accumulates in soils under natural conditions to interfere with the multiplication of nitrifying bacteria.

Just as all organic nitrogen must be ammonified before it can be changed by the nitrosomonas to nitrous acid, so all ammonia compounds must be oxidized to nitrous acid before the nitrobacter can convert them into nitric acid. The nitrite organism readily oxidizes nearly all nitrites in solutions containing 0.5 to 1 gram per liter, but larger quantities of the nitrites are toxic even to the nitromonas.

Organic Matter. - Winogradsky early learned that the nitrifying organisms will not grow in a medium containing soluble organic matter, and since that time numerous experiments have been made to account for this apparent discrepancy. It was well known that nitrification takes place in the soil and compost which contains organic material. Hence, the theory was soon advanced that organic matter in the form of humus is not injurious and may actually be beneficial, as is illustrated by the work of smimor:

Humus
Per cent
0.42
3.55

\begin{tabular}{|c|c|c|}
\hline & & \\
\hline $15 \mathrm{mg}$ & Atter 19 Days & $25.5 \mathrm{mo}$ \\
\hline $\begin{array}{l}1.3 \mathrm{mg} \text {. } \\
0.5\end{array}$ & $\begin{array}{l}14.0 \mathrm{mg} . \\
21.0\end{array}$ & $\begin{array}{l}20.0 \mathrm{mg} . \\
38.0\end{array}$ \\
\hline
\end{tabular}

After 73 Days $28.0 \mathrm{mg}$. 53.0

Müntz later concluded that humus even in larger quantities does not interfere with nitrification, but on the other hand it is favorable to it. Nor is an abundance of humus a necessary condition to nitrification, since soils poor in this constituent gradually develop intensive nitrification. He considers that the humus favors the multiplication of the nitrifying organisms and a soil which contains a large amount of humus is more abundantly supplied with these organisms and more apt to enter into rapid nitrification.

Coleman found dextrose, cane sugar, glycerin, and lactose, in small amounts, to favor nitrification, and in some cases even as much as 1 per cent. of dextrose has proved beneficial. This conclusion has been confirmed by numerous other workers. Where larger quantities of sugars are used there is usually a disappearance of nitrates. This is probably due to its favoring other organisms which produce protein from the nitrates rather than interfering with nitrification or accelerating to a great extent denitrification. The optimum amount of organic matter for most rapid nitrification varies with the moisture and nature of the soil. Fischer found even peat extract to favor nitrification, while Niklewski claims that nitrification occurs in solid stable manure when there is not much liquid manure mixed with it, and that on the first day nitrite bacteria are found in the manure coming originally not from the 
stock but from the straw, particles of earth, etc., that stick to the manure. These bacteria increase in number until at the end of four weeks there may be 1000 per gram of substance associated with these. Hence, we may conclude that the absence of nitrification which has been noted by various workers when organic matter is present may be due to some of the following factors: (1) Excessive quantities of soluble organic matter. This has been repeatedly found to be the case where excessive quantities of carbohydrates have been added to the media. (2) A low percentage of potassium as suggested by Renault. (3) The physical and chemical properties of the medium, as noted by Stevens and Withers. (4) The presence of organic acid, as is the case in peats and forest soils. In this condition it is the acid reaction which interferes with the process and not the organic matter present. (5) A substance may be toxic when tested by the solution method, whereas in the soil it may be inert or actually beneficial.

Energy.-The nitrifying organisms are devoid of chlorophyll and function best in the dark, yet they synthesize from the carbon dioxid complex organic compounds. The energy necessary for this synthesis is obtained by the nitrosomonas from the oxidation of ammonia:

$$
2 \mathrm{NH}_{3}+3 \mathrm{O}_{2}=2 \mathrm{HNO}_{2}+2 \mathrm{H}_{2} \mathrm{O}+157.6 \mathrm{Cal} \text {. }
$$

and by the nitrobacter from the oxidation of nitrous acid:

$$
2 \mathrm{HNO}_{2}+\mathrm{O}_{2}=2 \mathrm{HNO}_{3}+36.6 \mathrm{cal} \text {. }
$$

Lafar points out that if the quantity of nitrogen oxidized per unit of time be taken as the standard for measuring the chemical energy of these organisms, the nitrosomonas will be found the most active of the two. From this fact he concludes that the conversion of the trivalent nitrogen of nitrous acid into pentavalent nitric nitrogen requires the expenditure of a greater amount of internal force than is needed for the first step in the oxidation.

Metabolism.-The metabolism of these organisms has, therefore, been the subject of considerable study. Winogradsky early suggested that the ammonium carbonate in the first place probably gives rise to an amid, somewhat similar to the transforming of ammonium carbonate into urea:

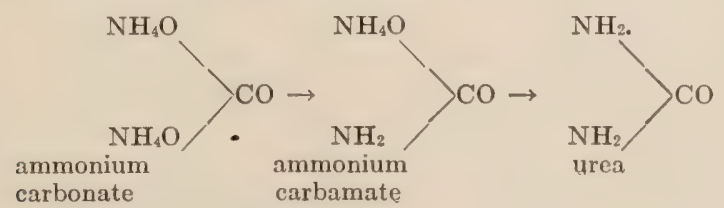


It is quite likely that all organic compounds are first transformed into ammonia by other organisms before they are nitrified. Demoussy found this to be true of monomethylamin, trimethylamin, anilin, prridin, and quinolin, and, according to Löhnis, calcium cyanamid. This is also true for carbamid, thiocarbamid, uric acid, acetamid, anilin sulphate, methylamin sulphate, ammonium oxalate, asparagin and ammonium sulphate, which, with the exception of thiocarbamid and anilin sulphate, are readily transformed, according to Busley, into ammonia by other bacteria and then nitrified. Hence, the early conclusion reached by Winogradskythat pure cultures of nitrifying bacteria are incapable of nitrifying organic nitrogen-has been borne out by other investigators. Where contrary results have been reported it has been due to the presence of other organisms by which the nitrogen has been converted into ammonia and then nitrified. The process is catalyzed by oxidizing enzymes which must be specific in their action, for Omelianski found the nitrifying organisms unable to oxidize mineral compounds such as sodium sulphite and phosphite.

Oxidation in this case cannot be regarded as being of a violent nature and it scarcely seems conceivable that the nitrosomonas should be able to oxidize ammonia direct to nitrous acid without passing through intermediate stages of oxidation. Most workers consider it probable that in the oxidation of the ammonium radical there are formed certain intermediate substances which must be regarded as more or less hydroxylated ammonium radicals.

Mulford, in a study of the bacterial oxidation of aqueous solutions of ammonium salts on experimental filters inoculated from actively nitrifying sewage filters found that the oxidation proceeded in a series of stages compatible with the hypothesis that the hydrogen atoms are successively hydroxylated with the subsequent elimination of water. Hydroxylamin salts and salts of hyponitrous acid and nitrous acids were found as intermediate compounds.

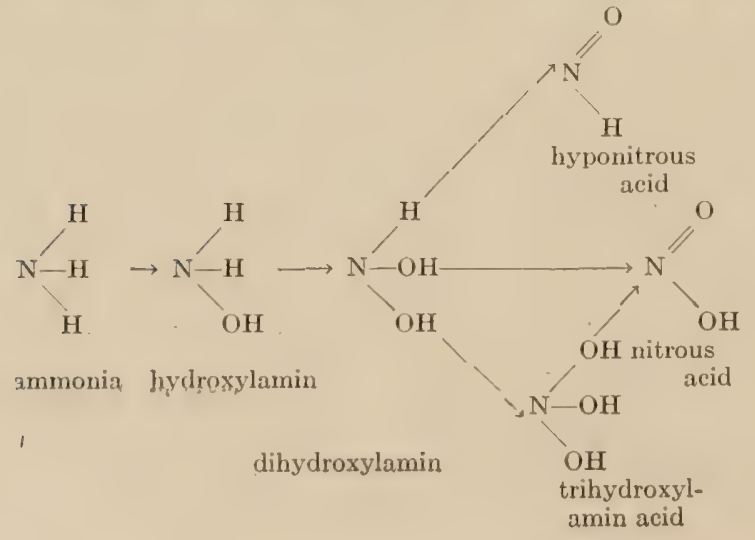


There are, however, two serious objections to these conclusions: (1) It is not evident that these initial changes noted by Mulford were due to the nitrifying organisms, as a mixed culture was used; (2) Boullanger and Massol found that while the nitrous organism accommodates itself to all ordinary carbonates, it does not attack hydroxylamin hydrochlorid.

The majority of workers have reported a loss of nitrogen in the nitrification process, there never being the theoretical yield of 100 per cent. of the ammonia transformed into nitrous acid, but this may be due to side reactions Lafar considers that the loss may be due to the reaction of the nitrous acid on the undecomposed ammonia in accordance with the equation:

$$
\mathrm{N}_{2} \mathrm{O}_{3}+2 \mathrm{NH}_{3}=3 \mathrm{H}_{2} \mathrm{O}+2 \mathrm{~N}_{2}
$$

The whole subject of the metabolism of nitrifiers is indefinite and in need of careful investigation using the latest refined methods. The only fact that does seem to be well established is that the process of nitrification goes in two stages from ammonia to nitrous acid and from nitrous acid to nitric acid. That these two steps are due to two classes of organisms is the claim of most investigators. However, Kaserer considers that there is an organism, $B$. nitrator, which can oxidize ammonia direct to nitric acid, the reactions being as follows:

$\mathrm{NH}_{3}+\mathrm{H}_{2} \mathrm{CO}_{3}+\underset{\mathrm{CH}_{2} \mathrm{O}}{\mathrm{O}_{2}}=\underset{\mathrm{O}}{\mathrm{HNO}}+\underset{\mathrm{H}_{2}}{\mathrm{CO}_{3}}+\mathrm{H}_{2} \mathrm{O}+\underset{\mathrm{CH}_{2} \mathrm{O}}{\mathrm{C}}-41 \mathrm{Cal}$.

It is interesting to note that the reaction catalyzed by the nitrifying ferments are similar to reactions catalyzed by ultraviolet rays. Gaudechon exposed solutions at temperatures of $335^{\circ}$ to $50^{\circ}$ (. for from three to nine hours at a distance of 3 to $6 \mathrm{~cm}$. from a lamp of 110 watts. Ender these conditions the ultraviolet rays oxidized solutions of ammonia in the presence of oxycen to nitrites. Nitrates were in no case formed. Ammonium salts were also oxidized to nitrites, the reaction being slower in the case of the sulphates and chlorids than the carbonates. Irea was first converted into ammonia and then into nitrites. Other organic nitrogen compounds, for example, ethyl- and methylamin, guanidin, hydroxylamin, acetamid, and acetonitril behaved similarly:

Morphology. - Winogradsky described two varieties of the organisms capable of changing ammonia to nitrites. One of these in several species was found in all the soils of the Old World (Asia, Africa and Europe) and is known as nitrosomonas. The second is peculiar to the soil of the New World and has received the name of nitrosococcus.

He described a single species of the nitrosomonas from European soils, namely, Nitrosomonas europoa. 'This organism is provided 
with a single short flagellum and in the early stages of the culture it exhibits active powers of locomotion. It appears as short rods 1.2-1.5 $\mu$ long and $0.9-1.0 \mu$ broad. The cells of Nitrosomonas jatanica obtained from the Botanical Garden at Buitenzorg, near Batavia, are globular and only attain a diameter of $0.5-0.6 \mu$, but they have a long flagellum, at times measuring as much as $30 \mu$. Those obtained from Tokio soil (Nitrosomonas japonica) and from Africa (Nitrosomonas africana), are very similar to the European species, differing only in that they are somewhat smaller.

Observations by Burri and Stutzer on impure cultures in mineral media led them to believe that there was a difference in oxidizing powers in organisms derived from different sources. By this means they distinguished five classes from German and one from African soil.

Joshi has recently described a new species from the soils of India which differ morphologically from others hitherto described.

The different species show a variation in sensitiveness to heat. Beddies found one species to live for one minute in steam at a temperature of $100^{\circ}$. The other two were more sensitive but survived for several minutes in dry heat of $80^{\circ}$ to $100^{\circ} \mathrm{C}$.

The genus, nitrococcus, found in the New World do not possess cilia nor do they form zoöglea. The one obtained from Quito (Ecuador) is a coccus 1.5-1.7 $\mu$ in diameter. The species, Nitrosococcus brazilicnsis, obtained from Brazil soil is much larger, being $2 \mu$ in diameter.

'The nitromonas or nitrobacter differ from those already described in physiological properties in that they oxidize nitrites into nitrates. Morphologically, they differ in being smaller and more slender. They are elongated, oval, mostly pear-shaped, 0.5) $\mu$ in length and $(0.15-0.25 \mu$ in breadth. In liquid cultures they develop a thin mucinous skin which adheres firmly to the walls of the ressel.

From the variation in sensitiveness to heat, Beddies isolated four forms of nitrobacter, one of which was capable of resisting the action of steam at $100^{\circ} \mathrm{C}$. for two minutes. But Burri and Stutzer's comparative experiments with nitric organisms derived from different localities showed no essential difference in phrsiological action.

Neither nitrosomonas nor nitromonas have been observed to form spores, but their resistance to drying and to heat, as shown by Berdlies, makes it appear possible that some species may form spores.

Influence of Moisture.-Long before the process of nitrification was known to be due to microörganisms, the underlying principles governing the speed of the reaction had been investigated nationally by France, (rermany and sweden. Among other things, they harl learned that there must be a certain proportion of water, and, in order that the maximum, rield of nitrates be obtained, that this 
must be diminished as the soil becomes richer in nitrates. As early as 1887 Dehérain found that the most active nitrification took place when the soil was allowed to become partially dry between the applications of water, and later he found that there was a relationship between the speed of nitrification and the moisture content of fallow soil, the nitrification increasing with the water. Boussingault taught that when soils contain as much as 60 per cent. of water they lose in a few weeks the greater part of their nitrates. This teaching gave rise to the general belief that denitrification may take place to a great extent in soils, but recent work has amply demonstrated that it is only extremely abnormal conditions where this becomes an important factor.

Deherain and Demoussy found that the bacterial action of a soil was at its maximum when a rich soil contained 17 per cent. of water, but that it decreased if the proportion of water fell to 10 per cent. or rose to 25 per cent. With soils less rich in humus a somewhat higher proportion of water was necessary to retard oxidation to any marked degree.

The optimum moisture content for nitrification, according to I)hérain, is 25 per cent. An insufficient supply of moisture checked both nitrification and nitrogen fixation. 'This occurred when the water had been reduced to 16.5 per cent. 'This, however, would vary with the soil, for Schlösing found bacterial activity less in fine-grained soils than in lighter, coarse-grained soils. In order that nitrification be equally active in both light and heary soils, the latter must have a higher percentage of water than the former, a difference in moisture content of soil of 1 per cent., according to I)afert and Bollinger, being sufficient to produce a marked change in the oxidation going on in the soil.

Fraps found that the number of nitrifying organisms in a soil varies with the moisture and that their activity was periodic, rapid nitrification being preceded and followed by periods of less activity. Later he found nitrification to be at its height in soil containing 55.6 per cent. of its water-holding capacity. Excessive quantities of water practically stopped nitrification and were much more injurious than too small a quantity. The water requirements, however, varied considerably with the soil. Coleman's work with a loam soil showed nitrification to be most active when the soil contained 16 per cent. of water. It was greatly retarded when the water content was reduced to 10 per cent. or increased to 26 per cent.

Patterson and Scott's work is interesting in that they found nitrification to be inactive in sand and clay soils which still contained about three times as much moisture as in their arerage airdry condition. At the lower limits of moisture less water starts nitrification in sand than in clay. At the higher limits of moisture less water stops nitrification in sand than in clay, while the opti- 
mum amount of water probably varies for each soil; it is higher for clay, yet for both soils it lies within the range of from 14 to 18 per cent. A rise above the optimum amount of water is more harmful than an equal fall below it.

The work of the Ctah Experiment Station demonstrated that the application of irrigation water to a soil has a distinct beneficial effect upon nitrification, being greatest where 15 inches of water were applied when the nitric nitrogen formed amounted to 28.5 pounds per acre-foot of soil. The greatest benefit per inch of water, however, was obtained where only 7.5 inches of water were applied, resulting in 3.8 pounds of nitric nitrogen per inch of water, while where 15 inches were applied it was 1.1 pounds of nitric nitrogen per inch of water applied, and when 25 inches of water were applied to the soil the nitric nitrogen produced was only 0.7 pound.

Münter and Robson found that hornmeal decomposed more rapidly in dry sandy soil than in clay or loam, whereas with higher moisture content there was little difference. Ammonia sulphate transformation increased with a higher water content. The best nitrate formation from hornmeal occurred in sandy soils. In clay and loam it was best with a medium water content. Sharp found that the water content most favorable for ammonification was not the optimum condition for nitrification. The former was most rapid with a 25 per cent. water content and was not markedly aflected by 3 per cent. differences. Nitrification was at its maximum when the soil contained 19 per cent. of water. When it was increased to 25 per cent. the rate of nitrification was decreased 50 per cent.

McBeth and Smith found a slight variation in the number and nitrifying powers of soil, depending upon the moisture content. However, Gainey considers that among the factors controlling the bacterial activity of a soil the available moisture probably plays a leading part. But the author has reported results which indicate that the nitrous nitrogen content of a soil is independent of the irrigation water applied up to 37.5 inches a year. Results recently published by the Utah Experiment Station clearly demonstrate that the influence exerted by water upon ammonifying, nitrifying, and nitrogen-fixing activities of the soil varies greatly with the organic matter in the soil and is much more marked in effect on soils recently manured than on those which have received no manure.

From the literature cited it may be seen that the nitrifying power of the soil is a function of the moisture content of the soil, and that the optimum varies with the physical and possibly with the chemical properties of the soil. Recent work at the Ltah Experiment Station shows a close correlation between the nitrifying powers of a soil and its water-holding capacity and varies only. 
slightly with the physical properties of a soil. 'Twenty-two soils varying widely in physical properties yielded maximum nitrification when the soil contained from 50 to 60 per cent. of their waterholding eapacity, as indicated in Fig. 30. Furthermore, the optimum moisture content for maximum nitrification is correlated

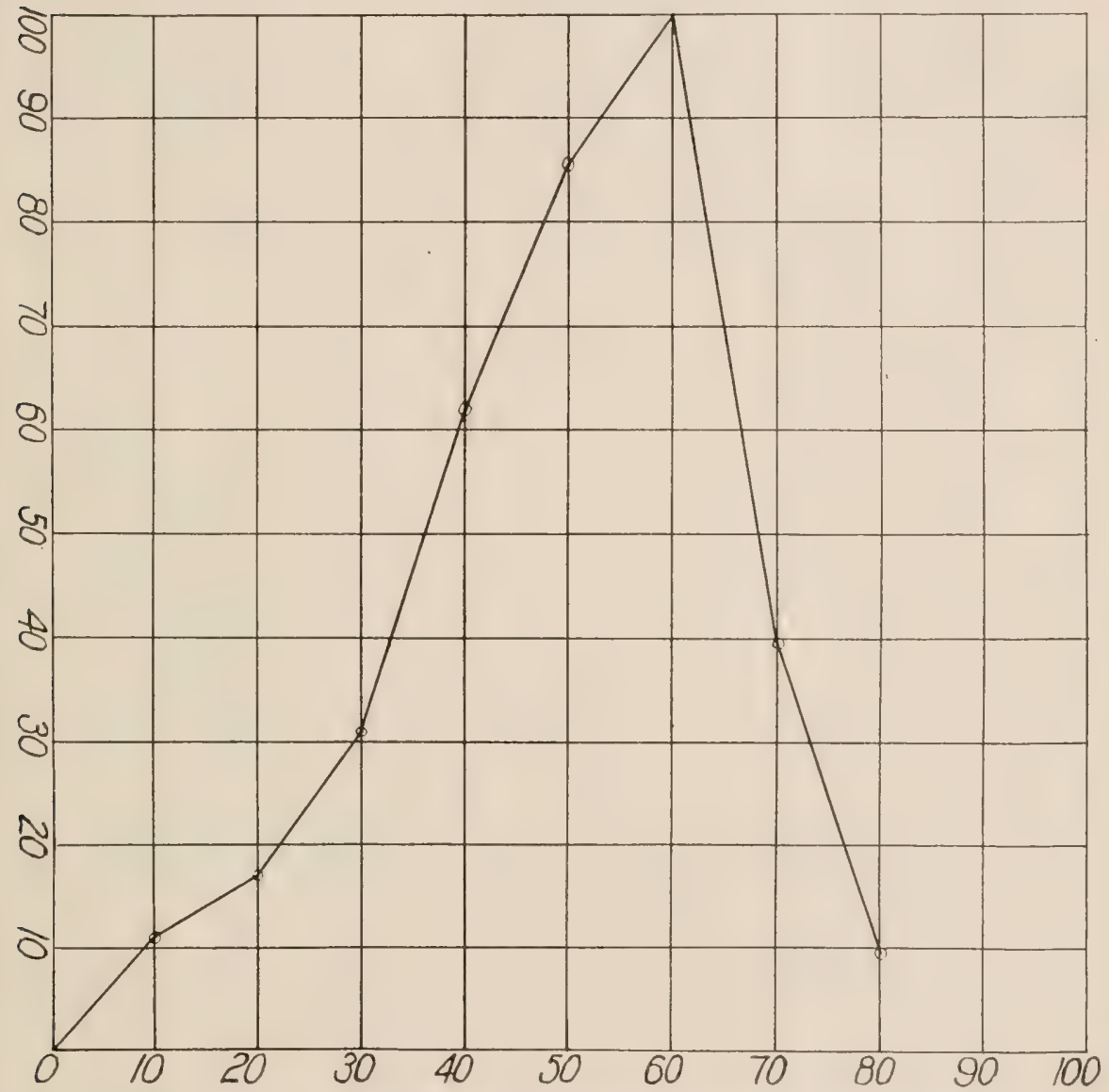

FIG. 32.-Average percentages of nitric nitrogen produced in soil receiving various quantities of water. The quantity produced at 60 per cent. is taken as 100 ; on the ordinate is given the per cent of nitric nitrogen formed, whereas on the abscissa is given water applied as per cent. of water-holding capacity.

with the other soil constants with a set of equations similar to those given for ammonification, page 201. Thus,

$$
\begin{aligned}
& \mathrm{Mn}=.55 \mathrm{C} \\
& \mathrm{Mn}=.8525 \mathrm{E}+11.55 \\
& \mathrm{Mn}=1.472 \mathrm{~W}+\mathbf{1 1 . 5 5} \\
& \mathrm{Mn}=2.163 \mathrm{H}+11.55
\end{aligned}
$$


$M n$ is written for per cent. of water for maximum nitrification, (' for moisture capacity as defined by Hilgard, II for wilting coefficient, $E$ for moisture equivalent, and II for hyrgroscopic coefficient.

Temperature.-The temperature is a factor which controls in a great measure the quantity of nitrates produced in unit time. Schlösing found nitrification very slow at $7.5^{\circ} \mathrm{C}$., quite marked at $11^{\circ}$, reached its maximum at $37^{\circ}$, and ceased entirely at 5i. ${ }^{\circ}$ I)ehérain found nitrification almost ceased at $5^{\circ} \mathrm{C}$. and begins rery slowly in soils which have been frozen, yet Conn found the freezing of soil increases its nitrifying powers. These temperatures are questioned by some, for example Warington states that he was unable to start nitrification at $40^{\circ} \mathrm{C}$.

Hutchinson gives the optimum temperature for nitrification in Pusa soil at $35^{\circ} \mathrm{C}$. No nitrates were formed at $40^{\circ}$, nor did nitrification take place in soil which had been kept at $40^{\circ} \mathrm{C}$. when its temperature was afterward reduced to $30^{\circ} \mathrm{C}$. 'These apparent contradictions may be due to different strains of the organisms varying in sensitiveness to heat. Berdies isolated four stable forms of nitric and three of nitrous ferments. One of the nitric forms was capable of resisting the action of steam at $100^{\circ} \mathrm{C}$. for two minutes and one of the nitrous bacteria lived for one minute in steam at the same temperature. The other two nitrous ferments could not withstand steam but survived for several minutes in a dry heat of $80^{\circ}$ to $100^{\circ} \mathrm{C}$. Moreover, Bazarewski found the most favorable temperature for nitrification in soils to be between $25^{\circ}$ and $27^{\circ} \mathrm{C}$., or about $10^{\circ} \mathrm{C}$. lower than in pure cultures in artificial media.

King, in his work, found that there was 1.26 times as much nitric nitrogen formed at $9^{\circ} \mathrm{C}$. as at $1^{\circ} \mathrm{C}, 2.76$ times as much at $20^{\circ}$, and 6.24 times as much at $35^{\circ}$, as at $1^{\circ}$. The significance of these figures is brought out more fully when we examine the amounts of nitric nitrogen obtained in some cases. At $1^{\circ} \mathrm{C}$. there were formed 120 pounds per acre; at $9^{\circ}, 150$ pounds per acre; at $20^{\circ}, 329$ pounds per acre; while at $35^{\circ}$ there were formed 747 pounds per acre.

Light Rays. - The nitrifying organisms are heat-loving and lightavoiding. 'They are dependent on the heat of the earth or of the sun, but they carry on their activities best in the absence of sunlight. 1)irect sunlight, partly due to the coagulation of the bacterial colloids by the rays of the ultraviolet light, soon proves fatal to them.

Aëration and Cultivation.-The nitrif ving bacteria are all aërobic; hence, nitrification is best-other things being equal-in a wellaërated soil. This is illustrated by the work of Schlösing who exposed soil for four months to an atmosphere containing different percentages of oxygen. Soil which contained 1.5 per cent. of oxygen yielded $45.7 \mathrm{mg}$. of nitric nitrogen, that containing 6 per 
cent yielded 95.7, that containing 11 per cent. yielded 13:2.5 mg., whereas that containing 16 per cent. of oxygen rielded $246.6 \mathrm{mg}$. of nitric nitrogen.

Plummer found there to be an optimum mixture of carbon dioxid and oxygen for the best production of nitrates. This he found to be one containing from 35 to 60 per cent. of oxygen. But Hutchinson found complete nitrification of ammonium sulphate took place under semi-anaërobic conditions in which no nitrification of oil cake occurred.

Stirring and pulverizing the soil is, therefore, of great importance, as further shown by the experiments of Deherain. A number of pots were filled with soil. Part of them were allowed to stand undisturbed, while the others were poured out upon the floor and frequently stirred. Those stirred invariably contained from ten to forty times as much nitrates as did the unstirred.

The work of King also shows that the stirring of the soil affects nitrification. He further found land plowed in the fall contained a different amount of nitrates than did the unplowed land, the difference being apparent throughout the following summer.

Crop and Fallow.- Even as early as 185; the work at Rothamsted had demonstrated that the beneficial effects of fallowing lies in the increase brought about in the available nitrogen compounds of the soil. Deherain and I)emoussy's work indicated that there is a larger production of nitrates in fallow than in cropped soils, and Pfeiffer considers fallowing an extreme form of soil robbery, for he found that it promotes the activity of the soil organisms, and hence hastens the exhaustion of the nitrogen supply. But, as it is so clearly pointed out by Warington, these results may not hold in a dry climate or during dry seasons; for here bare fallow may not necessitate this loss and much is to be gained by its practice. But it must always be borne in mind that if there be sufficient moisture the loss may be great. For instance, sichneidewind, Meyer and Münter record a loss in fallow plats of 5.5 .5 pounds per acre, which even exceeded the nitrogen removed by the growing plant on the cropped soil.

On the other hand, MrcBeth and smith claim that plats continuously cropped to alfalfa, potatoes, oats, and corn all show a higher nitrifying power than do corresponding fallow plats and that the stimulating effect of crop production on the nitrifying power of a soil is most marked in alfalfa soil. This is in keeping with the recent findings of Welbel, but is contrary to the findings of many other investigators, for Heinze found fallow to increase the pectin, cellulose and humus fermenters and also the ammonifiers, nitrifiers and dzotobacter. Russel finds that late summer fallow land is richer in nitrates than is cropped, even after allowing for the nitrogen taken up by the crop; and Heinze shows that 
repeated cultivation of fallow soil increased the number of organisms in the soil, while Ifiltner maintains that no nitrification occurs in soils where legumes are growing vigorously and fixing large quantities of nitrogen. This latter view, however, is the extreme, as is shown by much of the literature on the subject.

Welbel and Winkler found that fallow not only increased the assimilable nitrogen, but also the available phosphoric acid of the soil, and that the increased yield of wheat after fallow is due to these factors. But Bychikhin and Skalski point out that fall fallow is even more wasteful of soil nitrates than is summer fallow, for here the excessive rains wash the soluble nitrates from the soil as fast as formed. The cultivating of fallow further increases the nitrate content, as was shown by Richardson. Nitrification is related to fallow and crop, as may be seen from the following results obtained by the author:

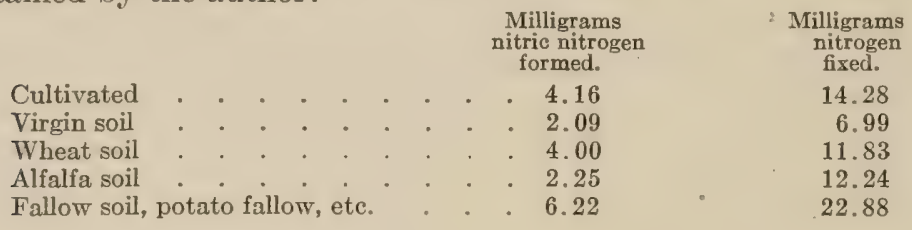

The results reported under milligrams of nitrogen fixed indicate that in an arid soil the increased nitrogen fixation in a fallow soil more than offsets the loss of nitrates, even though rapidly formed, for little, if any, would be lost in the drainage waters. These results have recently been confirmed by Reed and Williams. Moreover, the number of organisms in the soil and the rapidity of the bacterial activity within the same is going to vary greatly with the thoroughness and time of cultivation, as shown by Dehérain, Neish, King and Whitson, Chester and Quiroga, while the number and activity of the organisms in the soil may in a degree determine the speed with which the water evaporates from a soil.

The work at the Rothamsted station early demonstrated that the nitrates in the drainage water from the various plats varied greatly, depending upon the crop growing upon the soil, thus indicating a relationship between the available nitrogen in a soil and crop growing upon the soil. Since that time many experiments have confirmed this conclusion. Furthermore, King and Whitson found 22 per cent. more nitrogen developed from soil after clover than from soil after corn, and 13 per cent. more than after oats. Later work by them showed that there are greater quantities of nitrates throughout the entire season in soil under corn or potatoes than in soil under clover and oats. Stewart and Greaves found that different plants show a marked difference in their demands 
upon the nitrate content of the soil, there being a steady decrease in the concentration of the nitrate content of potato and corn lands as the season progressed, while that of fallow and alfalfa remained practically constant, the nitrate content of the latter being uniformly low through the season. According to Lyon and Bizzell, soil that had produced alfalfa for five years was higher in nitrates than soil that had grown timothy during the same period. Furthermore, the former nitrified ammonium sulphate more readily than did the latter.

Brown found that the rotation of crops caused an increase in number of organisms in a soil, also greater ammonifying, nitrifying and nitrogen-fixing powers than continuous cropping to either corn or clover. Furthermore, the crop on the soil at time of sampling was of more importance from the bacterial viewpoint than the previous crop. However, the preceding crop has a marked effect upon the nitrate content of the soil, as is seen from the work of Lyon and Bizzell, where plats that had been planted to certain crops were kept bare of vegetation in the early part of the growing season of 1911. Nitrate determinations of the soil were made and the nitrate present showed a distinct and characteristic relationship to the nitrate content found under the several varieties of plants previously grown upon the soil. Later they showed that alfalfa soil nitrified more rapidly than timothy soil, both in the soil on which the crops had been grown continuously and in that from which they had been removed and the soil kept bare for two seasons. The author has shown that the nitrifying powers of alfalfa soil, while slightly higher than that of virgin soil, is very low when compared with either wheat or potato and fallow soil. Furthermore, the extensive work which has been conducted at the L'tah Experiment Station demonstrates that there is a very pronounced relationship between the crop growing upon a soil and its nitrate content. However, in this work the nitrate content of the alfalfa and oat soil is very low, while that of potatoes and fallow is high, and we find the nitrifying powers of alfalfa and potato soil high as compared with fallow.

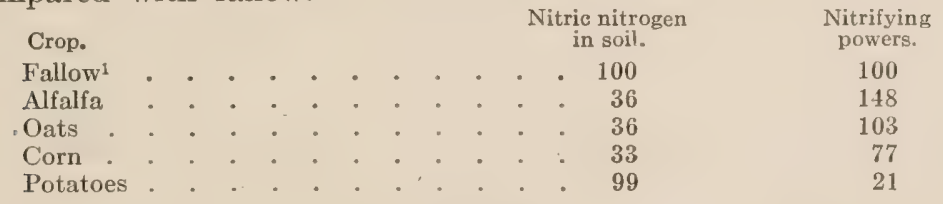

Hence, we can conchde that alfalfa not only feeds closer upon the soluble nitrates of the soil but also makes a much greater drain 
upon the insoluble nitrogen of the soil by increasing its nitrifying powers.

Season. - The season of the year has a marked influence upon the bacterial activities of the soil, but it is not necessarily correlated with the nitrate content of the soil. Schlösing found the nitrates in the drain water from both manured and unmanured soil high in spring, as compared with midsummer, fall, or winter, thus confirming the results obtained at the Rothamsted station. Shutt reports nearly five times the quantity of nitrates in fallow and cropped soil during June as during November. He does, however, find more during June than during May. The exact season of the year at which the maximum nitrate content is reached will vary with a number of factors, chief among which is the kind of crop growing on the soil, for King and Whitson found that the nitrates in the surface foot start in the spring comparatively low and increase rapidly until June 1 on clover and oat ground, and until July on corn and potato ground. From these dates they fall more or less rapidly and the work at the Utah Station demonstrates conclusively that there is a seasonal variation, depending upon temperature, crop and quantity of irrigation water applied to the soil.

Moreover, André has shown that the insoluble nitrogenous compounds of the surface soil are largely transformed into soluble compounds during the summer, and these are widely diffused through the deeper layers of soil during the winter, so that in the spring the lower layers of soil contain more soluble nitrogen than the surface soil. At the end of summer, however, the distribution is quite uniform. 'This finding has been amply verified by the results reported by Stewart and Greaves, Welbel, Jensen, and Lyon and Bizzell. The results will vary, however, with different soils, as shown by Russell who reports the fluctuations in nitrates more marked on loams than on clays or sands. Noreover, he found the bacterial activities much greater in early summer than later.

Moll even goes so far as to claim from his work that the season of the year is the principal factor in determining the biochemical transformation in a soil, and Heinze found that the number of organisms in a soil was highest in the summer months and lowest in the fall and spring. As already pointed out, the highest nitrifying power of a soil is not necessarily correlated with the highest nitrate content. The latter is highest in spring or early summer, while Vogel found the former to be highest in October and Norember, after which there was a falling off until April, when it rose again, but not so high as in autumn. This corresponds fairly well with the findings of Green, for the ammonifying powers of the 
soil. 'These findings, however, are contrary to those of Wojtkiewicz, who found the maximum number of organisms to occur in soil during the spring and the minimum in the winter. IIe also notes a correlation between bacteria present and the amount of nitrates in the soil.

Climate influenced the nitrifying powers of the soil, and Hilgard taught that the nitrifying powers of the arid soils are superior to those of the humid soils, but the extensive work by (. B. Lipman, both by laboratory and field experiments, in which soils have been transported from humid to arid districts, and vice versa, has shown just the opposite to be true-namely, that the biological activities of a soil are more pronounced under humid than under arid conditions.

Quantity of Nitrates Formed.-The quantity of nitrates produced in a given soil varies with all of the factors which have been considered; hence, any results obtained must be interpreted with this in mind. The greatest rate of nitrification noted by Warington, when working with an ordinary arable soil from the Rothamsted farm, vielded $0.58 \mathrm{~s}$ parts of nitrogen per million of air-dried soil a day. Similar soil supplied with ammonium chlorid nitrified about 0.924 parts per million in the same time.

Lawes and Gilbert, working with the far richer Manitoba soils and with a higher temperature, obtained in two cases (soils from Selkirk and Winnipeg) average daily rates of nitrification of 0.7 parts of nitrogen per million during three hundred and thirty-five days, the rates during the early portion of this period being as high as $1.03,1.24,1.36$ and 1.72 per million.

Dehérain, working with a soil containing 0.16 per cent. of nitrogen, obtained daily rates of nitrification rarying from 0.71 to 1.09 per million in ninety days. Working with a richly manured soil containing 0.261 per cent. of nitrogen, he obtained a maximum daily rate of nitrification during forty days of 1.48 of nitrogen per million of soil.

At times the difference in nitrification noted in different soils may be due to a difference in physiological efficiency of the nitrifying ferment, as Marcille compared the nitrifying powers of three different soils and found that the poorest yielded an organism nitrifying less rapidly than the others. Some soils nitrify ammonia more readily, while others nitrify cotton-seed meal more rapidly. This must be due to differences in the metabolism of the organism found in the various soils.

Hutchinson considers this variation at times due to toxins which develop under anaërobic conditions produced by water saturation. Subsequent aëration removes the toxic condition and the formation of nitrates takes place. He also found copper had a decided 
influence in neutralizing the toxic action. Several other observers, including Greig-smith and Bottomley, claim to have found soluble bacteria toxins in soil. Russell and IIutchinson, on the other hand, obtained wholly negative results and concluded that soluble bacterio-toxins are not normal constituents of soils, but must represent unusual conditions wherever they occur. But, as pointed out by Russell the possibility of the existence of toxins soluble in water still remains.

Loss of Nitrates. - The loss of nitric nitrogen from a soil may be either great or small, depending upon certain factors, the more important of which are as follows:

1. The rapidity of nitrification. Nitric nitrogen may be produced in some soils so rapidly that even luxuriant vegetation will not remove it as fast as formed, whereas in another soil it may be formed so slowly that it will not suffice for even meager growth. The loss in the first case may be very large, while that of the second would be nearly zero.

2. The nature of the soil. A tight soil, other things being equal, would retain the nitric nitrogen to a greater extent than would a loose porous soil, and a deep soil than a shallow soil.

3. The amount and distribution of rainfall. All other conditions being equal, thirty inches of precipitation throughout the year would remove more nitric nitrogen from the soil than would fifteen inches similarly distributed. But if the fifteen inches came within a short period, while the thirty was distributed throughout the year, the fifteen inches of rainfall under these conditions may remove more nitric nitrogen from the soil than would the thirty.

4. The rapidity with which the nitric nitrogen is removed by the growing crop. Alfalfa, oats and wheat are heavy feeders upon nitric nitrogen and in most soils remove it as fast as formed. Hence, little is left to be washed out by the drainage. Moreover, crops such as these rapidly remove the water from the soil and hence diminish the drainage from such soils. Moreover, crops growing during the rainy season tend to conserve the nitric nitrogen where fallow soils rapidly lose nitric nitrogen during this period.

5. The rapidity with which nitric nitrogen is transformed into protein nitrogen by soil microörganisms. It is now known that there are within the soil many microörganisms which transform nitric nitrogen into protein nitrogen, and the speed with which this change occurs may at times become important; work at the Utah Experiment Station indicates that this may at times reach twenty or thirty pounds per acre yearly.

The factors must always be kept in mind in an attempt to reach general conclusions from any special cases, yet it is instructive to 
examine a few results from the Rothamsted Experiment Station, as compiled by Dr. Hopkins:

\section{NITROGEN IN DRAINAGE WATERS. ROTHAMSTED EXPERIIENTS AVERAGE OF 12 YEARS (OR MORE).}

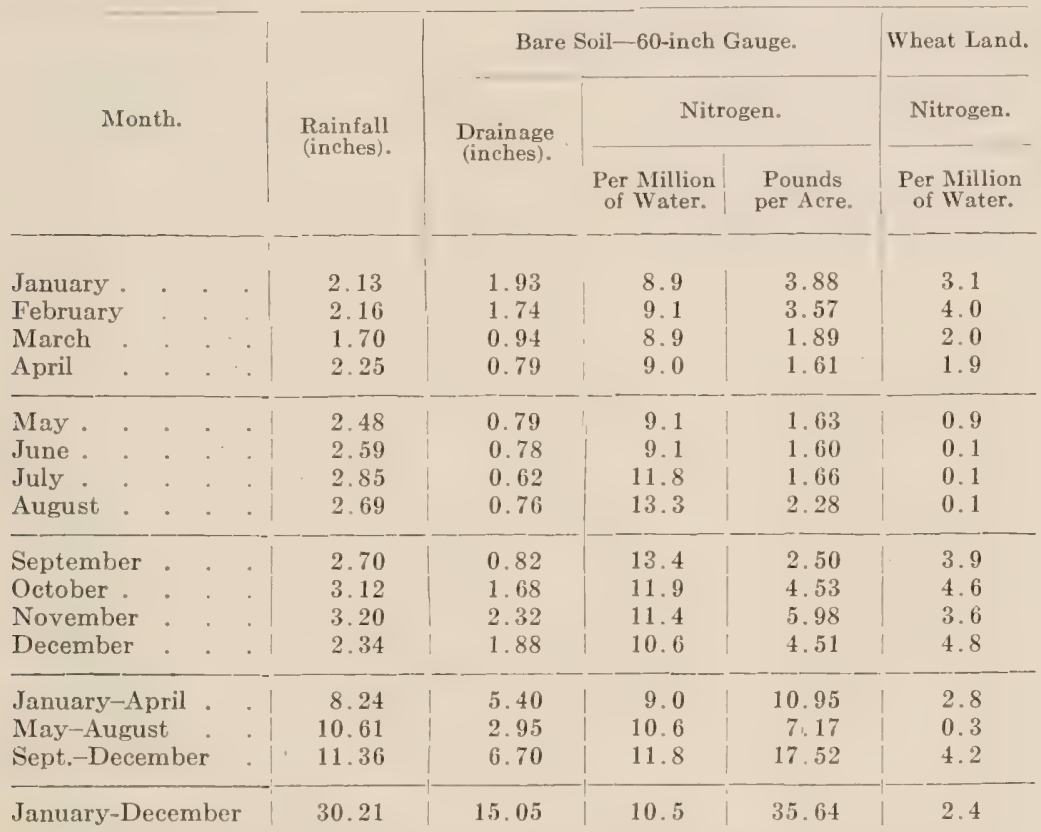

It does not necessarily follow that all of the nitric nitrogen which is carried to a depth of sixty inches is lost to the growing plant, for in work at the Ltah Experiment Station the author and coworkers have found in the spring a nitrate belt as low as the seventh and eighth foot-section. These nitrates had been carried to this depth by the winter and spring water. It was noted that later in the season as the water was brought to the surface by capillarity the nitrates also returned, and by June, Julv or August, depending upon the crop grown upon the soil and the quantity of irrigation water applied, the nitrate belt which in the spring was in the serenth and eighth foot-section had reached the surface foot-section. Moreover, the deep-rooted plants of the arid regions probably feed from lower depths than do the shallow-rooted plants of the humid regions.

The practical conclusion to be reached from these results is that the method of reducing the loss by leaching is by growing plants, 
the roots of which may absorb the plant-food as rapidly as it is made available.

The loss of nitric nitrogen from irrigated soil may be prevented by the judicious use of irrigation water. Experiments at the I'tah Station covering a period of fourteen years have demonstrated that the application of fifteen or twenty inches of irrigation water, distributed throughout the season, to deep soil causes little, if any, loss of nitric nitrogen from such a soil, whereas applications of from twenty-five to thirty-seven inches similarly distributed causes considerable diminution in the crop yield. This decrease in crop yield due to excessive quantities of water, up until the soil becomes waterlogged, is largely due to the rapid washing of the nitric nitrogen beyond the feeding area of the plant roots.

\section{REFERENCES.}

Löhnis: "Handbuch der Landwirtschaftlichen Bakteriologie."

Lafar: "Handbuch der Technischen Mykologie," Dritter Band.

Kossowiez: "Agrikulturmykologie," I-Bodenbakteriologie.

Warington, Robert: "Six Lectures on the Investigations at the Rothamsted Experimental Station," U. S. Dept. Agr. Off, Exp. Sta. Bul. 8.

Voorhees, Edw. B. and Lipman, Jacob.G.: "A Review of Investigations in Soil Bacteriology," U. S. Dept. Agr. Off. Exp. Sta. Bul. 194.

Chester, Frederick D.: "Bacteria of the Soil in Their Relation to Agriculture." Penn. Dept. of Agri. Bul. 98.

Greaves, J. E., Stewart, R., and Hirst, C. T.: "Influence of Crop, Season, and Water on the Bacterial Activities of the Soil." Jour. Agr. Rsch., vol. ix, pp. 293-341. Gibbs, W. M.: The Isolation and Study of Nitrifying Bacteria. Soil Science, 1919, vol. viii, pp. 427-481. 


\section{CHAPTER XXII.}

\section{DENITRIFICATION.}

IT has been known for a long time that under conditions which were not fully understood, there may and often does result a loss of soil nitrogen. Most of this is due to the loss of nitrates in the drainage water, but occasionally there are losses which cannot thus be accounted for. This has been attributed to various causes, namely: (1) the liberation of elementary nitrogen in the process of decay as the complex protein is broken down into simple products, (2) the reduction of nitrates or nitrites with the production of ammonia or elementary nitrogen, (3) the transforming of nitrates and ammonia into complex proteins through the action of microorganisms.

Often the losses from all of these processes have been grouped together and considered as denitrification. This vague usage of the term has led to considerable confusion and often erroneous conclusions. But the term denitrification in its proper and more limited sense refers only to the complete reduction of nitrates with the evolution of elementary nitrogen. It is, however, often applied in a broader sense to include all deoxidation processes whereby nitrates are partly or wholly reduced. But, as pointed out by Lipman, for practical agriculture the differences are of some moment. The partial reduction of nitrates to nitrites or to ammonia does not necessarily involve a loss of soil nitrogen, whereas the complete reduction of nitrates, wherever it occurs, must of necessity involve such losses. Hence, there is some justification for referring to the partial reduction of nitrates as denitrification. But it is not justifiable to classify under the head of denitrification all bacterial activities in the soil which lead to the disappearance of nitrates or even to the diminution in the total store of soil nitrogen. For it has been repeatedly demonstrated that the nitrates may completely disappear without involving any loss of nitrogen.

Early Theories. - We have seen that the early investigators attempted to explain nitrification by purely chemical theories. This was also true with denitrification. Kuhlman, as early as 1846 , expressed the belief that nitric nitrogen may be reduced in the soil to ammonia by the fermentation of organic substances. 'This same idea was brought out twenty-one years later by both Froehde and Angus smith, and it also appears prominently in the writings of Johnson in 1570, and I ary called attention to the fact that gaseous nitrogen was set free from decomposing organic matter in the soil. 
The splitting-off of free nitrogen, theoretically, could be due to the reduction of nitrates or the action of nitrous acid on ammonia or amins:

$$
\begin{aligned}
& 2 \mathrm{HNO}_{3}=2 \mathrm{H}_{2} \mathrm{O}+2 \mathrm{O}_{2}+\mathrm{N}_{2} \\
& \mathrm{NH}_{3}+\mathrm{HNO}_{2}=\mathrm{N}_{2}+2 \mathrm{H}_{2} \mathrm{O} \\
& \mathrm{CH}_{3} \mathrm{NH}_{2}+\mathrm{HNO}_{2}=\mathrm{N}_{2}+\mathrm{CH}_{3} \mathrm{OH}+\mathrm{H}_{2} \mathrm{O}
\end{aligned}
$$

Lawes, Gilbert, and Pugh showed that losses of nitrogen often take place when nitrogenous organic matter was made into an "agglutinated condition" with water and allowed to decompose in the presence of air. Practically no ammonia could be detected. Three possible reactions were suggested by Lawes and Gilbert: an oxidation analogous to that of the action of chlorin on ammonia by which free nitrogen is evolved; (2) a reduction similar to that of a great number of substances upon the oxygen compounds of nitrogen, by which the oxygen is appropriated and the nitrogen set free; (3) the two actions may operate in succession, the one to the other.

Organisms Concerned.-Gayon and Depetit, however, were the first to announce that the nitrogen originated from the nitrates. They found that the ferments which possess this power need organic matter for their development and that part of the organic nitrogen is transformed into ammonia and perhaps also into amido-derivatives of organic substance.

In 1856 they isolated two organisms $-B$. denitrificans, $a$ and $\beta$ - capable of reducing nitrates with the evolution of gaseous nitrogen. They also encountered a number of bacteria that could reduce nitrates to nitrites, and since that time the denitrifiers have been found very widely distributed.

The discovery by Bréal that many substances of organic origin, and especially straw, are the carriers of denitrifying organisms was of far-reaching importance. 'These organisms are, therefore, carried with the litter to the manure and later with the manure to the soil. It was found by Kumnemann that horse manure as a rule contains denitrifying organisms and these are usually of two species, one of them also being found on straw. The organism found only in manure reduces nitrates in symbiosis with $B$. coli and is $B$. denitrificans I of Burri and Stutzer; the organism occurring in both manure and straw is the $B$. denitrificans II of the same authors. 'The denitrifying organisms are less frequently present in cultivated soil and are usually a different lind. Yet they are abundant in the upper layer's of the soil. Bazarewski found them irregularly distributed in the deeper layers of the soil, but frequently they occurred abundantly at a deptlo of one meter. 'They have also been found to a great depth in the Nebraska soils. Putnam examined 201 species and 139 were found to reduce nitrates to nitrites, while the other species did not effect this reduction. Burri and Stutzer called attention to the fact that while there are many bacteria which will reduce 
nitrates to nitrites, those capable of reducing nitrates to ammonia or of setting nitrogen free are not very numerous. Severin isolated 32 different organisms from horse manure and studied 29 of these. Of this number eight species were capable of complete reduction of nitrates, provided the nitrate concentration be not too great. Nine of the other species were able to reduce nitrates to nitrites.

stoklasa divides the denitrifying organisms present in soils and manures into two principal groups. The first group) (ontains Clostridium gelatinsum, Proteus vulgaris, P. zenlieri, B. ramosus n. liquefaciens, B. mycoides, B. mogatherium, B. subtitis, and $B$. prodigiosus, and others. The characteristic of these organisms is that they reduce nitrates to ammonia without the formation of elementary nitrogen. The second group contains Bac. hartlehi, B. fuorescens liquefaciens, B. pyocyaneum, B. stutzeri, B. filefaciens, B. nitrovorum, B. centropunctatum, B. denitrificans, B. colicommun is, B. typhi-abdominalis, and others. These organisms as a rule reduce nitrates to elementary nitrogen.

Beer reasts (Laurent), especially those of Duclaux, reduce nitrates at $20^{\circ} \mathrm{C}$. Penicillum glancum, mucor racemosus, and similar organisms also have a reducing power.

It is, therefore, true that whereas active nitrogen fixation is a characteristic possessed by only a limited number of microörganisms, the opposite-denitrification - appears to be a characteristic possessed by many widely dissimilar organisms.

Reaction of the Media.-The denitrifying organisms are similar to the nitrogen-fixing organisms in that ther require a slightly alkaline medium in which to function. Ton Caron consider's that with a sugar concentration of more than 1 or 2 per cent., a depression of denitrification occurs. This probably is due to the formation of fatty acids by the butrric acid ferments of the soil. When it first became known that denitrification may take place in manure heaps, the practice became prevalent to add to the manure sulphuric acid to prevent denitrification. It was found that sulphuric acid is extremely active in preventing denitrification and 0.17 per cent. in the cultural medium was sufficient to prevent the derelopment of the denitrifying organisms.

Ampola and Garino found that the addition of ground peat showing an acidity of 9.85 per cent. checked the activity of the denitrifying organisms as well as that of other ferments. The organisms, howerer, were not killed and commenced their activity again as soon as the acidity was neutralized. The soil conditions are favorable to the neutralization of the acid of the peat, and thus the restraining effect of the latter on the denitrifying organisms is nullified. Moreover, an acid condition which would restrain denitrifiers in soil retards the other beneficial bacteria and higher plants. Hence, while acids may be used at times with some success on manures, it is not necessary nor practical to add it to soils. 
An excessive alkaline reaction is also inimical to the growth and activity of denitrifying organisms, as was early shown by Pfeiffer, but the application of such large quantities of caustic lime to soil as he found necessary to check denitrification tends to "burn out" the nitrogenous organic matter, as has been amply demonstrated by the work in Pennsylvania.

Food Requirements.- The food requirements of the denitrifiers are quite similar to those of other soil organisms. They ean, according to Richards and Rolfo, survive in purely mineral media, but in such media the reduction of nitrates takes place very slowly and incompletely. Jensen found a certain relationship between the nitrate destroyed and the carbon compounds used. No denitrification takes place without a source of carbon. The optional relation between the carbon and the nitrate used was found by ron Caron to be for two strong denitrifiers-B. pyocyaneus and $B$. fluorescens liquefaciens, a 1 per cent. dextrose to 1.6 per cent. potassium nitrate. Reduction of the nitrate supply far below that of carbon greatly reduces the intensity of the process. Furthermore, the destructive fermentation of nitrates depends to a great extent on the character of the organic substances in the nutritive medium, some being much better adapted than others to furnish the necessary energy for the breaking down of the nitrates. Stoklasa claims that most of the denitrifying bacteria causes no reduction of nitrates in media where chemically pure d. levulose and d. galactose are present. Nor is denitrification favored by glucose in nutritive solutions (Stutzer), but is promoted by the presence of salts of organic acids, like potassium lactate, or sodium citrate. The reason for this is that glucose is not as suitable for furnishing the molecular energy required for the breaking down of the nitrates as are the salts of organic acids. Stutzer tried four different organisms and found that they possessed the power of denitrification in a different degree. Their action on the different meat extracts on the market is also variable. $B$. hartlebii was the only organism tested by him which could destroy nitrates in a medium containing Liebig's beef extract. He suggested that this phenomenon may be due either to a difference in chemical constitution of the compounds or a difference in ionization. The knowledge we now possess concerning the specificity of enzymes would lead us to believe the former to be the true explanation.

Certain of the most widely distributed carbohydrates in soil and manures, as for example xylose and arabinose, are not especially good nutrients for denitrifying bacteria, according to Stoklasa and Vitek. The quantitative relationship which they found to occur is widely different with the various carbohydrates. Of the bacteria which reduce nitrates to nitrites and finally to ammonia, $B$. mycoides reduced 20.69 per cent. of the nitrate nitrogen present to ammonia in the presence of glucose 1.9 per cent. in the presence of levulose, 1.72 per cent, in the presence of galactose, and 1.91 per cent, in the 
presence of arabinose; B. subtilis, 2. 41 in the presence of glucose, 6.55 per cent. in the presence of levulose, and 6.2.2 per cent. in the presence of galactose; ('lostridium gelatinosin, 45.5.) per cent. in the presence of arabinose, and 9.68 per cent. in the presence of xylose; and $B$. prodigiosus, 2.58 per cent. in the presence of $x y$ lose. The reaction was in all cases relatively slow and was not alike for all the sugars.

Of the organisms which reduced nitrates to free nitrogen, B; hartlebii set free $93.9 \frac{\mathbf{z}}{\mathrm{z}}$ per cent. of the nitric nitrogen in the presence of glucose, 87.59 per cent. in the presence of levulose, 84.66 per cent. in the presence of galactose, 66.38 per cent. in the presence of arabinose, 83.38 per cent. in the presence of xylose, st.ts per cent. in the presence of sucrose, and 76.15 per cent. in the presence of lactose; $B$. centropunctatum, 5.17 per cent. in the presence of glucose. B. flitroworm, 5.17 per cent. in the presence of levulose; $B$. coli communis, 5.3t per cent. in the presence of galactose; and Boct. fluorescens liquefaciens, 7.os per cent. in the presence of arabinose. The reaction was as a rule rery intense both with the sugars and with the salts of organic acids, especially of lactic acid, and was accomplished by a gradual breaking up into carbon dioxid and hydrogen or into carbon dioxid and water. The hydrogen produced was thought to play a very important reducing rôle.

Xylan and araban, the most abundant and widely distributed carbohydrate materials in soils and manures, yields on hỵdrolysis xylose and arabinose which are very poor sources of carbon and energy for denitrifying organisms. However, Stoklasa and Vitek found that the typical denitrifying organism, B. hartlebii, assimilated 33.6 per cent. of the total nitrate nitrogen in a nutritive solution containing arabinose and converted it into protein compounds.

Sodium citrate, sodium acetate or glycerin added to a soil greatly increase denitrification, and it is generally considered that the addition of starch, straw, rape cake, compost, etc., to a soil farors denitrification, whereas well-rotterl manures, rape cake, and composts are much less apt to have this effect.

Metabolism of Denitrifying Organisms.-Dehérain found that reduction was more rapid in closed flasks than in the open air, the nitrogen escaping mainly in the form of protoxid. From this he argued that the organisms, being deprived of the necessary oxygen of the air, were forced to appropriate that contained in the nitrates and thus accomplish their reduction, but we now know that the denitrifiers do not necessarily require anaërobic conditions for denitrification, but do require a readily oxidizable carbohycdrate. Noreover, as pointed out by Stoklasa, there are two classes of denitrifiers -one which reduces nitrates to elementary nitrogen, the other which reduces it only to ammonia. Probably in hoth groups of organisms the first steps in the process are the same. 'The carbohydrates are broken down under the influence of the microörganism 
into lactic acid, alcohol, and carbon dioxid. The nitrate is reduced to nitrous acid and this in tum is reduced to ammonia or elementary nitrogen. The oxygen so obtained is utilized by the microörganisms for the further oxidation of the carbohydrates, and it is in this manner that the organism obtains its requisite energy.

Stoklasa and Vitek believe that nitrous acid is always the intermediate product in the reduction of nitrates. They consider that arbon dioxid and hydrogen are produced from the carbohydrates or organic acids of the cultural media and the nascent hydrogen combines with the oxygen of the nitrates to form water and thus reduces the latter to nitrites. Gayon and Depetit give this formula:

$$
5 \mathrm{C}_{6} \mathrm{H}_{12} \mathrm{O}_{6}+24 \mathrm{KNO}_{3}=24 \mathrm{KHCO}_{3}+6 \mathrm{CO}_{2}+18 \mathrm{H}_{2} \mathrm{O}+12 \mathrm{~N}_{2}
$$

The process is probably due to enzymes. Fred was able to demonstrate the production of both oxidases and peroxidases by $B$. denitrificans. Hulme considered that reduction may be divided into two parts: the bacterial reduction and the enzymatic reduction. However, we are led to doubt whether either is due to a true enzymie, for the enzymes which have been obtained in impure forms are not affected by heat and the reducing substances are not specific, as is the case with most enzymes, for they reduce chlorates to chlorids, arsenates to arsenites, and ferricyanids to ferrocyanids in the same manner as nitrates are reduced to nitrites.

Influence of Water.-Many of the results obtained on denitrification were with the use of liquids, and it is now known that denitrification in soils progresses differently from that in liquids, depending upon the nature of the bacteria and the physical conditions of the medium in which they are situated. In liquids and very wet soils from which oxygen is excluded, the bacteria take their oxygen from the nitrates present in the soil and thus liberate nitrogen, but in well aërated soils this does not occur, as the bacteria can use the oxygen of the air.

The author failed to find any evidence of denitrification in a highly calcareous soil to which had been added from 0 to 25 tons per acre of manure and from 12.5 to 22.5 per cent. of moisture, as may be seen from the following:

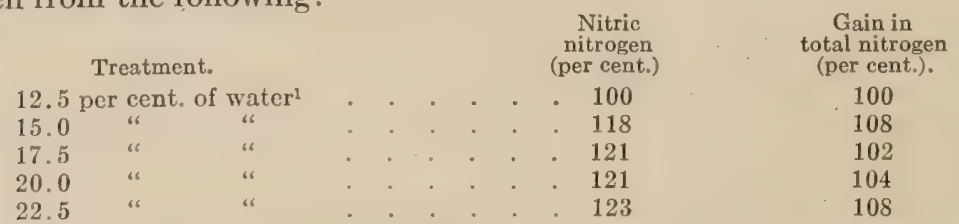

The results may vary with different soils, but Lemmermann found that in three greatly dissimilar soils it was greatest when the soil was saturated.

Therefore, when the moisture exceeds certain limits, it may

1 The soil containing 12.5 per cent, of water was taken as producing 100 per cent. 
promote denitrification. Tariations in the moisture within the usual limits, however, have little influence upon the process.

Temperature.- Kruger considers that the factors which exert the greatest influence upon denitrification are temperature and the mechanical condition of the material which furnishes the food for the organisms. 'These organisms function best at a temperature which is high enough to greatly retard nitrification. They act very energetically at a temperature of $37^{\circ} \mathrm{C}$. in pure cultures, but there is some evidence (von Bazarewski) that in mixed cultures they function better at a lower temperature. These factors make it probable that laboratory results on denitrification are high as compared with field conditions even where all of the other conditions are optimum.

The denitrifying bacteria are more resistant to light and drying than are the nitrifying or nitrogen-fixing organisms. Ampola found sunlight to have no effect upon two denitrifiers isolated by him- B. denitrificans $V$. and $B$. denitrificans VI. In pure distilled water these organisms were capable of surviving for seven months. When dried, $B$. denitrificans $V$ died within eight weelis and $B$. denitrificans VI was alive and active at the end of five months.

Losses of Nitrates from Mianure and Soil.-The finding of the denitrifying bacteria on straw and in manure, together with the establishment of the fact that they can under appropriate conditions decompose nitrates with the evolution of gaseous nitrogen, led Wagner in 1895 to emphatically declare that the application of cow or horse manures to a soil is often not only unprofitable but harmful, that when applied together with nitrates they cause, by virtue of the microörganisms contained in them, the destruction of the nitrates. More than that, the baneful effects do not stop here, for the nitrates as they are gradually formed from the organic matter of the soil are also attacked by the denitrifying bacteria and their nitrogen set free. In reality, then, the animal manures applied are not only useless in themselves but are harmful because of their destructive effects on the oxidized nitrogen derived from other sources.

These conclusions were criticized by Warington who pointed out that they were based on experiments in which the dressings of dung were enormous and the same would not occur under ordinary practice. The next year a serious attempt was made to solve the problem. When the German Agricultural Association called for a united effort on the part of the German experiment stations, offering to place the necessary means at their disposal, the Experiment Stations of Augsburg, Darmstadt, Jena, Rostock, Bonn, and Göttingen responded. The questions to be answered were as follows:

1. How are the great losses of nitrogen that take place in the decay of organic substances to be explained? How much of the nitrogen is liberated in the elementary state and how much as ammonia?

2. What means do we possess of checking these losses, and how does the substance thus employed act? 
The published reports of the various stations are voluminous and only the general conchusions reached can be considered here. They were as follows:

1. The losses of ammonia from manure are comparatively slight, but the setting free of elementary nitrogen which is due to microorganisms and not chemical means may be considerable.

2. With a limited supply of air in manure, the loss of elementary nitrogen and of organic substance are not extensive, but the greater the access of air the greater the loss of nitrogen, in some cases becoming as great as 40 or 50 per cent.

3. In ordinary conservation materials when applied in the usual quantities, do not stop entirely the loss of nitrogen, but burnt lime is quite effective in stopping denitrification. Solid excreta and straw lose their nitrogen very slowly and no conservation material is needed. It is only the nitrogen of urine which requires conservation.

It is sometimes found that the addition of large quantities of organic matter to a soil cause a decrease in crop yield. This is especially true with regard to the carbohydrates and it has often been interpreted as indicating rapid denitrification, but Pfeiffer and Lemmermann have pointed out that there are at least three factors which may play a part, namely: (1) direct injury to the growing plants by large quantities of organic matter; (2) fixation of soluble nitrogen by the increased activity of different organisms; (3) denitrification proper.

It is quite probable that the last is of the least importance, for Voorhees and Lipman after ten years' investigations under carefully controlled conditions conclude "that at least with cow manure, used at the rate of sixteen tons per annum for a period of ten years, no destruction of nitrogen takes place. In view of the long duration of the experiment and of the comparatively large amounts of manure used in the course of the ten seasons, we must assume that denitrification is not a phenomenon of economic importance in general farming and under average field conditions. We have no hesitation in emphasizing again the view expressed above-that under the wide range of field conditions, denitrification is not a phenomenon of economic significance to the general farmer."

Moreover, at Rothamsted a plot of ground, 0.001 acre in extent, has been kept free from regetation by hoeing for thirty-five years. I) uring this time it has lost one-third of its original stock of nitrogen, but all except 110 pounds of this is accounted for by the nitrates in the drainage water, as may be seen from the following:

\begin{tabular}{|c|c|c|c|c|c|}
\hline $\begin{array}{l}\text { Nitrogen } \\
1870\end{array}$ & $\begin{array}{l}\text { in soil. } \\
1905\end{array}$ & $\begin{array}{l}\text { ['ounds nitroge } \\
\text { per acre. } \\
1870 \quad 1905\end{array}$ & $\begin{array}{l}\text { Loss in } \\
35 \text { years. }\end{array}$ & $\begin{array}{c}\text { Nitrogen recovered } \\
\text { as nitrates. } \\
1870-1895\end{array}$ & $\begin{array}{l}\text { Nitrogen unaccounted } \\
\text { for. }\end{array}$ \\
\hline 0.146 & 0.102 & 3500 & 1050 & 940 & 110 \\
\hline
\end{tabular}


Russell, commenting upon the results, states: "The experiment is not fine enough to justify any discussion of the mising 110 prounds, but it shows that the loss of nitrogen is mainly due to leaching out of nitrates."

It is even doubtful if denitrification goes on to any appreciable extent in a well aërated soil even though it contains considerable nitrates. The nitrates, however, may disappear as seen from the following results in which the author mixed 2 grams of dried blood and 3724.5 parts per million of various nitrates with 100 grams of soil made the moisture up to 18 per cent. and after twenty-one days' incubation at $30^{\circ} \mathrm{C}$. recovered the various percentages of nitric nitrogen. The untreated soil was taken as 100 per cent.

\begin{tabular}{|c|c|c|c|c|c|c|}
\hline \multirow{2}{*}{$\begin{array}{l}\mathrm{NO}_{3} \text { added } \\
(\mathrm{p} \cdot \mathrm{p} . \mathrm{m} .)\end{array}$} & \multicolumn{6}{|c|}{ Per cent. of nitris nitrozen found in the presence of } \\
\hline & $\mathrm{NaNO}_{2}$ & $\mathrm{KNO}_{3}$ & $\mathrm{Ca}\left(\mathrm{NO}_{3}\right)_{2}$ & $\mathrm{Mg}\left(\mathrm{NO}_{3}\right)_{2}$ & $\operatorname{Mn}\left(\mathrm{NO}_{3}\right)_{2}$ & $\mathrm{Fe}\left(\mathrm{NO}_{3}\right)_{2}$ \\
\hline $\begin{array}{l}\text { None } \\
3724.8\end{array}$ & $\begin{array}{l}100 \\
-13.9\end{array}$ & $\begin{array}{l}100 \\
-41.2\end{array}$ & $\begin{array}{l}100 \\
-20.2\end{array}$ & $\begin{array}{c}100 \\
-354.7\end{array}$ & $\begin{array}{l}100 \\
-17.8\end{array}$ & $\begin{array}{r}100 \\
7.8\end{array}$ \\
\hline
\end{tabular}

This indicates a loss of nitrates where sodium, potassium, calcium, magnesium, and manganese nitrates had been applied to the soil.

An analysis of the soil for total nitrogen showed a loss only where the potassium nitrate was applied to the soil, and in this case it was only 5.96 mgms. in place of 41.2 per cent., as was indicated by the first results.

\section{Treatment.}

\begin{tabular}{|c|c|}
\hline Dried & blood \\
\hline & 6 \\
\hline 16 & 6 \\
\hline "6 & 66 \\
\hline if & IS \\
\hline 16 & "6 \\
\hline as & 16 \\
\hline
\end{tabular}

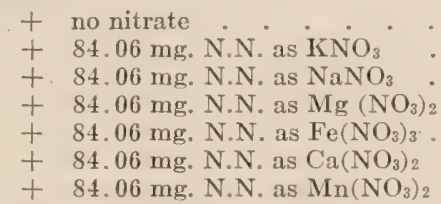

Gain (+) or loss (-) in nitrogen over soil receiving no nitrate.

0.00

-5.96 mgs.

1.34

25.14

37.04

42.54

48.54

Function of Denitrifiers. - Huge quantities of organic and inorganic nitrogen find their way into the septic tanks of large cities, and much of this is returned to the atmosphere by these bacteria. Noreover, that which reaches the lakes and oceans is also acted upon by denitrifying bacteria; hence, they play a part, although of minor importance in the nitrogen cycle.

\section{REFERENCE.}

Voorhees, Edward B., and Lipman, Jacob G.: "A Review of Investigations in Soil Bacteriology." U. S. Dept. Agr. Off. Exp. Sta. Bul. 194. New Jersey Exp. Sta. Ann. Rpts, 1901 and 1902. 


\section{CHAPTER XXIII.}

\section{AZOFICATION.}

THE maintenance of the nitrogen supply of the soil is the phase of soil fertility which has received greatest consideration both from the scientist and from the practical agriculturist. Nitrogen is one of the more expensive commercial fertilizers and is, in the majority of soils, the limiting factor of crop production. The supply of combined nitrogen on the earth is comparatively small and it is possible to calculate approximately the time necessary for its exhaustion. Basing his conclusion on such a calculation, at least one scientist has predicted dire calamity to the human race were science not able soon to solve this problem. Science has measured up to its requirements in this regard, for the synthetic production of combined nitrogen has been accomplished, and this in a manner so highly satisfactory that it is able to compete successfully with the product of natural deposits. Advancements have also been made in our knowledge of the underlying principles influencing the natural processes which gorern the fixation of nitrogen in the soil. Although there is much yet to be learned in this field it is upon the control of these natural processes that ultimate success will be based.

Historical. - It has been known for generations that uncropped soils increase in fertility. Less ancient, however, is the knowledge that this increase may be due to a gain of nitrogen in the abandoned soils. Eren more recent than this is the knowledge that it may be due to bacteriological action.

In the middle of the nineteenth century Boussingault wrote: "Tegetable earth contains living organisms-germs - the vitality of which is suspended by drying and reëstablished under farorable conditions as to moisture and temperature." He also hinted at the fact that these microörganisms take part in the process of nitrogen fixation. He spread out thinly $120 \mathrm{gm}$. of soil in a shallow glass dish and for three months moistened it daily with water free from nitrogen compounds. At the end of this time analysis showed that it had lost carbon, but had gained nitrogen. It was not until thirty years later that Hellriegel and Wilfarth made their discovery of nitrogen-fixation by symbiotic organisms. At that time the laboratory technic of modern bacteriology was still undeveloped. Since then, however, we have learned much concerning the relationship) of plants to free and combined nitrogen of the air and of the soil. 
We know that soil gains in nitrogen are of ten due to microörganisms, either living free in the soil or in company with the higher plants. The production of nitrogen compounds out of atmospheric nitrogen by bacteria independent of higher plants is designated non-symbiotic nitrogen-fixation, or azofication. When fixation is accomplished by bacteria living in connection with and receiving benefit from higher plants, it is called symbiotic nitrogen-fixation.

As early as 1S5:3 Berthelot undertook the study of soils as regards their relationship to free and combined nitrogen, and as a result of these studies he was the first definitely to recognize that gains which occur in bare unsterilized soils are due to microscopic organisms. He found that when $50 \mathrm{kgm}$. of arable soil were exposed to air and to rain in a vessel for seven months, after allowing for the small amount of combined nitrogen brought down by the rain, there was a gain in nitrogen of more than 25 per cent. In another experiment in which the soil was first washed free from nitrates, there was a gain of 46 per cent. Many other experiments showed gains from 10 to 15 per cent. Berthelot was not content with the bare knowledge that nitrogen is fixed in the soil by living organisms, but continued his work with the idea of isolating some of these organisms. With the aid of Guignard, he made soil inoculation into sterile bouillon and from this prepared gelatin plates. ("ultures were taken from the colonies growing on the plates and bacteria were tested for their nitrogen-fixing power. His results were conclusive that there exist within the soil chlorophyll-free bacteria capable of fixing atmospheric nitrogen. His work had shown that these organisms act best at summer temperatures, between $50^{\circ}$ and $104^{\circ} \mathrm{F}$., in the presence of a good supply of oxygen, a proportion of water in the soil not exceeding 12 to 15 per cent. and not falling below 2 to 3 per cent.

They require carbon, hydrogen and enough combined nitrogen to promote initial growth. The nitrogen, gained by the soil was proteinaceous in nature, being insoluble in water. Although some of his soils had gained large quantities of nitrogen, he considered that the fixation of atmospheric nitrogen by microörganisms has its limits, since the organisms isolated drew from the atmosphere only so long as the amount fixed in the medium was not great. Heating the soil to $230^{\circ} \mathrm{F}$. immediately stopped the process.

Prior to this a number of chemists, notably König and Kiesor, Armsby, Birner, Kellner, Dehérain and Arery had found that when organic matter in one form or another undergoes fermentation there is frequently an increase of nitrogen in the fermenting substance. Armsby states it thus: "We must conclude that decaring organic substances in the presence of caustic alkali are able to fix free nitrogen without the gain being manifest as nitric acid or ammonia, and probably without the formation of these bodies." His explana- 
tion of the process was that the nascent hydrogen evolved during the fermentation process reacted with the free nitrogen of the air. Others considered that the artive agents were compounds of iron, manganese, and lime existing in the soil and in some way acting as catalytic agents.

Berthelot's discovery interested Winogradsky who commenced work which eventually bridged the chasm. He employed, as a medium, a nutritive solution free from combined nitrogen, but containing mineral salts and dextrose. Fifteen separate species of soil bacteria were jsolated, but only one-a long sporebearing bacillus which developed normally in the absence of combined nitrogen and seemed to produce butyric fermentation-fixed nitrogen to any appreciable degree. Quantitative tests showed that the maximum fixation was attained where no combined nitrogen was purposel added, and that on the addition of such, fixation of nitrogen was diminished. For example, several determinations gave the following results:

$\begin{array}{llrrrrr}\mathrm{N} \text { as } \mathrm{NH}_{3} \text { in dextrose solution } & . & 2.1 & 4.2 & 6.4 & 8.5 & 21.2 \\ \mathrm{~N} \text { fixed } & . & 7.0 & 5.0 & 5.5 & 3.6 & 2.2\end{array}$

The presence of combined nitrogen tends to decrease fixation. He concluded that in order for any gain to be made, the ratio of the combined nitrogen to the sugar should not exceed $6: 1000$. Because of the characteristic formation of clostridia in his cultures, Winogradsky named the organism Clostridium pasteuriamum. The conclusion which the author reached, however, was that the power of fixing nitrogen is not general among microörganisms, but confined to a few special forms.

Following IVinogradsky, ('aron made some interesting discoveries. He found that soils under leafy crops contain greater numbers of bacteria than those under grasses. He also observed that the bacterial flora of soils in the spring are different from those in the fall both quantitatively and qualitatively. He used in regetation experiments pure cultures of the bacteria most frequently encountered in natural soils. Some soils were inoculated with bouillon culture, whereas others received only sterile bouillon. The crop yields were usually in favor of the inoculated plots, but showed variations from season to season. Fxceptionally good results were obtained with a sporebearing bacillus which he termed Bacillus ellenbachensis.

('aron's work led to the commercial exploitation of his cultures, one of which, "alinit," was the subject of much study and controversy. 'This culture was found to contain, according to severin, two closely-related bacilli which he chose to designate as $B$. cllenbachensis $A$ and $B$. 'These had the power to fix nitrogen to some extent. 'Tests 
with "alinit," however, have not confirmed to any great extent the claims of its exploiters.

In 1901 Beijerinck's investigations led to an extremely important addition to the history of non-symbiotic nitrogen-fixation. He described a new group of large aërobic bacilli to which he gave the generic name Azotobacter.

In an early paper published by Beijerinck and van I Selden, they maintain that Izotobacter are incapable of fixing appreciable quantities of nitrogen in pure culture, but are dependent to a large extent on Gramulobacter, Radiobacter, Aërobacter. They considered that in mixed cultures the Gramulobacter, Radiobacter, and Aërobacter possess the power of fixing nitrogen in the presence of Azotobacter, which grows at the expense of the combined nitrogen escaping from them into the solution.

A little later Gerlach and Vogel succeeded in isolating from soil the Arotobacter of Beijerinck and in showing that in pure cultures and in the presence of salts of organic acids, izotobacter are capable of active nitrogen-fixation. 'They obtained a fixation of $9 \mathrm{mgm}$. of nitrogen in a 1 per cent. solution of grape sugar. But Beijerinck challenged this assertion, claiming that their cultures were not pure but were mixed with other forms difficult to separate. The claims of Gerlach and Togel were substantiated by the work of Freudenreich, Foch and Lipman. The latter not only showed that the Izotobacter possess the power of fixing nitrogen in pure cultures, but he explained the failures recorded by others.

Although not necessary, the presence of other organisms often proves advantageous. Lipman found that in the presence of such forms as B. radiobacter and B. lecaniformus the nitrogen-fixation is faster and goes on at a more regular rate.

To the two species of Azotobacter- 1. chroücoccum and A. agilisdescribed by Beijerinck and van I)elden, Lipman, added 1. vinelandii, 1. beijerinclii, and 1. woodstormii. Later Löhnis and Westermann described 1. vitreum, and after a study of 21 cultures of various 1zotobacter concluded that they represented only four types. A. chroöcoccum is most widely distributed in the soils so far studied.

The discussion of the subject thus far has been more or less confined to the Izstobacter, but investigations of Beijerinck and van I)elden, Löhnis, Noore, ('hester, Bredemann and others have brought to light other microörganisms having the power to fix nitrogen. Among these are $B$. mesentericus (which fixes appreciable quantities of nitrogen), B. pneumoniæ, B. lactis viscosus, B. radiobacter, B. prodigiosus, B. asterosporus and B. amylobacter.

Bredemann, after a careful study of the morphological and physiological characteristics of eleven "original species" of other investigators and of sixteen cultures prepared by himself from various soils, concluded that all belong to the single species $B$. amylobacter of 
van Tieghem. Since this, however, there has been described at least one aërobic clostridium. Noreover, Omelianski considers that the Clostridium pasteurianum, isolated from the Russian soils, is clearly a morphologically distinct race. An idea of the activity of some organisms in fixing nitrogen may be obtained from the following results reported by Löhnis. In every 100 c.c. of 1 per cent. mannite, or grape sugar soil extract, there was fixed, in the course of three weeks, nitrogen as follows:

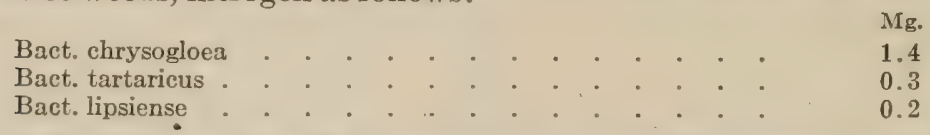

C. B. Lipman tested 18 organisms, including yeasts, pseudoyeasts, and molds, nearly all of which showed a more or less pronounced power of fixing atmospheric nitrogen.

Pringsheim has isolated from ordinary garden soil certain thermophilic organisms which fix from 3 to $6 \mathrm{mgm}$. of nitrogen per gram of dextrose when incubated at $61^{\circ} \mathrm{C}$. in a Vinogradsky's solution to which a little soil extract was added. Duggar and Davis have recently investigated the subject of the fixation of nitrogen by the filamentous fungi, Aspergillus niger, Macrosporium commune, Penicillium digitatum, Pexpansum, Glomerella, Gossypii, and Phoma betae, and of these only the last-named was definitely proved to be able to fix nitrogen. It is thus seen that the power of fixing nitrogen is a characteristic possessed by many microörganisms, in contradiction to the supposition of Winogradsky that this power is limited to a particular, or, at most, a few species. This is especially emphasized by the recent work of Emerson who examined soil which contained 2,400,000 organisms per gram which would develop on nitrogen-free media. Of these, 97 per cent. possessed the power of fixing nitrogen; they constituted at least four distinct groups. Nevertheless, the most important group yet discovered is the Azotobacter, and it is with these mainly that this chapter deals.

Distribution.- The nitrogen-fixing organisms are widely distributed, occurring in most soils. Lipman and Burgess, who studied the nitrogen-fixing flora, especially those of the Azotobacter group, of 46 soils from Egypt, India, Japan, China, Syria, the Hawaiian Islands, Guatemala, Costa Rica, Spain, Italy, Russia, Mexico, Asia Minor, Canada, L'nalaska, Samoa, Australia, Tahiti, Belgium, Queensland, and the Galapagos Islands, found every soil possessed the power of fixing nitrogen in mannite solution. About one-third of the soils contained Azotobacter; frequently the same soil showed the presence of two or three different species of Asotobacter. A. chroöcoccum, howerer, was the most prominent. It was also found most widely distributed in the various soils. Groenewege found Azotobacter in all but one of a series of Java soils.

Sereral hundred Ttah soils have been examined and all found to fix nitrogen, many of them without the addition of carbohydrates. 
Aërobic Azotobacter are present in nearly all Ltah soils. Hutchinson found the Azotobacter in all the Indian soils examined. 'They occur in cultivated more frequently and in greater numbers than in virgin soils. This probably accounts for the much higher nitrogen-fixing power of cultivated soils.

Azotobacter were found in only two out of $6+$ localities in the soils of Danish forests. Both of the soils which gave positive tests were from beechwood forests and contained calcium carbonate. Although the soils of these forests rarely contain enough carbonate to effervesce they are usually neutral or slightly alkaline. They contain calcium, but in forms other than the carbonate. It is generally understood that Asotobacter occur commonly in soils which contain sufficient calcium carbonate to effervesce when acid is added and that they scarcely ever occur in acid soils. Their disappearance from soil is usually due to the absence of basic substances, especially of calcium and magnesium carbonate, and not to the presence of toxic substances. However, they are frequently not present in peaty soils, where their absence cannot be attributed to a lack of lime.

'The aërobic nitrogen-fixers are probably more widely distributed in soils than are the anaërobic, for, although both groups are generally found in the Russian soils, the aërobic are found in the sands of Kirghese steppes and in the peat soils of the Province of Archangel in which the anaërobic forms are absent. Anaërobic nitrogenfixers are, however, quite widely distributed in soils and are at times found on the leaves of forests trees.

The nitrogen-fixing organisms are confined almost entirely to the first three feet of soil, although they have been found in soil at all depths down to the tenth foot in the very favorably constituted loose soils of Nebraska.

They are most active in the upper few inches of soil, as is indicated by results obtained by Ashby.

Soil.

Little Hoos

Little Hoos

Little Hoos
Depth

inches.

10

20

30
Average
nitrogen fixed.
mgm.

9.23

7.29

4.60

Reports on some Hawaiian soils show them to be equally active at all depths to 4 feet, but this must be considered an exception, for the examination of numerous soils in Utah has shown a gradual decrease in nitrogen-fixing powers with depth. The average of several hundred determinations, in both solution, and soil media, are given below:

Depth of sample.

First foot.

Second foot

Third foot
Nitrogen fixed in $100 \mathrm{gm}$. of soil + $1.5 \mathrm{gm}$. of mannite. mgm.

5.28

2.42

1. 55
Nitrogen fixed in 100 cc. of Ashby's solution with 1.5 gm. of mannite. mgm.

2. 11

0.77

0.58 
These samples were collected with such great care that there was no possibility of the mixing of one foot section with another. It is interesting to note that while the actual gain in nitrogen per gram of mannite is over twice as great in the soil as in the solution, ret the relative gain per foot section is the same in both. There is about one-half as much nitrogen fixed in the second as in the first foot, and one-fourth as much in the third as in the first.

The nitrogen-fixing organisms are not confined to the soil alone, for Beijerinck and van Delden first isolated Azotobacter agilis from canal water in Holland. Azotobacter chroöcoccum and B. Clostridium pasteurianum are both found in many fresh and salt waters, living on algæ and plankton organism.

Reaction of the Media. - The distribution and the phrsiological efficiency of the nitrogen-fixing organisms, especially of the Izotobacter species, are governed by the physical and chemical properties of the soil, foremost among which is the basicity of the soil, namely, its calcium or magnesium carbonate content. Ashby bases his method for obtaining pure cultures of Azotobacter upon this property, for he finds that by picking out the crystals of the carbonate from the soil and seeding them into nitrogen-free media the likelihood of obtaining the organism is greatly increased. The addition of calcium carbonate to a soil often increases its azofying power, the extent of which increase depends on the lime requiremerits of the soil and on the fineness of the added limestone.

Christensen has suggested that the Azotobacter be used as an index to the lime requirements of a soil. The test should include both a search for the organism in the soil and a test of their ability to grow when inoculated into the soil. He and Larson examined more than one hundred soils of known lime requirement. They determined the carbon dioxid set free by acids, the amount of calcium dissolved by an ammonium chlorid solution, the behavior of the soil toward litmus, and the biological test. 'The result of this test was that the biological test agreed with the known condition in 90 per cent. of the cases, the ammonium chlorid in 50 per cent., the litmus in 40 per cent., and the carbon dioxid failed more of ten than not to indicate the correct condition of the soil.

Fischer failed to find Azotobacter in a heary loam soil containing only 0.145 per cent. of lime, while adjoining limed plots had an 1zotobucter flora. The quantity of calcium carbonate which must be added to obtain maximum fixation varies with the soil.

A West Virginia Dekalb silt loam, which required 0.175 per cent. of calcium carbonate to render it neutral by the Veitch method, gave greatest nitrogen fixation when 0.375 per cent. of calcium carbonate was added. Above this concentration azofication decreased, but when phosphorus was applied with the lime it was not toxjo even when present in quantities as great as 0.5 per cent. It is 
certain that large quantities of calcium carbonate may be present in soil without injury to the azofiers.

The author found numerous _. Izotobacter and a very active nitrogen-fixation in a soil 4:3 per cent. of which was calcium and magnesium carbonate.

The organisms develop normally in the presence of either calcium or magnesium carbonate, but in liquid cultures the film develops earlier and it contains less foreign organism in the presence of magnesium carbonate than in the presence of calcium carbonate. 'The actual nitrogen fixed, as reported by Ashby, is also greater where the magnesium carbonate is used. This he attributes to the suppression by the magnesium of foreign organisms, especially of the butyric acid ferments.

There is, however, a marked difference in the action of calcium carbonate and magnesium carbonate when they are applied in large quantities. Lipman and Burgess found the calcium carbonate stimulating and never toxic to Lzotobacter chrö̈coccum in concentrations up to 2 per cent. in mannite solution. The magnesium carbonate was sharply toxic in higher concentrations up to 2 per cent. in mannite solution. The magnesium carbonate was sharply toxic in higher concentrations above 0.1 to 0.2 per cent. in such cultures. The calcium salt is without effect when added to most soils up to 1.4 per cent., but the magnesium carbonate is even more toxic in soils than in solutions. Moreover, their work indicates that calcium exerts a protective influence, in both soils and solutions, against the toxic influence of magnesium. The best ratio of calcium to magnesium varies with solution and soil.

In many soils lime increases the nitrogen fixed, for Krzemieniewski found limed soil to fix in ten days 17.52 $\mathrm{mgm}$. of nitrogen, whereas adjoining unlimed soil fixed only $7.15 \mathrm{mgm}$. There is, however, the possibility of applying too large a quantity of the caustic lime and thereby decreasing nitrogen-fixation, a condition which has never been experienced in the use of the carbonate.

Von Feilitzen, however, found neither a direct relationship between lime content of moor soil and the development of . Izotobacter, nor relationship between their development and the reaction of the soil. But this only serves to illustrate the fact that although lime and neutral or slightly alkaline media are essential, they will not ensure a rich . Izotobacter flora in a soil unless all other conditions are optimum. Remy found sodium and potassium carbonate less favorable for nitrogen-fixation than was calcium or magnesium.

So far as the writer is aware, Krainsky is the only worker who has found sodium carbonate more favorable than calcium carbonate. This may have been due to the sodium carbonate's liberating plantfood which was in the soil in an insoluble form but which was essential to the development of Hotobacter. Morkeridge has found that 
the presence of sodium salts is unnecessary and depressing at least to the growth of 1 zotobacter. The beneficial effect ascribed to sodium chlorid solution in inoculating agar plates is due to the fact that this liquid is isotonic with the cell content solution, but the sodium hydroxid is a far less adrantageous neutralizing agent than is calcium or magnesium carbonate. Furthermore, Lipman failed to stimulate the azofiers with any of the sodium salts.

Food Requirements of the Azofiers.-These organisms probably require for their nutrition the same elements as do the higher plants, namely carbon, hydrogen, oxygen, nitrogen, potassium, phosphorus, sulphur, calcium, magnesium, and iron, and possibly aluminum and manganese.

They obtain their carbon and hydrogen from organic compounds, preferably from carbohydrates, which are considered in detail under sources of energy. Oxygen is obtained either from the atmosphere or from combined sources depending on the species and the conditions under which they are grown.

A marked difference between these and the higher plants is that they possess the power of obtaining their nitrogen from the air, but in the presence of combined nitrogen they obtain but little from the air. Lipman, Stranak, Heinze, and Stoklasa found that small quantities of nitrates stimulated Azotobacter, whereas large quantities discouraged nitrogen-fixation since the organisms live on the nitrates. This is the case whether the nitrates are added to the soil or to the solution in which nitrogen-fixation is taking place. Coleman considers this action as due to several different factors: namely, $(a)$ a direct toxic action of the salt, $(b)$ antagonism of other organisms which it favors, $(c)$ the using up of the energy supply by these organisms, and $(d)$ the discouragement of fixation by the use of sodium nitrate. 'The last would seem to be the most important factor when viewed in connection with the following results reported by Hills:

\begin{tabular}{|c|c|c|c|c|c|c|c|}
\hline \multirow{3}{*}{$\begin{array}{l}\text { Treatment } \\
\text { nitrate. } \\
\text { Mgm. }\end{array}$} & \multirow{2}{*}{\multicolumn{3}{|c|}{ Relative number of organisms. }} & \multicolumn{4}{|c|}{ Relative per cent. of nitrogen fixed. } \\
\hline & & & & \multicolumn{2}{|c|}{ Sterilized soil. } & \multicolumn{2}{|c|}{ Unsterilized soil. } \\
\hline & $\mathrm{KNO}_{3}$ & $\mathrm{NaNO}_{3}$ & $\mathrm{Ca}\left(\mathrm{NO}_{3}\right)_{2}$ & $\mathrm{NaNO}_{3}$ & $\mathrm{Ca}\left(\mathrm{NO}_{3}\right)_{2}$ & $\mathrm{NaNO}_{3}$ & $\mathrm{Ca}\left(\mathrm{NO}_{3}\right)_{2}$ \\
\hline 0 & 100 & 100 & 100 & 100 & 100 & 100 & 100 \\
\hline 10 & 348 & 191 & 362 & 100 & 105 & 240 & 219 \\
\hline 50 & 8210 & 3150 & 4528 & 342 & 371 & 500 & 444 \\
\hline 150 & 12 & 117 & 763 & & & & \\
\hline 200 & 0 & 0 & 0 & 352 & 467 & 879 & 557 \\
\hline
\end{tabular}


The number of organisms developing and the nitrogen ${ }^{\top}$ fixed in the one receiving no nitrate is taken as 100 per cent.

It is quite evident from these results that although nitrates cause more active multiplication of Azotobacter, it grently reduces their physiological efficiency. The organisms used by Hills had probablygrown for a long time on media poor in nitrogen, and their ability to fix nitrogen was, therefore, high. But would they continue to exert this power if grown on media rich in nitrogen? The evidence points strongly to the conclusion that they would not. It is certain, howerer, that the nitrates are toxic in comparatively low concentrations. Nitrates and ammonium sulphate are rather effectire in stimulating nitrogen-fixation when the Azotobacter are grown in connection with the cellulose ferments. Even here, however, large quantities decrease this power. In pure cultures ammonium sulphate seriouslyretards nitrogen-fixation, whereas the nitrogen of humus, even in large quantities, appears to have no serious retarding influence. Nevertheless, a high nitrogen content of soils seems to be unfarorable to vigorous nitrogen-fixation.

Whether this would be the case where the nitrate content of the soils is kept low but with the readily decomposable protein nitrogen high, is yet to be answered. Hiltner and Störmer consider that when the nitrogen content of the soil passes beyond a certain limit, the decay bacteria increase rapidly, and in the struggle for existence they are able, with the advantage at their disposal, to suppress the more slowly growing Azotobacter.

Potassium is essential to the higher plants and camnot be replaced entirely by related elements, yet Gerlach and Vogel early reached the conclusion that potassium and magnesium are not essential to the Azotobacter. Their results were, however, generally considered erroneous, for while as much nitrogen was fixed in twenty days without as with potassium, after forty days there was no further fixation in the solution without potassium, but in its presence the nitrogen gain nearly doubled. It was, therefore, argued that the traces of potassium left in the chemicals and dissolved from the glass during sterilization had been enough to permit derelopment for a time. If these elements are essential, it must be in extremely minute quantities, for Vogel, using the purest chemicals obtainable, was able to prepare potassium-free media in which the Azotobacter developed. He did find, however, that potassium favors their development.

Phosphorus is required by these organisms, large quantities being used for the building of the nucleo-proteins and phospho-proteins in which their bodies are extremely rich. Moreover, it greatly accelerates the reaction and economizes the carbohydrates; hence it is rather evident that phosphorus plays a very essential part in Azotobacter metabolism. Possibly in the early stages of the process a 
definite chemical reaction occur's between the phosphate and the carbohydrate similar to that occurring in alcoholic fermentation.

\section{I. $2 \mathrm{C}_{6} \mathrm{H}_{12} \mathrm{O}_{6}+2 \mathrm{R}_{2} \mathrm{HPO}_{4} \rightarrow 2 \mathrm{CO}_{2}+2 \mathrm{H}_{2} \mathrm{O}+\mathrm{C}_{6} \mathrm{H}_{10} \mathrm{O}_{4}\left(\mathrm{PO}_{4} \mathrm{R}_{2}\right)_{2}+$ II. $\mathrm{C}_{6} \mathrm{H}_{10} \mathrm{O}_{4}\left(\mathrm{PO}_{4} \mathrm{R}_{2}\right)_{2}+2 \mathrm{H}_{2} \mathrm{O} \rightarrow \underset{2}{2} \mathrm{C}_{6} \mathrm{H}_{22} \mathrm{O}_{6}+2 \mathrm{R}_{2} \mathrm{HPO}_{4}$}

The inotobacter are able to utilize the phosphorus of di- and tri-basic sodium and potassium phosphate and of dibasic calcium phosphate.

Mockeridge obtained an increase of 23 per cent. in nitrogen fixation with basic slag. There were two maxima, one with $0 . t$ per cent. the other with 1.0 per cent. slag. 'This is attributed to the stimulating effect of the iron and manganese in the slag, the maximum effect of one being produced at 0.4 per cent., the other at 1.0 per cent. The tribasic calcium phosphate-bone ash, iron, and aluminum phosphate-all serve only as difficulty available sources of phosphorus. Raw rock phosphate and bone meal fail entirely to furnish enough arailable phosphorus for the development of Azotobacter.

The addition of phosphorus to a soil often greatly increases azofication.

Treatment
No lime
Lime.

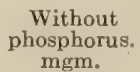

0.6

1.5

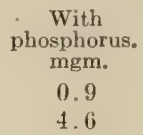

Moreover, Christensen has found soils in which phosphorus is the limiting element in Izotobacter growth. He entertains the hope that, in view of the relationship between Izotobacter growth and lime and phosphorus, it will become eventually possible by the determination of bacterial food requirements to secure a general expression for the soil content of plant-food available to crops. He further suggests that where a mannitol solution free from phosphorus produces a vigorous growth of Azotobacter after inoculation with a soil, it may be assumed that the soil is not deficient in arailable phosphorus. I)zierzbicki notes that if soils are deficient in available lime, phosphoric acid, or potash, nitrogen-fixing bacteria, such as Azotobacter, are either entirely absent or present only in small numbers.

There is a definite relationship between the carbon and phosphorus content of a soil and the nitrogen assimilated. According to Stoklasa, Azotobacter assimilates from 5.0 to 5.7 grams of free nitrogen for every gram of phosphorus used. Although these organisms are directly dependent upon a readily available supply of phosphorus to promote growth, they do not change it into the organic form as rapidly as do the ammonifying bacteria.

Sulphur is required by the azoficrs possibly for the formation of the 
proteinaceous material of their bodies. It is certain that the benefit derived by 1 zst tobacter from the sulphates of iron and calcium is due in a large measure to the sulphur which these compounds supply. No evidence has as ret been produced which would lead us to believe that the organisms can use sulphur as a source of energy.

Calcium carbonate and calcium oxid, in addition to furnishing a base which neutralizes the acid formed in the metabolic processes of the Izotobacter, also furnish calcium to the organism. ('hristensen brought out the fact that Azotobacter can derive their calcium from dibasic calcium phosphate and some calcium salts of organic acids. They could not, however, utilize the calcium of tribasic phosphate, of calcium chlorid or sulphate.

Iron is essential and either the ferric or ferrous sulphate is especially beneficial. Rosing found the amount of nitrogen fixed increased from 2.2:3 mgms. to $10.3 \mathrm{mgms}$. per gram of mannite when iron sulphate was added to the cultural media. This is due, in a great degree, to the iron which serves as food for the organisms, yet its colloidal nature may play a part, for both organic and inorganic colloidal substances have an especially favorable action on . Izotobacter, although the action of the inorganic colloids is fully manifest only in the presence of organic colloids. If used alone, large guantities of the ferric hydroxid are essential for the maximum effect, but in the presence of organic colloids very small quantities of iron are effective. This has been attributer to the action of the colloidal iron which adsorbs the nitrogen and oxygen of the air and brings them into more intimate contact with the Izotobacter'. 'This would not only accelerate the normal processes of the aërobic . Izotobacter by furnishing them with nitrogen and oxygen, but it would tend to suppress the anaërobic processes which are extremely wasteful of the food. According to Kaserer, these organisms also require aluminum. Although this may accelerate, it has not been proved to be essential to their growth.

While not essential to the organisms, manganese is an extremely active catalyzer in increasing proportions up to $6 \mathrm{mgm}$. per 100 c.c. of media. Above this concentration the reaction falls off rapidly, and at $20 \mathrm{mgm}$. it is less than in the absence of manganese. It is nxidized by Azotobacter, and in the proportion of 1 part to 2000,000 parts of soil it is an active stimulant. Olaru considers it likely that the increased rield obtained after the application of manganese compounds to a soil is due to its accelerating the action of the nitrogen-fixing organisms of the soil.

Organic Soil Constituents. - Reed found urea, glycocol, formamid, and allantoin active in depressing nitrogen-fixation. This he attributes to the compounds furnishing the 1 zotobacter an available source of combined nitrogen and not to a direct toxicity. But Walton found that the addition of urea, peptone, acetamid, aspar- 
agin, and casein to culture media had only a slight influence on the fixation of nitrogen by Azotobacter.

Caffeine, alloxan, betain, trimethylamin, legumin, cinnamic acid, aspartic acid, asparagin, hippuric acid, creatin, creatinin, xanthin, and hypoxanthin, are all toxic to Azotobacter even in small quantities. Only the first two have been tested in concentrations dilute enough to stimulate, which is remarkable, as many of these compounds stimulate the higher plants and some can be utilized directly by the plant.

Esculin, vanillin, daphnetin, cumarin, pyrocatechin, heliotropin, arbutin, resorcin, pyrogallol, phloroglucin, hydroquinon, salicylic aldehyd, oxalic acid, quinic acid, dihydrostearic acid, rhamnose and borneol, on the other hand, do not stimulate in any concentration. Nor are they toxic until fairly large quantities have been added. In this regard the nitrogen-fixing organisms appear to differ widely from the nitrifying bacteria and higher plants. The resistance of the nitrogen-fixers to various chemicals has likewise been called to our attention by Lipman in his study of the infuence of alkalies on nitrogen-fixation.

Influence of Colloids. - It was recognized early in the study of nitrogen-fixation that when sterilized soil is added to a nutritive medium it greatly increased the quantity of nitrogen fixed. This condition is due to several factors and is partly explained by Krzemieniewski's results wherein he found that nitrogen-fixation is decidedly increased by the addition of soil humus, either as free humic acid or as salts of potassium, sodium or calcium. Kaserer maintains that this is due to the inorganic nutrients, especially to aluminum and silicic acid supplied to the microörganisms through the humus. This is probably true in part, for the fixation varies with the humus derived from different sources. Moreover, artificial humus, prepared by boiling sugar with acids, fails to stimulate.

'That much of the beneficial effect is due to the constituents in the humus appears likely from the results obtained by Söhngen who found that colloidal iron oxid, aluminum oxid, and silicon oxid all greatly stimulated the nitrogen-fixing powers of Azotobacter chroöcocrum. 'This he attributed to the absorption of oxygen and nitrogen by the colloid, which he maintains would make them more readily available to the organisms. The boiling of natural humus with hydrochloric acid would either remove the foreign material or change it from the colloidal form, and thus, as has been found to be the (ase, render it inert. Löhnis and Green take exception to this explanation, for they found no adsorptive action exerted by humus on either the nitrogen or the oxygen. Furthermore, Rosing found that he could stimulate just as effectively with iron as with humic acids. But much larger quantities of colloidal iron are required when it is used singly than when used in conjunction with an organic 
colloid. The extent of the stimulation resulting varies with the form in which the iron is applied and is most effective in the form of the hydroxid and in the presence of cane sugar. In this case it is probable that the saccharate is the active substance. Hence, the contradictory results reported may be due to the different mineral constituents of the humus.

These facts make it certain that colloids of the metals act as stimulants to nitrogen-fixing bacteria, as does also crude humus. Carefully purified humates do not possess this property, but it is possessed by the aqueous extract, the alcoholic extract, and the phosphotungstic fraction of the aqueous extract from "bacterized" peat. Whether this influence is due to a catalytic effect, as suggested by söhngen, or whether the substance furnished a direct source of nutritive material is not clear at the present time.

Moreover, the colloid may act as a protection to the organism against poison; for, when 10 parts per million of soluble arsenic is maintained in a soil, it acts as a stimulant to Azotobacter. If, however, this proportion is added to the Ashby nutritive solution it stops all nitrogen-fixation. This is due in part to the adsorption of the arsenic by the soil. 'This adsorption would have to be attributed largely to the silica compounds, for the nitrogen-fixing organisms are stimulated by arsenic in quartz free from organic colloids. This could readily be due to the arsenic becoming concentrated at the surface layers of the silica, leaving the inner part of the water film comparatively free from arsenic, in which part of the water film the microörganisms multiply and carry on their metabolic processes. This being the case, one should and probably could find a water solution weak enough to stimulate bacteria. A great difference, however, between the solution and the sand-culture method is the greater aëration in the sand. That the aëration of a culture medium does play an important part in determining the activity of the nitrogen-fixing powers of a soil is strikingly brought out in Fig. 1S, page 124.

Sources of Energy for the Azotobacter. - The nitrogen-fixing organisms differ widely from other plants in their energy requirements. This is due to the fact that they are carrying on endothermic reactions in which nitrogen is concerned. This necessitates a greater supply of energy than is required by other bacteria. They are similar to most other bacteria in that this energy must be supplied by an organic compound, preferably one of the carbohydrates.

Berthelot in his early work maintained that the gains in nitrogen noted in some soils were due to the action of biological agents on the humus of the soil. 'This was followed by the observation of others that when forest leares are allowed to decompose in soil there is an increase in its nitrogen content. Koch in 1907 increased nitrogen-fixation by the addition to soil of dextrose, cane sugar or 
starch, but there was practically no increase when straw, filter paper or buckwheat was applied. Yet Stoklasa showed that the decomposition products of these substances acted as a valuable source of energy to the Azotobacter, and Stranak considered that the pentosans of the soil are of the greatest importance in the assimilation of nitrogen by soil bacteria.

A fair idea of the great variety and relative efficiency of substances which may serve as a source of energy to the azofiers may be obtained from the work of Löhnis and Pillai. They inoculated a nutritive solution with $10 \mathrm{gm}$. of soil and after ten days determined the gain in nitrogen.

Substance added.
Mannite
Xylose
Lactose
Levulose :
Inulin :
Galactose
Maltose
Arabinose
Dextrin
Sucrose :
Dextrose :
Starch
Sodium tartrate
Glycerin
Sodium succinate
Calcium lactate
Sodium citrate
Sodium propionate
Potassium oxalate
Calcium butyrate
Humus

Nitrogen fixed af ter 10 days $\mathrm{mgm}$.

9.40

9.54

9.12

8.52

7.72

7.86

7.44

7.62

7. 18

8.60

4. 62

3.36

2. 82

1.68

2.96

2.49

1. 42

1.10

0.12

0.02

$-0.96$

Other workers have noted larger gains of nitrogen than those noted by Löhnis and Pillai, but they can readily be attributed to the time of incubation - in this case, ten days being far too short for the complete utilization of the carbonaceous substance applied; the species of nitrogen-fixers which are bringing about the change; and whether pure or mixed cultures are used. The order of effectiveness noted above, however, is that recognized by most workers. Brown and Allison, however, do report results in which greater fixation was obtained with dextrose than with mannite. But in this case, calcium or sodium carbonate seems to be even more necessary than it is with the mamite. Moreover, some species utilize one carbohydrate most effectively and another species a different one. To this list may be added malate, gum tragacanth, ethylene glycol, methyl, ethyl, and propyl alcohols, lactic, malie, succinic and glycollic acids. Fatty acids are readily utilized, the amount of nitrogen fixed being greater with the increased molecular weight, from 1.47 mgm. with formic acid, to $6.08 \mathrm{mgm}$. with butyric acid. Most of the 
naturally oc'urring glucosides and many benzin derivatives are unsuitable as sources of energy for 1zotobacter. Molasses, which should serve as a useful source of energy, often results in a loss of nitrogen when applied to the soil. 'This may be due to the time of applying, for Peck maintains that molasses applied to a land lying fallow at an interval of several weeks before planting of the crop may produce beneficial results by increasing nitrogen-fixation.

Beijerinck early recognized that certain decomposition products of cellulose can also serve as sources of energy for Lotobacter, and Pringsheim found that Clostridium americanum does not fix atmospheric nitrogen on sterilized cellulose unless other carbohydrates like dextrose, lactose, mannitol, or sucrose are present. However, in the presence of cellulose, Clostridium will fix nitrogen and this more efficiently than it will in the regular carbohydrate medium. The same holds for agar. Just how completely cellulose must be broken down before it can be utilized by izotobacter is not definitely known, but it is known that izotobacter cannot utilize cellobiose except when grown in conjunction with Aspergillus niger or other organisms. It is, therefore, certain that the products which are utilized by the Azotobacter are comparatively simple.

Cellulose when applied to the soil may serve as a valuable source of energy, provided sufficient time is allowed for its decomposition. The cellulose ferment is probably the most efficient organism in the soil in bringing about this decomposition. But the number of soil fungi which possess this power is large.

Hoppe Seyler thinks that cellulose is decomposed according to the following formula: (a) the hydration of the cellulose with the formation of hexose,

$$
\left(\mathrm{C}_{6} \mathrm{H}_{10} \mathrm{O}_{5}+\mathrm{H}_{2} \mathrm{O}=\mathrm{C}_{6} \mathrm{H}_{12} \mathrm{O}_{6}\right. \text {. }
$$

the destruction of the carbohydrate with the formation of equal quantities of carbon dioxid and methane.

$$
\mathrm{C}_{6} \mathrm{H}_{12} \mathrm{O}_{6} \rightarrow 3 \mathrm{CO}_{2}+3 \mathrm{CH}_{4}
$$

None of the cellulose ferments studied by McBeth, however, yielded gaseous products when acting on cellulose or sugar; hence the A sotobacter probably gets from the cellulose ferments, pentoses and hexoses, and similar products upon which they can readily fix nitrogen.

At times in fermenting straw and manure, the thermophilic anaërobic bacteria play a major part, in which case fatty acids probably make up the greater part of the end products.

It is claimed by I)varak that substances with low carbon and high oxygen content are usually the best sources of energy for A. chrö̈coccum, which assimilated $5.73 \mathrm{mgm}$. of free nitrogen per $100 \mathrm{gm}$. of carbon in pine leaves as compared with $1237.9 \mathrm{mgm}$. per $100 \mathrm{gm}$. 
of carbon in red elover. He ohtained for other substances the following results:

$1456.5 \mathrm{mgm}$. of nitrogen per $100 \mathrm{gm}$. as glucose.

$280.4 \mathrm{mgm}$. of nitrogen per $100 \mathrm{gm}$. as cornstalks.

$596.8 \mathrm{mgm}$. of nitrogen per $100 \mathrm{gm}$. in stalks and root residues of corn.

$325.4 \mathrm{mgm}$. of nitrogen per $100 \mathrm{gm}$. in wheat straw.

The carbon-nitrogen ratio in compounds is no indication of their value to nitrogen-fixing organisms, for non-leguminous hays and straws are utilized just as effectively as are the legumes. Mockeridge found that the ratios of nitrogen fixed to the heat of combustion with the four lower fatty acids is almost constant. The same holds true with starch, dextrin, and gum arabic, when allowance is made for experimental error, which is greater with these compounds than with the simpler compounds. This close relationship is not, however, graduated and no such uniformity is observed with the series of monohydric alcohols.

The quantity of nitrogen fixed per gram of carbohydrate varies greatly with the species. Winogradsky found Clostridium pasteuriamum to assimilate 2 to $3 \mathrm{mgms}$. of nitrogen for each gram of sugar. But this like other anaërobic organisms is very wasteful of energy, leaving much of it in the butyric acid, acetic acid, and butyl alcohol formed. In the experiments of Bredemann with $B$. amylobacter and of Pringsheim with Clostridium americanum, the amounts fixed were at times much larger. Much greater fixations have been reported with Azotobacter, and Lipman has obtained as high as 15 to $20 \mathrm{mgms}$. of nitrogen per gram of mannite assimilated by 1 . vinelandii. This quantity is considerably greater than that fixed br any of the other members of the group.

Koch and Serdel claim that the usual method of estimating the nitrogen-fixing powers of Azotobacter is erroneous, as it does not represent accurately the intensity of the process. In a series of experiments made by them, the amounts of nitrogen fixed per gram of dextrose used were 53,70 to 80,20 to 30 , and 5 to 8 mgms. on the first, second, third, seventh, and eighth days, respectively.

Krainsky considers that there should be sufficient organic matter in the soil to permit that for 1 part of nitrogen formed there will be 90 parts of carbon for the use of the organism. The organisms, however, utilize the carbohydrates more economically when only small quantities are present. Walton finds with Indian soil that highest fixation is obtained per gram of mannite when 10 grams are used in 1 liter of nutritive solution. Young, vigorously growing cultures usually fix more nitrogen than the older ones. The nitrogen fixed is greatest in the first stages of the growth of the organisms, as is seen from Fig. 33 from the work of Omelianski.

The efficiency of these organisms is, therefore, greatest when they 
are rapidy multiplying, and it decreases as their metabolic products accumulate. Itoffmann and Hammer claim this to be due in impure cultures to a loss of nitrogen or free ammonia oreasioned by the decomposition of the cells of Azotobacter. This explanation would hardly hold in the presence of pure cultures, unless we ascribe the breaking down to an autolytic ferment secreted by the Izotobacter cell. According to Koch and Seydel this indicates that in the latter stages of fixation, when there occurs an accumulation of nitrogenous material in the medium, the organisms employ the carbohydrates

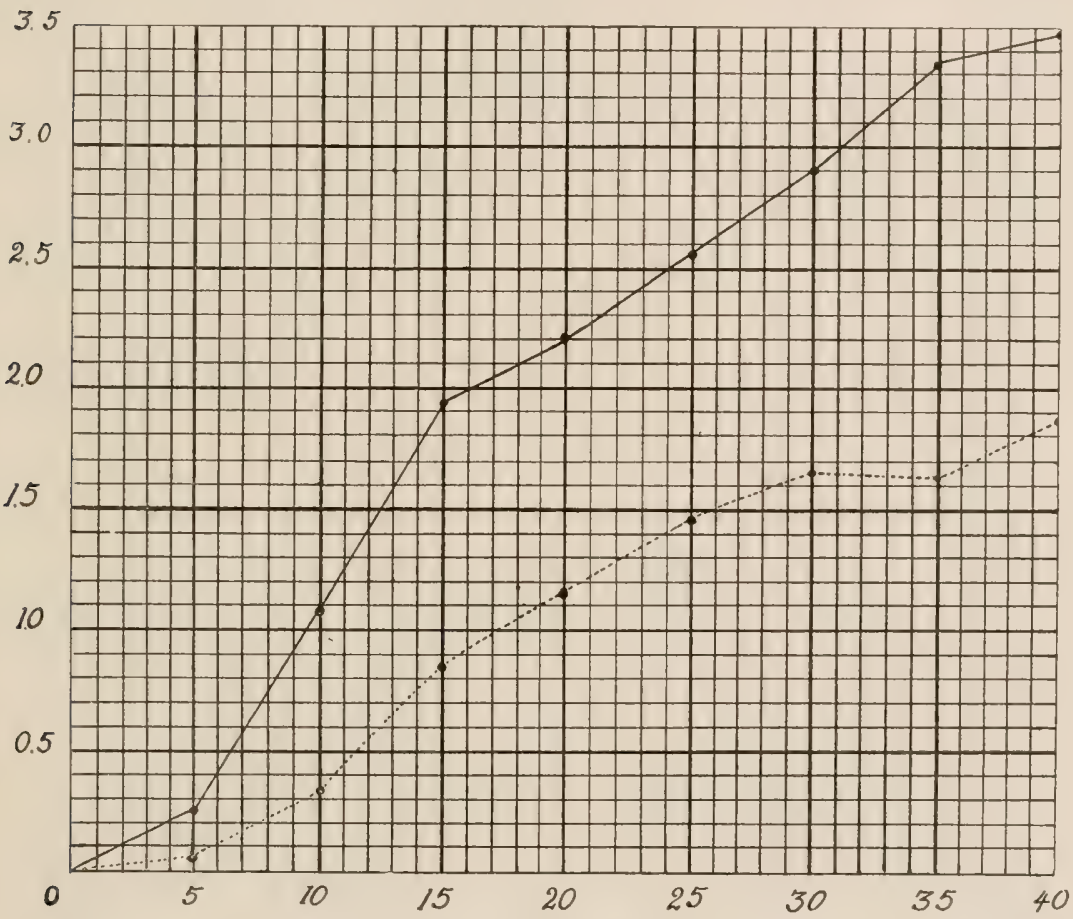

Frg. 33.-Graph showing the fixation of nitrogen and decomposition of sugar in mixed cultures of Azotobacter chroöcoccum and Clostridium pasteurianum.

for other purposes than for nitrogen-fixation. Inder natural conditions in the soil this accumulation and concentration of nitrogenous material by the Azotobacter is not likely to occur; hence, they assume that the organism will continue fixing nitrogen at the high ratio noted in the early part of laboratory experiments.

'The quantity of nitrogen fixed, howerer, is dependent upon factors other than the source of energy; $e$. g., Krzemieniewski found with A. chroöcoccum that the addition of humates to the cultural solutions increased the nitrogen fixed from a maximum of $2.4 \mathrm{mgm}$. to 14.9 
mgm. Moreover, Krainsky found Azotubacter to utilize from 100 to $200 \mathrm{gm}$. of sugar in the assimilation of $1 \mathrm{gm}$. nitrogen when grown in solution, but when grown on sand it required only 11 to $30 \mathrm{gm}$. for the same fixation.

They utilize their energy more economically in the presence of a liberal supply of phosphorus than when the quantity of available phosphorus is limited. This accounts, in a measure, for the high fixation noted in most Utah soils.

Manure. - It has been known for a long time that humus exerts a highly favorable effect on nitrogen-fixation. The great question, however, has been as to the manner of action. Humus, being such a complex, variable substance, varies greatly in action, depending upon its source. Remy considered that some of the products from humus are favorable sources of organic matter for Azotobacter. Definite and valuable information is furnished by the work of Löhnis and Green. They worked with mixed cultures of A. chrö̈coccum, 1. beijerinckii, 1. vinelandii, and 1 . vitrium in Beijerinck's mannite solution with various forms of organic matter.

Material.

Fresh straw

Fresh stable manure

Fresh peat

Green manure

Beijerinck's mannite solution
Nitrogen fixed in 100 cc. of solution after 3 weeks. $\mathrm{mgm}$.

10.0

$9: 8$

9.3

8. 0

5. 6

After humification, these substances were even more readily assimilated and the nitrogen-fixation was greater than when the unhumified substance was used.

The same year Hanzawa published results which show that stable manure even up to 3 per cent. greatly stimulated bacterial activities. Green manure humus was found by him to be injurious. From this it is certain that humus can act as a source of energy and usually stimulates bacteria, but the extent is governed largely by its composition and by the quantity of available combined nitrogen which is being supplied with it to the organism. In addition to this, corn roots, cornstalks, oak leaves, lupine, alfalfa, maple leaves, and pine needles may all serve as a useful source of energy to the nitrogenfixing organisms. Apparently, the tissues from the non-legume give a greater gain than do those from the legumes. Fulmer has recently confirmed these results.

The influence of stable manure upon the nitrogen-fixing powers of the soil under field conditions is seen from the following table in which the quantity of nitrogen fixed in the unmanured soil has been taken as 100 per cent. 
These results indicate clearly that stable manure has a beneficial effect upon the nitrogen-fixing powers of the soil, but if used in large quantities the benefit is not so pronounced as if used in smaller quantities.

This decrease in nitrogen-fixation with increased additions of manure must be considered as due to its physical effect upon the soil, for Richards found that Azotobacter grow and fix nitrogen in horse manure when it is well aërated and contains sufficient moisture and calcium carbonate. There is, too, a close connection between the diet and the effect. Horses fed on oats gave feces which induced the greatest fixation; horses on grass next; cattle receiving oatmeal cake third; but the feces from cattle fed on grass proved unsuitable.

Manures often contain nitrogen-fixing organisms of considerable activity. Their activity appears to be greatest in fermenting manures mixed with straw which serves as a source of energy.

Although Fulmer and Fred were unable to find 1zotobacter in any of the samples of manure examined, they did obtain many nitrogenfixing bacteria from it. One of these organisms, for which they suggested the name of $B$. azophile, is as efficient in fixing nitrogen as is Izotubacter. This would make it appear that manure may of ten carry to the soil nitrogen-fixing organisms.

IMetabolism of Azotobacter.-Much time has been given to a study of the metabolism of Azotobacter, yet our knowledge of this subject is far from satisfactory. It is well known that the organisms oxidize the various carbohydrates and with the energy thus obtained build up complex nitrogen compounds. Berthelot early recognized that the nitrogen so fixed is insoluble in water, thus indicating its protein nature. Lipman found that there was a small but appreciable quantity of nitrogen in both young and old cultures of $A$. vinelandii not precipitated by lead acetate and a large proportion not precipitated by phosphotungstic or by tannic acid. Further work indicated that the substances were either amino-acids or comparatively simple peptids. He considered that one of the early substances synthesized by these organisms is alanin. An analysis of the 1zotobacter membrane gave the following results:

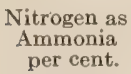

0.98

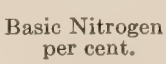

2.76

\section{Non-Basic \\ Nitrogen per cent.}

6.39
Nitrogen in MgO
Precipitate
per cent.

0.42
Total per cent.

Nitrogen per cent 
'This he finds corresponds remarkably closely with that of legumin. Experiments with plants indicate that the nitrogen of the Asotobacter cells is not readily assimilated.

Stoklasa found the 1zotobacter cells to contain 10.2 per cent. of total nitrogen and 8.6 per cent. of ash. The ash contained from 58 to 62.35 per cent. of phosphoric acid. Nitrogen and phosphorus were mainly in the form of nucleo-proteins and lecithin. The percentage of both nitrogen and phosphorus in the cell increase with age.

The most complete analyses of the Azotobacter cells, so far reported, show them to contain when grown on dextrin agar and rapidly dried at $30^{\circ} \mathrm{C}$., 6.63 per cent. of water, 4.12 per cent. of ash, and 12.92 per cent. of protein. 'The protein is similar to other plant proteins. It contains 10 per cent. of ammonia nitrogen, 26.5 per cent of diamino-nitrogen, and 60 per cent. of monoamino-nitrogen. The quantity of lysin present is very high, but the histidin is present only in traces.

Irzemieniewski states that Azotobacter produces no hydrogen or other combustible gases in its metabolism, but according to Stoklasa it does, and in the presence of nitrates it produces ammonia and nitrites. Moler claims that during its life, A. chrö̈coccum separates no soluble compounds, and it is only after death that it furnishes nitrogen to higher plants. Nor are their bodies readily broken down by proteolytic enzymes. Both 1 . agilis and A. vinelandii separate a soluble compound. The protein compounds so formed in soil are quickly broken down by other bacteria. Remy considers the nitrogen fixed by $A$ zotobacter in a readily available form for plant assimilation. Beijerinck found that 50 per cent. of the total nitrogen in Azotobacter cells when supplied to the soil is nitrified in about seven weeks. None of the Azotobacter so far studied produce nitrates in the media.

Turning now to the breaking down of the carbohydrates, we find that the organisms produce ethyl alcohol, glycocoll, acetic acid, butyric acid, lactic acid, carbon dioxid and hydrogen. The quantity and quality of the different products vary with the species and with the carbohydrate used.

It is likely that many of the end-products have not been determined, for Stoklasa starting with $15.9 \mathrm{gm}$. of dextrose recovered 7.9 as carbon dioxid, 0.3 as ethyl alcohol, 0.2 as formic acid, 0.7 as acetic acid, 0.2 as lactic acid, but could not trace the remaining 6.6 gm. The organisms are extremely active when growing under appropriate conditions, for $1 \mathrm{gm}$. weight of Azotobacter has evolved no less than $1.3 \mathrm{gm}$. of carbon dioxid in twenty-four hours. A great distinction between the Azotobacter and the other species is that the former decompose their sugar with carbon dioxid as the chief 
product, whereas the other species produce large quantities of but yric acid. Some of these products may be accounted for as follows:

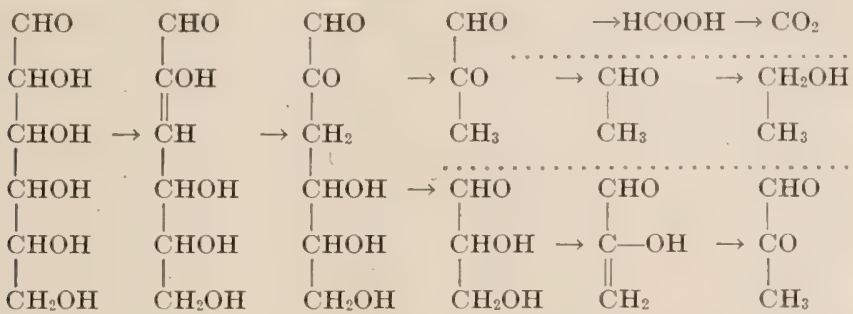

It is known that when sugars, such as glucose, levulose and mannose are acted upon by alkalies, there are produced a great many products, some of which are formic, carbonic, oxalic, lactic, pyruric tartronic, malic, malonic, tartaric, ribonic, saceharic, and gluconic acids in addition to many other either more or less complex compounds. We can readily conceive that the Izotobacter brings about a somewhat similar reaction, the stages, howerer, being more nicely. governed, because of enzymes. Many of the products would be oxidized to carbon dioxid and water with the liberation of energy necessary for the endothermic nitrogen reaction; others readily react with the resulting nitrogen compounds. We are completely in the dark as to what this first nitrogen compound is, but we know that the Irotobacter possess the power of changing nitrates or nitrites under appropriate conditions into ammonia. ¿p to date it has been impossible to detect nitrate formation; it is not impossible that nitrates are formed and utilized by intracellular enzymes. By using nitrates, nitrites or ammonia, we can offer a rough explanation of protein anabolism.

The endothermic reaction,

$$
2 \mathrm{~N}+2 \mathrm{H}_{2} \mathrm{O}=\mathrm{NH}_{4} \mathrm{NO}_{2},
$$

may take place and the ammonia thus formed may react with the decomposition products of the sugars, pyruvic acid for instance, with the formation of alanin which Lipman considered as one of the first products:

$$
\begin{aligned}
& \mathrm{CH}_{3}-\mathrm{CO}-\mathrm{COOH}+\mathrm{NH}_{3}=\mathrm{CH}_{3}-\mathrm{CHN}-\mathrm{COOH}+\mathrm{H}_{2} \mathrm{O} \\
& \mathrm{CH}_{3}-\mathrm{CHN}-\mathrm{COOH}+\mathrm{H}_{2}=\mathrm{CH}_{3}-\mathrm{CHNH}_{2}-\mathrm{COOH}
\end{aligned}
$$

or with glyoxylic acid forming glycocoll:

$$
\begin{aligned}
\mathrm{HCO}-\mathrm{COOH}+\mathrm{NH}_{3} & =\mathrm{HCNH}-\mathrm{COOH}+\mathrm{H}_{2} \mathrm{O} \\
\mathrm{CHNH}-\mathrm{COOH}+\mathrm{H}_{2} & =\mathrm{CH}_{2} \mathrm{NH}_{2}-\mathrm{COOH}
\end{aligned}
$$

By similar reactions other amino-acids may be formed. Moreover, Windas and Knoop have shown that methylimadazol may be 
produced from glucose and ammonia, presumably through the formation of pyruvic aldehyd and formaldehyd:

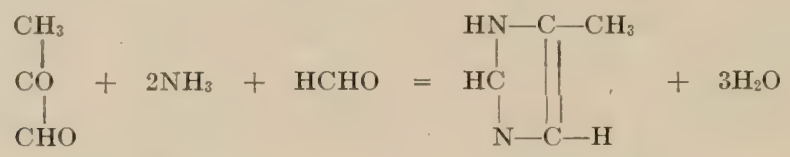

which is nearly related to the amino-acid, histidin:

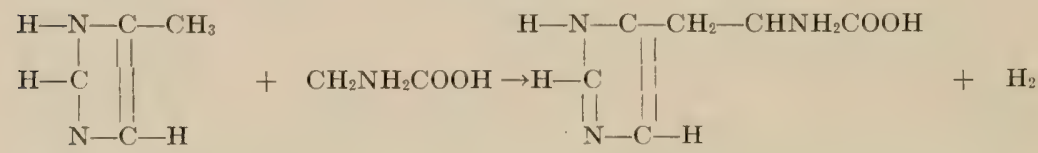

The various amino-acids may, through the intervention of proteinases, condense with the formation of dipeptids, thus:

$$
\underset{\mathrm{CH}_{3} \mathrm{CHNH}_{2} \mathrm{CONHCHCH} \mathrm{CH}_{3} \mathrm{COOH}}{\mathrm{CH}_{3}-\mathrm{CHNH}_{2} \mathrm{COOH}}+\underset{\mathrm{H}_{2} \mathrm{O}}{\mathrm{CH}_{3} \mathrm{CHNH}_{2} \mathrm{COOH}}
$$

By the continuation of this process and by condensing with phosphorus and sulphur-bearing compounds, probably through the intervention of other enzymes, there may result the complex protein of the Azotobacter cell.

Pigment Production by Azotobacter.-Most species of Azotobacter produce pigments. These vary in color from brown to black of the 1. chrcöccccum to a vellow or orange of the 1. vinelandii. The pigmented film usually develops on the culture media in from three to seven days. It is formed by 1 . chrö̈coccum earlier and in more abundance where old brownish cultures are used as the inoculating material. The pigment is produced and retained within the bacterial cell; it occurs in neither the capsule nor the medium. The pigment produced by 1 . chrö̈coccum is most pronounced when a dextrin agar medium to which calcium carbonate is added is kept at a temperature of $30^{\circ} \mathrm{C}$. under well aërated conditions. According to Jones, it is produced only when there is a lack of suitable available nutrient material and when organisms in the pigmented area have ceased to multiply. The color of the pigment is intensified if nitrates are added to the medium in which the organism is growing. The non-pigmented strains apparently fix nitrogen just as readily' as do those which have not lost the power of forming pigments.

The pigment from Azotobacter chrö̈coccum is insoluble in water, alcohol, ether, chloroform, benzol, and carbon bisulphid. It dissolves in alkalies, undergoing decomposition with the formation of a dark brown solution. Sackett maintains that the peculiar brownish color which is characteristic of certain "nitre spots" of some soils is due to the pigment produced by 1zotobacter. Such soils are high 
in nitrates and alkalies which would dissolve the pigments from the body of the organism. But Omelianski and sswewrowa are of the opinion that althought in some cases the dark color of vegetable soil may be due in a measure to the action of these microörganisms, it would be a mistake to attribute it to this factor alone. Furthermore, it has recently been proved that the brown color of the "nitre spots" is due to solvent and decomposing action of the nitrates on the colored organic compounds of the soil, for they may be produced at will in a rich greenhouse soil with an excess of sodium nitrate, and this too in soils which have been rendered sterile with a saturated solution of mercuric chlorid.

Morphology of the Nitrogen-fixing Organisms.-Of the many different bacteria which have been isolated and proved to have the ability to assimilate free nitrogen, Clostridium pasteurianum may be taken as a tỵpe of the anaërobic and Latobacter chrö̈coccum as a type of the aërobic.

Clostridium pasteuriamum is a short thick rod from 1.2 to $1.3 \mu$ in diameter and 1.5 to $2 \mu$ long in the roung cells; the older sporebearing cells take on a spindle shape. The bacteria stain a riolet brown with iodin. The spores when ripe are $1.6 \mu$ long and $1.3 \mu$ broad and often lie in a roughly triangular covering. 'The ripe spore escapes through the wall of the mother in a longitudinal direction. Their germination is polar.

Azotobacter chrö̈coccum occurs ordinarily as diplocoeci or short rounded rods 1 to $2 \mu$ thick and 1.5 to $3 \mu$ long, and according to Prazmowski the microörganism first presents itself in its vegetative stage as a bacterium, in the fruiting stage as a micrococcus, and possesses a nucleus which functions in the same way as that of higher animals. In the resting stage the nucleus assumes a globular form, having a strongly refractive nucleolus with clearly differentiated boundary layers. The individuality of the nucleus appears to be practically lost at times, because of its relation to the cytoplasm. The division of the nucleus marks the first stage of cell division. According to Bonazzi the organism shows peculiar granulations apparently not related to reproduction. These take the basic dyes and are neither fats, glycogen, starch nor chromatin, but appear to be of metachromatic nature and seem to have their genesis in the nucleus. Their disposition in the cells is not constant but changes in different individuals. Involution forms occur and cell division is preceded by a simple form of mitosis. Some, but not all, varieties have been observed to form spores. The rolutin bodies within the organism increase in number and size when the organisms are grown on media rich in nitrates. IIils suggests that they may have some relation to nitrogen-fixation, but his results appear to oppose this view; whereas the addition of nitrates to a medium greatly increased the reproduction, it very materially decreased the phisiological 
efficiency of the organism. It seems, therefore, more likely that. they are reserve protein material.

Löhnis and Smith have recently observed that Azotobacter, in common with many other bacteria, pass through a life cycle which is not less complicated than those of other microörganisms. Ender certain conditions they pass over into an amorphous or "symplastic" stage, appearing under the microscope either as an unstainable or a readily stainable mass without any easily distinguishable organization, which, if not discarded as dead, later gives rise to new regenerative forms. They multiple not only by fission, but by the formation of gonidia.

Methods.-Clostridium pasteurianum grows readily in a vacuum on carrots. The organism also grows on sliced potatoes, but ordinarily. is grown in an aqueous solution containing $1 \mathrm{gm} . \mathrm{K}_{3} \mathrm{PO}_{4}, 0.5 \mathrm{gm}$. $\mathrm{MgSO}, 0.1$ to $0.02 \mathrm{gm}$. $\mathrm{NaCl}, \mathrm{FeSO}_{4}$, and $\mathrm{MnSO}_{4}$, and $1.0 \mathrm{gm}$. $\mathrm{CaCO}_{3}$, and 10 to $15 \mathrm{gms}$. of a suitable carbohydrate in 1 liter of water. One method used by Winogradsky in isolating B. Clostridium pasteuriamum was to add garden soil to a non-nitrogenous solution and to allow a stream of nitrogen gas to pass through the solutions, after which several successive transfers were made into similar media. The final culture, after $B$. Clostridium pasteuriamum had formed spores, was heated to $80^{\circ} \mathrm{C}$.

The organism ferments certain carbohydrates with the formation of butrric acid, acetic acid, carbon dioxid, and water. When grown in nutritive solution devoid of combined nitrogen, it assimilates atmospheric nitrogen. Although in pure cultures it is an anaërobe, in impure cultures it may fix nitrogen under aërobic conditions. In nature it occurs in connection with two other bacteria which do not possess the power of fixing nitrogen, and their nitrogen requirements are small. When in conjunction with these organisms, Clostridium pasteurianum has the ability of growing in the upper layers or soil and of assimilating free nitrogen.

Azotobacter chroöcoccum grows readily on solid or liquid media, one of the best being:

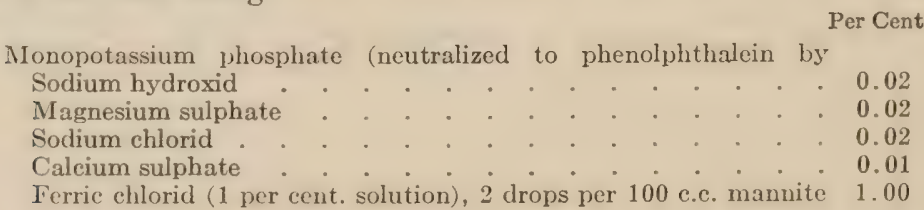

The organism is readily isolated by seeding this medium with soil. After the characteristic membrane forms, it is transterred by dilution to a similar medium containing agar in which the characteristic brownish black colonies form readily.

On mannite agar the colonies first appear as milk-white glistening drops, round and convex, which under a low magnification show 
a coarsely granular structure extending to the margin. 'The colonies rapidly increase in size, and after a week or more become brown at the center with concentric rings alternating dark and white to the circumference and darker streaks radiating from the center outward. In old cultures, where the agar has partly dried up, the cells are of ten united in sarcina-like packets; the cell walls are much swollen and the contents are aggregated to a small ball at the center. At the same time giant cells, both round and elongated and filled with oil drops, can be seen. Often a number of involution forms are seen, drawn out with long threads and false septa. By successive dilutions and transfers, it may be obtained in pure culture, although at times considerable difficulty is experienced in freeing it from a small organism $-B$. radiobacter.

Several different methods have been used for studying its nitrogen-fixing powers:

(a) Seeding into 100 c.c. of the medium given above and after a certain time determining the nitrogen.

(b) The use of the same medium, but the addition of sufficient sand for the formation of sand slopes on which the organism can grow.

(c) The addition of a definite quantity of a carbohydrate to a soil and the incubation of this.

Each of these methods has its value. The first is much more readily handled in the final Kjeldahl determination, but the others give much higher results.

Freudenreich found that when Azotobacter are grown upon gypsum, the gain in nitrogen is considerably in excess of that assimilated in the liquid media. Krainsky found Asotobacter to utilize from 100 to $200 \mathrm{gm}$. of sugar in the assimilation of $1 \mathrm{gm}$. of nitrogen when grown in solution, but when grown on sand it required only 11 to $30 \mathrm{gm}$. for the same fixation. Many other workers have noted similar variation when grown in the soil. Where the organisms have been grown on gypsum or soil, we may attribute the stimulation to certain soluble constituents, ret this explanation scarcely seems plausible when considered in relation to sand cultures. Three strains of Azotobacter were grown in Ashby's mannite solution and sand (nearly pure silicon dioxid) to which Ashby's solution was added, with the following results:

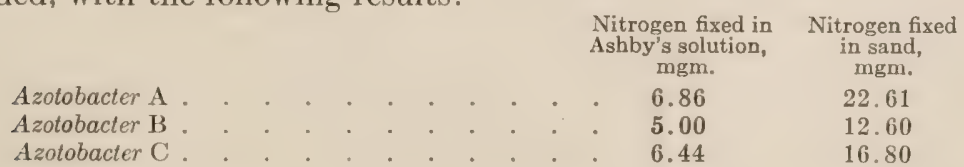

Moreover, arsenic is very toxic in the solution, whereas when added to the soil or to pure quartz, in small quantities, it stimulates. Although the total quantities of nitrogen fixed under the two 
methods differ greatly, the relative efficiency of the organisms is about the same in both cases. In testing soils similar results are obtained, as may be seen from the following results, which are the arerage for several hundred determinations made on different soils by the two methods.

Depth of Sample.

First foot.

Second foot

Third foot
Nitrogen fixed in:

$\begin{array}{cc}100 \mathrm{gm} \text {. of soil } & 100 \text { c.c. of Ashby's } \\ 1.5 \mathrm{gm} \text {. of mannite, } & \begin{array}{c}\text { mgm. } \\ \text { containg } 1.5 \mathrm{gm} . \\ \text { of manite } \\ \text { mgm. }\end{array} \\ \quad 5.28 & 2.11 \\ . \quad 2.42 & 0.77 \\ \text {. } 1.55 & 0.58\end{array}$

Although the greater aëration in the sand and soil culture probably play a great part, there is little doubt that the colloids also assist.

Relation of Azotobacter to other Organisms.--In the early study of nitrogen-fixation, the view was held that alga growing on or near the surface of soil are able to fix nitrogen. Frank in $18 S S$ had observed such a growth on sand exposed to light and found that the soil showed a considerable increase in nitrogen. In 1892 Schlösing and Laurent proved, both by determining the nitrogen fixed by a soil in a closed vessel and by observing the diminution of the nitrogen gas in the enclosed air, that a soil exposed to light gains in nitrogen if algae are allowed to grow on the surface, and that the gain is confined to the upper few millimeters. They did not, however, employ a pure soil or pure cultures of algæ. Kossowitsch, working with pure cultures of two green algæ, found no fixation, but observed a considerable increase of soil nitrogen when they were grown with soil bacteria. Later, Kruger and Schneidewind, employing pure cultures of many other chlorophycex, obtained no nitrogen-fixation, Hellriegel and Dehérain had found a large increase in the nitrogen content of sand in pots when exposed to the light, which was always accompanied by a development of algæ. In the light of such results, the conclusion has been reached that algre alone cannot assimilate free nitrogen, but only in concurrence with soil bacteria, the former producing carbohydrates which are used by the latter as a source of energy for the nitrogen-fixation. Heinze actually observed rapid fixation of nitrogen when cultures of algæ were inoculated with Azotobacter or other nitrogen-fixing organisms. Stoklasa found that dzotobacter are especially abundant in soils having a vigorous growth of blue-green alga. Azotobacter are often absent from virgin soils, but are always found in such soils when there is a rigorous growth of algae. Bottomley claims that both Azotobacter and Pseudomonas live in true symbiosis with cycas. It, therefore, appears certain that the nitrogen-fixing powers of Azotobacter are greatly enhanced when growing with algæe, but the exact rôle played by each is yet to be explained. 'This offers a rich and inviting field for research.

Nor is it alone in combination with algæ that these organisms 
may grow and thus be benefited. Beijerinck and van Delden early recognized that an apparent symbiosis exists between Azotobacter and other bacteria, and that the nitrogen fixed is considerably greater in the mixed than in the pure cultures. This symbiosis, though in many cases beneficial to Azotobacter, is not essential for nitrogen-fixation. Radiobacter, with which the Arotobacter are usually associated, have only slight nitrogen-fixing powers, yet they increase the nitrogen-fixing powers of Azotobacter. The carbohydrates disappear more rapidly from mixed than from pure cultures and with a greater fixation per gram of carbohydrate utilized. There is also a greater fixation when two strains of Azotobacter are grown in conjunction with each other. This is especially marked in an aqueous solution of mannite. Results have been reported where Azotobacter fixed twice as much in the presence of Pseudomonas as when grown alone.

The manner in which this mutual benefit is exerted is not clear. In some cases it may be due to the associated organism rendering more available the carbonaceous material.

Omelianski and Salunskov offer the following explanation concerning the association of aërobic and anaërobic nitrogen-fixers:

"The synergetic activity of nitrogen-fixing and accompanying microbes, is both in laboratory experiments and under natural conditions (cultivable stratum of the soil) of a different character according to the properties of the species taking part in the process and their environment; in both cases the function of the satellite organism seems to consist in fixing the oxygen of the air and creating the anaërobic environment for C'lostridium pasteurianum. The species added to the cultures of nitrogen-fixing microbes sometimes supply the compounds of carbon needed for the process of fixing nitrogen as energetic substance. In the case of the combination: Azotobacter and Clostridium pasteurianum, the function of the former is not confined to fixing the oxygen of the air only, and consequently to creating an anaërobic environment for the Clostridium. But this combination is also useful inasmuch as it destroys the injurious products of disassimilation created by the second (chiefly butyric acid) and maintains the action of the environment. (Azotobacter is alkaligenic and the Clostridium acidogenic.)

"'The satellite species may also unfavorably affect the nitrogenfixing microbe, either through products of assimilation or by consumption of the carbon compounds needed by this microbe for nitrogen-fixing. The energetic fixation of oxygen by the satellite aërobic species creates conditions favorable to the development of Clostridium pasteurianum, but at the same time hinders the growth of the Azotobacter, which is necessarily aërobic.

"The form endowed with the maximum vitality and at the same time the most common form in which combination of the nitrogen- 
fixing organisms takes place in the upper soil strata is that of symbiosis between the aërobic and anaërobic nitrogen fixers, principally betreen $A$ sotobacter and Clostridium pasteurianum. In spite of the opposite properties of the two species, their synergetic activity in the upper strata of the soil results in a harmonious mutual development producing the maximum economy in consumption of energetic substances."

So far, little has been done to determine the relationship of Azotobacter to the higher plants, but it is interesting to note that Beijerinck has observed a distinct relationship between the distribution of the organism and leguminous plants. Fischer suggests that some nitrogen-fixing bacteria presumably exist first as saprophytes, then as exoparasites in loose combination with green plants, then as endoparasites. Finally they develop the true symbiosis or root nodule bacilli. Hopkins has questioned whether there may not be a relationship between the legume bacteria and Azotobacter.

The Influence of Water.-Azotobacter are very resistant to drying; they may be dried for a considerable time in a desiccator over sulphuric acid. Pure cultures are just as resistant to drying as are mixed cultures. This would vary some with the media in which the bacteria are dried, for the survival of non-sporebearing bacteria in air-dry soil is due, in part, to the retention by the soil of moisture in the hygroscopic form. This, however, is not the only factor, for the longevity of bacteria in a solid is not directly proportional to its grain size and hygroscopic moisture. Giltner and Langworth found that bacteria resisted desiccation longer in a rich clay loam than in sand. Furthermore, if bacteria are suspended in the extract from a rich clay loam before being subjected to desiccation in sand, they live longer than if subjected to dessiccation after suspension in a physiological salt solution. Because of this, they consider that soils contain substances which have a protective influence upon bacteria, subject to desiccation.

Lipman and Burgess have found that many soils manifest a vigorous nitrogen-fixing power even after being air-dried and kept in stoppered museum bottles for periods varying from five to twenty years. In some cases the fixation was equally as high as in freshlycollected samples. The organisms from such soils are more easily attenuated than are other organisms which have not been so dried. The tendency is for soils gradually to decline in nitrogen-fixing power or drying. This may manifest itself as early as the second week.

During the periods of drying, the organisms are inactive, as they require moisture for growth and reproduction. For maximum nitrogen-fixation a definite moisture content is needed. Warmbold found the optimum moisture content to be 20 per cent. When it was below 10 per cent. there was no nitrogen fixed, and in some cases there was a decided loss of nitrogen. Krainsky allowed soil with 
rarying moisture content to stand for some time and then inoculated it into mannite solutions and obtained maximum fixation in the soils containing fairly small quantities of water. Later, however, he decided that soil should be damp-but not wet-and well aërated for maximum nitrogen-fixation. The water requirements vary with different soils. As a general rule, the higher the humus content of the soil, the more water will be required for optimum nitrogenfixation. The quantity of water present may, however, become so great that it may kill all Azotobacter in addition to stopping nitrogenfixation.

An insufficient supply of moisture checks both nitrification and nitrogen-fixation. This occurs in some soils when the water content has been reduced to 16.5 per cent. This again varies with the soil, for Schlösing found bacterial activity less in fine-grained soils than in lighter, coarse-grained soils. A difference in moisture content of 1 per cent. according to I) afert and Bollinger, is sufficient to produce a marked change in the oxidation going on in the soil.

The moisture requirement of the nitrogen-fixing bacteria, according to Lipman and Sharp, is more nearly that of the ammonifying than of nitrifying organisms. In a sandy loam it was found to vary between 20 and 24 per cent. the anaërobic nitrogen-fixers are most active, but the action of the aërobes is slightly depressed. Thus, in many soils two maxima of nitrogen-fixation occur, depending upon whether the conditions are favorable for the anaërobic or aërobic organisms.

Traaen's results differ from Lipman's in showing only the one maximum, as is seen from the following, which gives the milligrams of nitrogen fixed in $100 \mathrm{gm}$. of soil.

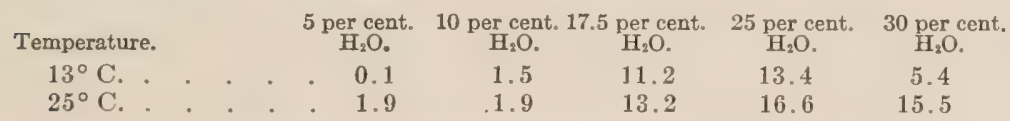

He used a loam soil with a maximum water capacity of 27.4 per cent. It is quite evident from his statement that anaërobic organisms played a prominent part in the fixation at the higher moisture contents.

Since the carbohydrates disappeared much more rapidly in the soils containing the greater quantities of water, it is quite possible that greater quantities of nitrogen per gram of carbohydrate consumed are fixed where the smaller quantities of water are applied. This, together with the different methods used by the several investigators, would explain the apparent discrepancy in their results.

In a series of pot experiments in which a calcareous loam receiving various amounts of water was used, the author found the moisture content for maximum nitrogen-fixation to lie between 15 and 22 per cent. These results also bring out the two maxima which were first 
noted by Lipman. These soils were kept at the various moisture contents for four months. All were then incubated at $25^{\circ} \mathrm{C}$. for twenty-one days with a moisture content of 20 per cent.

\section{Treatment. \\ Per cent.}

12.5

15.0

17.5

20.5

22.5
Nitrogen fixed. Per cent.

100

108

102

104

108

In this soil the optimum for the aërobes would appear to be at 17.5 per cent. and that for the anaërobes 22.5 per cent. or higher.

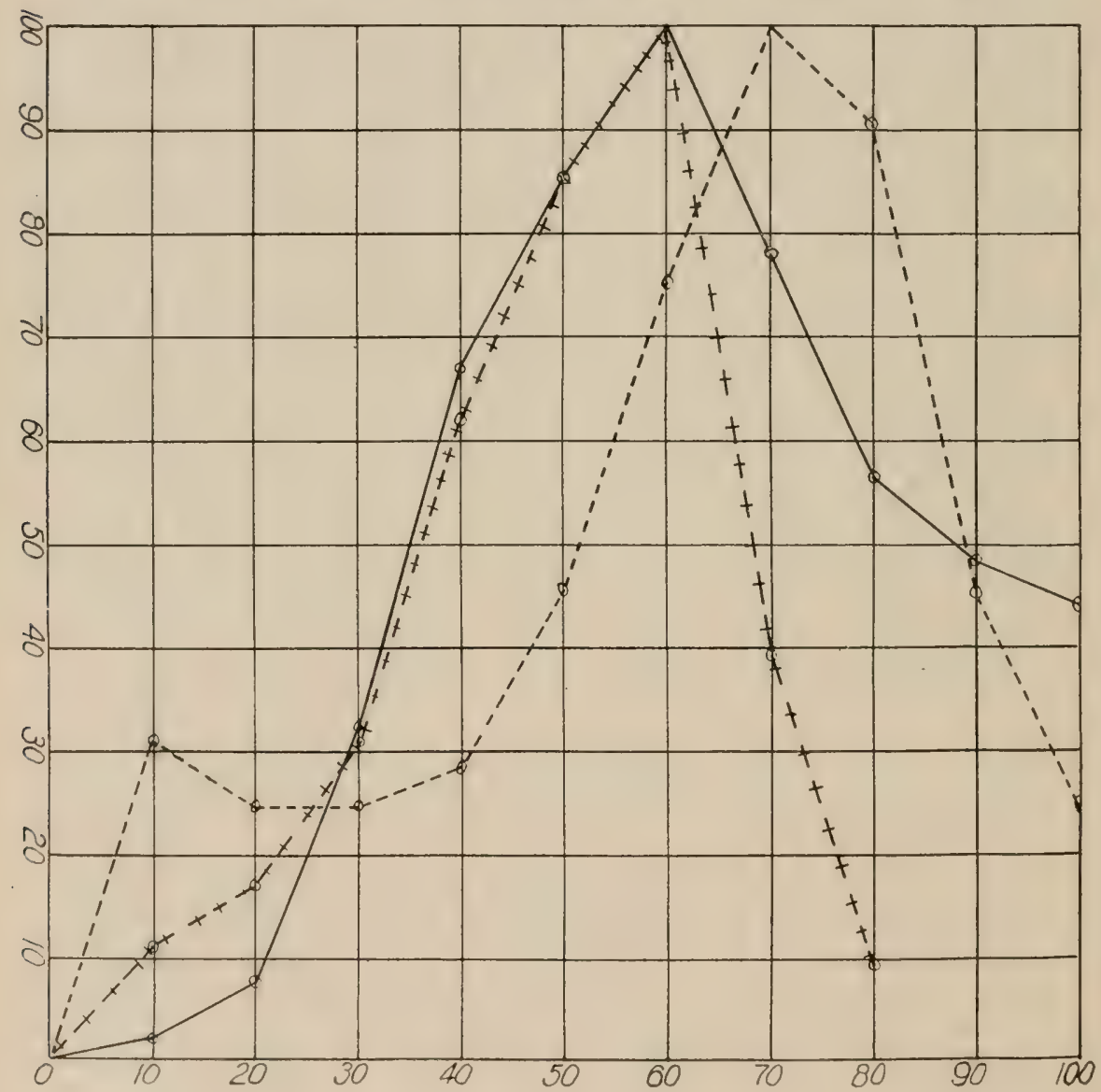

FIG. 34.-Average percentages of ammonia - and nitric nitrogen ++++ formed and nitrogen fixed - - - in soil receiving varying quantities of water. On the ordinate is given the per cent. increase of the respective substances and on the ahscissa the quantity of water applied as per cent. of water-holding capacity. 
When too large a quantity of water is applied there is a tendency to depress the total nitrogen fixed, as is illustrated by the following results in which rarious quantities of water were applied to a soil throughout the year under field conditions:

$$
\begin{gathered}
\text { Inches of } \\
\text { water applied } \\
\text { during summer. }
\end{gathered}
$$

\section{5}

25.0

15.0

None
Nitrogen fixed in 100 grams soil. mgm.

1.4

2.1

8.5

3.5

The maximum for anaërobic conditions does not appear in these results probably because the soil did not become filled with water and because under field conditions the water rapidly drains away or is evaporated. There would seem to be a correlation between the water content of a soil as measured in terms of its water-holding capacity irrespective of physical composition and its nitrogen-fixing powers. This is brought out in Fig. 34 in which water requirements for ammonification, nitrification, and nitrogen-fixation are compared.

Temperature.-Berthelot early recognized that the biological gain of nitrogen in soils is dependent upon a suitable temperature. He found nitrogen-fixation to occur best at summer temperatures between $50^{\circ}$ and $104 \mathrm{~F}^{\circ}$. The process was immediately stopped on heating to $230^{\circ} \mathrm{F}$. Later Thiele maintained that although Azotobacter possess the ability to fix small quantities of nitrogen under laboratory conditions, the temperature would be unfarorable under field conditions. Heinze, however, found that although the nitrogen-assimilating organisms are most active at a temperature between $20^{\circ} \mathrm{C}$. and $30^{\circ} \mathrm{C}$, they nevertheless fix appreciable quantities at temperatures as low as $S$ to $10^{\circ} \mathrm{C}$. Still more recent work has shown the optimum temperature to be $25^{\circ} \mathrm{C}$. and the limits of activity of Azotobacter chroöcoccum to lie between $9^{\circ} \mathrm{C}$. and $33^{\circ} \mathrm{C}$. 'The actual quantitative variation in nitrogen fixed is seen from the results reported by Löhnis. He inoculated 100 c.c. of a 1 per cent. mamnite soil extract with $10 \mathrm{gm}$. of soil and obtained the following fixation at the various temperatures:

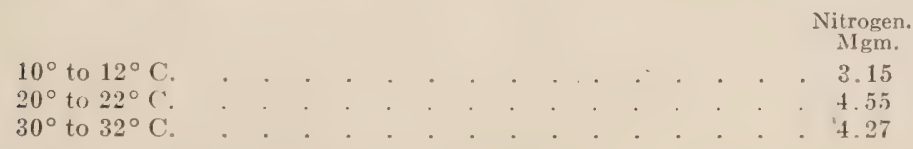

Better fixation at a lower temperature is noted when the soil is incubated and the gain in nitrogen determined directly. Koch obtained fixations of $3 \mathrm{mgm} ., 11 \mathrm{mgm}$., and $15.5 \mathrm{mgm}$. of nitrogen in $100 \mathrm{gm}$. of soil when incubated with a carbohydrate at $7^{\circ} \mathrm{C}$, 
$15^{\circ} \mathrm{C}$., and $24^{\circ} \mathrm{C}$., respectively. Traaen, using a loam soil with a maximum water-holding capacity of 27.4 per cent., obtained nearly as great a fixation at $13^{\circ} \mathrm{C}$. as at $25^{\circ} \mathrm{C}$. when the optimum moisture content was maintained. This is seen from the following:

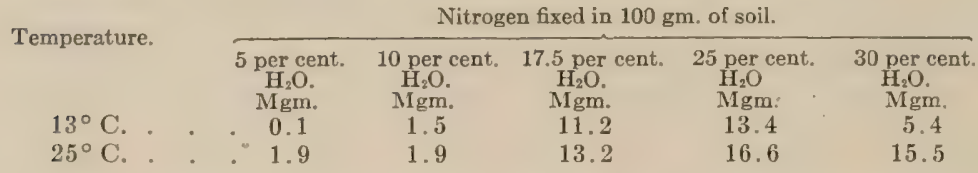

A temperature, favorable even though not ideal for nitrogenfixation, would occur in soils under natural conditions. 'The temperature of soil in Utah during the months if September averaged $14^{\circ} \mathrm{C}$, with a minimum of $10^{\circ} \mathrm{C}$. and a maximum of $17^{\circ} \mathrm{C}$. During June, July and August the mean temperatures would be much higher.

The mean daily temperatures of the soil for Bismarck, North Dakota; Key West, Florida; and New Brunswick, New Jersey; for the months of June, July, August and September were $18^{\circ} \mathrm{C} ., 28^{\circ} \mathrm{C}$., and $24.5^{\circ} \mathrm{C}$., respectively. From this it is evident that during a considerable period of each year an arable soil has a temperature high enough for moderately rapid nitrogen-fixation.

Although it is generally maintained that there is no nitrogenfixation in soils during the winter months, cold or even freezing does not injure the organism; for the cooling of a soil, even to the freezing point, increases its nitrogen-fixing powers. This is probably due to the suppression of competing species and to the establishment of a new flora. The same is true when the soil is heated, as may be seen from the results given below.

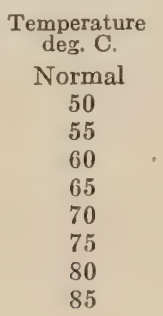

Nitrogen fixed,
per cent.
5.11
9.00
14.14
16.38
14.42
13.02
11.34
12.66
10.36

This soil had been autoclaved and then inoculated with a soil extract which had been heated to the temperature indicated. The stimulation could not, therefore, have been due to the heat rendering more of the plant-food in the soil available. The results indicate that many of the organisms which take part in nitrogen-fixation are highly resistant to heat. It is significant that the greatest stimulation is exerted in a soil which had been inoculated with solutions 
heated just above the temperature which Cunningham and Löhnis found to be the thermal death-point of soil protozoa.

Light and other Rays. - As a class, bacteria are sensitive to light, but the extent to which they can withstand it varies, among other things, with the conditions of exposure and the specific organism. Unfortunately, we have but fragmentary information concerning the effect of light upon azofiers, but what we do know would lead us to believe they are more resistant than many microörganisms-probably more so than many other soil bacteria. Berthelot recognized that nitrogen-fixation in the soil occurred both in daylight and in darkness, though more freely in the light. Jones found many Azotobacter to be alive in a small Petri dish of dried soil that had stood in the laboratory in front of a south window for two years. They can withstand the direct action of the violet and of the longer ultraviolet rays for five minutes, but are killed in much less time by the shorter ultraviolet rays. They are more resistant eren to these than are many other species.

The fixation of elementary nitrogen by A. chroöcoccum is distinctly increased when the air is activated by pitchblende. Somewhat better results are obtained with weak than with stronger radioactive intensity.

Aëration. - Under field conditions there is a mixed flora consisting of the anaërobic and aërobic nitrogen-fixing microörganisms. A soil condition which would be ideal for one species might be unfavorable for the other. It has already been pointed out that there are two maxima of nitrogen-fixation in soils, depending upon the moisture content. This is illustrated in Figure 32.

Although it is usually conceded that nitrogen-fixation is most rapid when soils are well aërated, this may not always be the case. Concerning this Murray reports the following results:

Kind of soil.

Nitrogen fixed

$\begin{array}{cc}\begin{array}{c}\text { Aërobic } \\ \text { conditions. } \\ \text { mgm. }\end{array} & \begin{array}{c}\text { Anaërobic } \\ \text { condition. } \\ \text { mgm. }\end{array} \\ 0.84 & 8.50 \\ 3.08 & 5.29 \\ 0.84 & 4.69\end{array}$

This condition must be attributed to a great difference in the physiological efficiency of the two groups found in these particular soils and not to a lack of aërobic nitrogen-fixing organisms, for more than ten times the number of organisms developed on nitrogenpoor media from these soils under aërobic as under anaërobic conditions.

Season.-Berthelot was unable to show any gain in nitrogen of his soils during the winter, but Koch found a considerable increase during this season in soils which were kept in a heap and shovelled 
over from time to time. Löhnis observed that Azotobacter membranes are more readily obtained in winter than in summer. $\mathrm{He}$ later found that the nitrogen-fixing power of soil varies from month to month throughout the rear, there being two maxima-one in spring and another in autumn. The extent of the rariation noted may be seen from the following:

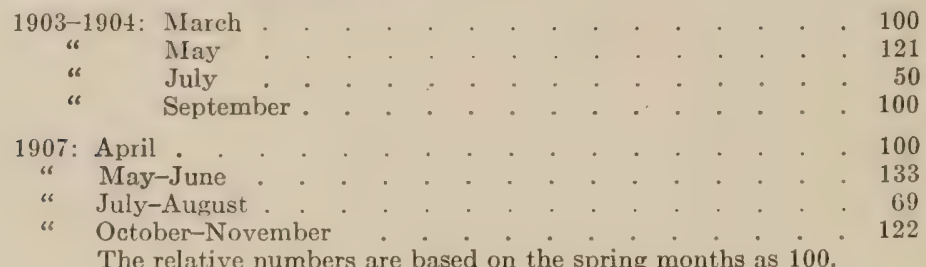

Green found nitrogen-fixation in 1 per cent. mannite solution to be low during August, September and April. In other months he noted a fairly constant fixation of about $10 \mathrm{mgm}$. of nitrogen per gram of mannite. He also noted a marked yearly variation in the nitrogen fixed during July and August.

Walton found nitrogen-fixation lowest in Indian soil between October and January and highest between June and September. This corresponds with moisture and temperature changes. Peterson has found that although the nitrogen-fixation of Utah soils is highest from June to September, the number of types of Azotobacter occurring in the soil was greatest in May. Moll goes so far as to maintain from his work that the season of the year is the principal factor in determining the biochemical transformation in soils. This would appear to be especially true as regards nitrogen-fixation.

Crop.-Heinze called attention to the fact that the fallowing of the soil increased its nitrogen-fixing power. This could be due to better aëration, moisture, temperature, etc., and not to any depressing influence exerted directly by the plant. Most experiments which deal with plant and bacterial activity could be interpreted in this light. Hiltner maintained that the free nitrogen-fixing bacteria are stimulated in their activities by the growing plant roots. There may be considerable truth in this, for here the higher plants are rapidly removing from the solution the soluble nitrogen compounds. In this case, the nitrogen-fixing organisms would be forced either to compete with the higher plant for the soil nitrogen or else to make use of their ability to live upon the atmospheric nitrogen. It is certain that different cultural methods vary sufficiently with crops to influence profoundly a soil's nitrogen-assimilating properties, for the Azotobacter occur more widely distributed in cultivated than in virgin soil. The analyses of hundreds of samples of cultivated and virgin soils in Itah have in nearly every case shown the virgin soil to have a low nitrogen-fixing power as compared with the culti- 
rated soil. This was the case even where the soil was incubated without carbohydrates and the nitrogen determined directly. 'The average results for many determinations were as follows:

\author{
Virgin soil . \\ Cultivated . \\ Wheat \\ Alfalfa \\ Fallow
}

Mgm. of
aitrogen fluid.
6.99
14.28
11.83
12.24
22.81

The fallow soil had received considerable manure, hence these results are undoubtedly high. It would, however, be possible to fallow or crop soils so continuously that extremely small quantities of plant residues would be returned to the soil, under which conditions there might be a decrease in nitrogen-fixation. The conditions of moisture and aëration are much more nearly ideal in a fallow soil than in a cropped soil. It is just possible that the high fixation noted where wheat is grown continuously may be due to the method in rogue in the arid districts of leaving the greater part of the straw on the soil. This mould act as readily assimilable carbonaceous material for the Izotobacter. Welbel and Winkler have found that fallowing not only increases the assimilable nitrogen but also the available phosphorus of the soil, a liberal supply of which causes the Azstobacter to utilize its energy more economically. That the increased nitrogen-fixation noted when soils are cultivated is not confined to the arid soil, is seen from the recent work of Reed and Williams. Brown's work indicates that crop rotation increases the nitrogen-fixing powers of a soil.

Climate. - It has been maintained for a long time that there is a close correlation between the chemical, physical, and biological transformations going on in a soil and the climatic conditions, but there was nothing definite on this subject until the highly interesting work of Lipman and Waynick appeared. They found a definite relationship between climate and the nitrogen-fixing powers of a soil. Remoral of California soil to Kansas increased the vigor of the Azotobacter flora and especially that of -1. chroöcoccum. It increased the nitrogen-fixation by 50 per cent. over that attained by the same soil in (alifornia. Similar results were obtained in California soils removed from Maryland. Kansas soil taken to ('alifornia lost its yower to produce a membrane in mannite solution, the Azotobacter flora became rather feeble, and the nitrogen-fixing powers of the soil were greatly reduced. The removal of the Kansas soil to Maryland increased the vigor of the Azotobacter and induced a higher fixation of nitrogen. The Maryland soil in California diminishes in nitrogenfixing powers, but not in so great a degree as does the Kansas soil. This also happened when the Maryland soil was taken to Kinsas. 
The bacterial flora of a soil, therefore, is dependent upon climatic conditions which affect many of the other properties of a soil.

Relationship of Azotobacter to Nitrate Accumulations.-The fact that certain spots in western cultivated soils were very rich in nitrates was first observed by Hilgard This he attributed to the rapid nitrification of the organic matter of the soil in the warm arid climate of the IVest when athe moisture limit was removed by irrigation.

A number of years later Headden noted these "nitre spots" in a number of Colorado soils, but he attributed it to the fixation of atmospheric nitrogen by the non-symbiotic bacteria which find in the western soils ideal conditions for growth and rapid nitrogen fixation. This conception has been further amplified by Headden and also Sackett. In the early work by Headden it is assumed that the Azotobacter not only fix the nitrogen but also produce the nitrates. It is known, howerer, that these organisms do not produce nitrates.

Moreover, there are a number of other vital objections to this theory. (1) Lipman has shown that for the fixation of the quantity of nitrogen which Headden maintains to have occurred, it would require from 1000 to 2000 tons of carbohydrates. There is no such visible supply of energy in these soils. True, many of these soils have a rich algæ flora, but it has not been proved that this will furnish a sufficient supply of available energy. (2) The average amount of nitrogen fixed in thirty-two samples collected in the nitrate region was $7.4 \mathrm{mgms}$. and the average nitrogen fixed in thirty-one samples of dry-farm alkali-free soil in Utah was 12.2 mgms. Yet there is no accumulation of nitrates in these latter soils. (3) The quantity of soluble salts occurring is often sufficient to stop the activity of all nitrogen-fixing organisms, if not to kill them. (4) The quantity of nitric nitrogen and of chlorin in any given "nitre spot" varies in the same spot from year to year or from period to period within a year. (5) The country rock adjacent to the nitrate accumulations and which has contributed to the soil formation contains abundance of nitrates to account for the accumulations noted. (6) Soils having a similar physical appearance may be produced in the laboratory in the absence of bacteria. Because of this, we must conclude that the accumulation of nitrates in spots in western soils have their origin as do other accumulations of soluble salts found in the soil and not in the fixation in place by bacterial activity.

Soil Inoculation.- High hope was entertained that the nitrogen problem in agriculture had been solved, when Caron announced that he had prepared a culture of bacteria which would enable nonleguminous plants to utilize free atmospheric nitrogen, provided certain precautions were observed. Many of the results which he 
reported on pot experiments were clearly in favor of the inoculated plant. Stoklasa was one of the first to study in detail the commercial preparation "alinit" which was placed on the market as a result of Caron's work. His findings were fully as favorable as Caron's, but the work of others soon demonstrated that "alinit" neither in the laboratory nor in the field had the ability to fix nitrogen. When Beijerinck discovered the free-living aërobic nitrogen-fixers, the hope that soil inoculation may be so perfected that it would be beneficial to crops was revived, and since that time many investigators have attempted to inoculate soil in order to increase its crop-producing powers, but usually with negative results. Stoklasa has made great claims for soil inoculation. He found that soils, inoculated with Azotobacter chroöcoccum and adequately supplied with carbohydrates and lime, showed an increase in the number of nitrogenfixing organisms, and also an increased yield both in quantity and quality of the crop. Stranak also obtained a pronounced increase in the production of beets, grain, and potatoes on inoculating with Azotobacter.

There may be a decrease in the crop during the first year when carbohydrates and Azotobacter are added to the soil with a marked increase in crop during the second and third year. Even then, the soil may be left richer in nitrogen than it was at first.

The effect of dextrose and sucrose on the productiveness and nitrogen content of the soil is shown below:

\begin{tabular}{|c|c|c|c|c|c|c|c|}
\hline \multirow{3}{*}{$\begin{array}{l}\text { Carbohydrate added per } \\
100 \text { gms. of soil. }\end{array}$} & \multicolumn{4}{|c|}{ Crops obtained. } & \multirow{3}{*}{$\begin{array}{c}\text { Total } \\
\text { nitrogen } \\
\text { remained } \\
\text { in crop, } \\
\text { gm. }\end{array}$} & \multirow{3}{*}{$\begin{array}{l}\text { Total } \\
\text { nitrogen } \\
\text { left in } \\
\text { soil } \\
\text { spring of } \\
1906, \\
\text { per cent. }\end{array}$} & \multirow{3}{*}{$\begin{array}{c}\text { Nitrogen } \\
\text { as } \\
\text { nitrates, } \\
\text { pts. per } \\
\text { mil. }\end{array}$} \\
\hline & \multicolumn{2}{|c|}{ Oats, 1905.} & \multicolumn{2}{|c|}{ Sugar beets, 1906.} & & & \\
\hline & $\begin{array}{c}\text { Dry } \\
\text { matter. }\end{array}$ & $\begin{array}{l}\text { Yield of } \\
\text { nitrogen. }\end{array}$ & $\mid \begin{array}{c}\text { Dry } \\
\text { matter. }\end{array}$ & $\begin{array}{c}\text { Yield of } \\
\text { nitrogen. }\end{array}$ & & & \\
\hline None . . . . & 100.0 & 100.0 & 100.0 & 100.0 & 0.9514 & 0.093 & 10 \\
\hline 2 per cent. dextrose. & 32.8 & 62.5 & 186.0 & 190.0 & 0.6814 & 0.105 & 17 \\
\hline 2 per cent. sucrose & 33.3 & 58.7 & 179.0 & 195.0 & 0.6800 & 0.105 & 15 \\
\hline 4 per cent. sucrose & 37.7 & 78.1 & 283.0 & 339.0 & 1.0092 & 0.119 & 37 \\
\hline
\end{tabular}

It is often the case that the addition of starch to a soil during the first year retards plant growth. This injurious action may be due to the augmented bacterial activity in the soil brought about by the carbohydrates which injure the roots of the plant by withdrawing oxygen and by forming hydrogen sulphid in the deoxygenated atmosphere of the soil through the reduction of sulphates by the bacteria.

The effect produced by the carbohydrate applications also varies with the season. If applied to the soil in the spring when the soil temperature is low and when other bacteria are more active than 
Azotobacter, the results are that they rapidly multiply and compete with the higher plants for the limited available plant-food. If, however, the carbohydrates are applied in the autumn directly. after the removal of the crop, when the soil is warm, Azotobacter are active, with the result that sufficient nitrogen is fixed to produce an increased crop the following season.

If the same quantity of carbohydrates per unit of nitrogen fixed be required by the organism under natural conditions, as are found necessary in laboratory experiments, enormous quantities would be required for the fixation of any considerable quantity of nitrogen; but it is possible that in the soil they are more economical with their energy or they may live in symbiosis with other organisms which furnish them part of their carbon.

Many workers have noted either no effect or even a detrimental influence when soils are treated with the carbohydrates and then inoculated with Azotobacter. 'This may be due in a great measure to any or all of the following factors: (a) Absence of a suitable environment, as temperature, moisture, aëration, food and alkalinity; (b) absence of a suitable host from which Azotobacter may obtain part of its carbon; $(c)$ injurious effects due to the decomposition products of the carbohydrate added.

There is considerable interest in the work of Bottomley who uses bacterized peat, or humogen. The bacterizing process consists of three stages: (a) Treatment of peat with a culture solution of the special "humating" bacteria and an incubation of it at constant temperature for a week or ten days, during which period soluble humates are formed; $(b)$ destruction of the humating bacteria by sterilization with live steam; (c) treatment of this sterilized peat with mixed cultures of nitrogen-fixing organisms-Azotobacter chroöcoccum and Bacillus radicicola-and an incubation at $20^{\circ} \mathrm{C}$. for a few days, after which it is ready for use.

Theoretically, there is much in this process which recommends it, for there is no abrupt change in environmental conditions for the organism added, as would be the case when added from laboratory culture. Moreover, they are added in enormous quantities and with a source of carbon which is not far different from that found in the soil. Russell, however, after carefully reviewing all of the experimental evidence on the subject, concludes: "There is no evidence that humogen possesses any special agricultural value. 'There is not the least indication that it is fifty times as effective as farmyard manure, to quote an often repeated statement, and there is nothing to show that it is any better than any other organic manure with the same nitrogen content." Furthermore, he concludes that there is no definite evidence that "bacterization" really" adds to the value of peat.

The conclusion is evident that soil inoculation, in order to be 
successful, must be accompanied by the rendering of the physical and chemical properties of the soil ideal for the growth of the specific organisms to be added. A few organisms placed in a new environment already containing millions can never hope to gain the ascendency over the organisms naturally occurring in the soil, for they have been struggling for countless generations to adapt themselves to the environment and only those which are fitted have survived. The problem becomes even more complicated when we recall the findings of Lipman that the bacterial flora of a soil is in many cases entirely changed by climatic conditions. On this account, it would appear that erer to make soil inoculation a success the chemical, phrsical, and even the biological condition must be made suitable for the growth of the specific organism added. Furthermore, strains of the organism must be used which have been evolved under similar climatic conditions.

soil Gains in Nitrogen. - It is well established that many forms of microscopic organisms possess the power of fixing nitrogen either when grown alone or in combination with other organisms of the soil. Many of these have been obtained in pure culture and their morphology and physiology carefully studied. 'The most farorable conditions for their maximum nitrogen-fixation in pure cultures in liquid solutions have been accurately determined. Some of the conditions requisite for their activity in soils are known, but on this phase of the subject there are many gaps in our knowledge and much work must yet be done before we can state definitely the part which they play in the economy of nature and before we can say which are the very best methods for increasing their usefulness. Nevertheless, it is interesting to consider the results obtained by a few workers.

Berthelot's early laboratory experiments led him to believe that sands and clays may fix in a year from 75 to 100 pounds of nitrogen to the acre. In two exceptional instances he noted that nitrogen was fixed by sands at the rate of 5:5 pounds and 980 pounds an acre, but soils which contained fairly large quantities of nitrogen never made markedly rapid gains.

Thiele, on the other hand, maintained that while there is no doubt that Azotobacter possessed the power of fixing free nitrogen, under laboratory conditions, yet it is not certain that conditions would be such in soils for any gain of nitrogen due to the activity of these organisms. We have already seen, however, that the izotobacter do not require as high a temperature for nitrogen-fixation in soil as he thought necessary. It is also certain that in most arable soil the temperature is sufficient during a large part of the year for a fairly rapid nitrogen-fixation by bacteria.

Krainsky thinks that even better results should be obtained in soils than in pure culture, for there the nitrogen-fixers grow in symbiosis with autotrophic organisms which make organic compounds 
available to the Azotobacter. In soils the nitrogen fixed is rapidly removed by other plants, because of which the slowing-up process that becomes perceptible so early in laboratory experiments should not occur.

In addition to an optimum temperature and moisture content of the soil, the Azotobacter are dependent upon a supply of carbon jior energy and inorganic nutrients for the building of cell protoplasm. Unfortunately, it is too of ten the case that under natural conditions those soils which are deficient in nitrogen are also lacking in availa ble carbon, and especially in phosphorus, which are so essential for rapid nitrogen-fixation. Then there are the technical difficulties which the chemist encounters in determining the gain or loss of nitrogen which occurs in soils under natural conditions and which may be attributed to non-symbiotic nitrogen-fixation.

There are, however, several cases in which the gain has been measured with a fair degree of accuracy.

Lipman, in pot experiments carried on with a soil containing about 5000 pounds of nitrogen per acre-foot of soil, found a gain of more than one-third this amount in two short seasons. Much of this must be attributed to non-symbiotic nitrogen-fixation. To these soils had been applied solid and liquid manure, which furnished to the organisms readily-available supplies of energy and vacious necessary inorganic constituents. This fixation was not near:y so rapid where legumes were turned under as green manures.

Koch found a gain of from 0.019 to 0.093 per cent. in soil nitrogen during two seasons which must be attributed to non-symbiotic nitrogen-fixation. In addition to this there was a threefold gain in the nitrogen content of the crops - oats, buckwheat, and sugar-beets - which must also be attributed to the action of Azotobacter.

Hall noted an annual gain of 100 pounds of nitrogen on Broadbalk field at Rothamsted and 25 pounds on Grescroft field. He feels that much of this gain must be due to the action of non-symbiotic bacteria. Lipman points out that the actual gains of nitrogen are even greater, for this does not take into consideration the various losses which are sure to occur even under the best of conditions. Hopkins takes the stand that the apparent gain is due in a large measure to drifting dust and plant residues coupled with the difficulty of obtaining representative samples of soil at the two different periods. Even when all of these factors are considered the evidence points to a gain of nitrogen through bacterial activity.

The analysis of a great number of soils in Utah showed that the average nitrogen content of the soil which had grown wheat and other non-leguminous plants for from twenty to fifty years was 0.2009 per cent., whereas adjoining virgin soil on the arerage showed only 0.1984 per cent. of total nitrogen. The evidence is very strong that considerable nitrogen has been added to these soils by microscopic organisms, for: 
(a) In nearly every case the cultivated soil fixed much more nitrogen in the laboratory than did the virgin soil. 'This was the case when the soil was incubated with or without the addition of carbonaceous material.

(b) There is a richer nitrogen-fixing bacterial flora in the cultivated than in the virgin soil.

(c) The conditions of moisture, alkalinity and food constituents in the soil were ideal for rapid nitrogen-fixation, and the temperature of the soil was high enough during a considerable part of the year for the growth of Azotobacter.

(d) The cultivation of the soil would increase aëration and arailable phosphorus in the soil.

(e) The large quantity of plant residues would act as a supply of carbon which is readily rendered available by the soil's rich flora of cellulose ferments. If these soils had produced a wheat crop every alternate year and all of the nitrogen which had been added to the soil without loss from leaching or bacterial activity taken by the crop, it would have necessitated the addition of 25 pounds an acre rearly, which is evidently the very minimum which can be attributed in these soils to non-symbiotic nitrogen-fixation.

Eighty different samples of these soils were incubated in the laboratory for twenty-one days and the gains in nitrogen determined by comparing with sterile checks. The soils were incubated without the addition of anything except sterile distilled water. At the end of the period the arerage gain per acre for the cultivated soils was 202 pounds and that for the virgin soil was 92 .

True, fixation would not continue long at this rate, for when the nitrogen content of the soil passed berond a certain limit decay bacteria would increase rapidly, and in the struggle for existence ther are able, with the advantage at their disposal, to suppress the more slowly growing Azotobacter, which would gain the ascendency again only when the nitrogen of the soil became low.

Thus, there is an upper as well as a lower limit to the nitrogen content of the soil as far as bacterial activity is concemed, but by making the conditions for nitrogen-fixation as nearly ideal as possible we may maintain in a soil the upper and not the lower nitrogen content.

In conclusion, it may be stated that although the part played by Azotobacter in maintaining the nitrogen of the soil has not been definitely measured, it is nevertheless an important factor. Hall found it to be at least 25 pounds, Löhnis 35.7 pounds, and the author 25 pounds per acre annually. It is, therefore, conservative to state, as has Lipman, that these organisms, under favorable conditions, add from 15 to 40 pounds of available nitrogen to each acre of soil yearly.

Greaves, J. E.: Azofication, Soil Science, 1918, vi, 163-217. 


\section{CHAPTER XXIV.}

\section{SYMBIOTIC NITROGEN FIXATION.}

Frour the earliest day of agricultural practice it has been the experience of practical men that legumes under appropriate conditions render the soil more productive. It was the practice of the Roman farmers to plow under lupines in order to enrich their soil. This practice has persisted through all the succeeding ages by the farmers of Europe and Asia. But it is only within the memory of men now living that we have been able to state the cause of the increased fertility.

Early Theories. - Liebig, by applying the exact methods of chemistry to agriculture, was able to demonstrate that plants get their carbon from the carbon dioxid of the air and not from the carbon compounds of the soil. He came to regard the ammonia of the air as analogous to the carbon dioxid and taught the doctrine that the plants are able to derive their nitrogenous food from the atmosphere. He wrote: "If the soil be suitable, if it contains a sufficient quantity of alkalies, phosphates, and sulphates, nothing will be wanting. The plants will derive their ammonia from the atmosphere as they do carbonic acid." Liebig considered all crops capable of securing the nitrogen from the air, but the legumes and other broad-leafed plants were especially fitted for this task, as is witnessed by the fact that they benefit the succeeding cereal crops and do not respond as readily to nitrogenous fertilizers.

It was soon proved that the ammonia and other nitrogen compounds of the air which were brought down by snow and rain were very small and would account for only a small fraction of the nitrogen removed by the crops.

Lawes and Gilbert (1855) reached the conclusion that nonleguminous plants require a supply of some nitrogenous compound, nitrates and ammonium salts being about equally effective. The amount of ammonia obtainable from the atmosphere is insufficient for the need of crops. Leguminous plants behave abnormally.

They took the precaution of calcining the soil and removing all of the ammonia from the air before it was admitted to the vessel in which the plants were grown. Their results and those of Boussingault agree fully in pointing to the conclusion that free nitrogen of the air was not available to the plants. These conclusions were accepted as decisive for a number of years, although much evidence 
pointed in the other direction. Pot and field experiments carried out in England, France, Germany, and the Inited States during the early eighties furnished unmistakable evidence that the legumes possessed the power of utilizing atmospheric nitrogen. Atwater's experiments (1S83-84) fully demonstrated this. In some of his trials the nitrogen gained was 50 per cent. or more of the total quantity harvested. However, the mystery was not solved until 1886 when Hellriegel and Wilfarth announced that the fixation of free nitrogen is a property possessed by the legumes and is due to the bacteria associated with them in the root tubercles.

Early Observations on Root Tubercles.-The presence of tubercle on the roots of leguminous plants had long before been noted by Malpighi. He regarded them as root galls. Later they were regarded as buds of incomplete plants, or as rudimentary roots. In 1866 Woronin found in them numerous minute bodies which bore some resemblance to bacteria. "They were rod-shaped but often slightly forked to "T"- or "I"-shaped bodies. On account of this irregularity in shape the discoverer was unable to say whether they were true bacteria or not. He, therefore, called them bacteroids, and regarded them as the cause of the tubercles. In 1874 Erickson found that in the early stages of the development of the tubercle it was filled with long, branching threads resembling the mycelium of fungi, and to these hyph he attributed the formation of the tubercles. In later stages of the growth of the tubercles he found bacteroids, but was unable to determine whether they had any connection with the hyphæ or not.

Frank (1879) not only showed that tubercles are almost invariably present on the roots of legumes but that their formation may be prevented by the sterilization of the soil. He was thus in possession of facts which might have revealed to him the true nature of the root tubercles. However, he accepted the interpretation of his pupil, Brunchhorst, who claimed the bacteria-like bodies, were merely reserve food materials.

Marshall Ward not only proved that tubercle formation is due to outside infection but that such infection may be brought about by placing pieces of old tubercles in contact with the roots of growing leguminous plants.

Hellriegel found, as the result of a long series of experiments, that when pea plants were grown in sterilized soils as a rule no tubercles were formed, but when the plants were watered with soil infusions made by allowing water to act upon soil in which peas had been grown, the tubercles appeared in abundance. If the soil infusion was sterilized by boiling before it was put upon the plants no tubercles appeared. These experiments were thought to prove that the tubercles were really caused by living organisms in the soil infusion, which were killed by heat. The tubercles could not, therefore, be 
regarded as normal products of the roots, but were certainly infections from the soil. In a series of researches, undertaken with the assistance of Wilfarth these results were thoroughly confirmed. They showed that in sterilized soil the legume behaves the same as the non-legume and dies of nitrogen hunger if not supplied with suitable forms of nitrogen. When the sterilized soil was inoculated with fresh soil on which legumes had made a normal growth they then made a vigorous growth in sterilized soil. Under similar conditions non-legumes did not recover. The recovery of the starving legume was found to coincide with the formation of root tubercles.

Wigand (1SS7) found that the tubercles contained true bacteria and the following year these were obtained in pure cultures by Beijerinck. He found further that there were bacteria associated with all tubercles, and although the bacteria differed somewhat in the tubercles of different species of plants, still there were certain constant characteristics to be seen in them all. He, therefore, regarded the tubercles as the result of the action of bacteria and gave to the organism producing the tubercles the name of Bacillus radicicola. Beijerinck regarded the so-called bacteroids of Woronin as degenerate forms of the bacteria-involution forms, which appeared only after the bacteria had lost their vigor. In a later investigation, after isolating the bacteria and keeping them in pure cultures for many months, he was able to produce the tubercles at will by inoculating soils in which his plants were grown with the pure cultures of the organisms.

Prazmowski (1890) published researches which confirmed all of Hellriegel's results, showing conclusively that if sufficient precautions were taken to sterilize the soil in which leguminous plants were grown no tubercles were ever produced. He further showed that the tubercles grow on plants developing both in the light and in the dark, but are larger on plants growing in the light; that they only appear on healthy plants; that there are very few on plants growing in well-washed sand; that if plants growing in sterilized soil be watered with brook or river water, tubercles occasionally develop but never in abundance; and that the infection of the roots occurs early in the germination of the plant and cannot take place in the older roots.

'Two years later Schlösing and Laurent demonstrated the fixation of atmospheric nitrogen through the joint activities of leguminous plants and Pseudomonas radicicola by the actual diminution of the amount of elementary nitrogen in the inclosed atmosphere surrounding the plants.

Species.- Whether the different varieties of legume bacteria are distinct species is a perplexing question which today camot be definitely answered. It is known that certain legumes are readily. 
infected by one variety, whereas with another varicty--infection is accomplished with difficulty or not at all. MIoreover, the serological test rielded by different rarieties is specific. These facts have led some observers to consider the types as quite distinct, whereas others consider them as simply physiological varieties of the same general species. On the whole, the consensus of opinion at the present time seems to be decidedly in faror of this latter view.

some of Hellriegel's experiments indicated that bacteria from clover could not produce tubercles on lupines and serradella. Similar results were obtained by Nobbe and his associates, yet they were finally led to conclude that the root invasion of legumes is caused by a single species. Long-continued growth of the organism on a legume adapts it to that legume so it no longer invades the roots of other legumes. But Petermann (1893) considered it probable that every genus of plant has its specific bacteria. Buhlert considered that all of the organisms are forms of $B$. radicicola but that the bacteria best adapted to a given species of leguminous plant are those naturally found upon that plant. Howerer, cross inoculation is possible within certain limits. From the root tubercles of some leguminous plants he obtained bacteria which seemed to be very highly specialized, but he considers that this specialization does not extend to differences that may be regarded as specific.

As a result of a large number of experiments with different kinds of legumes, Maassen and Müller (1907) reached the conclusion that: (1) 'The organisms of Pisum satium will inoculate Vicia faba, I'. sativa, $F$. villosa, Lens esculenta, Lathyms satims, L. odoratus, and L. silvestris; (2) that of Trifolium incamatum will inoculate T. pratense; (3) that of Medicago sativa will inoculate $M$. Iupulina and Melitotus officinalis; and (4) that of Lupimus lutens will inoculate L. angustifolius and Ornithopus satimus. The organisms of Phaseolus vulgaris, Soja hispida, and Robinia pseudacacia, according to Maassen and Müller, will apparently not inoculate any other plant. Similar conclusions were reached regarding the organisms of C'oronilla varia, Onobrychis satava, Inthyllis vulneraria, Sar, thamnus scoparius, Amorpha fruticosa, Caragana frutescens, and Acacia lophanta.

De Rossi (1907) described a specific organism derived by him from root tubercles of $\Gamma$. faba which produces root tubercles and which he claimed is morphologically, biologically, and culturally widely' different from Bacillus radicicola Beijerinck.

Nobbe and coworkers (190S) showed that pure cultures of bacteria from tubercles of one member of a genus are effective on other member's of the same, and, as a rule, only of the same genus. 'They found, however, complete interchangeability in case of peas and vetches and partial in case of lupines and serradella.

Zipfel (1912), with the hope of throwing light upon the kinship among the rarious nodule bacteria, made use of the agglutination 


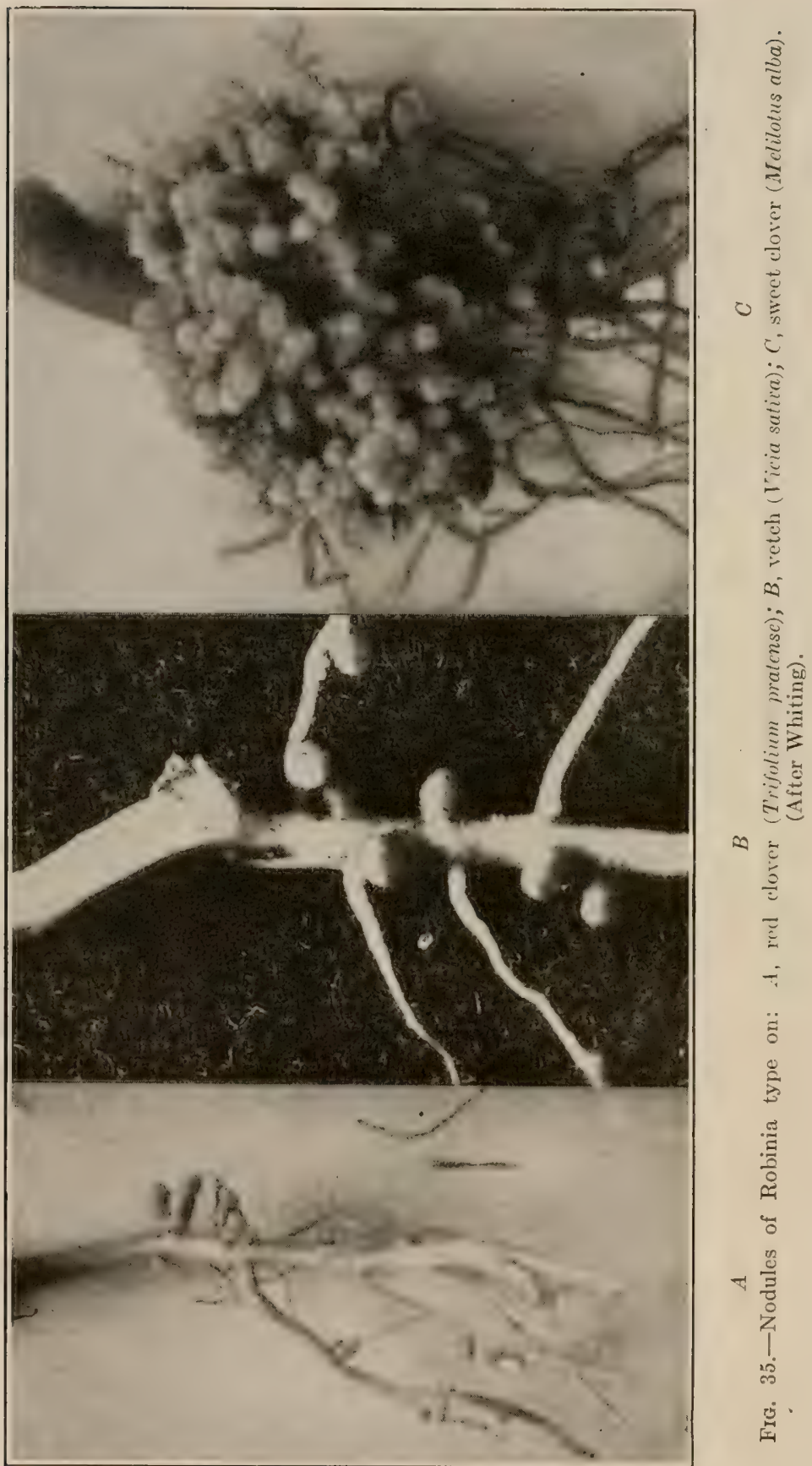


method. From his results he concluded that the nodule bacteria were not varieties of the same species, but that distinct species existed.

Klimmer and Krïger two years later used serological tests to distinguish species. They used the agglutination method principally and complement binding and precipitation for confirmation and control. Working with organisms from eighteen legume species, they divided the bacteria, according to their methods, into nine species which they asserted differed sharply from one another.

Simon (1914) tested various cultures upon seedlings of several legume species and compared the results with those obtained by using Zipfel's agglutination method. He found that the results of both methods agree substantially. His grouping of the organisms is in general agreement with that of Klimmer and Kruiger. He concluded, however, that "the root bacteria of legumes are rather to be conceived as more or less constant adaptations of the species Bacillus radicicola."

Burrill and Hansen (1917), after an extensive study of various legume bacteria both with the pot-culture method and the agar test-tube method of Garman, divided the nodule organisms into the following eleven groups according as they are interchangeable for the purpose of inoculation:

\section{Group I.}

Mammoth red clover, Trifolium pratense perenne.

Alsike, or Swedish clover, T'rifolium hybridum.

Crimson clover, Irifolium incarnatum.

Berseem, or Egrptian clover, Trifolinm alexandriamum.

White clover, Trifolium repens.

Zigzag, or cow clover, Trifolium medium.

\section{Group II.}

White sweet clover, Melilotus alba.

Yellow sweet clover, Melilotus officinalis.

IVild yellow sweet clover, Melilotus indica.

Alfalfa, Medicago sativa.

Alfalfa, Medicago falcata.

Bur clover, Medicago hispida.

Black medick, or yellow trefoil, Medicago lupatina.

Funugreek, Trigonella foenum-graecum.

Cowpea, Vigna sinensis.

Group III.

Partridge pea, Cassica chamaecrista.

Peanut, Archis hypogoea.

Japan clover, Lespedeza striata. 
Slender bush clover, Lespedeza virginica.

Velvet bean, Mucuna utilis.

Wild indigo, Baptisia tinctoria.

Tick trefoil, Desmodium canescens.

Tick trefoil, Desmodium illinoense.

Acacia, Acacia armata.

Acacia, Acacia floribunda.

Acacia, Acacia longifolia.

Acacia, Acacia melanoxylon.

Acacia, Acacia semperflora.

Acacia, Acacia from California.

Dyer's greenweed, Genista tinctoria.

\section{Group IV.}

Common garden pea, Pipsum sativum.

Field pea, or Canada field pea, Pisum sativum arvense.

Hairy vetch, Vicia villosa.

Spring vetch, Vicia sativa.

Broad bean, Vicia faba.

Narrow-leaved vetch, Vicia angustifolia.

Vetch, Vicia daysiecarpa.

Lentil, Lens esculenta.

Sweet pea, Lathyrus odoratus.

Perennial pea, Lathyrus latifolius.

Soybean, Glycine hispida.

\section{Group V.}

\section{Group VI.}

Garden bean, Phaseolus vulgaris.

Garden bean, Phaseolus angustifolia.

Scarlet runner bean, Phaseolus multiflorus.

\section{Group VII.}

Lupine, Lupinus perennis.

Serradella, Ornithopus sativus.

\section{Group VIII.}

Hog peanut, Amphicarpa monoica.

\section{Group IX.}

Lead plant, Amorpha canescens. 


\section{Group X.}

Trailing wild bean, Strophostyles helvola.

\section{Group XI.}

Black, or common locust, Robinia pseudo-acacia.

Hiltner and Stormer (1903), however, arranged the tubercle bacteria into two groups possessing, according to them, well-defined morphological and physiological differences. One of these groups is included under the species Rhiz bium radicicola and the other under Rhiz)bium beijerinckii. The former comprises the organisms from lupines, serradella, and soybeans, whereas the latter comprises all of the others.

Grieg-Smith $(1902)$ reports having found three races of the nodule bacteria in the same nodule, while Gino de Rossi (1907) reported the finding of two organisms which differ in that one forms a large hyaline colony not developing well on beef and peptone gelatin, while the other forms white non-transparent colonies on beef gelatin. He believes that the one is morphologically, biologically, and culturally widely different from Bacillus radicicola (Beijerinck).

Cultural Characteristics. - The nodule bacteria grow well on a great variety of cultural media, perhaps best on a medium of ash-maltoseagar or one of legume extract to which has been added a sugar, dextrose, sucrose, or maltose, and dipotassium phosphate.

In an agar stab typical drop-form colonies are produced at the surface, while a thin gray growth follows the line of the needle. In standard beef broth the growth of the organism is slow. 'The liquid becomes cloudy, a gray-white ring is formed, and a thin membrane covers the surface. Later a flocculent precipitate settles to the bottom of the tube. In standard beef broth gelatin the grow th of the organism is at first funnel-shaped and then stratiform. Gelatin is slowly liquefied, the process sometimes requiring two or three months for completion. In gelatin stabs the growth sometimes seals over the stab with a drop-form growth and liquefaction does not occur. On the ordinary cultural media the organisms do not show any very characteristic growth. The most noticeable difference between various strains is the rapidity of development. Slight alkalinity to +2()$^{\circ}$ to $+25^{\circ}$ acid (Fuller's scale) with phenolphthalein is tolerated; neutral to $+10^{\circ}$ is best.

The results obtained by Fred and Davenport clearly indicated that the nodule bacteria from different plants behave differently toward acid. They divided the legume bacteria into five groups depending upon their sensitiveness to acid.

1. Critical pH 4.9
2. Critical pH 4.7
3. Critical pH 4.2
4. Critical pH 3.3
5. Critical pr 3.15
Alfalfa and sweet clover.

Garden pea, field pea and vetch.

Red clover and common beans.

Soybeans and velvet beans.

Lupines. 
The alfalfa organism is the most sensitive of the legume bacteria to acidity and conversely the lupine organism is the most resistant to acidity.

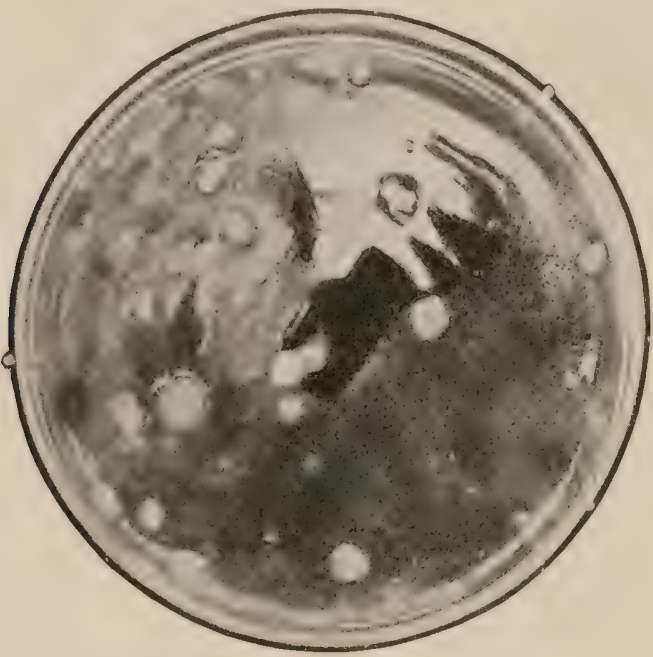

FIG. 36

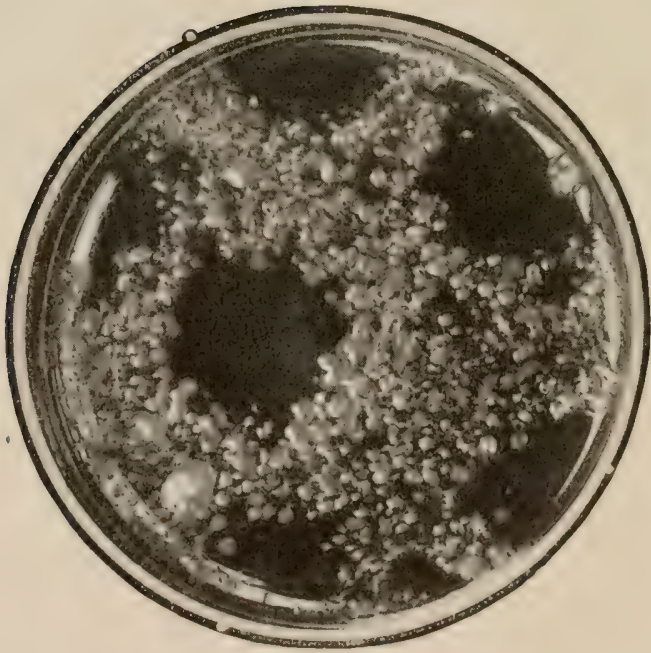

FIG. 37

Figs. 36 and 37.-Ash-agar plate from bean (Phaseolus vulgaris), showing giant colonies in a thickly seated plate. Ash-agar plate from perennial pea (Dathyrus latifolius); the clear spaces are due to sterilized fluid carried over with pieces of nodule tissue. (After Burrill and Hansen). 
The zone of optimum temperature (Zipfel) is between $15^{\circ}$ and $20^{\circ}$ C.; the limits of growth are $3^{\circ}$ and $45^{\circ} \mathrm{C}$; and the upper limits of life are from $60^{\circ}$ to $62^{\circ} \mathrm{C}$. Burrill gives a considerably higher optimum temperature-2.5 to $28^{\circ} \mathrm{C}$. Grieg-Smith found the best temperature for the production of slime to be $22^{\circ} \mathrm{C}$. with most organisms and $26^{\circ} \mathrm{C}$. for one obtained from Robinia. The organism is aërobic, and he found that diffused sunlight of the laboratory is not harmful; even exposure to direct sunlight for sereral months without transferring did not kill the organisms when grown upon favorable media with precautions to prevent evaporation.

Ball found that the organism endures at least two years in dry soil. Harrison and Barlow found that the limit of viability on ashmaltose-agar varied somewhat, but in the majority of cases it was about two years. Iow long the organism will exist in a soil under field conditions is not yet known, but practical observations indicate that it must be many years.

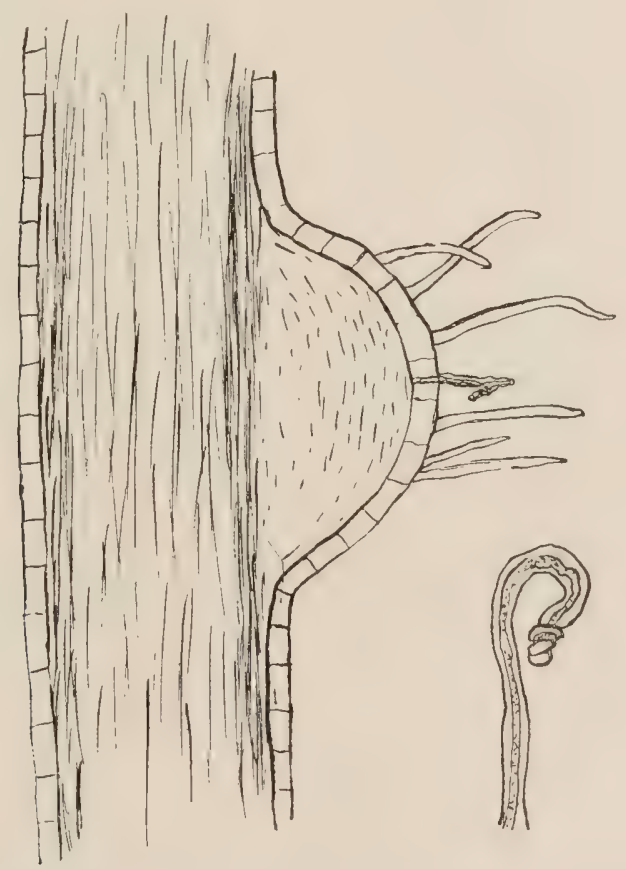

FIG. 38.-Young nodule magnified, showing affected root hair and same root hair more highly magnified. (After Atkinson.)

IMorphology of the Colonies. - Two types of colonies appear on agar plates-buried and surface colonies-and are thus described by Burrill and Hansen: 
"Buried colonies are small and submerged, most frequently lens, or spindle-shaped, with smooth and even edges. They are rather opacque, granular in structure, and in color are cream to a chalk white. They increase slowly in size, eventually appearing on the

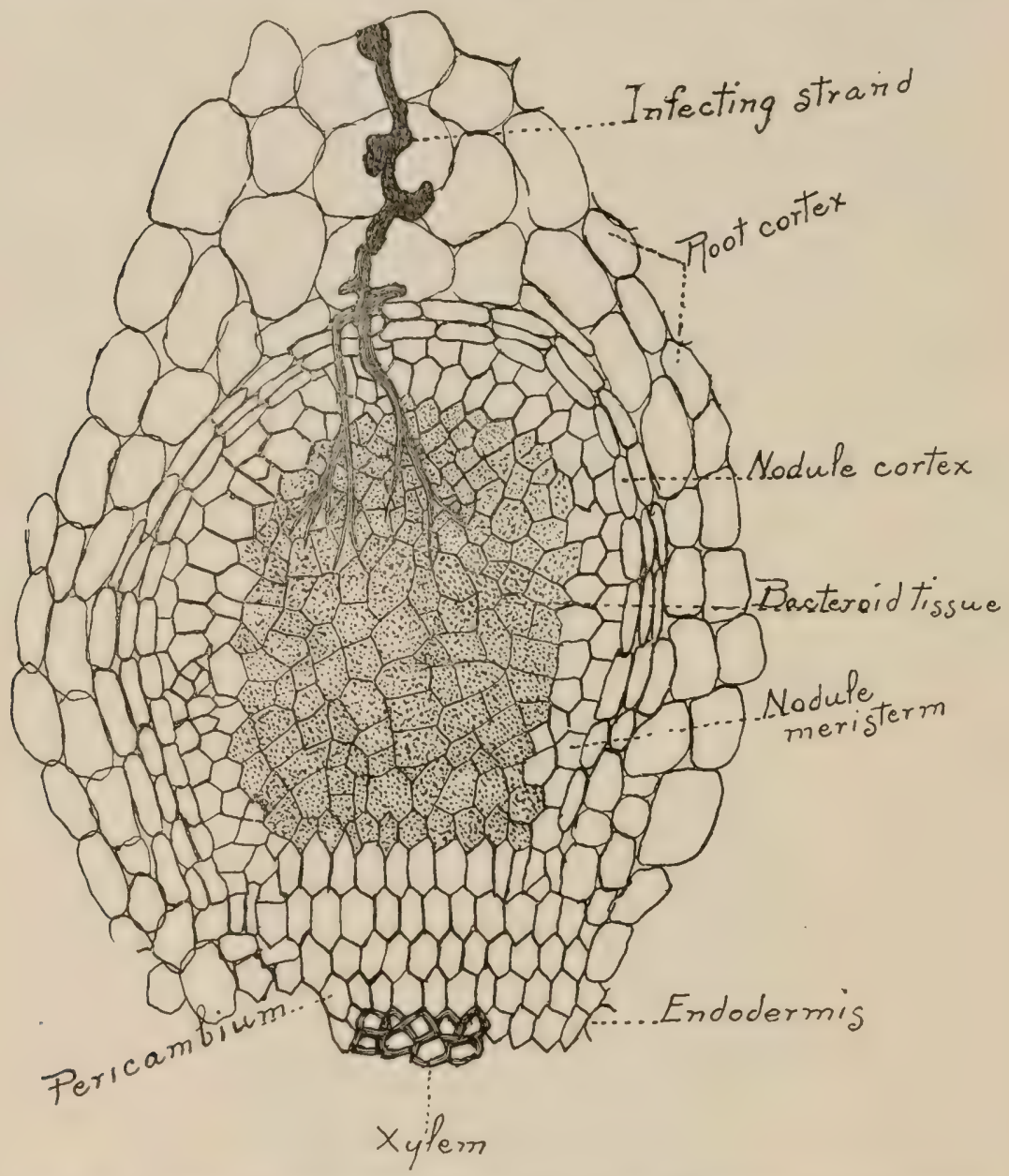

FIG. 39.-Young nodule, showing the beginning of the differentiation of its tissues. (After Prazmowski.)

surface of the agar as surface colonies, when the growth becomes rapid. The lens colonies, however, remain visible for many days in the center of the new growth.

"Surface colonies originate at or near the surfaces of the agar or develop from buried colonies. They are drop-form, watery, muci- 


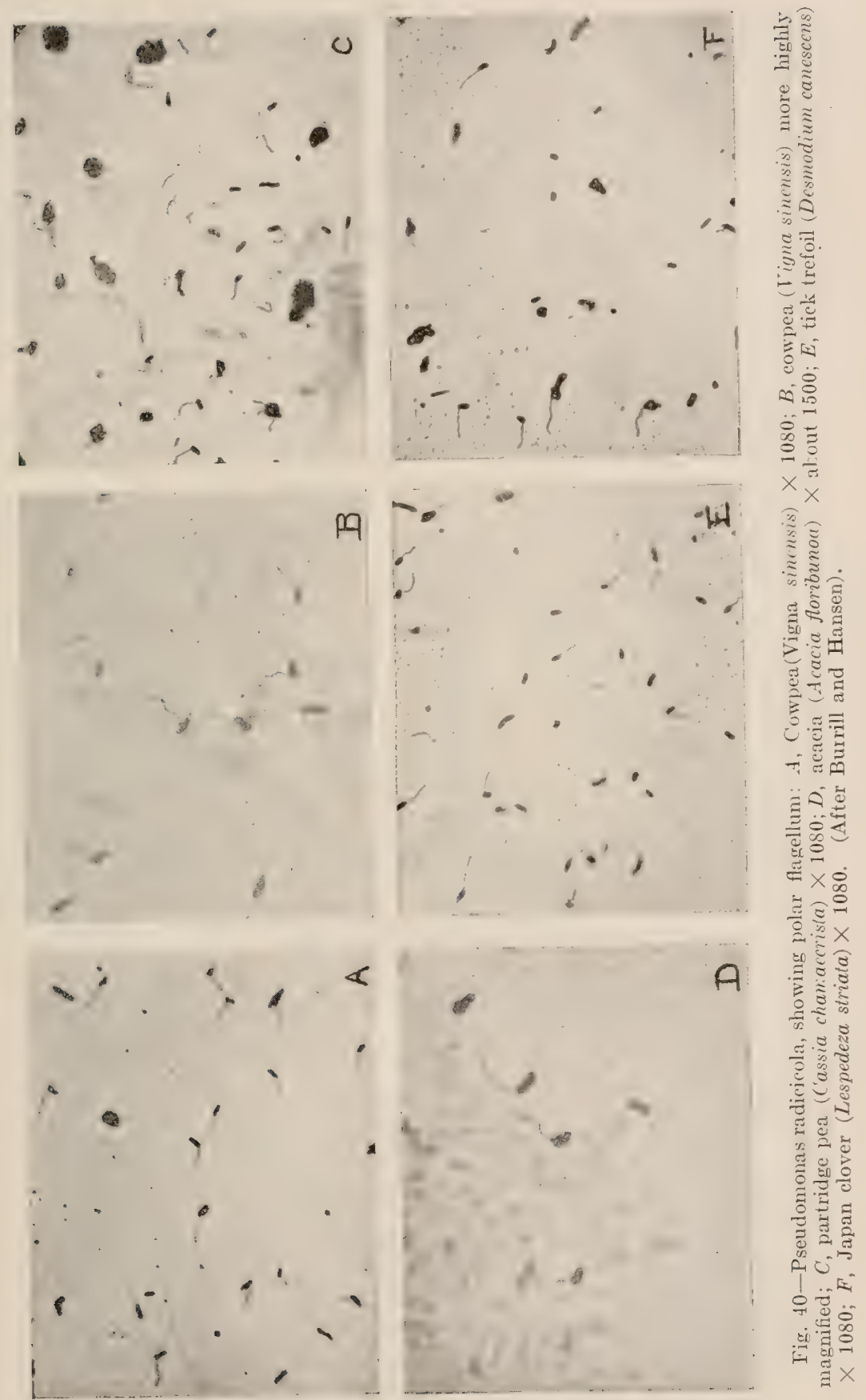


laginous (in appearance, though not always to the touch), graywhite to pearly white in color, glistening, and semitranslucent to opaque. The edges are smooth and even. Under the low power the interior is granular. 'Ther frequently attain considerable size, a centimeter or more in diameter.

"Plates made direct from the nodule lack uniformity to a marked degree. The undiluted plate (first plate) begins to show a few colonies in two to four days. These colonies become extremely large in a very short time, their rapid growth being due to small pieces of nodule tissue or to clumps of bacteria carried over into the agar. In five or six days numerous colonies begin to make their appearance, most of them as submerged colonies, which later grow to the surface.

"The dilution-plate (second plate) colonies are always extremely slow in growth. Generally colonies are large enough for transfer in six to fourteen days, the plates should not be discarded for two or even three weeks.

"The rate of growth of colonies also varies with the organisms of different nodules. Among the fast growers are the organisms from pea (Pisum), vetch (Vicia), lentil (Lens), sweet pea (Lathyrus), bean (Phaseolus), lupine (Lupinus), wild bean (Strophostyles), clover (Trifolium), sweet clover (Melilotus), alfalfa (Medicago), and fenugreek (Trigonella). The organisms appreciably slower in growth are those from the cowpea (V igna), Japan clover (Lespedeza), tick trefoil (Desmodium), acacia (Acacia), partridge pea (Cassia), false indigo (Baptisia), dyer's greenweed (Genista), peanut (Arachis), soybean (Glycine), and hog peanut (Amphicarpa)."

Morphology of the Bacteria.-They are bacilli and when full-grown vary in length from 1 to 4 or $5 \mu$. It is not uncommon to find them from 0.5 to $0.6 \mu$ wide and from 2 to $3 \mu$ long and some have been found to measure only $0.18 \mu$ wide and $0.9 \mu$ long. The bacilli prevail in the young nodule, whereas the branched forms or bacteroids predominate in the older structure. In the cowpea nodules Burrill frequently found large club-shaped bacteroids, though the branched forms were not so numerous. The bacteroids are best demonstrated when the young nodule is just beginning to show a reddish interior. At this stage the characteristic $x$ and $y$ forms occur in great number and show considerable racuolation and unevenness in staining, especially when stained with carbol-fuchsin.

"In the old, decomposing nodule the bacteroids are extremely vacuolated and ghost-like, showing small, oval, deep-staining bodies within. The inference is that these bodies are motile swarmers which later free themselves from the ghost-like capsules, rather than bud off, as has been described by some writers. Frequently the swollen rods have a beaded appearance with unstained bands or areas. $A$ few motile rods may sometimes be seen in hanging drops 
in this stage, and sometimes a bacteroid is seen to oscillate as though swung about by some propelling force in one end. Division of the bacteroids into bacilli, as represented by Dawson, may also occur.

"When first plated out, the young colonies consist of small rods which show considerable variation in length. No bacteriods are present, though the rods are sometimes slightly club-shaped and sometimes show racuolation. Howerer, they never attain the size of bacteroids. With frequent transfers the rods become quite uniform in size and stain deeply and evenly, especially with anilingentian violet:

"In very old cultures (three months on ash agar, without transfer) the small, oval swarmers and the normal rods predominate, though a few club-shaped and a few branched bacteroids are found. The bacteroids produced upon artificial media are never so large nor so numerous as those seen in mounts direct from a young nodule.

"Staining. - The organisms do not stain well with ordinary aniline stains. ('arbol-fuchsin and aniline-gentian-riolet (used steaming) are the most satisfactory stains. Though carbolfuchsin was preferred, anilin-gentian-riolet stains were always used as checks, because the former stain accents the vacuolated appearance, particularly in bacteroids. ('arbol-fuchsin is especially useful in staining bacteroids, direct from the nodule and also old agar cultures. Kiskalt's amyl-Gram stain, described by Harrison and Barlow, is useful since the amyl alcohol clears up the field, leaving the bacteria stained, though not so intensely. 'This stain, however, should not be considered a means of identifying Ps. radicicola.

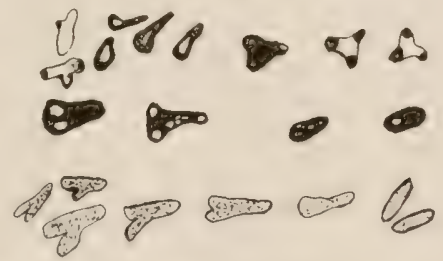

FIG. 41.-Bacteroids, showing shape and occurrence of vacuoles. (After Whiting).

"Bacteroids. - While $P$ s. radicicola produces no spores, it produces bacteroids which are very evidently more resistant than the normal rods. ¿nfarorable conditions, such as unsuitable media, infrequent transfer, or addition of caffein to the medium, cause their appearance. This is in accord with what takes place in the nodule. In the growing nodule, when development is most rapid, the bacteroids are at their maximum; they enable the organisms to multiply rapidly in spite of the resistance offered by the plant cells. Transferred to farorable media from this stage the normal uniform bacilli are produced. The bacteroid then must be regarded as a normal and 
a rery necessary stage in the life of the organism. Its significance in the actual fixation of nitrogen, however, is pure speculation.'

The organisms are actively motile and when viewed under the microscope may be seen darting about with amazing rapidity, now tumbling end over end, now spinning violently on the short axis and then sweeping across the field in a darting, jerking course. They contain from 6 to 20 flagella. The number and distribution of the flagella are variously given by the different investigators due probably to either variation in organisms or to the difficulty with which flagella is demonstrated owing to the gum or slime produced by the organism.

Mode of Entrance into Host.-The method of inoculation and the growth of the nodule is described as follows by Whiting:

"As the tip of the root hair of the legume pushes itself out into the soil, it chances to come into intimate contact with the organism, B. radicicola. Some seientists have exploited the view that the organism is attracted to the plant by chemotaxis, believing that the plant excretes a substance, probably a carbohydrate, which diffuses into the soil solution and attracts the motile organism. While it has been rather definitely shown that this organism progresses in the soil at a rapid rate, nevertheless the number of root hairs infected is too small to lend support to a chemotactic theory. Howerer the case may be, the organisms cluster at the tip of the hair and by means of an enzyme (or otherwise) rapidly dissolve the cellulose of the cell wall, thus enabling the organism to enter the root hair. As a result, there is a decided bending of the tip, causing it to resemble a shepherd's crook. This was early observed as a sign of complete infection. It is claimed that other root hairs which form after infection are immune to the attack of other leguminous bacteria.

"The organisms, by rapid division and growth, advance through the center of the infected root hair. Prazmowski found organisms in the cell sap and even in the epidermis only two days after inoculation. In this advance an infection strand (Infektion-schlauche) is formed, which consists of gelatinous material, and in the earlier stages of development this strand may be traced from the root hair into the inner tissue of the root and from cell to cell throughout the nodule. This infecting strand is not supposed to constitute a portion of the living tissue, nor is it a well-defined tube; but, as Fred has recently shown, it consists of a large number of zoöglea occurring adjacent to one another, in which separate bacteria can be distinguished. 'The infecting strand branches profusely and it was this habit of growth which caused the early investigators to consider it the mycelium of a fungous growth.

"Growth of the Nodule.- The presence of $B$. radicicola in the tissues of the root causes a rapid cell division in the pericycle. 'These cells become larger and contain more protoplasm than the 
surrounding cells, and as growth takes place the cortical parenchyma and epidermis are forced outward, thus forming a nodule. The growth of the nodule is apical. The various tissues common to the plant are present. In the central portion of the nodule is the socalled bacteroidal tissue, which is ochre, flesh, or gray in color, according to the age of the nodule, and in this portion the infecting strand (Infektion-schlauche) is distinguished in the young nodule. It ramifies throughout the cells, causing those which it enters to lose their power of cell division but not of growth. Later, or in older nodules, the infecting strand is not visible, and the bacteroidal tissue loses its firmness. At the period when seed formation is at its height, most of the nodules are soft, and the internal tissues slough off', leaving the more resistant epidermal tissue a mere shell, which later decays. The endurance of the nodule depends upon several factors, - chiefly, however, upon the kind of legume plant on which it is produced and the need of nitrogen by that plant.

"Pierce considers the nodules as originating endogenously from the same layer of cells as the lateral roots, and as being morphologically similar to them; howerer, as the lateral roots rupture the epidermis the above statement is not entirely in accord with what actually takes place.

"The nodules are largest and most numerous where "aëration is best in the soil. In saturated soils they occur at the surface and are often found colored green, very similar to sunburned potatoes. Nodules form in solutions, and exceptionally well in certain nutrient solutions. Sereral interesting instances have been brought to the attention of the Experiment Station, in which the observers believed that the nodules had grown above the ground. These peculiarities were undoubtedly caused by unobserved physical conditions occurring at the time of infection or afterward."

Relationship to Host.-Even today the relationship between Ps. radicicola and its host is a mooted question. Some authors claim that they are true parasites and that the relationship between the tubercle organisms and their host plants is that of two contending parties and the bacteria draw on the nitrogen of the air in their endeavor to make up the deficiency of nitrogenous substances which have been taken from them by the plant. Moreover, inoculation experiments have demonstrated that $P$ s. radicicola causes a certain resistance similar to that produced by an organism in combating a true parasite.

IHiltner has given the six following conditions as instances in which immunity demonstrates itself:

1. The organisms cannot get into the plant.

2. The organisms gain admission into the plant, but do not produce nodules because the plant, by its greater resistance, absorbs the bacteria. 
3. The organisms enter the plant and produce nodules, but no fixation of nitrogen occurs.

4. The organisms enter, produce nodules, and nitrogen is fixed and assimilated by the plant.

5. The organisms are so efficient in comparison with the plant that the latter is injured.

6. The organisms are parasitic and the plant is actually killed.

Certain products which are produced by the invading organism in connection with the host have been taken as evidence of the parasitic nature of the bacteria, whereas others consider the nodule which forms on the legume root a result of irritation due to a parasite. Grieg-Smith, however, considers the formation of root tubercles not as a result of irritating parasitic action but rather as the consequence of the production of nutrients at that place resulting in better nourishment and growth of the cells than in other parts of the roots.

Fuhrmann considers that the fixation of atmospheric nitrogen by the root-tubercle organisms begins when the bacteroids have reached a stage when they are colored brown-red by addition of tincture of iodine. This occurs only when the organisms are feeding almost exclusively upon carbohydrates and the available nitrogen compounds have been almost completely exhausterl. Many workers prefer to call the relationship up until this stage a true parasitic and later a true mutual symbiosis.

Br careful staining Fred was able to demonstrate the entering of the bacteria through the root hairs, immediately after which a tubercle started to form. A series of sections showed that mitosis goes on in the nodules much the same as it does in diseased tissue of animals. 'The mitotic figures are larger, very irregular, and not well marked and have an uneven number of chromosomes. In the normal roots the mitotic figures are about one-sixth as large, very clear, and the chromosomes in numerous pairs. This he considers bears out the theory that the legume bacteria are symbiotic parasites of the plant.

If we accept Whiting's definition of mutual svimbiosis "as the contiguous association of two or more morphologically distinct organisms not of the same kind, resulting in an acquisition of assimilated food substances which implies that the organisms concerned have the power of independent existence, but that both are benefited by the close association," we must conclude that all the evidence bears out the idea that the relationship existing between P's. radicicola and legumes is one of mutual symbiosis.

Mechanism of Fixation (Metabolism).-For a long time it wats believed that the nitrogen fixed by legume bacteria and assimilated by the plant was obtained through the leaves. The organisms on the roots were considered to in some way stimulate the plant so that it possessed the power to assimilate nitrogen. Stoklasa considered 
that amids were first formed and that these migrated to the nodules, reacted with glucose and produced protein which served as the nutrient medium for the bacteria. In this connection he advanced the idea that the bacteria produced an enzyme which enabled the plant to fix the nitrogen. This theory, howerer, was shown to be untenable by Whiting who grew sorbeans and cowpeas under careful control conditions. One lot received a definite proportion of oxygen, and carbon dioxid, a second oxygen and carbon dioxid, while a third received ordinary air. He found that these plants utilize atmospheric nitrogen through their roots and not through their leares.

Nobbe and Hiltner (1893) considered the root tubercles to be the parts of the leguminous plants where the free nitrogen is assimilated and that the direct agents of the assimilation are the bacteroids and not the bacteria themselves. As to the metabolism of the nitrogen by these bacteroids the ideas at present are very indefinite. Loew and Aso (1908) suggested that ammonium nitrite was the first compound produced, the nitrous acid being readily reduced to ammonia.

Gautier and Drouin considered that the nitrogen is oxidized to nitrous and nitric acids, whereas Winogradsky has advanced the idea that the free nitrogen in the plasma of the organism may unite with nascent hydrogen and form ammonia which by oxidation would become assimilable.

Gerlach and Vogel concluded that there is a direct union of free nitrogen with some organic compound inside the bacterial cell. Heinze thinks it probable that nitrogen is at once brought into combination with a carbohydrate (glycogen) and suggests that a salt of carbonic acid may be formed first, or that carbonic acid may be produced from cyanamid. All of these theories, howerer, are purely speculative as there is little experimental evidence on the subject.

It is in keeping with our knowledge of bacteria to assume that the changes are catalyzed by enzymes produced by the bacteria, and Hiltner reported the findings of a substance which is produced by the legume bacteria which can dissolve the cell wall and root hairs. Tet Beijerinck claims that no enzyme has been found which attacks starch, cellulose, or saccharose. No true proteolytic enzyme has been reported, but Benjamin has reported the presence of urease in the nodules of various legumes. This enzyme is, hovever, found quite generally in plants and may have come from the host and not the bacteria. Fred, although unable to detect a proteoly tic enzyme, has obtained evidence of the presence of oxidases in the slime of various legume bacteria.

There are two main suppositions regarding the assimilation of the nitrogen by the plant as follows: (1) That the bacteroids are bodily absorbed by the plant fluids; and (2) that the bacteroids, by some 
sort of change, produce the substance containing the assimilable nitrogen which the plant used.

There appears to be considerable evidence in favor of this second theory. Stefan thinks that the transfer of the assimilable nitrogen from the organism to the host plants follows the ordinary physical laws of osmosis, and Golding has conducted some very interesting experiments on the removal of the products of growth in the assimilation by nitrogen by legume bacteria. He reasoned that the plant played an important rôle in the removal of the products produced by bacteria in the nodules aside from the mere furnishing of suitable food. He used a porous Chamberland filter candle placed in a culture vessel to serve to imitate natural conditions. 'The parts of the plants used in some of his experiments were sterilized in order to avoid the possibility of plant enzyme action. As a result of his method of experimentation he obtained a much greater fixation of nitrogen than other experimenters had obtained. He concluded that the plant plays a part in the remoral of soluble products of growth, thus permitting a more rapid reaction than where the products accumulate.

The results of Golding's most extensive experiment are summarized as follows:

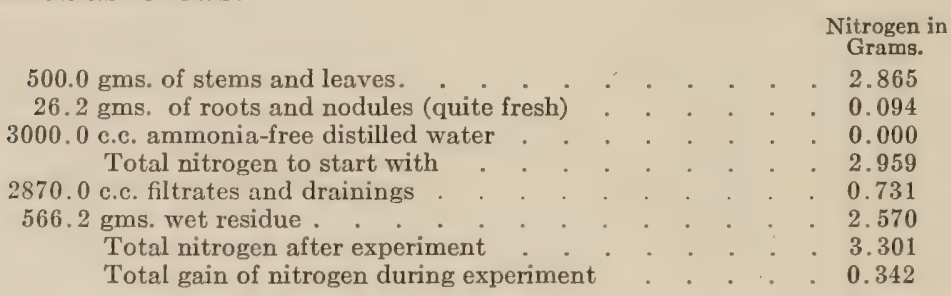

Attempts have been made to obtain an insight into the transformation going on in the nodules by various analyses. These have been summarized by Whiting as follows:

"Chemical-The chemical composition of legumes from the standpoint of their nitrogenous constituents has been inrestigated to some extent, but the studies closely related to this point are relatively few. The following data are very general in character and relate to studies concerning the total nitrogen content of the different parts of legumes at different periods of growth. Studies upon some of the various nitrogenous compounds are also included.

"In 1895 Stoklasa, working with lupines (Lupinus luteus and $L$. (minustifolius), found that the nodules were richest in the element nitrogen at the time of blooming, while the roots appeared to be richest in that element at the fruiting period. His results are given in 'Table I. 'The figures for the nodules indicate the nitrogen is either taken up by the plant for seed production or diffused into the soil. 
TABLE I. - TOTAL NITROGEN IN LUPINUS LUTEUS: RESULTS OBTAINED BY STOKLASA. (PERCENTAGE ON DRY BASIS).

Period.

Blooming

Fruiting

Maturity
Roots.

1.64

1.84

1. 42
Nodules.

5.22

2.61

1. 73

"Stoklasa also determined protein, amids, and asparagin in lupine nodules. The protein was obtained by the Stutzer method, the amids by the Kjeldahl method, and the asparagin by calculation from the ammonia obtained by distillation with magnesium oxid. Table II shows his results.

TABLE II.-NITROGEN COMPOUNDS IN LUPINE NODULES: RESULTS OBTAINED BY STOKLASA. (PERCENTAGE ON DRY BASIS).

Period.

Blossoming

Maturity
Protein.

3.99

1. 54
Amids.

0.35

0.15
Asparagin.

0.34

Trace

The presence of asparagin in the nodule is important, as it is thought to be intimately related with the formation of protein.

"In 1901 Wassilieff studied the nitrogen compounds in white lupine (Lupinus alba) seeds and seedlings. He found that the seeds contained 7.68 per cent. of total nitrogen; and that of this, 6.89 per cent. was in the form of protein and 0.53 per cent. was precipitated by phosphotungstic acid, leaving a difference of 0.26 per cent., asparagin. The occurrence of asparagin in large amounts in the seedlings is shown by the data given in Table III.

TABLE III.-NITROGEN COAIPOUNDS IN FOURTEEN-DAY-OLD GREEN SEEDLINGS OF WHITE LUPINES: RESULTS OBTAINED BY WASSILIEFF (EXPRESSED IN PERCENTAGE ON DRY BASIS).

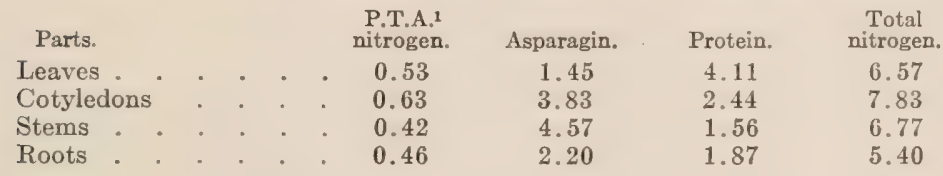

Wassilieff also demonstrated the presence of leucin and tyrosin in the cotyledons of one-week-old seedlings of white lupines. These and other amino-acids would be expected to be present when the protein of the seed is breaking down for the nutrition of the seedling.

"Knisely analyzed the leaves, pods, stems, roots, and nodules of lupine plants for total nitrogen at three distinct periods of development. His results show better than the others presented where the nitrogen accumulates as the plant matures.

\footnotetext{
1 Phosphotungstic acid.
} 
TABLE IV.-TOTAL NITROGEN IN LUPINES: RESULTS OBTAINED BY KNISELT. (EXPRESSED IN PERCENTAGE ON DRY BASIS).

\begin{tabular}{|c|c|c|c|c|c|}
\hline Period. & Leaves. & Pods. & Stems. & Roots. & Nodules. \\
\hline Full bloom & 4.02 & 3.07 & 1.15 & 0.92 & 5.17 \\
\hline Pods well formed & 3.70 & 3.38 & 0.88 & 0.83 & 3.29 \\
\hline Pods very large & 3.41 & 3.68 & 0.90 & 0.66 & 3.70 \\
\hline
\end{tabular}

"Schulze and Barbieri examined lupine and soybean seeds and seedlings for nitrogen and obtained the results shown in Table V.

TABLE V. - NITROGEN IN LUPINE AND SOYBEAN SEEDS AND SEEDLINGS: RESULTS OBTAINED BY SCHULZE AND BARBIERI (EXPRESSED IN PERCENTAGE ON DRY BASIS).

\begin{tabular}{|c|c|c|c|c|}
\hline Material. & $\begin{array}{c}\text { Total } \\
\text { nitrogen. }\end{array}$ & Protein. & $\begin{array}{c}\text { P.T.A. } \\
\text { nitrogen. }\end{array}$ & $\begin{array}{l}\text { Filtrates } \\
\text { from P.T.A. }\end{array}$ \\
\hline Lupine seeds & 8.63 & 8.17 & 0.24 & 0.22 \\
\hline Soybeans . . . . & 6.73 & 6.32 & 0.13 & 0.28 \\
\hline $\begin{array}{l}\text { Lupine dark seedlings, } \\
\text { eleven to twelve days old }\end{array}$ & 10.64 & 3.40 & 1.60 & 5.64 \\
\hline $\begin{array}{l}\text { Lupine dark seedlings } \\
\text { twelve days old } \\
\text { Soybean seedlings fifteen }\end{array}$ & 10.51 & 2.33 & 2.17 & 6.01 \\
\hline days old & 7.42 & 3.86 & 0.56 & 3.00 \\
\hline
\end{tabular}

"They also found a large amount of asparagin in both the lupine and the soybean seedlings.

"Schulze has made a careful study of the compounds in plants, and has formulated the hypothesis that the same decomposition products arise from protein in the plant as outside it, but that in the plant the compounds are further altered, thereby affecting in varying degree the individual products of the hydrolytic decomposition. A comparison of the analyses of pea seedlings one week old and those three weeks old show the following differences:

\begin{tabular}{ccll} 
& Leucin. & Tyrosin. Arginin. & \multicolumn{1}{c}{ Asparagin. } \\
1 week . . . & Abundant & Little Present & Absent. \\
3 weeks . . . Much less Absent Almost absent & Very abundant.
\end{tabular}

Arginin and amido-acids were shown to be present in the lupine cotyledons, but asparagin was absent, although the latter substance was found in the stem of the seedling. It has been suggested that the occurrence of asparagin is associated with the disappearance of amido-acids and not of protein. Phenylalanin, tyrosine, and tryptophane have been reported in the white lupine (Lupinus alba), tyrosin and tryptophane in vetch (Vicia sativa), and tryptophane in the garden pea (Pisum sativum).

"Smith and Robinson found 4.19 per cent. of nitrogen in soybean nodules and 3.90 per cent. in cowpea nodules. 'They observed that inoculation increased the protein content of soybean plants without increasing the yield of beans. This has been noted by other experimenters. 
"IIopkins has reported the analyses of cowpea plints for total nitrogen with and without inoculation. The nodules, root, and tops were analyzed separately, as will be seen by reference to Table VI.

TABLE VI.-NITROGEN FIXATION BY COWPEAS: RESULTS OBTAINED BY HOPKINS. (EXPRESSED IN MGS.)

\begin{tabular}{|c|c|c|c|c|}
\hline Treatment. & Tops. & Roots. & Nodules. & $\begin{array}{l}\text { Nitrogen } \\
\text { fixed. }\end{array}$ \\
\hline Ten plants with bacteria & 146 & 9 & 11 & 125 \\
\hline Ten plants without bacteria & 38 & 3 & & \\
\hline Ten plants with bacteria & 171 & 10 & 18 & 140 \\
\hline Ten plants without bacteria & 55 & 4 & & \\
\hline Ten plants with bacteria & 143 & 8 & 17 & 124 \\
\hline Ten plants without bacteria & 40 & 4 & & \\
\hline
\end{tabular}

The inoculated plants contained a much greater percentage of nitrogen than the uninoculated, the average content of the inoculated being 4.24 per cent. in the tops, 1.48 per cent. in the roots, and 5.92 per cent. in the nodules, while the average content of the uninoculated was 2.48 per cent. in the tops and 0.88 per cent. in the roots.

"The ash and the ash constituents of the nodules and the roots of lupines have been determined by Stoklasa, as presented in Table VII. The total ash of the nodules was found to be 6.32 per cent., while that of the roots was found to be 4.55 per cent.

TABLE VII.-ASH CONSTITUENTS IN LUPINE NODULES AND ROOTS: RESULTS OBTAINED BY STOKLASA. (EXPRESSED IN PERCENTAGE.)

Constituents.

$$
\text { Si }
$$

S

$\mathbf{P}$

$\mathrm{Na}$

$\mathrm{Mg}$

$\mathrm{Ca}$

$\mathrm{Fe}$

$\begin{array}{cr}\text { Nodules. } & \text { Roots. } \\ 1.59 & 1.90 \\ 4.90 & 6.38 \\ 6.51 & 4.28 \\ 17.31 & 12.05 \\ 16.94 & 19.94 \\ 7.41 & 7.05 \\ 7.64 & 12.04 \\ 0.83 & 0.75\end{array}$

"The analyses of red-clover nodules show a potassium content of 2.63 per cent. in the dry matter. The nodules, therefore, are relatively rich in mineral elements as well as nitrogen compounds; and Stoklasa's results (See Table VII) show that the chief differences between the roots and the nodules in the composition of the ash constituents are in phosphorus, potassium, calcium, and sodium. The nodules are richer in the first two elements and the roots in the latter two.

"In brief, the chemical data which have been considered, although small in amount, show the relative richness in nitrogen of the nodule as compared with other parts of the plant. They point to the accumulation of nitrogen in the seeds, at the expense of the other parts, as the plant matures. That the nitrogen exists in the form 
of protein, asparagin, and other soluble forms, is also clear. 'The presence of various aliphatic and carbocyclic amino-acids has been mentioned."

Sources of Energy. - Under natural conditions the legume bacteria undoubtedly obtain the energy required for the endothermic reaction which they catalyze from the plant carbohydrates. It has long been known that decoctions of the legumes makes the best media on which to grow these organisms. Temple found that the presence of ground alfalfa caused a rapid multiplication of the organisms either in solution or in soil. Grieg-Smith found dextrose, levulose, saccharose, maltose, and mannite to furnish a good source of carbon for the organisms, but lactose was a very poor nutrient. Temple found saccharose and dextrose superior to lactose, whereas he found levulose wholly unsuited to their needs.

No one so far has attempted to measure their energy requirements when growing under their natural symbiotic condition. Fred has studied their growth apart from the host plant and found that when considered per unit of carbohydrate consumed the legume bacteria fix as much or more nitrogen than Azotobacter.

"Aëration. - The legume bacteria are all aërobic and the nodules on the roots of the plants are usually near the surface. Although nodules will form on plants grown in water cultures, yet they are not as large and active as when grown in a well aërated soil. The addition of oil to a soil or water culture in which legumes are growing prevents the formation of the nodules. Moreover, as shown by Whiting, the legumes get their nitrogen through the root and not the leaves. The result of cultivation of legumes is, therefore, threefold: (1) The loosening up of the soil, thus making available to the nodule bacteria atmospheric nitrogen and oxygen; (2) the working of the soil increases other bacterial activity which in turn renders soluble potassium, phosphorus, and other essential elements in the soil; (3) the loose aërated surface tends to conserve the moisture of the lower layers which can be drawn on by the plant, thus making more nearly optimum moisture conditions.

Moisture.-The root systems of plants vary greatly with the moisture content of the soil. Gain found that legumes grown in moist soil spread widely, were full of water, became covered with root hairs, and presented a large surface of young tissues. In the dry soil the roots were less spreading and the epidermis was greatly thickened.

In moist soil the tubercles of the peas were scattered all orer the roots, were five or six times as abundant as in the dry soil, and were about four times as large and ovoid in shape; while in the dry soil no tulbercles were produced on the superficial roots. At a depth of about 20 centimeters some tubercles were found of a hemispherical shape and much smaller than those grown in moist soil. 
On beans about twenty times as many tubercles were found in the moist soil and microscopic examinations showed important differences in the number of bacteria present and the structure of the tubereles. Similar results were obtained with lupines and other plants. This is what is to be expected, for when the root system is not actively functioning the nodules are slowly destroyed by the nodule-forming bacteria within and the saprophytic organisms without. The nitrogen fixed by the plant is proportional to the number and size of the nodules. Hence, the gains made in combined nitrogen are dependent upon the water applied to the legume. This optimum will vary with different soils. Kalantarov found in a loam soil that nodule bacteria require for their growth a minimum moisture content of about 30 per cent., whereas Prucha found in a sandy soil the optimum moisture content was from 20 to 40 per cent. Wilson found that an increase in moisture content from 35 to 45 per cent. more than doubled the production of nodules, while with an increase from 45 to 55 per cent. it was nearly doubled. Therefore, water is necessary for the normal functioning of the plant and bacteria, and it tends to leach out the soluble nitrogen and thus stimulates to greater action the legume bacteria, for it is known that the legume feeds first on the combined nitrogen of the soil and turns to the atmosphere only when this is greatly reduced.

Excessive quantities of water may exclude the nitrogen from the roots and also favor anaërobic action, both of which would be detrimental to the legume bacteria.

Temperature. - It is a well-known fact that the temperature of a soil varies with its moisture content and a water-logged soil is slow to heat up. Gain found the temperature of moist soil at midday to be 7 degrees cooler than dry soil. This difference in temperature persists throughout the day and night and is noted in a diminished degree even to a depth of four feet. This difference may be sufficient in some soils to greatly decrease or increase the metabolism of the organism which Zipfel finds is at its optinum at a temperature between 18 and $20^{\circ} \mathrm{C}$.

Influence of Fertilizers. -The legume bacteria require the same elements for their growth as do other plants, and the application of fertilizers to a soil which increases the available potassium and phosphorus is attended by an increased bacterial activity. However, it has long been known that nitrates inhibit nodule formation. Wilson found that nodule development was prevented by the presence of nitrates, sulphates, and ammonium salts, although the organisms retain their vitality in the presence of these salts. It is thought by some that the addition of soluble nitrates to the soil decreases by a kind of compensatory action the formation of root tubercles by legumes. Legumes growing on soil rich in nitrates may actually be immune to the nodule bacteria and prevent their 
entrance into the roots. Simall quantities of nitrates tend to stimulate.

Legumes Associated with Non-legumes. - For centuries it has been the practice in China, Japan, Western Asia, Northern Africa, as well as ancient Rome, to grow legumes and non-legumes in combination and there is no doubt that time and again practical farmers have noted the more vigorous growth and darker green of non-legumes when so grown, long before the investigations of Hellriegel and his associates established the fact that legumes are capable of utilizing atmospheric nitrogen. His discovery gave the key to the mystery,

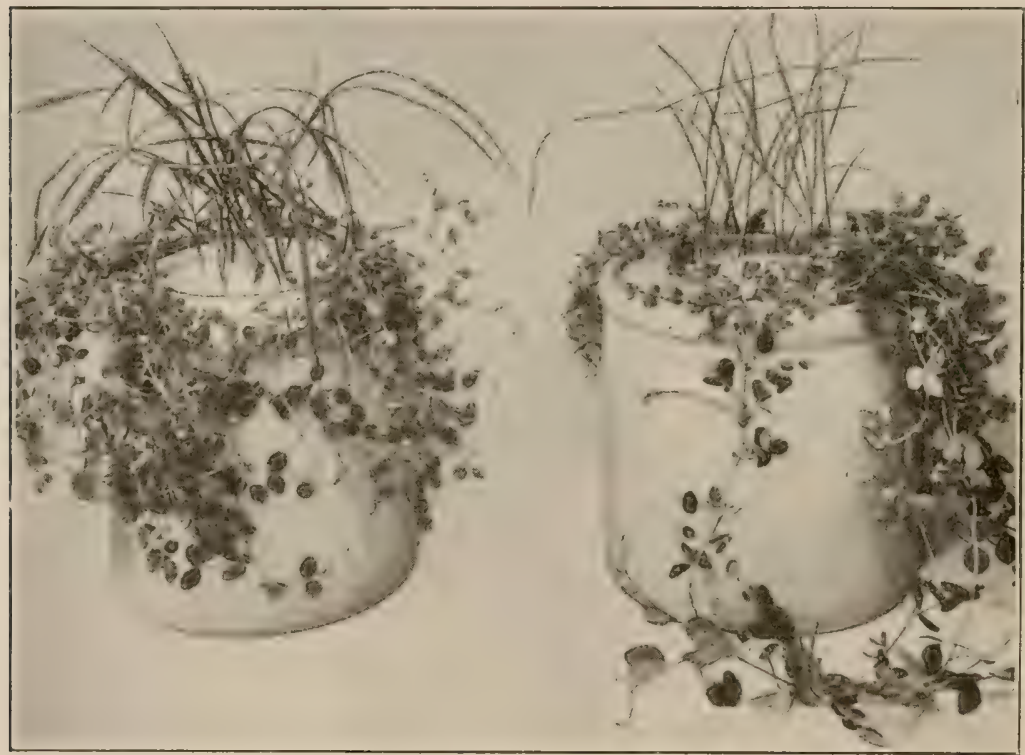

Fig. 42.-Double pots used in showing influence of Legume on non-legume. (After Lipman).

-the non-legume was getting combined nitrogen from the legume. This was strikingly demonstrated by a very ingenious experiment conducted by Lipman. He grew non-leguminous plants in soil in a porous pot surrounded by earth in a larger glazed earthenware pot in which leguminous plants were growing and found that under favorable conditions non-legumes associated with legumes may secure large amounts of nitrogen from the latter. 'This power of supplying nitrogen to non-legumes varies wth different legumes. At times it may appear as an increased yield, whereas at others it may appear as an increased proportion of nitrogen in the dry matter of the non-legume or both. The following table gives the per- 
centages of increase in the protein content and length of leaf in the grasses grown with clover over grasses grown alone (Fvans).

Kind of grass.

Timothy grown in lawn plat .

Timothy grown in field

Protein $_{1}$
$\mathbf{n} \times 6.25$
18.89
7.68

Length of leaf.

21.27

19.41

This, howerer, varies with the soil and there may be conditions in which not only the protein content of the non-legume is slightly reduced by the association with the legume, but that the percentage of nitrogen in the legume may decrease as the proportion of nonlegume in the mixture increases as noted by Westgate. Eren in these cases the total nitrogen of the combined crops is usually increased, provided the legumes are properly inoculated.

Soil Gains in Nitrogen.-The gains made by soil in nitrogen are dependent upon a number of factors.

(1) It is self-erident that the soil must be in good physical condition for maximum nitrogen gains. (2) The soil must contain the elements essential to plant growth, with the exception of nitrogen. The law of minimum holds rigidly in this case and the gains in nitrogen are limited by the limiting element of plant production other than nitrogen. (3) Soils which contain sufficient arailable nitrogen for the production of good crops gain little, if any, nitrogen from the growth of legumes, for the plants together with the bacteria feed first upon the combined nitrogen of the soil and only upon atmospheric nitrogen when the soil nitrogen is exhausted. Soils may contain an abundance of combined organic nitrogen which for some reason is not rendered available and still gain from the turning under of properly inoculated legumes. (4) The legume must be properly inoculated; otherwise it obtains its nitrogen as do other plants. (5) The soil must be a suitable home for the legume and bacteria, that is, it must have a correct reaction, moisture, temperature, and aëration for maximum nitrogen fixation. Hence, we can expect to find a wide divergence in the results reported by investigators.

Frank in 1891 found that soil which had been green-manured with legumes showed an appreciable gain of nitrogen. And it is a wellknown fact that, in sand culture experiments in which the nitrogen of the soil is rery low much more nitrogen may be remored in the legume crop than was found at first in the soil, and after the removal of the crop the soil mar have gained in nitrogen. But what would happen in normally productive soil? The most reliable data now existing are contributed by the Illinois Experiment Station and indicate that two-thirds of the nitrogen in legumes grown on soils of normal productive power is obtained from the air. These figures were obtained from the analysis of inoculated and uninoculated legumes from like areas of normal soils and as a result of pot experiments. Computed by these data a four-ton alfalfa crop adds 132 pounds, a 
four-ton (rop of clover adds $10 \bar{\gamma}$ pounds, a four-ton crop of cowpea hay adds 115 pounds.

These are the quantities of nitrogen which reach the soil under ideal conditions, but some may be lost under natural conditions with the drainage, and possibly by other means. 'The New Jersey Experiment Station has reported a gain of 200 pounds per acre where crimson clover has been grown, whereas the Rhode Island Experiment Station, as a result of pot culture experiments, reports a gain of 400 pounds per acre yearly. This experiment extended over five years, and legumes were grown both in the summer and in the winter. The tops of the summer legumes (cowpeas and soybeans) were removed from the soil, while the winter legumes (vetch) were turned back into the soil.

Shutt, in pot and plat experiments extending over two years in which mammoth red clover was grown on soil and turned under, showed a gain of 179 pounds of nitrogen per acre to a depth of 9 inches in the pot experiments and 175 pounds to a depth of 4 inches in the plat experiments. A light sandy loam with a sandy subsoil, when planted to clover continuously and reseeded every two years, doubled in nitrogen in ten years. 'This was a yearly gain of nitrogen of 50 pounds per acre.

Soil Inoculation.-The early experiments demonstrated that legumes assimilate atmospheric nitrogen only when properly inoculated. Since that time much has been written on soil inoculation. However, it is being found that in the majority of cases where the physical and chemical conditions of the soil are optimum, the ordinary legume bacteria are already present. This is especially true where that particular legume has been grown in that district for some time. 'The legume organism may have been in the virgin soil, having come from the native legume, or carried into the soil with manure or dust. When a new legume is being introduced into a district, one should see that the soil is properly inoculated for the members of that group. Successful seed inoculation can be performed with fresh properly prepared artificial cultures, but in many cases this has not proved successful and in the majority of cases inoculation with soil known to be infected is to be preferred. The method suggested by the Illinois Experiment Station for large seeds, such as soybeans, is very satisfactory. The seeds are thoroughly moistened by a 10 per cent. solution of glue and sufficient dry pulverized infected soil sifted on to absorb all of the moisture. The seed is shovelled over a few times. Such infected seed should be planted very soon or else spread out to dry to prevent mould action. Neither infected seed nor soil should be long exposed to bright sunshine, as this is very destructive to the bacteria.

Where the old plants are to be inoculated a few hundred pounds of soil may be obtained from an old infected field spread on the new field and harrowed. 
Dr. C. B. Lipman gives the following method for inoculating beans, and in a modified form it can be used for other legumes:

"Method Involving the Use of One Commercial Culture.-Prepare one-half barrel full of good loam soil ( 150 pounds) with sufficient water to make about optimum moisture conditions. This soil can be kept in a shallow vat about a foot in depth or in some other convenient receptacle where it can be well aërated. Purchase one commercial culture from any of the commercial firms selling legume bacterial cultures, choosing a culture for beans of the variety desired. The amount usually sold in a culture for one acre is sufficient. Shake this up with a few quarts of boiled water. The shaking should be continued for about ten minutes to get all the bacteria in suspension. Pour this suspension all over the surface of the soil in the vat and add to the solution about one-quarter of a pound of ordinary sugar per one hundred pounds of soil used in the rat. This should be distributed as evenly as possible through the soil and the latter thoroughly mixed with a spade or hoe, thus distributing both the sugar solution and the culture. After that the inoculated soil is to be kept in a warm place like a kitchen or a warm stable and the moisture content maintained at optimum until you are ready to use it for the inoculation of beans when they are planted. It is well to allow a period of two or three months for such incubation.

"At the end of the incubation period or when getting ready to plant, shake up some of the inoculated soil with clean water for a few minutes as before to get a good suspension of the bacteria. Pour enough of this suspension over the bean seed in large tanks or similar receptacles to wet the seed thoroughly, but not enough to allow any excess of water. Then spread the bean seed out on a canvas in a thin layer in the shade. As soon as the seed is air-dry and will not stick, place in a planter and plant immediately. In cases in which only small quantities of seed are to be planted, the suspension need not be made, but the inoculated soil in small quantities can be mixed with the seed in the planter and allowed to drop with the beans as they are dropped from the machine, thus introducing the bacteria into the soil with every seed, or nearly so.

"Alternative Method.-Where it is not desired even to purchase one commercial culture, inoculation can also be carried out entirely successfully by obtaining soil from a garden in which beans have grown successfully for some years and using that soil for making up the soil suspension or for mixing with the seed as above described. In other words, this garden soil, which contains the necessary bacteria, will serve fully as well as the inoculated and incubated soil just described above. This is of course the simpler method to those who have access to garden soil which has produced beans successfully. Soils like this may also be obtained from old and more extensive bean fields, where successful bean-growing has been carried out. 
For small plots, such soil can be directly harrowed into the soil to be inoculated after being spread (about one bushel per acre) in moist condition on a cloudy or rainy day."

Commercial Cultures. - Because inoculation by means of soil from old fields may transmit fungus diseases, weed seed, and necessitates the transference of large quantities of soil numerous workers have endeavored to inoculate with pure cultures. The first attempt was made by Nobbe and Hiltner who placed on the marliet a preparation called "nitrogin." Eight kinds were prepared suitable for the different legumes and were sent out on gelatin. Some of the results were satisfactory, but on the whole the percentage of failures was so great that the method was largely discredited.

Later the subject was investigated by Moore who considered the failures of Noble due to the fact that he had grown his cultures on gelatin. This contained combined nitrogen in abundance and the bacteria lost their virulence and no longer possessed the power of forcing their way into the roots of leguminous plants and producing nodules. Noore used a nitrogen-free medium for the growth of his cultures, thus increasing their nitrogen-fixing power. They were distributed on cotton. Later liquid cultures were used and since that time many different media, including even soil humus have been used by different workers with varying degrees of success. As a result, at the present time some commercial cultures are being put upon the market which are probably just as efficient as are the natural-occurring soil organisms. However, some workers claim to have dereloped organisms possessing a high physiological efficiency. But after taking all the tacts into consideration, one must conclude that at the present time the pure cultures have little adrantage over the natural-occurring organisms.

\section{REFERENCES.}

Löhnis: Handbuch der Landwirtschaftlichen Bakteriologie.

Lafar: Handbuch der Technischen Mykologie.

Voorhees and Lipman: A Review of Investigations in Soil Bacteriology, U. S. Dept. Agr., Off. Exp. Sta. Bull. 194.

Whiting: A Biochemic Study of Nitrogen in Certain Legumes, Illinois Exp. Sta. Bull. 179.

Burrill and Hansen: Is Symbiosis Possible between Legune Bacteria and Noulegume Plants, Illinois Exp. Sta. Bull. 202. 


\section{CHAPTER XXV.}

\section{CROP RO'TA'TION.}

Frour time immemorial it has been considered a self-evident fact that where crop rotation is practised there is a bigger and better rield. The farmers of ancient Rome understood that crops following beans, peas and retches were usually hetter than those following wheat or barley, but it was not until the last quarter of the nineteenth century that it was learned that the leguminous plants, with the aid of associated bacteria, have the power of feeding on the free nitrogen of the air, whereas the non-leguminous plants have not this power and require a supply of combined nitrogen. Today the best farmer's practise some șistem of crop rotation. They have learned from experience that where crop rotation is practised the crops are bigger and better than under the single crop system. This is usually interpreted as indicating that crop rotation has increased the fertility of the soil. Many farmers plant legumes for a number of years on run-down soil, remove the entire crop and feel confident that their soil is becoming richer in plant-food. Let us examine some of the results obtained in carefully plamned experiments to see if this conclusion is warranted by the experimental evidence.

Essential Elements.-Plants are composed of ten elements, each one of which is absolutely essential to growth and seed formation. Only two-carbon and oxygen-are secured from the air by all plants; only one-hydrogen-from the water; the other seren are secured by all plants from the soil. One class of plants-the legumes-may, under appropriate conditions, obtain their nitrogen from the air. six elements-phosphorus, potassium, magnesium, calcium, iron and sulphur - are obtained from the soil by the growing plant.

Element Added by Legumes.-The great majority of agricultural soils contain large quantities of all these elements, with the excep)tion of nitrogen, phosphorus and potassium. These are used by the growing plant in larger quantities than are any of the other elements which are obtained directly from the soil. In the great majority of soils nitrogen, phosphorus, or potassium is the limiting element in crop production. Therefore, our problem resolves itself into the question: Can crop rotation maintain these elements in the soil in quantities sufficient for maximum yields? Phosphorus 
and potassium are obtained by the growing plant only from the soil; it is, therefore, self-evident that no simple system of crop rotation can maintain the phosphorus and potassium, since the quantity within the soil must of necessity be reduced with each crop removed, the extent depending upon the specific crop grown. Hence, nitrogen is the only element which we can hope to maintain by crop rotation. But this is the element which is found in the soil in smallest quantity and removed by most plants in larger quantities than the phosphorus or potassium. Moreover, large quantities of this element are at times lost from the soil by leaching, while the loss of the others is comparatively small. It is of the greatest importance, therefore, that this nitrogen be supplied to the soils in sufficient quantities for crop production and in the cheapest manner possible. The total quantity of these three elements found in an acre-foot section of two Utah agricultural soils, assuming one acre-foot to weight 3,600,000 pounds, is given below:

Nitrogen

Phosphorus

Potassium
Greenville Farm (Utah), pounds per acre.

4,904

2,700

60,560
Nephi Farm (Utah), pounds per acre.

3,744

8,388

87,840

Both soils contain an abundance of potassium, but the supply of phosphorus and nitrogen is much lower. A study of these results shows that a 50-bushel crop of wheat each year for fortynine years would remove the equivalent of the total quantity of nitrogen in the Greenville soil to a depth of one foot, while a similar crop on the Nephi farm would accomplish this in just thirty-seven years. It would, however, require a 50-bushel crop one hundred and serenty years to remove the phosphorus from the Greenville soil and five hundred and twenty-five years to remove it from the Nephi soil. Of course a crop would never remove all the nitrogen or phosphorus from a soil, but in actual practice the elements are slowly removed, the crop yields beng reduced each year until a certain minimum is reached. When crops can no longer be produced economically then the owner abandons his soil, moves on to virgin soils, or if it be in an old district he resorts to the expensive commercial fertilizer. The illustration is, however, sufficiently accurate to make it clear that the limiting factor, in so far as soil fertility is concerned in both of these soils, is the nitrogen. And it is true of the great majority of all soils that an increased nitrogen supply means an increased yield. This principle is one of the fundamentals of soil fertility.

Nitrogen.--Nitrogen exists in the atmosphere in inexhaustible quantities, every square yard of land having seven tons of nitrogen lying over it, or if the quantity covering one acre could be combined into the nitrate it would be worth as a fertilizer $\$ 125,000,000$. 
Now it has been demonstrated that the legumes-peas, beans, alfalfa, etc. - when properly infected have the power of feeding on this limitless supply of atmospheric nitrogen, while the non-legumes - barley, wheat, oats, ete.-must depend upon the supply within the soil, and the farmer must take advantage of this fact to supply nitrogen for his crops, as the commercial fertilizer camnot be economically used for the production of most crops, as is seen from the fact that the nitrogen in a 50-bushel wheat crop would cost $\$ 14.40$, or 20 tons of sugar-beets $\$ 15.00$, or 1 ton of alfalfa hay $\$ 5.50$, if bought as a commercial fertilizer. But will the legume draw nitrogen from the atmosphere while there is a supply in the soil, or will it follow the line of least resistance and turn only to the atmosphere when nitrogen is lacking in the soil? If it does, it must first drain. the soil of its valuable nitrogen and thus leave it no richer than it was before the legume was grown upon the soil. 'This is the problem which this chapter is to answer.

Rothamsted Rotation.-Crop rotation has been practised for centuries, but the oldest system on which we have accurate information is the one on Agdell Field at the Rothamsted Experiment Station. This system was inaugurated in 1848 and is still being carefully followed. It consists of a four-year rotation, as follows:

First year: Swede turnips (rutabagas).

Second year: Barley.

Third year: Clover or beans.

Fourth year: Wheat.

Still another system has been running parallel and similar to this, except that fallow cultiration is practised in the third year instead of growing a legume. The average rields for twenty-rear periods are given below. These systems are of special interest to western farmers, for when we substitute sugar-beets for the turnips and alfalfat or peas for the clover or beans, we have nearly an ideal rotation for our soils.

Legumes.

Fallow.

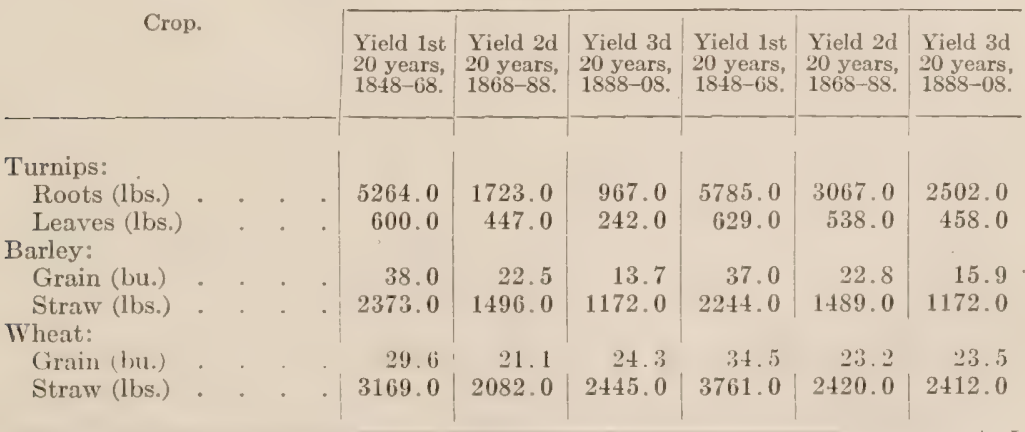


Eren where the legume was used in the system there had been a decline in the rield. The rield of the turnips during the first twenty years mas 5264 pounds, the second 1723 , and the third only 967 pounds, thus showing a decrease of about fire-sixths the original in sixty years.

The results with the barley are no better, for there is a drop from the fair yield of 38 bushels per acre during the first perior to only 13.7 during the third. The wheat which followed the legume in the rotation, and hence occupied the most farored place in the system, shows a decrease of 5.3 bushels. Not even a good rield has been maintained for the clover, for from 1850 to 1874 the average yield was 4165 pounds, while from 1882 to 1906 the yield was only 1246 pounds. In reality we find no greater decline in the yields where fallow cultivation is practised. But both systems strongly testify to the fact that rotation is not maintaining the productive powers of this soil. And the evidence is strong that the legume gets no more nitrogen from the air than that which is removed with the plant. Otherwise, we should expect better results in the legume system than in the fallow system.

Nitrogen Obtained from Atmosphere by Legumes.-That the alfalfa, when grown on fertile soil and the crop removed, does not increase the nitrogen of the soil is seen from experiments conducted by Dr. Hopkins at the L'niversity of Illinois. The experiments were made possible by the fact that many of the Illinois soils do not normally contain the symbiotic bacteria which make it possible for the alfalfa to obtain nitrogen from the air. This being the case, a field was taken which had not grown alfalfa and which did not contain the symbiotic nitrogen-gathering bacteria. This was planted to alfalfa, only one-half of it being inoculated with the legume organism. To some of the plots were added lime and phosphorus to make sure that these were not the limiting factors. The results thus obtained are given below:

\begin{tabular}{|c|c|c|c|c|c|}
\hline \multirow{3}{*}{ Plot No. } & \multirow[b]{2}{*}{ Treatment applied. } & & \multicolumn{2}{|c|}{ Pounds in crop: } & \multirow{2}{*}{$\begin{array}{l}\text { Pounds, nitrogen } \\
\text { fixed by bacteria. }\end{array}$} \\
\hline & & & Dry matter. & Nitrogen. & \\
\hline & None . . & & 1180 & 21.81 & \\
\hline 16 & Bacteria & . & 2300 & 62.04 & 40.23 \\
\hline $2 a$ & Lime & . & 1300 & 26.20 & \\
\hline $2 b$ & Lime bacteria. & . & 2570 & 68.02 & 41.82 \\
\hline $3 a$ & Lime phosphorus & . . . & 1740 & 35.40 & \\
\hline $3 b$ & Lime phosphorus & bacteria & 3290 & 89.05 & \\
\hline
\end{tabular}

It is evident from these results that the alfalfa had obtained from 40 to 53 pounds of nitrogen from the air, depending upon the treatment. There was slightly more than one-third as much nitrogen in the alfalfa crop from the uninoculated as in the inoculated. 'Therefore, it is quite evident that the alfalfa in these plats had obtained one-third of its nitrogen from the soil and two-thirds from 
the air. Now, nitrogen is required by the root for its growth as well as for the growth above the ground, and we have every reason for believing that the root also would obtain it in the same proportion from air and soil as did the hay crop.

Distribution of Nitrogen in Legumes. - If we examine dry matter and total nitrogen occurring in the roots and stalks of alfalfa, we should be able to decide whether more nitrogen is being returned to the soil in the roots and residues than is remored by the growing plants.

The results for this comparison have been obtained from Illinois and Delaware experiments and are tabulated below:

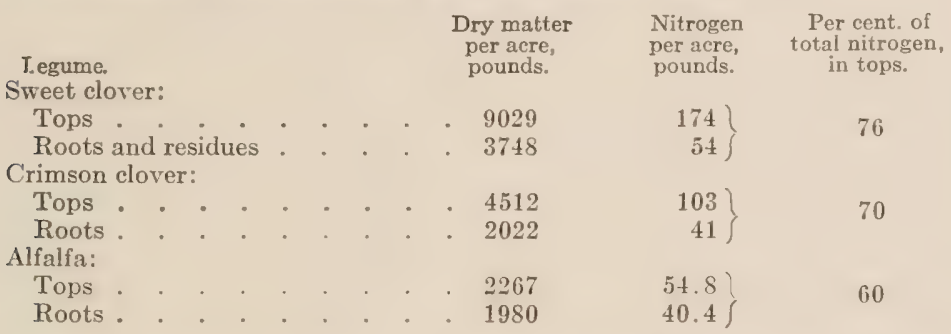

With the clover, three-fourths of the total nitrogen is found in the plant above ground and only one-fourth in the roots, while alfalfa shows a greater proportion in the roots - 40 per cent. This represents the proportion for the first-year growth for alfalfa and it is not likely that in the older plant this proportion of the total nitrogen would be maintained in the roots. Hence, it is quite certain that if only two-thirds of the total nitrogen of the plant is obtained from the air the quantity returned to the soil with the roots and plant residues does not exceed that removed from the soil by the growing plant, which would give no increase in soil nitrogen from the growing of a legume where the entire crop is removed, and this even where the roots are allowed to remain and decay. Iet we find some farmers who remove the roots from the soil and even then expect an increase in their soil fertility.

Legumes Feed on Nitrates. - It is, therefore, rather certain that the legume, where the crop is harrested, does not increase the soil nitrogen of the fertile soil of Illinois and other soil fairly rich in nitrogen. But what will happen on the arid and semi-arid soil where nitrogen in many cases is the limiting element and is present in much smaller quantities than it is in the soils on which the experiments considered have been conducted. Experiments which have been conducted at the Ltah Experiment Station during the last twelve rears have demonstrated that even on soils poor in nitrogen the legume first feeds upon the combined nitrogen of the soil. It is known that plant residues and other complex nitrogen 
compounds found in the soil are transformed by bacteria into ammonia, and this in turn by another class of bacteria into nitric nitrogen, and it is mainly on this nitrogen that the growing plant feeds. The quantity of this found in the soil at different periods under different plants has been measured at the I'tah Experiment Station and the average results for twelve years are given in tabular form below, stated as pounds of nitric nitrogen per acre to a depth of six feet.

\begin{tabular}{|c|c|c|c|c|c|c|c|c|c|}
\hline \multirow{2}{*}{\multicolumn{6}{|c|}{ Crop. }} & \multicolumn{3}{|c|}{ Season. } & \multirow{3}{*}{$\begin{array}{c}\text { Average. } \\
23.6\end{array}$} \\
\hline & & & & & & Spring. & Midsummer. & Fall. & \\
\hline Alfalfa. & . & . & . & . & . & 22.3 & 15.8 & 32.8 & \\
\hline Oats. & . & . & . & . & . & 35.7 & 14.1 & 20.6 & 23.5 \\
\hline Corn . & . & . & . & . & . & 24.8 & 18.9 & 22.0 & 21.9 \\
\hline Potatoes & . & . & . & . & . & 81.1 & 60.8 & 54.2 & 65.3 \\
\hline Fallow & . & . & . & . & . & 81.5 & 53.6 & 62.6 & 65.9 \\
\hline
\end{tabular}

The legume, alfalfa, removes the nitric nitrogen from the soil equally as fast as do the non-legumes. Tet this soil was wellinoculated with the symbiotic bacteria which undoubtedly assisted the alfalfa in obtaining free nitrogen from the air when needed, but not until the soluble nitrogen had been drained from the soil to its full extent, as shown by the fact that alfalfa soil never contains more than does oat and corn land, and is very poor as compared with potato and fallow soil.

Nitrification in Soils.-It may be argued that the small quantity of nitric nitrogen in the alfalfa soil is due to a lack of its formation, as it is not needed by the legume, and hence not formed. This conclusion, however, is not warranted by the facts in the case, as may be seen from the results obtained where nitrification was measured. These also are the average results extending over a number of years and obtained at the Utah Experiment Station.

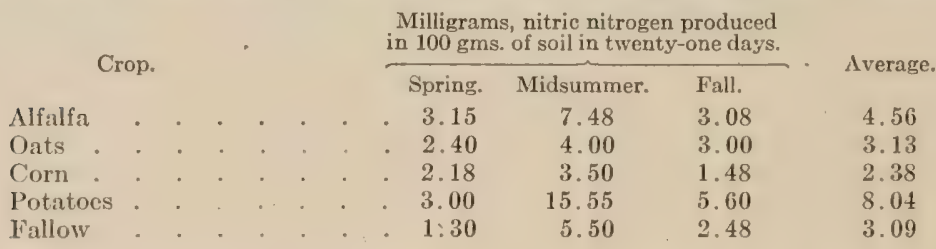

Here the quantity of soluble nitrogen produced in the alfalfa soil is greater than that produced in either the oat, corn, or fallow soil. There is no doubt that this is one reason why an increased vield is obtained the year following the plowing up of legumes for this increased action also occurs the next year after an alfalfa field is planted to some other (rop. 'This is due to the stimulation of bacterial organisms of the soil by the alfalfa plant so that they make arailable faster the nitrogen of the soil, but this only depletes the soil of its nitrogen more readily than the non-legume, as it is the nitrogen alrearly combined in the soil on which the nitrifying 
organisms act. Hence, we must conclude that alfalfa not only feeds closer on the soluble nitrates of the soil, but it also makes a greater drain upon the insoluble nitrogen of the soil by increasing its nitrifying powers and would therefore deplete the soil if the entire crop be removed, more readily than would other crops-a conclusion which is borne out by the direct analysis of the soil.

The analysis of a great number of Ctah soils which have grown various crops for a number of years-some of them having been into alfalfa or wheat for upward of thirty years-revealed the fact that almost invariably the alfalfa soil contained less total nitrogen than did the wheat soil. The arerage for a great number of determinations made from alfalfa soils was 72:32 pounds per acre of total nitrogen, while the average for a great number of wheat soils was 7.395 pounds. These are average results from at great number of determinations made on adjoining alfalfa and wheat soil and they clearly indicate that in ordinary farm practice the alfalfa is making just as heary a drain upon the soil nitrogen as is the wheat.

Hence, from a consideration of the rields obtained in crop rotation, the relative quantities of nitrogen obtained from the atmosphere and the soil by the alfalfa, the feeding and stimulating effect of the alfalfa upon nitrification, and finally the actual quantity of total nitrogen remaining in the soil after wheat and legumes, we must conclude that the legume does not increase the nitrogen of a common agricultural soil-even in the arid region where the nitrogen is low-when the entire crop is removed.

This conclusion does not, however, mean that crop rotation should not be practised, for there are many reasons why crop rotation commends itself to the careful farmer, but it must not be used and the legume remored with the intention of maintaining soil fertility. This mar appear to be an unfortunate conclusion, but it is just the reverse, and if its teachings be heeded it means a fertile soil and an economic gain to the farmer from the system of farming which it requires him to adopt.

How to Maintain Soil Nitrogen.-There are two practicable methods of maintaining the nitrogen content of the soil. (1) Plamning systems of crop rotations with legumes, the legumes being plowed under and allowed to decay, thus furnishing nitrogen to the succeeding crop; ( $(2)$ practising a combined system of crop rotation and livestock farming.

Three tons of alfalfa contain 150 pounds of nitrogen, all of which we could assume came from the atmosphere. Assuming the quantity found in the roots as coming from the soil, this is the equivalent of the nitrogen found in the grain and straw of 75 bushels of wheat. If the alfalfa is plowed under some of the nitrogen would be lost to the growing plant in the processes of decay and leaching, but that the total nitrogen of the soil may 
actually be increased by the turning under of the legume is certain from field experiments.

The l)ominion of ('anada Experiment Stations grew mammoth clover for two successive seasons on a soil very low in nitrogen. The two cuttings of mammoth elover with all the residues were turned under each year with the result that the soil gained as an average 177 pounds per acre of total nitrogen which is the quantity of nitrogen found in three 40-bushel crops of wheat, provided the straw was returned to the soil, as two tons of this contains 20 pounds of nitrogen. On the other hand, work on the soil of the [tah Nephi Experiment Farm, with a rotation of wheat and peas where the peas were plowed under, showed a gain in total nitrogen of 240 pounds in four years. That is, in addition to furnishing the small quantity of nitrogen required by the wheat crop, the peas had added to the soil an average of 60 pounds of nitrogen per year.

The second method of maintaining the nitrogen and organic matter of the soil - the combined rotation and livestock methodis the more practical, and if systematically practised will not only maintain the nitrogen of the soil but will prove of great economic value to the individual following it. For it consists of a rotation in which the legume plays a prominent part. The legume to be fed and all the manure returned to the soil, which would mean the selling from the farm of the hay crop in the form of butter, milk or beef which carries from the soil only a fraction of the nitrogen stored up by the legume. Moreover, it brings for the producer much greater returns than does the system in which the legume is plowed under.

It must, however, be remembered in this system that only threefourths of the total nitrogen of the feed is recovered in the dung and urine. So that in place of three tons of alfalfa adding 150 pounds of nitrogen to the soil from the air, it would add only 120 pounds, and this is where all of the liquid and solid excrements are collecterl and returned to the soil. But where the alfalfa is to be ferl and the manure returned to the soil, the legume can occupy a much longer period in the rotation and that with greater economy than where the legume is to be plowed under directly.

IIence, we find that if these principles which have been established for soils even low in nitrogen be systematically applied to the soil, it will result in greater revenue from an increased livestock industry and will maintain the soil rich in nitrogen and organic matter in place of depleting it of its stored-up nitrogen, as is so often the case with the present methods.

\section{REFERENCES.}

Hopkins: Soil Fertility and Permanent Agriculture.

Greaves, Stewart and Hirst: Influence of Crop, Season and Water on the Bacterial Activities of the Soil, Jour. Agr. Research, ix, 293-341. 


\section{CHAPTER XXVI.}

\section{CELLULOSE-DECOMPOSING ORGANISMS.}

THE plant residues which find their way into the soil contain, in addition to protein, non-protein compounds. These are decomposed by microörganisms, thus liberating the energy and returning the carbon to the atmosphere so that it is again available to plants. The reactions occurring in this process are probably the reverse of those occurring in the fixation of carbon by the plant.

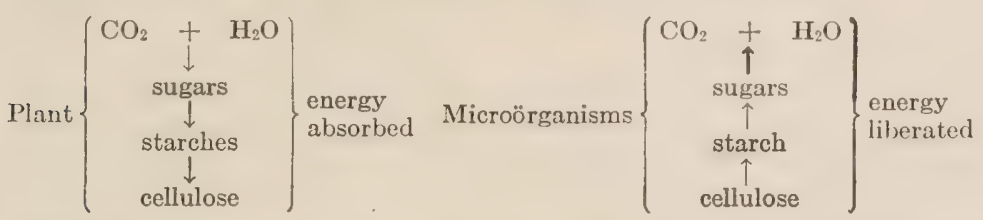

Cellulose.- The term cellulose does not designate a single individual compound but undoubtedly a whole series of compounds. All of these are extremely complex and pass gradually from the tender hemi- or pseudo-cellulose of the young plant, which is comparatively soluble in acids and alkalies, to the more complex and very resistant lignocelluloses. All are forms of cellulose, but their properties are exceedingly different. The first may serve as - food even to man, but the latter is highly resistant to all the common solvents. It is, however, dissolved by a few special solvents, such as ammoniacal solutions of copper oxid, carbon bisulphid in sodium lrydroxid, and a few others. Cellulose is nitrogen-free and is made up of carbon, hydrogen, and oxygen having the empirical formula, $\left(\mathrm{C}_{6} \mathrm{H}_{10} \mathrm{O}_{5}\right)_{n}$. On hydrolysis, it yields various sugars, depending upon its source, as glucose, mannose or xylose. In the process of hydrolysis, there results certain intermediate dextrin bodies, a study of which has shown cellulose to be extremely complex. Besides these there are certain gums, pectins, lignins and similar compounds, which are nearly related to cellulose and which have not been differentiated from the true cellulose by many investigators. The results are that the power of decomposing cellulose has been attributed to certain organisms but a careful study of the subject has revealed later that the organism decomposed some of the related compounds but left cellulose unaltered.

Early Observations. - That carbon passes through a definite cycle from the solid organic tissues of plants to the gaseous form of the 
atmosphere has been known for a long time, but it was usually thought of as passing from the solid complexes to the gaseous compounds through its direct combination with oxven at a high temperature. In fact, this was considered as being the only method until Pasteur pointed out that there were other means. He considered it as being brought about by molds. Later Mitscherlich (18:0) observed that when moist potatoes decay the cell wall is dissolved and the starch gradually passes out. "This he thought to be due to a group of organisms, but nothing was done to show that it was the work of any species until about fifteen years later when Trecúl isolated an organism which had the power of decomposing young plant tissues and which was stained blue by iodine. 'To this organism he gave the name amylobacter. The organism he claimed had the power of decomposing cellulose with the formation of butyric acid, carbon dioxid, and hydrogen. As all of his work, however, was carried on with plant tissues, it leaves a question as to whether the amylobacter had actually decomposed cellulose or only some of the nearly related compounds.

The decomposition of cellulose in manure was studied by l)ehérain, Gayon, Herbert and Popoff. The last investigator was the first to recognize the similarity between the method of production of methane in servage and the intestines of animals. He studied the action which took place when a medium containing Swedish filter paper was seeded with sewage, and obtained a large volume of gas, an analysis of which showed it to consist of carbon dioxid, methane and hydrogen. The first two he thought to be due to a cellulose ferment, but the latter to a butyric acid ferment. At the end of the incubation period, there was a gummyr mass in the fermentation flasks.

For a long time after this the attention of the investigators seemed to be directed mainly to a quantitative study of the resulting products of fermentation. 'This is especially true with the work of Tappeiner and Hoppe-Seyler. The former, with the idea of determining the bacterial changes which take place normally in the intestinal canal, introduced finely divided cotton or paper into flasks containing a 1 per cent. neutral solution of beef extract. The flasks and contents were sterilized and then inoculated with small quantities of pancreatic juice and incubated at $35^{\circ} \mathrm{C}$. They were so arranged that the gases could be collected and analyzed. The resulting product consisted of acetic acid, isobutyric acid, acetaldehyd, methane and carbon dioxid. 'The last two were in the ratio of 1 to 7.2 at the beginning of the process and 1 to 3.4 at the close. In another set of experiments he used an alkaline medium and obtained the same qualitative but different quantitative results, there being a large amount of hydrogen evolved in the alkaline medium. 
From his work, he concluded that cellulose undergoes a fermentation in the first stomach of ruminants and in the alimentary canal of all herbivora. In later work he tried to decide whether this fermentation was due to an organized or to an unorganized ferment. 'This he did by inoculating suitable flasks with the contents of the alimentary canal of oxen. The flasks were divided into three sets and treated as follows: (1) Heated, (2) treated with antiseptics (thrmol and the like) and (3) untreated. Fermentation occurred only in the last set from which he concluded that it was due to bacterial action. From his work in general he decided that bacteria have the power of decomposing cellulose with the formation of carbon dioxid and methane and that this process plays a large part in the digestive processes of herbivorous animals.

Hoppe-heyler, who considered the fermentation process mainly from the changes which take place when cellulose is decomposed in soil or beneath water, commenced his experiments by collecting and analyzing the gases given off from soils and swamps. These he found to consist mainly of carbon dioxid and methane. Later he carried out laboratory determinations by placing 25.773 grams of filter paper into 1000 c.c. flasks containing 700 c.c. of water and inoculated with mud. They were so arranged that the gaseous products were collected over mercury. Ile incubated them at room temperature for four years. 1)uring the first year there was considerable gas evolved, but the evolution gradually became slower until at the end of four years the evolution of gas had practically ceased. An analysis showed that 15) grams of the cellulose had been decomposed with the formation mainly of carbon dioxid and methane. He was unable to find any of the true sugars, although he thought it possible that there were some of the dextrin compounds in the solution. When air was excluded he found that there was a greater production of methane and a smaller one of carbon dioxid. From his work he considered the reaction proceeded in two stages: First, a hydration of the cellulose with the formation of a hexose according to the equation, $\mathrm{C}_{6} \mathrm{H}_{10} \mathrm{O}_{5}+$ $\mathrm{H}_{2} \mathrm{O} \rightarrow \mathrm{C}_{6} \mathrm{H}_{12} \mathrm{O}_{6}$. From the hexose, carbon dioxid and methane was formed $\left(\mathrm{C}_{6} \mathrm{H}_{12} \mathrm{O}_{6} \rightarrow 3 \mathrm{CO}_{2}+3 \mathrm{CH}_{4}\right)$, or perhaps acetic acid was an intermediate product and then carbon dioxid and methane were formed according to the equation, $\mathrm{CH}_{3} \mathrm{COOH} \rightarrow \mathrm{CO}_{2}+\mathrm{C}_{4}$.

In 1889 Schlösing published his quantitative results of the investigation on the decay of manure. He collected the gases given off in the course of two months in the decay of manure and analyzed them. He concluded that the change was similar to alcoholic fermentation.

Three years later the work of Herbert appeared. He inoculated 5 per cent. solutions of potassium carbonate or ammonium car- 
bonate containing finely divided straw with manure. At the end of three months, when the evolution of carbon dioxid and methane had nearly ceased, he examined the residue with the following results:

Substance in the straiw.
Cellulose
Wood gum :
Vasculose

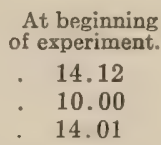

$\begin{array}{cc}\begin{array}{c}\text { At end } \\ \text { of process. }\end{array} & \text { Loss. } \\ 6.18 & 56.2 \\ 4.67 & 53.3 \\ 11.75 & 16.1\end{array}$

Deherain studied the substances given off in the decomposition of manure with the following results:

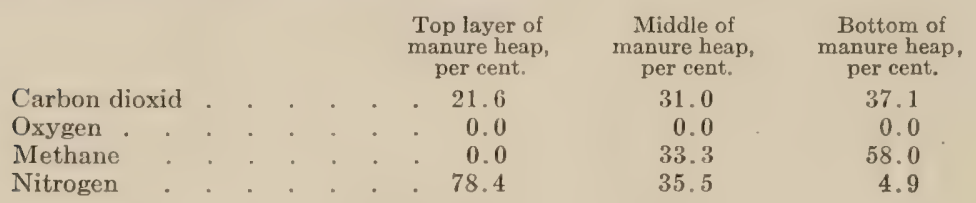

In the layers in which there was considerable oxygen, as may be seen, the amount of combustible gas given off was zero, but in the middle and lower layers of the manure heap the resulting methane was over half of the gaseous product. Similar results were obtained by Gayon, who studied the changes resulting with a limited and free access of air and found that methane was obtained in much larger quantities when the air had been excluded. From this, he concluded that methane fermentation is due to an anaërobic organism.

Preceding this work was that of van Senus, who found that cotton and plant tissues were decomposed by microörganisms with the formation of carbon dioxid, methane, hydrogen, butyric acid, acetic acid, alcohol, aldehyd and a trace of the higher fatty acids. He thought the methane was formed through the reduction of acetic acid by means of hydrogen. He considered the action as being brought about by two organisms - one the amylobacter of Trecúl, and another very small bacillus which he had isolated from the alimentary canal of a rabbit. He considered that they acted by means of an excreted enzyme, which he precipitated by means of alcohol and found an aqueous solution of the same had the power of decomposing cellulose.

Work of Omelianski. - As may be seen from the preceding brief summary of the work, practically all that had been done on the subject prior to 1895 was directed at a study of the chemistry of the process and little had been done in trying to isolate in pure cultures the specific organism or organisms which had the property of decomposing cellulose. It was at this point that the work was taken up by Omelianski, who studied very carefully the chemical and bacteriological phases of cellulose fermentation. 
In his work, the following medium was used:

Potassium phosphate

Magnesium sulphate

Ammonium sulphate

Sodium chlorid

Distilled water
$17 \mathrm{gm}$.
$1 \% "$
1 "
trace
1000 c.c.

In some cases he replaced the ammonium salt with 0.5 per cent. asparagin, 1 per cent. peptone, or 0.5 per cent. beef extract. The solutions were placed in flasks containing filter paper and then inoculated. Inasmuch as the incubation period of cellulose fermentation is long and variable, he found it best to seed with considerable of the organism. Ordinarily, this was done by taking a small piece of the decomposing paper from an old culture.

Soon after inoculation there was observed a slight turbidity in the flasks. Then the paper thickened and assumed a decayed appearance. It was covered with little specked places where it had been decomposed by the organisms. This latter appearance varied; at times the holes were large and few, and at other times they were small and very numerous. At still other times the paper seemed to thicken and then to fall to pieces. At the end of the process there remained a residue entirely different from the original paper. In old cultures the white appearance of the paper had disappeared and it had taken on a yellowish brown color, which often appeared even in the surrounding solution. The gases given off had the odor of decayed cheese. At the height of the process particles of filter paper were carried to the surface of the liquid by the gas. The above description applies to the process as brought about by both the hydrogen and methane organisms which Omelianski succeeded in isolating in pure cultures by the method of repeated heating $\left(75^{\circ}\right.$ (. for fifteen minutes), which is based on a difference in the life history of the two organisms. The methane fermentation organism develops more rapidly than the other rariety and gains the supremacy in the early stages of the process. If heat be applied at this stage the more slowly germinating spores of the hydrogen-fermenting organism, being in a resistant stage, survive.

Morphology and Physiology. - A microscopic examination of the hydrogen ferment reveals the following: In the young culture the bacillus is about $0.5 \mu$ in width and from 4 to $\delta \mu$ in length. In old cultures they are from 10 to $15 \mu$ in length. They never occur linked together in chains but appear as slightly bent rods. In still older cultures they take the drumstick form which gradually develops into a round spore about $1.5 \mu$ in diameter. They are readily stained by the anilin dyes. In old cultures they give the characteristic colors for the spore and surrounding sheath with carbol-fuchsin and methylene blue. They are not stainerl blue 
with iodin, and conseduently are different from the amylobacter of 'Trecul. No growth occurs usually in the ordinary cultural media, though Omelianski has observed on some occasions very minute translucent colonies on potatoes.

This investigator carried out quantitative determinations of the substances rielded by the organism. It was done in flasks containing $300^{\prime}$ c.c. of a mineral salt solution containing calcium carbonate and swedish filter paper. The flasks were inoculated with the organism and incubated for thirteen months. On analysis the following results were obtained:
Cellulose at beginning of process
Cellulose at end of period
Decomposed
3.4743
0.1272
3.3471

$\begin{array}{ll}\text { Resulting products. } & \\ \text { Fatty acids } & 2.2402 \\ \text { Carbon dioxid } & 0.9722 \\ \text { Hydrogen } & 0.0138\end{array}$

Chief among the fatty acids yielded were acetic, butyric, and valeric acid. Besides these there were traces of the higher acids found.

The methane fermentation, according to Omelianski, takes place if a flask containing filter paper, lime and a mineral neutral solution be inoculated with mud or fresh horse manure and kept under anaërobic conditions at a temperature of from $35^{\circ}$ to $37^{\circ} \mathrm{C}$. After a short time a careful examination of the filter paper revealed numerous bacilli. By successive subculturing, while the methane fermentation was at its height, the hydrogen ferment was soon eliminated. The methane organism is rod-shaped, slightly more bent than the hydrogen ferment. It never develops in chains, but in old cultures assumes the trpical drumstick form with a spore in the end. The organism is $0 . \dot{t} \mu$ in width and $\bar{\delta} \mu$ in length. It is not stained blue by iodine and hence is different from the amylobacter of 'Trecul. From this it may be seen that both the regetative cell and spore are slightly smaller than the hydrogen ferment. Though morphologically very similar, phrsiologically they are very different, since one yielded hydrogen and the other methane. This is shown by the quantitative studies of Omelianski. They were conducted in 500 c.c. flasks containing 2.0685 gms. of Swedish filter paper, 4.9482 gms. of calcium carbonate, and a 0.1 per cent. solution of ammonium sulphate. They were inoculated with 0.013 gm. of filter paper from an old culture. Orer one month elapsed before fermentation became perceptible and eren then it was very slow as is shown by the fact that the gaseous material evolved never exceeder 1.1 c.c. in twenty-four hours, and at the end of four and a half months had dropped to 0.01 c.e. for twenty-four hours. The resulting gas was mainly carbon dioxid and methane, $0.7146 \mathrm{gm}$. of the carbon dioxid and $0.1372 \mathrm{gm}$. of the methane. In the flask there remained only a small amount of cellulose but 
a large amount of acetic and butyric acids. In fact over one-half of the decomposed cellulose had been transformed into these acids.

Later Work on Cellulose Fermentation. - Later work which has been carried out by van Iterson has shown that there are certain of the non-sporeforming, denitrifying organisms which have the power of decomposing cellulose. In the presence of nitrates, the chief products are nitrogen and carbon dioxid. Aceording to this investigator, the decomposition is brought about by Bucillus ferrugineus, which is the chief cause of the brown color of humus due to a pigment formed from cellulose by this organism.

Recently Kellermann and McBeth have questioned the work of Omelianski. While they admit the great importance of these organisms in the formation of humus in agricultural soils, they claim that the organisms described by Omelianski were not pure cultures and furthermore that cellulose is decomposed under aërobic conditions. These investigators have isolated thirty-six species from various sources. These were found to be much more active than the ones described by Omelianski. They were all rodshaped organisms varying in length from 0.8 to $3.5 \mu$. Involution forms have been observed for only three species. Five species have been found to produce spores. Twenty-seven species are motile; of these, seven are pseudomonas and twenty are bacilli. A few are facultative anaërobes. The optimum temperature lies between $25^{\circ}$ and $33^{\circ} \mathrm{C}$., but they grow well from $20^{\circ}$ to $37.5^{\circ} \mathrm{C}$. They grow readily on solid media such as beef agar, gelatin, starch and potato. Nineteen species liquefy gelatin. They rapidly decompose cellulose and other carbohydrates with the production of acids, but none of the organisms so far studied produce a gas.

Function. - It may be well to call attention to the great part taken by this class of organisms in returning carbon to the atmosphere. This is especially the case with the material which passes off in the sewage. In septic tanks there are millions of these organisms busy changing the most resistant organic matter into gaseous products, and many large cities today depend upon this for the disposal of their sewage. Organisms also take a great part in the purification of a city's water supply. 'They also take part in the formation of soil humus, as was pointed out by Omelianski when he gave the general reaction, $2 \mathrm{C}_{6} \mathrm{H}_{10} \mathrm{O}_{5} \rightarrow 5 \mathrm{C}^{\prime} \mathrm{O}_{2}+5\left(\mathrm{CH}_{4}+2 \mathrm{C}\right.$, and he says, "It is possible that a general reaction of this sort forms the basis of the universal processes of humification, that is, the gradual transformation of organic substances into a mixture of brown and black substances with a high content of carbon, such as is characteristic of fossil coals. But whatever the mechanism of these transformations, the active participation of microörganisms in the latter cannot be denied."

The cellulose ferments break the plant residues into less com- 
plex organic compounds which are fermented by other organisms with the generation of large quantities of organic acids. These would react with the minerals of the soil rendering them available. This is very likely the cause of the good results obtained from raw rock phosphate and stable manure on phosphorus-poor soil. The fermentation of the cellulose yields acids which render soluble the phosphorus. This formation of acids may at times, howerer, become excessive, giving rise to the sour humus of moors and heaths.

It is well known that the fermentation processes in the soil resulting in the decomposition of organic matter may give rise to large quantities of carbon dioxid, methane and hydrogen. The hydrogen and methane do not all pass into the atmosphere, but according to the researches of recent investigators furnish energy to numerous soil organisms, the importance of which remains almost wholly for future workers to develop. The first work on this subject was done by Immendorff, who in 1892 found that hydrogen and oxygen may be made to unite under the influence of soil. He found that the oxidation of hydrogen was brought about only by normal soil and not by soil previously treated with chloroform vapor. This observation remained unnoticed until recently when two papers appeared-one by Kaserer and the other by Solmgen-which throw considerable light on this phase of carbon and hydrogen transformation. They used an inorganic solution containing dipotassium phosphate, ammonium chlorid, magnesium sulphate, sodium bicarbonate, and a trace of ferric chlorid. This, they inoculated with a small quantity of soil and confined in an atmosphere consisting of a mixture of hydrogen, oxygen and carbon dioxid. Growth took place and the hydrogen disappeared. The presence of a small quantity of carbon dioxid seemed to be necessary for the development of the organisms, and it would appear that like the nitrifying bacteria they can produce bacterial protein in inorganic solutions, deriving their carbon from carbon dioxid. This reaction, according to Lipman, is of great significance in agriculture, for a great loss of energy is prevented by the bacterial oxidation of hydrogen formed in the deeper layers of the soil by anaërobic ferments. It also partly counteracts the rapid mineralization of organic materials, in that it leads to the formation of complex compounds from carbon dioxid, hyidrogen and oxygen.

Kaserer and Solmgen also obtained organisms capable of utilizing methane as the sole source of energy in their life process. The latter investigator secured pure culture of an organism which he named Bacillus methanicus. When grown in inorganic solutions confined in an atmosphere of one-third methane and two-thirds air, it caused the disappearance of the methane with the production, of considerable quantities of organic material. 
The cellulose ferments also perform other direct functions in the soil, as for instance, the liberating of plant food which is bound up in plant residues. Heinze has very recently ascribed to bacterial activities much of the benefits obtained from summer fallowing. In quantitative studies he found them to be more numerous in fallow soil than in cropped soil, and he thinks it to be due to their activities in rendering the cellulose more suitable as a carbon supply for the Azotobacter that causes the increase of soil nitrogen in fallow land noted by a number of recent workers. One of the more important problems of today in soil bacteriology is the relationship between this class of organisins and other important soil organisms, especially the nitrifiers and the nitrogen fixers.

\section{REFERENCES.}

Lafar: Handbuch der Technischen Mykologie.

McBeth: Studies on the Decomposition of Cellulose in Soils, Soil Science, i, $437-488$. 


\section{CHAPTER XXVIII.}

\section{BAC'TERIA IN AIR.}

BACTERIA require for their growth moisture, food, a suitable temperature and usually the absence of direct sunlight. The moisture conditions of the atmosphere at times may be optimum for the growth and reproduction of bacteria, but none of the other conditions are. Hence, bacteria do not multiply and grow in the atmosphere as they do in water, soil and milk. These substances may and do have a natural bacterial flora, but we cannot consider the air as having a definite one, for the number and kind continually vary with many factors and there are scarcely two places having the same number and species of microörganisms.

How Bacteria Enter Air.--The earth is surrounded by the atmosphere, which when "looked at as a whole, its calms are exceptional, and its movements are the rule. We may find the gentle breeze, the cyclonic wind or the restless tornado, but always active. These movements do not confine themselves to horizontal paths, but the gases rise and plunge, pursue broad curves and narrow spirals, and would present-to an eye that could see them from above-a tumult like the sea in storm." In all this activity it is picking up bits of sand, organic matter and oftentimes even water. These contain microörganisms which are carried into the air and may subside with the particle to which they adhere or become free and float about for a period.

As the waters of the ocean, lakes, rivers and smaller streams beat against some barrier the fine spray so formed carries into the air bacteria, as do' also the hurrying feet and rattling wheels in a crowded street. Furthermore, individuals speaking or coughing force from the mouth numerous bacteria which for a time help to make up the microbial inhabitants of the atmosphere.

Number and Kind.-The number and kind of organisms found in the air are governed largely by the locality. 'They are most plentiful in densely populated areas and within buildings such as churches, theaters and other places where a large number of people congregate. Miquel found that as an average 1 cubic meter of air from the streets of Paris contained 3480 bacteria, laboratory air, 7420, the air of old houses 36,000 , whereas the air of the Paris IHospital contained 79,000$)$ bacteria in 1 cubic meter. It is quite evident from these figures that air of inhabited districts contains many bacteria. These are carried on the dust particles. It does not, however, always follow that the number of bacteria in the air is an exact 
measure of the number of dust particles. An examination of the air of the London streets showed it to contain between 300,000 and 500,000 dust particles per cubic centimeter, but there was only one microörganism to every $38,300,000$ dust particles. The number of species present will vary with the locality, but probably in the majority of cases it is not great. Fischer states that an examination of the street dust in the city of Freiburg showed it to contain from five to seventeen different species of bacteria in 1 gram of dust which contained from 24,000 to 2,000,000 organisms per gram. Graham Smith found at the top of the Clock T'ower of the House of Parliament in London only one-third the number of bacteria that were found at ground level. IVhipple found 1330 bacteria per cubic foot in air at street level, while at the tenth story of the John Hancock Building in Boston the air contained 330.

Factors Governing Number and Kind.-The sprinkling of the streets greatly increases the number of bacteria in the dust, but it decreases the number in the air. This is due to the fact that the moist particles are not dislodged and carried into the air as freely as are the dry.

The air of the country contains fewer bacteria than does the air of the city. Miquel found as an average 300 organisms per cubic meter of air taken outside the city of Paris and 5445 bacteria per cubic meter of air taken within the city.

The number of bacteria in air over oceans is low and varies with the nearness to land. (lose to shore there are often very many, while at great distances from land the air may be free from bacteria.

On mountain tops, in deserts, and in other uninhabited regions the air is nearly free from bacteria. The classical illustration of this fact is found in the experiments carried on by Pasteur to refute the doctrine of spontaneous generation. He exposed flasks containing organic infusions in various localities. Of 20 such flasks exposed to the air of Mer de Glace 19 showed no contamination. In similar experiments Tyndall exposed 27 flasks containing beef infusion to the air of the Aletsch Glacier $(8000)$. None showed contamination, whereas 90 per cent. of a similar number opened in a hayloft did.

The number of organisms in air decreases with the altitude as well as locality. Jean Binot did not find a single microörganism in 100 liters of air taken on the summit of Mount Blanc. The number rapidly increased on descending.

On the summit

At the Grand Plateau

At the Grand Malet 
The number of bacteria in the air varies with the season, increasing from winter to summer and decreasing from summer to winter. There is also a marked decrease in the number of bacteria in the air after a rainstorm. The rain carries them to the ground and also moistens the surface so that particles of dust are not carried into the air by every breeze. But the added moisture of the soil greatly increases the speed of multiplication so that later as the surface soil dries out more dust and with it a greater number of bacteria are carried into the air. It is also true that the number of microörganisms in the air decreases in the winter months not because cold is inimical to the life of the microörganisms-for just the reverse is true-but the conditions are not as good for them to find their way into the atmosphere. This is due to the fact that the soil is covered with snow or the greater moisture prevents the dust from being carried into the atmosphere.

It is quite evident that there would be a relationship between the number of bacteria in the atmosphere and the climate of that region. Bacteria would multiply rapidly in the soil of a warm, humid district and these in turn may be carried into the atmosphere, but the rains would quickly wash them out. Hence, there would be a great variation in a short time, whereas in an arid region the number in the air may be smaller but will not vary as greatly as in the humid region.

'The stay of the bacteria within the atmosphere will vary, depending upon a number of factors:

1. The hardy spore-forming saprophytes may remain suspended in the air for days or even weeks, whereas the frail non-sporeforming pathogens soon perish due to either drying or the sterilizing action of the sun's rays.

2. Small particles settle out more slowly than do large ones, for as the size of an object is decreased the surface area decreases less rapidly proportionately than does the volume. Hence, those bacteria which are floating free in the atmosphere would subside more slowly than those attached to dust particles.

3. The time of suspension is also determined by the velocity of the air current. Organisms settle out of a still atmosphere more readily than from one in motion, whereas it may require an air current of considerable velocity to dislodge microörganisms and bring them in suspension a slight current will sustain them.

4. Moisture in the atmosphere tends to cause particles to adhere together and as they grow in size the tendency for them to settle out is increased proportionately.

5. Although the air of London and many large cities contains numerous particles of dust, the number of living organisms is comparatively small as the various gases thrown into the atmosphere have a slight germicidal effect upon the bacteria. 
Bacteria in Inspired and Expired Air.-Inasmuch as the atmosphere contains numerous bacteria it is to be expected that many will be inhaled with the inspired air. It is estimated that a person living in London breathes about 300,000 bacteria each day and individuals living in other districts may take many times this number. Most of these are harmless and are caught on the moist mucous membranes of the upper respiratory passages, rery few finding their way into the deeper alveoli.

The expired air, during normal respiration, is practically free from bacteria. But during the acts of coughing, sneezing and speaking the air is forced out and with it bacteria, some of which may be pathogens and if inhaled by a second individual may give rise to the specific disease.

Air-borne Infection.-The air has long been considered as the chief rehicle for the spread of communicable diseases. This was but natural, for until recently the virus of these diseases was believed to be gaseous or at least readily diffusible and borne by air currents. After the bacterial nature of disease was discovered and it was found that the discharges from the nose and mouth of the diseased body often contains the causative organisms, and hence could readily find their way into the air, this was a farorite method for explaining infection. Recent work, however, has demonstrated that the pathogens do not long retain their vitality when free in air, and where infection is convered br air it is rlue to dust or droplet infection.

Dust infection occurs only in the case of those diseases caused by organisms which can survive considerable periods of drying. The most important is that of tuberculosis and is here confined to rooms and dusty places which have been occupied by careless consumptives. The extent to which dust is a factor in the transmitting of disease is not well known, but it probably is not great.

Flugge and his students were the first to demonstrate that minute droplets may be emitted from the mouth during talking, coughing and sneezing. The droplets may be carried in a quiet room as far as twenty or thirty feet. The large ones soon settle out, whereas in the smaller ones there is a great tendency for many pathogens to perish. Hence, droplet infection is conveyed only a few feet. 


\section{CHAPTER XXVIII.}

\section{WATER BACTERIOLOGY.}

Common things are often little prized, and this is true of water. Yet there is no other compound which plays so many and such vital parts as does this substance. It composes two-thirds of the body weight, entering into the make-up of every tissue. The muscles which do our work contain 75 per cent. water; the liver which acts as the body protector against poisons consists of 75 per cent.; the bones, which possess a tensile strength of 25,000 pounds per square inch and are one and one-fourth times as strong as cast-iron, consist of 40 per cent.; the brain, the most complicated and wonderful organ of the body, consists of 85 to 90 per cent.; the bloorl, that cosmopolitan fluid which visits erery tissue of the body bearing to it nutrients and from it waste products, contains over 90 per cent. water. All the secretions of the digestive glands consist mainly of water, and it is not there merely as a vehicle in which are conveyed the active principles, for it enters into practically every chemical reaction through which carbohydrates, fats and proteins pass in the process of digestion and metabolism. It is the fluid in which are held the mineral nutrients which play such a rital part in the life phenomena. Water gives to the tissues their plumpness, carries off waste products, regulates the body temperature and acts as a catalyzer in most reactions. Hence, a substance which is of such vital importance and so often polluted or infected must receive more than passing notice by the bacteriologists.

Classification of Waters.-From a bacteriological viewpoint, natural waters are best classified according to their relation to the rich lavers of bacterial growth upon the surface of the earth. There are four distinct classes: (1) Atmospheric water, (2) surface waters, (3) stored waters and (4) ground waters.

1. Atmospheric water consists of rain and snow. It is really water which has been vaporized and then condensed. It contains none of the non-volatile substances and should, therefore, more nearly approach pure water than any of the other natural sources. But even this is far from pure, for as it falls through the atmosphere it absorbs gases and collects large amounts of floating dirt. Every one has observer how a shower will wash the air so that it becomes boantifully clean and clear. The minute the water reaches the 
earth further contamination occurs and it is a well-known fact that some of the filthiest water used for domestic purposes comes from rainwater tanks. This is due both to the methods of collecting and of storing which pollutes but usually does not infect it.

2. Surface waters include rivers, creeks and smaller streams and are immediately exposed to contamination. 'They vary greatly in composition, depending upon the nature of the catchment basin. Waters flowing through rock, gravel or sand formation are better than are those which flow over or drain loam or swamps. But even the waters from sand and gravel regions may be polluted or eren infected, depending upon the relationship borne by the drainage basin to animal life, and especially to human beings. In the thickly settled portions of the country and as the new districts build up these waters must be more carefully protected. Sanitary workers are being forced to the conclusion that it is impossible to protect such water's against contamination, and as far as possible such waters should be purified before they are used.

3. Stored waters include lakes and large ponds. These, when fresh and kept free from the pollution with the wastes of human life and industry make admirable sources of water. On account of the limited area of the drainage basins they are more easily protected than large streams. Noreover, the natural agencies for purification-time, sedimentation and enormous dilution-play a great part in freeing the water from any accidental foreign material which may find its way into the water.

4. Ground waters are of two classes: (a) Deep springs and wells, from which most bacteria and other suspensoids have been removed by filtration. Such waters in passing through the soil take up large quantities of carbon dioxid which has been set free by the decay of organic matter. Water heavily charged with carbon dioxid has a great solvent action for lime and other inorganic constituents. Hence, while such waters are usually safe they are hard and carry large quantities of organic material. (b) Shallow springs and wells correspond more nearly to surface waters and are often polluted and at times infected.

Waters are also classified as polluted and infected. A good water is one of high standard quality, as determined by physical inspection, sanitary survey of the watersheds, clinical experience, bacteriological and chemical analysis.

A polluted water is one containing organic waste of either animal or plant origin. A polluted water is not'necessarily a dangerous water but is always looked on by the bacteriologist with suspicion.

An infected water is one which contains the specific microorganism which causes disease and is always dangerous. The bacteriologist in examining seldom proves that a water is infected, but draws his conclusions from indirect evidence. 
Numbers of Bacteria in Waters.-The bacterial content of the several waters varies greatly. Atmospheric waters after a longcontinued storm may be free from bacteria, whereas rain after a long drought may contain many. There is also a variation in the number, depending upon whether the rain is collected in the country or city. Miquel obtained for the period 1883-1886 an average of 4.3 bacteria per cubic centimeter in the country and 19 per cubic centimeter in Paris. Snow contains rather higher numbers than does rain. Janowski found in freshly fallen snow from 34 to 463 bacteria per cubic centimeter of snow-water.

Surface waters are never free from bacteria, but the numbers vary greatly from a few hundred, in the case of clear mountain streams, to millions, in the case of the sewage polluted rivers.

The number varies with the turbidity of the stream. The Thames River carries 277 bacteria per cubic centimeter in April, whereas the Illinois carries between 6000 and 8000 per cubic centimeter. The number also varies with the season of the year. In May the Potomac River carries about 750, while in March it carries 11,500 per cubic centimeter. The number is increased when the drainage basin is manured with the various animal manures, as it is also by the entrance of sewage into the streams.

The bacterial content of lakes is usually lower than that of streams, but shows wide variations. Lake Michigan near Chicago gives count for from 68 to 2000 per cubic centimeter, while Lake Lucerne's variation is from 8 to 51 per cubic centimeter.

The same wide variation is shown in ground waters. Shallow wells and springs often contain as many and just as dangerous organisms as do surface waters. But deep wells and springs contain few organisms, and it is not an uncommon experience to find some which are sterile.

The seasonal variation of bacteria in deep wells and springs is zero, and where we have seasonal variation in these sources of water it indicates surface contamination, and with shallow wells and springs it is often enormous.

Surface waters are subject to marked variations in bacterial contents, especially during spring and fall, due to melting snow and rains of these seasons. A heavy shower is likely to increase contamination by introducing fresh material from the surface of the ground. Prolonged moderate rains may have the opposite effect and after the main impurities have been washed away may dilute the stream with a better water than itself. 'The net effect, therefore, depends upon the character of the stream as well as the atchment basin. A stream highly polluted with sewage may actually contain fewer bacteria after a heavy storm than before, but a normal stream contains more, as emphasized by the following data compiled by Prescott and Winslow: 
MONTILY VARIATION OF BACTERIA IN A NORMAL AND POLLUTED STREAM.

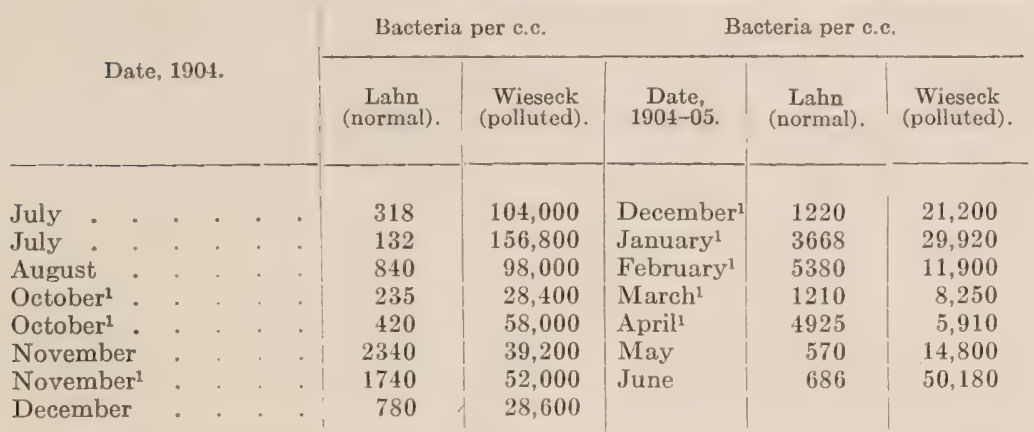

Sedimentation.-Bacteria disappear more rapidly from still or slow-flowing streams than from rapid-flowing streams, due to the fact that the transporting power of a stream varies as the sixth power of its relocity. A current moving six inches a second will carry fine sand; one moving twelve inches a second will carry gravel; four feet a second, stones of about two pounds' weight; and thirty feet a second, blocks of three hundred and twenty tons.

The sedimentation of bacteria themselves takes place very slowly even in still water, for the difference in numbers between the top layer and the bottom layer of water in tall jars in laboratory experiments of a few days' duration is rery slight, being quite within the limits of experimental error. In the natural streams however, the bacteria are, to a great extent, attached to larger solid particles, and upon these the action of gravity is more important. Sedimentation is one of the most important factors, according to Jordan, in purifying waters. He states that "it is noteworthy that all the instances recorded in the literature where a marked bacterial purification has been observed are precisely those where the conditions have been most favorable for sedimentation."

Light.-Light is one of the best germicides, for when it plays upon the naked protoplasm of the bacterial cell it kills both regetative and spore forms in a short time. Opinions vary, however, as to the part played by light in destroving bacteria in natural waters. Buchner found that plates containing $B$. tuberculosis were sterilized in four and one-half hours at a depth of five feet, but were unharmed at a depth of ten feet. Plates exposed at various depths and containing various saprophytes gave the following counts after three hours:

1 Rain or high water due to previous thaw. 


$\begin{array}{lcrc} & \text { Before exposure. } & \text { Sunshine. } & \text { Darkness. } \\ \text { At surface of water (per c.c.) } & 2100 & 9 & 3103 \\ \text { Under 20 inches of water (per c.c.) } & 2103 & 10 & 3021 \\ \text { Under 40 inches of water (per c.c.) } 2140 & 2115 & -3463\end{array}$

Few studies have been made of the effect of light on bacteria in flowing water. Jordan, after an investigation of several Illinois streams, concluded that at least in eight moderately turbid waters the sun's rays are virtually without action. Much, therefore, depends on the turbidity and speed of the current, the maximum germicidal effect being produced in shallow, clear, slow-moving water.

Temperature. - The action of temperature apon the bacteria varies with the food and specific organism. When they are in a medium in which they can grow and multiply, warmth within reasonable limits farors their development. This is true of the natural bacterial flora and may, as was found to be the case at Harrisburg, Pennsylyania, hold for $B$. coli. But this does not hold for the pathogens which in the majority of cases do not multiply in water, and, as pointed out by Prescott and Winslow, "when a bacterium cannot multiply, the only vital activity which can take place is a katabolic wasting away, which soon proves destructive, and the higher the temperature the more rapidly the fatal result is reached. A frog in winter lives at the bottom of a pond breathing only through its skin and eating not at all, but as soon as the temperature rises it must eat and breath through its lungs or perish." The trphoid bacilli will survive longer in ice than in water. The speed with which they perish varies inversely with the temperature, as was found by Houston.

Temperature
0
5
10
18

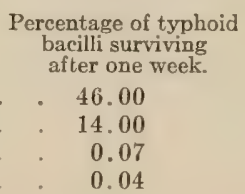

Period of final
disappearance of
bacilli, weeks.

9

7

5

4

In the natural-occurring waters probably many factors play a part; sometimes it is the inhibiting action of microörganisms and their products on one another; at other times protozoa which feed upon bacteria and the development of which is directly proportional to the temperature of the medium in which they are growing.

Hinds found that in pure, natural and distilled water $B$. coli and $B$. typhosus die from starvation at a regular rate. The rate of death increases with the temperature and is similar to the rate of a chemical reaction, thus following the mono-molecular law.

Food.-Bacteria are dependent upon food and respond quickly to comparatively slight changes in their food supply. Whecler found that typhoid bacilli would persist in almost undiminished 
numbers in sterilized water from a polluted well containing considerable organic matter and kept in the dark at 20 degrees, while in purer water or in the light they died out in from two to six weeks. In unsterilized water the results may be just the opposite, for in the presence of an abundant supply the saprophytes may multiply at the expense of the pathogens.

Whipple and Mayer find that the presence of oxygen is essential to the existence of typhoid and colon bacilli in water, and even small quantities of acid and alkali are fatal. It is for this reason that we find few organisms in acid and alkali water of various regions. The factors, therefore, which are at work on the purification of water are numerous, and "although it is hard to estimate the exact importance of each factor, the general phenomena of the self-purification of streams are easy to comprehend. A small brook, immediately after the entrance of polluting material from the surface of the ground, contains many bacteria from a diversity of sources.

"Gradually those organisms adapted to life in the earth or in the bodies of plants and animals die out, and the forms for which water furnishes ideal conditions survive and multiply. It is no single agent which brings this about, but that complexity of little-understood conditions which we call the environment."

Classes of Bacteria. - The bacteria found in water may be roughly classed as: (1) Natural-water bacteria, (2) soil bacteria and (3) sewage or intestinal bacteria. There is no hard and fast line between these classes, for organisms belonging to the water flora are found in the soil and water draining from manured soil will contain intestinal organisms. The classification, however, is valuable; for the first two groups usually contain the saprophytes, whereas the third contains the pathogens.

A number of attempts have been made to classify water bacteria. Ward, in his study of the bacterial flora of the Thames River, arranged them into twenty-one groups. But the work is beset with certain difficulties which were recognized by Ward, for he made the following statement: "My work goes to show that species cannot be marle out, but that the limits of the species are, in most cases, far wider than is assumed in descriptions-in other words, that many so-called species in books are merely variation forms, whose characters, as given, are not constant but depend on treatment. INow far this is true for any given case will have to be tested on the particular form in question."

Fuller and Johnson, from a study of the bacteria in the rivers of America, suggested a classification containing thirteen groups. Their system was based mainly on morphological data, and hence they experienced considerable difficulty in differentiating short bacilli from cocci. 
Jordan studied 543 strains of bacteria from the Illinois, Missouri and Mississippi Rivers and grouped them into the following classes, depending upon their biochemical properties:

I. B. coli communis.

II. B. lactis aerogenes.

III. B. proteus.

IV. B. enteritidis.

V. B. fluorescens liquefaciens.

VI. B. Aluorescens non-liquefaciens.

VII. B. subtilis.

VIII. Non-gas formers, non-fluorescent, non-sporeforming bacteria which liquefy gelatin and acidify milk.

IX. Similar to Group VIII, save that milk is rendered alkaline.

X. Similar to Group VIII, save that gelatin is liquefied.

XI. Similar to Group IX, save that gelatin is not liquefied.

XII. Similar to Group XI, save that the reaction of milk is not altered.

XIII. Chromogenic bacteria not included above.

XIV. Chromogenic staphylococci.

XV. Non-chromogenic staphylococci.

XVI. Sarcinæ.

XVII. Streptococci.

The natural water flora are saprophytes and the most important members found were:

Group V (B. Aluorescens liquefaciens) is probably more often found in water than any other species. It liquefies gelatin and produces a green fluorescence.

Group VI (B. fluorescens non-liquefaciens) produces colonies with a fluorescent shimmer and does not liquefy gelatin. They are often very abundant in river water.

Group VIII: Organisms which liquefy gelatin and acidify milk. These are closely related to the proteus group and some of them are $B$. liquefaciens, $B$. punctatus, $B$. circulans. These are found more commonly at some seasons than at others.

Groups XIII and XIV: Chromogenic bacilli and cocci. The red-pigmented $B$. prodigiosus belongs to this type, as does also $B$. ruber, $B$. indicus, $B$. rubescens and $B$. rubefaciens. Those producing a yellow or orange pigment and belonging to this group are $B$. aquatilis, B. ochraceus, B. aurantiacus, B. fulvus. At times there occur organisms which produce violet-pigment- $B$. violaceus. The chromogenic cocci occurring in water are not so numerous; of these, Sarcina lutea is the most common species. The nonchromogenic cocci, which Jordan classes as Group XV, are more numerous.

Soil Bacteria.- The flood waters are continually carrying to the surface waters soil organisms, so we may at times find any of 
the bacteria which occur in soil also in water. Many of these find this an unsuitable medium for growth and multiplication and soon perish. But some species, among which are $B$. mycorides, $B$. subtitis, B. Imegaterium and B. Mescntericus vulyatus persist for a considerable time.

Intestinal Bacteria.- These are usually of sewage origin. To this class belongs a heterogeneous group of microörganisms which find their way into water from sewage. Many of them are true saprophytes and of themselves are not injurious, but their presence in a water constitutes a danger signal to the bacteriologist. 'This is especially true of the $B$. coli group of organisms, the natural habitat of which is the intestinal tract of the higher animal-man. Hence, whenever there is opportunity for these organisms to find their way into waters there may also be opportunity for the pathogens which cause typhoid fever, cholera and dysenteria to reach the water. It is, therefore, certain that even a little sewage may cause much damage if it enters a water supply for only a few hours at rare intervals, but it is the slight continuous infections which can give rise to a prolonged outbreak of disease. It is well established that typhoid bacteria die quite rapidly in ordinary waters, and so far as known never multiply in such waters, as is seen from the following (Mills): "To prove whether typhoid-fever germs would survive in the Merrimac River water, when at the low temperature of the month of November, long enough to pass from the Lowell sewers to the service-pipes in Lawrence, a series of experiments was made by the Board by inoculating water from the service-pipes with typhoid-fever germs, and keeping the water in a bottle surrounded by ice, at as near freezing as practicable, for a month and each day taking out one cubic centimeter and determining the number of typhoid germs. The number continually decreased, but some survived twenty-four days.

"On the first day there were 6120 germs.

On the fifth day there were 3100 germs.

On the tenth day there were 490 germs.

On the fifteenth day there were 100 germs.

On the twentieth day there were 17 germs.

On the twenty-fifth day there were 0 germs."

At a higher temperature the life of the organism would have been of even shorter duration.

Our information in regard to the cholera vibrio is not quite as definite, but experiments indicate that it may multiply to some extent in sterilized river or well water, and that it maintains its vitality in such water for several weeks or even months.

Natural Purification of Water.-Nature's methods of purifying water are mainly: 
1. Eraporation and condensation which gives the purest of natural waters. Millions of gallons of water are amnally evaporated from the surface of the globe. Thus, we have an enormous natural still by which water is constantly being purified in Nature.

2. The self-purification of rumning streams which although important is often hard to estimate quantitatively. It is due to many factors, chief among which are: (a) Chemical-the oxidation and reduction of organic and inorganic constituents of the water with the formation of simple substances which are not well suited to the maintenance of life and growth of many forms of bacteria, and the germicidal influence of sunlight which is an important but very variable factor. (b) Biological-the death of microörganisms through various not well-understood conditions grouperl under the heads of symbiosis, antibiosis, time and various other means. (c) Physical-of which dilution and sedimentation are the more important.

3. The storage in lakes and ponds which through the prolonging of the time of action greatly intensifies those factors at work in the natural purification of running streams.

4. The combined physical, chemical and biological action of soil upon water which filters through the soil. This is one of Nature's greatest purifying agents and stands second to evaporation and condensation in effectiveness.

Artificial Purification.--Those methods which are so effective in the purification of water under natural conditions are usually the methods which are made use of in the artificial purification of water. Only a few of the best known can be briefly considered here. The sturlent who is more deeply interested in the subject is referred to any of the many comprehensive works on this subject.

The slow sand filter frees water from impurities through the interaction of serlimentation, filtration, and the biological destruction of organic matter and bacteria. It has been extensively used for over one hundred rears, but a great impetus was given to this measure when Koch, in 1893, showed that the proper filtration of the water from the Elbe River saved Altona from an epidemic of cholera which devastated IIamburg which was using unfiltered water.

The method consists in causing water to pass through a layer of sand of such fineness and thickness that the requisite removal of suspended substances is accomplished. The filter as usually constructed is a basin having a water-tight concrete base on the surface of which are laid perforated tiles or pipes. These are covered with about a foot of gravel graded in size from 25 to $3 \mathrm{~mm}$. in diameter from bottom to top. Over this is placed three or four feet of sand whirh acts as the real filter. The water passes through this and is conveyed to the mains by the underlying pipes. The 
suspended material, including bacteria, is removed by the sand which becomes more efficient as used, due to the rapid formation of a mat of finely divided sediment, in which protozoa often multiply, and assist biologically in removing many bacteria. In time the mat becomes rery thick and the filtration although effective is unduly slow. 'The water is then allowed to subside below the surface and about half an inch of the sand removed, after which filtration is resumed. The sand removed is washed to free it from collected impurities and is later replaced on the bed after successive scrapings have reduced the filter to about one foot in thickness.

The filters are usually divided into units of convenient size, about half an acre, so that one unit may be cleaned without interruption of the system. The slow sand filter remores about 99 per cent. of the bacteria, about one-third of the coloring matter and its long effective use has established the fact that it has a farorable effect upon the health of the community where used.

Chemical Method.--The chemical disinfection of water on a large scale is now almost exclusively effected with substances rielding chlorin, chief of which are bleaching powder (chlorid of lime), sodium hypochlorite and free chlorin. The action of these substances is essentially similar and dependent upon the quantitative active chlorin which they contain. They are usually added in quantities sufficient to give from (0.5) to 1 part of active chlorin per million parts of water.

The use of bleaching powder in the purification of waters is (heap, reliable, harmless and easy of application, which makes it an attractive method, but when used on impure waters containing organic matter it gives rise to amins, chloramins and other compounds of unknown composition which impart to the water unpleasant flavors.

Alum is often used either alone or in connection with the mechanical sand filter, and if used under controlled conditions is very effective and leaves no undesirable constituents in the water. The quantity should be accurately determined for each water as it varies with the turbidity and quantity of calcium carbonate contained in the water.

Potassium permanganate is often used in the disinfecting of small quantities of waters, but its effectiveness cannot be depended upon except against the cholera spirillum. Moreover, the disagreeable taste and the color imparted to the water are a serious drawback.

('hlorazene, the new disinfectant suggested by l hakin, has much which commends itself for use in the disinfection of small quantities of water, as in the concentration of $1: 300,000$ it will sterilize ordinarily heavily contaminated water in thirty minutes. Such a concentration imparts a very slight taste to the water but is perfectly palatable. It is non-toxic and if used for only short intervals 
would probably be without effect upon the health of the individual. The compound, chlorazene (p-sulphondichloraminobenzoic acid$\mathrm{Cl}_{2} \mathrm{NO}_{2} \mathrm{SC}_{6} \mathrm{H}_{4} \mathrm{COOH}$ ), is excreted in the urine as p-sulphonamidobenzoic acid.

Ice.-It is often the case that water which one would not consider fit for drinking is used in the manufacture of ice. This should not be the case as the freezing of water reduces only slowly the number of organisms present. In fact Keith considers that low temperatures alone do not destroy bacteria. On the contrary, cold appears to favor longerity doubtless by diminishing destructive metabolism.

Probably the decrease in number is due to mechanical rupturing of the cell, lack of oxygen, food and moisture which are due to the low temperature. Although there is a decrease of bacteria, yet experiments have demonstrated that even the pathogen Bacillus typhosus may persist in ice for one hundred days. The cholera vibrio perish much sooner. Hence, the evidence is conclusive that just as pure a water should be used in the manufacture of ice as is required in domestic supplies. 


\section{CHAPTER XXIX.}

\section{WATER AND DISEASE.}

History is replete with facts indicating that early in the history of the race there was a general conception that water might cause disease. Early tribes sought out those streams and springs which yielded a generous supply of cool, clear water. They followed them on their course to the sea and learned that some furnished water which promoted health, whereas the user of other waters suffered certain plagues. Centers of population sprang up in ancient times around those points where water was readily available and great expenditures of labor and treasure were made to protect and carry it to places where it was needed. About 400 B.c. Hippocrates pointed out the danger from polluted water and advised the filtering and boiling of such water. But apparently during the following centuries no relationship was observed between the character of the drinking water and the epidemics of typhoid, cholera and other intestinal diseases which swept over Europe. During the Dark Ages the belief that water caused diseases of the human race became very popular. But the attributing factor was thought to be witches who by some occult magic poisoned pure wells, springs and streams.

The statements in the literature during the beginning of the nineteenth century became more definite, showing that the relationship - between the character of the drinking water and the prevalence of intestinal diseases was being recognized. By the middle of the century Michel had collected such a mass of statistics as to warrant the conclusion that there is a direct relationship between the purity of a drinking water and typhoid ferer.

Disease First Definitely Proved as Due to Water.-The first clearcut demonstration that disease is caused by infected water was that of the now famous Broad Street well (1854) so ably studied by Snow. During this outbreak of cholera in London there was an enormous concentration of cases in a very limited area just east of Regent Street. There were during a period of about six weeks over 600 fatal cases. A careful study of the site, soil, subsoil, streets, density and character of population, dwellings, yards, closets, cesspools, vaults, drains, conditions of cleanliness and atmospheric conditions revealed nothing of importance. A study of the water supply revealed the following facts: 
1. Nearly all of the cases were nearer a certain public pump in Broad street than any other source of water and most of them gave a definite history of getting water from the pump.

2 . Of the few cases which dereloped outside of the area supplied by the pump most of them were known to have drunk water from the Broad Street well.

3. The few scattered cases in distant parts of London were individuals who had used water from the well.

4. Right in the midst of the district was a workhouse with 2.35) immates and a brewery with 70 employees, each having its own well, and there were only is deaths in the workhouse and none in the brewery.

5. It was shown that a priry vault and cesspool in an adjoining house discharged through a leaky drain which ran within two feet of the Broad Street well.

6. There were 4 fatal cases of cholera in the house at the time of the outbreak and earlier cases which were probably cholera.

It was not until 1880 that the typhoid bacillus was isolated by Eberth and studied in detail by Gafky in 1884 that we had definite information concerning the causative agent of typhoid ferer, the way in which it leaves the body, and the routes by which it may reach drinking water. This same rear Koch isolated the cholera vibrio from stools of patients suffering with the disease. He also isolated the organism from tankwater in India. We now know that water is a vehicle for a number of infections such as typhoid ferer, cholera, dysentery and other intestinal diseases. It may be the medium for convering infections not now generally regarder as water-borne. It may carry inorganic poisons such as lead, or may be of such a nature as to bring about derangements of metabolism resulting in goiter, or may lower resistance, so as to favor infections not water-borne. It occasionally conveys animal parasites, amebre and worms.

Amount of Sickness due to Water.- Water is probably responsible for more sickness and death than any other article of diet except milk. This is due to the facts: (1) That it is used raw, while many other substances are rendered sterile by cooking; (2) water comes in contact with numerous substances upon the earth's surface and is a universal solvent; (3) it is used as the great rehicle for the removal of waste, much of which may contain pathogenic organisms.

It is difficult to obtain statistics to indicate accurately the morbidity and mortality due to impure water, but Whipple states that the average trphoid death-rate in American cities is about 3.) per 100,000 , while cities with a good water supply arerage 20 . He, therefore, attributes 40 per cent. of the typhoid fever of the Inited States to infected water. ('hapin, however, considers it would be more conservative to place it at 15 per cent. for the whole country rather than at 40. But even these figures show a large 
unnecessary mortality and morbidity when we remember there were 25,000 deaths in the United States in 1910, representing at least 250,000 cases.

Dysentery and diarrhea, although not as fatal as typhoid fever or cholera, are not to be neglected, for when we consider the sickness and economic loss resulting each year in the United states from these causes, much of which is due to infected water, we find that they are not negligible. Moreover, the better care of drinking water has resulted in a marked decrease in the ravages of dysentery, for it is estimated that the mortality from dysentery in England toward the end of the last century was but a fraction of a per cent. of what it was in the middle of the century. Moreover, the reduction of dysentery in the Lnited States has kept pace with the advancement made in water protection and purification, as seen by the fact that the death-rate from dysentery in this country in 1850 was 6.32 per cent.; of the total mortality in 1860 , 2.65 per cent.; $1870,1.6$ per cent.; and in 1880 , less than 1.5 per cent.

The Mills-Reincke Phenomenon.-Mills, of Lawrence, Massachusetts, and Reincke, of Hamburg, Germany, in 1893 noted that the purification of the water supplies of their respective towns was followed by a decline in the general death-rate which was more rapid than could possibly be accounted for by the death from typhoid fever. This condition was later searchingly studied by Sedgwick and MacNutt who gave to it the name of the "MillsReincke Phenomenon." Later (1904) Hazen, a sanitary engineer formulated a numerical expression for the comparative effect of purified water upon the typhoid fever and total mortality as follows: "Where one death from typhoid fever has been avoided by the use of a better water, a certain number of deaths, probably two or three, from other causes have been avoided." This proportion varies greatly in different instances. It was 1 to 16 in Hamburg, in Lawrence 1 to 4.4, Lowell 1 to 6 , Albany 1 to 4.4 and 1 to $1.5 \mathrm{in} \mathrm{Binghamton.} \mathrm{Hence,} \mathrm{in} \mathrm{all} \mathrm{of} \mathrm{the} \mathrm{cases} \mathrm{studied} \mathrm{by} \mathrm{Sedg-}$ wick and MacNutt it appears to be sound and conservative, but in some of the American cities more recently studied it does not appear so exact.

The cause of this decline in mortality is not clearly understood. It may be due to the exclusion of specific pathogenic organisms, to increased vital resistance resulting from the use of a better water, or in some cases the appearance and taste of the water may be improved with the result that greater quantities are used, and hence a better condition of the body in general. Probably many factors are at work and these studies have revealed a remarkable relationship between polluted water and infant mortality. Rosenau considers that it bids fair to assume a causal importance in gastro-intestinal disturbance of children second only to that of contaminated milk. 
Cholera. - I'ater has been proved to be the causative agent in the conveying of cholera in a number of instances. The two best known cases are that of the Broad Street well, which has already been considered, and the epidemic of 1892 in Hamburg. This latter will ever remain classic on account of the clearness of the circumstances and the fact that there is no missing link in the chain of evidence, as the cholera vibrio was isolated from the Elbe River water.

The Hamburg epidemic occurred in 1592, and in a little over two months there were 17,000 cases with 8605 deaths, whereas Altona, which in reality forms with Hamburg one large city, was practically free. The two cities are built on the same soil, provided with the same sewage system, and have the same climatic conditions. They have the same social customs and were separated only by a political boundary line. The boundary runs through a street on one side of which is Altona and on the other Hamburg. They have separate water supplies, but both derive their water from the Elbe River which is a grossly polluted stream. However, the water supply for the city of Altona was purified by filtration, while that of Hamburg was not. The boundary of the epidemic was just as clear as was that of the water system, or in the words of Koch, "cholera in Hamburg went right up to the boundary of Altona and there stopped. In one street, which for a long way forms the boundary there was cholera on the Hamburg side, whereas the Altona side was free from it."

Typhoid.-Contaminated water was the first recognized and probably the most significant vehicle of typhoid infection. The improvement in water supplies during recent years has been responsible for the reduction in typhoid morbidity. 'The results compiled by Kober clearly show the effect of improved water supplies on typhoid mortality in American cities.

EFFECT OF WATER PURIFICATION ON GENERAL AND TYPIIOID DEATH-RATE.

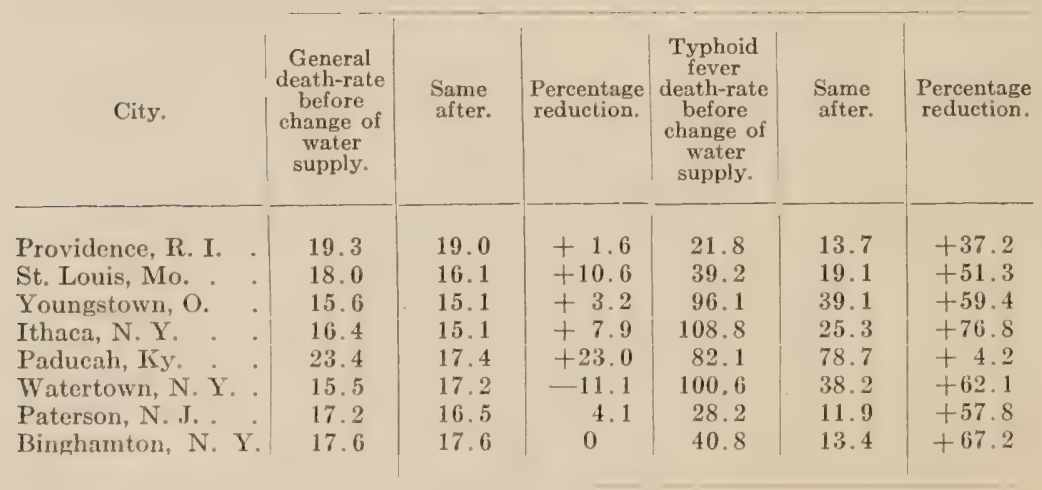


Water still remains the most important single channel by which the typhoid bacilli reach the human body. Estimates vary as to the actual percentage of typhoid cases which are referable to water infection. It is placed by various authors at from 10 to 4() per cent. According to Gay, Schuder found that of 640 typhoid epidemics 22 per cent. were due to water. Sichegehdahl found that of 682 cases about :33 per cent. were water-borne. Trphoid is, therefore, the most important water-borne disease.

The proof that a typhoid epidemic is due to water infection is usually indirect, for the actual isolation of the offending organism is effected with considerable difficulty and has been accomplished in only seren or eight cases. Howerer, in those cases where it is found it is not always possible to prove that it was present at the time the infection occurred. Strong presumptive evidence is given whenever waters are proved through the presence of colon bacillus to have been infected by sewage.

The best evidence, however, obtainable that a specific typhoid outbreak is due to polluted water is that obtained by the epidemiologist. He knows that the important characteristics of waterborne epidemics are:

1. They may be preceded by a period of dysentery.

2. The epidemic usually has a sharp onset, the curve rising to a peak and the decline being rapid.

3. The cases are quite evenly divided over the city, that is, provided the city is served by a municipal supply.

4. They nearly always occur in the spring, fall, or winter.

5. The pollution is usually nearby and the epidemic is of short duration unless there be a contimous source of new inferting material.

The work of the epidemiologist is vividly portrayed by Ilil as follows:

"To illustrate the general principles, let us suppose notification be received that a typhoid ferer outbreak exists in a far-off community. The public health detective packs his grip and goes. He knows no details; he has never heard of this particular community before; he has not even any general information about the character of the country; he enters the community with no preconceived ideas. But he does know how typhoid ferer originates and how it spreads. Water, milk, food, flies and fingers are the routes-typhoid ases or typhoid carriers, the source. His duties are to find both; and to find them, not as a scientific amusement, or as a matter of record; not to furnish food for speculation-above all not to make a show of doing something-but to stop the outbreak, and then to advise measures to prevent recurrence.

"The public health detective on entering the community affected by typhoid fever does not first examine the water-supply, the 
milk supply, the sewage disposal sistem, the markets, the back alleys, the dairies, or any thing else. He goes directly to the bedsides of the patients. Of course he must obtain the names and addresses of the patients from someone-from the local health officer, if he has them; from the attending physician, if the health officer has no list; from the lay citizens themselves, if no one else is immediately available. The more complete the list, the faster he can work, because then he is not compelled to hunt up the cases personally. But if there be no list, he begins making one himself. Ilis intention is to see just as many patients as he can, for each furnishes evidence and he wants it all. But he knows that it is not always necessary at this stage to see absolutely all the patients, so long as he sees the majority.

"Reaching the patient's bedside, his investigation begins. Automatically, almost mechanically, he decides whether or not the patient has typhoid fever or not. Satisfied on that point, his first question is not, "Tell me all the different water supplies you have used, or all the sources of milk you have used.' 'The first question is, "When did you first show the earliest symptoms of the disease?' Why? Because this date once fixed, at which infection entered the patient's mouth is fixed also, $i$. $e$., a date between one and three weeks previous to the date of the earliest symptoms. Remember that at that stage the detective may not have even an inkling as to which of the usual factors-water, milk, food, flies or fingers - is involved. Still less can he guess which particular water supply, milk supply, ete., of the many possible ones, may be the guilty one. But the answer to this question reduces possib]e routes to those used by this patient - not at any time-but during a specific period, $i$. $e$., from one to three weeks preceding his date of earliest symptoms.

"Not ret, however, are the milk and water questions offered. The second question is 'Where were you during that period?' Why" Because if the patient were not in the community during that period, he could not have contracted his infection within it, and does not helong to the outbreak under examination at all but to some other. He is in brief an 'imported case,' and while, of course, he is to be supervised lest he spread his infection to others, he cannot help to locate the source of the main outbreak-unless perchance he he himself that source, $i$. $e$., the introducer to the community of the original infection. If he be an imported case he is noterl for further reference and the detective goes to another patient. If not, the questions continue. But not ret is water or milk or flies mentioned. The third question is, "Were you associated during your period of infection with any then known typhoid ("ase"? Why? Because such association, especially if intimate, makes it more probable that the case under examination received 
his infection from the preceding case, rather than from any general route and that he is, therefore, a 'secondary case.' If he had such associations, this is noted for further reference and the investigator pasises on to another bedside. If not, the questions continue, and now at last take up milk, water, food, etc., but of course only so far as to determine those used by the patient during his infection period.

"Then the investigator passes to the next patient. What has he learned so far? Nothing much yet. But he has narrowed the possible routes of infection to certain water supplies, certain milk supplies, certain food supplies, etc., $i$. $e$., those used by the first patient during a certain period, and he has done this in thirty minutes -in scarcely the time it takes for the old-style investigator to get his bottles ready to collect his first water sample.

"At the bedside of the second patient, the same inquiries in the same order are made. If this second patient be an imported case, or a secondary case, he also is merely noted for future reference. If he be a primary, however, the origin of his drinking water, milk, food, etc., during his infection period are also ascertained. Perhaps he coincides with the first patient in every detail of alimentary supplies, in history and associations. If so, nothing much has been added to the detective's knowledge. But more than likely, dissimilarities have developed. Since the responsible water supply, milk supply, ete., must be one of those water supplies, milk supplies, etc., used in common by primary cases, all those not common to both of these primary cases may be dropped from consideration (except in rare instances of multiple routes). Thus, if both have used the same water, water from that origin remains as a possibility. But if the water supplies have been different, water is eliminated from the question entirely. If the milk supplies are identical, milk remains as a possible route of infection; if not, milk is eliminated from the question entirely.

In brief, provided the information obtained be reliable, and it is part of the public health detective's training to distinguish at a glance truth from falsehood, the honestly mistaken, or forgetful, or stupid replies from the reliable ones-and above all never to believe anything (to the extent of recording it) unless it is checked, confirmed and established as a fact, the modern investigator has in one hour narrowed his investigation to a point which the oldstyle investigator often would not reach for weeks.

"And so from patient to patient the inquiry proceeds. In the course of the day the investigator has seen perhaps 30 patients. The tabulation (probably already made in his own mind) shows, say, 3 imported cases, 5 secondaries, 2 uncertain or indefinite. The remaining primary cases show in common, say, 1 water supply. only, the milk, etc., varying; or 1 milk supply only, the water, 
etr., varying; or no romnection except attendance at some one social function.

"Foing straight to the route thus indicated, the public health detective quickly confirms the indications of his results. Ile linous that the route indicated must be the guilty one, for only that route can account for all the cases. II concentrates on that route until the evidence is complete-when and how that route became infected, when and by what sub-routes the infection was distributed, why it infected the patients found and not others, etc.

"In this illustration I have assumed complete ignorance on the part of the epidemiologist as to everything connected with the community he is investigating, except what he finds by cross-examining the patients. As a matter of fact, every epidemiologist, however much a stranger to the particular community he enters, begins to learn about it from the moment he enters it.

"Thus, almost unconsciously he notes the size of the town and compares it with the number of cases reported as existing; if it is summer time he almost automatically notes the presence or absence of open toilets in the backyards, of manure piles and of garbage cans-all bearing upon $\mathrm{fly}$ infection. If it is winter time or the community be well sewered, he does not even consider flies. If the cases are grouped in one quarter of the town, while the public water supply extends all over it, he tentatively eliminates the water supply before he asks a question. If good surface drainage and a sandy soil exist, or driven wells are chiefly in vogue, he tentatively eliminates well water-even before he registers at the hotel.

"This is not and cannot be a complete synopsis of all the combinations of circumstances which the epidemiologist meets. It is intended to illustrate his methods and to show why they are incredibly rapid and incredibly accurate-how they eliminate speculation and guarantee a correct solution-which means, of course, the achievement of the great end, the finding of proper measures for suppression.

"As soon as the route is indicated, he must go to that route, and establish beyond peradventure that it was in truth responsible. A water supply cannot convey typhoid if typhoid fever discharges have not entered it. There is no object in attributing an outbreak to fly infection from toilets into which typhoid feces have not been discharged at such a time as to account for the cases. A milk supply, not handled at some point by an infected person, nor adulterated at some time with infected extraneous matter cannot convey typhoid. Whatever his results, they cannot be true unless they are consistent - they should not be accepted unless they are provable- and proved.

"If the public health detective is familiar with the community 
where the outbreak occurs, including its water supplies, its milk supplies, the sociological relationships of its people, ete., he can often tentatively determine the cause of the outbreak by a mere inspection of the names and addresses of primary cases, especially if plotted on a map of the community, taking into account also the time of rear, and other general points. But such deductions, while often wonderfully reliable, can never be as conclusive and satisfactory as are the results of an investigation by even a total stranger, if the investigation be conducted as above described."

\section{REFERENCES.}

Savage, W. G.: The Bacteriological Examination of Water Supplies.

Harracks, W. H.: An Introduction to the Bacteriological Examination of Water. Prescott and Winslow: Elements of Water Bacteriology.

Thresh: The Examination of Water and Water Supplies.

Mason: Water Supplies.

Rosenau: Preventative Medicine and Hygiene.

Don and Chisholm: Modern Methods of Water Purification. 


\section{CHAPTER XXX.}

\section{SEWAGE AND SEWAGE DISPOSAL.}

Mix early learned that both esthetic and sanitary reasons demand that sewage be properly treated. In the early history of the race and also of a district the pit or trench was used for the disposal of the refuse. Later this was lined with stone, brick or cement to partly prevent diffusion into the surrounding soil, and hence the contamination of the well. This, when properly covered, became the cesspool which is largely in use in the rural districts today. As population increased with its constantly growing volume of human waste the old methods became inadequate, and hence there has developed the modern sewage șistem.

Source, Composition and Quantity of Sewage.-A city's sewage consists of the public water supply carrying human and animal excreta, refuse from the kitchen, laundry, manufacturing establishments and the dust and dirt of the streets. Its quantity is directly proportional to the consumption of water in the district. In small cities it may be as low as forty or fifty gallons per capita daily, whereas in larger cities it may reach from 100 to 200 gallons or over.

Its composition depends upon the density of population, the number and kinds of manufacturing establishments, and whether there is a separate or combined system. Where the combined system is used the composition and quantity of the sewage varies with the rainfall and street washing. There is also a diminution in quantity and composition at night.

Fuller gives the estimated amount of dry suspended solids in the New York City sewage per 1000 inhabitants annually as follows:

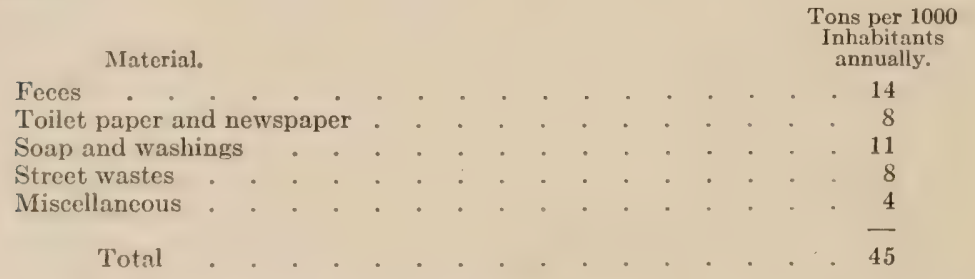

From the viewpoint of purification sewage contains proteins, carbohydrates, fats, soaps, urea and other organic substances. 
The important elements present are nitrogen and sulphur. 'The quantity of these present determines the nature and repulsiveness of the resulting products.

Bacteria in Sewage. - The number and kind of bacteria in sewage varies widely with its composition and origin. According to Fuller it contains 320 billion for each person connected with the sewer system. Johnson found $B$. coli to average about 500,000 per c.c. He isolated the following species from the crude sewage of ('olumbus:

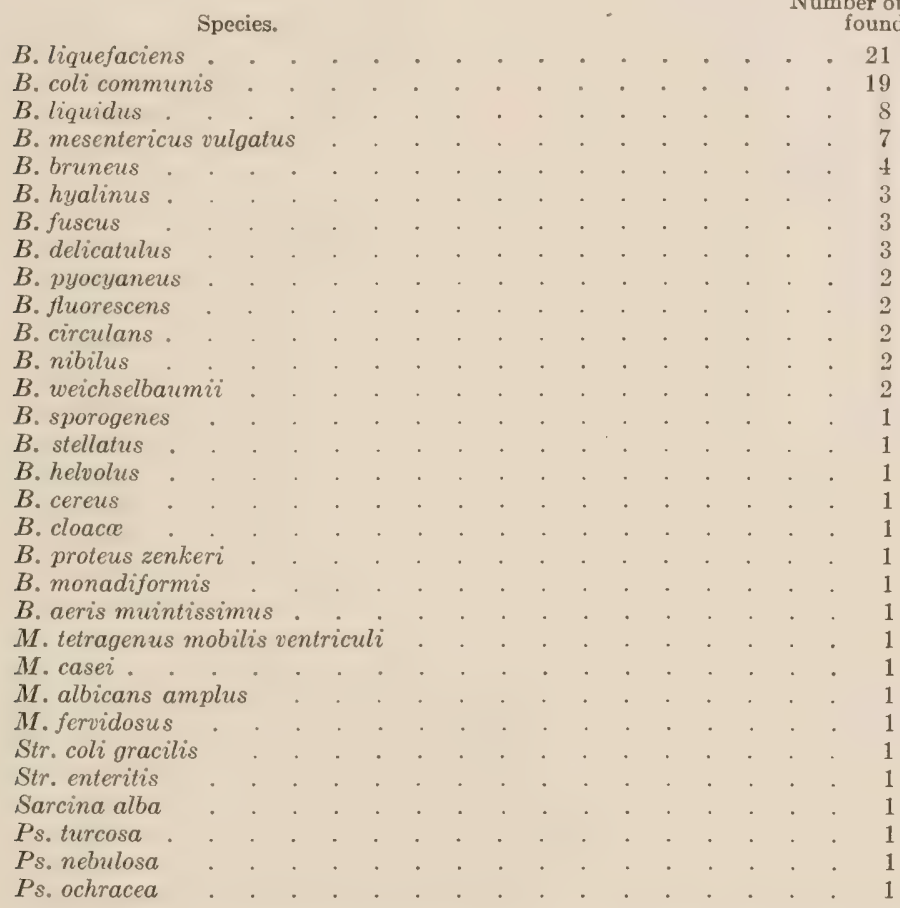

Number of times found.

In addition to these, many of the pathogens may find their way into sewage and survive for various lengths of time.

However, the interest centers more in the changes produced by the various bacteria found in sewage than in the specific classes. Most of them are not only harmless, but of genuine importance in the economy of Nature through the scavengering work which they accomplish. A few of them are dangerous on account of their causing certain infectious diseases. Many of them play an important rôle in decomposing sewage with the formation of malodorous gases and products associated with putrefactive nuisances.

The modern tendency is, therefore, to classify sewage bacteria 
from a physiological viewpoint. They may roughly be divided into four classes - hydrolyzing, oxidizing, reducing and pathogenie.

Fuller gives the estimated constituents of average sewage as follows:

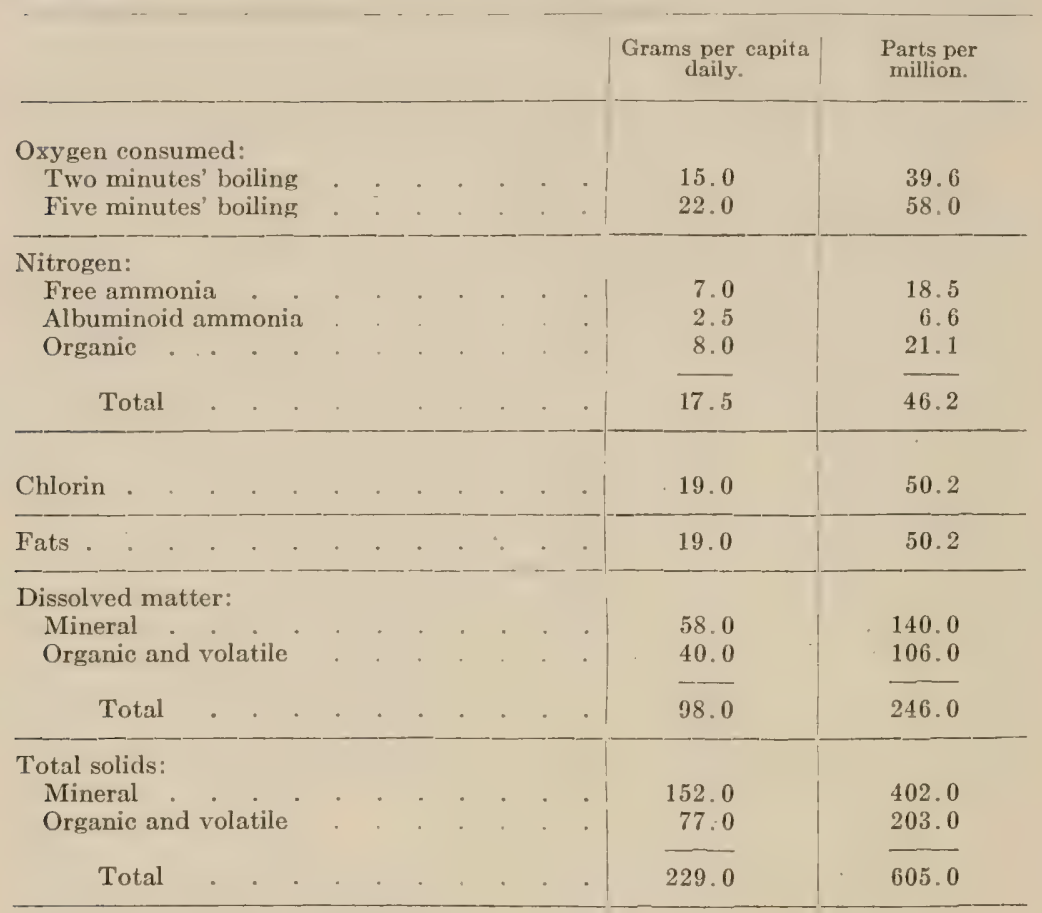

Bacteria, 322 billion per capita daily.

Hydrolyzing Bacteria.-Probably most of the early changes which occur are hydrolytic, that is, the substance is caused to take up water, becomes unstable, and for some reason falls into fragments, thus often passing from a non-soluble compound of complex constitution to a simple soluble substance.

Protein liquefaction belongs to this type of changes and is brought about by a great variety of bacteria working in conjunction with each other. The proteins are hydrolyzed by successive stages to proteoses, peptones, peptids, amino-acids and finally to ammonia, carbon dioxid, methane, hydrogen, ete. It probably corresponds in the main with the changes which have been considered under ammonification. The final products vary widely, depending upon whether the process is being carried on under aërobic or anaërobic conditions. The tendency is for it to partake more of putrefaction in the septic tank and decay in soil. 
Cellulose fermentation, next to protein hydrolysis, is the most important work of bacteria in sewage purification. Paper, cotton fabric, wood and other cellulose-containing substances are rapidly attacked by various organisms with the production of soluble substances-starches, sugars, acids and finally (arbon dioxid, methane and hydrogen.

Probably fewer organisms possess the power of saponifying fat than of liquefying proteins or hydrolyzing cellulose. For this reason and also due to the fact that the fat tends to rise to the surface out of the sphere of bacterial action, there is a great tendency for the fat to accumulate. At times this may accumulate around some solid and give rise to "grease balls" which cause clogging of pipes. The fat which is acted upon by bacteria is broken into fatty acids and glycerin. 'The fatty acids are quite resistant to further bacterial activity, but the glycerin is rapidly broken into simpler products.

Oxidizing Bacteria.-The complex microflora of the sewage must have energy. This they get in a great degree from the oxidation of the comparatively simple products yielded through the hydrolysis of the proteins, carbohydrates and fats. These are changed probably similarly to the acetic acid fermentation with the production of acids and finally carbon dioxid and water.

The ammonia liberated through the deaminization of the aminoacids is oxidized by the Nitrosomonas to nitrous acid and by the Nitromonas to nitric acid.

Reducing Bacteria.-The nitrites and nitrates formed by the nitrifying bacteria are in a great measure reduced to free nitrogen through denitrification. The sulphur in the protein molecule is liberated as sulphates, sulphur dioxid and hydrogen sulphid. The sulphate formed is reduced to hydrogen sulphid. This reacts with the small amounts of iron and other metals present with the resulting black residue of metallic sulphids always found on the bottoms of tanks and streams in which sewage is decomposing.

Each of these processes is going on simultaneously in sewage and the one is dependent upon the other, there being a true biological cycle, as is pointed out by Whipple.

"The decomposition and oxidation of the organic matter in sewage are brought about by bacteria, and the bacteria serve as food for protozoa and other forms of microscopic animal life. The dissolved organic matter in sewage serves as food for algae. These algæ and protozoa are, in turn, consumed by rotifers and crustacea, while the latter form the basis of food supply for various aquatic animals and fishes. 'Thus, there is a continuous biological cycle. Again, animal forms require oxygen and produce carbonic acid, while plants consume carbonic acid and produce oxygen. Where these processes occur normally and with a proper equilibrium main- 
tained between animal and plant life, offensive conditions do not result, but where abnormal conditions are produced, as, for example, by the discharge of excessive quantities of sewage or trade wastes into a stream, a depletion of the dissolved oxygen may follow, or there may be an overproduction of algre so that the conditions become offensive. It is coming to be realized that in order to properly determine the dilution required in any particular case the conditions required to bring about this condition of biological equilibrium must be determined."

Pathogenic Bacteria.-Owing to the origin and nature of sewage it may at any time contain pathogenic bacteria. The ones with which the sanitarian is most concerned are the typhoid, cholera and dysenteria, but it is always possible for many other species to find their way into sewage and from it cause infection. This is especially true of $B$. tuberculosis which is quite resistant to putrefaction. With the exception of the cholera and dysentery organisms, there is no evidence that they ever multiply in sewage, and they produce no appreciable change in its composition.

The majority of the pathogens soon die in sewage. The results as reported by Whipple for typhoid bacilli are given in Fig. 44.

The speed with which the typhoid bacilli disappear from water varies with the vitality of the organism, the temperature of the water, the organic matter, and the bacterial antagonism exerted by other organisms. Typhoid bacilli seem to die more quickly in sewage than in fairly pure water, probably because of the great bacterial antagonism existing. Furthermore, the absence of oxygen probably plays an important part, as Whipple found oxygen necessary for longevity of typhoid bacilli. Jordan thus summarizes our present knowledge of the longevity of typhoid bacilli:

"Laboratory experiments have shown that the typhoid bacillus can survive in sterile water in glass vessels for upward of three months, and for possibly two or three weeks in unsterilized ground or surface water. Other evidence indicates that the bacillus is able to travel in water a distance of at least $140 \mathrm{kms}$., and to retain its vitality in natural bodies of water for at least four or five days. It is possible that water may continue to be the vehicle of infection during a much longer period, but the available data point to a comparatively short duration of life of the specific germ in the water of flowing streams. Under ordinary conditions no multiplication of the typhoid bacillus takes place in water, even when a considerable amount of organic matter is present, but, on the contrary, a steady decline in numbers goes on. The history of typhoid epidemics tends to show that sewage pollution is to be feared chiefly when the sewage is fresh, and that the danger of infection diminishes progressively with the lapse of time.

"In soil in the fecal matter of privy vaults the duration of life 
of the typhoid bacillus is much longer than in water. Levy and Kayser found typhoid bacilli in soil that had been manured fourteen days previously with the five-months-old contents of a vault. The evidence that any genuine multiplication can take place in the

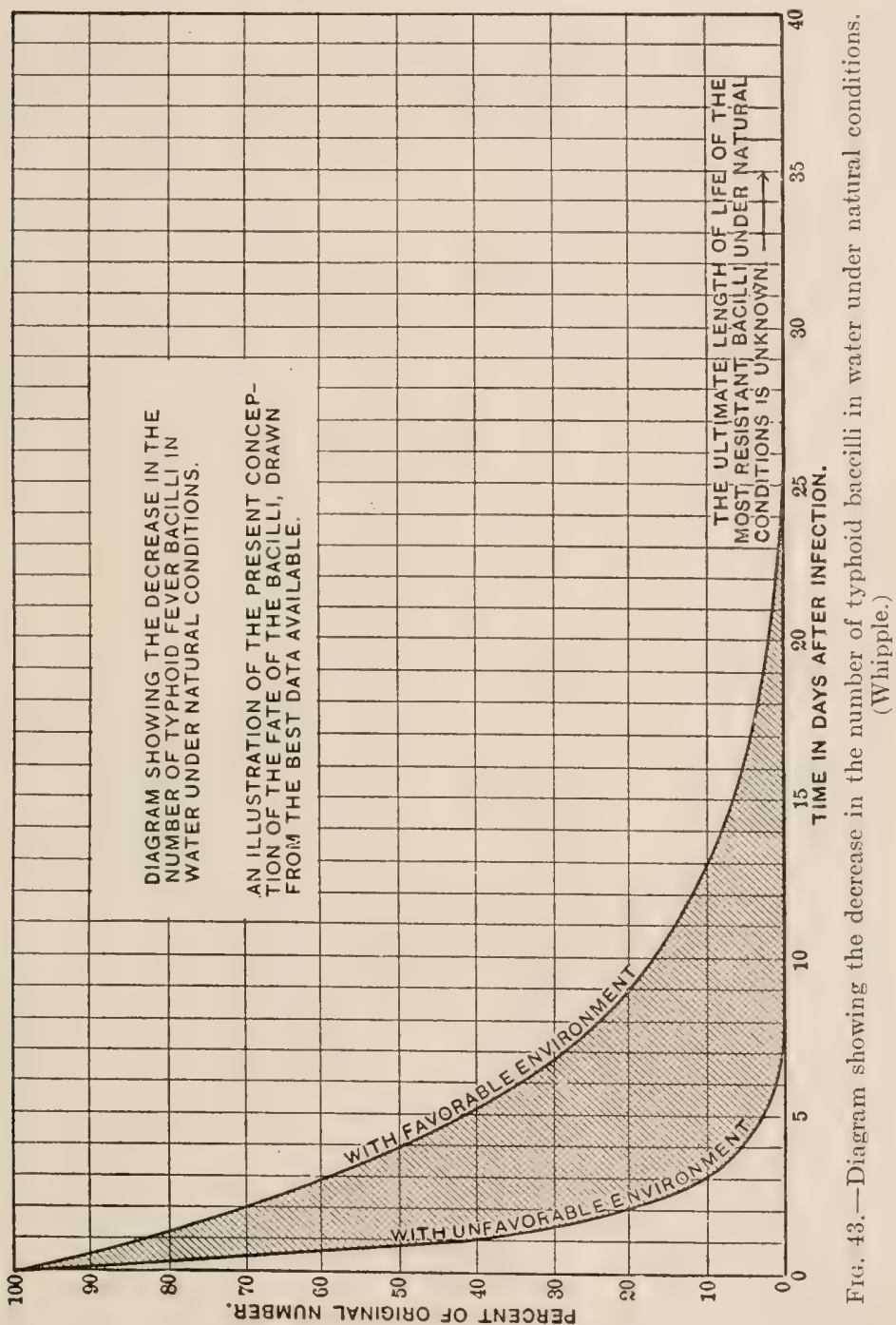

soil is not convincing, but it has been proved that the bacillus may be carried by water-currents to a considerable distance from the point where it was first introduced. Infection of wells and small water-courses is thus brought about sometimes by the wash- 
ing of bacilli out of soil in which they may have lain dormant for many months. The persistence of typhoid ferer around certain habitations may be plausibly explained on the supposition of an extensive soil infection. There is 110 doubt that the practice of using human excrement for manuring vegetable gardens entails a danger no less real because often unrecognized.'

Necessity of Sewage Disposal. - Sewage is obnoxious to the senses because of its appearance, and especially because on decomposing it yields malodorous compounds. It is usually considered that hydrogen sulphid is the main offender, but indol, skatol, cadaverin, mercaptan and some other compounds are considerably more repulsive and exist in sewage.

More important still is the fact that sewage contains bacteria which have come from persons sick with typhoid fever, dysentery, tuberculosis and other diseases, as these may reach the food or water of healthy individuals and thus give rise to epidemies. Statistics show that the abandonment of privies and the substitution of a good sewerage system have greatly reduced the general deathrate in many a city.

What Should be Accomplished in Sewage Disposal-The sanitary engineer attempts to dispose of sewage as rapidly as possible, with the least nuisance to the smallest number of people, with the least damage to health or property, and at the smallest cost. Sewage can be made entirely harmless only by the complete destruction of its organic matter and hacteria. A complete purification is not attempted normally as the plant required for such would be so elaborate and too expensive. Moreover, practical experience has shown this to be unnecessary.

Methods of Disposal. - The method selected for sewage disposal will vary with the district, location and means at the disposal of the sanitary engineer. However, in all cases he must keep in mind convenience and public health. In rural districts the wellconstructed cesspool may of necessity be used, whereas in the urban district this may not be tolerated. One of the readiest methods, and the one which until the last few years has been universally used in this country, is to allow the sewage to flow without treatment into the nearest stream, lake or harbor. 'This is very' successful as long as the quantity is not excessive, the dilution great, and the receiving water is not used by other communities for drinking and culinary purposes. There this method is used the dilution should be great. The ('hicago drainage camal was designed on the basis of :3.3 cubir feet per second for 1000 people. The efficiency of purification, however, varies with the nature of the sewage. 'The presenere of trade wastes, especially those of an sily nature, which float on the surface, may form scums which interfere with the alsorption of oxygen from the air. Rapidly 
flowing streams, on account of their absorption of oxygen, tend to purify themselves more rapidly than do slower ones. Cold water holds more oxygen than does warm, and fresh than salt water; hence, there is a greater tendency for oxidation in cold fresh waters than in warm or salty waters.

There is, however, a growing demand that sewage be treated before it is thrown into streams or lakes. This may be done by various methods, such as sedimentation, sub-surface irrigation, broad irrigation and other means. For a description of each together with its relative value the student is referred to any of the standard works on sewage.

\section{REFERENCES.}

Whipple, George C.: Sewage Disposal.

Rosenau: Preventative Medicine and Hygiene.

Phelps, Earle B.: Microbiology of Sewage.

Marshall: Microbiology.

Folwell, A. Prescott: Sewerage.

Samtee, E. M.: Farm Sewage.

Whipple, George C.: Typhoid Fever.

Fuller, George W.: Sewage Disposal. 


\section{CHAPTER XXXI.}

\section{MILK BACTERIOLOGY.}

ABotr ten billion gallons of milk are produced ammually in the Inited States, one-fourth of which is consumed as milk and the other three-fourths as butter and cheese. The quantity of milk consumed varies in different localities, being greater in the North than in the South and greater in the country districts than in the city. It also varies with different classes, as seen from a survey made by Williams of fifteen sections of Rochester, New York. He found that the average consumption of milk by 21,600 individuals was little more than 0.24 pint per capita. Furthermore, he found that the poor not only used less milk and bought it in smaller quantities than the well-to-do, but the use of store milk and of condensed milk was largely confined to the laboring classes. In other words, the people who most needed to be careful in their buying used smaller quantities of the cheapest food which they bought in the most expensive manner. It is usually stated that about 16 per cent. of the arerage dietary in the United States consists of milk and milk products, yet the average daily consumption per capita of milk as such is only 0.6 pint, which is about half what it should be.

Milk as Food.-Milk has been regarded from the earliest times as a most important article of food, and although little was known as to its chemical composition previous to the eighteenth century, the ancients attributed many and peculiar hidden virtues to it.

Good whole milk or skimmed milk are among the best and cheapest of foods. Good fresh milk is all but essential to the welfare of young children, and to the babe that for any reason is deprived of its mother's milk, cows' milk is practically indispensable. The reason is due to its composition. The composition of human and cow's milk is as follows:

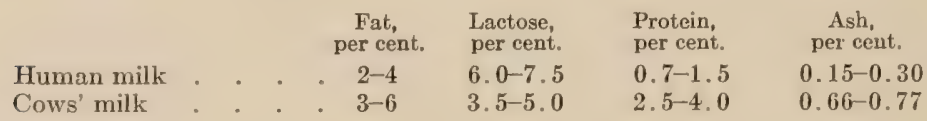

Besides these substances both cows' and mothers' milk carry organic substances which contain little or no nitrogen, one of which is soluble in ether and alcohol, the other in water. 'The true chemical nature of these is unknown. The amount of these substances in human milk at the beginning of lactation is about 1 per cent.; in 
the middle period of lactation about 0.5 per cent. Cows' milk at the middle of lactation contains about 0.3 per cent.

It is usually stated that one quart of milk is about equal in food value to any one of the following:

Salt codfish
Fresh fish
Chicken
Beets .
Turnips.
Butter .
Wheat flour
Cheese.
Lean round beef
Potatoes .
Spinach
Lettuce
Cabbage
Eggs

2 pounds
3 pounds
2 pounds
4 pounds
5 pounds
$\frac{1}{6}$ pound
$\frac{1}{3}$ pound
$\frac{1}{3}$ pound
$\frac{3}{4}$ pound
2 pounds
6 pounds
7 pounds
4 pounds
8 pounds

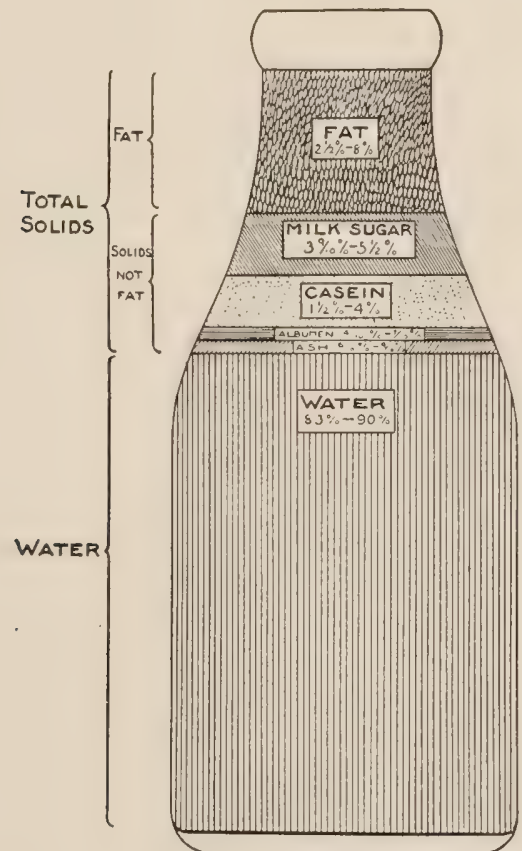

FIG. 44.-Composition of cow's milk, showing variations. (Report on milk investigation, Boston Chamber of Commerce, 1915.) (MacNutt, The Modern Milk Problem.)

This, however, considers milk only from the total calories yielded. Digestibility and assimilation must be considered as well as chemical composition and caloric value; when this is done milk ranks even higher than suggested by the foregoing. Moreover, milk has other 
functions and furnishes essential constituents to the growing animal which is not furnished by many other foods and which cannot be measured in heat units. It contains "vitamins" or "accessories," substances belonging to a group of agents which are widely distributed in nature and which are now regarded as essential factors in diet.

Hopkins clearly demonstrated that the feeding of very small quantities of milk to rats which had been living on a diet inadequate for normal growth brought about a rapid growth in the animals. Moreover, Osborne and Mendel in their extensive experiments on the growth of animals have for several years been employing "protein-free milk" as an indispensable ingredient of their basic diet to which certain isolated food substances are added. They find that no artificial imitation of this natural mixture has been derised to replace it satisfactorily for considerable periods of time. The weight and health of adult rats can be maintained for many months on a ration consisting of protein, starch, sugar, protein-free milk, and lard. Young animals kept on this mixture decline after a time. If, however, butter is substituted for the lard growth is resumed. The active constituent is the fat soluble vitamin of the butter in contrast to the water soluble accessories present in the protein-free milk. Ordinary skimmed milk contains both the fat-soluble and water-soluble accessories. The influence of milk and sour milk upon the growth of chicks is seen from the following summary of a great many tests made by Rettger:

Fed sour milk

Gain per chick, Pounds.

Fed sweet milk:

Given no milk.

0.48

0.44

0.39

Moreover, individuals who have lived to extreme old age have used milk in some of its forms. Several French laborers whose diet consisted largely of milk lived to be one hundred and ten years or over. There are also authentic records of a number of individuals in the Balkans, Persia, Arabia, and in the Caucasus Mountains who have reached extreme old age, whose main diet was milk.

Scientists have long studied the habits of these centenarians and their diet was found to contain large quantities of sour milk. Metchnikoff attributes their long life as due to specific bacteria taken into the alimentary tract with the sour milk, and the organism, Bacillus bulgaricus, is sometimes known as "the bacillus of long life" and is often used by the physician in combating certain digestive disturbances-sometimes with good effects and at other times without. The cause of these failures is only at the present time being fully understood.

Eiven the acid-forming bacteria cannot gain the ascendency when growing on a protein-rich diet, but if grown on a carbohydrate diet 
soon produce sufficient acid to check, if not kill, the putrefiers which give rise to ptomaines.

Milk undoubtedly owes its beneficial action to its lactose which is slowly absorbed and hence regulates the biochemical changes which take place in the lumen of the intestines. Inull and Rettger have conclusively demonstrated that a high lactose diet markedly influences the intestinal flora of man.

Hence, nothing should be done or said to decrease the ('onsump)tion of milk, but much should be done to see that the milk consumed is pure, clean, and freefrom disease-producing bacteria. For although milk is one of the cheapest and best of foods it is responsible for more sickness and deaths than perhaps all other foods combined.

Classes of Milk. - Milk is often roughly divided into three classes, depending upon the care exercised in its production and handlingcertified milk, inspected, or guaranteed milk, and common milk.

Certified milk has no unusual properties other than those of exceptional cleanliness and purity. It is milk which has been produced according to the regulations and under the supervision of a medical milk commission. The cows from which the milk is produced are tuberculin-tested. The stable and cows are kept extremely' clean and no dust is allowed in the stable at the time of milking. Small-top sterilized pails are used. The cows are carefully groomed long enough before milking to let the dust settle. The cow's udder and flanks are washed just before the milking. The milker wears a white suit and washes his hands before milking each cow. The milk is cooled either before or after bottling. The caps are so constructed that they completely cover the top of the bottle, and many dairies use a double cap. The caps are sterilized before use and the milk is kept cool during transit. The number of bacteria should not exceed 10,000 per c.c. of milk. Moak gives the average count of 321 samples of certified milk delivered in Brooklyn during 1910 as 4095 bacteria per c.c.

Such milk is as near pure as it is possible to produce it on a commercial scale, and although it is required that it be delivered to the consumer within thirty hours after production, yet it will keep for a great length of time. At the Paris Exposition in 1900 certified milk from the Inited States, to the astonishment of the judges, was placed on exhibition in perfectly sweet condition after a journey of fourteen to eighteen darss, or 3000 to 4000 miles, in midsummer.

It is probable that in none of our large cities does the production of certified milk exceed 1 per cent. of the total supply. 'This is due to the greater price which must be charged for such milk, and the tendency at the present time is to produce a high grade of milk under less ideal conditions which can be sold at a more moderate price.

This is being met in the selected, inspected or guaranteed milk 
which is being placed on the market. 'This is milk produced from herds free from tuberculosis and which are housed and cared for under good sanitary conditions. Nearly as great care is taken in its production as in that of certified milk. Some milk so produced compares favorably with certified milk.

Common milk is all milk not classified under the preceding heads and may vary in microbial content from a few thousand to many millions. The number and kind vary with the different dairies which produce the milk and often with the city or state in which it is produced, depending upon the nature of the law and the strictness with which it is enforced.

The number of bacteria reported by Hill and slack for Boston milk is given below:

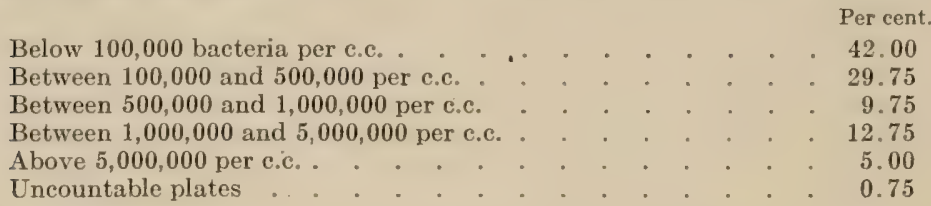

Bacteria in Milk. - Milk is one of the best foods for man. It is also an excellent food for bacteria, as is seen from the facts that millions are often found in a few drops, and in many cases the bacteriologist finds it one of the best mediums on which to grow his laboratory cultures. Therefore, milk should be protected from substances which contain bacteria, especially the disease-producing ones. It is the methods by which they enter and the speed with which they multiply that we want to consider. But it should be stated at the outset that large numbers of bacteria in milk indicate dirt, lack of refrigeration, or age. It may or may not contain the germs of disease, but there is the possibility. So milk with a high bacterial content is not necessarily harmful, but when used as a food-particularly for children-is a hazard too great to be countenanced, or, as stated by Conn: "Good, clean, fresh milk will have a low bacterial count, and a high bacterial count means dirt, age, disease, or temperature. A high bacterial count is, therefore, a danger signal and justifies the health officer in putting a source with a persistently high bacterial count among the class of unwholesome milk."

The number of bacteria occurring in milk varies with age, initial contamination, the care with which it is handled and kept, temperature, and age. Nilk may contain only a few or millions in each drop, or some market milks at times contain as many, but not as dangerous, organisms as sewage.

Initial Contamination. - The source of bacteria in milk are: Intramammary, (2) introduced during milking process, (3) from milk utensils, (4) from the use of special milk apparatus, (5) con- 
tamination in transit, (6) contamination on sellers' or consumers' premises.

Milk as it is secreted is a sterile fluid, but it is fairly well established that as it is excreted from the udder it is not sterile. ITarding and Wilson examined 1230 samples from the udders of 78 cows which showed an average of 428 bacteria per c.c. The numbers vary widely with different cows, some vielding milk with as few as 25) per c.c., whereas others vielded milk with bacterial contents up to 100 ,oon. The organisms obtained from the healthy udder are nonpathogenic and are almost invariably staphylococci, streptococci, and other forms of cocei. It is regarded as certain that the origin of these bacteria is from the outside of the teat. 'They find their way in through the orifice of the teat and extend up the milk column, thus infecting the milk cistern and ultimately the ramifications of the milk tubes through the udder. The work of Savage makes it appear that the number found in freshly drawn milk is determined by the numbers entering the teat, and the selective action of the specific animal.

The bacteria introduced during the milking process are derived from $(a)$ the coat, udder, and teats of the cows, $(b)$ from the milking shed and clothes of the milker, and (c) from the hands of the milker. It is impossible to produce clean milk from cows, the color of which cannot be distinguished even a few rods away because of the filthy condition of their coat. Even where the animal is in a fairly clean condition the wiping of the udder just before milking greatly reduces the number of bacteria in the milk. An average of thirteen experiments at the storrs Experiment Station vielded the following results:

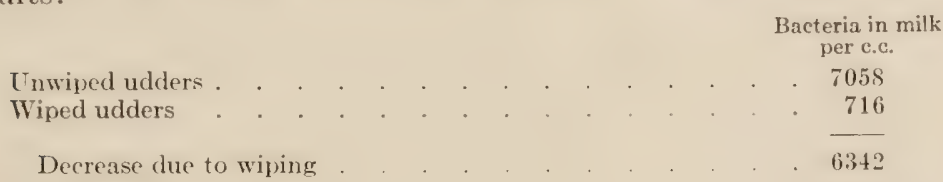

Numerous investigators have shown the presence of bacteria in large numbers in cowsheds, and many individuals have seen stables or milk houses in which each beam of light passing through the crevices seems to be filled with myriads of dancing specks. These dust particles carry bacteria and will increase the bacteria content of milk. However, recent work at the New York and Illinois Experiment Stations has demonstrated that under fair conditions this is a negligible factor.

Then the hands of the milker may not be quite clean, or perchance they have come in contact with disease germs from his own or some one's else body, and these may find their way into the milk and at times multiply with an enormous rapidity.

The influence of the milker in adding bacteria is clearly illustrated 
by the following experiment reported by stocking. The average of 19 tests with two milkers, one who had had no training indairy sanitation, and one who had, showed 17,105 bacteria per c.c. for the untrained man and 245.j for the trained man. The only difference was the knowledge possessed by the trained man.

Even more important than the surroundings in contaminating milk are the utensils. Many buckets are wrongly constructed or not scalded each time so that every seam contains hidden away millions of bacteria. These immediately grow on reaching the fresh, warm milk. Then the strainer may contain a good seeding of bacteria. It would be a great step in advance could the strainer by some means be done away with, for then greater care would be taken in the production of milk; otherwise, it would be unsalable. The condition is somewhat similar to that which existed when it was first suggested that bread be wrapped. There was a baker's convention and the subject had come up for consideration and the members had practically agreed that all bread offered by them should be wrapped, when an old reteran arose and said, "If we wrap our bread in white paper and handle it as we do now the paper will be so dirty that when it reaches the consumer he will refuse to buy." So it is with milk; if it had to be sold in the condition in which it comes at times from the barn, it would be refused. Not that the strainer reduces the number of bacteria in the milk, for it does not. It only removes the particles which are visible to the naked eye after they have been washed nearly free from bacteria.

Prucha and coworkers studied the influence of all the utensils that normally come into contact with the milk both at the barn and at the dairy. They found that when they were all carefully steamed the germ content of the milk in the bottles was about 4566 bacteria per ('e. When similar conditions obtained, except that the steaming of the utensils was omitted, the germ content of the milk approximated 257,240 bacteria per c.c.

Of all the various utensils coming into contact with the milk at the barn and at the dairy, it was found that the clarifier and the bottle-filler, when unsteamed, proved to be the most prolific sources of contamination.

It would, therefore, seem that the most important factor in producing good milk is the scrupulous cleanliness of the milk utensilsand not so much surroundings, as has been so much taught in the past.

It is rlfficult to accurately measure the contamination in transit and on the seller's premises, but it is quite erident that at times it is large. (Orr reported average increases as high as 22.7 per cent., whereas it should be zero under ideal conditions.

Growth of Bacteria in Milk. - Saprophytic and many pathogenic bacteria multiply in milk so that the number found in milk is 
governed, in addition to the factors considered above, by age and temperature. The influence of temperature is illustrated by the following:

Temperature
maintained for
twelve hours $\mathrm{F}$
40
45
50
55
60
70
80

\begin{tabular}{|c|c|c|}
\hline & $\begin{array}{l}\text { eria per c.c. at } \\
\text { f twelve hours. }\end{array}$ & $\begin{array}{l}\text { Hours to curdle } \\
\text { at } 70^{\circ} \mathrm{F} \text {. }\end{array}$ \\
\hline . & 4,000 & 75 \\
\hline . & 9,000 & 75 \\
\hline . & 18,000 & 72 \\
\hline . & 38,000 & 49 \\
\hline . & 453,000 & 43 \\
\hline & $8,800,000$ & 32 \\
\hline . & $55,300,000$ & 28 \\
\hline
\end{tabular}

All of these samples at first contained the same number of bacteria but were kept for twelve hours at the different temperatures and then all maintained at the high temperature. We find over ten thousand times as many bacteria at the end of twelve hours in the sample kept at a high temperature as the one kept at a low. Although the difference in temperature was maintained for only twelve hours, the milk at $40^{\circ}$ kept three times as long as did that at $80^{\circ}$.

Changes Produced in Milk by Bacteria.-The changes occurring in milk are governed by the specifie bacterial flora which it contains and the temperature at which it is kept. Normal clean milk, if kept at a temperature of between $10^{\circ}$ and $21^{\circ} \mathrm{C}$., passes through a sequence of changes which can be divided into four stages.

First Stage.-The first of these is known as the germicidal stage, and lasts a few hours after the milk has been drawn from the udder. During this stage there is a decrease in the number of organisms, as shown by the plate method. The extent of this decrease varies with the milk of different cows and the temperature at which the milk is kept. The higher the temperature, the more marked the decrease, the sooner the end of the germicidal period is reached. There is a great difference in opinion among bacteriologists concerning the nature of the phenomenon. Some would account for it on the grounds that milk is a farorable cultural media for many bacteria, but not all. The ones for which it is unsuited rapidly die off. Others consider that the milk, like the blood and many other body fluids, possesses bactericidal power which is very weak and soon lost. Rosenau and McCoy, however, consider that the bacteria are agglutinated and not killed. On plating, the clump gives rise to the colony in place of each individual organism, as is normally the case.

This germicidal power is lost on boiling the milk or heating to a temperature of $80^{\circ} \mathrm{C}$., and some have urged this as an objection against pasteurization, but in the "holder" process this is not a warranted objection. 
Second Stage.-This stage extends from the end of the germicidal period to the time of curdling. There may be a gradual increase during this time of many species, but the predominating types are the Bact. lactis acidi. These rapidly produce lactic acid which exerts a suppressing influence on many species. When the milk reaches an acidity of .75 to .80 per cent. it usually curdles. The lactic acid organisms seldom produce more than 1.25 per cent. acid.

Third Stage.--This stage extends from the time of curdling until the neutralization of the acid. The acidity becomes so great that the action of the lactic acid bacteria is checked and their number, which at first may be as high as $100,000,000$ per c.c., rapidly decreases. The predominating species become Ö̈dlum lactis, certain species of molds and yeasts. The proteins are broken down with the formation of ammonia which neutralizes the acidity.

Fourth Stage.-The liquefying and peptonizing bacteria which remained inactive in the sour milk find suitable conditions in the alkaline media for their growth. They rapidly decompose the casein.

Abnormal Changes in Milk. - At times foreign undesirable organisms find their way into milk and produce abnormal and objectionable changes. The B. coli communis and the Bact. lactic aerogenes types produce considerable gas and disagreeable odors and flavors in the milk. B. lactis viscosus produces a slimy or ropy condition of the milk. The slimy condition is supposed to be due to the mucin containing capsule which surrounds these bacteria. Milk may be normal in color when first produced, but on standing may turn blue due to $B$. cyanogenes or red due to $B$. crythrogenus or $B$. prodigiosus. At times a bitter taste develops in milk some time after it has been drawn from the udder. 'This, according to Conm, is due to a micrococcus.

Although these changes are very objectionable when considered from the standpoint of the dairymen, they are not known to be the cause of illness. However, when milk putrefies with the production of a bitter alkaline milk illness often does result from its use. This may be due to the poisonous action of the ptomaines which it contains, or probably more of ten to the bacterial infection.

Classes of Bacteria.-The bacteria found in milk are a heterogeneous lot but, according to Hastings, may be roughly divided into five classes, as follows:

1. Acid-forming Bacteria.-There are constantly present in milk many acid-forming bacteria. These vary in morphology, cultural characteristics, and products of fermentation. 'They may be divided into five groups. The number and kind vary greatly in milk, depending upon the methods of handling.

(a) The most important organism of this group is Bact. lactis acidi. 'The group, however, includes a number of organisms. They produce no gas, a mild acid flavor, and are desirable. 
(b) The best known representatives of this group are $B$. coli communis and Bact. lactis aerogenes. These organisms give to milk a sharp tang and are the particular enemies of the cheese maker as they are the cause of gassy curd. They are especially numerous in milk which is produced and handled under unsanitary conditions and in such milk outnumber those of Group $a$, but the rapid growth and acid production of Group $a$ soon checks them.

(c) 'This is represented by Bacillus bulgaricus and the rod-shaped organisms which have been especially studied by de Freudenreich. They produce a curd which is easily broken by shaking and shows no tendency to express whey. They give to the milk a pleasant acid flavor and are desirable.

(d) Acid-forming Udder Bacteria.-These are the characteristic bacterial flora of the healthy udder and consist mainly of cocci with few bacilli. They are slow growers and may curdle milk, but the curd so formed resembles that formed by rennet. They produce acetic, propionic, butyric, and caproic acid but no lactic acid. They are an unimportant group of organisms, so far as the milk is concerned.

2. Peptonizing Bacteria. -These organisms digest the casein either with or without coagulation at times with the formation of an alkaline reaction. Most of these are bacilli of various shapes and sizes, some of them being the largest organism found in milk. There are both motile and non-motile varieties. Many develop very strong putrefactive odors. Barny or cowy odor's are caused by this type of bacteria. They are all undesirable and their presence in milk indicates unsanitary condition of production and handling.

3. Bacteria Producing Mill of I musual (tharacter. -Oceasionally bacteria which produce ahnormal changes or so-called "diseases" of milk find their way into milk from unclean surroundings. They produce various queer milks, for example, red, blue, and green. Sometimes milk derelops a bitterness after it is drawn. This is due to the products from a number of bacteria and yeast. At other times milk is changed to a slimy or ropy consistency and may at times result in considerable economic losses. These organisms are quite resistant to heat and frequently pass uninjured through the ordinary methods of cleaning and scaldings. Because of this, dirty utensils once infected become a constant source of infection.

4. Inert Organisms. - These are mostly cocci which produce no appreciable change in milk and are unimportant.

5. Pathogenic Bacteria.-This class consists of the pathogenic bacteria, B. dysenteria shiga, B. dysenteria flexner, B. typhosus, B. paratyphosus a. and B. paratyphosus $\beta$., V. cholera, Bact. diphtheriox, Bact. tuberculosis, B. lactimorbimic melitensis. These organisms produce no perceptible change in the milk in which they grow but are dangerous and may give rise to epidemics. 


\section{CHAPTER XXXII.}

\section{MILK AND DISEASE.}

Altiovgri milk is one of the cheapest and best of foods, yet it is responsible for more sickness and death than perhaps all other foods combined. The reasons for this have been summarized by Rosenau as follows:

"1. Bacteria grow well in milk; therefore, a very slight infection may produce widespread and serious results. (2) Of all foodstuff's, milk is the most difficult to obtain, handle, transport, and deliver in a clean, fresh, and satisfactory condition. (3) It is the most readily decomposable of all our foods. (t) Finally, milk is the only standard article of diet obtained from animal sources consumed in its raw state."

Diseases conveyed through milk are of two classes: (1) Definite diseases of animal origin-tuberculosis, foot-and-mouth disease, malta fever, and anthrax, and indefinite ailments as diarrheal infections and probably contagious abortion. (2) Diseases of human origin-typhoid fever, paratyphoid fever, diphtheria, scarlet fever, tuberculosis, septic sore throat, and possibly others.

Sources of Infection.-Infection of bovine origin is very common, especially in the case of tuberculosis wherein the animal is suffering with open cases of this disease and the organism gets into the surroundings from the respiratory or alimentary tract. Extreme care in the milking process may decrease the infection from this source, but not so in the case of tuberculosis of the udder, which probably accounts for the main cases where the tubercle bacilli find their way into milk.

As a rule milk becomes infected from human sources. This may be either direct or indirect human infection.

Direct human infection may come from a person either suffering with the disease or carrying the infective organism. The more common are the following:

1. The most common method is where the milkers or other handlers of milk are suffering with a communicable disease in a mild unrecognized condition.

2. A second common source of infection is where the milker or vender of milk has been brought in contact with sufferers of communicable diseases and still attends to his regular work in the handling of milk. 
3. A third and probably very important source of infection comes from carriers who work on the farms, in dairies, or other places where milk is handled.

Indirect human infection comes largely from the use of infected water which is used in the washing of buckets, bottles, and other milking utensils. Cows often have access to polluted water and infection from this source may find its way into the milk from being on the body of the animal.

Character of Milk-borne Diseases.-Milk-borne diseases have characteristies which greatly assist the epidemiologist in his work. The most important are the following:

1. The cases usually follow the route of the milkman and it is often possible to plot his route from the cases of the specific disease. There would thus be the inhabitants of homes where the infected milk is used suffering with the disease, while neighbors who use other milk escape. There may be many purchasers of the infected milk who may escape, but when careful inquiry is made it is found consumers of the implicated supply furnish a much higher percentage of cases than does the rest of the community. The smallest percentage invasion of households is met with in scarlet fever outbreaks. But this is easily explained when one considers the number of missed cases in this disease.

2. The outbreaks from infected milk are usually explosive. Sometimes the majority of the cases occur within a few days of each other. Usually there is little secondary infection and the decline is rapid on removal of the source of infection. The epidemic at Stamford, Connecticut, in 1895, is a good example. 'There were 386 cases of typhoid fever and 22 deaths in the period from April 15 to May 28. There were 176 persons stricken during the first week.

Atthough the explosive type of epidemic is usually characteristic of milk-borne outbreaks, yet Parker points out that the smoldering kind may be very commonly due to infected milk. Ile cites as an example the experience of Hill of North Branch, Ninnesota, where one of the physicians pointed out that in his seventeen years of practice during the first twelve there was no typhoid fever, but in the last five years native cases of unknown origin had been frequent. Acting on this information, a list of 21 cases of typhoid fever that had appeared in the town in the last five years was made, and inquiry showed that seventeen of the patients were regular customers of a dairyman who came to town five years before, two others were irregular customers, and two others may have used milk from his dairy. It was learned that the wife of the dairyman, whowashed the cans, had suffered with typhoid fever twenty-two years before and gave a positive Widal reaction, but typhoid bacilli were not isolated from her stools. She was forbidden to have anything more to do with the dairy and the proprietor was told that if another 
primary case developed among his customers his dairy would be closed. Rumors of the aflair spread through the town and his customers left him and the family moved away, after which there was no more typhoid fever.

3. It frequently happens that the better class suffer more than do the poor, as they can afford more milk and use it more freely.

t. There is a special incidence among milk drinkers, there frequently being an individual who dislikes milk escaping, whereas the remainder of the family is attacked.

5. Women and children are more often victims in milk-borne typhoid than are the adult male population due to their use of raw milk.

6. There is some eridence which indicates that the incubation period is shorter and the mortality lower in milk-borne epidemics than in others.

The mild character of the disease is usually attributed to the attentuation of the pathogenic properties of the microörganisms through their growth in milk.

7. Milk epidemics of typhoid spread over a rather short milk route, whereas when milk is brought from a considerable distance there is not the likelihood of infection, thus indicating that typhoid germs tend to disappear from milk under certain conditions.

Extent of Milk-borne Disease. - The extent of milk-borne epidemics cannot be accurately measured, as eren at the present day many cases go undetermined or perhaps attributed to other causes. But the experience of Boston, Massachusetts, which has a fair milk supply indicates the gravity of the subject.

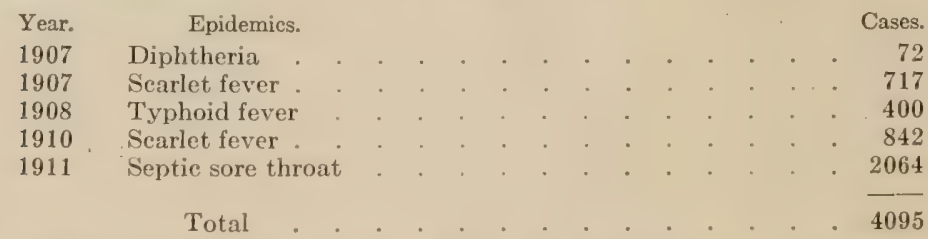

This indicates that scarlet fever and septic sore throat may be conveyed even more often than typhoid fever.

Tuberculosis is the most important of all milk-borne diseases, both because of the frequency with which it is conveyed and the seriousness of the disease. It may be either bovine or human in origin. Human infection is rarer than bovine, but it is certain that a tubercular patient may infect milk, and Hess in 1918 actually isolated the human tuberculosis bacillus from a sample of market milk.

Foch in 1901 anmounced that there was practically no danger of man's contracting tuberculosis from cattle, but his statement was immediately challenged by many bacteriologists who have since brought forth conclusive evidence of the falseness of Koch's dictum. 
The summarized English, German, and American findings in 1511 cases are given below:

\section{COMBINED TABULATION SHOWING ORIGIN OF CASES OF TUBERCULOSIS.}

\begin{tabular}{l|c|c|c}
\hline $\begin{array}{c}\text { Diagnosis of cases } \\
\text { examined. }\end{array}$ & $\begin{array}{c}\text { Adults sixteen } \\
\text { years and over. }\end{array}$ & $\begin{array}{c}\text { Children five to } \\
\text { sixteen years. }\end{array}$ & $\begin{array}{c}\text { Children under } \\
\text { five years. }\end{array}$ \\
\hline
\end{tabular}

Human. Bovine. | Human. | Bovine. Human. | Bovine.

Pulmonary tuberculosis

Tuberculosis adenitis, axillary or inguinal

Tubereulosis adenitis, cervical

Abdominal tuberculosis

Generalized tuberculosis, alimentary origin

Generalized tuberculosis

Generalized tuberculosis, including meninge, alimentary origin

Tubercular meningitis .

Tuberculosis of bones and joints

Genito-urinary tuberculosis

Tuberculosis of skin

Miscellaneous cases:

Tuberculosis of tonsils

Tuberculosis of mouth and cervical nodes

Tubereulosis sinus or abscess

Sepsis, latent bacilli

- - - -

Totals

\begin{tabular}{r|r|r|r|r|r}
778 & 3 & 14 & $\ldots$ & 35 & 1 \\
3 & $\ldots$ & 4 & $\ldots$ & 2 & $\ldots$ \\
36 & 1 & 36 & 22 & 15 & 24 \\
16 & 4 & 8 & 9 & 10 & 14 \\
6 & 1 & 3 & 4 & 17 & 15 \\
29 & $\ldots$ & 5 & 1 & 74 & 7 \\
5 & $\ldots$ & 11 & $\ldots$ & 81 & 11 \\
1 & $\ldots$ & 3 & $\ldots$ & 28 & 4 \\
32 & 1 & 41 & 3 & 27 & $\ldots$ \\
22 & 1 & 2 & $\ldots$ & $\ldots$ & $\ldots$ \\
10 & 3 & 4 & 6 & 2 & $\ldots$ \\
$\ldots$ & $\ldots$ & $\ldots$ & 1 & $\ldots$ & $\ldots$ \\
$\ldots$ & 1 & $\ldots$ & $\ldots$ & $\ldots$ & $\ldots$ \\
$\ldots$ & $\ldots$ & $\ldots$ & $\ldots$ & $\ldots$ & $\ldots$ \\
\hline 940 & 15 & 131 & 46 & 292 & 76
\end{tabular}

The percentage incidence of bovine infection would, therefore, be as follows:

\begin{tabular}{|c|c|c|c|}
\hline & $\begin{array}{l}\text { Adults sixteen } \\
\text { years and over. }\end{array}$ & $\begin{array}{l}\text { Children five } \\
\text { to sixteen years. }\end{array}$ & $\begin{array}{l}\text { Children under } \\
\text { five years. }\end{array}$ \\
\hline Pulmonary tuberculosis . . & . 0.4 & 0 & 2.8 \\
\hline Tuberculosis adenitis, cervical & 2.7 & 38.0 & 61.0 \\
\hline Abdominal tuberculosis . & 20.0 & 53.0 & 58.0 \\
\hline $\begin{array}{l}\text { Generalized tuberculosis, alimenta } \\
\text { origin }\end{array}$ & 14.0 & 570 & 470 \\
\hline Generalized tuberculosis & 0 & 16.0 & $\begin{array}{r}48.0 \\
8.6\end{array}$ \\
\hline Generalized tuberculosis, includi & ing & & \\
\hline meningitis, alimentary origin . & 0 & 0 & 66.0 \\
\hline Tubereular mentingitis & 0 & 0 & 4.6 \\
\hline Tuberculosis of bones and joints & 3.3 & 6.8 & 0 \\
\hline Tuberculosis of skin . & 23.0 & 60.0 & 0 \\
\hline
\end{tabular}

It is probable that the majority of all cases of bovine tuberculosis in man are due to infected milk, as there is little danger from meat since it is usually cooked and tuberculosis of the muscles is very rare.

Tuberculosis is quite prevalent among cows, varying in different places from a few to as high as 50 per cent. Savage gives from 
Dallar the following as being the percentage found in various places: England, 20 per cent.; Denmark, 31 per cent.; Sweden, 42 per cent.; Norway, 8.4 per cent.; Belgium, 60 per cent.; Massachusetts (1897), 58.9 per cent.

It is a general conception that tubercle bacilli occur only in milk obtained from animals suffering with tuberculosis of the udder; this is not strictly true as is seen from the following conclusions by Mohler:

"The tubercle bacillus may be demonstrated in milk from tubercular cows when the udders show no perceptible evidence of the disease either macroscopically or microscopically.

"The bacilli of tuberculosis may be excreted from such udder in sufficient numbers to produce infection in experimental animals both by ingestion and inoculation.

"The presence of the tubercle bacilli in the milk of tubercular cows is not constant, but varies from day to day.

"Cows secreting virulent milk may be affected with tuberculosis to a degree that can be detected only by the tuberculin test.

"The physical examination or general appearance of the cow cannot foretell the infectiveness of the milk.

"The milk of all cows which have reacted to the tuberculin test should be considered as suspicious and should be subjected to sterilization before using."

Shroeder, however, concluded that only 40 per cent. of the cows which react to the tuberculin test actively expel tubercle bacilli.

Market milk often contains the tubercle bacilli, as may be seen from the following table compiled by Parker.

TUBERCLE BACILLI IN MARKET MILK.

\begin{tabular}{|c|c|c|c|c|c|}
\hline $\begin{array}{l}\text { Date. } \\
1899\end{array}$ & $\begin{array}{l}\text { Place. } \\
\text { England }\end{array}$ & $\begin{array}{l}\text { Investigator. } \\
\text { Macfayden }\end{array}$ & $\begin{array}{c}\text { Samples } \\
\text { examined. } \\
77\end{array}$ & $\begin{array}{c}\text { Number } \\
\text { positive. } \\
17\end{array}$ & $\begin{array}{l}\text { Percentage } \\
\text { positive. } \\
22.1\end{array}$ \\
\hline 1904 & Germany & Mäller & 1596 & 97 & 6.2 \\
\hline 1904 & Germany & Beatty & 272 & 27 & 10.0 \\
\hline 1898 & Liverpool & Delepine & 12 & 22 & 17.6 \\
\hline 1897 & Liverpool & Hope & 228 & 12 & 5.2 \\
\hline 1900 & London & Klein & 100 & 7 & 7.0 \\
\hline 1893 & St. Petersburg & Scharbekow & 80 & 4 & 5.0 \\
\hline 1900 & Kiew & Pawlowsky & 51 & 1 & 2.0 \\
\hline 1900 & Krakow & Bujwid & 60 & 2 & 3.3 \\
\hline 1900 & Naples & Marconi & 14 & 7 & 50.0 \\
\hline 1898 & Berlin & Petri & 64 & 9 & 14.0 \\
\hline 1900 & Berlin & Beik & 56 & 17 & 30.3 \\
\hline 1898 & Schev & Ott & 27 & 27 & 11.1 \\
\hline 1898 & Königsburg & Jaeger & 100 & 7 & 7.0 \\
\hline 1908 & Leipzic & Eber. & 210 & 22 & 10.5 \\
\hline 1905 & Rotterdam & Smit & 567 & 14 & 2.7 \\
\hline 1906 & Rotterdam & Smit & 1584 & 45 & 2.8 \\
\hline 1908 & Washington & Anderson & 223 & 15 & 6.7 \\
\hline 1909 & Lonisville & Field & 119 & 46 & 29.5 \\
\hline 1909 & New York & Hess & 105 & 17 & 16.2 \\
\hline 1909 & Philadelphia & Campbell & 130 & 18 & 13.8 \\
\hline 1910 & Chicago & Tonney & 144 & 15 & 10.5 \\
\hline 1910 & Rochester & Goler & 237 & 30 & 12.6 \\
\hline
\end{tabular}


It has been shown that man is susceptible to the bovine type of tuberculosis and that the organism often is found in market milk, and Rosenau estimates that probably 7 per cent. of the cases of tuberculosis thus have their origin. The significance of these figures becomes apparent when we realize that 160,000 individuals die each year in the Lnited States of this disease, and 11,200 would get their infection from milk.

This is a needless loss of human life; for the information now available is sufficient to prevent every one of these cases if milk be obtained only from cows which have given negative tuberculin tests.

The Tuberculin Test.--This reaction should be applied to all cows and is carried out as follows:

"Inspections should be carried on while the herd is stabled. If it is necessary to stable animals under unusual conditions or among surroundings that make them uneasy and excited, the tuberculin test should be postponed until the cattle have become accustomed to the new conditions. The inspection should begin with careful physical examination of each animal. This is essential, because in some severe cases of tuberculosis no reaction follows the injection of tuberculin on account of saturation with toxins, but experience has shown that these cases can be discovered by physical examination. The latter should include a careful examination of the udder and of the superficial lymphatic glands and auscultation of the lungs.

"Each animal should be numbered or described in such a way that it can be recognized without difficulty. It is well to number the stalls with chalk and transfer these numbers to the transfer sheet, so that the temperature of each animal can be recorded in its appropriate place without danger of confusion. 'The following procedure has been used extensively and has given excellent results:

(a) "Take the temperature of each animal to be tested at least twice at intervals of three hours before tuberculin is injected.

(b) "Inject the tuberculin in the evening, preferably between the hours of 6 and 9 P.M. The injection should be made with carefully sterilized hypodermic syringes. The most convenient point for injecting is back of the left scapula. Prior to the injection the skin should be washed careiully with a 5 per cent. solution of carbolic acid or other antiseptic.

(c) "The temperature should be taken nine hours after the injection, and temperature measurements repeated at regular intervals of two to three hours until the sixteenth hour after the injection.

(d) "When there is no elevation of temperature at this time (sixteen hours after injection) the examination may be discontinued, but if the temperature shows an upward tendency, measurements must be continued until a distinct reaction is recognized or until the temperature begins to fall. 
(c) "If the reaction is detected prior to the sixteenth hour the measurements should be continued until the expiration of this period.

$(f)$ "If there is an unusual change of temperature of the stable or a sudden change in the weather, this fact should be recorded on the report blank.

(9) "If a cow is in a febrile condition tuberculin should not be used, because it would be impossible to determine whether, if a rise in temperature occurred, it was due to the tuberculin or to some transitory illness.

(h) "Cows should not be tested within a few days after or before calving, for experience has shown that the results at this time may be misleading.

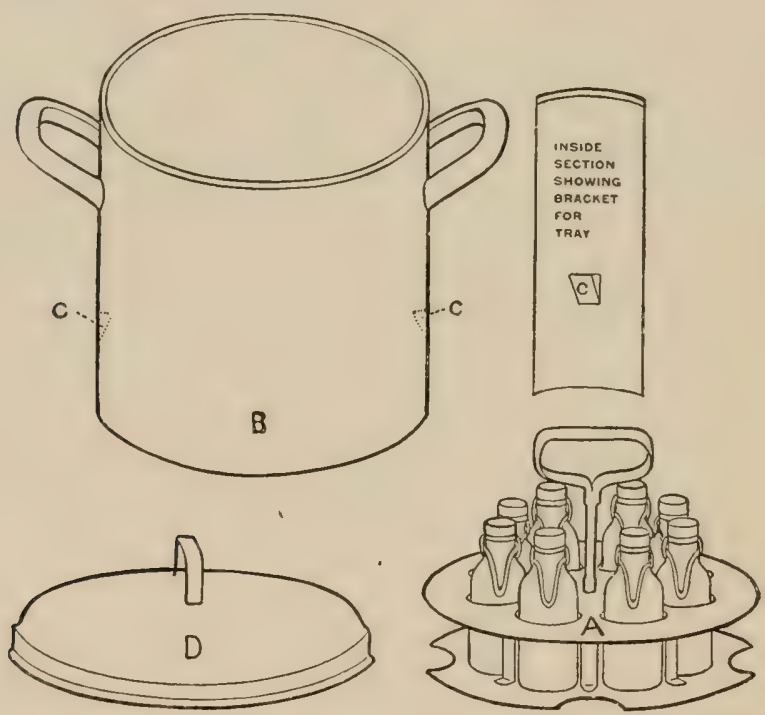

FIG. 45.-Straus's home pasteurizer. (From Rosenau's Preventative Medicine.)

(i) "The tuberculin test is not recommended for calves under three months old.

(j) "In oll, emaciated animals and in retests use twice the usual dose, for these animals are less sensitive.

(k) "Condemned cattle must be removed from the herd and kept away from those that are healthy.

1. "In making postmortems the carcasses should be thoroughly inspected and all the organs should be examined.

"No animal whose temperature exceeds $39.5^{\circ} \mathrm{C} .\left(103^{\circ} \mathrm{F}\right.$.) is a fit subject for the tuberculin test.

"A rise of temperature to above $40^{\circ}\left(\mathrm{C} .\left(104^{\circ} \mathrm{F}\right.\right.$.) in any animal 
whose temperature at the moment of injection was below $39.5^{\circ}$ ('. $\left(103^{\circ} \mathrm{F}\right.$.) is to be regarded as a positive reaction.

"Any rise in temperature between $39.5^{\circ} \mathrm{C} .\left(103^{\circ} \mathrm{F}\right.$.) and $40^{\circ} \mathrm{C}$. $\left(104^{\circ} \mathrm{F}\right.$.) must be regarded as of doubtful significance; animals exhibiting such require special study."

Milk-conveyed typhoid fever can be handled nearly as effectively as can tuberculosis by excluding typhoid carriers as producers and handlers of milk. This can be very easily and efficiently done by requiring the blood test for all dairymen and their workers.

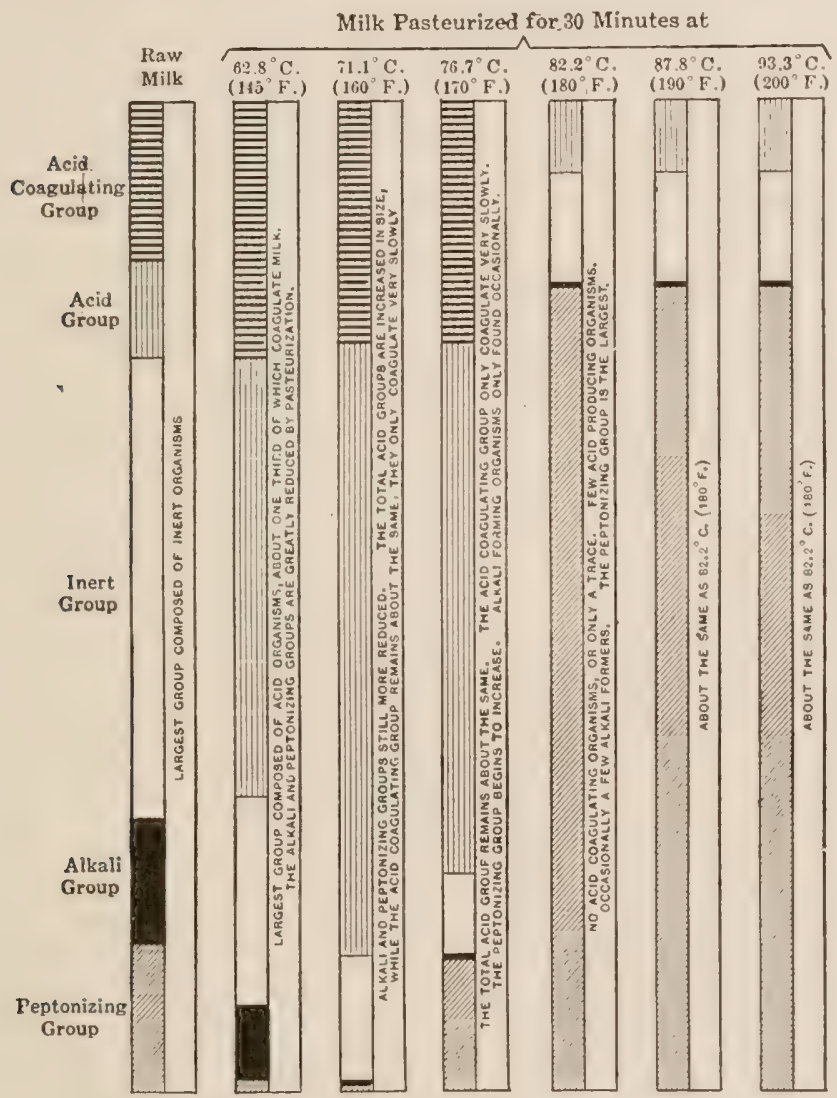

FIG. 46. - The hypothetical relation of the bacterial groups in raw and pasteurized milk. (Tanner, after Ayers and Johnson.)

Pasteurization.-There are two methods of pasteurization--the "flash" and "continuous" processes. In the flash method the milk is heated to $80^{\circ}$ or $90^{\circ} \mathrm{C}$. for from one to five minutes and then cooled to $50^{\circ} \mathrm{C}$. or below. This method is rapid, cheap, and much 
in vogue but does not give uniform results, is not entirely reliable, and does not meet the approval of the sanitarian.

The continuous method is much to be preferred and consists in heating the milk to a temperature of $65^{\circ} \mathrm{C}$. for thirty minutes and then cooling to $50^{\circ} \mathrm{C}$. or below.

The ideal methorl for home pasteurization of milk is outlined by Rosenau as follows:

"Pasteurization in the bottle is the perfection of the art. It is the ideal method, because the danger, however slight, of recontamination is entirely eliminated. In order to pasteurize milk in bottles the bottles must be well sealed with a tight cork and cap, or equally effective stopper. The bottles containing the milk may either be immersed in a water bath, brought to the proper temperature, held there a sufficient length of time and then chilled; or the method used in beer pasteurization, such as the Loew pasteurizers, may be used. In this case the bottles are subjected to a spray or shower of heated water.

"After the bottles have been thoroughly cleaned they are placed in the tray (1) and filled with the milk or mixture used for one feeding. Then put on the corks or patent stoppers without fastening them tightly.

"The pot $(B)$ is now placed on the wooden surface of the table or floor and filled to the support $(C)$ with boiling water. Place the tray (.1) with the filled bottles into the pot $(B)$ so that the bottom of the tray rests on the support $(C)$, and put cover $(D)$ on quickly.

"After the bottles have been warmed up by the steam for five minutes, remove the cover quickly, turn the tray so that it drops into the water, replace the cover immediately. This manipulation is to be made as rapidly as possible to avoid loss of heat. 'Thus it remains for twenty-five minutes."

\section{REFERENCES.}

Rosenau: The Milk Question.

McNutt: The Modern Milk Problem.

Savage: Milk and the Public Health.

Parker: City Milk Supply.

Lane, Clayton: Milk and Its Hygienic Relations.

Heineman: Milk.

Douglass: The Bacillus of Long Life. 


\section{CHAPTER XXXII.}

\section{BACTERIA IN OTHER FOODS.}

ALL foods except those cooked just previous to eating contain bacteria, the number and kind varying with the specific product and especially the method of handling. The greater part of such bacteria are without special significance. Some are beneficial and play an important rôle in the ripening or other changes through which the food passes. These are considered in a later chapter, the present one being reserved for a consideration of those bacteria which cause spoilage of food though not necessarily injurious to health, but of importance from an economic standpoint, and the pathogenic organisms which find their way into food and may infect the consumer.

Bacteria in Butter.- Many of the bacteria which occur in unclean milk multiply and give bad flavors to the butter produced from such milk. This is true to such a degree that most dairies first sterilize their cream and then add to it a pure culture for the ripening of the cream.

Any pathogenic bacteria which find their way into the milk may persist in the butter. While the typhoid organism grows well in fresh milk the increased acid production tends to check their multiplication and may actually kill many. They are, however, fairly resistant to lactic acid, as seen from the following results (Krumwiede and Noble):

Days.
0
7
8
9
10
11.

$\begin{array}{cr}\begin{array}{c}\text { Reaction. } \\ \text { Per cent. }\end{array} & \begin{array}{c}\text { Number of typhoid } \\ \text { bacilli. }\end{array} \\ 1.0 & 392,000 \\ 2.2 & 65,000,000 \\ 5.0 & 300,000,000 \\ \ldots . & 113,000,000 \\ \ldots . & 181,000 \\ 10.0 & 400\end{array}$

Ience, lactic acid cannot be depended upon to free butter from the typhoid bacilli. Moreover, numerous investigators have found typhoid bacilli in butter after varying lengths of time-Bolley, five to ten days; Heim, twenty-one days; Pfulel, twenty-four days; Buck, twenty-seren days. Washburn obtained the organism after one hundred and fifty days from butter which had been experimentally infected with typhoid bacilli, and Boyd reports an epidemic of typhoid fever which resulted from butter. Probably the longevity of $B$. typhosus in butter would vary greatly with the temperature and other factors, but it is quite evident that butter should not be produced from infected milk.

Tubercle bacilli multiply only slowly-if at all-in milk; hence, it is the initial contamination which counts. But we have seen in 
the preceding chapter that these organisms often find their way into milk, and the following table after Briscoe and MacNeal indicates that they often occur in butter.

INCIDENCE OF TUBERCLE BACILLI IN MARKET BUTTER.

\begin{tabular}{|c|c|c|c|c|c|c|}
\hline Author. & Date. & Place. & $\begin{array}{l}\text { Samples } \\
\text { exam- } \\
\text { ined. }\end{array}$ & $\begin{array}{l}\text { Samples } \\
\text { positive. }\end{array}$ & $\begin{array}{l}\text { Per cent. } \\
\text { positive. }\end{array}$ & Remarks. \\
\hline Brusaferro & 1890 & Turin & 9 & 1 & 11.1 & \\
\hline Roth . . & 1894 & Zurich & 20 & 2 & 10.0 & Microseopic method. \\
\hline Obermüller & 1895 & Berlin & 13 & 8 & 61.0 & \\
\hline Schuchardt & 1896 & Marburg & 42 & 0 & 0.0 & \\
\hline Obermüller & 1897 & Berlin & 14 & 14 & 100.0 & 16 tested, 2 lost. \\
\hline Gröning . & 1897 & Hamburg & 17 & 8 & 47.0 & \\
\hline Himesch . & 1897 & Wien & $?$ & 0 & 0 & \\
\hline Rabinowitsch. & 1897 & Berlin & 30 & 0 & 0 & \\
\hline Rabinowitsch. & 1897 & Philadelphia & 50 & 0 & 0 & \\
\hline $\begin{array}{l}\text { Petri } \\
\text { Hormon and }\end{array}$ & 1897 & Berlin & 102 & 33 & 32.3 & \\
\hline Morgenroth & 1897 & Berlin & 10 & 3 & 30.0 & \\
\hline Rabinowitsch. & 1899 & Berlin & 15 & 2 & 13.3 & First series. \\
\hline Rabinowitsch. & 1899 & Berlin & $?$ & $?$ & 87.2 & Second series. \\
\hline Rabinowitsch. & 1899 & Berlin & 15 & 15 & 100.0 & Third series. \\
\hline Rabinowitsch. & 1899 & Berlin & 19 & 0 & 0 & Fourth series. \\
\hline Obermüller . & 1899 & Berlin & 10 & 4 & 40.0 & \\
\hline Korn . . & 1899 & Freiburg & 17 & 4 & 23.5 & \\
\hline Ascher. & 1899 & Königsburg & 27 & 2 & 7.4 & \\
\hline Jäger · · & 1899 & Königsburg & 3 & 1 & 33.3 & \\
\hline Coggi & 1899 & Milan & 100 & 12 & 12.0 & \\
\hline Weissenfield . & 1899 & $\begin{array}{l}\text { Bonn } \\
\text { Wien }\end{array}$ & 32 & 3 & 9.4 & \\
\hline $\begin{array}{l}\text { Grassberger } \\
\text { Herbert }\end{array}$ & $\begin{array}{l}1899 \\
1899\end{array}$ & $\begin{array}{l}\text { Wien } \\
\text { Tübing }\end{array}$ & $\begin{array}{l}10 \\
43\end{array}$ & 0 & $\begin{array}{l}0 \\
0\end{array}$ & \\
\hline $\begin{array}{l}\text { Herbert } \\
\text { Herbert }\end{array}$ & $\begin{array}{l}1899 \\
1899\end{array}$ & $\begin{array}{l}\text { Tübingen } \\
\text { Württem- } \\
\text { burg }\end{array}$ & $\begin{array}{l}43 \\
58\end{array}$ & $\begin{array}{l}0 \\
0\end{array}$ & $\begin{array}{l}0 \\
0\end{array}$ & $\begin{array}{l}\text { Pseudotuberculosis, } \\
5 \text { per. }\end{array}$ \\
\hline Herbert & 1899 & Berlin & 20 & 0 & 0 & $\begin{array}{l}\text { Pseudotuberculosis, } \\
8 \text { per. }\end{array}$ \\
\hline Herbert . & 1899 & München & 5 & 0 & 0 & $\begin{array}{l}\text { Pseudotuberculosis, } \\
4 \text { per. }\end{array}$ \\
\hline Abenhausen & 1900 & Marburg & 39 & 0 & 0 & \\
\hline Hellström & 1900 & Helsingfors & 8 & 1 & 12.5 & 12 samples, 4 lost. \\
\hline Bomhoff . & 1900 & Marburg & 28 & 0 & 0 & 39 samples, 11 lost. \\
\hline Pawlowsky & 1900 & Kiew & 23 & 1 & 4.3 & \\
\hline Tobler . & 1901 & Zurich & 12 & 2 & 16.7 & \\
\hline Lorenz & 1901 & Dorpat & 30 & 0 & 0 & \\
\hline $\begin{array}{l}\text { Markl } \\
\text { Herr and }\end{array}$ & 1901 & Wien & 43 & 0 & 0 & \\
\hline $\begin{array}{l}\text { Herr and } \\
\text { Beninde }\end{array}$ & 1901 & Bresla & 52 & 6 & 11.1 & Two were doubtful. \\
\hline Aujeszky . & 1902 & Budapest & 17 & 3 & 17.6 & \\
\hline Thu . . & 1902 & Christiania & 16 & 0 & 0 & \\
\hline Teichert . & 1904 & Rosen & 40 & 12 & 30.0 & \\
\hline Reitz . . & 1906 & Stuttgart & 94 & 8 & 8.5 & $\begin{array}{l}\text { Butter from eighty- } \\
\text { eight dairies. }\end{array}$ \\
\hline $\begin{array}{l}\text { Eber } \\
\text { Briscoe and }\end{array}$ & 1908 & Leipzic & 150 & 18 & 12.0 & \\
\hline $\begin{array}{l}\text { Briscoe and } \\
\text { MacNeal }\end{array}$ & 1911 & Urbana, Ill. & 6 & 2 & 33.2 & \\
\hline Eber . . & 1912 & 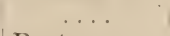 & & & 15.6 & Creamery butter. \\
\hline Rosenau el al & 1914 & Boston & 21 & 2 & 9.4 & $\begin{array}{l}52 \text { per cent. of the } \\
\text { samples contained } \\
\text { acid-fast bacilli. }\end{array}$ \\
\hline Marehiotti & 1917 & & 25 & $\cdots$ & 24.0 & \\
\hline
\end{tabular}


Tuberele bacilli have also been found in oleomargarine. Briscoe and MacNeal tabulated the analysis of 209 samples, 4.3 per cent. of which were found to contain tubercle bacilli.

The longevity of tuhercle bacilli in butter is eren greater than that of B. typhosus, for s'chroeder and ('olton demonstrated their presence in butter which had been kept for one hundred and sixty days;

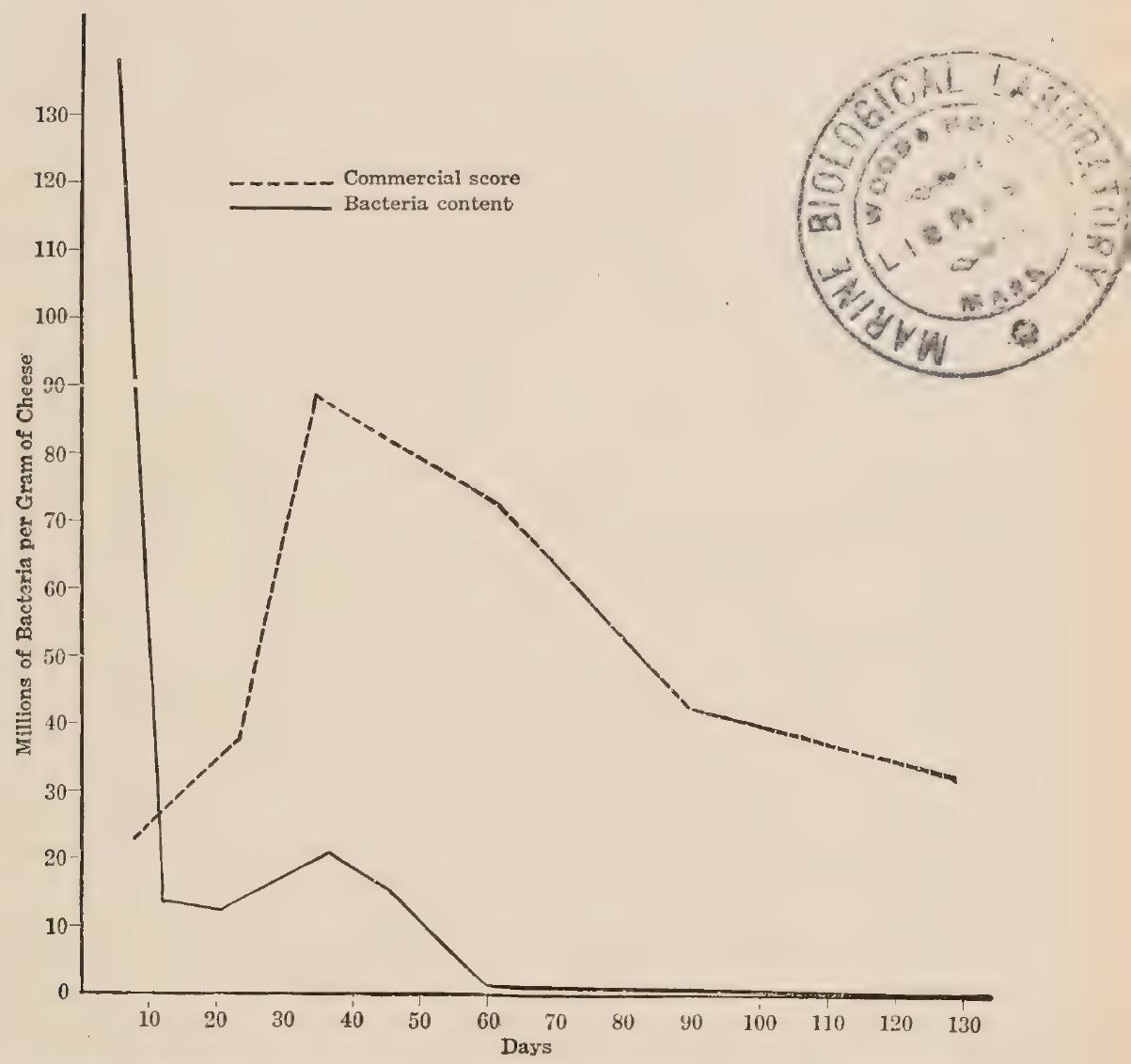

FIg. 47.-Bacteria content and commercial score of Cheddar cheese. (After Harding and Prucha, 1903.)

and contrary to prevailing opinion Mohler, Washburn, and Rogers found tubercle bacilli were not devitalized by cold storage, and in salted butter they were found to retain their virulence for six months.

Diphtheria bacteria have been found in butter, and an outbreak at Lewiston, Minnesota, was believed to have been caused by eating infected butter. There had been no diphtheria in the place until a 
boy returned from the "Twin Cities" after an attack of diphtheria. The milk from the farm where he lived was sent to a creamery and every family in the place, in which there was diphtheria, was found to have used butter from this creamery. Experiments have shown that the diphtheria bacilli can live in butter for a month.

Bacteria in Cheese. - If undesirable species of microörganisms are present in the milk they will pass into the cheese and there produce their harmful effect. This is more important in cheese-making than in butter-making since it has not been found possible to make many of the important varieties of cheese from pasteurized milk. The bacteria most dreaded by the cheese manufacturer are those of the $B$. coli aerogens group. These give rise to the formation of large holes which can be often taken to indicate bad flavor as the organisms produce in addition to hydrogen and carbon dioxid offensive smelling and tasting compounds.

The bacteria of cheese increase during the first few weeks (Fig. $45)$, after which there is a decrease, but even in ripened cheese there are millions of bacteria.

Pathogenic bacteria which are in the milk will find their way into the cheese, as Schroeder and Brett purchased 256 sample s of cheese on the Washington market and examined them for tubercle bacilli by means of guinea-pig inoculation; 7.42 per cent. contained tubercle bacilli. Probably many of the tubercle bacilli die during the ripening process, but this cannot be entirely depended upon, as Washburn and Done prepared a cheese from infected milk and after 220 days produced generalized tuberculosis by injection into guinea-pigs, and even after 260 days injection of emulsions caused slight lesions. According to the findings of Rowland, B. typhosus and $M$. cholerce soon perish in cheese.

Bacteria in Ice Cream.- The number of bacteria in ice cream may at times be enormous. There is only a slight decrease on storage, as is seen from the following results of Hammer and Goss:

SHOWING THE EFEECT OF STORAGE ON THE NUMBER OF BACTERIA IN ICE CREAM.

\begin{tabular}{|c|c|c|c|c|c|c|c|}
\hline Mixed & & 236,000 & $32,800,000$ & 120,000 & $172,500,000$ & $110,000,000$ & $120,000,000$ \\
\hline Frozen & & 735,000 & $30,850,000$ & 146,000 & $271,000,000$ & $170,000,000$ & $140,000,000$ \\
\hline \multicolumn{8}{|c|}{ Days old: } \\
\hline 1 & & 360,000 & $7,750,000$ & 137,000 & $157,000,000$ & $194,000,000$ & $70,000,000$ \\
\hline 2 & & 310,000 & $4,450,000$ & 216,000 、 & $128,000,000$ & $216,000,000$ & $71,000,000$ \\
\hline 3 & & 260,000 & $2,435,000$ & & $52,000,000$ & $102,000,000$ & \\
\hline 4 & & & $1,150,000$ & 152,000 & & & \\
\hline 5 & . & 310,000 & . & 300,000 & $34,000,000$ & $39,000,000$ & $41,000,000$ \\
\hline 6 & & . & . & 139,000 & & & \\
\hline 7 & . & . & . & 156,000 & $31,000,000$ & $54,000,000$ & \\
\hline 8 & . & . & . & . & . & & $61,000,000$ \\
\hline 9 & & . & . & . & . & $36,000,000$ & \\
\hline 10 & & . & . & & 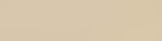 & $15.000,000$ & \\
\hline 11 & & & & .. & - & & \\
\hline
\end{tabular}


Freezing does not kill the bacteria in milk or cream; hence, ice cream may and does convey all of the milk-borne diseases. Furthermore, the ice cream is often made in unsanitary places and handled in an unsanitary manner; so that even though the milk be safe there are numerous opportunities for infection, especially where ice cream is vended on the street or from the little ice-cream stands on the corner.

Bolton reported experiments on the freezing of B. typhosus in cream. One-twentieth of the organisms were alive after one month and even after forty-five days some of the organisms were alive. Furthermore, epidemics of typhoid have actually been traced to ice cream. Cumming reported 23 cases which developed among twenty-nine persons who partook of ice cream at a school picnic at IJelm, California, in 1916. Ice cream was the only food partaken of by all, and as chocolate ice crream was the favorite flavor this was determined to be the source of the infection. This was because (1) those not partaking of it did not become ill, (2) those partaking of it but no other food were taken ill, (3) those eating chocolate ice cream were taken with acute intestinal symptoms, and ( 4 ) those eating the largest quantity of chocolate ice cream were the most seriously ill.

Dysentery is also often spread by means of ice cream. Smillie studied 75 cases and found the etiology of them to be as follows:

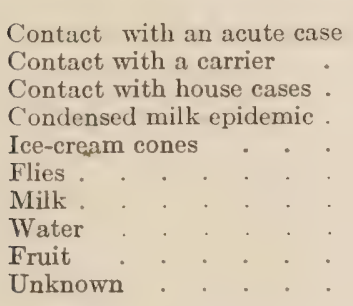

Cases.

Contact with an acute case . . . . . . . . . . . 21

Contact with a carrier . . . . . . . . . . . . . . . 2

Contact with house cases . . . . . . . . . . . . 4

Condensed milk epidemic . . . . . . . . . . . . . . . . . 15

Ice-cream cones . . . . . . . . . . . . . . 9

Flies . . . . . . . . . . . . . . . . . 6

Milk _ . . . . . . . . . . 1

Water . . . . . . . . . . . 1

Fruit . * . . . . . . . . . 1

The dysentery bacillus of Flexner was actually isolated from the ice-cream cones.

Hamilton has pointed out that ice-cream epidemics can be prevented by (1) the use of ingredients with a clean sanitary history, (2) the use of properly cleaned utensils and a clean factory, and (3) the proper handling of materials by individuals with a clean bill of health. The first of these is to be controlled by the pasteurization of the milk and cream; the second by frequent inspection; and the last requires regular and careful inspection of all workers for communicable diseases.

Bacteria in Condensed IMilk. - Sweetened condensed milk is not intended to be sterile. The large quantity of sugar added prevents the growth of microörganisms. But the unsweetened or evaporated 
milk is sterilized after sealing, and hence when properly done the finished prorluct should contain no bacteria. The organisms which at times survive pasteurization and later may cause spoilage are B. subtilis, B. mesentericus, and B. coagulans.

The degree of heat to which all the condensed, concentrated, and powdered milk are subjected is probably sufficient to kill all tubercle bacilli and typhoid bacilli, but Andrew's' work would indicate that at times condensed milk may act as a differential medium for Staphylococci. He reports instances where at time of condensation a few Staphylococci Pyogenes aureus were present, but later when the cans were opened many were present.

Bacteria in Bread.-The interior of the loaf reaches a temperature of $101^{\circ}$ to $103^{\circ} \mathrm{C}$. and the crust $125^{\circ}$ to $140.5^{\circ} \mathrm{C}$. in the baking process; hence only the more resistant sporebearing organisms would survive the baking process. Disease germs, therefore, seldom -if ever-occur in the freshly baked bread. However, B. mesentericus culyatus, and probably other organisms which cause slimy or ropy bread, may survive and cause considerable economic loss.

When they have found their way into a bakery the ease with which they are orercome depends upon whether they are in the yeast, on the utensils, or in the flour. If they are in the veast, a new start must be obtained, and Kayser suggests the use of acidulated water for washing all of the apparatus and even states that some of the apparatus may have to be discarded. (rreat economic loss, however, results when the flour is the infected material.

Although bread is free from pathogenic bacteria when it leaves the oven, this is often not true when it reaches the consumer, for unwrapped bread must ever remain a constant danger. But when once wrapped, the danger is not as great, for the wrapper acts as a protection and if carelessly handled tells the tale to such an extent that it may be refused by the consumer.

Bacteria in Eggs. - All investigators have found more bacteria in the egg rolk than in the egg white, and many of those who have found no bacteria in egg white have assumed that this part of the egg possesses a bactericidal action. Rettger considers that the contents of normal fresh eggs are as a rule sterile, although he considers it quite probable that an egg yolk may become invaded before it is expelled from the ovary. But this he considers an uncommon occurrence, except when the ovary is infected with the organism of bacillary white diarrhea.

The percentage of infected eggs found by different investigators as reported by Tanner is given below:

$$
\text { Author. }
$$

Rettger

Rettger (10 c.c. samples)

Bushnell and Mauer.

Mauer

Hadley and Caldwell

$\begin{array}{cc}\begin{array}{c}\text { Number } \\ \text { examined. }\end{array} & \begin{array}{c}\text { Per cent. } \\ \text { infected. }\end{array} \\ 3516 & 9.5 \\ 647 & 3.86 \\ 27.59 & 23.70 \\ 600 & 18.10 \\ 2520 & 8.70\end{array}$


The kim of organism and the number of times found hy Rettger are listed below:

Fresh eggs.

Number of times found.

Staphylococcus, usually aureus and albus

74

Subtilis group, usually B. mesentericus and B. ramosus . . . . 60

$B$. coli and closely related organisms

Proteus group

30

Streptococcus . . . . . . . . . . . . . . . . 14

Micrococcus (tetragenus, etc.) . . . . . . . . . . . . . . . . 9.9

Streptothrix . . . . . . . . . . . . . . . . . 6

Diphtheroid bacillus . . . . . . . . . . . . . . 5

Putrefactive anaërobes . . . . . . . . . . . . . 5

B. fluorescens . . . . . . . . . . . . . . . . 2

Mold . . . . . . . . . . . . . . . . 4

B. mucosus . - . . . . . . . . . . . . . . . 3

Mixed . . . . . . . . . . . . . . . . 2

Total

Hadley and ('aldwell studied forty different strains isolated from eggs. They were divided as follows: rods, 2S; cocci, 11 ; spirillum, 1. They found no member of the hemorrhagic septicemia, intestinal, proteus colon, enteritidis, typhoid, dysentery, nor diphtheria group.

Rettger considers that under normal conditions the shell is bacterium-proof. Moisture lessens its impervious character, however, and when combined with dirt or filth makes it possible for microorganisms to enter and bring about decomposition. Ilence, eggs should be stored under sanitary conditions.

Cold storage, frozen, and dried eggs often contain millions of bacteria, ret of all food, so far as known, eggs are less liable to contain harmful products or to convey disease than any other single food of animal origin. They have an exceptionally clean health record. There is no known infection of the hen transmissible through the eggs to man. The literature is exceptionally free from instances where sickness has been attributed to eggs except in the case of anaphylaxis which is undoubtedly due to an idiosynerasy of the individual and not to any inherent injurious constituent of the egg.

Bacteria in Meat.-It is usually considered that the tissues of healthy animals are free from bacteria, but Iaagland states that certain bacteria (chiefly micrococci) may be normally present in the carcass of healthy animals slaughtered for beef. These bacteria he considers possess no pathological significance and do not appear to multiply in the cold-stored carcasses, provided the cold storage room is maintained at the proper temperature.

Meat kept for some time may contain many bacteria. Weinzirl and Newton found that four out of ten samples of meat which had been stored at $-10^{\circ} \mathrm{C}$. for one year, contained over $10,000,000$.

Chopped meats invariably contain many bacteria for the reason that meat used for that purpose is often that which has been dis- 
carded for other purposes and then the hashing carries the bacteria throughout the mass which is an excellent medium for their multiplication. This is recognized by the fact that Weinzirl and Newton proposed a bacterial standard of not over 10,000,000 per gram for hamburger and then found that 50 per cent. of the samples examined by them had to be condemned.

Sausage always contains numerous bacteria, but as pointed out by Carey the kind of organism present is more important than the number. He isolated the following organisms from 34 samples of sausage purchased on the market in Chicago:

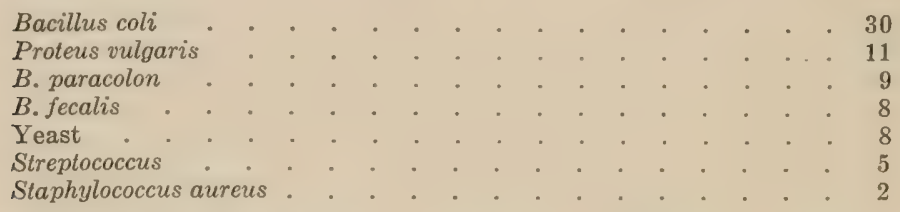

Bacteria in Canned Foods. - The majority of the canned meats and fruits are free from bacteria, but in the case of swelled and spoiled products numerous organisms are found.

Some of the organisms identified by Donk as causing spoilage of canned goods were as follows:

$M$. acidi in cheese.

M. candicans in roast beef, sardines, and bulk granulated sugar.

M. candidus in baked beans.

$M$. cereus in baked beans.

M. lactis in cheese.

M. luteus in corn.

$M$. pyogenes in two samples of Maine style corn and one sample of canned corn on cob.

M. stellatus in canned roast beef.

$B$. cloace in canned roast beef.

$B$. detrudens in cheese.

$B$. licheniformis in stringbeans.

B. megatherium in sauerkraut brine (not canned) and cheese.

B. mesentericus in cheese.

B. pammellii in cheese.

B. subtilis in corn.

B. tenus in cheese.

B. viscosus in cheese.

B. vilatis in spinach and bulk granulated sugar.

B. welchii in corn.

B. vulgatus in two samples of corn. 


\section{CHAPTER XXXIV.}

\section{BACTERIA AND FOOD-POISONING.}

The term "food-poisoning," or ptomain poisoning, in the past has been used to cover a multitude of physiological disturbances. As Jordan points out, "that convenient refuge from etiological uncertainty 'ptomain poisoning' is a diagnosis that unquestionably has been made to cover a great variety of diverse conditions from appendicitis and pain caused by gall-stones to the simple abdominal distention resulting from reckless gorging:" But even when account is taken of this, its toll of human life and suffering is great. Food-poisoning is also a great cause of inefficiency, depression, sluggish mental processes, dissatisfaction, or abnormal irritability which are often overlooked or attributed to other causes.

Classes of Food-poisoning. - Present knowledge permits the following rough classification of food-poisoning:

1. Poisoning due to the eating of foods which naturally contain poisonous products.

2. Poisoning due to the eating of foods containing mineral poisons added either intentionally or accidentally.

3. The eating of foods which are normally non-poisonous but which have been obtained from animals suffering from disease.

4. The eating of food which has been accidentally infected with pathogenic bacteria in handling or preparation.

5. The eating of foods which contain poisonous products of bacterial katabolism-toxins.

6. The eating of a normal food by an individual who possesses peculiar idiosyncrasies toward a specific food.

Poisonous Foods. - The first group consists of naturally-occurring plants and animals which are always poisonous or become so during certain seasons of the year. According to Chestnut there are 16,673 leaf-bearing plants included in Heller's Catalog of North American Plants. Of these nearly 500 have been alleged to be poisonous, but fortunately only a few are ever accidentally partaken of by man. Chestnut lists about thirty important poisonous plants occurring in the United States and some of these are not known to be poisonous except to domestic animals. Some of the more common are as follows:

American false hellebore (Veratrum viridi) - mistaken for marshmarigold. 
Kentucky coffee tree (Gymrnocladus disica) - mistaken for honeylocust.

Broad leaf laturel ( Kalmiu litifolia)-mistaken for wintergreen.

Water hemlock (cicutu moculuta) - roots mistaken for horseradish, artichoke, parsnip, etc.

By far the most common of these cases of plant-poisoning is due to the eating of the poisonous mushrooms or "toadstools" (-Imaneta muscaria), (A. phalloides), (A. verna).

The symptoms of poisoning with 1 . phalloides is thus described by Ford:

"Following the consumption of the fungi there is a period of six to fifteen hours during which no symptoms of poisoning are shown by the victims. This corresponds to the period of incubation of other intoxications or infections. The first sign of trouble is sudden pain of the greatest intensity localized in the abdomen, accompanied by vomiting, thirst, and choleraic diarrhea with mucous and bloody stools. The latter symptom is by no means constant. The pain continues in paroxysms often so severe as to cause the peculiar Hippocratic facies, la face vulteuse of the lirench, and though sometimes ameliorated in character, it usually recurs with greater severity. The patients rapidly lose strength and flesh, their complexion assuming a peculiar yellow tone. After three to four days in children and six to eight in adults the victims sink into a profound coma from which they cannot be roused and death soon ends the fearful and useless tragedy. Convulsions rarely if ever occur and when present indicate, I am inclined to believe, a mixed intoxication, specimens of Imanita muscaria being eaten with the phalloides. The majority of individuals poisoned by the 'deadly' Amanita' die, the mortality varying from 60 to 100 per cent. in various accidents, but recovery is not impossible when small amounts of the fungus are eaten, especially if the stomach be very promptly emptied, either naturally or artificially."

Metallic Poisons.-Various canned goods have been repeatedly accused of causing poisoning, but the cases in which this has occurred when the foods have been sterilized by the pressure method are extremely rare. Where it has caused trouble it is usually due to some metallic poison found in the cans and not to poisons developed in the food due to bacterial activity.

Asparagus is often looked upon as one of the canned products most likely to cause poisoning. This is due in a large measure to the fact that asparagus takes up large quantities of tin, and some individuals are especially susceptible to this substance. The quantity of tin, and especially copper, which is taken up in most cases varies with the amount and kind of acid found in the fruit or vegetables. Noreover, when a low or poor grade of copper is used, it is more readily attacked by the fruits than are the pure compounds. 
Fairly large quantities of copper have to be eaten before death results, and it is doubtful whether many foods would dissolve sufficient to result fatally. Whereas a small small quantity of one of the metallic poisons taken once may cause no ill effects, their constant use would, for their action is cumulative. Moreover, sanitarians insist that chemical substances likely to be irritating to the human tissues in assimilation or elimination should not be employed in food. Each new irritant, even in small quantities, may add to the burden of organs already weakened by age or previous harsh treatment.

Animals Suffering from Disease.-The milk and flesh of animals suffering with certain diseases are continually being used without adequate cooking, the result being that thousands die each year from this cause. The majority of these cases come from the use of milk, which has been considered' in an earlier chapter. A typical outbreak of paratyphoid due to the eating of diseased meat is thus given by Jordan:

“'The most characteristic examples of 'food poisoning,' popularly' speaking, are those in which the symptoms appear shortly after eating and in which gastro-intestinal disturbances predominate. In the typical group-outbreaks of this sort all grades of severity are manifested, but as a rule recovery takes place. The great majority of such cases that have been investigated by modern bacteriological methods show the presence of bacilli belonging to the so-called paratyphoid group (B. paratyphosus or B. enteritidis). Especially is it true of meat-poisoning epidemies that paratyphoid bacilli are found in causal relation with them. IIübener enumerates forty-two meat-poisoning outbreaks in Crermany in which bacilli of this group were shown to be implicated, and sarage gives a list of twenty-seven similar outbreaks in Great Britain. In the Inited States relatively few outhrealis of this character have been placed on record, but it cannot be assumed that this is due to their rarity, since no adequate investigation of food-poisoning cases is generally carried out in our American communities.

"Typical Paratyphoid Outbreaks. - Kaensche describes an outbreak at Breslau involving over eighty persons in which chopper beef was apparently the bearer of infection. The animal from which the meat came had been ill with sever diarrhea and high fever and was slaughtered as an emergency measure (notgeschlachtet). On examination a pathological condition of the liver and other organs was noted by a veterinarian who declared the meat unfit for use and ordered it destroyed. It was, however, stolen, carried secretly to Breslau, and portions of it were distributed to different sausagemakers, who sold it for the most part as hamburger steak (IIackfleisch). The meat itself presented nothing abnormal in color, odor, or consistency. Nevertheless, illness followed in some cases after 
the use of very small portions. With some of those affected the symptoms were very severe, but there were no deaths. Bacilli of the Bacillus cnteritidis type were isolated from the meat.

"A large and unusually severe outbreak reported by Mclleeney occurred in November, 1908, among the inmates of an industrial school for girls at Limerick, Ireland. There were 73 cases with 9 deaths out of the total number of 197 pupils. The brunt of the attack fell on the first or Senior class comprising 67 girls between the ages of thirteen and seventeen. Out of 55 girls belonging to this class who partook of beef stew for dinner 53 sickened, and 8 of these died. One of the two who were not affected ate the gravy and potatoes but not the beef. Some of the implicated beef was also eaten as cold meat by girls in some of the other classes, and also caused illness. Part of the meat had been eaten previously without producing any ill effects. "The escape of those who partook of portions of the same carcass on October 27 and 29 (five days earlier) may be accounted for either by unequal distribution of the virus or by thorough cooking which destroyed it. Some of the infective material must, howerer, have escaped the roasting of the 29th, and multiplying rapidly, have rendered the whole piece intensely toxic and infective during the five days that elapsed before the fatal Tuesday when it was finally consumed.' The animal from which the forequarter of the beef was taken had been privately slaughtered by a local butcher. No reliable information could be obtained about the condition of the calf at, or slightly prior to, slaughter. The meat, however, was sold at so low a price that it was evidently not regarded as of prime quality. In this outbreak the agglutination reactions of the blood of the patients and the characteristics of the bacilli isolated showed the infection to be due to a typical strain of Basillus enteritidis."

Offending Foods.-Meat is so often the cause of poisoning that the terms "meat-poisoning" and food-poisoning" have come to be used almost synonymously. Of meats, chicken and pork are more likely to cause poisoning than are meats from other animals, while the internal organs-liver and kidney-are more likely to contain disease-producing bacteria than are the muscular tissues. Sausages, hamburger steaks, meat pies, puddings, and jellies are especially likely to cause food-poisoning. This is probably due to the products from which they are made, the methods of treating, and the fact that the heat used in cooking such foods is not sufficient to kill the bacteria in the food. IVhile there are a few cases on record where individuals have been poisoned by the eating of freshly wellcooked meats they are so rare as to be of little importance: so the thorough cooking of meat greatly diminishes the likelihood of trouble. 
Human Infection. - It is necessary that food be protected from contamination during the whole process of preparation and serving to prevent its infection with pathogenic bacteria, as is illustrated by the remarkable instance reported by Sawyer where ninety-three typhoid cases were caused by eating Spanish spaghetti served at a public dinner. Investigation showed that the dish had been prepared by a woman typhoid-carrier who was harboring living typhoid bacilli at the time she prepared the dish. The dish was baked after it was infected, but the baking was'shown by laboratory experiments to have incubated the bacteria instead of sterilizing the food.

Then there is the celebrated case of Typhoid Mary, investigated by Saper. In the pursuit of her work as a cook in and about New York City she is known to have caused at least seren typhoid outbreaks in various families and one extensive hospital epidemic.

The danger from this source is roiced by Chapin as follows: "There are doubtless 200,000 cases of this disease (typhoid fever) in the Lnited States each year. If only 3 per cent. of these become chronic carriers, and if a carrier remains such only three years, we should have a carrier population of 18,000 persons, practically unknown and taking no precautions against infecting others. If we add to these the 25 per cent. of convalescents, who for some weeks are excreting the bacilli in their urine, it appears that there is a very respectable army of unrecognized sources of typhoid infection."

This is a situation which will be solved only when all handlers of food in public places are examined for various diseases which are transmissible through food. A move in the right direction has been made by the California State Board of Health which enters into the following agreement with all carriers discovered:

"I have this day been informed that my excreta contain typhoid bacilli and that, unless unusual precautions are taken, persons will contract the infection from me. Realizing this danger I agree to observe the precautions stated below, and request that I be permitted to remain in free communication with other persons.

"1. I will take no part in the preparation or handling of food which will be consumed by persons outside of mr immediate family, and I will not participate in the management of a boarding house, restaurant, food store, or in any other occupation involving the preparation or handling of food.

"2. I will not dispose of my excretions in a toilet to which flies have access without first exposing such excretions to either a 5 per cent dilution of liquor formaldehyd or 5 per cent. phenol (carbolic acid).

"3. I will notify the local health officer of any cases of typhoid among persons with whom I come in contact.

"4. I will inform the local health officer of any contemplated 
change of residence so that he can notify the State Board of Iealth and obtain its approval.

"5. I will submit specimens for examination when requested by the State Board of Health.

" 6 . I will fill out the following report blank when submitted to me semi-annually, and return the same to the California State Board of Health:

'I have, during the last six months, complied to the best of my knowledge with the five separate agreements entered into between myself and the California State Board of Health. Precautions involved in these separate agreements are for the purpose of preventing typhoid infection." "'

Ptomain Poisoning.-Plant and animal tissues under appropriate temperature, moisture, and aëration putrefy. The proteins are broken down with the formation of basic, often highly toxic, substances spoken of as "animal alkaloids" or ptomains. These compounds are not poisonous in every case. The presence of oxygen in the compound seems to be necessary for the development of strong toxicity. In putrefying mixtures these toxic bodies appear on or about the fifth to seventh day after putrefaction sets in and disappear through further cleavage more or less rapidlly yielding less complex nitrogenous substances that are non-toxic. It was formerly thought that they played a very important part in food-poisoning. But recent work has indicated that they are seldom the causative agent. Taughan and Navy, who have made an extensive study of ptomains, have proposed a very elaborate nomenclature for supposed foodpoisoning due to their ingestion. Some of them are as follows:

Cheese-poisoning

Fish-poisoning

Food-poisoning

Meat-poisoning

Milk-poisoning
Tyrotoxismus

Ichthyotoxismus

Bromototoxismus

Kreatoxismus

Galactotoxismus

Botulism. - Botulism results from the eating of food in which the Bacillus botulimus has grown and elaborated a poison. The organisin is a large bacillus 4 to $6 \mu$ by 0.9 to $1.2 \mu$, having slightly rounded ends and they may arrange themselves in pairs, end to end, or in an unfavorable environment in long chains. It is a strict anaërobe, but may grow under imperfect anaërobic conditions if in symbiosis with certain aërobic bacteria. The optimum temperature for the growth of the bacillus and for the elaboration of the poison is between $20^{\circ}$ and $30^{\circ}($. The regetative cells are easily destroyed hy heat, but the spores are quite resistant (acoording to Van Ermengen, $85^{\circ} \mathrm{C}$. for fifteen minutes), but I ickson considers them even more resistant. Thom and associates isolated strains from asparagus which survived steaming under 10 pounds' pressure for fifteen minutes, or a temperature of $100^{\circ}$ ( . for one hour. They remain visable, according to 
Dickson, for months or even years if protected from the action of light and air, even though the medium in which they are immersed is of acid reaction. The toxin which they produce is quickly destroyed by exposure to the action of light and air, but will maintain its virulence for six months or more if kept in the dark and sealed. According to Van Ermengen, the toxicity is diminished by heating at $56^{\circ} \mathrm{C}$. for three hours and destroyed by heating to $\$ 0^{\circ} \mathrm{C}$. for half an hour or by boiling. I lickson found that the toxin may develop in mediums such as green corn, artichokes, asparagus, apricots, and peaches to which no traces of animal proteins have been added in addition to the various meats.

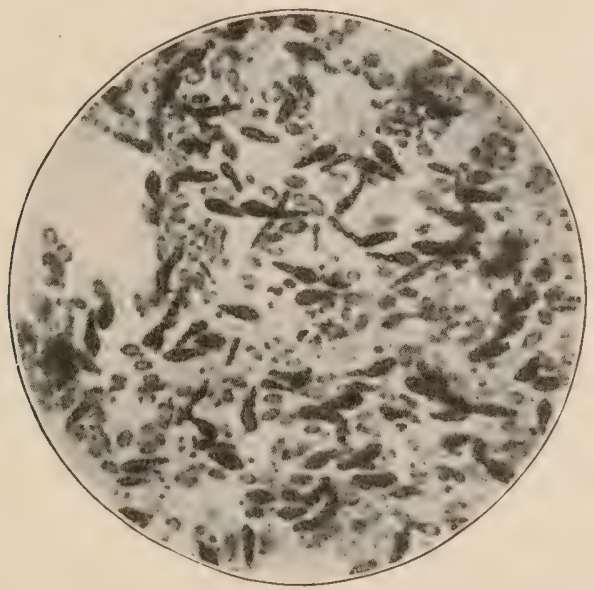

FIG. 48.-Bacillus Botulinus. (After Dickson.)

The pronounced symptoms which develop on the ingestion of the toxin are thus described by Wilbur and Ophüls:

"( irl, aged twenty-three, Tuesday evening, November 23, 1913, ate the dimner including the canned stringbeans of the light green color together with a little rare roast beef. The following day she felt perfectly normal except that at 10:00 in the evening the eves felt strained after some sewing. Thursday morning, thirty-six hours after the meal, when the patient awoke, the eyes were out of focus, appetite was not food, and she felt very tired. At night she had still no appetite, was nauseated, and vomited the noon meal apparently undigested. Friday morning, two and one-half days after the meal, the eyes were worse, objects being seen double on quick movement, and it was noticed that they had a tendency to be crossed. A peculiar mistiness of vision was also complained of. She was in bed until late in the afternoon, when she visited Dr. Black. She had had some disturbance in swallowing previous to 
this time and stated that it felt as if 'something came up from below' that interfered with deglutition. The fourth day she remained in bed, was much constipated, and noticed a marked decrease in the amount of urine voided. There was at no time pain except for occasional mild abdominal cramps, no headache, subnormal temperature, and a normal pulse. The fourth and fifth days the breathing became difficult at times and swallowing was almost impossible. The patient complained of a dry throat with annoying thirst. The sixth day there were periods of a sense of suffocation with a vague feeling of unrest and as if there might be difficulty in getting the next breath. The upper lids had begun to droop. The voice was nasal. When the attempt was made to swallow liquids they passed back through the nose. The patient felt markedly weak.

"Physical examination at this time showed ptosis of both upper eyelids, dilatation of the right pupil, sluggish reaction to light of both pupils, apparent paralysis of the internal rectus of the left eye, normal retina, inability to raise the head, control apparently having been lost of the muscles of the neck, inability to swallow, absence of taste. The tongue was heavily coated and the throat was covered with a viscid whitish mucus clinging to the mucous membrane. The soft palate could be raised but was sluggish, particularly on the right side. The exudate on the right tonsil was so marked that it resembled somewhat a diphtheritic membrane. The seventh day there was some change in the condition; occasional periods occurred when swallowing was more effective, and there was less tendency to strangle. On the eleventh day there was some improvement of the eyes, still strangling on swallowing, sensation of taste was keener, and the general condition improved. The twelfth day the patient was able to move her head, but was unable to lift it except when she took hold of the braids of her hair, and pulled the head forward. The eyes could be opened slightly, speech was less nasal and more distinct, and improvement in swallowing was marked. At the end of two weeks the patient was able to take soft diet freely, and at four weeks she was up in a chair for a couple of hours complaining only of general weakness and inability to use her eyes. At the end of five weeks she was able to leave the hospital and return to her home and later to resume her regular work.'

Prevention. - The prevention of food-poisoning from cammed foods consists of processing the material according to the best experience available, the selection of good, sound material and the rejection of any infected material. Dirty, wilted, and partly rotted food carries many more organisms into the canning process than does fresh, sound, clean fruits and vegetables. Dirty tables, dirty jars, lids, and sewage-polluted water and flies are sources of contamination which should be eliminated.

When a can presents a convex appearance (technically called a 
"blown can"), or on opening a can a foul smelling gas escapes, it is a warning to the consumer that the contents should be destroyed, not salvaged, fixed up into salads, mincemeat, or made-over dishes for human consumption, nor should it be fed to lower animals as there are many cases in which chickens and other animals have been killed by such products. This probably distributes the organism on the premises.

At other times the products have a peculiar rancid odor resembling spoiled butter which becomes more pronounced on standing. Such vegetables should not be tasted, but destroyed. All vegetables which have been put up by any other than standard methods should be boiled before being eaten or even tasted, and no such products should be served as salads unless they have been cooked after removing from the container.

Boldnau: Food Poisoning.

REFERENCES.

Jordan: Food Poisoning.

Tanner: Bacteriology and Mycology of Food.

Dickson: Botulism Monographs of the Rockefeller Institute for Medical Research. 


\section{CHAPTER XXXV.}

\section{PRESERVATION OF FOOD.}

WIIERE a race is dependent upon a local or seasonal supply of food it occurs that in one district or during one season there is an abundance, whereas in another locality or at another season there may be a scarcity which at times amounts to a famine. This state of affairs was very common in the earlier history of the race, but modern methods of transportation and food preservation has made it possible for the modern individual to have a sufficient and varied diet at all seasons. A varied diet is more certain to contain all those constituents which are essential to the body needs than is a restricted or monotonous diet. Moreover, it is well recognized today that nutritional disorders are more likely to occur on a restricted than on a varied diet. Ifence, the general result of the expansion in the kinds of foor consumed is good, but the food should be preserved in a manner such that as little as possible of the mutrient constituents are lost; so there is little change in appearance and taste and nothing is added nor developed in the food which is deleterious to health.

Ileat, colrl, drying, and the use of some chemicals have long been in use for the preservation of food, but it is only recently that the art has been developed to its highest perfection. This is due to the fact that the art of food-preserving depends upon the science of bacteriology, and today it is possible to preserve some foods indefinitely without injuring their nutritive value or seriously interfering with their taste and appearance, and all such methods are legitimate.

But "the chief harm has come from the blind use of chemical germicides without regard for their harmful properties. The simplest and cheapest way to preserve food is by adding one of these chemicals and the method was, therefore, seized upon by alert men whose chief interest was of the pecuniary kind. "The question was to find the smallest percentage of a chemical which would prevent the decay of some particular food product, trusting to luck that the preservative used would prove harmless to the consumer. Often these chemicals were added with a liberal hand; further, it was soon found that chemical preservatives could be used to preserve food products for the market from materials already so decayed as to be unsalable in their original condition."

Methods of Preserving Foods.-Methods of preserving foods may be roughly classified as follows: 
1. Physical - The more important methods of this class are heat, cold, and drying. The last two are regarded by the sanitarian as antiseptic rather than germicidal, as they usually arrest the growth of the organisms, but do not kill them.

2. Chemical.-Under this class we have two groups.

(a) Those chemicals which preserve through their influence upon the medium in which they are placed. The majority of these act by increasing the osmotic pressure of the solution, and the important constituents used are salt and sugar. These are without objection from the hygienic standpoint.

(b) Those substances which bring about a chemical change within the medium in which they are placed or which combine chemically with the living protoplasmic substance, or inhibiting their natural functions. Their function is then to prevent bacterial digestion. They are for the most part injurious, for if bacteria have attempted to digest food and failed, man need not try.

Cold.-Cold has come in recent times to be of inestimable value in food preservation, and such food usually commands a higher market value than food preserved by other means. This is due to the fact that refrigerated foods in most cases very closely resemble in appearance, taste, and nutritive value the fresh article. Food can be kept in a satisfactory condition in cold storage for a very long time. The time varies with the specific article, its condition when placed in cold storage, and the temperature at which it is kept. Moreover, some foods such as meats pass through a stage of ripening while in cold storage so that when removed they have developed a tenderness and even more delicate flavor than that of the fresh product.

The temperature at which foodstuff's must be kept varies with different articles. Fish are usually frozen, dipped in water, and refrozen. The formation of a coating of ice acts as a protection against bacteria and also prevents dessication. They àre then stored at $16^{\circ} \mathrm{C}$. Smith has shown that fish may be so kept for as long as two years without depreciating in mutritive or sanitary value.

Meats are usually surface-dried before they are placed in cold storage. This prevents the formation of a film of water on the surface which under some conditions may act as a good cultural medium. Eggs and milk are materially injured by freezing; hence, they are ordinarily kept at a temperature just above $0^{\circ} \mathrm{C}$.

Cold is a disinfectant and not a germicide, and although a temperature of $0^{\circ} \mathrm{C}$. will prevent the growth of pathogens, some saprophytes may actually multiply at this temperature, but as the temperature is decreased the pathogens slowly succumb. Nevertheless, cold alone should not be relied upon as a protection against pathogenic bacteria.

Most animal parasites die if kept in cold storage long. Rosenau 
gives the following periods for some: Trichinze die at or below $5^{\circ} \mathrm{C}$. in twenty days; Taenia sayinata, the beef tapeworm, dies in twentyone days; but Taenia solium, the pork tapeworm, may live more than twenty-nine days.

Food spoilage in cold storage is usually due to wrong temperature. This is often true of the home icebox which is usually placed so as to be convenient, not considering practicability, and a survey of such refrigerators revealed the fact that the temperature is often $15^{\circ} \mathrm{C}$. or higher. Such a temperature is ideal for rapid bacterial growth.

Foods taken from cold storage spoil rapidly as the bacteria in and on the food have not been killed and the freezing has loosened up the texture so the microörganisms can gain entrance. Noreover, the enzymatic change which proceeds in the cold-storage product gives rise to substances which accelerate bacterial activity.

Drying.-Nature's method of preserving foods is by drying, for this is the universal principle used in preserving seeds. Bacteria must have moisture to grow and multiply, and if the dessication be great enough they die. Pathogens die quite rapidly when dried. Furthermore, fruits, vegetables, and meats when preserved by this method are usually cooked before eating; hence, the process has a decided sanitary as well as economical significance. Although nothing is added to the dried food and only water is lost, yet some dried food loses its savor and probably at times decreases in digestibility.

The effectiveness of drying as a means of food preservation depends upon the completeness of dessication and the specific food. Those foods which are rich in soluble constituents are easily preserved by this method, for while the moisture present may be considerable yet the osmotic pressure in the solution is too great for bacterial growth. This is the reason grapes, apples, and prunes are so easily preserved by drying, whereas meats and some fruits are preserved with difficulty.

A great variety of foods, such as meat, fruit, eggs, and even milk, can be successfully kept by drying. According to Rohn's classificntion the following groups of foods can be kept by this methorl:

Group I
Group II
Group III
Group IV

Protein Foods

Carbohydrate Foods

Proteins + Carbohydrates

Acids + Proteins + Carbohydrates

Pressure.-The use of pressure for the preservation of foods is yet in the experimental stage. Hite and coworkers found that the bacteria which cause spoilage in many fruits can be killed by pressure. Apple juice kept for five years after being subjected to a pressure of from 90,000 to 120,000 pounds. Peaches and pears exposed to a pressure of 60,000 pounds for thirty minutes never 
spoiled. Inconsistent results were obtained with blackberries, raspberries, and tomatoes, thus indicating that more work is necessary before it can be used on a commercial scale. Larson, Hartzell and Diehl found that a direct pressure of 6000 atmospheres kills non-spore-forming bacteria in fourteen hours. A pressure of $\cdot 12,000$ atmospheres for the same length of time is required to kill spores. They think sterilization by means of pressure may prove valuable from a medical viewpoint as cultures so killed were found very effective in immunization. They are disposed to attribute the sterilization to the sudden change in the osmotic tension of the fluid in which the bacteria were suspended. However, Bridgman's results indicate that it may be due to the coagulation of the bacterial protoplasm.

Canning.--This process in most cases leaves the food sterile. It is, therefore, a sanitary safeguard, and can be used with most meats, fruits, and vegetables, and if properly conducted vields very satisfactory products.

The method used and the success met with varies with the different products and their condition at the time of canning. Acid foods or those containing large quantities of soluble constituents are canned with considerable ease as compared with the neutral substances (corn, peas, and beans).

The various methods used may be arranged under three groups:

1. The heating of the products under pressure for a sufficient time to sterilize. This method although it requires the use of an autoclave is more efficient and requires less time than the other methods. It is used very extensively in large canneries, whereas the intermittent and continuous methods are used to a greater extent in the home.

2. The intermittent method consists of heating the products on three successive days, maintaining the food at a temperature between heating such that spores will vegetate. The objection to this method is the time necessary in the preparation of the finished product, and anaërobic organisms may not germinate in the intervals between heating but may later with the production of toxins.

3. The continuous or cold-pack method is being extensively used of late, but Dickson and later Thom and coworkers have shown that the temperature is not always sufficient to insure the death of all injurious organisms.

Sugar and Salt.-Sugar and salt preserve by increasing osmotic pressure and are very extensively used as they are without injury upon the health of the consumer.

Sugar is largely used in the manufacture of jellies and preserves. These substances are cooked in the preparation, and this together with the high osmotic pressure of the solution renders them free from pathogens. 
Salt is extensively used in the preservation of meats and pickles, and our knowledge concerning the action of salt is more exact than it is concerning sugar.

Tanner lists the various reasons which have been ascribed for the keeping powers of salt as follows:

I. Exerts a poisonous action.

II. Renders the moisture unavailable for microörganisms.

III. Destroys the cells by plasmolysis.

Salt does not render the medium sterile but exerts a selective action upon the bacterial flora. A 7 to 10 per cent. solution of salt, according to Stadler, inhibited the grow th of the following organisms: B. Coli commume, B. morbificcius bovis, B. enteriditis, B. (proteus) vulgaris, and $B$. botulinus.

De Freytag and Stadler found that a saturated salt solution had the following effect upon bacteria:

INFLUENCE OF CONCENTRATED SALT SOLUTION ON BACTERIA.

\begin{tabular}{|c|c|c|c|}
\hline Author. & & & $\begin{array}{l}\text { Organism. } \\
\text {. }\end{array}$ \\
\hline Fraytag & & & $\begin{array}{l}\text { B. anthracis } \\
\text { B. anthracis spores }\end{array}$ \\
\hline $\begin{array}{l}\text { Freytag } \\
\text { Freytag }\end{array}$ & & & $\begin{array}{l}\text { B. anthracis spores } \\
\text { B. typhosus }\end{array}$ \\
\hline Stadler. & & • & B. typhosus \\
\hline Freytag & & . & B. diphtherio \\
\hline Stadler. & & • & B. diphtherice \\
\hline Freytag & & * & B. tuberculosis \\
\hline Stadler. & & & B. pestis \\
\hline
\end{tabular}

Observation.

Not killed after a number of hours.

Not killed in six months.

Killed after five months.

Not killed in six weeks.

Not killed in three weeks.

Not killed in four and a half weeks.

Not killed in three months.

Not killed in sixteen weeks.

Homer found that $B$. botulinus does not develop in media containing over 6 per cent. of salt, and he considers meat which is properly covered with brine safe. But much higher concentrations -12 to 19 per cent. acting for seventy-five days - are necessary to destroy the bacteria, and even then ptomains which had previously been formed in the food would not be rendered harmless.

It is cuite evident from these results that salt is an efficient food preservative. It does not, however, destroy pathogens, and in dilute solutions the organisms involved in food-poisoning may develop.

Chemical Preservatives.-All authorities are agreed that the preservation of food by drying, refrigeration, heating, canning, salting, and preserving with sugar is justified on theoretical grounds as well as practical experience, whereas the use of sulphites in sausage and chopped meat, the addition of formaldehyd to milk, or of boric acid or sodium flourid to butter are objectionable from the standpoint of public health. The addition of sulphites to meat is especially objectionable, as it places in the hands of the unserupulous dealer a method of concealing the signs of decomposition in meat, in addition to being injurious to the health.

The use of other preservatives such as benzoic acid and sodium 
benzoate is defended by some authors, while others argue that any chemical which is poisonous in large quantities should be considered as poisonous in small quantities until the contrary is proved. This can be determined only by tests extending over long periods, for whereas one dose may not be injurious the continuous use may. So it is best to exclude as far as practical the use of chemical preservatives from food. The subject is well summarized by Jordan as follows:

"The remedy is obvious and has been frequently suggestednamely, laws prohibiting the addition of any chemical to food except in certain definitely specified cases. The presumption then would be - as in truth it is - that such chemicals are more or less dangerous, and proof of innocuousness must be brought forward before any one substance can be listed as an exception to the general rule. Such laws would include not only the use of chemicals or preservatives, but the employment of substances to 'improve the appearance' of foodstuffs. As already pointed out, the childish practice of artificially coloring foods involves waste and sometimes danger. It rests on no deep-seated human need; food that is natural and untampered with may be made the fashion just as easily as the color and cut of clothing are altered by the fashionmonger. The incorporation of any chemical substance into food for preservative or cosmetic purposes could wisely be subject to a general prohibition, and the necessary list of exceptions (substances such as sugar and salt) should be passed on by a national board of experts or by some authoritative organization like the American Public Iealth Association."

An advance in the right direction was made by the passage of the National Food and Drug Law in 1906. 'This is being rapidly incorporated in the statutes of the various states. According to this law a food is adulterated:

1. "If any substance has been mixed and packed with it so as to reduce or lower or injuriously affect its quality or strength.

2. "If any substance has been substituted wholly or in part for the article.

3. "If any valuable constitnent of the article has been wholly or in part abstracted.

4. "If it is mixed, colored, powdered, coated, or stained in any manner whereby damage or inferiority is concealed.

5. "If it contains any poisonous or other added deleterious ingredient which may render such article injurious to health.

6. "If it consists in whole or in part of a filthy, decomposed or putrid animal or vegetable substance or any portion of an animal unfit for food, whether manufactured or not, or if it is the product of a diseased animal or one that has died otherwise than by slaughter." 
Those chemical preservatives concerning which there is a question as to their influence upon the health need only be listed on the article leaving the consumer to decide for himself as to whether he cares to use it.

\section{REFERENCES.}

Rosenau: Preventative Medicine and Hygiene.

Tanner: Bacteriology and Mycology of Foods.

Wiley: Foods and Their Adulteration. 


\section{CHAPTER XXXVI.}

\section{BACTERIA IN THE ARTS AND INDLSTRIES.}

BACTERLA play an ever-increasing part in the arts and industries and man is learning that the majority of them are his friends and not his enemies. In addition to the processes considered in the preceding pages bacteria play a leading rôle in many important industries, a few of which are briefly considered below.

Alcoholic Fermentation. - The development of bacteriology as a science is intimately associated with the history of fermentation. Some of Pasteur's classic studies dealt with this subject and ever since it has commanded considerable attention.

Although from a commercial viewpoint the reasts are of first importance in alcoholic fermentation, ret there are many bacteria which produce alcohol, for instance:

B. fitziamus, ferments glycerin with the formation of ethyl alcohol.

B. ethaceticus ferments glycerin, starch, sucrose, lactose, glucose, mannite, and arabinose with the formation of ethyl alcohol and acetic acid.

A number of bacteria, chief among which are B. butylicus, $B$. $B$. orthobutylicus, B. amylozyme, and Beijerinck's genus Granulobacter, ferment carbohydrates with the production of butyric acid.

Recently Northrop and coworkers have outlined a method of producing acetone on a commercial scale, ethyl alcohol being a byproduct. The organism used is B. aceto-ethylicum which acts on a solution of beet molasses. The fermentation yielded from $\$$ to $\$ .5$ per cent. of the sugar as acetone and 20 to 21 per cent. as ethyl alcohol.

Milk usually undergoes lactic acid fermentation, yet Koumiss, Matzoon, Keffir, and Leben all contain alcohol and bacteria play an important rôle in their fermentation.

Vinegar.-Many species of bacteria have been described which produce acetic acid. They are all closely related but differ slightly in morphology and fermentative porver. It is believerl that the oxidation of the alcohol is due to an intracellular enzyme. All of the organisms are bacilli and a few of the most common species are as follows:

Bacterium pasteuriamum-non-motile rods, $1 \mu \times 2 \mu$, that do not form spores. Their optimum temperature is about $34^{\circ}$ ('. 'They develop best in solutions not over 9.5 per cent. of alcohol and produce under favorable conditions about 6 per cent. of acetic acid. 
Bacterium schiitzenbachi and several related species are the main factors in the production of vinegar by the quick-rinegar process. The organisms vary considerably in size $-0.3-0.4 \mu \times 3-6 \mu$. Their optimum temperature is $25^{\circ}-30^{\circ} \mathrm{C}$. They produce as high as 11.5 per cent. acetic acid. In the absence of sufficient alcohol the acetic acid may be oxidized by them to carbon dioxid and water.

Two methods of preparing vinegar are in general use-(1) the Orleans and (2) the Quick, or German Method.

1. The Orleans Method is the oldest commercial method and produces vinegar of the highest quality. There are many morlifications of this method but they all contain essentially the same principles. The filtered wine is placed in barrels or covererl vats furnished with openings so the entrance of air is facilitated and can be controlled. The receptacle is filled about two-thirds full of a mixture of four parts of good, new vinegar and six parts of wine, preferably that which has been pasteurized at $55^{\circ} \mathrm{C}$. At times there is placed a light wooden grating which floats and helps to support,the bacterial film. A small quantity of a good bacterial film is placed in as a starter. Periodically a portion of the contents is drawn off and replaced by wine, and so the process continues.

2. In the Quick or German Method the liquid to be acetified is allowed to trickle through barrels filled with beech chips, the pressed pomace of red wines, rattan shavings, corn cobs, or charcoal. Although the main function of these is to increase aëration, yet the best results are obtained with the beech shavings or pomace.

Sauerkraut.-The cabbage is cleaned, cut into pieces of convenient size, and tightly packed with from 1 to 3 per cent. of salt into wooden or earthen ressels on the top of which is placed a weighted perforated cover. This, together with the osmotic pressure of the salt, draws from the vegetable considerable water. The respiration of the cells of the leaf and the yeast soon remove all oxygen. The mass undergoes lactic acid fermentation which in time reaches from 0.5 to 1 per cent. The brine is then drawn off and replaced by 4 to $S$ per cent. salt solution. In this the vegetable will keep for a considerable time. Many substances are produced in the process, the chief of which are lactic acid, alcohol, succinic acid, volatile acids, mannite, amil bodies, carbon dioxid, hydrogen, methane, and various aromatic esters.

The bacteria responsible for the process come from the regetable. Although Weiss has isolated 65 different species of bacteria from sauerkraut, probably the principal changes are due to a few species. The lactic acid is usually produced by Streptococens lacticus and Bacterium lactus acidi.

By similar means other vegetables-stringheans, cucumbers, etc.-may be preserved. 
Ensilage.--The changes through which ensilage passes during its curing was looked upon a few decades ago as being entirely microbic in origin, but due to the work of Babcock and Russell (1906-10) opinion swung in the opposite direction to such an extent that microörganisms were generally considered as of little if any significance in the normal fermentation of silage. Later (1912) Esten and Moson considered the process entirely bacteriological. Three chief fermentations were thought to take place: the lactic acid, alcoholic, and acetic acid fermentation. The lactic acid fermentation was thought to be due to organisms similar to those concerned in the souring of milk. It was also believed by these workers that yeasts cause an alcoholic fermentation and that acetic acid bacteria then oxidize the alcohol so formed to acetic acid. Samarani concludes that the acetic acid fermentation in silage is due to the respiration of the plant cells, while the lactic acid fermentation is due to bacterial action. The organisms responsible for the latter process were identified by him as a bacillus and a coccus which occurred in about equal proportions. The former he designated as the $B$. acidi lactici of Hulppe, and the latter was considered identical with the common streptococcus of milk.

Counts made by Sherman on silage juice showed the presence of from $1,500,000,000$ to $4,800,000,000$ per cubic centimeter, most of which were slender rods, and he considered the organisms concerned to be nearly related to the B. bulgaricus group of milk and the $B$. acidophitus groups.

Ilowever, the temperature, kind of silage, and other factors would govern the bacterial flora, and Gorini distinguishes four types of grass-silage prepared in pits, depending upon the predominating type of bacteria as follows: (1) Butyric, (2) lactic, (3) putrefactive, and (4) sterile or atypical. If the silage stage reaches a temperature of $60^{\circ} \mathrm{C}$. butyric organisms predominate; if $50^{\circ} \mathrm{C}$. lactic organisms prevail; putrefaction occurs at lower temperatures, and sterile or atypical when the mass becomes superheated. Butyric silage is objectionable because of the odor and taste which it is apt to impart to the milk and the bacteria which enter from the surroundings render the milk unsuitable for cheese-making.

The acid-producing bacteria of silage are found constantly on corn fodder, so that silage made from corn is always amply seeded with the organisms, but Gorini achieved considerable success by inoculating fresh grass-silage with lactic acid bacteria, and Crolhois found that the inoculating beet silage with lactic acid organisms preserves it better, furnishes a more nutritive product, and suppresses the diseases to which the cattle fed on non-inoculated pulp are subject.

At least from a theoretical basis this would seem quite probable, for it is known that beets contain in addition to many other products 
cholin and betain. The quantity of this last product in the ripe beet is 0.1 per cent., in the unripe beet 0.25 per cent., and in the beet molasses as high as 3 per cent. The quantity may be even greater in the leaves and upper part of the beet than in the main beet.

Now certain organic reactions are known which relate these products to a toxic substance. Cholin on oxidation and the subsequent elimination of a molecule of water passes into betain:

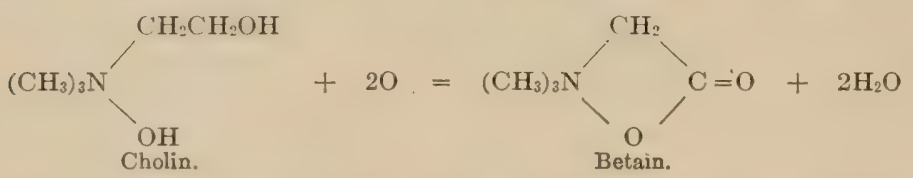

This is a typical oxidation and dehydration reaction which could be brought about by mold or bacteria under aërobic conditions, whereas betain can be converted into muscarin through being made to take up water and reduced thus:

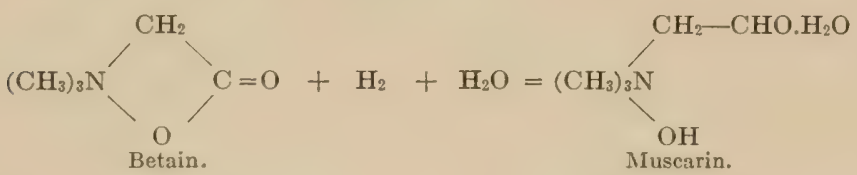

This is a reaction which theoretically could be catalyzed by bacteria or molds and would probably occur under anaërobic conditions.

It, therefore, appears plausible that under appropriate temperature, moisture, aëration, and microflora there may develop in beet silage toxic compounds.

Retting. - The separation of the fibers of flax and hemp is brought about by a complex fermentation in which bacteria dissolve certain pectin bodies which cement the fibers together. The reaction occurs best at a temperature of $30^{\circ}$ to $32^{\circ} \mathrm{C}$. and is due to many species of bacteria. In the water-retting of hemp, the anaërobic butyric acid bacteria (Clostridia) play a leading rôle, and the waterretting of flax is ascribed to a specific anaërobic bacillus (Granulobacter pectinovorum).

Tanning.-Animal skins are tanned in order to increase their resistance to decomposition and also to increase their adaptability to the various purposes to which leather is put. In tanning bacteria play important parts. When the skin is soaked in baths rich in organic matter an energetic bacterial flora soon develops which quickly softens the hide. Bacteria cause the depilation and removal of the hair by which the dermis is separated from the epidermis and the hair which accompanies it. This is true in the sweating and lime methods, whereas the alkaline sulphid and arsenic sulphid are both chemical methods.

The third step in the process is conducted in the excrement or 
bathing tubs which contain the droppings of hens, pigeons, and dogs. Here a true digestion of the hide is carried on by bacteria. Wood has isolated 90 species of bacteria from such a tube, no one of which possessed the power of bringing about the desired change, but all acting conjointly gave the desired product. The heated hides are next placed in a tan pit or in bark liquor. Numerous bacteria reast and molds occur in the bark liquor and play a part in the finishing of the product.

Vaccines. - A raccine is a killed or weakened (attenuated) suspension of organisms to be inoculated into the body for the purpose of causing the development of an active immunity.

The vaccine is usually prepared from a fresh twenty-four-hour growth of the microörganism on agar. The surface growth only is taken, thus avoiding secondary metabolic products which may be formed. The cultures are usually killed by exposure to heat at from $53^{\circ}$ to $60^{\circ} \mathrm{C}$. for one hour. High heat, while certain to kill the virus, is undesirable for the reason that it coagulates the protein substances in the bacterial cell and otherwise alters its chemical structure. The closer the vaccine approaches the virus the better the result and higher the resulting immunity. For this reason many workers prefer to kill the bacteria with chemicals, carbolic acid, chloroform, or some other suitable germicide.

The attenuated virus is obtained by passing the microörganism through the body of some animal, as smallpox through the heifer by which its virulence for man is reduced. At other times it is grown under adverse conditions-high temperatures, artificial media, or in the presence of antiseptics, after which it becomes less virulent. Drying is used in the case of the virus of rabies.

In the preparation of antitoxins the bacterial cell or some of its products are injected into a suitable animal, and after sufficient time has elapsed blood is drawn and after appropriate treatment is used for the cure or prevention of disease.

\section{REFERENCES.}

In addition to the references listed at the end of the several chapters, the following have been freely consulted and to these, the students are referied for further information. The date given is that in which the first volume appeared.

Abstracts of Bacteriology, 1917, vol. i.

Agricultural Index, 1916, vol. i.

Biedermann's Centralblatt für Agrikulturchemie, 1872, Bd. i.

Botanical Gazette, 1876, vol. i.

Centralblatt für Bakteriologie, 1887, Abt. I, Bd. i.

Centralblatt für Bakteriologie, 1892, Abt. II, Bd. i.

Chemical Abstract, 1907, vol. i.

Experiment Station Record, 1888, vol. i.

Comptes Rendus Académie des Sciences, 1835, vol. i.

Experiment Station Bulletins.

International Catalogue of Scientific Literature, 1911.

Jahresbericht über die Fortschritte der Agrikulturchemie, 1858, Bd. i. 
Jahresbericht über die Landwirtschaft, $1886, \mathrm{Bd}$. i.

Journal of Agricultural Science, 1906, vol.i.

Journal of the American Chemical Society, 1875, vol. i.

Journal of the American Medical Association.

Journal of Agricultural Research, 1913, vol. i.

Journal of the Infectious Diseases, 1904, vol. i.

Journal of American Society of Agronomy, 1910, vol. i.

Journal of Bacteriology, 1916, vol. i.

Journal of Biological Chemistry, 1906, vol. i.

Journal of Industrial and Engineering Chemistry, 1909, vol, i.

Journal für Landwirtschaft, 1853, Bd. i.

Landwirtschaftliches Jahrbuch der Schweiz, 1887, Bd. i.

Landwirtschaftliche Versuchs-Stationen, 1859, Bd. i.

Phytopathology, 1911, vol. i.

Soil Science, 1916, vol. i.

United States Department of Agriculture Bulletins. 


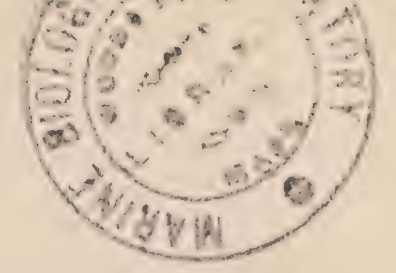

\section{INDEX OF AUTHORS.}

A

Abenhausen, 388

Adler, 180

Allen, 141

Allison, 262

Ampola, 245

Ampola and Garino, 241

Anderson, 382

Andre, 234

Andrews, 392

Armsby, 249

Armstrong, 75

Arrhenius, 95, 99, 106, 111

Ascher, 388

Ashby, 219, 221, 253, 273

Atkinson, 299

Atwater, 291

Aubin, 217

Aujeszky, 388

Avery, 249

Ayers, 385

\section{B}

BABCOCK and Russeli, 413

Ball, 299

Barbieri, 310

Barlow, 299, 303

Barthel, 153

Bassler, 156

Baumann, 210

Bayliss, 73, 81

Bazarewski, 230, 240, 245

Beatty, 382

Beckwith, 123

Beddies, 226, 230

Beijerinck, 27, 57, 93, 144, 251, 263, $266,268,276,292,293,297,307,411$

Beijerinck and Van Delden, 53, 251, 254,275

Beik, 382

Beninde, 388

Benjamin, 307

Bergonzini, 56

Berman, 70

Bernard, 65

Berthelot, 60, 249, 250, 261, 267, 278, 281,287
Berzeluis, 71

Biedermann, 415

Bienstock, 190

Binot, 337

Birner, 249

Bizzell, 131, 140, 219, 233, 234

Black, 401

Bodenstein, 74

Boldnau, 403

Bolley, 387

Bollinger, 227, 277

Bolton, 391

Bomhoff, 388

Bonazzi, 271

Borisson, 78

Bornemann, 153

Bottomley, 138, 235, 236, 274, 286

Bouilhac, 122

Boullanger, 221, 225

Boullanger and Massol, 221, 225

Bouonami, 18

Boussingault, 209, 218, 227, 248

Boyd, 387

Breal, 218, 240

Bredemann, 157, 251, 264

Brenchley, 122

Brett, 390

Briailles, 130

Bridgman, 106, 407

Brieger, 189

Briggs, 201

Briscoe, 152, 388, 389

Briscoe and MacNeal, 388, 389

Brown, 41, 96, 129, 135, 140, 141, 142, $144,152,158,162,174,199,200,203$, 233,283

Brown and Allison, 262

Brown and Hitcheock, 146

Brunchorst, 291

Brusaferro, 388

Buchanan, 30, 94, 106

Büchner, 72, 79, 83, 101, 343

Buck, 387

Buffon, 19

Buhlert, 292

Bujwid, 382

Burgess, 122, 124, 140, 195, 252, 255, 276

Burri, 216, 226, 240

Burri and Stutzer, 216, 226, 240 
Burrill 27, 295, 298, 300, 302, 318

Burrill and Hansen, 295, 298, 299, 300, 318

Bushnell and Mauer, 392

Busley, 224

Bychiklin, 175, 232

Bychiklin and Skalski, 232

\section{C}

Caldivell, 392, 393

Campbell, 382

Carbone, 202

Carey, 394

Caron, 151, 241, 242, 250, 284, 285

Carter, 159, 180, 199, 201

Causemann, 157

Celli-Zuco and Herneus, 210

Chamberlain, 182

Chapin, 352, 399

Chester, 51, 141, 161, 163, 164, 196, $217,232,238,251$

Chestnut, 395

Chick, 111, 113, 117

Chick and Martin, 113

Chisholm, 359

Christen, 98

Christensen, 254, 258,' 259

Christensen and Larson, 254

Cienkowski, 55

Clark and Gage, 123

Clausen, 95

Clayton, 386

Coggi, 388

Cohn, 21, 46, 55, 57, 190

Coleman, 136, 138, 221, 222, 227, 256

Colton, 389

Conn, 64, 96, $162,164,165,166,167$, $168,170,197,372,376$

Conn and Brown, 96

Cook, 182

Coudon, 194

Cramer, 61

Crochetelle, 218, 220

Crolhois, 413

Crooks, 183

Cumming, 391

Cunningham, 126, 128, 173

Cunningham and Löhnis, 126, 281

Czapek, 118

\section{D}

Dafert and Bollinger, 227, 277

Dakin, 113, 114, 115, 117, 349

Dakin and Dunham, 113, 117

Dallar, 382

Darbishire and Russell, 130

Davenport, 297

Davis, 252

Davy, 239
Dawson, 303

De Bary, 16.5

Dehérain, 145, 151, 227, 230, 231, 232, $235,243,249,274,328,330$

Dehérain and Demoussy, 151, 227

Delepine, 382

Delwiche, 156

Demolon, 123

Demoussy, 151, 22t, 227, 231

Depetit, 240, 244

DeSchweinitz and Dorset, 59

Dezani, 142

Dickson, 400,401, 403, 407

Dieh], 407

Doleris and Pasteur, 190

Don, 359

Done, 390

Donk, 394

Dorset, 59

Douglass, 386

Drouin, 307

DuBois and Raymond, 105

Duclaux, 98, 241

Duggar and Davis, 252

Dumas, 208

Dumont, 145, 218, 220

Dumont and Crochetelle, 218, 220

Duncan, 181

Dunham, 113, 117

Dusch, 20

Duschechkin, 153, 158

Dvarak, 263

Dzierzbicki, 199, 202, 203, 258

E

EBer, 382, 388

Ebermayer, 141

Eberth, 352

Effront, 190, 193, 206

Egorou, 128

Ehrenberg, 54, 56, 123, 141

Ehrlich, 84

Einecke, 152

Ellis, 180

Elwell, 218

Emerson, 252

Emmerich, 152

Emmerling, 197

Engberding, 140, 143, 144, 151, 158

Engelmann, 109

Erickson, 291

Escherich, 56, 190

Esten and Moson, 413

Euler, 81

Evans, 315

\section{F}

FABRicius and von FieiLitzen, 151

Feilitzen von, 151, 225

Fernan and Pauli, 103 
Field, 382

Fischer, 29, 77, 97, 98, 140, 151, 153, $158,188,200,203,219,222,254,276$

Fletcher, 132

Flexner, 391

Flügge, $38,57,165,166,168,190$

Folwell, 367

Ford, 396

Forster, 96

Fraenkel, 216

François, 118

Frank, 53, 127, 210, 274, 291, 315

Frankfurt and Duschechkin, 153, 158

Frankland, 165, 167, 210

Fraps, 139, 227

Fred, 129, 131, 133, 136, 137, 244, 267, $304,306,307$

Fred and Davenport, 297

Fred and Gainey, 136

Fred and Hart, 145

Fresenius, 198

Freudenreich, 251, 273, 377

Freytag, 408

Friedländer, 83

Froehde, 239

Fromberz, 206

Frost, 54

Fuhrmann, 79, 306

Fuller, 193, 345, 360, 361, 362, 367

Fuller and Johnson, 345

Fulmer, 266, 267

Fulmer and Fred, 267

\section{G}

GAFKY, 352

Gage, 123, 196 .

Gain, 312,313

Gainey, 136, 203, 228

Gandechon, 225

Garino, 241

Garman, 295

Gärtner, 216

Gasperini, 169

Gay, 355

Gay-Lussac, 77

Gayon, 240, 244, 328, 330

Gayon and Depetit, 240, 244

Gerlack and Vogel, 69, 154, 251, 257, 307

Gibbs, 212, 213, 238

Gilbert, 191, 209, 235, 240, 290

Giltner and Langworth, 276

Girard, 127

Godlewski, 221

Golding, 308

Goler, 382

Goodsir, 55

Gorini, 413

Goss, 390

Gottheil, 165, 166

Grassberger, 388
Grazia, 151, 175

Greaves, $126,146,149,159,162,164$, $180,199,201,218,232,234,237,238$, $244,255,277,289,326$

Greaves and Carter, 159, 180, 199, 201

Greaves, Stewart and Hirst, 238

Green, 200, 203, 234, 260, 266, 282

Gregory, 28

Greig-Smith, 138, 235, 236, 297, 299, 306,312

Greig-Smith and Bottomley, 235, 236

Groenewege, 252

Groning, 388

Grove, 74

Grunner, 118

Guatier and Drouin, 307

Guffroy, 143

Guignard, 249

\section{$\mathrm{H}$}

HAAGLAND, 393

Haas, 99

Hadley and Caldwell, 392, 393

Haeckel, 29

Hall, 172, 288, 289

Hamilton, 391

Hammer, 265, 390

Hammer and Goss, 390

Hansen, 27, 295, 298, 299, 300, 318

Hanzawa, 266

Harden, 83, 86

Harding, 164, 373, 389

Harding and Wilson, 373

Harracks, 359

Harrison and Barlow, 299, 303

Hart, 145

Hartleb, 216, 217

Hartwell, 141

Hartz, 51, 169

Hartzell, 407

Hastings, 376

Hauser, 56, 190

Hazen, 353

Headden, 118, 284

Hecker, 151

Heim, 387

Heineman, 386

Heinze, 128, 135, 153, 157, 231, 234, $256,274,278,282,307$

Heller, 395

Hellriegel, 27, 248, 274, 291, 293, 314

Hellriegel and Wilfarth; 248, 291

Hellstrom, 152, 388

Helmholtz, 21

Heraeus, 210

Herbert, 328, 329, 388

Herr and Berninde, 388

Herzfield and Lange, 118

Herzog, 41

Hess, 382

Hilgard, 141, 191, 201, 230, 235, 284 
Hill, 44, 80, 157, 355, 372, 379

Hill and Slack, 372

Hills, 256, 257, 271

Hiltner, 232, 282, 305, 307, 318

Hiltner and Stormer, 129, 133, 151, $160,164,257,297$

Himesch, 388

Hinds, 344

Hinterberger, 197

Hippocrates, 351

Hirschler, 188

Hirst, 238, 326

Hiss and Zinsser, 99

Hitchcock, 146

Hite, 406

Hoelling, 52

Hoffmann and Hammer, 265

Homer, 408

Hope, 382

Hopkins, 63, 183, 237, 276, 288, 311, $322,326,370$

Hopkins and Whiting, 175

Hoppe-Seyler, 263, 328, 329

Hormon and Morgenroth, 388

Houston, 344

Hull and Rettger, 371

Hulme, 244

Hulppe, 413

Hutchinson, 121, 123, 130, 135, 137, $138,230,231,235,236,253$

\section{I}

IMMENDORFF, 334

Itano, 204

\section{J}

JACKSON, 123

Jaeger, 382, 388

Janowski, 342

Jeannert, 188

Jenner, 24

Jennings, 108

Jensen, 52, 53, 67, 234, 242

Jodidi, 206

Johnson, 132, 138, 239, 345, 361, 385

Jones, 281

Jordan, 46, 82, 343, 344, 346, 364, 395, $397,403,409$

Joshi, 226

\section{K}

IKAEnsche, 397

Kalantarov, 313

Karg and Sehmori, 42

Kaserer, 52, 216, 225, 259, 260, 334

Kayser, 194, 365, 392

Keith, 350
Kellermann and Beckwith, 123

Kellermann and McBeth, 333

Kellermann and Robinson, 140, 143

Kelley, 141, 176, 199

Kellner, 249

Kellogg, 141

Kendall, 37, 44, 62, 70, 88, 94, 188

Kern, 57

Kiesow, 249

King, 151, 230, 231, 232, 234

King and Whitson, 232, 234

Klebs, 59

Klein, 382

Klimmer and Kruger, 295

Knisely, 309, 310

Knoop, 269

Kober, 354

Koch, 24, 54, 99, 127, 131, 133, 157, $160,251,264,265,279,281,288$, $348,352,354,380$

Koch and Seydel, 264, 265

Kochenavsk, 219

Kolle and Zetnow, 41

Kopeloff and Coleman, 136, 138

Korn, 388

Kossowiez, 180, 187, 238

Kossowitsch, 274

Krainsky, 255, 264, 266, 273, 277, 287

Kresslig, 59

Krober, 175

Krogh, 182

Kronig, 112, 249

Kruger, 140, 245, 274, 295

Kruger and Heinze, 128

Krumwiede and Noble, 387

Kruse, 62, 70

Krzemieniervski, 255, 260, 265, 268

Kuhlmann, 239

Kuhlmann and Dumas, 208

Kuhne, 72, 215

Kunkel, 118

Kunnemann, 240

Kurth, 56

\section{L}

LABAViUS, 71

Ladd, 218

Lafar, 94, 178, 179, 180, 187, 207, 223, $225,238,318,335$

Landolt, 210

Lange, 118

Langworth, 276

Larson, 254, 407

Latham, 123

Laurent, 158, 241, 274, 292

Laws and Gilbert, 191, 235, 240, 290

Lazear, 27

Leach, 62

Leeuwenhoek, 17, 18, 42

Lemmermann, 141, 162, 198, 244

Lemmermann and Ernecke, 152 
Lemmermann and Fresenius, 198

Leoncini, 144

Lery and Kayser, 365

Libby, 28

Liebig, 21, 23, 71, 189, 290

Lipman, C. B., 142, 143, 145, 146, 164, $196,199,200,218,235,252,255,260$, $277,278,287,317$

Lipman, J. G., 27, 60, 135, 138, 140, $141,152,159,191,193,197,202,203$, $204,207,238,239,246,247,251,256$, $264,267,269,288,289,314,318,334$

Lipman and Brown, 129, 140, 199, 200

Lipman, Brown and Owen, 140

Lipman and Burgess, 122, 124, 140, $143,195,252,255,276$

Lipman and Green, 203

Lipman and Sharp, 146, 277

Lipman and Waynick, 200, 283

Lipman and Wilson, 123

Lister, 26

Locy, 28

Loeb, 108, 117

Loew, 386

Löhnis, 38, 126, 138, 160, 161, 198, 207 , $221,224,238,251,252,260,262,266$, $272,279,281,282,289,318$

Löhnis and Green, 260, 266

Löhnis and Smith, 272

Löhnis and Pillai, 262

Lorenz, 388

Lumia, 145

Lyon and Buzzell, 131, 140, 219, 233, 234

\section{M}

MAassen and Mưlleer, 293

Macaulay, 24

Macfayden, 382

MacNeal, 64, 388, 389

MacNutt, 353, 369, 386

Makrinov, 143

Malpighi, 291

Marchal, 194, 195, 196, 203, 204

Marchiotti, 388

Marcille, 221, 235

Marconi, 382

Markl, 388

Marshall, 70, 94, 367

Martelly, 190

Martin, 113

Mason, 359

Massol, 221, 225

Mauer, 392

Mayer, 345

McBeth, 145, 228, 231, 263, 333, 335

MeBeth and Smith, 228, 231

McBeth and Wright, 145

McClendon, 117

McCoy, 375

MeLean and Wilson, 197, 204

McWeeney, 398
Mendel, 370

Metchnikoff, 32,370

Meyer, 44, 59, 231

Michel, 351

Migula, 38, 46, 168

Millard, 153

Mills, 347,353

Miquel, 96, 336, 337, 342

Mitscherlich, 328

Miyaka, 204

Moak, 371

Mockeridge, 255, 258, 264

Mohler, 382, 389

Molisch, 180

Moll, 153, 234, 282

Montanan, 144

Moore, 73, 251, 318

Morgan, 131

Morgenroth, 388

Morrey, 18

Moson, 413

Mueller, 54

Mulder, 208

Mulford, 224, 225

Müller, 209, 293, 382

Münter, 170, 231

Münter and Robson, 228

Müntz, 157, 209, 210, 217, 222

Müntz and Aubin, 217

Müntz and Coudon, 194

Murray, 281

Myer, 196

$\mathrm{N}$

NADSON, 173, 196

Nathan, 70

Navy, 400

Neale, 156

Needham, 19

Neish, 232

Nencki, 188

Neubauer and Fromberz, 206

Newton, 393

Niklewski, 52, 153, 222

Nishimwia, 60

Nobbe, 293, 307, 318

Nobbe and Hiltner, 307, 318

Noble, 387

Northrop, 411

OBERLIN, 127

Obermuller, 388

Olaru, 144, 259

Omelianski, 159, 224, 252, 264, 271. $275,330,331,332,333$

Omelianski and Salunskov, 275

Omelianski and Sswewrowa, 271

Ophüls, 401 
Orr, 374

Osborne and Mendel, 370

Ostwald, 75, 77

Ott; 382

Owen, 140, 201, 203, 219, 221

\section{$\mathbf{P}$}

PAGET, 28

Pagnoul, 198

Parker, 379, 382, 386

Pasteur, 20, 21, 23, 24, 25, 26, 28, 72, $182,190,209,328,337,411$

Paterson, 141, 142, 143

Paterson and Scott, 227

Paul and Kronig, 112

Pauli, 103, 105

Pawlowsky, 382, 388

Peck, 140, 144, 263

Perotti, 175

Peterson, 141, 282

Peterson and Wollny, 141

Petit, 151

Petri, 382

Pettenkofer, 182

Pfeiffer, 57, 108, 156, 198, 242

Pfulel, 387

Phelps, 367

Pichard, 142

Pierce, 305

Pillai, 262

Platt, 210

Plenge, 174

Plummer, 231

Popoff, 328

Potter and Synder, 206

Prazmowski, 57, 271, 292, 300, 304

Prescott and Winslow, 344, 359

Pringsheim, 252, 263, 264

Prucha, 313 374, 389

Pugh, 240

Putnam, 240

\section{Q}

QuiroGs, 232

\section{R}

IRABINOWITSCII, 388

Radot, 28

Rahn, so, 199

Raymond, 105

Redi, 19

Reed, 232, 259, 283

Reed and Williams, 232, 283

Reincke, 353

Reitz, 388

Remy, 141, 151, 161, 255, 266, 268

Remy and Fiseher, 151
Renault, 145, 223

Rettger, $56,67,70,204,370,371.392$, 393

Richards, 242, 267

Richards and Rolfo, 242

Richardson, 232

Riviere and Bouilhac, 122

Robertson, 81

Robinson, 140, 143, 310

Robson, 228

Rogers, 389

Rohn, 406

Rolfs, 242

Rosenau, 111, 353, 359, 367, 375, 378, $383,384,386,388,394,405$

Rosenbach, 51, 55, 190

Rosing, 259, 260

Rossi, 293, 297

Roth, 388

Rowland, 390

Ruppel, 59

Russell, 92, 121, 123, 130, 131, 136, $137,138,231,234,236,247,286,413$

Russell and Hutchinson, 121, 123, 130, $131,136,137,138,236$

\section{S}

SACKeTt, 270, 284

Samtee, 367

Sanarani, 413

Sanfelice, 169

Saper, 399

Savage, $359,373,381,386,397$

Sawyer, 399

Scharbekow, 382

Schegehdahl, 355

Sehettenhelm, 174

Schlösing, 145, 209, 210, 214, 227, 230, $234,274,292,329$

Schlösing and Laurent, 274, 292

Schlösing and Müntz, 210

Schmori, 42

Schneider, 152

Schneidewind, 231, 274

Schönbein, 208

Schreiner, 193

Schroeder and Brett, 390

Schroeder and Dusch, 20

Schroeter, 55, 174

Schuchardt, 388

Schuder, 355

Schultz, 156

Schultz and Borisson, 78

Schulze, 20, 310

Sehulze and Barbieri, 310

Schwann, 20

Seott, 143, 227

Sedgwick and MacNutt, 353

Senus, 330

Setchell, 96

Severin, 142, 177, 178, 241, 250 
Seydel, 264, 265

Sharp, 146, 201, 277

Shedd, 123

Sherman, 413

Shroeder, 382,389

Shutt, 23t, 316

Silberberg, 123

Simon, 295

Sirker, 135

Skalski, 232

Skinner and Sullivan, 143

Slack, 372

Smillie, 391

Smirnov, 222

Smit, 382

Smith, 138, 228, 231, 235, 236, 239, 272, $297,299,306,310,312,337,405$

Smith and Robinson, 310

Snow, 351

Snyder, 191

Solmgen, 334

Sörenson, 204

Spallanzani, 19

Sstwewrowa, 271

Stadler, 408

Stefan, 308

Stevens, 153

Stevens and Withers, 158

Stewart, 232, 234, 238, 326

Stewart and Greaves, 232, 234

Stigell, 151

Stocking, 374

Stoklasa, 60, 122, 131, 135, 152, 177, $241,242,243,244,256,258,262,268$, $274,285,306,308,309,311$

Stoklasa and Vitek, 242, 243, 244

Störmer, 129, 133, 151, 160, 257, 297

Stranak, 256, 262

Straus, 384

Stutzer, 216, 217, 226, 240, 242, 309

Stutzer and Hartleb, 216, 217

Sullivan, 143

Sulunskov, 275

Synder, 206

\section{$T$}

TANner, 385, 392, 394, 403, 408, 410

Tappeiner and Hoppe-Seyler, 328

Taylor, 94, 204

Teichert, 388

Temple, 152, 312

Thaysen, 138

Thorn, 407

Thomasen, 217

Thomson, 75

Thresh, 359

Thu, 388

'Tissier and Martelly, 190

Tobler, 388

Tonney, 382

Traaen, 277
Trecol and Fremy, 23

'Trecül, 328, 332

Trevisan, 5t, $5 \pi$

Troop, 151

Truog, 178

Tsiklinsky, 96

Tyndall, 23, 24, 26, 72, 337

\section{V}

VAN Delden, 53, 178, 251, 25t, 275

Van Ermengen, 400, 401

Van' Helmont, 18, 71

Van't Hoff and Arrhenius, 95, 99, 106

Van Tieghem, 55, 252

Vaughan, 62, 91

Vaughan and Novy, 400

Veillon and Zuber, 190

Vitek, 242, 243, 244

Voelcker, 123

Vogel, 69, 123, 151, 234, 251, 257, 307

Vollery, 28

Voltaire, 19

Vorhees, 138, 141, 193, 203, 207, 238, $246,247,318$

Vorhees and Lipman, 138, 193, 207, $238,246,247,318$

\section{W}

WAGNER, 131, 151, 245

Waksman, 170

Walton, 259, 264, 282

Ward, 291, 345

Warington, 130, 145, 153, 210, 215, 218, $220,230,231,238,245$

IV arnbold, 276

Washburn, 387, 389, 390

Washburn and Done, 390

Wrassilieff, 309

Waynick, 200, 283

Weichselbaum, 55

IVeinzierl and Newton, 393, 394

Weiss, 412

Weissenfield, 388

Welbel, 153, 218, 231, 232, 234, 283

Welbel and Winkler, 232, 283

IVenner, 56

Vestgate, 315

Wheeler, 62, 344

Whipple, 337, 345, 363, 364, 365, 367

Whipple and Mayer, 345

White, 219

Whiting, 294, 303, 304, 306, 307, 308, 312,318

Whitson, 232, 234

Wigand, 292

Wilbur and Ophüls, 401

Wiley, 218, 410

IViley and Elwell, 218

Wilfarth, 27, 248, 291, 292 
Wilhemy, 197

Williams, 44, 232, 268, 283

Wilson, 123, 197, 204, 313, 373

Windas and Knoop, 269

Winkler, 232, 283

Winogradsky, 27, 53, 153, 159, 179, $180,211,214,215,216,220,221,222$, $225,250,252,264,272,307$

Winogradsky and Omelianski, 159

Winslow, 344, 359

Withers, 139, 158

Withers and Fraps, 139

Wohl, 84

Wohltmann, 153

Wojtkiewiez, 235
Wollny, 128, 141, 153

Wood, 415

Woronin, 291, 292

Wright, 145

\section{Z}

ZEIT, 103, 104

Zetnow, 41, 43

Zinsser, 91, 99

Zipfel, 293, 295, 299, 313

Zopf, 55

Zuber, 190

Zueo, 210 


\section{SUB.JECT INDEX.}

A

Abiogenesis, 19

Acid, acetic, production of, by bacteria, $85,411,412$

butyric, production of, by bacteria, 86

carbonic, influence on calcium carbonate, 172

citric, production of, by mold, 87

formic, produced by bacteria, 85,87

gluconic, from dextrose, 86

hippuric, action of bacteria on, 92

lactic, mechanism of formation, 86 production of, by bacteria, 85

oxalic, produced by molds, 87

phosphates, action on calcium carbonate, 172

propionic, from propyl alcohol, 86,87

sulphuric, produced by sulphur bacteria, 179

uric, action of bacteria on, 91

valeric, produced by molds, 87

Acid-forming bacteria in milk, 376

Acids, amino-, from proteins, 86

influence on denitrification, 241 on potassium of soil, 180

produced by Azotobacter, 269

by bacteria, 84

in soil, 172

in cellulose fermentation, 328,330

in milk, 376

by nitrifying organisms, 176,178

Actinomyces in soil, 169

Aëration, influence on ammonia production, 202, 203

on Azotobacter, 281

on denitrification, 242,246

on nitrification, 230

on number of bacteria in soil, 162

on Ps. radicicola, 312

on toxicity of arsenic in soil, 124

Aërobacter, 251

Aërobes, 69, 109

Air, bacteria in, 336, 339 inspired and expired, 339

factors governing number and kind of bacteria in, $336,337,338$

how bacteria enter, 336

Air-borne infection, 339

Alcohol as disinfectant, 111, 112
Alcoholic fermentation, 83, 411 reactions of, 83,84

Algx, blue-green, 30, 31 relationship to Azotobacter, 274

Alinit, 250, 251, 285

Alkali, influence on nitrification, 220

Amaneta muscaria poisoning, 396

Amidases, production of ammonia by, 206

Amino-acids, alcohol from, 84 ammonification of, 206

in Azotobacter, 268

formation of, by Azotobacter, 270

in legume nodules, 309,310

Amins, formation of, by bacteria, 90

Ammonification, 27, 34, 92, 194-207

by actinomyces, 170

chemistry of process, 204-207

fungi-producing, 197

influence of aëration on, 202, 203

of antiseptics on, 130, 135

of arsenic on, 119

of calcium carbonate on, 139

chloride on, 142

of carbohydrates on, 199

of climate on, 200

of crop on, 200

of green manure on, 156-159

of gypsum on, 142

of iron sulphate on, 142

of lime on, 141

and magnesia on, 203

of manganese salts on, 143,144

of manure on, $153,154,155,159$

of moisture on, 200, 201

of phosphorus on, 203, 204

of potassium salts on, 144, 145

of season on, 200

of sodium salts on, 145

of soil on, 200

of water on, 154,155

methods of studying, 198

organisms concerned in, 194, 195

reactions, 192, 193

stimulation by salts, 147

toxicity of salts on, 149

variation with substrate, 199

Ammonifiers, distribution, 196, 197

Amygdalin, 80

Amylobacter, 328, 330, 332

Anabolism of Azotobacter, 269 
Anabolism, bacterial, 71

Anaërobes, 69

Animals and plants, differences in, 29

Anthrax, organism discovered, 24

vaccine, 25

Antiseptic action on ammonifiers, 130 on bacterial activities of soil, 127 , 128

on oxidation in soil, 130

on plants, 128

on soil, 127

theories concerning, 133-138

Grieg Smith's, 138

Hiltner's and Störmer's, 133

Koch's, 133

Russell's and Hutchinson's, 135,136

definition of, 110

Antitoxins, 415

Arsenic, action in soil, 120

influence of aëration of soil on toxicity of, 125

on ammonification, 119

on azofication, 120

on Azotobacter, 261

on bacterial activities, 118-126

on nitrification, 119

on soil phosphorus, 122

occurrence in soils, 118

solubility of, 118

Ash of bacteria, 69

Aspergillus, influence of salts on, 67

Azofication, 248-289

definition of, 249

history of, 248-252

influence of aëration on, 281, 282

of climate on, 283-284

of colloids on, 260, 261

of crop on, 282, 283

of light on, 281

of manure on, 266, 267

of reaction on, $254-256$

of season on, 281, 282

of temperature on, 278-281

of water on, 276-278

methods of studying, 272-274

Azofiers, distribution of, 252-254

food requirements of, 256-259

influence of organic substances on, 259-261

metabolism of, 267-271

morphology of, 271,272

pigment production by, 270,271

relationship to nitrate accumulation, 284

to other microörganisms, 274-276

soil gain in nitrogen from, 287-289

inoculation with, 284-287

source of energy for, 261-266

Azotobacter agilis, 251

occurrence in water, 254

ash of, 268
Azotobacter beijerinckii, 251

influence of manure on, 266

calcium requirements of, 259

carbonic acid generated by, 177

chroöcoccum; 251

calcium carbonate on, 255

formation of calcium carbonate by, 173

humates on, 265

manure on, 266

methods of growing, 272

morphology of, 271

pigments of, 270,271

physiology of, 272

radium rays on, 103

soil inoculation with, 284-287

composition of, 59,60

distribution, 252,253

food of, 256-259

index of lime requirements, 254 of phosphorus requirements, 258

influence of aëration on, 281

of aluminum on, 259

of antiseptic on, 137

of arsenic on, 121, 122, 261

of carbon bisulphid on, 128

of carbonates on, 254-257

of climate on, 283

of colloids on, 259

of drying on, 106, 276

of green manures on, 157

of humus on, 266

of light on, 281

of manganese on, 259

of nitrates on, 256,257

of phosphorus on, 176,177

of season on, 281,282

of sodium on, 256

of temperature on, 278, 279, 280

of water, 276,277

in fallow soil, 335

iron requirements of, 259

isolation of, 251

life cycle of, 272

metabolism of, 267-270

nitrogen of, 268

fixed in different media by, 273 , 274

phosphorus requirements of, 257-259

potassium requirements of, 257

products of, 86

relationship to cellulose ferments 257

to higher plants, 276

to other organisms, $274-276$

soil gains in nitrogen due to, 289

sulphur requirements of, 258,259

symbiosis amongst, 276

utilization of cellulose by, 263

vinelandii, 251

composition of, 60

forms of nitrogen in, 267, 268

nitrogen fixed by, 264 
Azotobacter vinelandii, pigments of, Bacillus denitrificans, enzymes of, 244 270,271

vitrium, 251

influence of manure on, 266

woodstownii, 251

\section{B}

"Babes Ernst" granules, 43

Bacilli, 37

Bacillus, aceto-ethylicum, formation of acetone by, 411

acidophilus, in ensilage, 413

aëris munitissimus, in sewage, 361

amylobacter, nitrogen fixation by, 251

amylozyme, formation of butyric acid by, 411

anthracis, action of salt on, 67,408

influence of pressure on, 107

temperature relations, 97,98

aquatilis, in water, 346

asteroporus, nitrogen fixer, 251

aurantiacus, 346

azophile, 267

bifermentans sporogens, 190

botulinus, 400, 401

acid production by, 86

influence of salt on, 408

morphology of, 400

bulgaricus, 370,377

in silage, 413

centropunctatum, as denitrifier, 241 243

cereus, 167,168

cultural characteristics, 167,168

morphology of, 167

physiology of, 168

in soil, 165

cholera, action of salt on, 67

circulans in sewage, 361

in water, 346

cloacx in canned beef, 394

in sewage, 361

coagulans, survive pasteurization, 392

coli, 243

action of copper on, 123

on phosphates, 174

aërogens in cheese, 390

communis in milk, 376,377

in eggs, 393

indol and skatol production by, 89

products formed by, 85

as putrefier, 190

in sausage, 394

in water, 346

weight of, 64

cyanogenes in milk, 376

pigment production of, 93

delicatulus in sewage, 361

denitrificans, 240, 241

longevity of, 245

detrudens in cheese, 394

diphtherix in butter, 389

influence of salt on, 408

in milk, 377

temperature relations, 98

diplococcus griseus in putrefaction, 190

dysenteriæ, Flexner, in milk, 377

Shiga, in milk, 377

ellenbachensis, 250

action on cyanamid, 221

enteritidis in food, 397

in water, 346

erythrogenes in milk, 376

ethaceticus, alcohol produced by, 83 , 411

fecalis in sausage, 394

ferrugineus, 333

filefaciens, as denitrifier, 241

fitizianus, alcohol-producing, 83, 411

flitrovorum, as denitrifier, 243

fluorescens, action on cyanamid, 221

in eggs, 393

liquefaciens, carbon requirements, 242

denitrifier, 241, 243

in water, 346

non-liquefaciens, in water, 346

pigment production by, 93

in sewage, 361

fulvus in water, 346

fuseus, 361

hartlebi, denitrifier, 241, 242, 243

helvolus in sewage, 361

hyalinus in sewage, 361

icteroides, ammonia-producing, 196

janthinus, pigment production by, 93

kirchneri, action on cyanamid, 221

lactimorbimic melitensis, in milk, 377

lactis acidi, in milk, 376

aërogenes in water, 346

viscosus in milk, 376

nitrogen fixer, 251

lepræ, nitrogen requirements, 68

levaniformus, nitrogen fixer, 251

licheniformis in string beans, 394

liquefaciens in sewage, 361

liquidus in sewage, 361

megatherium, 165, 166

action on eyanamid, 221

ammonia produced by, 196

cultural characteristics of, 165

denitrifier, 241

in foods, 394

morphology of, 165

physiology of, 165, 166

in soil, 165

mesentericus, in bread, 392

in cheese, 394

in eggs, 393

nitrogen fixer, 251 
Bacillus mesentericus, survive pasteurization, 392

vulgatus, 196 in sewage, 361

methanicus, 334

monadiformis in sewage, 361

mucosus in eggs, 393

mycoides, 166,167

action on cyanamid, 221

on phosphates, 174

ammonia produced by, 194-196

cultural characteristics of, 167

denitrifier, 241, 242

morphology of, 166

optimum conditions for, 195

physiology of, 167

in soil, 165

nibilus in sewage, 361

nitrator, 225

nitrovorum, denitrifier, 241

ochracens in water, 346

orthobutylicus, formation of butyric acid by, 411

pammellii in cheese, 394

paratyphosus, in food, 397

in milk, 377

perfringens in putrefaction, 190

pestis, influence of salt on, 408

phosphorescens, influence of temperature on, 96,98

pneumonæ, nitrogen fixer, 251

prodigiosus, denitrifier, 241,243

in milk, 376

nitrogen fixer, 251

pigment produced by, 93

in water, 346

proteus, indol and skatol formation by, 89

in putrefaction, 190

vulgaris, action on phosphates, 174 ammonia-producing, 196 denitrifier, 241

in water, 346

zenkeri, as denitrifier, 241. in sewage, 361

pseudodiphtherix, influence of pressure on, 107

punctatus in water, 346

putidum, action on cyanamid, 221

putidus in putrefaction, 190

putrificus in putrefaction, 190

pyocyaneus, carbon requirements of, 242

denitrifier, 241

pigment produced by, 93

radicicola (See Ps. radicicola)

nitrogen fixer, 251

ramosus, ammonia-producing, 196

in eggs, 393

non-liquefaciens, as denitrifier, 241

rubefaciens in water, 346

ruber in water, 346

rubescens in water, 346
Bacillus simplex in soil, 165

sporogenes in sewage, 361

stillatus in sewage, 361

stutzeri, as denitrifier, 241

subtilis, action on cyanamid, 221

on phosphates, 174

in corn, 394

as denitrifier, 241, 243

physiological solution for, 142

in soil, 165

survives pasteurization, 392

temperature relationship of, 98

in water, 346

tenus in cheese, 394

tetani, acid produced by, 86

thermophilis, temperature relations of, 96,98

tumescens, ammonia-producing, 196

typhosus, acid produced by, 85

action of copper on, 123

in cheese, 390

in cream, 391

as denitrifier, 241

in ice, 350

influence of freezing on, 100

of salt on, 408

longevity of, in butter, 387

in milk, 377

in sewage, 364

in water, 344

vilatis in spinach, 394

violaceus, pigment production by, 93 in water, 346 .

viscosus in cheese, 394

vulgaris, action on cyanamid, 221

ammonia-producing, 196

in putrefaction, 190

vulgatus, ammonia-producing, 196 in corn, 394

weichselbaumii in sewage, 361

welchii in corn, 394

zopfi lepsiense, action of, on cyanamid, 221

in putrefaction, 190

Bacteria, acid production by, 84

action of drying on, 105

on fats, 87

on hippuric acid, 92

on minerals, 92

on proteins, $87,88,89$

on sulphur, 175,178

on urea, 91

on uric acid, 91

in air, 336-339

expired, 339

inspired, 339

methods of entering, 336

number and kind of, 336,337

amins, formation of, 90

in arts and industries, 411, 416

autotrophic, 67

in body, 3132

in bread, 392 
Bacteria, Brownian movement of, 40, Bacteria, metachromatic granules, 43 41

in butter, 387

in canned foods, 394

capsules of, 43

carbohydrates in, 58

carbon requirements of, 68

cellulose in, 42

changes produced in milk by, 375 , 376

in cheese, 289,390

chitin in, 43

classes of, in milk, 376

in water, 345,346

classification of, 46-57

composition of, 58-62

cytoplasm of, 43

definition of, 29

discovery of, 17

in eggs, 393

in ensilage, 413

energy for, 65

extractives in, 58

factors influencing number and kind in soil, 162, 164, 337, 338

food requirements of, 63-70

gradation of, 38

hemicellulose in, 42

hydrolyzing in sewage, 362

hydrogen requirements of, 68

in ice cream, 390,391

indol, production by, 89

influence of antiseptics on, 129-138

of calcium carbonate on, 139

chloride on, 142

of chemicals on, 108-117

of cold on, 100

of electricity on, 103

of gypsum on, 142

of heat on, 95

of iron sulphate on, 142

of light on, $95,101,105$

of lime on, 141

of magnesium salt on, 143

of manganese salts on, 143, 144

of manure in soil, $151,153,154$

of moist heat on, 99

of moisture in soil on, 154, 155

of osmotic pressure on, 106

of oxygen on, 105

of potassium salts in soil on, 144, 145

of radium rays on, 103

of Röntgen rays on, 103

of salts on, 139

of shaking on, 107

of sodium salts in soil on, 145

of temperature and light on, 95-102 involution forms, 38

as liberators of phosphorus, 174

longevity of, 45

in lungs, 32

in meat, 393

method of determining number of, 160

in milk, 31, 372, 373

certified, 371

common, 372

condensed, 391, 392

sources of, 372,373

speed of growth in, 374, 375

moisture in, 65

content of, 58

morphology of, 37-45

motility of, 17,42

nitrogen requirements of, 69

occurrence of, 31

oxygen requirements of, 69

phosphorus requirements of, 69

pigment production of, 93

in plants, 32

pleomorphism of, 38

potassium requirements of, 69

production of heat by, 94

light by, 94

ptomains produced by, 91

rôle in nature, 32

in sewage, 361

oxidizing in, 363

pathogens in, 364, 365, 366

reducing in, 363

sheath of, 43

skatol formation by, 89

soil formers, 33, 171, 172

in soils, kinds of, 164,165

number of, 161,162

spores of, 44

stimulation by salts, 147

in stomach, 32

sulphur requirements of, 69

toxicity of salts for, 149

vital movement of, 41

vitamine requirements of, 70

in water, 342

classes of, 345,346

influence of light on, 343

of sedimentation on, 343

of temperature on, 344

weight of, 39

zoöglœa, 43

Bacterial activities, influence of arsenic on, 118-126

of enzymes on, 71-81

of manure on, 150-159

of salts on, 139-149

counts, value of, 161

metabolism, 71-94

products of, 81-94

toxins, 91

Bacteriology, agricultural, 27, 36

dairy, 36

definition of, 29

development of, 17-2S

industrial, 36

pathological, 36 
Bacterium, acetic acid produced by, Cellulose decomposition by actinomy85

chrysogloa, nitrogen fixer, 252

diphtherix in milk, 377

lactis aërogenes in milk, 376,377

lactus acidi in sauerkraut, 412

lipsiense, nitrogen fixer, 252

pasteurianum, acid produced, 85,86

morphology of, 411

pneumoniæ, alcohol-forming, 83

schutzenbachi, morphology of, 412

tartaricus, nitrogen fixed by, 252

termo, in putrefaction, 190

tuberculosis, in butter, 388

composition of, 59

influence of salt on, 408

in milk, 377,382

in oleomargarine, 389

in sewage, 364

temperature relation of, 96,98

Bacteroids, 291, 302, 303

\section{C}

Calcium carbonate formed in soil, 173 losses in soil, 172, 173

on soil flora, 139

transformation in soil, 172,173

Capsules, 43

composition of, 61

Carbohydrates, action of, in soil, 246

in bacteria, 58

influence on ammonia production in soil, 199

on denitrification in soil, 242, 243

on nitrification in soil, 222

on nitrogen fixation in soil, 262

products formed from, by Azotobacter, 268

as source of carbon, 68

Carbon bisulphid, action of, on soil, 127, 128

on Azotobacter, 128

on plants, 127

compounds, influence of, on denitrification, 243

cycle, 182,183

nitrogen ratio influence on nitrogen fixation by Azotobacter, 263 264

in soil, 191

sources of, for bacteria, 68

for nitrifiers, 220, 221

for plants, 290

Catalyzers, definition of, 75

as ferments, 71,73

Canned food, bacteria in, 394

Canning, 407

Cellulose, 327

in bacteria, 42

decomposing ferments, 327-335

early observations on, $327-330$

cetes, 170

ferments, aërobic, 333

function, 333, 334, 335

involution forms of, 333

isolation of, 330,331

morphology of, 331-333

products formed by, 332

recent work on, 333

in sewage, 363

temperature relations of, 333

sources of energy for Azotobacter, 263

Cell wall of bacteria, 42

Cheese, bacteria in, 389, 390

Chemical preservation of foods, 408, 409

Chemicals, influence of, on bacteria, 108-117

Chemotaxis, 108, 109, 304

Chitin in bacteria, 43

Chlorinated lime as disinfectant, 115

Chlorine compounds as disinfectants, 114

Cholera due to water, $351,352,354$

vibrio, composition of, 61

Classification of bacteria, $46-57$

bacterial products, 82

difficulties of, 46,48

from food requirements, 67

Jensen's, 67

Migula's, 46

in regard to heat, 96

Soc. Am. Bact., 50

of bacterial enzymes, 79

pigments, 93

Linnaean system of, for plants, 48

of waters, 340,341

Climate, influence of, on nitrogen fixation, 283, 284

Clostridium, 86

americanum, nitrogen fixed by, 264 utilization of cellulose by, 263

gelatinosum, 241

nitrogen liberated by, 243

pasteurianum, discovery of, 250 method of growing, 272

morphology of, 252,271

nitrogen fixed by, 264

occurrence of, in water, 254

physiology of, 272

symbiosis with Azotobacter, 276

Cocci, 37

Cold, influence of, on pathogens, 406 preservation of food by, 405

Colloids, influence on Azotobacter, 260, 261

Composition of bacteria, 58-61 of water bacillus, 60

Copper, action of, on soil bacteria, 122, 123

in food, 397

Crenothrix polyspora, 180 
Crop, influence of, on bacterial flora, 250

on nitrates of soil, 236

on nitrification, 230,231

on nitrogen fixation, 282,283

production, essential elements in, 319 rotation, 319-326

Cycle, biological, in sewage, 363 of carbon, 182,183 of elements, 181-187 of nitrogen, 183, 184 of phosphorus, 184, 187 of sulphur, 184

Cytoplasm, composition of, 61

\section{D}

DECAY, 188-193

definition of, 188 products of, 190, 191

Denitrification, 239-247

by actinomyces, 170

early theories.on, 239,240

enzymes concerned with, 81

influence of media reaction on, 241, 242

of temperature on, 245

of water on, 244,245

losses of nitrogen in, 245, 246, 247

organisms concerned in, 240,241

reactions of, 92

Denitrifiers, food requirements of, 242 , 243

function of, 247

metabolism of, 243,244

Deodorants, 110

Desiccation, influence on Azotobacter, 276

Diplococci, 37

Disease due to meat, 397 to milk, 378

to water, 351,352

milk-borne, character of, 379,380

extent of, 380-383

Disinfectant, chlorinated lime as, 115

definition of, 110

formaldehyd as, 116

hydrocyanic acid as, 117

mereuric chlorid as, 117

sulphur dioxid as, 116

Disinfectants, chlorin compounds as, 114

classes of, 111

emulsions as, 113,114

influence of medium on, 113

of moisture on, 111

of temperature on, 111

laws governing action of, 111 mode of action, 111

Drying, preservation of food by, 406

Dysentery due to water, 353

\section{E}

ECTOPLASM, 42

composition of, 61

Eggs, bacteria in, 392, 393

Electricity, germicidal influence of, on bacteria, 104

influence of, on bacteria, 103 on medium, 104

Emulsion, 80

Energy, liberation by enzymes, 80 sources of, 64

for Azotobacter, 261-266

for denitrifiers, 243

for nitrifiers, 223

Ps. radicicola, 312

Ensilage, 413,414

Enzymes, 71-81

action of, on phosphates, 175

classification of, 79

concerned in ammonification, 204, 206

in cellulose fermentation, 330

in denitrification, 243

in nitrification, 224

in Ps. radicicola metabolism, 305

definition of, 72,73

factors governing action of, 76-79

hydrolytic, 79

influence of poisons on, 79

of temperature on, 77, 79

of time on, 78

oxidizing, 81

properties of, 76

reversible action of, 78

specificity of, 77

terminology of, 75,76

Epidemiologist's method of working, 355-358

Extractives in bacteria, 58, 59

\section{F}

FALLOW, influence of, on nitrification, 231-235

loss of nitrates from, 231

Fats, action of bacteria on, 87

Fermentation, 188-193

of alcohol, 83, 84

alcoholic, 411

definition of, 188

early theories of, 21, 71, 72

enzymes of, 79

Ferments, extracellular, 72

intracellular, 72

organized, 72

unorganized, 72

Fertilizers, influence of, on legumes, 313,314

Food, bacteria in, 387-394

function of, for bacteria, 64

milk as, $368-370$

preservation of, 404-410 
Food, preservation of, by canning, 407 by chemicals, 408,409

by cold, 405

by drying, 406 importance of, 404 methods of, 404,405

pressure, 406,407

by sugar and salt, 407,408

pure, law, 409, 410

requirements of bacteria, 63-70 maximum, 64

minimum, 63

Food-poisoning, 395-403

botulism, 400,401

classes of, 305

diseased animals causing, 397

foods causing, 398, 399

metallic, 396, 397

paratyphoid eausing, 397, 398

prevention of, 402,403

ptomain, 400

Formaldehyd as disinfectant, 116

Freezing, influence of, on bacteria, 100 in soil, 162,163

Fruits, preservation of, by pressure, 107

Fungi, ammonia production by, 197 filamentous, nitrogen fixers, 252

Fusel oil, produced in alcoholic fermentation, 84

Future work in bacteriology, 27

\section{G}

GASES, in cellulose fermentation, 329, $332,333,334$

Germicidal action of moist heat, 99

Germicide, 110

Glucose, alcohol from, 83, 84

energy from, 65

lactic acid from, 86

succinic acid from, 86

Glycogen in bacteria, 62

Gonococcus, 37

Gradation of bacteria, 38

Granules, "Babes-Ernst," 43 metachromatic, 43

Granulobacter, 251

\section{$\mathrm{H}$}

HEAT, influence of moist, on bacteria, 98,99 on nitrifiers, 226

production of, by bacteria, 94

relationship of bacteria to, 96

Hemicellulose in bacteria, 42

Humates, influence of, on nitrogen fixation, 265

Humus, chemistry of formation of, 192 , 193

formation of, 190
Humus, formation of, by cellulose ferments, 333

influence of, on Azotobacter, 266

on nitrification, 227

on water requirements in nitrification, 227

value of, in soil, 191, 192

Hydrocyanic acid, 117

Hydrogen requirements of bacteria, 68

Hydrolytic enzymes, 79

\section{I}

IcE, bacteria in, 350

cream, bacteria in, 390

disease due to, 399

Indican, formation of, 90

Indol, formation of, 89

Infection, air-borne, 339

caused by food, 399

sources of, in milk, 378, 379

Inorganic constituents in bacteria, 61

Insecticide, hydrocyanic acid as, 117 sulphur dioxid as, 116

Involution forms of bacteria, 38

Iron, action of bacteria on, 92

bacteria, 180

influence of, on nitrification, 219

requirements of Azotobacter, 259

\section{K}

Katabolisa, bacterial, 71

Keffir, 411

Kinase, 76

Kumiss, 411

L

LEAD, influence of, on soil bacteria, 122

Leben, 411

Lecithin, hydrolysis of, 174

Legumebacter, species of, 295, 296, 297

Legumes, chemical composition of, 308-312

elements added to soil by, 319,320

feed on nitrates, 323,324

influence of, on non-legumes, 314,315

immunity to Ps. radicicola, 305

methods of assimilating nitrogen by, 307

nitrogen in, 323

power to fix nitrogen, 291

sources of nitrogen for, 322,323

Life cycle of Azotobacter, 272

Light, influence of, on Azotobacter, 281 on bacteria, 101, 105

on denitrifiers, 245

production of, by bacteria, 94

Lime, influence of, on ammonification, 203 
Lime, influence of, on nitrification, 219 on nitrogen fixation, 255

requirements of soil, Azotobacter as an indicator of, 254

Lipases, 80

Listerism, 26

Longevity of bacteria, 45

\section{M}

MAGNESIUM carbonate, influence of, on nitrification, 219

salts, influence of, on bacteria, 143

Maltose, 79, 80

Manganese salts, influence of, on bacteria, 143, 144

Manure, denitrifying organisms in, 240 green, ill effects from use of, 158 influence of, on soil, 152, 156, 159 influence of, on ammonification, 153 on Azotobacter, 266, 267

on bacteria, 151-153

on bacterial activities, $150-159$

on moisture of soil, 151

on nitrification, 153

on nitrogen fixation, 153,154

on temperature of soil, 151

products of decomposition, 330

Mass and enzyme action, 78

Matzoon, 411

Micrococcus acidi in cheese, 394

albicans amplus, 361

candicans in beef, 394

candidus in baked beans, 394

casei in sewage, 361

cereus in beans, 394

fervidosus amplus in sewage, 361

flavus liquefaciens in putrefaction, 190

gonorrheæ nitrogen requirements, 68 temperature relationship of, 98

lactis in cheese, 394

luteus in corn, 394

meningitidis, vitamine requirements of, 70

pyogenes in corn, 394

stellatus in beef, 394

tetragenus mobilis ventriculi, 361

ureæ, 81

Micron, 39

Microörganisms, kinds of, in soil, 164

Microspira æestuarii, action of, on sulphates, 179

desulphuricans, action of, on sulphates, 179

Mills Reincke phenomenon, 353

Milk, abnormal changes in, 376

acid-forming bacteria in, 376,377

bacteria in, 372

bacteriology of, 368-377

bitter, 376

certified, 371
Milk, changes produced in, by bacteria, $375-376$

classes of, 371

of bacteria in, 376,377

common, 371

composition of, 368

disease and, 378-386

factors influencing number of bacteria in, 372,373

as food, $368,369,370$

growth of bacteria in, 374, 375

influence of, on intestinal microflora, 371

pasteurization of, 385,386

pathogenic bacteria in, 377,378

peptonizing bacteria in, 377

quantity consumed, 368

sources of infection in, 378, 379

tubercle bacilli in, 382

tuberculosis due to, 381

Milk-borne disease, character of, 379. 380

extent of, 380,381

Mineralization of soil constituents, 171-180

Moisture in bacteria, 58,65

function of, in organism, 66

influence of manure on soil, 151

requirements of nitrifiers, 226-230

Molds, acid produced by, 87

as denitrifiers, 241

difference of, from bacteria, 30

in eggs, 393

Morphology of Azotobacter, 271

of bacteria, 37-45

of cellulose ferments, 331

of clostridium pasteurianum, 271

of nitrifiers, 225,226

Motility, organs of, 42

Mustard, as green manure, 157

\section{$\mathrm{N}$}

Nitrate accumulations, relationship of, to Azotobacter, 284

influence on loss from soil, 247

losses of, from soil, 236, 237

prevention of, 238

quantities formed in soil, 153, 158, 235,236

used by legumes, 323,324

Nitrification, 28, 34, 208, 238

of calcium cyanamid, 221

chemistry of process, 223, 224

discovery of organisms concerned, 209, 210

early knowledge of, 208

theories of, 208, 209

energy transformations in, 223

influence of aëration, 230, 231

of antiseptics on, 134

of arsenic on, 119 
Nitrification, influence of calcium on, 142

carbonate on, 139

of chloroform on, 210

of crop on, $231,232,233,324,325$

of cultivation on, 230,231

of fallow on, 231-233

of green manure on, 156-159

of gypsum on, 142

of iron sulphate on, 142

of light on, 230

of lime on, 141

of magnesium salts on, 143

of manganese salts on, 143,144

of manure on, $153,154,155$

of moisture on, $154,155,226-230$

of organic matter on, 211,222

of potassium salts on, 144, 145

of reaction on, 218, 219

of season on, 234

of sodium salts on, 144,145

of temperature on, 230

of water-holding capacity of soil on; 228,229

isolation of organisms concerned, 211-215

stimulation of, by salts, 147

toxicity of salts on, 149

Nitrifying ferments, distribution of, 217,218

function of, in soil, 215

influence of depth of soil on, 218 of heat on, 226

isolation of, 211-215

metabolism of, 223,224

Nitrite nitrogen in soil, 228

Nitrobacter, 214, 216

morphology of, 226

sources of energy for, 214, 215

Nitrogen in crops, 320,321

cycle, 183,184

fixation, chemical theory of, 249,250 early theories of, 290, 291 energy for, 312

influence of aëration on, 312

of arsenic on, 120

of combined nitrogen on, 250

of cultivation on, 283

of fertilizers on, 313

of green manures on, 156-159

of heated soil on, 131

of manure on, 151

of moisture on, 312

of season on, 282

of temperature on, $279,280,313$

mechanism of, 306-312

in soils, 34,35

fixed by Azotobacter, 264, 265

in legumes, 323,324

liberation of, by bacteria, 243

losses in nitrification, 225

in nodules, 309

soil gains in, 287, 315, 316, 352
Nitrogen, soil losses of, 239

sources of, for bacteria, 68

in Utah soils, 320,325

"Nitrogen," 318

Nitrosococcus, morphology of, 226

Nitrosomonas, influence of, on phosphates, 175

media for, 220

morphology of, 214, 225, 226

sources of nitrogen for, 221

Nodule, ash of, 311

bacterial growth of, 304, 305

composition of, 309

Nuclein, action of bacteria on, 174

ÖDIUM lactis, action of, on lactic acid, 87

influence of pressure on, 107

in milk, 376

Oleomargarine, tubercle bacilli in, 389

Organic compounds, action of, on Azotobacter, 259, 260

on denitrification, 243

in bacteria, 58

as energy for Azotobacter, 262, 263

bacteria, 159

of soil, 193

manures, speed of decomposition, 199

Osmotic pressure, 67

on bacteria, 106

influence of, in soil, 149

Oxidation, of acids, 87

incomplete, 82

Oxidizing enzymes, 79, 81

Oxygen, influence of, on bacteria, 105

requirements of bacteria, 69

\section{$\mathbf{P}$}

Pathogenic bacteria in cheese, 390

Peat, bacterized, 286

denitrification in, 241

Penicillium, influence of salt on, 67

Peroxidases, 81

Phosphate, action of bacteria on, 176

reaction in soil, 175

required by zymaise, 83

Phosphoproteins, action of bacteria on, 174

Phosphorus, action of cellulose ferments on, 334

cycle, 184-187

requirements of Azotobacter, 257258

of bacteria, 64

in soil, 173

in Utah soil, 320 
Pigment, production of, by actinomycetes, 169,170

by Azotobacter, 94, 270, 271

Pigments, classes of, 93 production of, 93

Plants, classes of, 30,31 elements in, 181 poisonous, 395,396

Plasmolysis, 67

Pleomorphism, 38

Pneumococcus, 37

Poison, metallic, 396, 397

Poisoning, 395-403

classes of, 395

food causing, 398

from diseased meat, 397,398

from ensilage, 414

prevention of, 402,403

ptomain, 400

symptoms, 397, 398

Poisonous foods, 395, 396

Polar bodies, 43

Potassium carbonate, influence of, on nitrification, 218, 219

liberation of, by bacteria, 180

requirements of Azotobacter, 257 of bacteria, 69

salts, influence of, on bacteria, 144, 145

in Utah soils, 320

Preservative, definition of, 110

Pressure on bacteria, 106, 107

for preserving food, 107

preservation of food by, 406, 407

Proteases, 80

Protein, action of bacteria on, 88

hydrolysis, 204, 205

liquefaction in sewage, 362

as source of carbon, 68

Protista, 29

Protozoa, action of antiseptic on, 131 of arsenic on, 121 of heat on, 131

Protozoan theory, 135

Pseudomonas fluorescens, 168 ammonia-producing, 196 morphology of, 168 physiology of, 168 in soils, 165

nebulosa in sewage, 361

ochracea in sewage, 361

radicicola, 292

bacteroids of, 303, 304

commercial cultures of, 318

cultural characteristics of, 297-299

entrance into host, 304

influence of acids on, 297

of aëration on, 312

of drying on, 299

of fertilizers, 313,314

of moisture on, 312

of phosphorus in soil, 178
Pseudomonas radicicola, influence of temperature on, 299,313

metabolism of, 306-308

morphology of, 299-303

relationship to host, 305,306

sources of energy for, 312

species, 292-299

staining of, 303

turcosa in sewage, 361

Psychrophelic bacteria, 96, 97

Pteridophytes, 30

Ptomain poisoning, 400

Ptomains, 90, 91, 189

Putrefaction, 188-193

definition of, 188

organisms concerned with, 190

products of, 190, 191

\section{$\mathbf{R}$}

RABIES, 26

Radiobacter, 251

Radium rays, action of, on bacteria, 103

Rain, influences of, on soil nitrates, 236

Rays, ultraviolet, as catalyzers, 225

Reducing enzymes, 79,81

Reductase, 81

Retting of flax, 414

Rhizobium beijerinckii, 297 radicicola, 297

Röntgen rays, influence of, on bacteria, 103

Rotation and soil fertility, 325

Rothamsted, 321, 322

\section{S}

SALT, influence of, on bacteria, 67

Salts, influence of, on bacteria, 139, 147 on bacterial activities of soil, 139149

toxicity of, 145, 146, 149

Sarcina alba in sewage, 361

aurantiaca, pigments of, 93

lutea, pigment of, 93

production of ammonia by, 196 in water, 346

Sauerkraut, 412 .

Schizases, 79

Schutz-Borissow law, 78

Season, influence of, on Azotobacter, 281,282

Sewage, bacteria in, 361,362

composition of, 360

disposal of, 366,367

hydrolyzing bacteria in, 362, 363

oxidizing bacteria in, 363

pathogenic bacteria in, 364, 365, 366 reducing bacteria in, 363,364

Shaking, influence of, on bacteria, 107

Sheath, 43 
Silage, temperature of, 94

Silkworm disease, 23

Skatol, formation of, by bacteria, 89

Smallpox, 24

Sodium salts, influence of, on bacteria, 145

Soil actinomycetes, 169

arsenic in, 118

bacteria, action of, on proteins, 88 as formers, $32,33,171,172$ number of, $161,162,163,164$ in water, 346,347

biological changes produced in, by bacteria, 150

definition of, 171

flora, 160,170

gain in nitrogen, $248,287,289,315$, 316

influence of antiseptics on, 127

of carbon bisulphid on, 128, 129 , 131

of freezing on, 100, 101

of green manure on, $156-159$

of heat on, 127, 131, 132

of manure on, 150

inoculation, 284-287

methods of, $316-317$

loss of nitrates from, 236, 238

organic constituents of, 193

phosphorus, liberation of, 173-175

plant food in Utah, 320

potassium, liberation of, 180

psychrophilic bacteria in, 96, 97

temperature, 151, 154, 280, 313

Spirillum choleræ asiaticæ, 97, 98

desulphuricans, 178

Spirophyllum ferrigineum, 180

Spontaneous generation, 18, 19

Spores, 44, 45

germination, 45

resistance, 44

Staphylococci in eggs, 393

Staphylococcus aureus, pigment of, 93 survives pasteurization, 392

pyogenes albus in putrefaction, 190

Streptococcus coligracilis in sewage, 361

enteritis in sewage, 361

lacticus, absence of katalase in, 81 acid produced by, 85

in sauerkraut, 412

pyogenes in putrefaction, 190

Substrata, 75

Sugar and salt, as preservatives, 407

Sulphates, action of bacteria on, 93 reduction of, by enzymes, 81

Sulphur, action of bacteria on, 175, 178

bacteria, 179

cycle, 184

dioxid as a disinfectant, 116

requirement of Azotobacter, 259 of bacteria, 69
Sulphuric acid, catalytic production of, 76

Symbiosis, 306

among Azotobacter, 276

\section{T}

TANNING, 414, 415

Temperature, and coagulation of bacterial protoplasm, 96

fatal, 98

influence of, on bacteria, 95, 100, 101 on enzymes, 79

on denitrification, 245

on legume bacteria, 313

on manure in soil, 151,154

on nitrification, 230

on nitrogen fixed, 279,280

on reactions, 95

on soil, 154

on water bacteria, 344

relationships of bacteria, 97

Thallophytes, 30,31

Thermal death point, 99

Thermophilic bacteria, 96,97

organisms as nitrogen fixers, 279 , 280

Thiothrix, 179

Toluene, action of, on soil, 136

Toxic compounds in ensilage, 414

Toxicity of salt for bacteria, 149

Toxins, 91

bacterial, in soil, 138, 236

formation of, in soil, 235

influence of heat on, 132

Tryptophan, action of bacteria on, 89

Tubercles, root, early observations on, 291,292

Tuberculin test, $383,384,385$

Tuberculosis among cattle, 381, 382 due to milk, 380, 381

Typhoid bacilli, resistance of, to lactic acid, 387

carriers, 399

cause of, how determined, 355-359

character of outbreak of, 355

due to milk, 379,380

to water, $351,352,354$

para, outbreaks, 397,398

\section{U}

UREA, action of bacteria on, 91

Urease, 80

Uric acid, products from, 91

Uricarse, 92

\section{v}

VACCINE, for anthrax, 25

Vaccines, 415 
Vinegar, bacteriology of, 411, 412 oxidase, 81

Vital movement, 41

Vitamin requirement of bacteria, 70

Vitamins in milk, 370

\section{W}

WATER, catalytic action of, 66

chemical purification of, 349

cholera due to, 352,353

classes of bacteria in, 345,346

classification 'of, 340,341

disease and, 351-359

diseases transmitted by, 352

drainage, nitrogen in, 237

dysentery due to, 353

ground, 341

importance of, 340

influence of, on ammonification, 200 , 201

on Azotobacter, 276, 277

on denitrification, 244

of food on number of bacteria in, 344,345

of light on number of bacteria in, 343,344

on nitrification, $226-230$

on nitrogen fixation, $276-278$

on Ps. radicicola, 312, 313

of sedimentation on bacteria in, 343
Water, influence of temperature on number of bacteria in, 344

intestinal bacteria in, 347

natural purification of, 347,348

purification of, by alum, 349

by chlorazine, 349

by potassium permanganate, 349

soil bacteria in, 346,347

solvent, 66

stored, 341

surface, 341

typhoid due to, 354, 355

Water-holding capacity of soil, relationship of, to ammonification, 201

\section{$\mathbf{Y}$}

YEAST, action of, on phosphates, 175

as denitrifier, 240

difference of, from bacteria, 30

nitrogen fixed by, 252

production of ammonia by, 194

Yellow fever, 26

\section{$\mathrm{z}$}

Zinc, action of, on bacteria, 123, 124

Zoöglœa, 43

Zymase, phosphorus requirements of, 83

Zymases, 80

Zymo-excitor, 76

Zymogen, 76 






